\title{
Interspecific Interactions between Olive Trees and Grapevines in Vineyard Agroforestry Systems in an Arid Climate Region
}

\author{
A Thesis \\ presented to
}

the Faculty of the Graduate School

at the University of Missouri-Columbia

In Partial Fulfillment

of the Requirements for the Degree

Master of Science in Agroforestry

by

KATHERINE FAVOR

Advisors:

Dr. Michael Gold

Dr. Megan Hall

Dr. Samniqueka Halsey

Dr. Rosana Vallone 
(C) Copyright by Katherine Favor 2021

All Rights Reserved 
The undersigned, appointed by the Associate Vice Chancellor of the Office of Research and Graduate Studies, have examined the thesis entitled:

\section{INTERSPECIFIC INTERACTIONS BETWEEN OLIVE TREES AND GRAPEVINES IN} VINEYARD AGROFORESTRY SYSTEMS IN AN ARID CLIMATE REGION

presented by Katherine Favor, a candidate for the degree of Master of Science in Agroforestry, and hereby certify that, in their opinion, it is worthy of acceptance.

Dr. Michael Gold

Dr. Samniqueka Joi-Weaver Halsey

Dr. Megan Hall

Dr. Rosana Vallone 


\section{ACKNOWLEDGEMENTS}

I would like to express my sincere gratitude to all of the people and institutions who have contributed to this research project, who have taught me, and who have supported me along the way.

Dr. Rosana Vallone, Cátedra de Edafología, Facultad de Ciencias Agrarias, Lujan de Cuyo, Mendoza, Argentina. Thank you for taking me in under your wing and for giving me countless hours of planning, guidance, support, and wisdom. You are an incredible teacher, role model, and servant of our planet. I could not have done this research without you.

Dr. Michael Gold, College of Agriculture, Food and Natural Resources, University of Missouri, Columbia. Thank you for serving as my advisor and for your consistent support, guidance, and encouragement throughout my entire graduate career.

Dr. Megan Hall, College of Agriculture, Food and Natural Resources, University of Missouri, Columbia. Thank you for serving on my thesis committee, for your support, and for sharing your invaluable experience in viticulture with me.

Dr. Samniqueka Halsey, College of Agriculture, Food and Natural Resources, University of Missouri, Columbia. Thank you for serving on my thesis committee, for your support, and for sharing with me your indispensable knowledge of statistics.

Dr. Ranjith Udawatta, College of Agriculture, Food and Natural Resources, University of Missouri, Columbia. Thank you for your support, your invaluable knowledge, your guidance, and your generous willingness to help me with my many questions.

Dr. Christine Spinka, College of Agriculture, Food and Natural Resources, University of Missouri, Columbia. Thank you for your support and guidance through the process of statistical analysis.

Gerardo Catapano, Owner, Catapano Family Vineyard. Thank you for allowing me to use your vineyard as a research site.

Mario Santo Delgado, Vineyard Manager, Catapano Family Vineyard. Thank you for your support, flexibility, hours of labor, and willingness to help with whatever task was at hand.

Lucas Vila, Ingeniero de Recursos Naturales. Thank you for the countless hours of labor and support that went far beyond what was asked of you.

Ing. Agrónomo Jorge Esteban Perez Peña, National Institute of Agricultural Technology (INTA), Argentina. Thank you for your generous support, guidance, and time.

Facultad de Ciencias Agrarias, Universidad Nacional de Cuyo, Lujan de Cuyo, Argentina. College of Agricultural Sciences, National University of Cuyo, Lujan de Cuyo, Argentina. Thank you for providing labor, resources, transportation, knowledge transfer, financial support, and endless guidance. Thank you for receiving me into your university and supporting me as if I were an alumnus.

Dorris D. and Christine M. Brown Fellowship. Thank you for the generous financial support that allowed me to perform this research in Argentina. This research would not have been possible without this assistance, and I am extremely grateful. 
"Cada persona, en su existencia, puede tener dos actitudes: Construir o Plantar. Los constructores pueden demorar años en sus tareas, pero un día terminan aquello que estaban haciendo. Entonces se paran y quedan limitados por sus propias paredes. La vida pierde el sentido cuando la construcción acaba.

Pero existen los que plantan. Éstos a veces sufren con las tempestades, las estaciones, y raramente descansan. Pero al contrario que un edificio, el jardín jamás para de crecer. $Y$, al mismo tiempo que exige la atención del jardinero, también permite que, para él, la vida sea una gran aventura. Los jardineros se reconocerán entre sí, porque saben que en la historia de cada planta está el crecimiento de toda la Tierra."

PAULO COELHO 


\section{TABLE OF CONTENTS}

ACKNOWLEDGEMENTS ................................................................

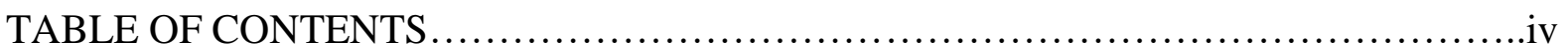

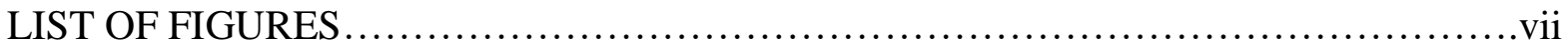

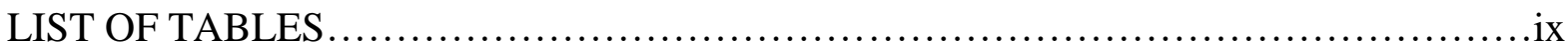

ABBREVIATIONS AND ACRONYMS ...............................................

ABSTRACT ...................................................................

CHAPTER I: Literature Review Introduction.......................................... 1

I.1. Abstract.............................................................

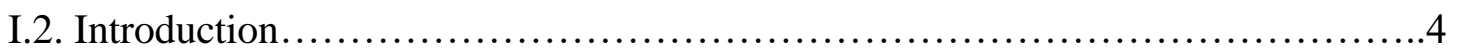

CHAPTER II: Below Ground Services in Vineyard Agroforestry Systems ..................6

II.1. Introduction........................................................

II.2. The Effect of Trees on Water Parameters in Vineyards......................... 7

II.2.1. Issues Surrounding Water in Conventional Viticulture.................. 7

II.2.2. Increased Water Conservation in Vineyard Agroforestry Systems......8

II.2.3. Competition Between Trees and Grapevines for Water...............10

II.2.4. Striking Water Stress Balance in Grapevines........................ 10

II. 3. The Effect of Trees on Vine Nutrition Parameters............................ 18

II.3.1. Issues Surrounding Nutrition in Conventional Viticulture.............18

II.3.2. Increased Nutrient Availability in Vineyard Agroforestry Systems....19

II.3.3. Reduced Nutrient Losses in Vineyard Agroforestry Systems...........21

II.3.4. Competition Between Trees and Grapevines for Nutrients.............23

II.3.5. Striking Nutritional Balance in Grapevines..........................24

II.4. The Effect of Trees on Vine Root Systems................................25

II.4.1. Issues Surrounding Vine Rooting Patterns in Conventional

Viticulture.......................................................25

II.4.2. Improved Soil Structure in Vineyard Agroforestry Systems............26

II.4.3. Soil Niche Competition Between Tree and Grapevine Roots...........29

II.4.4. Balancing Competition Through Root Plasticity in Vineyard

Agroforestry Systems............................................... 31

II.5. Conclusion............................................................. 34

CHAPTER III: Agroforestry for Enhanced Integrated Pest Management in Vineyards .......35

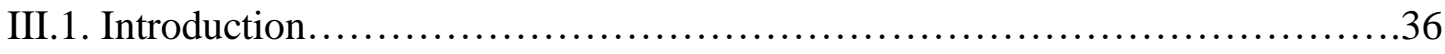

III.2. Issues Surrounding Pests and Diseases in Modern Viticulture................. 37

III.2.1. Diversity as a Means to Combat Pests and Diseases...................38

III.3. Integrated Pest Management in Vineyard Agroforestry Systems ................40

III.3.1. Improved Management of Insect Pests...........................440

III.3.2. Improved Management of Viruses and Bacteria.....................47

III.3.3. Improved Management of Fungal Diseases........................49

III.3.4. Precision Pesticide Application.................................50

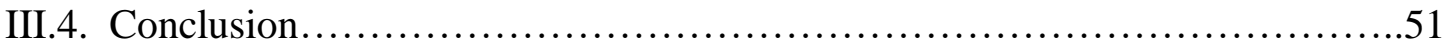

CHAPTER IV: The Effect of Trees on Light in Vineyard Agroforestry Systems............53

IV.1. Introduction........................................................ 54 
IV.2. The Effects of Sun and Shade on Wine Grapes in General.

IV.2.1. The Effects of Sun and Shade on Grapevine Physiological

Parameters .55

IV.2.2. The Effect of Sun and Shade on Grape Yield.......................58

IV.2.3. The Effect of Sun and Shade on Grape and Wine Quality............61

IV.3. The Effects of Sun and Shade in Vineyard Agroforestry Systems..............67

IV.4. Conclusion....................................................... 72

CHAPTER V: The Effect of Trees on Microclimate in Vineyard Agroforestry Systems......74

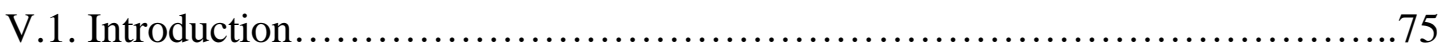

V.2. The Effect of Trees on Wind Patterns in Vineyard Agroforestry Systems........76

V.2.1. The Negative Effects of Wind in Conventional Vineyards...............76

V.2.2. Windbreaks as a Solution in Vineyard Agroforestry Systems...........78

V.3. The Effect of Trees on Microclimate in Vineyard Agroforestry Systems.........82

V.3.1. Microclimatic Issues in Conventional Viticulture.....................82

V.3.2. Microclimatic Regulation in Vineyard Agroforestry Systems..........86

V.4. Negative Impacts of Trees in Vineyards...................................90

V.5. Conclusion.......................................................91

CHAPTER VI: Conclusion........................................................ 93

VI.1 Practical Implications............................................... 94

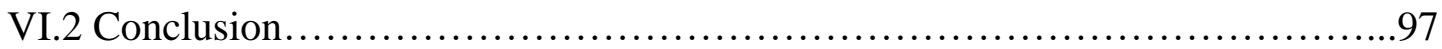

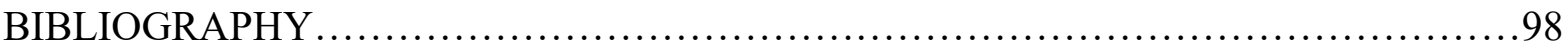

CHAPTER VII: Interspecific Interactions between Olive Trees and Grapevines in Vineyard Agroforestry Systems in an Arid Climate Region........................................118

VII.1. Abstract.................................................................. 119

VII.2. Introduction.......................................................... 120

VII.3.Purpose and Objectives................................................ 120

VII.3.1. Specific Objectives.......................................121

VII.4. Materials and Methods.................................................. 123

VII.4.1. Site...................................................... 123

VII.4.2. Experimental Design......................................124

VII.4.2.i. Background Uniformity Checks..........................125

VII.4.2.ii. Selection of Observational Units........................127

VII.4.3. Data Collection................................................. 130

VII.4.3.i. Quality Parameters..................................130

VII.4.3.ii. Vine Growth Parameters...............................131

VII.4.3.iii. Production Parameters...............................132

VII.4.3.iv. Vine Nutritional Parameters..........................132

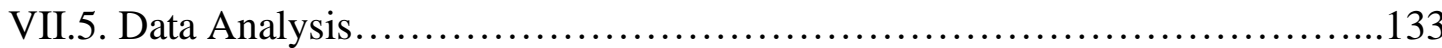

VII.6. Results......................................................... 135

VII.6.1. Quality Parameter Results......................................135

VII.6.1.i. Glucose/Fructose..................................135

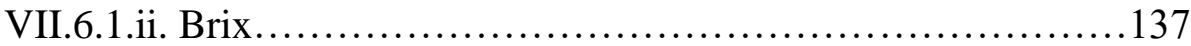

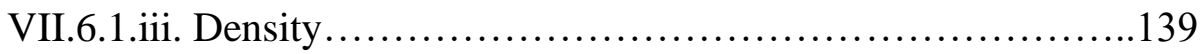

VII.6.1.iv. Total Acidity.......................................141 
VII.6.1.v. pH. 143

VII.6.1.vi. Malic Acid............................................... 144

VII.6.1.vii. Yeast Assimilable Nitrogen...........................144

VII.6.1.viii. Total Skin Phenolics.................................145

VII.6.1.ix. Total Skin Anthocyanins.............................146

VII.6.1.x. Total Skin Tannins......................................146

VII.6.1.xi. Total Seed Phenolics.................................148

VII.6.1.xii. Total Seed Tannins.....................................148

VII.6.2. Growth Parameter Results.......................................149

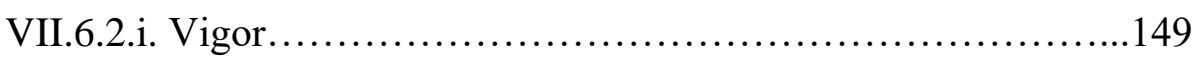

VII.6.2.ii. Ravaz Index...........................................151

VII.6.3. Production Parameter Results.................................152

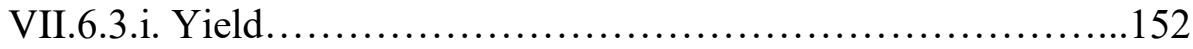

VII.6.4. Nutritional Parameters Results...................................154

VII.6.4.i. Petiole Nitrate.........................................154

VII.6.4.ii. Leaf Blade Total N...................................... 154

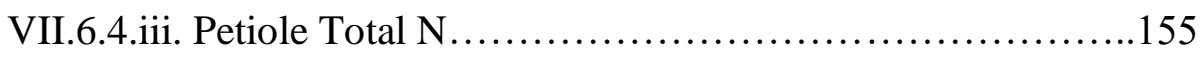

VII.6.4.iv. Leaf Blade P.......................................155

VII.6.4.v. Petiole P............................................. 155

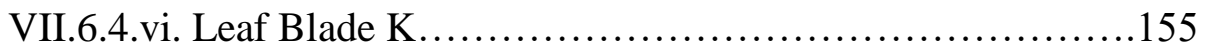

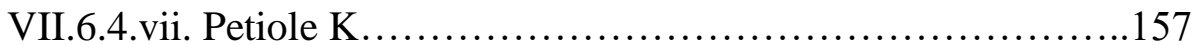

VII.6.4.viii. Leaf Blade Mg..................................... 158

VII.6.4.ix. Petiole Mg......................................158

VII.6.4.x.Nutritional Results Summary.........................158

VII.7. Discussion..................................................... 161

VII.7.1. The Relationship Between Nutrients, Yield, and Vigor.............161

VII.7.2. The Influence of Light, Wind, and Competition for Water...........163

VII.7.2.i. Speculations About the Effect of Light Competition.......163

VII.7.2.ii. Speculations About the Effect of Water Competition......166

VII.7.2.iii. Speculations About the Effect of Wind ..................167

VII.8.Conclusion.............................................................. 167

VII.8.1. Conclusion................................................. 167

VII.8.2. Future Research................................................ 169

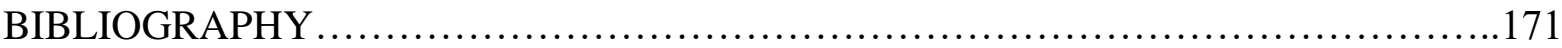

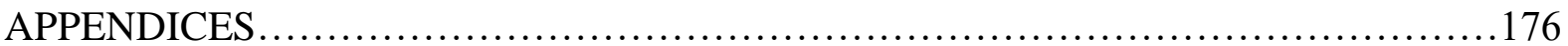

APPENDIX A - Regional Soil Characteristics.................................... 176

APPENDIX B - Background Site Uniformity Tests ............................ 177

APPENDIX C - Selection of Observational Units.............................179

APPENDIX D - Raw Data for Quality, Production, Growth, and Nutritional

Parameters............................................................. 182

APPENDIX E - Normal Values of Macro and Micronutrients in Grapevine Tissue at

Full Bloom in Mendoza, Argentina..........................................186

APPENDIX F - SAS Statistical Output Using the GLM Procedure................187

APPENDIX G - SAS Statistical Output Using the Glimmix Procedure..............271

APPENDIX H - SPSS Statistical Output for Vine Diameter......................283 


\section{LIST OF FIGURES}

Figure 1. Daily precipitation and volumetric soil water content at 12:00 noon $(n=4)$ for crop and agroforestry treatments for 5-, 10-, 20-, and 40-cm depths during 2007 at the Greenley Research Center, University of Missouri, USA. Source: Udawatta et al.

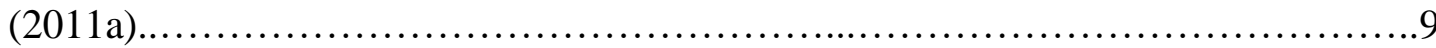

Figure 2. Effect of irrigation treatments of 25\% Plant Available Moisture (PAM), 90\% PAM, $25 \%$ PAM stress during fruit set alone, 25\% PAM stress during ripening alone, and trickle irrigation (concentrated irrigation) at $90 \%$ PAM on the cumulative berry mass of Colombard grapes during the 1979/80 season in South Africa. Source: Van zyl (1984)

Figure 3. Effect of vineyard floor management on soil moisture levels in Cabernet Sauvignon vineyard in Hawke's Bay, New Zealand. Source: Wheeler and Pickering (2005)

Figure 4. Effect of chicory cover crop on perceived ripeness of aroma and flavor in 4-yearold Cabernet Sauvignon wine in Hawkes Bay, New Zealand. Source: Wheeler and Pickering (2005).....

Figure 5. Relationship between vine root density (RD) $\left(\mathrm{kg} / \mathrm{m}^{2}\right)$, vine root mass (RM) (kg/vine) and plant density (PD) (number of vines/ha). Source: Archer \& Saayman (2018)....

Figure 6. Relationship between root density (RD) $\left(\mathrm{kg} / \mathrm{m}^{2}\right)$ and vegetative potential (vigor or shoot mass, VP) per square m of surface unit. Source: Archer \& Saayman (2018)

Figure 7. Major pathways for reducing the impact of pests and diseases via the introduction of plant species diversity in agroecosystems. Source: Ratnadass et al.

2012

Figure 8. Relationship between several types of biodiversity and their role in pest regulation in a diversified vineyard. Source: Altieri et al. (2005).

Figure 9. Nymphal densities of Empoasca vitis in monoculture (conventional) and agroforestry (traditional) vineyards in northwestern Portugal in 1999. Source: Altieri and Nicholls (2002)....

Figure 10. Infestation of grape inflorescences by Lobesia botrana in monoculture (conventional) and agroforestry (traditional) vineyards in northwestern Portugal in 1999. Source: Altieri and Nicholls (2002).

Figure 11. Mean number of damaged berries per cluster $( \pm S E)$ in nocturnal exclosures (bats absent) and controls (bats present) in three vineyards in central Chile over 6 sampling periods from December 2017 to March 2018. Source: Rodríguez-San Pedro et al.

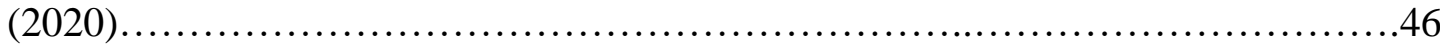

Figure 12. Nightly recorded activity (passes per night) of bats in vineyards in Northern California within the vineyard interior and adjacent to remnant vegetation for: (a) all species combined (b) E. fuscus (c) M. yumanensis and (d) T. brasiliensis. Source: Kelly et al. (2016)...

Figure 13. Temperature of exposed and shaded 'Carignan' berries, relative to the air temperature at cluster height on February 10, 1972. Source: Millar (1972).

Figure 14. The effect of light intensity on the mean number of bunch primordia per bud for the basal 12 buds on shoots. Source: Buttrose (1970). 
Figure 15. Evolution of total flavonol content per berry (A), \% kaempferol (B), \% quercetin (C), and \% myricetin (D) under ambient ( $0 \%$ shading factor) and under two shade nets (20 and 40\% shading factor) covering the fruit-zone of cv. Cabernet Sauvignon grapes. Source: Martínez-Lüscher et al. (2019)......................................66

Figure 16. Schematic representations of potential light availability patterns around a single tree of height $\mathrm{H}$ when integrating the shadows case from said tree from 1 April to 21 September in at a latitude of $43.8^{\circ} \mathrm{N}$, with tree height $\mathrm{H}$, and ellipsoid tree canopy shape. Source: Grimaldi (2018) and Dupraz et al. (2005)........................71

Figure 17. Schematic Model of radiation exchanges above and within a forest. Source: Oke

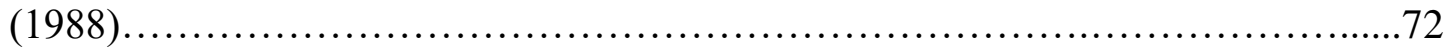

Figure 18. Percentage of erosion for wind and rain on different land management systems in Spain. Source: Marzen et al. (2019) ...........................................78

Figure 19. Modifications of the incoming radiations for an understory crop in the vicinity of a tree. (Source: Grimaldi (2018) ....................................................90

Figure 20. Experimental design setup of Catapano Vineyard, with five treatment blocks at five distances from an olive tree hedgerow..................................129

Figure 21. Average photosynthetic photon flux density measurements $\left(\mu \mathrm{Mol} / \mathrm{m}^{2} / \mathrm{S}\right)$ in grapevine rows at $2 \mathrm{~m}, 4 \mathrm{~m}, 6 \mathrm{~m}, 12 \mathrm{~m}$, and $40 \mathrm{~m}$ from an olive tree hedgerow from the hours of 8 am to $7 \mathrm{pm}$ on a clear spring day in Mendoza, Argentina.............130

Figure 22. The relationship between distance from an olive tree hedgerow and glucose/fructose levels in grape must at harvest in 8-year-old Malbec grapevines in Mendoza Argentina, 2020...................................................137

Figure 23. The relationship between distance from an olive tree hedgerow and brix levels in grape must at harvest in 8-year-old Malbec grapevines in Mendoza Argentina, 2020 .

Figure 24. The relationship between distance from an olive tree hedgerow and density levels of grape must at harvest in 8-year-old Malbec grapevines in Mendoza Argentina, 2020

Figure 25. The relationship between distance from an olive tree hedgerow and total acidity levels in grape must at harvest in 8-year-old Malbec grapevines in Mendoza Argentina, 2020.

Figure 26. The relationship between distance from an olive tree hedgerow and total skin tannin levels in grape must at harvest in 8-year-old Malbec grapevines in Mendoza Argentina, 2020.

Figure 27. The relationship between distance from an olive tree hedgerow and pruning weight taken in dormancy in 8-year-old Malbec grapevines in Mendoza Argentina, 2020

Figure 28. The relationship between distance from an olive tree hedgerow and total yield per vine of 8-year-old Malbec grapevines in Mendoza Argentina, 2020 .

Figure 29. The relationship between distance from an olive tree hedgerow and leaf blade $\mathrm{K}$ levels in 8-year-old Malbec grapevines in Mendoza Argentina, 2019.

Figure 30. Mean foliar nutrient values for grapevines at Catapano Family Vineyard, Maipu, Mendoza, Argentina, as compared to typical nutrient values for grapevines in the Mendoza, Argentina region. 


\section{LIST OF TABLES}

Table 1. Effect of partial root drying on yield, water use and fruit composition of Cabernet Sauvignon grafted to Ramsey. Source Wheeler and Pickering (2005).

Table 2. Average root length density per unit area and per unit of volume for different crops under field conditions. Source: Smart and Coombe

(1983)

Table 3. Mean separations of yield, percentage of shriveled berries per cluster at harvest from 2010 to 2012 in Douro, Portugal. Source: Oliveira et al. (2014)

Table 4. Influence of cluster temperature and exposure to sunlight on flavonol concentrations in Merlot berry skins in the Yakima Valley, Washington, 2000. Adapted from Spayd et al.

Table 5.Growth response of Cabernet Franc to wind in Eden Valley, South Australia. Source: Dry and Botting

(1993).

Table 6. The effect of wind on yield parameters of Chardonnay grapes. Source: Bettiga et al. (1996) 82

Table 7. Quality parameters in grape must at different distances from an olive tree hedgerow....

Table 8. Grapevine production and growth parameters for the 2019/2020 growing seasons.

Table 9. Grapevine nutritional parameters from tissue samples taken at bloom, November 2019

Table 10. Fisher's Least Squares Means post-hoc analyses at 0.05 significance level for glucose/fructose levels $(\mathrm{g} / \mathrm{L})$ in must from grapevines at different distances from an olive tree hedgerow....

Table 11. Fisher's Least Squares Means post-hoc analyses at 0.05 significance level for brix levels in must from grapevines at different distances from an olive tree hedgerow....

Table 12. Fisher's Least Squares Means post-hoc analyses at 0.05 significance level for density levels in must $(\mathrm{g} / \mathrm{L})$ from grapevines at different distances from an olive tree hedgerow

Table 13. Fisher's Least Squares Means post-hoc analyses at 0.05 significance level for total acidity levels $(\mathrm{g} / \mathrm{L})$ in must from grapevines at different distances from an olive tree hedgerow....

Table 14. Fisher's Least Squares Means post-hoc analyses at 0.05 significance level for total skin tannin levels (mg/g fruit) in must from grapevines at different distances from an olive tree hedgerow

Table 15. Fisher's Least Squares Means post-hoc analyses at 0.05 significance level for pruning weights $(\mathrm{g})$ in grapevines at different distances from an olive tree hedgerow ....

Table 16. Fisher's Least Squares Means post-hoc analyses at 0.05 significance level for vine yield $(\mathrm{kg})$ in must from grapevines at different distances from an olive tree hedgerow....

Table 17. Fisher's Least Squares Means post-hoc analyses at 0.05 significance level for leaf blade potassium levels ( $\mathrm{g} / 100 \mathrm{~g}$ dry tissue) in grapevines at different distances from an olive tree hedgerow 
Table 18. Mean foliar nutrient values for vines at different distances from an olive tree hedgerow, taken at Catapano Family Vineyard, Maipu, Mendoza, Argentina, during the flowering period of 2019

Table 19. Correlations between various nutrients in both petioles and leaf blades and yield and vigor. 


\section{ABBREVIATIONS AND ACRONYMS}

C, Carbon

CEC, cation exchange capacity

CWSI, Crop Water Stress Index

$\mathrm{DBH}$, diameter at breast height

EC, electrical conductivity

$\mathrm{K}$, Potassium

Ksat, saturated hydraulic conductivity

$\mathrm{m}$, meters

$\mathrm{N}$, Nitrogen

OM, organic matter

P, Phosphorous

PAM, Plant Available Moisture

PAR, photosynthetically active radiation

PAR $_{\mathrm{T}}$, transmitted photosynthetically active radiation

PD, plant density

$\mathrm{RD}$, root density

SS, soluble solids

TA, Total Acidity

UV, ultraviolet

$\mathrm{VP}$, vegetative potential

$\mathrm{W} . \mathrm{m}^{-2}$, watt per square meter

WUE, water use efficiency

YAN, yeast assimilable nitrogen

$\mu \mathrm{mol} / \mathrm{m}^{2} / \mathrm{s}$, micromoles per square meter per second 


\begin{abstract}
In the face of climate change and environmental degradation, conventional viticulture risks the threats of reduced soil fertility, increased heat stress, water scarcity, unseasonal frost, extreme climate events, wind damage, reduced biodiversity, increased erosion, and increased pest and disease pressure. Agroforestry is a sustainable land-use system proven to address many of these conservation and production issues, and yet, agroforestry's applications in viticulture have been severely overlooked. This thesis summarizes the existing body of knowledge surrounding vineyard agroforestry systems in an extensive literature review, and also contributes new research about olive tree and wine grape vineyard agroforestry systems in an arid and irrigated grape growing region in Mendoza, Argentina.

The existing body of knowledge surrounding vineyard agroforestry systems shows that the incorporation of trees into vineyards reduces pest and disease pressure, prevents wind damage and erosion, increases stomatal aperture and leaf area, and protects vines against heat and frost damage. Existing research on competition for resources in vineyard agroforestry systems suggests that competition for water may not affect grapevines in a negative way, but that competition for nutrients may affect vines within $4 \mathrm{~m}$ of trees, although other studies suggest that trees may actually improve vineyard soil quality. Existing literature also shows that vine yield is reduced within $4 \mathrm{~m}$ of trees.
\end{abstract}

Our experiment on a Malbec/olive tree alley cropped vineyard agroforestry system examined the effects of olive trees on grape quality, growth, and production parameters at five different distances from an olive tree hedgerow. Results revealed that proximity of grapevines to the hedgerow was associated with significantly higher quality must, including higher glucose/fructose levels, higher brix levels, higher must density, and higher total acidity. However, within $4 \mathrm{~m}$ of the hedgerow, grapevines also experienced significantly lower yield, with yield reductions up to $50 \%$ in vines at $2 \mathrm{~m}$ from the hedgerow. Our study 
also revealed that there were no significant differences in nutrient status between treatments in any pattern that would indicate competition, suggesting that competition for nutrients was not a major competitive factor.

The information summarized in this literature review, along with the results of our study, broaden our understanding of vineyard agroforestry systems in different growing contexts and can help determine under which conditions agroforestry should be utilized as an appropriate technology in vineyards. In an arid region with a tree-crop combination of olives and grapevines, the presence of trees was correlated with higher must quality but lower yields. Depending on winemaker goals, the beneficial effects that trees impart on grape must quality parameters, in addition to their whole-farm benefits and ecosystem services, may be determined to outweigh the negative effects that trees have on yield in the rows nearest to trees. Additionally, as many arid grape growing regions anticipate higher temperatures in the coming years due to climate change, utilizing trees in vineyards may be an adaptive strategy for preventing future quality and yield reductions. 
CHAPTER I

LITERATURE REVIEW INTRODUCTION 


\section{I.1 ABSTRACT}

In the face of climate change and environmental degradation, conventional viticulture risks the threats of reduced soil fertility, increased heat stress, water scarcity, unseasonal frost, extreme climate events, wind damage, reduced biodiversity, increased erosion, and increased pest and disease pressure. Agroforestry is a sustainable land-use system proven to address many of these conservation and production issues, and yet, agroforestry's applications in viticulture have been severely overlooked. So as to better understand how agroforestry might help address the issues currently threatening conventional viticulture, this review uses published peer-reviewed literature, as well as some grey-literature, to summarize the current knowledge surrounding both the below-ground and above-ground interactions between trees and grapevines (Vitis vinifera L.) and their effects on water availability, nutrient availability, grapevine rooting patterns, pest and disease pressure, light patterns, wind patterns, and microclimatic factors in vineyard agroforestry systems.

Existing studies reveal that the presence of trees in vineyards imparts a neutral to positive effect on parameters surrounding grapevine water status despite competition, due to trees' ability to reduce evaporation and transpiration, modify the microclimate, and distribute water through hydraulic lift. In terms of nutritional parameters, one study showed that within $4 \mathrm{~m}$ of trees, vines may have reduced nutrient status, however, other studies suggest that trees may actually improve vineyard soil quality, and trees may also potentially increase vine rooting depth and root density by improving soil structure and inducing root plasticity. The incorporation of trees into vineyards has also been shown to reduce pest and disease pressure, prevent wind damage and erosion, increase stomatal aperture and leaf area, and protect vines against heat and frost damage.

Despite the presence of trees being associated with reduced grapevine yields within 4 $\mathrm{m}$ of trees; overall, the incorporation of trees into vineyards can create more resilient 
agroecosystems, can improve certain grape quality and production parameters, can increase farmer savings, and can better the environment in numerous ways. More studies on tree/vine interactions are needed, especially ones that examine different tree/vine species combinations, grape trellis systems, row orientations, and growing zones. However, existing evidence, as summarized in this review, indicates that agroforestry has great potential applications in viticulture despite tradeoffs, especially in the face of the extreme temperatures, pests, plagues, and weather events that are predicted to occur in the coming years with climate change. 


\section{I.2 INTRODUCTION}

Conventional viticulture faces a multitude of issues including erosion and topsoil loss, reduced soil fertility, biodiversity loss, increased pest and disease pressure, increased reliance on agrochemicals, direct and indirect wind damage, heat stress, unseasonal frost, water scarcity, yield and quality reductions due to erratic weather patterns from climate change, and the associated economic losses that accompany all of these challenges (Francis et al. 2004; Martínez-Casasnovas and Ramos 2006; Pimentel 2006; Dunn and Martin 2008; Henderson and Rex 2012; Borrelli et al. 2013; Pachauri and Meyer 2015; Pagay and Collins 2017; Ferreira et al. 2018; Rodrigo-Comino et al. 2018). Agroforestry, defined as the intentional incorporation of trees into agricultural systems (Gold and Garrett 2009), is a sustainable landuse system proven to address many of these conservation and production issues, and it is one solution for creating more sustainable viticulture systems while simultaneously providing numerous other ecosystem services. Agroforestry has great promise for applications in vineyards but until recently, these applications have been overlooked (Grimaldi 2018). This review uses published peer-reviewed literature, as well as some grey-literature, to summarize the current knowledge surrounding the below-ground and above-ground interactions between trees and grapevines, so as to better understand how agroforestry can help address the issues currently facing modern viticulture.

Although vineyard agroforestry systems were, for centuries, the traditional method of wine grape cultivation, since the beginning of the $19^{\text {th }}$ century with the rise of industrialization, vineyards have shifted to monocultures, and the use of trees has largely been abandoned (Fabre 2014). Other than some vineyards in Argentina, Portugal, Spain, Nepal, Italy, Iran, and Greece, the practice is not very common (Amouretti 1988; Bartolucci and Dhakal 1999; Altieri and Nicholls 2002; Raj and Lal 2014; Wezel et al. 2014; Gholami et al. 2018; NPCS Board of Consultants and Engineers n.d.). This shift has brought with it a 
multitude of problems that affect vineyards; which, paired with the extreme weather and environmental patterns caused by climate change, result in yield losses and/or economic losses (Grimaldi 2018). In order for the wine grape industry to continue to thrive in the coming years despite environmental changes, sustainable solutions must be implemented now.

Today, agroforestry in vineyards is being looked to once again as one such sustainable solution. Agroforestry has beneficial applications in viticulture in terms of the below-ground services that it can provide to vineyards, including affecting water parameters, nutritional parameters, and grapevine rooting patterns. Agroforestry also benefits viticultural systems in numerous ways in terms of the above-ground services that it provides, by altering light patterns, wind patterns, pest presence, and the viticultural microclimate. Although some of the interspecific interactions between grapevines and trees have negative effects, many of their interactions are positive. Paired with the fact that trees also provide a host of ecosystem services including purifying water, mitigating pollution, sequestering carbon, conserving biodiversity, and maintaining a beautiful landscape aesthetic (Garcia et al. 2018), the case can be made that agroforestry's applications in vineyards have the potential to create regenerative viticultural systems that are able to both resist and mitigate many of the issues that modern viticulture is confronted with (Raj and Toppo 2018). 
CHAPTER II BELOW-GROUND SERVICES IN VINEYARD AGROFORESTRY SYSTEMS 


\section{II.1. INTRODUCTION}

Tress affect below-ground parameters in vineyard agroforestry systems by influencing elements surrounding water, nutrition, and grapevine rooting patterns. What makes a soil suitable for growing grapes is dependent on many factors, including soil structure, available water holding capacity, nutrient availability, organic matter (OM) quantity, bulk density, porosity, and $\mathrm{pH}$ (Thomazini et al. 2015). Trees have been proven to improve many of these below-ground soil quality parameters in vineyards, causing greater water infiltration and water-holding capacity, greater nutrient availability, better soil quality, and more efficient vine rooting patterns. Trees do have negative impacts on vineyard below-ground parameters as well, such as competing for nitrogen $(\mathrm{N})$ and water, and can negatively impact the growth, quality, and yield of grapevines within $4 \mathrm{~m}$ of trees. However, the benefits of agroforestry on below-ground parameters in vineyards may outweigh its costs, especially in the face of the environmental changes predicted to come in the following years.

\section{II.2. THE EFFECT OF TREES ON WATER PARAMETERS IN VINEYARDS}

\section{II.2.1. Issues Surrounding Water in Conventional Viticulture}

Premier wine grape production typically takes place in semi-arid climates that receive little rainfall, most commonly in Mediterranean, maritime, and continental climate regions (Stevenson 2005). In the coming years, climate change predictions estimate that both periods of drought and periods of extreme precipitation will increase in these regions (Di Carlo 2019). Although grapevines themselves are a drought-resistant species, because of the low rainfall that wine growing regions tend to receive, conserving moisture is still of the greatest priority in most vineyards (Charrier et al. 2018). Additionally, although it is difficult for drought to kill grapevines outright, drought can stunt vegetative growth, reduce fruit quality, and even suppress fruit production completely (Medrano et al. 2003; Charrier et al. 2018). In 
areas where vines are irrigated, excess drought can result in expensive water bills for farmers and even the drying up of groundwater (Cooley et al. 2015). Conversely, increased precipitation can also have negative impacts on the quality of wine (Di Carlo et al. 2019).

\section{II.2.2. Increased Water Conservation in Vineyard Agroforestry Systems}

Trees conserve soil moisture in agroforestry systems through a variety of mechanisms. Shade from trees conserves soil moisture by decreasing temperature and solar irradiance levels, which results in decreased evaporation (Lin 2007). The mulching effect from tree litterfall and prunings also reduces evaporation by covering soil and reducing soil temperatures (Riha and McIntyre 1999). Both the mulching effect of trees and the simple presence of lateral tree roots reduce runoff as well, slowing the flow of water and resulting in higher infiltration rates (Riha and McIntyre 1999). The mulching effect of trees also reduces kinetic impact from rain; reduced kinetic impact from rain maintains surface soil structure intact and therefore sustains high water infiltration rates (Lanyon et al. 2004). Water infiltration is also influenced by the amount of macropores in the soil. Trees increase the quantity of macropores in soil by breaking up compacted soils with their roots and leaving behind old root channels that serve as passages for increased water infiltration (Young 1989a).

Trees increase soil water holding capacity as well by improving overall soil structure. Trees improve soil structure by boosting both OM and microbial populations, each of which leads to the formation of water-stable aggregates that create micro and mesopores in the soil, capable of holding increased amounts of water (Lal 1989). Agroforestry systems can increase OM by up to $100 \%$, and on average, every $1 \%$ increase in OM increases soil-available water holding capacity by $1.9 \mathrm{~mm} 100 \mathrm{~mm}^{-1}$, or $1.9 \%$ (Young 1989b; Minasny and McBratney 2015). A comparison was done between the soil recharge capacity of corn (Zea mays L.)- 
soybean [Glycine max (L.) Merr.] systems as compared to agroforestry systems, and researchers found that the agroforestry systems had significantly higher soil water recharge capacity (Udawatta et al. 2011a) (Figure 1). All in all, agroforestry systems are able to significantly increase soil moisture, water infiltration rates, water recharge capacity, and water holding capacity (Young 1989b), which in turn, results in greater drought resistance and less reliance on irrigation (Shantz 1927).
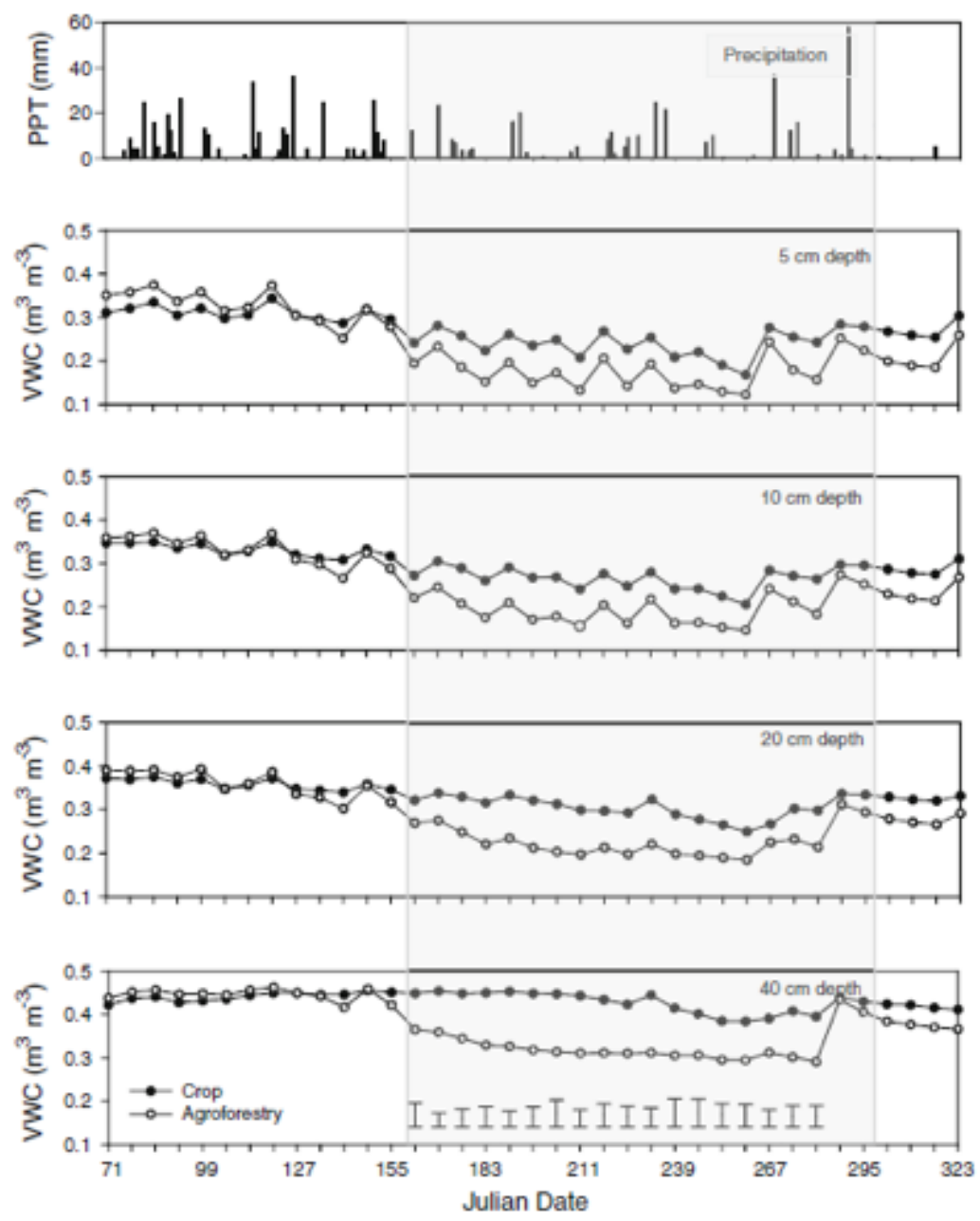

March, April , May | June July, August | Sept. Oct. | Nov.

Figure 1. Daily precipitation and volumetric soil water content at 12:00 noon $(n=4)$ for crop and agroforestry treatments for 5-, 10-, 20-, and 40-cm depths during 2007 at the Greenley Research Center, University of Missouri, USA. Bars on the 40-cm depth graph indicate LSD values for significant differences in water content between crop and agroforestry treatments at the $\alpha=0.05$ level. Source: Udawatta et al. (2011a). (Reproduced with permission). 


\section{II.2.3. Competition Between Trees and Grapevines for Water}

Despite the increased infiltration rates, increased water holding capacity, reduced runoff, and reduced evapotranspiration due to the incorporation of trees in cropping systems, some competition for water between trees and crops in agroforestry systems is inevitable (Udawatta et al. 2011b, 2014, 2016). Although little research has been done on competition for water between trees and grapevines specifically, there is research that has shown that competition for water between grapevines and other crops, including cover crops, does exist, and that this competition can result in varying degrees of water stress (Celette and Gary 2013).

Excess competition can result in high levels of water stress, which, if great enough, can reduce both the number of bunches per vine, berry weight, and the total yield per vine (McCarthy et al. 1983). Various studies have confirmed that excessive water stress reduces photosynthesis, both because of reduced leaf area and increased stomatal closure, which results in lower berry sugar levels (Winkel and Rambal 1993; Gómez-del-Campo et al. 2002; Schultz 2003). In a study on the effect of different irrigation treatments on Colombard grapevines, both fruit growth and vegetative growth were found to be inversely correlated with increases in water stress (Stevens et al. 1995). Additionally, when grapes experience significant water stress, sugar metabolism and flavor development are negatively affected as well (Jones and Webb 2010; Bondada and Keller 2012).

\section{II.2.4. Striking Water Stress Balance in Grapevines}

Although excess competition can cause undesirable levels of water stress in grapevines, some water stress is actually desirable for high quality wine grape production. High water availability is considered undesirable when growing grapes because it promotes excess vigor in grapevines and diversion of resources from developing fruit to shoot tips 
(Wheeler and Pickering 2005). As stated by Lanyon et al. (2004), "Optimum berry quality is seldom achieved if vines are excessively vigorous," due to a number of factors. Excess vigor manifests as higher leaf area, greater trunk growth, and excessive shoot growth rates (Wheeler and Pickering 2003). Excessive shoot growth rates subsequently cause high incanopy shading, which can cause a reduction in anthocyanin and sugar development and an increase in must potassium (K) content and $\mathrm{pH}$ (Wheeler and Pickering 2005). High moisture levels affect overall yield as well; two studies in France - one on Grenache vines and one on Cabernet Sauvignon vines - both found that excess water inhibits the bud burst of basal and primary shoots, resulting in lower bud break and lower yield (Carbonneau and Casteran 1979; Mériaux et al. 1981). In another study in Australia, researchers compared three irrigation treatments: 40\%, 20\%, and 0\% replacement of evaporated water (McCarthy et al. 1983). They found that greater amounts of irrigation water applied resulted in increased berry weight, due to an increased amount of water in the berries, which in turn led to delayed sugar accumulation and diluted sugars and flavors. In this study, increased irrigation reduced wine quality as well; highly irrigated vines produced wine with less-brilliant wine color, lower amounts of anthocyanins, lower total phenolics, higher $\mathrm{pH}$, and increased $\mathrm{K}$, which are all indicators of poor wine quality. Increased in-canopy shading - which was caused by increased vegetation, which was in turn caused by increased irrigation - was not the only culprit of these adverse wine quality effects; even when vigor was controlled for by applying the plant growth regulator, ethephon, poor wine quality was still observed with high levels of irrigation. Excessive vegetative growth can also indirectly reduce grape yield and quality by creating microclimatic humidity that causes vines to be more vulnerable to powdery mildew and other harmful fungi (Smart and Robinson 1991).

For these reasons, mild water stress is indeed desirable when growing wine grapes. In addition to the reasons stated above, mild water stress has been shown to improve wine 
quality by increasing the sugar:acid ratio, lowering malate and total titratable acid concentrations, and increasing total soluble solids (Van zyl 1984). Mild water stress increases grape phenological profiles as well; a study comparing irrigated to non-irrigated Tempranillo grapes found that non-irrigated grapes had significantly higher total phenols and total tannins in grape skins (Esteban et al. 2001). Mild water stress can also increase sugar concentration in berries. In a study comparing the effects of $25 \%, 50 \%, 70 \%$, and $90 \%$ soil moisture regimes, soil moisture regimes of $25 \%$ were found to produce the smallest berries and subsequently the highest concentrations of sugars and phenological compounds (Figure 2).

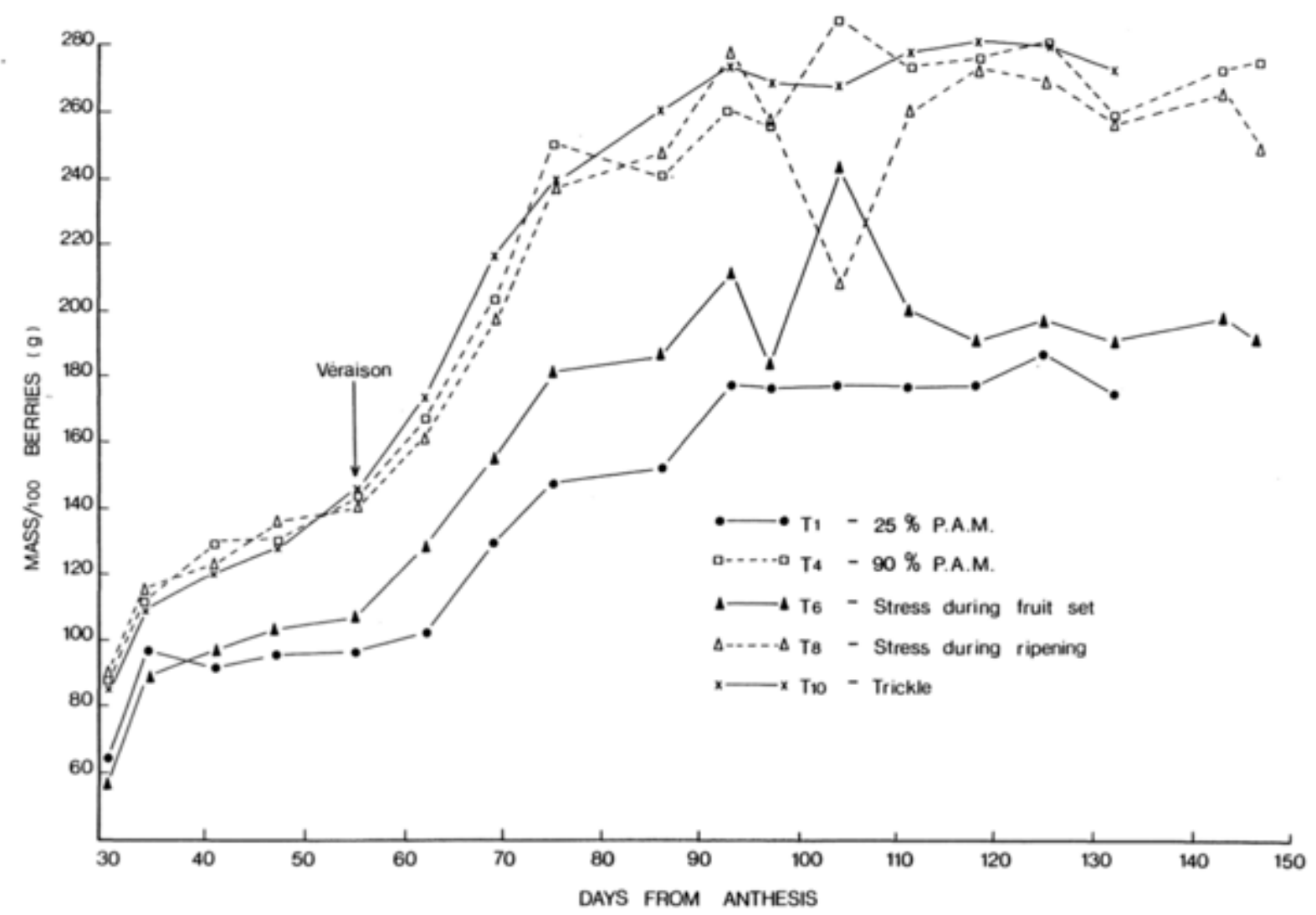

Figure 2. Effect of irrigation treatments of 25\% Plant Available Moisture (PAM), 90\% PAM, $25 \%$ PAM stress during fruit set alone, 25\% PAM stress during ripening alone, and trickle irrigation (concentrated irrigation) at $90 \%$ PAM on the cumulative berry mass of Colombard grapes during the 1979/80 season in South Africa. Source: Van zyl (1984). (Reproduced with permission). 
Grape yield and wine quality are not negatively affected by moderate water stress, but they can be affected by the time at which water stress occurs. Water stress that occurs at certain periods within a vine's growth cycle can positively affect vines, while water stress that occurs at other periods can affect vines negatively (Van zyl 1984). Mild water stress during the period from bud burst to flowering, for instance, can suppress shoot growth, which results in less vegetative growth and thus, the potential for higher wine quality (Van zyl 1984). During flowering and phase I of berry development, however, grapes are very susceptible to water stress, and water stress can cause stunts in cell division, lower fruit set, and desiccation of clusters (Hardie and Considine 1976; Van zyl 1984). After veraison, when cell division is no longer occurring, berry mass is not as sensitive to water stress (Van zyl 1984), although extreme water stress can still result in failure of fruit to mature (Hardie and Considine 1976). In general, neither water stress nor water excesses after the period of veraison impact berry sugar accumulation. Sugar concentration might be increased by water stress during the ripening period due to berry shrinkage, but actual sugar accumulation is affected neither by water deficiencies nor excesses during this period in the grapevine growth cycle (Hunter et al. 2014).

With grapevine growth, striking the balance between too-much water and too-little water is of the utmost importance. Vines must receive sufficient water at the right times in order to produce the minimum amount of vegetative growth that is needed to support fruit development and ripening, and in order to support cell development for sufficient yield. However, vines also must experience slight water stress so as to prevent excessive vegetative growth and so as to not divert nutrient sources away from fruit production (Wheeler and Pickering 2003). To illustrate, a study on Cabernet Sauvignon vines in California applied water in increasing amounts in four different treatments and found that vines receiving high amounts of water experienced delayed maturity and lower yield compared to vines receiving 
moderate amounts of water. However, vines receiving low amounts of water and vines receiving no water also had lower yields than the "moderate water" treatment (Neja et al. 1977). This study reflects the importance of balancing water stress in grapevines; some competition is a good thing, but too much competition can be detrimental.

For these reasons, viticulturists often employ techniques to actually cut back water to ideal-stress levels and to induce slight water competition (Wheeler and Pickering 2005). Such soil-water-reducing techniques include regulated deficit irrigation, partial root zone drying, root pruning, high-density vine planting, and cover crop-induced competition (Wheeler and Pickering 2003; Wheeler and Pickering 2005). Such stress-inducing techniques result in more balanced acidity, more brilliant color $\left(\mathrm{mg} \mathrm{g}\right.$ fruit weight $\left.{ }^{-1}\right)$, higher glycosyl-glucose (mol $\mathrm{g}$ fruit weight ${ }^{-1}$ ), and increased perception of ripeness of aroma and flavor (Dry et al. 1996; Wheeler and Pickering 2003; Wheeler and Pickering 2005). Benefits of these techniques can be summarized in Table 1, Figure 3, and Figure 4. Competition for water from tree roots in vineyard agroforestry systems is also speculated to be a valuable technique for inducing desirable levels of water stress.

Table 1. Effect of partial root drying on yield, water use and fruit composition of Cabernet Sauvignon grafted to Ramsey. Source Wheeler and Pickering (2005). (Reprinted with permission).

\begin{tabular}{|c|c|c|c|}
\hline Parameter & $\begin{array}{l}\text { Control } \\
\text { (Fully } \\
\text { irrigated } \\
\text { vines) } \\
\end{array}$ & $\begin{array}{l}\text { Treatment (Vines } \\
\text { irrigated with partial } \\
\text { rootzone drying) }\end{array}$ & Significance \\
\hline Yield $\left(\mathrm{kg} \mathrm{vine}^{-1}\right)$ & 4.73 & 4.88 & ns \\
\hline $\begin{array}{l}\text { Water use efficiency ( } \mathrm{g} \text { fruit } \mathrm{L} \\
\left.\text { irrigation }^{-1}\right)\end{array}$ & 4.9 & 7.2 & $<0.01$ \\
\hline Total soluble solids ( $\left.{ }^{\circ} \mathrm{Brix}\right)$ & 22.8 & 22.9 & ns \\
\hline $\mathrm{pH}$ & 3.44 & 3.26 & $<0.05$ \\
\hline Titratable acidity $\left(\mathrm{g} \mathrm{L}^{-1}\right)$ & 5.8 & 8.4 & $<0.05$ \\
\hline Color (mg g fruit weight ${ }^{-1}$ ) & 1.19 & 1.72 & $<0.05$ \\
\hline $\begin{array}{l}\text { Glycosyl-glucose (mol g fruit } \\
\text { weight }^{-1} \text { ) }\end{array}$ & 2.64 & 3.75 & $<0.05$ \\
\hline
\end{tabular}




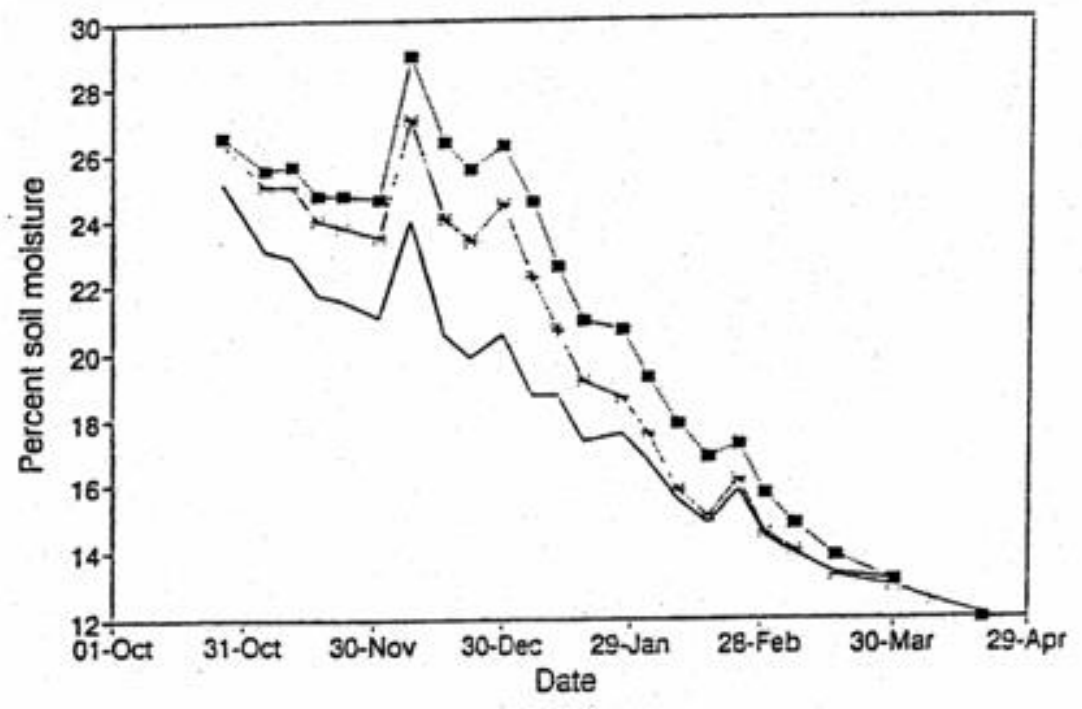

$\rightarrow-$ Bare soil $\rightarrow$ - Rye grass - Chicory

Figure 3. Effect of vineyard floor management on soil moisture levels in Cabernet Sauvignon vineyard in Hawke's Bay, New Zealand. Chicory and ryegrass (Lolium perenne L.) cover crop treatment resulted in lower soil moisture. Source: Wheeler and Pickering (2005) (Reproduced with permission).

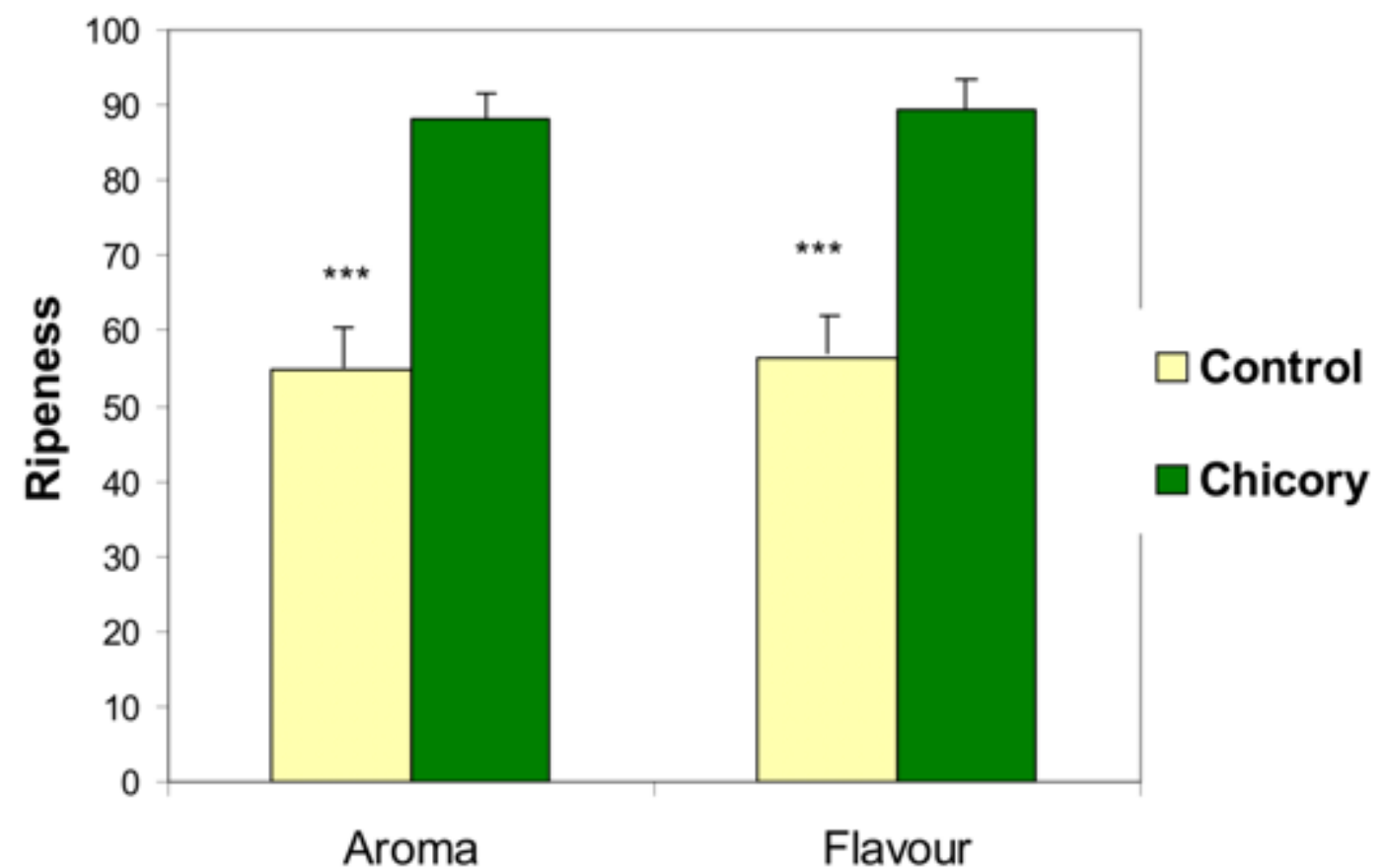

Figure 4. Effect of chicory cover crop on perceived ripeness of aroma and flavor in 4-yearold Cabernet Sauvignon wine in Hawkes Bay, New Zealand. Data shown are mean values $[\mathrm{n}=44]+$ std error; $* * *$ indicates treatments are significantly different at $\mathrm{p}<0.001$. Source: Wheeler and Pickering (2005). (Reproduced with permission). 
More research is needed to determine whether the competition for water rendered by trees in vineyards would result in overall positive or negative effects for grapevines. This is an exactitude that would of course depend on the species of trees being intercropped, the soil available water, the architecture of both species' root systems (which is dependent on both species type and management practices) as well as the amount and timing of transpiration from each species (Grimaldi 2018). The amount of competition would also depend on management practices; trees that are pruned and/or root pruned, and systems that are irrigated more would experience less competition (Sudmeyer and Flugge 2004).

Although much research has yet to be done in this area, in the grey literature there does exist an extensive study at the Restincliéres agroforestry site in Montpellier, France, in which competitive effects between certain types of trees and vines were quantified. In this study, Syrah and Grenache vines were intercropped with sorb (Sorbus domestica L.) and stone pine (Pinus pinea L.) in both N/S and E/W orientations, at both high (15 $\mathrm{m} \mathrm{x} 2.5 \mathrm{~m})$ and low $(15 \mathrm{~m} \times 3.75 \mathrm{~m})$ tree densities. Early grapevine water stress was estimated using the apex method and late-stage soil water stress was quantified using environmental isotope hydrology. Between all treatments, all tree planting densities, and all row orientations, no negative effects from competition for water were observed between trees and grapevines (Trambouze and Goma-Fortin 2013). In a similar unpublished study, GreenSeeker technology was used to measure the Normalized Difference Vegetative Index of vines at different distances from fruit trees. No significant differences in vegetative growth were noted between vines growing near trees and vines growing far from trees (Dufourcq et al. 2017).

In a similar yet different study at the Restinclières experimental site, data on the Crop Water Stress Index (CWSI) of vines in a vineyard agroforestry system was collected using thermal infrared imagery. Results showed that, overall, there were not significant differences 
in CWSI at different distances from tree hedgerows (Grimaldi 2018). Yet another study at the Restinclières viticulture experimental site also found that competition for water between trees and grapevines was negligible, although competition for $\mathrm{N}$ was significant (Trambouze et al. 2017). Available literature suggests that this could be due to trees' ability to redistribute water from deep in the ground through the process of hydraulic lift, reduce evaporative losses from the soil by modifying the climatic demand, reduce transpiration losses by creating a cooler microclimate, and increase water storage capacity by increasing soil OM and porosity (Trambouze et al. 2017; Grimaldi 2018).

There is evidence that both tree roots and grapevine roots exhibit hydraulic redistribution, defined as the transfer of water from deep edaphic sources to drier soils (Smart et al. 2005). In both trees and grapevines, this process occurs both vertically (roots draw water up from deep profiles into shallower ones) and also laterally (roots draw water from irrigated areas to non-irrigated areas) (Smart et al. 2005). This phenomenon allows both tree and vine roots to expand to unirrigated parts of the soil, allowing them to absorb nutrients and maintain strong anchorage across a broader area. The fact that both grapes and trees have the capacity for hydraulic redistribution is hypothesized as one of the reasons why low competition appears to exist between grapevines and trees in vineyard agroforestry systems (Grimaldi 2018).

Overall, the existing studies on agroforestry in vineyards suggest that trees have a neutral to positive effect on parameters surrounding grapevine water status. Grapevines are a drought tolerant species which are capable of producing higher quality berries and higher yields under slight water stress (Carbonneau and Casteran 1979; Mériaux et al. 1981; Wheeler and Pickering 2005; Charrier et al. 2018). Although trees and grapevines do impart some levels of water stress through competition and root niche overlap, trees can also conserve water in vineyards by reducing evapotranspiration through increased shade and 
mulch, by increasing water infiltration through improvements in soil structure and water holding capacity, and by distributing water from wet to dry zones through hydraulic distribution (Young 1989a, 1989b; Morlat and Jacquet 1993; Riha and McIntyre 1999; Lanyon et al. 2004; Smart et al. 2005; Kailis and Harris 2007; Lin 2007; Bhadha et al. 2018). Given all tradeoffs, research findings suggest that trees would not induce damagingly high levels of water stress through competition for water, and grey-literature studies have confirmed that trees in vineyards did not increase CWSI in vines (Grimaldi 2018) and that water is not responsible for reductions in fruit quality, vegetative growth, nor yield (Trambouze et al. 2017). More studies on the effects of tree/vine competition for water are needed, especially ones that examine different tree species, grape trellis systems, row orientations, and layouts, in order to definitively determine the effects of trees on grapevine water status.

\section{II.3. THE EFFECT OF TREES ON VINE NUTRITION PARAMETERS}

\section{II.3.1. Issues Surrounding Nutrition in Conventional Viticulture}

Conventional vineyards commonly face nutritional issues in soil due to low organic matter levels, high levels of erosion, low microbial activity, and compaction (Pool et al. 1990; Garcia et al. 2018). Globally, soil erosion is increasing at epidemic rates of $2.5 \%$ per year - a rate 10 to 40 times faster than the rate of soil renewal (Pimentel 2006; Borrelli et al. 2013). Viticulture is not immune to these losses; in fact, conventionally cultivated vineyards are considered one of the most erosion-prone land use practices because of the lack of ground cover, the high rates of tillage, and high levels of compaction associated with traditional management practices (Coll et al. 2011). Several studies have quantified these erosion effects. Vineyards in the Bairrada wine region of Portugal have been shown to experience sediment loss at alarmingly high rates, up to $29 \mathrm{Mg} \mathrm{ha}^{-1} \mathrm{yr}^{-1}$, with total $\mathrm{N}$ losses of up to $20 \mathrm{~kg}$ 
$\mathrm{ha}^{-1} \mathrm{yr}^{-1}$ (Ferreira et al. 2018). Similarly, bare-soil vineyards in an eight-year study in Tuscany, Italy experienced $\mathrm{N}$ losses of $12.5 \mathrm{~kg} \mathrm{ha}^{-1} \mathrm{yr}^{-1}$ and phosphorous (P) losses of $5 \mathrm{~kg} \mathrm{ha}^{-1} \mathrm{yr}^{-1}$ (Napoli et al. 2017). Soil erosion results in the loss of soil organic carbon as well; in a study on vineyards in Sicily, Novara et al. (2018) found that soil organic carbon was lost at a rate of $0.20 \mathrm{Mg} \mathrm{ha}^{-1} \mathrm{yr}^{-1}$, and that total sediment loss was $16 \mathrm{Mg} \mathrm{ha}^{-1} \mathrm{yr}^{-1}$. Fertility losses such as these result in the need to apply high amounts of fertilizers and can cause real economic losses for farmers (Novara et al. 2018). Using data from vineyards in northeastern Spain, economists estimated that the amount of $\mathrm{N}$ lost by normal, bare-soiled vineyards each year amounts to $2.4 \%$ of a vineyard's annual income, and that the amount of $\mathrm{P}$ lost each year amounts to $1.2 \%$ of annual income (Martínez-Casasnovas and Ramos 2006).

Conventional vineyard floor management generally leads to impaired soil structure and reduced soil water holding capacity as well (Biddoccu et al. 2017; Rodrigo-Comino et al. 2018), which in turn results in reduced biological activity and consequently diminishing levels of OM and nutrients over time (Pool et al. 1990). Many studies have proven the importance of incorporating cover crops and other service crops into vineyards to address these issues (Garcia, et al., 2018), but few studies have looked at the incorporation of trees specifically. The use of trees in agroforestry systems in general can have dichotomous effects on crop nutrition; trees can both cause nutrient stress due to increased competition between species, but trees can also increase nutrient availability through a variety of mechanisms.

\subsubsection{Increased Nutrient Availability in Vineyard Agroforestry Systems}

Trees increase the soil nutrients available for crop uptake by increasing OM, cycling nutrients from deep soil profiles to shallow ones, fixing $\mathrm{N}$ (in the case of leguminous trees) and transforming nutrients into a more plant-absorbable form through increased microbial activity (Young 1989b). Although vineyards do not necessarily require high levels of $\mathrm{N}$, they 
do perform better when there are adequate levels of soil OM and nutrients (Pool et al. 1990). Research suggests that the increased nutrient availability imparted by trees in vineyard agroforestry systems may balance out some of the competition for nutrients that occurs in these systems.

Agroforestry systems have the potential to increase soil OM by $50-100 \%$ (Young 1989b). They have been shown to return an average of 7.4 tons of OM per hectare per year in the form of prunings alone, and they also produce OM through litterfall, root slough, and root exudates (Nair 1993b; Schroeder 1993; Thevathasan and Gordon 2004). Nutrients that take the form of $\mathrm{OM}$ are released slowly at rates comparable to rates of plant-absorption, and they are in a stable molecular form that is resistant to leaching (Young 1989b). Organic matter produced by trees serves as a source of food for microbes, which results in increased microbial populations; indeed, trees in agroforestry systems have been shown to increase soil microbiological activity by up to $30 \%$ (Young 1989a). Microbes excrete enzymes that mineralize nutrients, that stabilize carbon and $\mathrm{N}$ in the soil, and that decompose $\mathrm{OM}$ into simple, plant-available forms, resulting in higher plant nutrient uptake (Paudel et al. 2011; Adetunji et al. 2017). Increased OM in agroforestry systems also results in increased cation exchange capacity (CEC), which translates to a greater ability of soil to hold onto exchangeable cations. This results in better retention of applied nutrients and resistance from nutrient leaching (Young 1989b; Maher et al. 2008).

Trees increase nutrient cycling in agroforestry systems as well by drawing nutrients up from deep in the ground, converting them into plant tissue and OM, dropping OM to the ground in the form of leaf litter and above-ground debris, and thereby releasing nutrients into the upper soil profiles, making them available for other crops to take up (Ramachandran et al. 1999). Nitrogen-fixing trees are capable of cycling $\mathrm{N}$ from the atmosphere into the soil as 
well, through the process of $\mathrm{N}$ fixation. Depending on the species, trees can fix $\mathrm{N}$ at average rates of 40 to $200 \mathrm{~kg} \mathrm{~N} \mathrm{ha}^{-1} \mathrm{yr}^{-1}$ (Nair 1993a).

\section{II.3.3. Reduced Nutrient Losses in Vineyard Agroforestry Systems}

Trees also allow more nutrients to remain in cropping systems by reducing nutrient losses from leaching, erosion, and runoff. There is an abundance of evidence supporting the use of vegetative ground cover in general in vineyards to reduce such nutrient losses due to leaching and erosion. A study in Italy compared the erosion rates of conventionally-tilled vineyards to those of vineyards with a grass cover crop by measuring infiltration rates, runoff discharge, and sediment yield at various rainfall intensities in each system. In the summer after high rainfall events, grass-covered vineyards experienced $83 \%$ less mean annual soil loss than did conventionally-tilled vineyards (Bagagiolo et al. 2017). Another study in Germany compared the erosion rates between a bare-soil vineyard and a grass-covered vineyard and found that soil losses and runoff rates were significantly higher in the bare-soil vineyards (Kirchhoff et al. 2017). Other studies have measured the erosion rates of bare-soil vineyards as well, and they support the conclusion that bare soils are one of the greatest determining causes of soil erosion in vineyards (Cerdà and Rodrigo-Comino 2018; Rodrigo-

Comino et al. 2018). These studies have suggested the use of tree hedgerows, a type of agroforestry system, as a possible solution for halting erosion in vineyards (Cerdà and Rodrigo-Comino 2018).

Although there is little research on erosion reduction in vineyard agroforestry systems in specific, other studies have shown that agroforestry in general reduces soil erosion levels. As mentioned above, agroforestry systems have been shown to increase soil OM by up to $100 \%$ (Young 1989b), and just a 10\% increase in OM results in a decrease in soil erodibility by roughly 13-23\% (Young 1989c). Litterfall from trees in agroforestry systems translates to 
increased groundcover, which also results in reduced surface runoff and thus reduced erosion (Kimmins 1997; Pimentel 2006). While bare soil is exposed to the kinetic force of rain, which "seals the surface" of soils, breaks down soil structure where impact has occurred, dislodges soil particles, and reduces infiltration rates; agroforestry systems have a layer of surface mulch that protects soil from kinetic impact (Riha and McIntyre 1999; Cerdà and Rodrigo-Comino 2018). Indeed, studies comparing hedgerow intercropped agroforestry systems to monoculture systems found that the agroforestry systems in question had saturated hydraulic conductivity (Ksat) rates of $50 \mathrm{~cm} \mathrm{hr}^{-1}$, while the monoculture systems had rates of only $18.5 \mathrm{~cm} \mathrm{hr}^{-1}$ (Riha and McIntyre 1999). In a study comparing silvopasture agroforestry systems to treeless pastures in Missouri, Kumar et al. (2012) saw 31 times greater quasisteady state infiltration (qs) and 46 times greater saturated hydraulic conductivity (Ksat) in the agroforestry systems than in the treeless pastures. Similarly, Seobi et al. (2005) observed 14 times greater Ksat in grass and agroforestry buffers compared to a corn-soybean rotation in Missouri. Increased infiltration results in reduced runoff, which results in fewer nutrients that are carried out of the system (Seobi et al. 2005). Agroforestry reduces erosion potential by reducing compaction as well (Seobi et al. 2005; Kumar et al. 2008; Udawatta et al. 2011a).

Because nutrient loss due to soil erosion is such a large problem for vineyards, addressing soil erosion can result in significant farmer savings on fertilizer inputs. Depending on a number of factors such as vineyard size, slope, and soil type, among others, it is estimated that, on average, European viticulturists could save up to 1,088 Euros ha ${ }^{-1}$ annually by planting vegetative cover in vineyards, due to the increased nutrient retention that vegetative cover provides (Galati et al. 2015). It is speculated that agroforestry systems could be one such vegetative cover that is suitable for addressing erosion issues and maintaining nutrients within the cropping system (Cerdà and Rodrigo-Comino 2018). 


\section{II.3.4. Competition Between Trees and Grapevines for Nutrients}

Despite the increased nutrient availability that trees provide to crops, trees do compete with crops for nutrients. In general, competition for below-ground nutrients is more of a limiting factor for crop growth in agroforestry systems than even light is (Gillespie et al. 2000) and this pattern may very well extend to vineyard agroforestry systems as well. In an unpublished study on a 13-year-old vineyard agroforestry system in France in which grapevines were intercropped with Stone Pine (Pinus pinea L.), and Service Tree (Sorbus domestica L.), at densities of 222 trees $\mathrm{ha}^{-1}$, data on vine nutrient status, vigor parameters, yield, berry quality, and soil electromagnetic conductivity was collected. Results showed that beyond $4 \mathrm{~m}$ from tree rows, no negative effects on grapevine yield due to competition for nutrients were experienced. However, at distances of $2.5-3.23 \mathrm{~m}$ from tree rows, high levels of competition for nutrients, especially N, were experienced. These negative effects manifested as reductions in vine vigor and yield, however, no reductions in berry quality were observed. No negative effects from water competition were experienced; nutrients and/or light were speculated to be the limiting factors (Trambouze and Goma-Fortin 2013).

In line with these results, another study examining competition between vines and cover crops also discovered that vines are sensitive to $\mathrm{N}$ competition in particular, more than other factors. In a study comparing five vineyard floor management treatments: bare soil without tillage, bare soil with tillage, sawdust mulch, chicory cover crops without tillage, and permanent chicory cover crops, researchers found that vines which received the bare-soil treatment (no competition) had the highest petiole nitrate concentration. Vines receiving cover crop treatments (both with tillage and without), on the other hand, had lower tissue $\mathrm{N}$ content, lower shoot growth, and lower pruning weights, showing that the presence of cover crops in vineyards does indeed result in competition for nutrients (Wheeler et al. 2005). A similar experiment comparing clean cultivation to cover crop treatments echoed these 
findings and found that, while cover crops increased water infiltration and did not compete excessively with vines for water, they did cause a significant decrease in the tissue $\mathrm{N}$ status of grapevines (Saayman and Huyssteen 1983). All of these findings point to the conclusion that nutrients, rather than water, are most likely the limiting factor for grapevine growth.

\section{II.3.5. Striking Nutritional Balance in Grapevines}

Agroforestry's applications in vineyards could negatively affect grapevine nutrient status (Trambouze et al. 2017). However, in instances when vines are excessively vigorous, some competition for $\mathrm{N}$ can be beneficial. High soil fertility does not necessarily equate to higher yield nor higher quality wine grapes, and in grapevines there exists a fine balance between healthy competition and excessive competition for nutrients (Wheeler and Pickering 2003). Too little $\mathrm{N}$ can result in severe stress, reduced yields, and decreased bud fertility, but too much $\mathrm{N}$ can result in reduced fruit set, excess allocation of resources to vegetative growth, increased in-canopy shading, and poor fruit quality (Wheeler and Pickering 2003). Vegetative imbalance from excessive $\mathrm{N}$ can delay crop maturation, prevent berry sugar accumulation, reduce phenolic concentration, and increase susceptibility to diseases such as powdery mildew and Botrytis cinera (Wheeler and Pickering 2005). Additionally, excess vegetative growth leads to increased production costs from an increased need for spraying, trimming, leaf pulling, and thinning (Smart and Smith 1988). In general, grapevines have lower $\mathrm{N}$ requirements than many other crops, and they can maintain high yields and high quality production in soils that are slightly deficient in N (Smart and Smith 1988; Martison 2010).

In wine grape growing, striking the balance between excessive and healthy levels of competition for nutrients is of the utmost importance (Smart and Smith 1988). Nutrients are more of a limiting factor for grapevines than is water (Ussahatanonta et al. 2008) and 
nutritional balance can be difficult to achieve (Smart and Smith 1988). Although grapevines thrive under levels of slight nutrient deficiency, both nutrient surpluses and extreme nutrient deficits negatively impact vine growth, grape quality, and yield (Wheeler and Pickering 2005). In vineyard agroforestry systems, trees provide many nutritional benefits to the soil by increasing OM, cycling nutrients from deep soil profiles to shallow ones, fixing $\mathrm{N}$, supporting microbial activity, increasing CEC, resisting nutrient loss from leaching and erosion, and increasing plant absorbability of nutrients (Young 1989a, 1989b; Nair 1993b; Schroeder 1993; Ramachandran et al. 1999; Thevathasan and Gordon 2004; Paudel et al. 2011; Adetunji et al. 2017). These positive benefits may balance out some of the negative effects on nutrient status caused by competition between trees and vines. However, the current literature reveals that, overall, trees do cause negative effects on grapevine yield and growth within $4 \mathrm{~m}$ of tree hedgerows, likely due to competition for $\mathrm{N}$ (Trambouze et al. 2017). Thus, it is most likely that the negative effects that trees have on on vine nutritional parameters outweigh their positive benefits within $4 \mathrm{~m}$ of trees (Trambouze et al. 2017). Beyond $4 \mathrm{~m}$ of distance, there does not seem to be any effect, neither positive nor negative, but further evidence is needed to confirm the current studies' findings (Trambouze et al. 2017).

\section{II.4. THE EFFECT OF TREES ON VINE ROOT SYSTEMS}

\section{II.4.1. Issues Surrounding Vine Rooting Patterns in Conventional Viticulture}

Competition for nutrients and competition for water are two limiting factors that can hinder grapevine production in vineyard agroforestry systems when not managed correctly. Even though grapevines can, as proven, thrive at some levels of competition with other deeprooted plants, excess competition can be damaging. However, much of the ability of vines to absorb both water and nutrients in the face of competition depends on the health and spatial 
distribution of the vine's root system (Morlat and Jacquet 1993). Yield and overall quality of grapes is largely dependent on the ability of a vine's root system to exploit soil resources, and as such, it is important to examine the effects that interspecific interactions have on the roots of vines in specific (Morlat and Jacquet 1993). Research suggests that the depth and expansion of grapevine roots is highly dependent on soil structure and permeability, even more so than genotype (Smart et al. 2006), and that grapevine root plasticity is also influenced by planting density and competition (Hidalgo 1968). Yield decline as a result of reduced soil permeability and increased compaction is a common occurrence in conventional vineyards and must be addressed (Pool et al. 1990).

\section{II.4.2. Improved Soil Structure in Vineyard Agroforestry Systems}

Although trees in vineyard agroforestry systems can compete with vines for nutrients and water, these negative effects can be balanced by the positive influences that trees have on soil structure and quality (Smart et al. 2006). Soil structure consists of the spatial arrangement of individual soil particles, their aggregates, and the pore space that is formed between them (Lanyon et al. 2004). Soil structure affects soil strength, water holding capacity, nutrient retention, aeration, friability, erodibility, plant root movement, and biological activity (Lanyon et al. 2004). High-quality soil structure allows for deeper and stronger vine root systems that are better able to exploit soil resources (Smart et al. 2006), and thus, it allows for higher grape production and quality despite competition.

According to Northcote (1988), soil porosity, and the increased aeration and waterholding capacity that comes with it, is an even more important determinant of quality wine grape production than nutrient availability is. High aggregate stability (which leads to high porosity, high levels of water infiltration, low bulk density, and consequently, greater root expansion) was also found to be a major wine grape quality determinant (Oliver et al. 2013). 
Soil penetrability, also determined by soil structure, is an important determinant of grapevine yield and quality as well (Henry 1993). An experiment was conducted in which grapevines were grown in soils with varying compaction levels. Researchers found that both size and depth of grapevine root systems decreased with increasing bulk density, and that grapevine roots did not occupy pores $<200 \mu \mathrm{m}$ in diameter (Henry 1993). In a large-scale study across a variety of soil conditions throughout Australia, Myburgh et al. (1998) found that compacted soils with higher bulk density, greater incidence of cemented hardpans, and lower porosity were correlated with higher levels of grapevine root restriction and subsequent reduced yield and fruit quality.

Agroforestry has been shown to improve soil structure - including soil porosity, penetrability, aggregate stability, water holding capacity, and strength - through a variety of mechanisms. As such, it has the potential to improve grapevine rooting potential, and consequentially, production and fruit quality (Young 1989a, 1989b). Depending on what kinds of trees are used in vineyard agroforestry systems, a mulching effect from litterfall and pruning materials can occur that can have considerable beneficial effects on topsoil structure (Riha and McIntyre 1999). Soil cover improves soil structure by reducing raindrop and irrigation impact, which leads to conserved surface macro-porosity, which leads to greater water infiltration rates and resultingly, improved soil penetration (Lanyon et al. 2004). An eight-year study on different groundcover treatments including red fescue sod (Festuca rubra L.), post-emergence herbicides, pre-emergence herbicides, and mulch confirmed that mulch lowers bulk density, decreases compaction, increases soil porosity, and increases water infiltration compared to bare-soil treatments and even the cover crop treatment (Oliveira and Merwin 2001).

Agroforestry systems also improve soil structure through the high amounts of root biomass that trees produce (Seobi et al. 2005). Tree roots in agroforestry systems improve 
soil macroporosity by breaking up compacted soils and leaving behind old root channels that grapevine roots are able to occupy for greater rooting depth capability (Mckenry 1984; Young 1989a). Finer roots also contribute to improved soil structure. In a study on agroforestry buffers in corn-soybean systems, researchers observed that tree buffer treatments produced higher porosity, increased coarse mesoporosity, and improved soil structure, most likely due to the increased root development in the tree buffer treatments (Seobi et al. 2005). In the case of vineyards, improved soil quality, such as seen in this experiment, would result in greater vine rooting capacity (Henry 1993).

The increased OM content that agroforestry systems impart to soil is another major contributor to improved soil structure. Soil structure is largely influenced by the amount of OM in soil (Young 1989b). In addition to increasing water infiltration and fertility, as mentioned previously, higher levels of OM translate to higher aggregate stability and overall improved structure (Balesdent et al. 2000). Organic matter contains sticky substances from bacterial exudates, organic gels, fungal hyphae, and excretions from fauna, and is able to "glue" soil particles together, thereby creating stable soil pores (Rashid et al. 2016). Agroforestry systems have been proven to increase soil OM by $50-100 \%$, thus increasing porosity, reducing bulk density, and increasing soil water holding capacity (Young 1989b). It can be speculated that because of this increase in OM, agroforestry's applications in vineyards would result in improved soil structure, resulting in increased rooting capability, and subsequently, higher yields and higher quality fruit production (Henry 1993).

\section{II.4.3. Soil Niche Competition Between Tree and Grapevine Roots}

Based on typical interspecific competitive interactions in agroforestry systems in general (Chirko et al. 1996), it is speculated that interspecific competition in vineyard agroforestry systems would be dependent on the measured extent of associated tree roots. In 
order to avoid competition within agroforestry systems in general, it is important to take into consideration crop and associated tree root distribution patterns. Within the top $30 \mathrm{~cm}$ of any intercropped system there is typically intense competition between roots for nutrients and water, which results in lower yields and lower plant biomass production (Jose et al. 2009). However, below-ground competition be tempered through spatial separation of tree and crop roots; for example, by combining deep-rooted trees with short-rooted crops (Lott et al. 1995). In the case of agroforestry's applications in vineyards, both tree roots and vine roots can be very long. Although the majority of grapevine roots are found in the top 1-2 $\mathrm{m}$ of soil, their roots, like those of trees, can reach much greater deep depths (Smart et al. 2006). It is estimated that $63 \%$ of grapevine roots are found in the upper $60 \mathrm{~cm}$ of soil, $80 \%$ of grapevine roots are found in the upper $1.0 \mathrm{~m}$ of soil, and that the remaining roots can extend to depths of $12 \mathrm{~m}$ (Lavee 2000; Smart et al. 2006). In contrast, 77\% of coniferous forest tree roots are found in the upper $60 \mathrm{~cm}$ of soil, and $91 \%$ of coniferous tree roots are found in the upper 1.0 $\mathrm{m}$ of soil, revealing that grapevines might have a higher concentration of roots at deeper soil profiles than even some trees do (Jackson et al. 1996). Laterally, grapevine roots can spread outwards from the vine trunk up to $10 \mathrm{~m}$ (Smart et al. 2006).

The amount of overlapping soil niche occupation between grapevine roots and tree roots depends on the kind of trees that are utilized in the vineyard agroforestry system. Of the few vineyard agroforestry systems in existence today, most consist of grapes intercropped with olives (Olea europaea L.), Portuguese Oak (Quercus lusitanica Lam.), elm (Ulmus sp.), poplar (Populus sp.), and wild cherry (Prunus sp.) (Altieri and Nicholls 2002). Due to a lack of research, it is not known which trees might be most compatibly grown with grapevines (Lanyon et al. 2004). In the case of olive trees, lateral tree roots generally extend up to $12 \mathrm{~m}$, and vertical roots grow even deeper (Kailis and Harris 2007). Like grapevines, the majority of nutrient uptake occurs in the top $1 \mathrm{~m}$ of soil, and water uptake occurs within the top $1.2-$ 
$1.7 \mathrm{~m}$ of soil (Morlat and Jacquet 1993; Kailis and Harris 2007). These results suggest that there may be substantial below-ground niche overlap in these systems. Similarly, a study on an 11-year-old Sorbus domestica L./grapevine agroforestry system found that tree roots and vine roots occupied the same soil profile at distances of up to $8 \mathrm{~m}$ from the tree rows (Trambouze and Goma-Fortin 2013).

However, even though tree and vine roots occupy similar soil profiles, findings surrounding grapevine root morphology propone that there are still sufficient morphological and physiological differences between tree roots and vine roots to allow water and nutrient capture in different areas (Grimaldi 2018). Grapevine roots have been shown to exploit biopores left behind by dead tree roots and have been known to occupy "fracture lines" created by tree roots as well (Mckenry 1984). Because of this phenomenon, research suggests that grapevine roots evolved in competition with trees, and that it is possible for tree roots and grapevine roots to occupy different niches, even though they might exist within the same soil profile (Mckenry 1984).

The extent of interspecific competition for nutrients also depends on the root density (RD) per unit area volume of the competing species. The absorption rate of nutrients in plants is dependent on root length density and thus, higher root length density in competing species can result in higher rates of competition for N (Fargione and Tilman 2006). Average root length density per unit area and per unit volume varies by species (Table 2). More research must be done to determine which tree species are most compatible with grapevines, both in terms of spatial root distribution and also in terms of nutrient and water absorption potential (Jonsson et al. 1988). 
Table 2. Average root length density per unit area and per unit of volume for different crops under field conditions. Source: Smart and Coombe (1983). (Reprinted with permission).

\begin{tabular}{|c|c|c|}
\hline & $\begin{array}{c}\text { Root length } \\
\left(\mathrm{cm}_{\text {root }}, \mathrm{cm}_{\text {soit }}^{-2}\right)\end{array}$ & $\begin{array}{c}\text { Root density } \\
\left(\mathrm{cm}_{\text {root }} \cdot \mathrm{cm}_{\text {soil }}^{-3}\right)\end{array}$ \\
\hline Grapevines & $0.9-4$ & $0.002-0.03$ \\
\hline Apple trees & $0.8-24$ & $0.01-0.2$ \\
\hline Pear trees & $7-69$ & $0.12-0.56$ \\
\hline Prune trees & $15-68$ & $0.13-0.56$ \\
\hline Conifers & $5-126$ & $0.5-0.69$ \\
\hline Cereals & $100-4000$ & \\
\hline
\end{tabular}

\section{II.4.4. Balancing Competition through Root Plasticity in Vineyard Agroforestry Systems}

Inferences about how grapevine roots will perform in vineyard agroforestry systems can be drawn based on evidence of how grapevine roots perform when in competition with cover crops and with other vines in high-density plantings. Archer and Strauss (1985), in a study on grapevine root distributions at varying planting densities, found that vineyards with narrower spacings were able to utilize soil more efficiently and exploit more nutrients and water while occupying a smaller space. This study found that when grapevine roots compete with other vines for water at higher planting densities, the horizontal space occupied by roots decreases, but RD increases, showing that grapevine root morphology can be modified to better exploit a smaller area, if necessary. Similarly, Hidalgo (1968) also found that throughout the entire soil profile, as plant density increased, root mass per vine decreased, but that RD increased (Figure 5). Root density is positively correlated with vine vigor (Figure 6). These findings point to the possibility that reduced nutrient availability from competition might be at least partially compensated for by increased root plasticity due to competition. Branas and Vergnes (1957) also found that as vine planting density increased, the quantity of shallow roots $(25-45 \mathrm{~cm})$ decreased, while the quantity of deep roots $(65+\mathrm{cm})$ increased, showing better utilization of soil volume in response to competition. It can be speculated that 
grapevines experiencing competition from tree roots rather than other vine roots would exhibit similar RD distribution patterns and exhaustive exploitation of soil resources.

Grapevine root plasticity can be induced by competition for water as well; the available soil water supply can determine the quantity of roots and the vertical distribution of roots (Morlat and Jacquet 1993). Studies have shown that more grapevine roots are produced under dry irrigation regimes than wet irrigation regimes, demonstrating that grapevine roots can indeed exhibit plasticity in response to resource scarcity as well (Freeman and Smart 1976; Freeman et al. 1982).

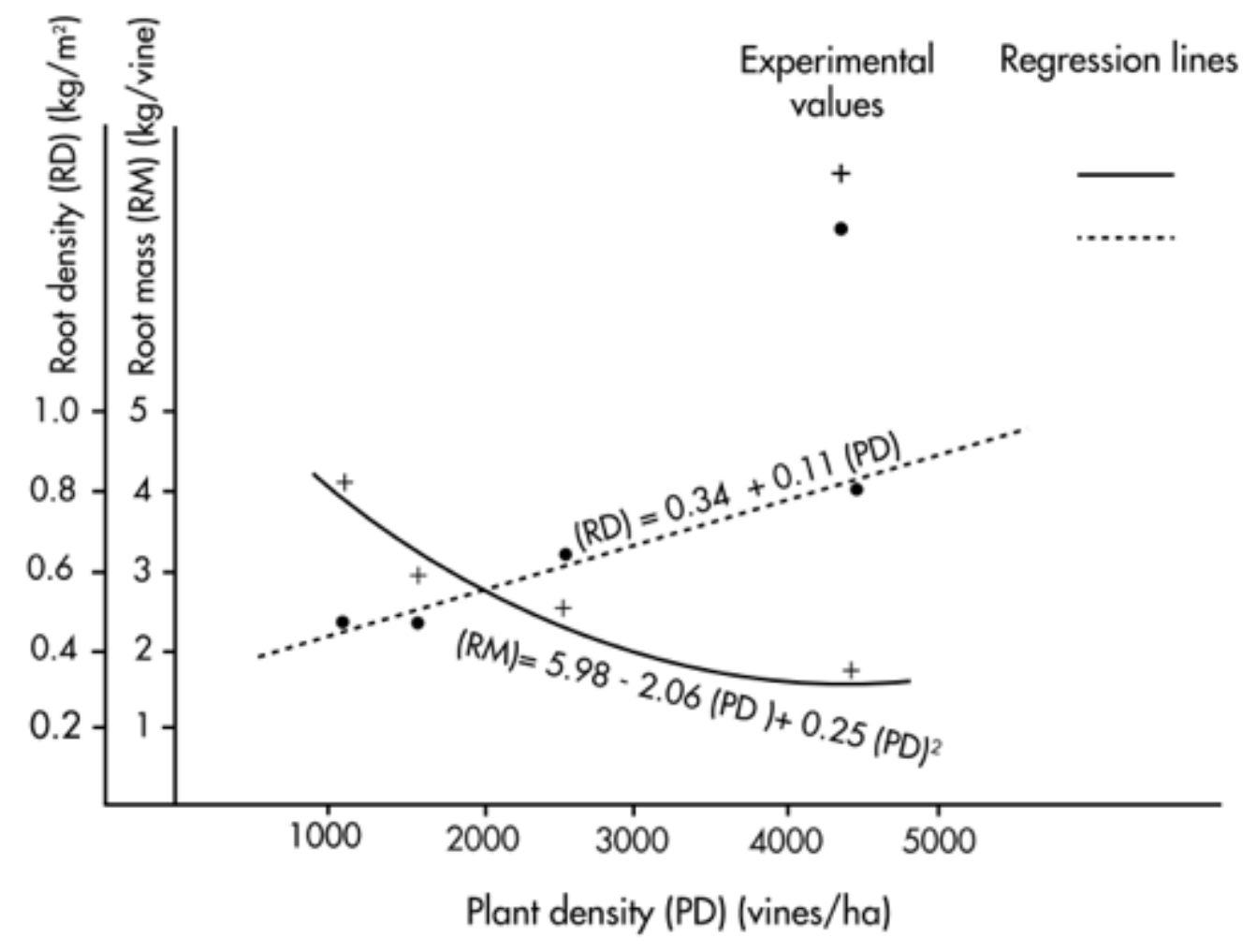

Figure 5. Relationship between vine root density (RD) $\left(\mathrm{kg} / \mathrm{m}^{2}\right)$, vine root mass (RM) (kg/vine) and plant density (PD) (number of vines/ha). Source: Archer \& Saayman (2018). (Reproduced with permission). 


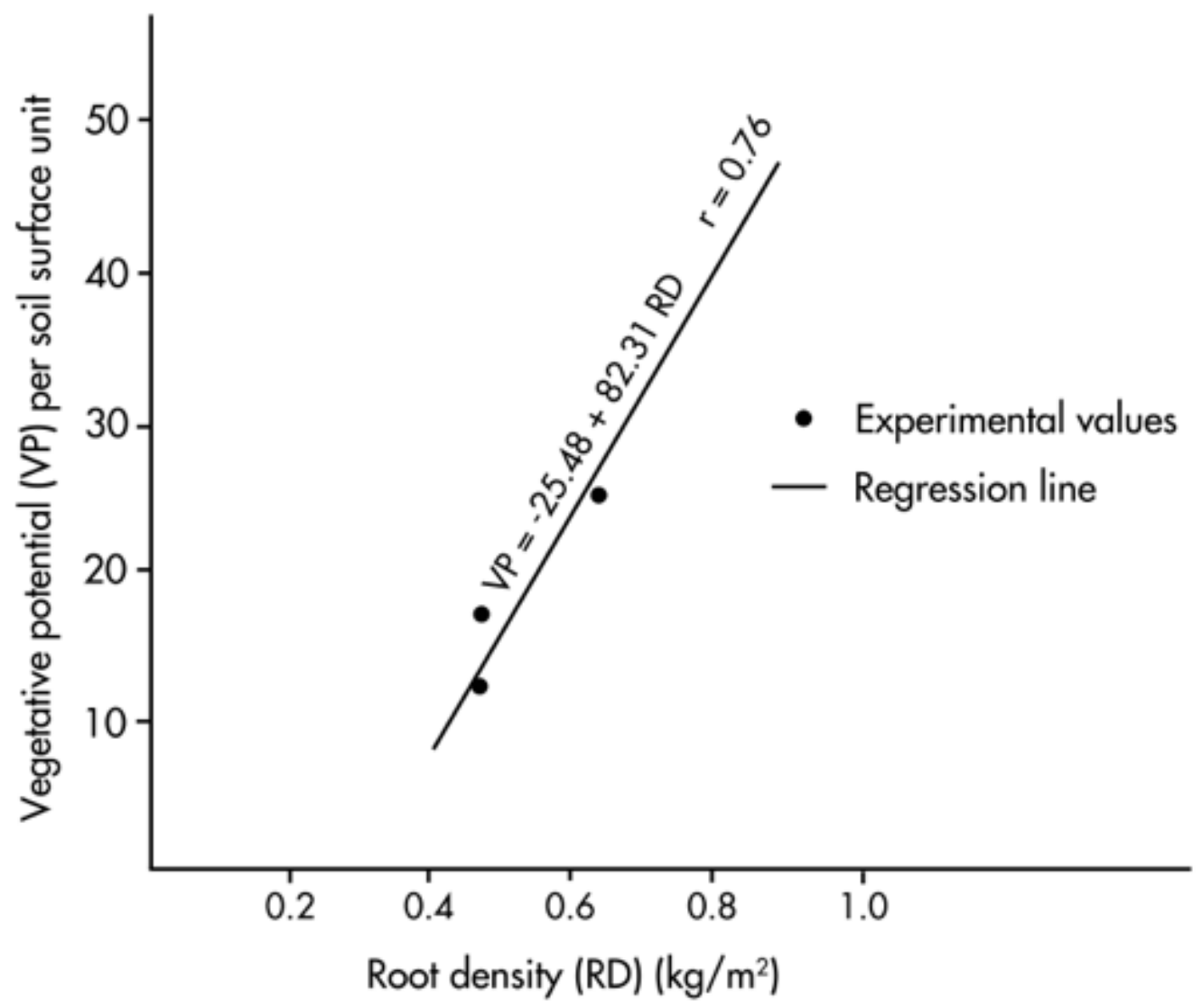

Figure 6. Relationship between root density (RD) $\left(\mathrm{kg} / \mathrm{m}^{2}\right)$ and vegetative potential (vigor or shoot mass, VP) per square m of surface unit. Source: Archer \& Saayman (2018). (Reproduced with permission).

The positive effects that trees impart on soil structure, soil quality, and root plasticity allow for deeper and stronger grapevine root systems that can better absorb nutrients and water despite competition from trees (Smart et al. 2006). Trees and vines are both perennial species with roots that occupy many of the same soil niches, which can result in high levels of competition (Morlat and Jacquet 1993; Kailis and Harris 2007). However, trees increase OM, aggregate stability, macroporosity, mesoporosity, water infiltration, water holding capacity, penetrability, and overall quality in soils, and they decrease bulk density, the incidence of hardpans, and irrigation impact, which all contribute to a soil environment that allows grapevine roots to grow more deeply (Young 1989a, 1989b; Henry 1993; Lanyon et al. 2004; Seobi et al. 2005). Fracture lines left behind by tree roots also allow opportunities 
for grapevines to grow even deeper than they otherwise would have (Mckenry 1984).

Additionally, competition from tree roots can trigger grapevine root plasticity, which results in increased root length density and increased nutrient and water absorption capacity per $\mathrm{cm}$ of soil (Branas and Vergnes 1957; Hidalgo 1968; Freeman et al. 1982; Fargione and Tilman 2006). Tree roots and grapevine roots are indeed be able to adapt to competition and thrive despite occupying overlapping niches.

\section{II.5. CONCLUSION}

Trees that are grown in association with grapevines both positively and negatively influence below-ground soil parameters in vineyards such as vine water status, vine nutrient status, and rooting patterns. Existing studies reveal that the presence of trees in vineyards imparts a neutral to positive effect on parameters surrounding grapevine water status and water stress despite competition, due to trees' ability to reduce evaporation and transpiration, modify the microclimate, and distribute water through hydraulic lift. Studies show that trees likely have a slight negative effect on grapevine nutrient status within $4 \mathrm{~m}$ of trees; however, trees also have been proven to significantly improve vineyard soil quality. Trees may also potentially increase vine rooting depth and density by improving soil structure and inducing root plasticity. Overall, the positive below-ground services that trees provide in vineyards, paired with the ecological and cost-saving benefits that trees impart to a viticultural ecosystem as a whole, might very well balance out these negative effects. Although more research on the below-ground interactions between trees and grapevines must be done, there is growing evidence that incorporating trees into vineyards could play a valuable role in the future of viticulture in the coming years. 
CHAPTER III

AGROFORESTRY FOR ENHANCED INTEGRATED

PEST MANAGEMENT IN VINEYARDS 


\section{III.1. INTRODUCTION}

The simplified monocultural designs in conventional viticulture are associated with a multitude of issues surrounding pest management including increases in pest and disease pressure, pesticide resistance, increased reliance on agrochemicals, and higher overall farm vulnerability (Altieri and Nicholls 2002; Francis et al. 2004; Nicholls et al. 2008; Meehan et al. 2011; Henderson and Rex 2012; Mahmood et al. 2015). These issues, coupled with yield and quality reductions due to erratic weather patterns from climate change, erosion, soil fertility losses, drought, and damage due to high winds, highlight the need for more sustainable vineyard practices and new vineyard designs (Altieri and Nicholls 2002; Martínez-Casasnovas and Ramos 2006; Pimentel 2006; Dunn and Martin 2008; Borrelli et al. 2013; Pachauri and Meyer 2015; Pagay and Collins 2017; Ferreira et al. 2018; Grimaldi 2018; Rodrigo-Comino et al. 2018). Agroforestry, defined as the intentional incorporation of trees into agricultural systems (Gold and Garrett 2009), has the potential to remedy many of these production issues, while simultaneously sequestering carbon, providing ecosystem services, and mitigating many of the ecological issues that the planet as a whole is confronted with (Dupraz et al. 2009; Raj and Toppo 2018).

Agroforestry has been demonstrated to have favorable applications in viticulture in terms of the below-ground services that it can provide to vineyards, including increasing drought resistance, reducing erosion, building organic matter, bettering soil structure, and improving vine rooting capability (Hidalgo 1968; Mckenry 1984; Young 1989a, 1989b; Schroeder 1993; Riha and McIntyre 1999; Thevathasan and Gordon 2004; Smart et al. 2005, Seobi et al. 2005; Minasny and McBratney 2015; Favor and Udawatta 2020). Agroforestry has also been shown to improve vineyards in numerous ways in terms of the above-ground services that it provides, including slowing wind, increasing photosynthetic capacity, buffering temperature extremes, protecting against frost, protecting against heat stress, and 
mitigating climate change; all without causing significant competition for light (Norton 1988; Dupraz et al. 2009; Dupraz et al. 2018; Grimaldi 2018).

This paper reviews the ways in which agroforestry's applications in viticulture affect integrated pest management. Although more research regarding vineyard agroforestry systems must be undergone, there is already evidence, as summarized in this paper, that agroforestry can play a significant role in the integrated pest management of vineyards. The utilization of trees in vineyards has the potential to increase associated biodiversity and reduce windspeeds, thus impacting insect, viral, bacterial, and fungal pathogen pressure, while also preventing dependence on chemical pesticides and facilitating precision pesticide applications. In order for the wine grape industry to continue to thrive in the coming years despite environmental changes and increased pest pressure, sustainable pest management solutions must be implemented now, and agroforestry may be one such solution.

\section{III.2. ISSUES SURROUNDING PESTS AND DISEASES IN MODERN VITICULTURE}

With the expansion of monocultures, the decrease of on-farm vegetational diversity, and the trend of landscape simplification during the past century, agricultural systems worldwide are experiencing more pest and disease pressure than before (Altieri et al. 2005; Meehan et al. 2011; Bellamy 2013; Wetzel et al. 2016; Grab et al. 2018). Monoculture systems in general have been proven to be both less able to withstand disturbance, and also less able to recover from disturbance after it occurs, than are diversified cropping systems (Francis et al. 2004). The simplified landscapes intrinsic to monocultures provide an abundance of the preferred food sources, habitat, and resources of pests, allowing unbridled dispersal, reproduction, and colonization to occur (Risch et al. 1983; Margosian et al. 2009). Monoculture vineyard designs also cause reductions in bird, insect, and other natural enemy 
communities within vineyards, which results in systems that are less able to self-regulate, causing pest populations to increase at unchecked rates (Corbett and Rosenheim 1996; Francis et al. 2004; Altieri et al. 2005; Grab et al. 2018; Peralta et al. 2018).

Increased pest and disease pressure in vineyards causes yield losses and/or the dependence on chemical pesticides (Altieri et al. 2005; Nicholls et al. 2008; Meehan et al. 2011). In California in 2005 alone, 20 million $\mathrm{kg}$ of pesticides were applied in vineyards to combat the increased pest pressure of monocultures (Altieri et al. 2005). Increased pesticide usage creates a cycle of dependence on these same pesticides, as pesticides kill both grape pests and their natural enemies, and because repeated pesticide application over time can result in the evolution of pesticide-resistant pests (Mahmood et al. 2015). As a result, farmers are often forced to choose between using harsher and harsher pesticides in order to protect their crops, or losing their yields entirely. This reliance on pesticides can result in severe human and environmental health issues, ranging from endocrine issues to cancer to even death (Nicolopoulou-Stamati et al. 2016; California Department of Pesticide Regulation 2017). Reliance on pesticides can also cause economic strain on farmers; it is estimated that landscape simplification and the resulting pesticide reliance in specific are responsible for losses of $\$ 69$ million per year in Midwestern farms (Meehan et al. 2011). In the winegrape industry in particular, the expenses associated with the high-input demands of monoculture have been shown to be some of the main barriers to profitability for small vineyards (Sellers and Alampi-Sottini 2016).

\section{III.2.1. Diversity as a Means to Combat Pests and Diseases}

There are many causal pathways that explain why diversified cropping systems are more resistant to pests and diseases than monoculture systems are (Figure 7). Agroforestry systems in particular are presumed to suppress pest and disease pressure through the 
following mechanisms. 1. The Natural Enemies Hypothesis proposes that floristically-diverse systems are able to support greater quantities of natural enemies, which are thus able to regulate herbivore pests through higher rates of predation and parasitism (Andow 1991). In general, research has supported this hypothesis and has shown that agricultural diversification of the landscape is correlated with increases in natural enemy populations and consequently, parasitism rates of crop pests (Altieri et al. 2005; Grab et al. 2018). 2. The Resource Conservation Hypothesis proposes that diverse vegetation dilutes visual and olfactory cues that pests might receive from their target food source, making them less likely to find and attack said crops (Root 1973). 3. Another mechanism for reducing pest and pathogen pressure is the spatial separation of host-plants by non-host-plants that occurs in floristically-diverse cropping systems, which may prevent herbivores from proliferating or disseminating rampantly (Ratnadass et al. 2012). 4. In some circumstances, intercropping can utilize pushor pull-mechanisms to either repel pests away from crops through various volatiles that they emit, or draw pests towards them, as in the case of trap crops (Cook et al. 2007). 5. Enhancement of below-ground biodiversity is another resistance-increasing mechanism that reduces pathogens by increasing the likelihood that beneficial microbes might antagonize pathogens or exhibit direct antibiotic effects (Altieri 1999; Peralta et al. 2018). Agroforestry systems in particular have been proven to increase soil microbiological populations by $30 \%$ (Young 1989), and thus, they have a high potential for soil pathogen suppression through this mechanism. 6. Diversified systems including agroforestry systems also can reduce fungal prevalence by slowing wind and thus preventing the spread of spores of certain fungal diseases (Schroth et al. 2000).

All of these resilience-increasing causal pathways are inherent to agroforestry systems. The increased diversity imparted by agroforestry enhances natural enemy effectiveness, reduces herbivore access to resources, elevates herbivore suppression, and 
increases both resistance against and resilience from pests and pathogens (Mineau and McLaughlin 1996; Letourneau et al. 2011; Cardozo et al. 2015).

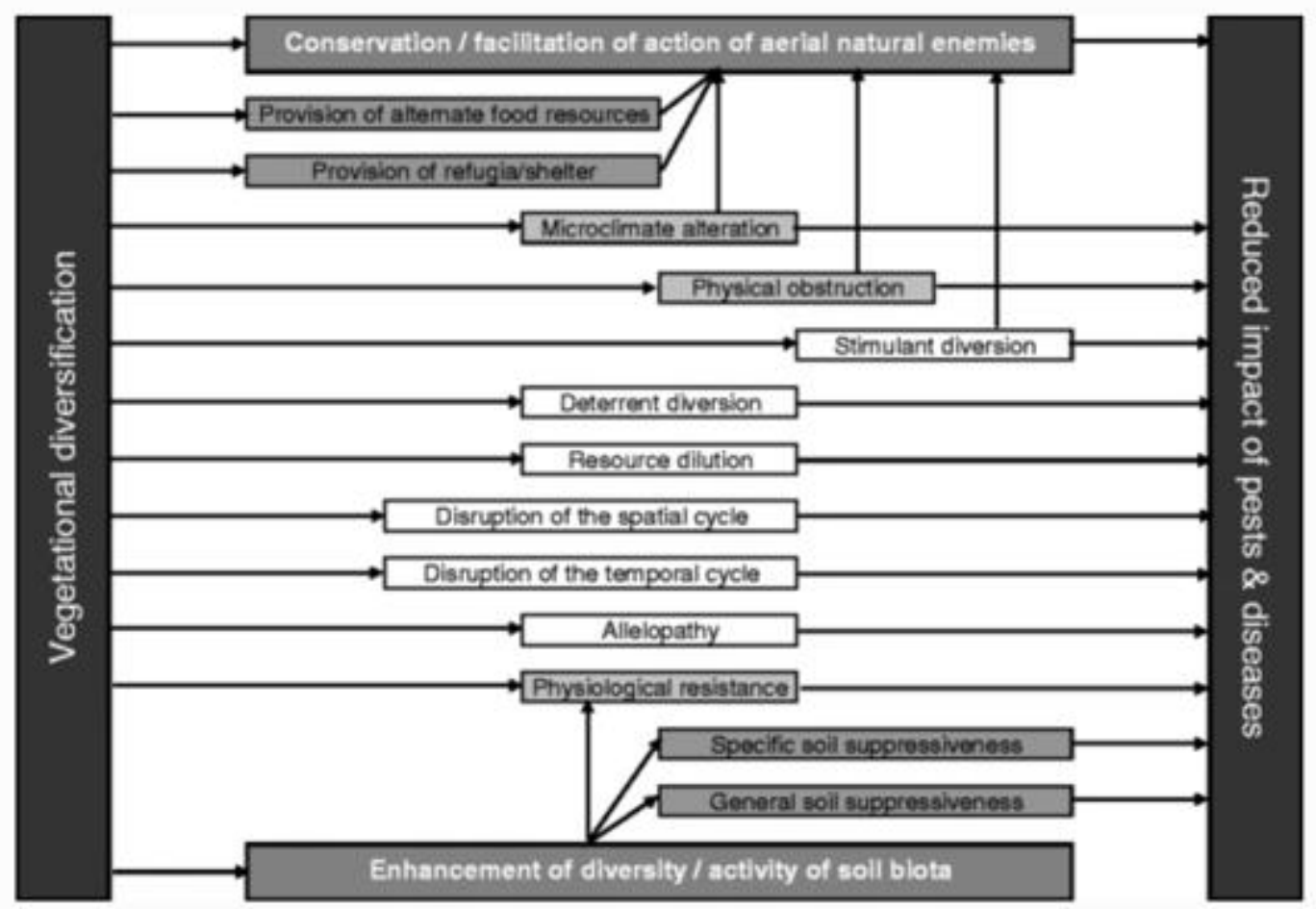

Figure 7. Major pathways for reducing the impact of pests and diseases via the introduction of plant species diversity in agroecosystems. Source: Ratnadass et al. (2012) (Reproduced with permission).

\section{III.3. INTEGRATED PEST MANAGEMENT IN VINEYARD AGROFORESTRY SYSTEMS}

\section{III.3.1. Improved Management of Insect Pests}

Although vineyard agroforestry systems are still relatively uncommon, the existing literature on vineyard agroforestry systems and on vineyards located within biologically diverse landscapes has proven that trees play a positive role in the management of insect pests in vineyards. Biodiversity from woody vegetation can have an influence on vineyards either in the form of surrounding biodiversity (i.e. adjacent forests, adjacent riparian zones, etc.), or in the form of planned biodiversity (i.e. the intentional incorporation of trees into vineyards themselves through agroforestry) (Altieri et al. 2005). In both the cases of 
surrounding biodiversity and planned biodiversity, the resulting effect is an increase in associated biodiversity (i.e. predators and parasitoids), which helps to regulate vineyard pests and keep the agro-ecosystem in balance (Figure 8).

In terms of surrounding biodiversity, many studies have shown that vineyards located in close proximity to surrounding woody vegetation experience reduced insect pest pressure. Wilson et al. (2017a) compared vineyards with varying gradients of landscape diversity and found that vineyards which had a higher percentage of "natural habitat" (consisting or riparian or oak woodland areas) within a $0.5 \mathrm{~km}$ radius were associated with increased biological control of the Western grape leafhopper, Erythroneura elegantula, due to increased presence of the natural enemy parasitoids Anagrus erythroneaurae and Anagrus daanei. In this study, researchers found that the approximation of vineyards to trees in surrounding landscapes was more of a prerequisite for insect pest control than even the presence of flowering cover crops within vineyards themselves was; this is to say that vineyards closer to surrounding woody vegetation experienced even higher parasitism rates and lower pest pressure than did vineyards that had flowering cover crops within the vineyard itself but no surrounding woody vegetation. These results emphasize the importance of woody perennial diversity in specific as a resilience-enhancing tool in vineyards. In another study, Kido et al. (1984) found that French prune (Prunus domestica L.) orchards surrounding vineyards served as overwintering habitat for important leafhopper enemies, the parasitic wasps of the Anagrus genus, and thus, enhanced parasitism rates and biological control of E. elegantula Osborn in vineyards. Several other studies have echoed these findings and have also observed that vineyards which were surrounded by French prune trees (Prunus domestica L.) experienced higher leafhopper parasitism and thus lower damage from leafhoppers (Erythroneura elegantula Osborn), due to increases in Anagrus populations (Corbett and Rosenheim 1996; Murphy et al. 1996). Researchers hypothesize that the 
favorable control of E. elegantula Osborn seen in these vineyards was due to both trees' ability to serve as overwintering sites, which allowed early-season Anagrus populations to proliferate before E. elegantula Osborn populations did, and also trees' ability to provide a windbreak effect, which helped beneficial Anagrus insects colonize vineyards at a higher rate. Another study found similar results and showed that vineyards which were surrounded by woody riparian habitat experienced higher parasitism of E. elegantula by Anagrus epos due to the ability of woody riparian vegetation to serve as overwintering sites for Anagrus epos (Doutt and Nakata 1973). All of these findings point to the need for diversified viticultural landscapes that include woody vegetation.

In the case of planned biodiversity in vineyard agroforestry systems, several studies have examined vineyard agroforestry systems in particular and have shown that the incorporation of trees into vineyards significantly reduces insect pest pressure. Altieri and Nicholls (2002) compared 30 vineyard agroforestry systems (consisting of vines intercropped in various patterns with Quercus lusitanica, Ulmus sp., Populus sp., and Prunus sp.) to 20 monoculture vineyards in the Minho region of Portugal and found that vineyard agroforestry systems had greater insect species diversity than did the monoculture vineyards, including higher numbers of predator and parasite insect species. Resultingly, the vineyard agroforestry systems also had higher rates of parasitism. Researchers found that there were significantly fewer leafhopper nymphs (Empoasca vitis) on leaves and significantly fewer European grapevine moth larvae (Lobesia botrana) on inflorescences in the vineyard agroforestry systems than in the monoculture vineyards (Figures 9 and 10). Other studies have also found that agroforestry hedgerows serve as hosts for some of the most important grapevine-specific natural enemy insects, including Orius spp., Geocoris spp., Coccinellidae, Chrysopidae, Nabidae, and Syrphidae (Earnshaw 2018; Miles et al. 2012). Additionally, a 10-year study in France comparing monoculture vineyards to adjacent vineyard agroforestry systems 
intercropped with Pinus pinea and Sorbus domestica found that, in most years, densities of the beneficial predatory mite, Phytoseiidae, which preys upon vineyard pest mites, were significantly higher in the agroforestry plots as compared to the monoculture plots (Barbar et al. 2010; Tixier et al. 2015). It is speculated that the reason for the abundance of mite natural enemies in vineyard agroforestry systems is that trees provide beneficial shelter and shade to predatory mite species, reducing UVB light waves, reducing temperatures, and providing an abundance of pollen, factors all of which allow natural enemy mite species to thrive (Kasap 2005; Broufas et al. 2007; Onzo 2010).

Agroforestry can also promote insect control in vineyards by providing habitat for insectivorous animals such as bats. Baroja et al. (2019) found that the bat Rhinolophus hipposideros effectively controlled the grape pests Lobesia botrana, Sparganothis pilleriana, and Drosophila suzukii, along with 52 other insect pests, in vineyards in the Rioja wine region in Spain. Another study examined the influence of bats on pest control in vineyards by installing nocturnal exclosures to exclude bats from vineyards at night, and by then comparing pest damage in these bat-excluded vineyards to pest damage in control vineyards. Researchers found that bats perform significant pest control in vineyards, enough to reduce yield losses considerably; herbivore insect damage on clusters was 7\% lower in plots where bats were present $(0.48 \pm 0.20)$ as compared to plots excluded from bats $(2.42 \pm 0.66)$ $(\mathrm{F}(1,20)=13.94 ; p=0.001)$ (Figure 11). Researchers estimated that the savings in grape yield due to pest control from bats at similar sites could equal $595 \mathrm{~kg} / \mathrm{ha} / \mathrm{year}$ in yield, which translates to farmer savings of US\$188-\$248/ha/year (using the market value of winegrapes in 2017/2018) (Rodríguez-San Pedro et al. 2020). Insectivorous bats indeed are a valuable component of insect control in vineyards, and creating diversified vineyard landscapes that serve as habitat for bats should be a fundamental component of an integrated pest management plan in vineyards (Boughey et al. 2011; Baroja et al. 2019; Rodríguez-San 
Pedro et al. 2020). Several studies on vineyards in specific have found that bat activity in vineyards is significantly increased by closer proximity to hedgerows (Froidevaux et al. 2017) and by increased surrounding landscape structural heterogeneity (Kelly et al. 2016). Using acoustic surveys to track bat activity, Kelly et al. (2016) found that total bat activity amongst three bat species (E. fuscus, M. yumanensis, and T. brasiliensis) was significantly higher in rows adjacent to woody vegetation as compared to rows isolated from woody vegetation (Figure 12). Researchers concluded that incorporating trees into and around vineyards through agroforestry is a way to increase the landscape complexity required to increase insectivorous bat activity.

Despite the evidence demonstrating agroforestry's favorable effects on insect control in vineyards, other studies have shown that windbreaks can increase the concentration of pest insects in downwind areas, due to the fact that flying insects prefer to settle in areas where windspeeds are lower than their flight speeds (Pasek 1988). The same favorable conditions which allow for the proliferation of beneficial predator insects - such as shelter, vegetational diversity, abundant food sources, and microclimatic alterations - also allow for proliferation of pests (Altieri and Nicholls 2008). However, it appears that, because increases in insect pests are accompanied by increases in insect predators along with other pest-regulating factors, vineyard agroforestry systems become balanced and self-regulating, and the benefits of incorporating trees appear to outweigh their disadvantages (Altieri and Nicholls 2008). 


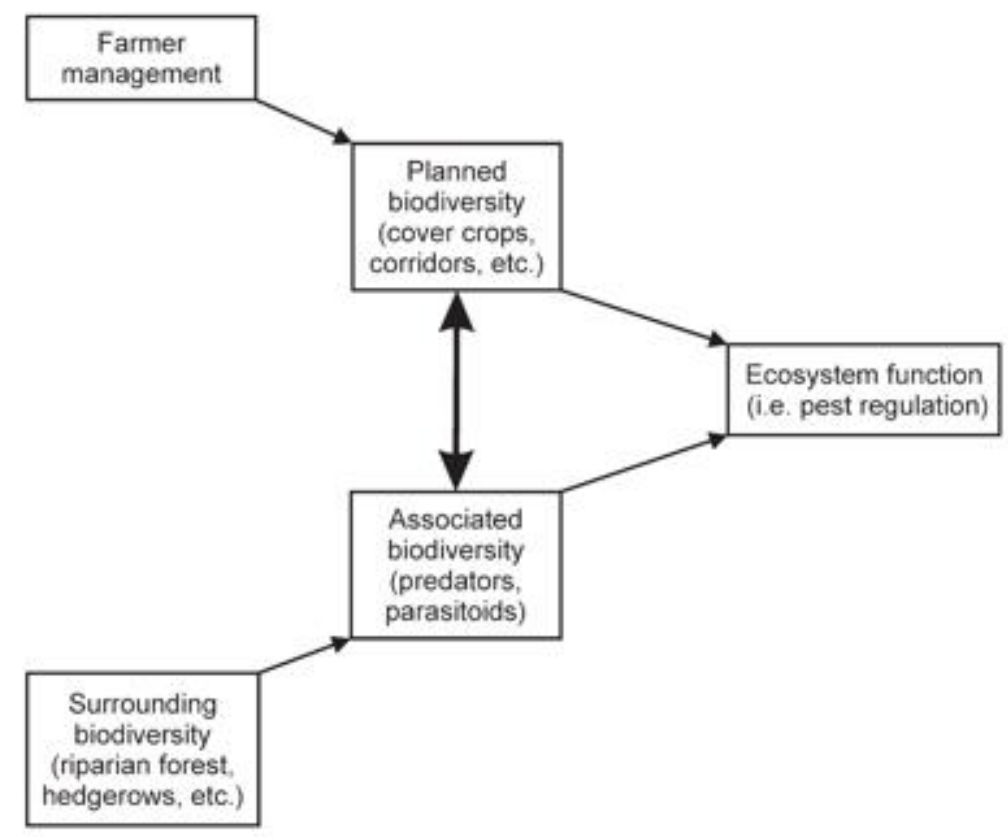

Figure 1 Relationship between several types of biodiversity and their role in pest regulation in a diversified vineyard

Figure 8. Relationship between several types of biodiversity and their role in pest regulation in a diversified vineyard. Source: Altieri et al. (2005). (Reproduced with permission).

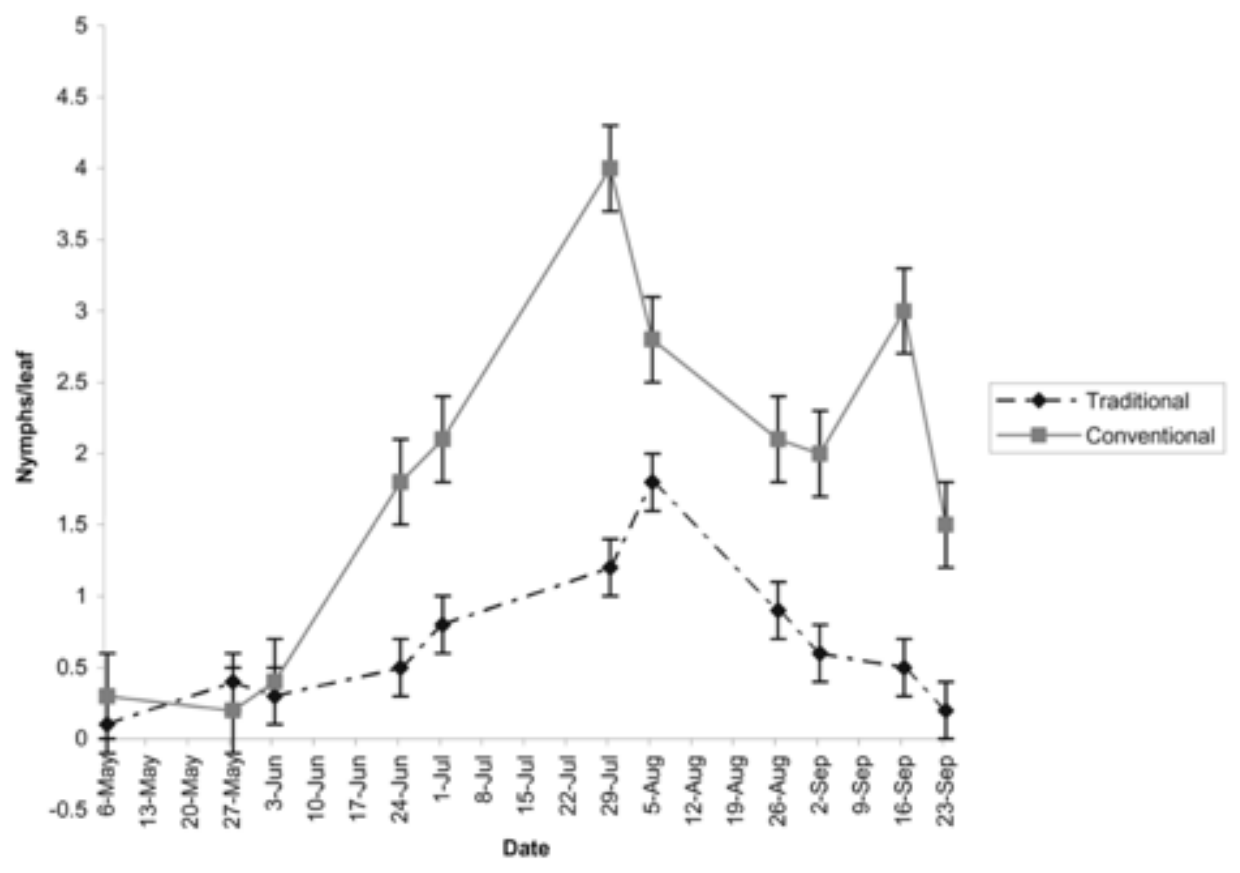

Figure 9. Nymphal densities of Empoasca vitis in monoculture (conventional) and agroforestry (traditional) vineyards in northwestern Portugal in 1999. Source: Altieri and Nicholls (2002). (Reprinted with permission). 


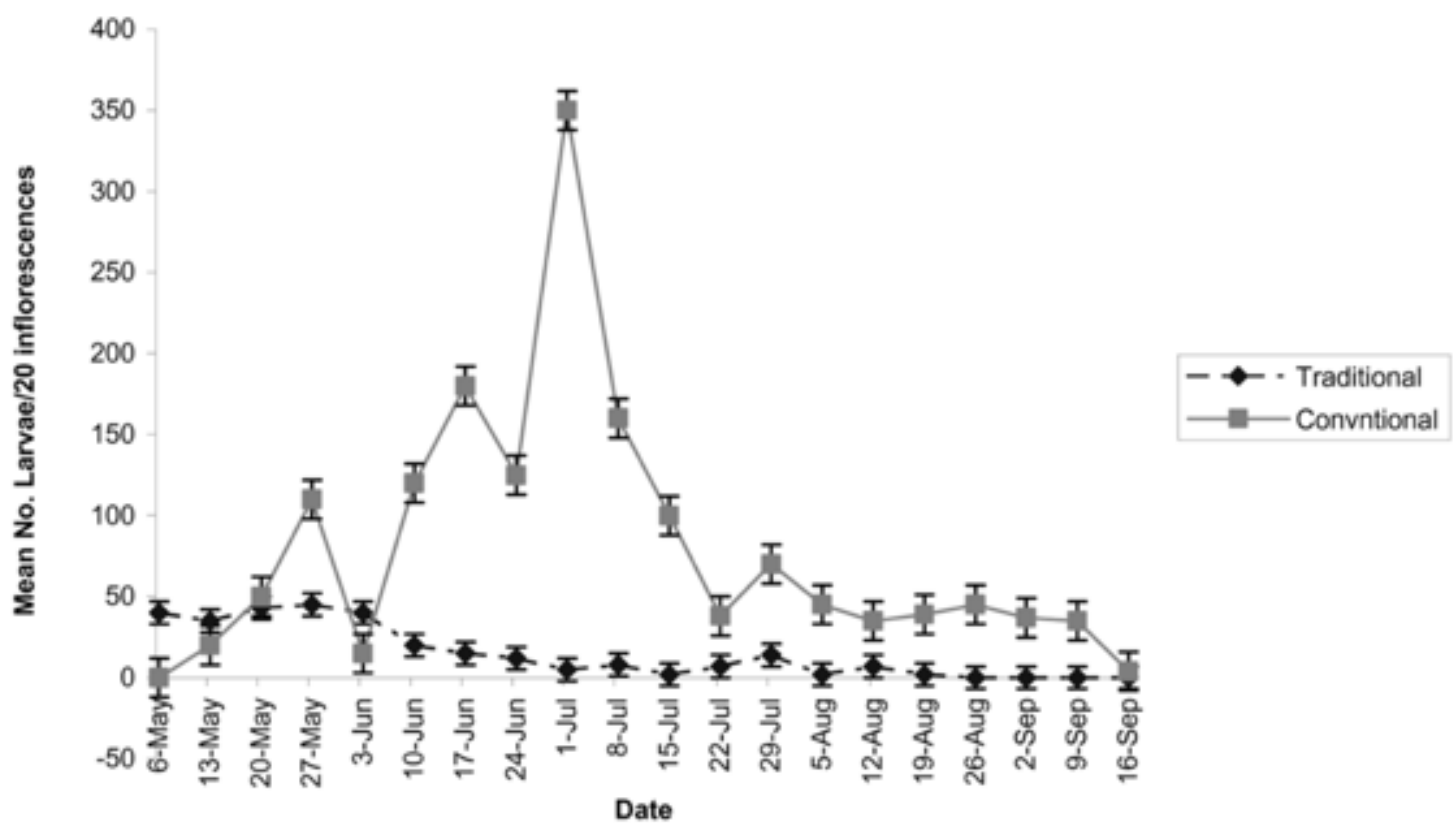

Figure 10. Infestation of grape inflorescences by Lobesia botrana in monoculture (conventional) and agroforestry (traditional) vineyards in northwestern Portugal in 1999. Source: Altieri and Nicholls (2002). (Reprinted with permission).

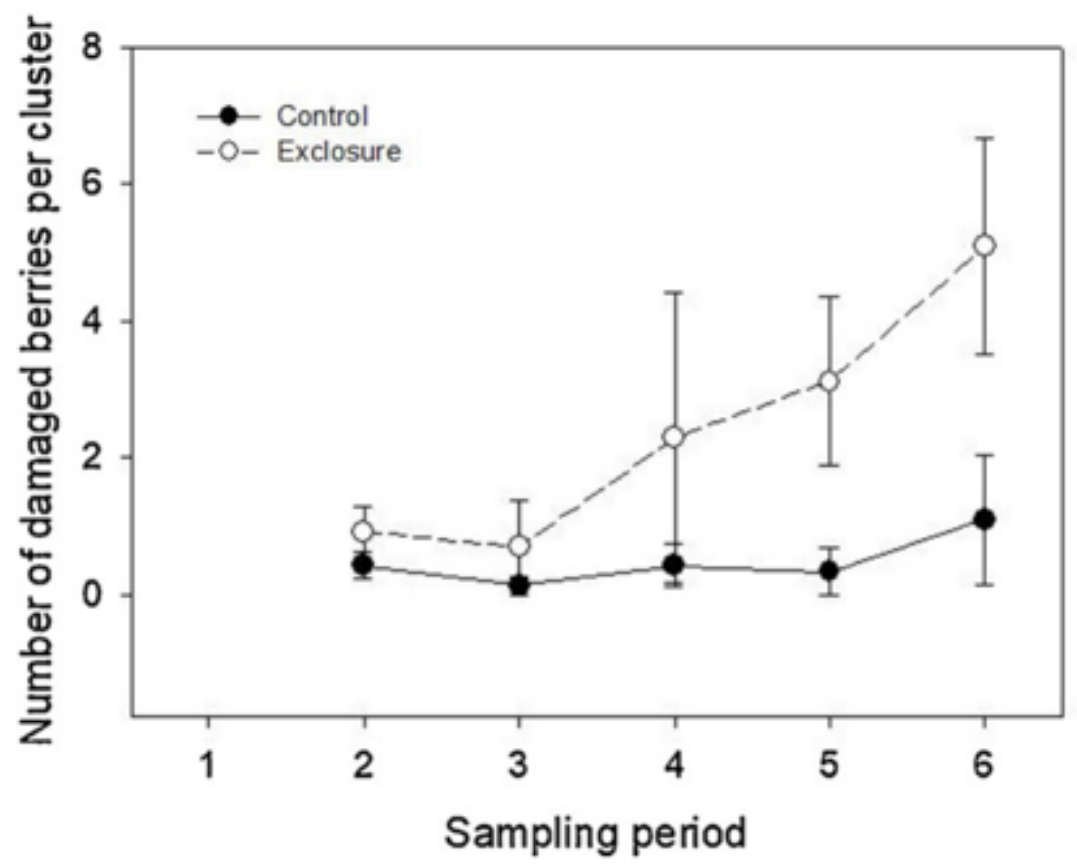

Figure 11. Mean number of damaged berries per cluster $( \pm \mathrm{SE})$ in nocturnal exclosures (bats absent) and controls (bats present) in three vineyards in central Chile over 6 sampling periods from December 2017 to March 2018. Source: Rodríguez-San Pedro et al. (2020). (Reprinted with permission). 

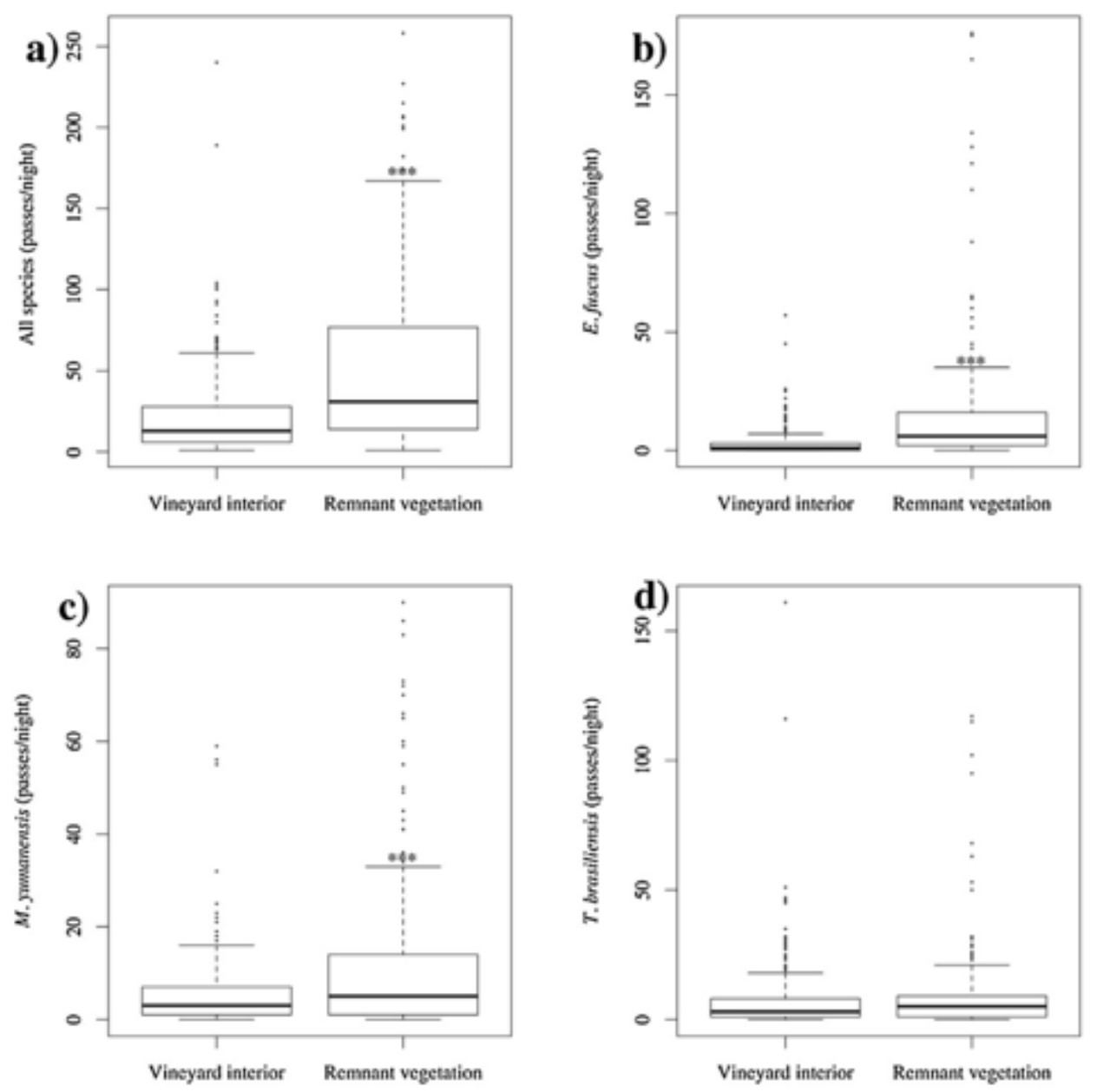

Figure 12. Nightly recorded activity (passes per night) of bats in vineyards in Northern California within the vineyard interior and adjacent to remnant vegetation for: (a) all species combined (b) E. fuscus (c) M. yumanensis and (d) T. brasiliensis. The middle line is equal to the median nightly passes, boxes indicate interquartile range, the whiskers extend to 1.5 times the interquartile range, and values beyond this range are indicated by $\left({ }^{\circ}\right)$. Source: Kelly et al. (2016). (Reprinted with permission).

\section{III.3.2. Improved Management of Viruses and Bacteria}

There are more than 70 known virus species that can affect grapevines, and three major bacterial diseases, and many of these are spread by insect vectors (Szegedi and Civerolo 2011; Wallingford et al. 2015; Martelli 2017). To our knowledge, no research on viral nor bacterial infection in vineyard agroforestry systems in specific has been undergone. However, existing research on agroforestry systems in general suggests that agroforestry 
could either increase viral and bacterial disease incidence, by providing breeding ground for disease vectors (Bondole 1999) or decrease viral and bacterial disease incidence, by controling insect vectors (Schroth et al. 2000; Moreira et al. 2019).

Research shows that, in general, polycultures have lower rates of insect-trasnmitted viruses than do monocultures, due to their inherent greater plant species richness, which imparts greater vector control (Brunt et al. 1996; Ratnadass et al. 2012). However, research has drawn conflicting conclusions regarding the effect of windbreaks on grape viral vectors. Some grape virus vectors, such as mealybugs (Pseudococcidae) and soft scales (Coccidae), which transmit leafroll ampeloviruses (GLRaV-1 and -3) and 'rugose wood'-associated vitiviruses (GVA), are largely dispersed by wind. Windbreaks, such as those found in many vineyard agroforestry systems, may prevent their colonization (Franco et al. 2009; Hommay et al. 2012). However, windbreaks and ornamental fruit trees planted near vineyards have also been observed to serve as host sites for mealybugs (Soares Cariri Lopes et al. 2019).

One of the most threatening grape bacterial vectors, the glassy-winged sharpshooter, Homalodisca vitripennis, which transmists Xylella fastidiosa and causes Pierce's Disease, has been known to host upon trees such as acacia (Acacia cowleana), avocado (Persea americana), eucalyptus (Eucalyptus wandoo), almond (Prunus dulcis), peach (Prunus persica), olive (Olea europaea), plum (Prunus L.), mulberry (Morus L.), citrus (Citrus L.), and many other woody species (Rathé et al. 2014; Stancanelli et al. 2015). Several studies have shown windbreaks to increase glassy-winged sharpshooter infestation in vineyards in California, in particular, jojoba and eucalyptus windbreaks (Daane et al. 2006; Wistrom et al. 2010). In areas where Pierce's Disease is common, intercropping grapevines or lining vineyards with windbreaks composed of glassy-winged sharp shooter host trees would be highly discouraged. 


\section{III.3.3. Improved Management of Fungal Diseases}

Fungal infections in grapevines are largely dependent upon light, temperature, and humidity (Zahavi et al. 2001; Austin and Wilcox 2012), factors all of which can be manipulated by the presence of trees. Under traditional monoculture vineyard designs, grapevines are exposed to high amounts of sunlight, which does help to control fungal development. Sunlight is made up of a majority of infrared wavelengths, but $8-9 \%$ of light is made up of ultraviolet light, consisting of UV-A wavelengths (315-400 nm), UV-B wavelengths (280-320 nm) and UV-C wavelengths (100 to $280 \mathrm{~nm}$ ) (Frederick 1993). Ultraviolet light is important for certain grape development qualities and it protects grapes against many pathogens, including pathogenic grape fungi, whose conidia and thalli are damaged by UV light (Hollósy 2002; Austin and Wilcox 2012). The long wave radiation component of sunlight is responsible for tissue heating, sometimes elevating grape tissues to up to $13{ }^{\circ} \mathrm{C}$ higher than ambient temperatures, which also prevents fungal infections from establishing (Spayd et al. 2002). Shade from trees can reduce both the amount of heat and UV light reaching grapevines, which may increase fungal development in grapevines, although to our knowledge no conclusive studies have been undergone regarding fungal development due to shade in vineyard agroforestry systems.

Powdery mildew (Erysiphe necator), one of the most prevalent grape fungal pathogens, has been shown to be inhibited by high light intensity and enhanced under shade conditions (Zahavi et al. 2001). Austin and Wilcox (2012) found that shade increased powdery mildew severity by 49 to $75 \%$ on grapevine leaves, and by 20 to $40 \%$ on grapevine clusters. They determined that the main causes were reduced temperatures and reduced UV-B radiation due to reduced shade. Researchers concluded that minimizing shade, both withincanopy and also externally, was important for preventing powdery mildew infestations. This 
conclusion implies that intercropping vines with trees, given the associated shade that trees provide, would cause higher rates of powdery mildew infection.

However, although powdery mildew proliferation increases under shade, it decreases when its host plant is less vigorous. Powdery mildew proliferation and vine vigor are positively associated; as vine vigor and turgor of tissue increase, powdery mildew infection rates increase as well. This is due in part to the fact that high vigor leads to poorly ventilated canopies, thus favoring the conditions for fungal infestations, and that epidemic spread of fungal spores is more possible with dense vine canopies (Valdés-Gómez 2008; Calonnec et al. 2009). A study on a vineyard in France found that vines exposed to interspecific competition by perennial cover crops had lower early-season shoot growth, and subsequently, fewer powdery mildew hosts early in the season, which led to lower powdery mildew infestation of berries at harvest (Valdés-Gómez et al. 2011). Valdés-Gomez et al. (2008) found similar results in a sister study; researchers found that plots in which vines experienced interspecific competition from tall fescue (Festuca arundinacea Shreb) and ray grass (Lolium perenne L.) had one-fourth the amount of botrytis infections as did vines that were treated with chemical weed control. In the case of vineyard agroforestry systems, reduced vigor caused by competition from trees may be favorable for reducing the proliferation of powdery mildew. Additionally, the wind-slowing effect of trees may prevent the spread of fungal spores, thus slowing the rate of colonization within the vineyard (Schroth et al. 2000). More studies should be undergone in this area.

\section{III.3.4. Precision Pesticide Application}

One of the core tenets of integrated pest management is applying pesticides at the proper intervention thresholds, when pest and disease pressure is at optimal levels (Barzman et al. 2015). However, the EPA mandates that pesticides be only be applied when wind 
speeds are lower than three to ten miles per hour (depending on the chemical), meaning that farmers are often unable to apply pesticides at the precise moment that they would be most beneficial (Norton 1988; United States Environmental Protection Agency 2019). Windbreaks have been shown to reduce pesticide drift by up to $80-90 \%$ in some cases, thus allowing for more precise timing of pesticide application, when pest thresholds are at the optimal levels (Norton 1988; Ucar and Hall 2001).

\section{III.4. CONCLUSION}

The existing research on integrated pest management in vineyard agroforestry systems demonstrates the effectiveness of utilizing agroforestry to create heterogeneous vineyard landscape designs as a way to combat pests and diseases. Monocultural vineyard designs are associated with numerous pest management issues that leave vineyards vulnerable to losses, dependent on pesticides, and economically less-resilient. Creating diverse vineyard agroforestry systems by incorporating trees into vineyards has been shown to benefit insect pest management efforts by providing habitat for natural enemy insects and vertebrates, which results in increased abundance of natural enemies, increased parasitism rates, reduced insect pest pressure, and subsequently, reduced yield losses. Although vineyard agroforestry systems can cause increases in pest insect abundance as well, the existing literature shows that the accompanied increases of natural enemy populations result in overall increased insect pest control and reduced herbivore damage. Vineyard agroforestry systems may also control bacterial and viral infections by controlling the insect vectors that transmit these pathogens, however, great care must be taken to avoid intercropping grapevines with trees that could be hosts for harmful viral and bacterial vectors. The prevalence of fungal infections in vineyard agroforestry systems may be increased by the increased shade that trees impart, but may be reduced by trees' windbreak effects and by the beneficial reductions 
in vine vigor that occur as a result of below-ground competition between trees and vines. The presence of trees in vineyards also facilitates the proper timing of precision pesticide applications by slowing wind and creating conditions conducive to pesticide application at the precise moment when pest pressure is at the proper threshold. More research must be undergone regarding integrated pest management in vineyard agroforestry systems; however, the existing literature demonstrates that there are significant benefits to incorporating trees into vineyards. These benefits, in addition to the above-ground, below-ground, and ecosystem services that trees provide to both vineyards and to the broader environment, make the case that designing diverse vineyard agroforestry systems is an effective way to manage pests and diseases while benefiting the environment. 


\section{CHAPTER IV}

THE EFFECT OF TREES ON LIGHT IN VINEYARD AGROFORESTRY SYSTEMS 


\section{IV.1. INTRODUCTION}

In the face of climate change and environmental degradation, agroforestry is being looked to as a sustainable solution to address many of the issues that modern viticulture is facing. Agroforestry, defined as the intentional combination of agriculture and forestry into a single integrated system (Gold and Garrett 2009), has been shown to enhance vineyard functionality by improving conditions for pest and disease suppression, reducing farmer dependence on chemical pesticides, preventing both direct and indirect wind damage, increasing vine photosynthetic capacity, protecting against heat stress, protecting against frost, increasing drought resistance, reducing erosion, building organic matter, bettering soil structure, and improving vine rooting capability (Hidalgo 1968; Mckenry 1984; Young 1989a, 1989b; Schroeder 1993; Riha and McIntyre 1999; Altieri and Nicholls 2002; Thevathasan and Gordon 2004; Smart et al. 2005, Seobi et al. 2005; Udawatta et al. 2011b; Minasny and McBratney 2015; Favor and Udawatta 2020). These farm benefits, in addition to the ecosystem services that trees provide, suggest that incorporating trees into vineyards may be an appropriate solution to address the many challenges that modern viticulture faces, especially in the face of a changing climate (Pachauri and Meyer 2015; Garcia et al. 2018; Raj and Toppo 2018).

Despite the many proven advantages of agroforestry's applications in vineyards, many farmers remain wary of incorporating trees into their vineyards for fear of competition for light (Zelba et al. 2016; Dupraz et al. 2018). This review paper explores the many ways that trees influence light patterns in vineyards, and subsequently, how they both positively and negatively influence wine grape physiological, production, and quality parameters. Although more research must be undergone on light interference in vineyard agroforestry systems, the existing knowledge surrounding the role of light in vineyards in general, along with several studies on light in vineyard agroforestry systems in particular, suggests that the 
positive above- and below-ground services that trees impart to vineyard agroforestry systems may outweigh the negative effects of competition for light.

\section{IV.2. THE EFFECTS OF SUN AND SHADE ON WINE GRAPES IN GENERAL}

\section{IV.2.1. The Effects of Sun and Shade on Grapevine Physiological Parameters}

Generally speaking, sunlight has photosynthetic, thermal, and phytochromatic effects on grapevines (Kliewer and Smart 1989). Radiation from sunlight influences grapevine physiology by supplying the quantity of photosynthetic photon flux density in photosynthetically active radiation (PAR) necessary for photosynthesis, by altering the microclimate and providing warmth, and by influencing growth through quality of light (Smart 1987a). Grapevines depend on PAR radiation in the wave band $400-700 \mathrm{~nm}$ for photosynthesis, they depend on thermal radiation in the 300-1500 nm wavelength for tissue heating, and they depend on light quality with a ratio of red:far red radiation of above 1.1 for growth and production (Smart 1987a, Gommers et al. 2013).

In general, the growth rate of unstressed crops, also known as net primary productivity, is positively related to the quantity of PAR absorbed, up to a point, until it reaches light saturation (Monteith 1972; Smart and Robinson 1991; Medlyn 1997). The light saturation point in grapevines has been found to be around $0.55 \mu$ mol quanta $\mathrm{m}^{-2} \mathrm{~s}^{-1}$ (During 1988). However, in grapevines, photosynthesis rate is more responsive to ambient temperature, water stress, and reductions in the ratio of red:far red light than to reductions in PAR quantity (Greer and Weedon 2013; Zhang et al. 2019), thus, although high PAR is generally associated with higher rates of photosynthesis, this relationship is not linear (Medlyn 1997; Sun and Wang 2018). Shade does reduce PAR, but it also reduces thermal radiation, which can have positive or negative effects on photosynthesis, depending on the ambient temperature of the growing region. The ideal temperature range for photosynthesis in 
grapevines is between $25-28{ }^{\circ} \mathrm{C}$. When ambient temperatures are higher than this, direct sunlight can have detrimental effects on photosynthesis by increasing leaf temperatures excessively (Kriedemann 1968). When leaf temperatures become high, leaf water potential is reduced, which in turn can cause a reduction in stomatal conductance, and thus, photosynthesis (Smart 1974; Greer and Weedon 2013). Shade, on the other hand, can reduce both ambient temperature and leaf temperature, thus actually increasing photosynthesis when grapevines are experiencing heat stress, despite lowering transmitted photosynthetically active radiation $\left(\mathrm{PAR}_{\mathrm{T}}\right)$ (Marshall 1967).

Shade also significantly reduces the temperatures of berries themselves. Studies have observed berries to have temperatures up to $17^{\circ} \mathrm{C}$ higher than ambient temperature (Figure 13; Millar 1972; Smart and Sinclair 1976; Spayd et al. 2002; Tarara et al. 2005). Grape berries are extremely sensitive to temperature, and their cell division can halt when temperatures exceed $35^{\circ} \mathrm{C}$ (Kliewer 1977; Dokoozlian 2016). On hot days, minor increases in shade can positively impact berry cell functioning in significant ways (Smart and Sinclair 1976; Pereira et al. 2005).

Shade changes the quality of light that reaches grapevines as well; different wavelengths of light have different effects on grapevine physiological and morphological characteristics (Krueger 1981; Šebela et al. 2017). Red and blue light rays are the most photosynthetically active rays, and thus promote the most photosynthesis, while yellow and orange light promotes cell elongation. Interactions between infrared and red light control plant hormones, which can subsequently control morphological changes such as flowering and tissue production (Krueger 1981), while the ratio of red:far red light interacts with the plant phytochrome system to affect regulatory enzymes, cell development, fruit ripening, and the development of other grape compounds (Smart 1987b; Wright 1989). Shade affects the quantity of UV light reaching grapevines as well. Sunlight is made up of a majority of 
infrared wavelengths, but 8-9\% of light is made up of UV light, consisting of UV-A wavelengths $(315-400 \mathrm{~nm}), \mathrm{UV}-\mathrm{B}$ wavelengths $(280-320 \mathrm{~nm})$ and UV-C wavelengths (100 to $280 \mathrm{~nm}$ ) (Frederick 1993). UV light is important for certain grape development qualities, and it protects grapes against many pathogens, but it can also cause sunburn and tissue damage (Hollósy 2002; Austin and Wilcox 2012). Shade can reduce the amount of UV light reaching grapevines, thus preventing tissue damage (Parsons et al. 1998).

All in all, shade can alter the photosynthetic, thermal, and phytochromatic environment and thus affect grapevine physiological parameters in numerous ways, both positively and negatively. Climate change models estimate that temperatures in wine growing regions may rise $1.7^{\circ} \mathrm{C}$ in the next 50 years; an estimation that, although small, could still affect wine production (Jones 2005). It is predicted that under a $2{ }^{\circ} \mathrm{C}$ global warming scenario, $51 \%$ of current wine regions would no longer be able to grow high-quality grapes (Morales-Castilla et al. 2020). If these predictions prove true, increased shading in vineyards may be a vital adaptation strategy for maintaining optimal grapevine physiology in a majority of the current grape growing regions of the world. 


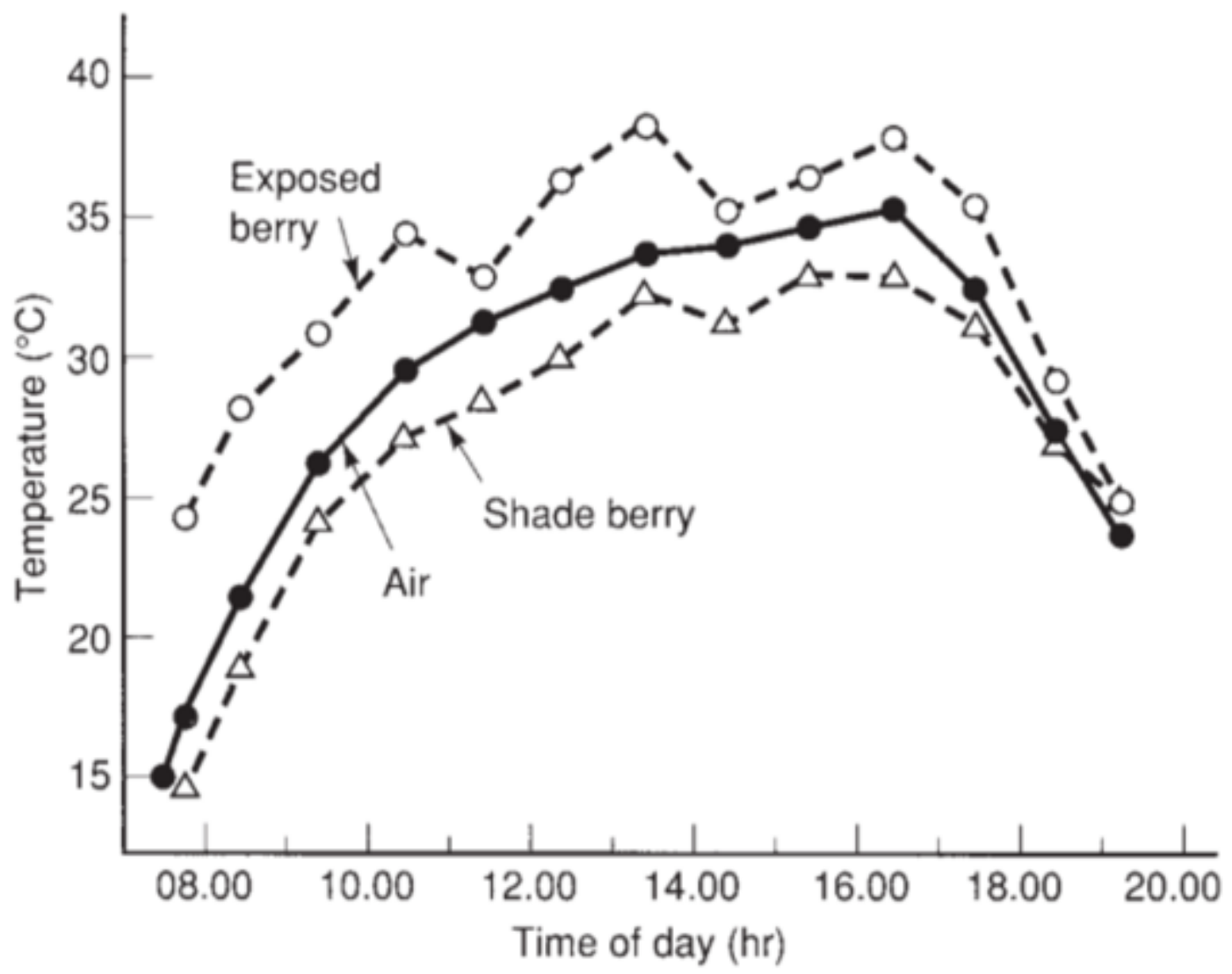

Figure 13. Temperature of exposed and shaded 'Carignan' berries, relative to the air temperature at cluster height on February 10, 1972. Source: Millar (1972).

\section{IV.2.2. The Effect of Sun and Shade on Grape Yield}

Shade can negatively affect wine grape yield by decreasing bud fruitfulness, fruit bud initiation, and inflorescence formation. Shade decreases the number of bunch primordia per bud (Buttrose 1970) (Figure 14) and decreases fruit bud initiation as well (May and Antcliff 1963; Baldwin 1964; Kliewer 1982; Shaulis 1982), which results in direct yield reductions. The negative effects of shade on bud initiation can even impact yield years into the future; shade not only causes reduced bud break in the current year, but also caused decreased budbreak, lower numbers of fruitful shoots, and reduced cluster weight in the following year (Hopping 1975). All in all, grapevines need on average 10 hours of sunlight per day to reach maximum fruitfulness, and when light levels are lower than this, yield is significantly reduced (Baldwin 1964). 
Shade can either negatively or positively affect flower formation, depending on temperature conditions. Grapevine flowering is dependent upon cytokinin synthesis, which is dependent upon light (Mullins et al. 1992; Lombard et al. 2006; Roman et al. 2016). The triggering of inflorescence formation is also dependent upon high intensity of light and high temperatures at budburst (Antcliff and Webster 1955; Buttrose 1970; Buttrose 1974; Kliewer 1975; Palma and Jackson 1981; Srinivasan and Mullins 1981; Dunn and Martin 2008). However, beyond a short pulse of four to five hours of temperatures $20{ }^{\circ} \mathrm{C}$ or higher, high temperatures can actually negatively affect the number of flowers per inflorescence (Buttrose 1974; Srinivasan and Mullins 1981; Petrie and Clingeleffer 2008; Vasconcelos et al. 2009). While high temperatures create more inflorescences per branch, lower temperatures create more flowers per inflorescence (Pouget 1981; Martin 2000; Petrie and Clingeleffer 2008). Therefore, although heat and PAR are important for inflorescence formation, slight levels of shade that reduce thermal radiation might not have a negative influence on overall numbers of flowers formed.

Under extremely hot growing conditions, shade can actually increase yield. Today, more and more wine growing regions are being impacted by unusually high temperatures, which can result in yield losses due to shriveling, sunburn, and raisining (McCarthy 1997; Coombe and McCarthy 2000; Spayd et al. 2002; Keller 2010; Krasnow et al. 2010; Bonada et al. 2013a, 2013b). In such areas impacted by climate change, shade can reduce heat stress and sunburn, and can thereby reduce yield losses (Chorti et al. 2010; Oliveira et al. 2014; Bayer 2015). In the Douro region of Portugal, for example - a region often affected by extreme temperatures - researchers found that shading in the fruit zone of the vine canopy during different points in grapes' phenological cycle (both from fruit set to harvest and also veraison to harvest) reduced the percentage of shriveled berries per cluster and increased yield significantly (Table 3). This research suggest that the negative effects of hot growing regions 
can not only be combatted by reducing ambient temperature, but also by reducing the quantity of sunlight radiation reaching grapes itself.

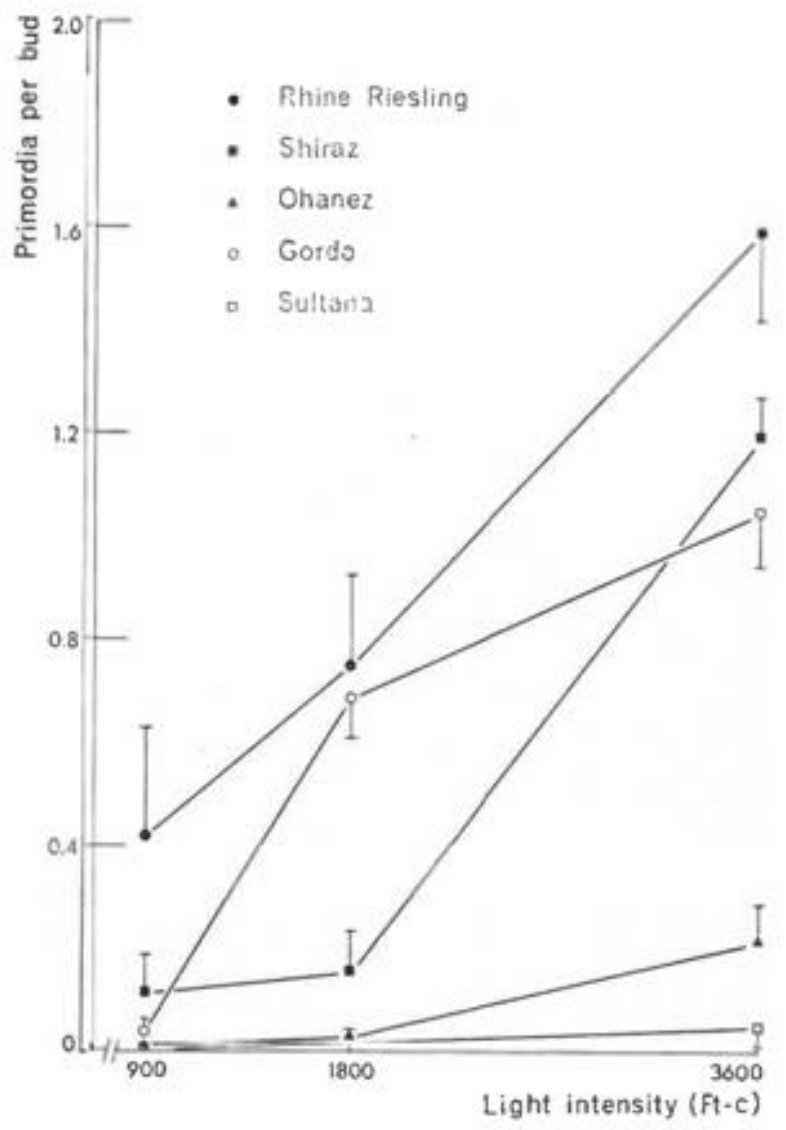

Figure 14. The effect of light intensity on the mean number of bunch primordia per bud for the basal 12 buds on shoots. Daylength was 16 hours at $25^{\circ} \mathrm{C}$. The vertical bars equal $1 \mathrm{x}$ standard error of the mean. Source: Buttrose (1970).

Table 3. Mean separations of yield, percentage of shriveled berries per cluster at harvest from 2010 to 2012 in Douro, Portugal. Source: Oliveira et al. (2014).

\begin{tabular}{|l|l|l|}
\hline Treatment & Yield $\left(\right.$ g plant $\left.^{-1}\right)$ & $\begin{array}{l}\text { \% Shriveled berries per } \\
\text { cluster }\end{array}$ \\
\hline Control & $1503.5^{\mathrm{a}}$ & $13.7^{\mathrm{a}}$ \\
\hline Shade Fruit Set - Harvest & $2172.0^{\mathrm{b}}$ & $5.8^{\mathrm{b}}$ \\
\hline Shade Veraison - Harvest & $2075.6^{\mathrm{b}}$ & $6.7^{\mathrm{b}}$ \\
\hline
\end{tabular}

Different superscript letters indicate a significant difference (Tukey's a $\leq 0.05$ ). 


\section{IV.2.3. The Effects of Sun and Shade on Grape and Wine Quality}

Shade affects grape must and wine quality as well. Grape must quality and wine quality are subjective concepts but can be generally quantified through measuring levels of sugars/soluble solids (SS), pH, Total Acidity (TA), tartaric acid, malic acid, anthocyanins, tannins, polyphenols, and other flavonoids (Archer and Strauss 1989; Sadler and Murphy 2010; Boudreau et al. 2018; Blancquaert et al. 2019; Kemp et al. 2019).

Sugar content in grapes, measured as soluble solids (SS), is the biggest indicator of ripeness and determines post-fermentation alcohol content (Jordão et al. 2015; Kemp et al. 2019). Heat, influenced in part by sunlight, is the greatest driver of SS accumulation, with higher temperatures (up to $30^{\circ} \mathrm{C}$ ) generally associated with greater and more rapid SS accumulation (Winkler et al. 1974; Coombe 1987; Mullins et al. 1992; Sadras and Moran 2012; Rienth et al. 2014). However, even though heat usually increases grape SS content, under certain circumstances, SS accumulation can be delayed or even halted entirely by heat (Sepúlveda and Kliewer 1986; Bergqvist et al. 2001; Greer and Weston 2010; Lecourieux et al. 2017). Reduced photosynthesis due to heat stress is speculated to be a cause of this phenomenon (Greer and Weston 2010). In areas impacted by high temperatures, shade can actually reduce the negative effects of heat upon SS accumulation (Abeysinghe et al. 2019).

Soluble solid accumulation is also influenced by PAR or the lack thereof, although the effect of shading on clusters is different from the effect of shading on vine canopies. The effect of cluster shading in specific on SS development in grapes has been widely debated, with some studies finding that cluster shading has no effect upon SS levels at harvest (Crippen and Morrison 1986; Rojas-Lara and Morrison 1989; Morrison and Noble 1990; Haselgrove et al. 2008; Spayd et al. 2002; Downey et al. 2006; Lee 2017) and others finding that cluster shading reduces SS levels (Reynolds et al. 1986; Kliewer and Smart 1989; Dokoozlian and Kliewer 1996; Chorti et al. 2010). The effects of canopy shading are clearer; 
many researchers have found that the process of SS accumulation is slowed down (although not inhibited) in the presence of shade due to reduced PAR (Lakso et al. 1989; Rojas-Lara and Morrison 1989; Morrison and Noble 1990; Mullins et al. 1992; Cartechini and Palliotti 1995; Abeysinghe et al. 2019). However, in hot regions where temperature negatively affects SS accumulation, reductions in light can lower temperature and balance out the negative effects of reduced PAR, to result in overall equal or greater SS accumulation rates (Abeysinghe et al. 2019).

Acids in grape must and wine are also affected by shade. Acids balance sulfur dioxide content in wine, determine the stability of anthocyanins and thus color, determine conduciveness to fermentation, keep harmful microorganisms in check during fermentation, and are fundamental to achieving a crisp, high-quality flavor (Pedroza et al. 2017; Comuzzo and Battistutta 2019). Acid synthesis is partially dependent upon light exposure and partially dependent upon temperature. Temperature is the driving influencer of acid synthesis and degradation, especially at later stages of grapevine development, with higher temperatures causing reduced levels of TA, and subsequently, lower quality wine (Buttrose et al. 1971; Ruffner et al. 1976; Bergqvist et al. 2001; Spayd et al. 2002; Keller 2010; Bonada et al. 2013b; Sweetman et al. 2014; Martínez-Lüscher et al. 2017). Shade has been shown to have either little effect on acidity overall (Kliewer and Antcliff 1970; Morrison and Noble 1990; Oliveira et al. 2014) or even positive effects on acidity, due to its temperature-reducing properties (Spayd et al. 2002). Shade's effects on acidity in a given environment would, however, depend on the amount of shade received, the climate of the particular growing region, the trellis system, the grape variety being grown, and many other factors (Cartechini and Palliotti 1995; Greer and Weedon 2013).

Flavonols are a type of flavonoid that bond with anthocyanins to stabilize wine and form co-pigment complexes, and they also scavenge free radicals, protect plants against UV 
damage, and protect against pathogens (Flint et al. 1985; Mattivi et al. 2006; Azuma et al. 2012). Sunlight exposure is the main factor in influencing flavonol content in wine grapes, with higher light exposure directly resulting in higher flavonol quantities (Price et al. 1995; Tarara et al. 2005; Martínez-Lüscher et al. 2019). In a study comparing shaded and sunexposed Merlot clusters in Yakima Valley, Washington, Spayd et al. (2002) found that sunexposed clusters had 10 times the amount of flavonols as did shaded clusters, even when temperature was decoupled from irradiance (Table 4). Many other studies have examined the effect of light on flavonol content as well and have found that flavonol content in lightexposed berries is consistently higher than flavonol content in light-excluded berries (Fujita et al. 2006; Azuma et al. 2012; Sun et al. 2017). In particular, the flavonols kaempferol, quercetin glycoside, and quercetin aglycone have been shown to be especially sensitive to shade (Price et al. 1995; Martínez-Lüscher et al. 2019) (Figure 15).

Anthocyanins are the pigments that create color in wine, and they are primarily found in grape skin (Mattivi et al. 2006; Kennedy 2008). The concentration of anthocyanins increases under greater light exposure and is suppressed by shade (Morrison and Noble 1990; Gao and Cahoon 1994; Dokoozlian and Kliewer 1996; Keller and Hrazdina 1998; Oliveira et al. 2014) but only up to irradiance levels of $100 \mathrm{mmol} / \mathrm{m}^{2} / \mathrm{s}$ (Bergqvist et al. 2001; Tarara et al. 2005). Once grapevines receive $100 \mathrm{mmol} / \mathrm{m}^{2} / \mathrm{s}$ of sunlight, anthocyanin levels actually begin to decline with increased sunlight, largely because with greater sunlight exposure come higher temperatures, which negatively affect anthocyanins (Buttrose et al. 1971; Haselgrove et al. 2008; Bergqvist et al. 2001; Spayd et al. 2002; Downey et al. 2006; Yamane et al. 2006; Mori et al. 2007; Tarara et al. 2005; Azuma et al. 2012; Blancquaert et al. 2019; Gouot et al. 2019). Because of this, providing grapevines with enough shade to reduce thermal radiation without causing irradiance to drop below $100 \mathrm{mmol} / \mathrm{m}^{2} / \mathrm{s}$ could be a way to maintain optimal anthocyanin production even with the increased temperatures that are predicted to occur with 
climate change (Buttrose et al. 1971; Downey et al. 2006). The incorporation of trees into vineyards may be a way to do this.

Although sunlight is less of an influencing factor on anthocyanin production than is temperature, researchers have observed higher anthocyanin content in the wines made from sun-exposed grapes, even though they did not observe higher anthocyanin content in the grape skin of sun-exposed grapes (Price et al. 1995). Researchers speculate that this could be due to the higher quercetin aglycone levels that sun exposure causes, which may promote the polymerization of anthocyanins in wines, thus leading to greater stability of anthocyanins over time, even though grapes themselves might not have higher anthocyanin levels under different light treatments (Price et al. 1995; Kennedy 2008).

The biggest indicator of wine quality is balance - when acids, tannins, sugars, anthocyanins, phenolics, and alcohol levels are present in balanced ratios within a wine (Jackson and Lombard 1993; Jones et al. 2005; Rienth et al. 2016). Because of climate change and higher temperatures, many wine growing regions, especially those in warmer climates, will find it hard to continue to produce quality and balanced wine in the coming years (Jones et al. 2005; Keller 2010; Mira de Orduña 2010; Rienth et al. 2016; Drappier et al. 2019). Higher temperatures cause sugars to develop at accelerated rates, leading fruit to mature long before other components such as aroma and polyphenols have time to develop (Jones and Davis 2000; Chuine et al. 2004; Webb et al. 2008; Rienth et al. 2016). Higher temperatures also lead to higher levels of alcohol, which results in the masking of other complex aromas, and higher temperatures can directly degrade many other quality-related compounds as well (Jones et al. 2005; Stock et al. 2005; Keller 2010; Mira de Orduña 2010; Rienth et al. 2016; Lecourieux et al. 2017; Drappier et al. 2019; Gouot et al. 2019; MoralesCastilla et al. 2020). Utilizing shade in vineyards may be an important strategy for maintaining balanced wine in the face of increased temperatures in wine growing regions in 
the coming years. All in all, shade reduces both PAR and microclimatic temperature,

resulting in both positive and negative effects on wine quality. Shade lowers wine quality by reducing flavonol synthesis and reducing long-term anthocyanin stability in wine over time. However, under the projected temperature increases predicted by climate change models, shade could actually increase wine quality by slowing sugar accumulation, moderating alcohol levels, maintaining high acidity levels, and maintaining anthocyanin levels, resulting in overall wine balance and persistent wine quality.

Table 4. Influence of cluster temperature and exposure to sunlight on flavonol concentrations in Merlot berry skins in the Yakima Valley, Washington, 2000. Adapted from Spayd et al. (2002).

\begin{tabular}{|l|l|l|l|l|l|l|}
\hline & \multicolumn{3}{|c|}{ SUN } & \multicolumn{3}{c|}{ SHADE } \\
\hline & Control & Blower & Cooled & Control & Blower & Heated \\
\hline Total flavonols & $82.70 \mathrm{a}$ & $82.70 \mathrm{a}$ & $76.00 \mathrm{a}$ & $10.20 \mathrm{~b}$ & $22.90 \mathrm{~b}$ & $17.80 \mathrm{~b}$ \\
\hline $\begin{array}{l}\text { Quercetin 3- } \\
\text { glucoside }\end{array}$ & $59.90 \mathrm{a}$ & $62.80 \mathrm{a}$ & $56.60 \mathrm{a}$ & $7.50 \mathrm{~b}$ & $14.60 \mathrm{~b}$ & $12.50 \mathrm{~b}$ \\
\hline $\begin{array}{l}\text { Myricetin 3- } \\
\text { glucoside }\end{array}$ & $9.12 \mathrm{a}$ & $8.50 \mathrm{a}$ & $8.15 \mathrm{a}$ & $0.01 \mathrm{~b}$ & $3.15 \mathrm{~b}$ & $1.80 \mathrm{~b}$ \\
\hline $\begin{array}{l}\text { Kaempferol 3- } \\
\text { glucoside }\end{array}$ & $13.70 \mathrm{a}$ & $11.40 \mathrm{a}$ & $11.30 \mathrm{a}$ & $2.68 \mathrm{c}$ & $6.72 \mathrm{~b}$ & $4.80 \mathrm{bc}$ \\
\hline
\end{tabular}

Mean separation within years within rows by Duncan's new multiple range test $(p=0.05)$. Means followed by the same letter do not differ. 


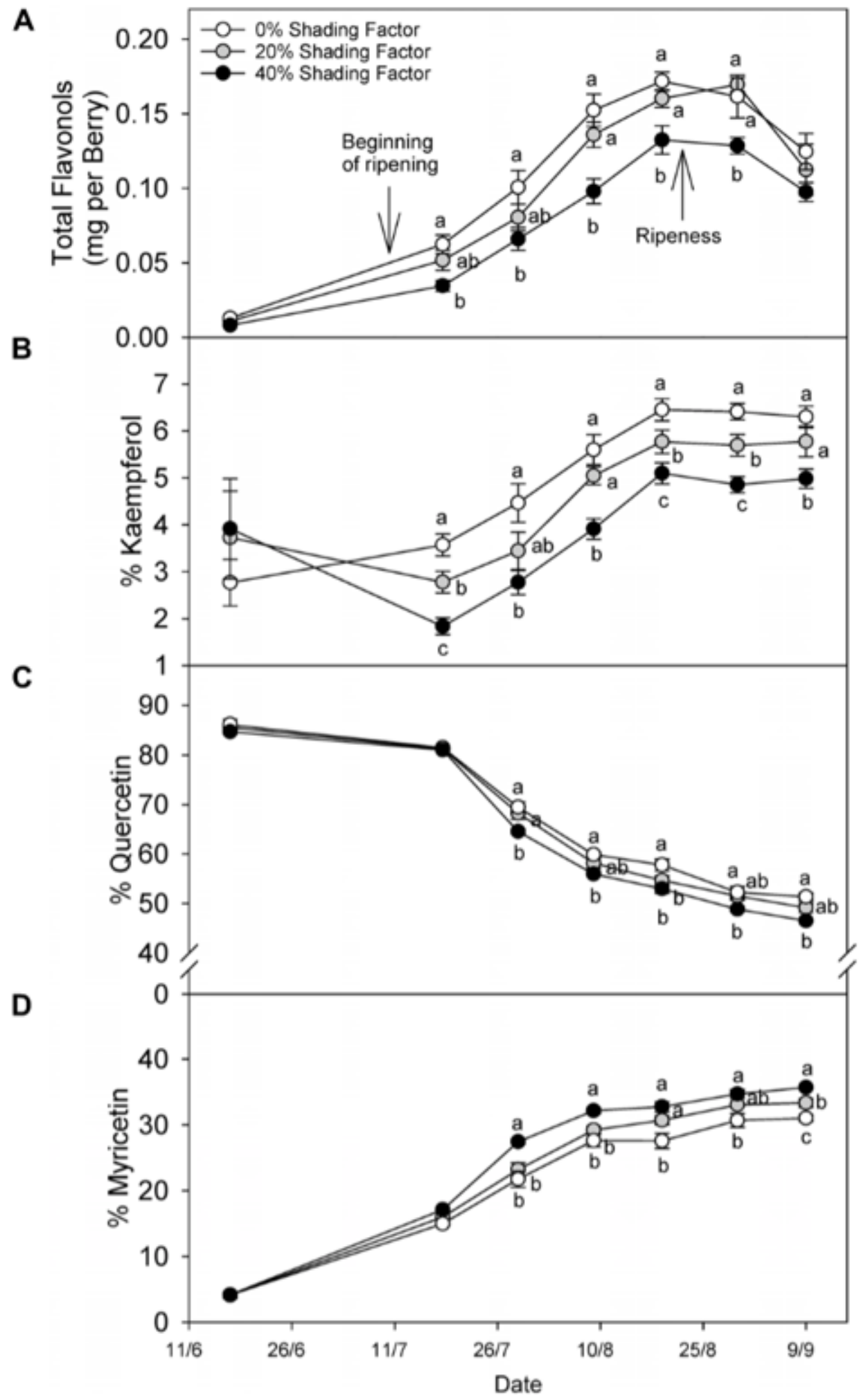

Figure 15. Evolution of total flavonol content per berry (A), \% kaempferol (B), \% quercetin (C), and \% myricetin (D) under ambient ( $0 \%$ shading factor) and under two shade nets (20 and 40\% shading factor) covering the fruit-zone of cv. Cabernet Sauvignon grapes. Ripening is considered from color change (ca. $12 \circ$ Brix) to soluble solids of ca. $22^{\circ}$ Brix and over-ripening from $23^{\circ}$ Brix to harvest. Means in the same time point with no letters in common differ (ANOVA-LSD; $p<0.05$ ). Source: Martínez-

Lüscher et al. 2019. 


\section{IV.3. THE EFFECTS OF SUN AND SHADE IN VINEYARD AGROFORESTRY SYSTEMS}

Shade in-and-of-itself can have negative effects on grapevine physiological, production, and quality parameters, such as decreasing SSs, flavonols, long-term anthocyanin stability, bud fruitfulness, fruit bud initiation, and inflorescence formation, along with potentially negatively affecting acids under certain conditions. However, despite these negative effects, shading from trees in specific is a more complex matter with many moving parts at play. In fact, current research suggests that shade from trees might minimally affect wine grape production and quality parameters (Gillespie et al. 2000; Dupraz et al. 2009; Trambouze and Goma-Fortin 2013; Grimaldi 2018). The presence of trees in vineyards does impact the quantity of PAR, thermal radiation, and light quality that reaches grapevines (Kliewer and Smart 1989), but not always in significant nor negative ways.

Light interference was observed in vineyard agroforestry systems in several extensive, 20-year studies at the Restincliéres Agroforestry site in Montpellier, France, in which grapevines were intercropped with Pinus pinea L., Pinus brutia Ten., Cupressocyparis leylandii, Cupressus sempervirens, Pyrus communis L., and Sorbus domestica L. In these studies, grapevines were observed to have lower yield within $4 \mathrm{~m}$ of tree rows, however, this was speculated to be mainly caused by competition for $\mathrm{N}$, rather than competition for light (Gillespie et al. 2000; Dupraz et al. 2009; Trambouze and Goma-Fortin 2013; Grimaldi 2018). Under this same research project, a Discrete Anisotropic Radiative Transfer (DART) model was developed to predict how much grapevines would be impacted by shading from trees under various growing conditions (Grimaldi 2018). The model used meteorological data, radiative data, typical vineyard agroforestry system shading patterns, and actual recorded data from dozens of vineyard experimental sites in France. Data was grouped into categories: vines under large trees vs. vines under small trees, and vines on south sides of tree 
rows vs. vines on north sides of tree rows. The model showed that vines exposed to shade from trees did indeed absorb lower levels of radiative energy; in the "large tree" treatment, grapevines to the south of tree rows absorbed $4 \%$ more PAR than tree rows to the north, while in the "small tree" treatment there was no difference. However, even though the presence of trees did reduce vine PAR absorption in this study, the model predicts that these reductions in PAR are not enough to significantly reduce neither photosynthesis nor yield (Grimaldi 2018). These studies and models suggest that shade from trees would not negatively impact grapevines in a significant way. There are many reasons to explain why this might be the case.

In terms of the quantity of PAR reaching grapevines in vineyard agroforestry systems, every agroforestry system is different, but trees do reduce the amount of sunlight reaching understory crops (Oke 1988). The amount of light that penetrates the understory through tree canopies depends on tree species, height, and density, and the angle of solar incidence (Oke 1988). In forests, only $20 \%$ of incident short-wave light reaches the understory, but in agroforestry systems, the percentage is higher (Oke 1988). Estimations for the light interception patterns around a single tree during the grapevine growing season in the Northern Hemisphere (April 1 - September 21) can be summarized in Figure 16. These estimations are specifically for a latitude of $34.8^{\circ} \mathrm{N}$ and trees with an ellipsoid canopy shape, but they can be a good indicator of general shading patterns in other trees and latitudes. In general, estimations for PAR reaching the understory to the north of trees is roughly 15 to $50 \%$ of full-sun irradiance, estimations for PAR reaching the understory to the east and west of trees is roughly 40 to $50 \%$ of full-sun irradiance, and estimations for PAR reaching the understory to the south of trees is roughly $25-70 \%$ of full-sun irradiance (Dupraz et al. 2005). However, studies from Guyot (1989) show that, although tree canopies do shade grapevines, the many leaves in tree canopies also act as reflectors, reflecting radiation onto the vines 
below. Short-wave radiation can be reflected off of the ground, off of understory vegetation, and off of the underside of tree canopies as well, which causes understory plants, grapevines in this case, to receive amounts of short-wave radiation that are often still sufficient for growth (Oke 1988). Figure 17 sums up the general light distribution patterns that occur when radiation comes into contact with tree canopies. Overall, PAR is predicted to be only $10-15 \%$ lower in vineyard agroforestry systems than in vineyard monocultures (Grimaldi 2018).

In terms of the effect of trees on the quality of light reaching grapevines, tree canopies in general absorb (and therefore deplete for understory crops) quantities of red and blue $(0 \cdot 40$ to $0.45 \mu \mathrm{m})$ light, therefore leaving higher ratios far red and infrared light $(0.65$ to $0.75 \mu \mathrm{m})$, which is less suitable for photosynthesis (Oke 1988). Deciduous trees absorb most of sunlight's red and blue light rays, leaving understory plants below to absorb mostly orange, yellow, green, and infrared light (Krueger 1981). However, coniferous trees absorb mostly blue light, allowing some red light to also filter through to understory plants (Krueger 1981). Because red and blue light rays are the wavelengths primarily responsible for photosynthesis, reductions in quantities of these light rays can indeed have an impact on understory crop photosynthesis (Krueger 1981, Oke 1988); thus, shade from deciduous trees is likely to have a more negative effect on understory grapevine photosynthesis than shade from coniferous trees. Shade causes the red:far red ratio to drop below 1.1 as well, which is also less conducive to photosynthesis (Gommers et al. 2013; Grimaldi 2018). Reductions in red light have other negative consequences as well; the reduction in red light caused by tree shade causes a reduction in the creation of important plant enzymes, such as PAL and invertase, which in turn causes a reduction in lignin production, flavonoid production, and sucrose hydrolysis (Wright 1989; Tauzin and Giardina 2014).

Despite the reduction in PAR and light quality that tree shade causes, the photosynthesis-enhancing effects that tree shade imparts on the vineyard microclimate, such 
as the buffering of extreme temperatures, could outweigh any negative effects upon photosynthesis (Grimaldi et al. 2017; Grimaldi 2018). In fact, daytime shading from trees has been shown to reduce vines heat stress, which actually increases photosynthesis (Oke 1988; Grimaldi et al. 2017; Grimaldi 2018). Although lower amounts of PAR and diminished light quality do of course correspond to lower photosynthesis rates, shade can cause lower heat stress and lower evaporative demand, which encourages stomata to open, thus allowing photosynthesis to occur more efficiently (Oke 1988). More studies must be undergone to examine the tradeoffs between reduced PAR, reduced light quality, and the increased stomatal opening that occurs in vineyard agroforestry systems in specific due to shading, but the models from Grimaldi (2018) suggest that grapevine photosynthesis is not significantly affected by shade in vineyard agroforestry systems. Another reason why grapevine photosynthesis might not be affected by reduced light is that grapevines adapt to low light intensities by increasing leaf chlorophyll content and modifying their canopy architecture (Cartechini and Palliotiti 1995).

Because of its temperature-buffering effects, shade from vineyard agroforestry systems may also create conditions for optimal cellular division, and thus growth, in grape berries (Dokoozlian 2016). Since grape berry development is largely influenced by temperature and is halted above temperatures of $35^{\circ} \mathrm{C}$, some shade from trees, especially in hot growing regions or in regions impacted by climate change, may beneficially affect berry development (Dokoozlian 2016).

The predicted amount of shade as indicated by Grimaldi's models might not be sufficient to impact wine quality parameters in a negative way either; many wine quality indicators such as flavonol content and SS levels are indeed inhibited by shade, but only high levels of shade have been shown to have a significant impact. For instance, Gao and Cahoon (1994) did observe lower total SS and anthocyanin levels in grapes treated with a 95\% shade 
treatment as compared to a 55\% shade treatment and a full-light shade treatment, but they did not observe differences between the $55 \%$ shade treatment and the full-light treatment. Thus, grape quality parameters in vineyard agroforestry systems might not be significantly impacted by the PAR reductions that occur in vineyard agroforestry systems, although more research is needed in this area. All in all, the existing research suggests that, under hot growing conditions such as those that are predicted to occur in the coming years with climate change, the positive impacts that tree shade imparts to the vineyard microclimate may very well outweigh the negative effects from reduced PAR and reduced light quality.

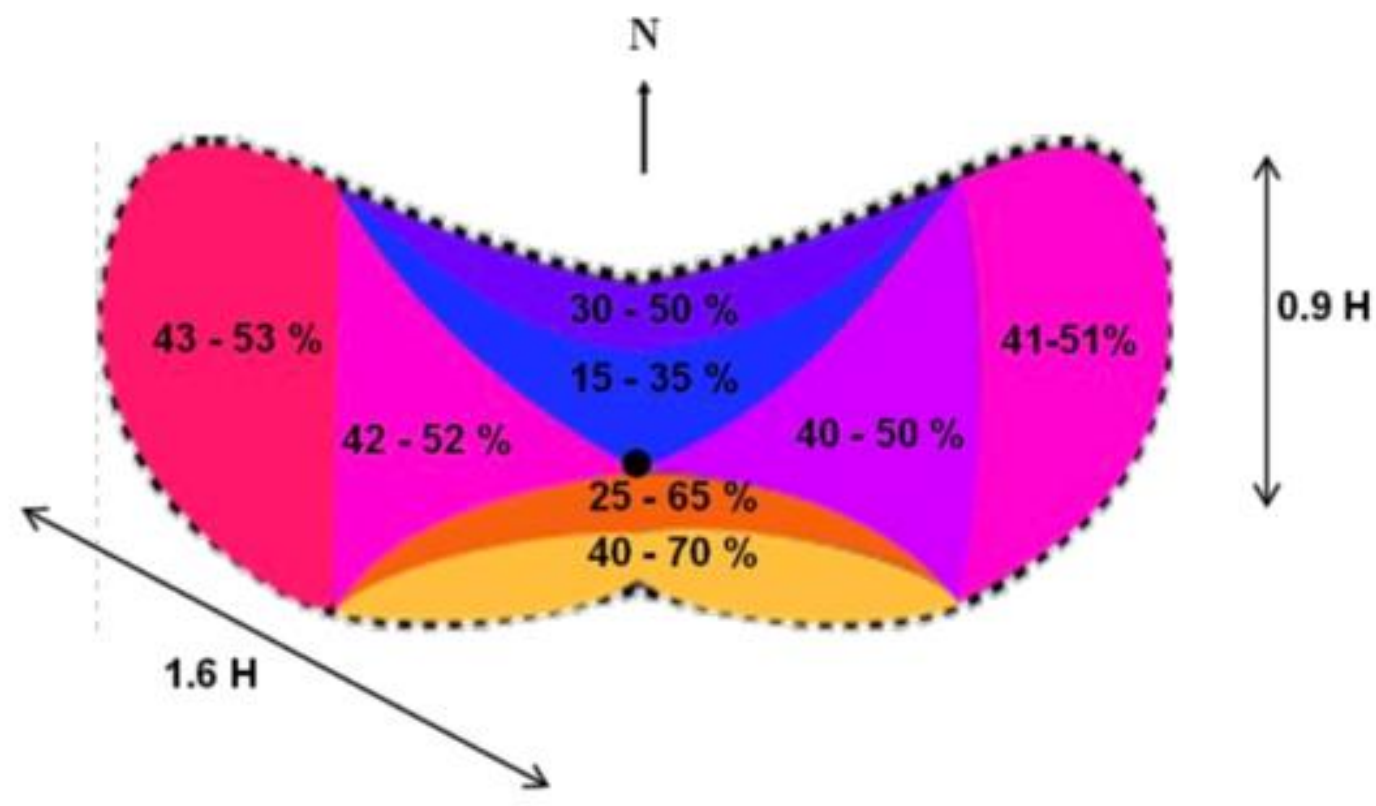

Figure 16. Schematic representations of potential light availability patterns around a single tree based on the tree's shadows from April 1 to September 2, at a latitude of $43.8^{\circ} \mathrm{N}$, with tree height H, and ellipsoid tree canopy shape. Source: Grimaldi (2018) and Dupraz et al. 2005. 


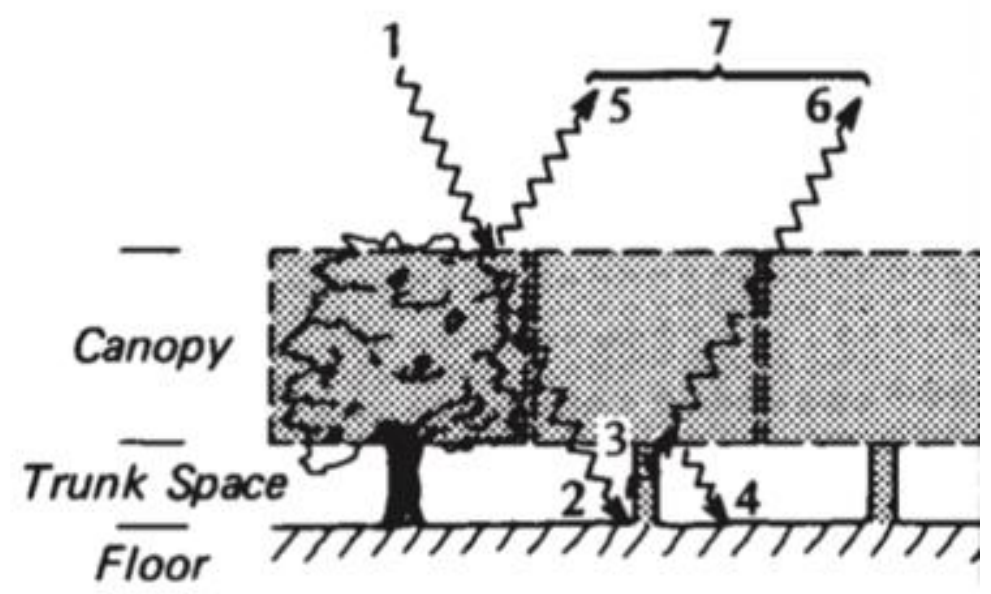

Figure 17. Schematic Model of radiation exchanges above and within a forest. Dashed lines indicate partial transmission through the canopy. Flux 1 indicates the short-wave radiation that comes down onto trees from the sun. Flux 2 indicates the short-wave radiation that is transmitted to the understory. Flux 3 indicates the initial short-wave radiation reflected from the floor upwards. Flux 4 indicates the reflection between the floor and the underside of the canopy or the underside of the understory crop. Flux 5 represents the short-wave radiation that is reflected by the tree canopy. Flux 6 represents the short-wave radiation reflected from the floor onto understory plants. Flux 7 represents that total short-wave radiation reflected from both the canopy (Flux 5) and the floor (Flux 6). Source: Oke (1988).

\section{IV.4. CONCLUSION}

The presence of trees in vineyard agroforestry systems impacts light patterns, which, in turn, affect wine grape physiological, production, and quality parameters in both positive and negative ways. Trees reduce the quality and quantity of light that reaches understory crops, trees reflect light from their canopies onto understory crops, and tree shade reduces temperature. The small body of current research on vineyard agroforestry systems today indicates that shade from trees may not significantly affect grapevine photosynthesis nor quality, and that rather, below-ground competition for resources may be more of a limiting factor than is competition for light. More studies must be undergone on vineyard agroforestry systems in specific, but existing studies examining shade from other sources in vineyards suggests that, in regions that are predicted to be impacted by climate change in the coming years, shade may impact grapevines in positive ways. In wine growing regions impacted by 
high temperatures and more frequent heat waves, shade from trees may benefit grapevines by reducing sunburn from UV radiation, maintaining photosynthesis rates, preventing yield losses from shriveling, maintaining adequate sugar levels, preventing acid degradation, allowing anthocyanin development, and promoting synchronized development of flavor profiles for an overall balanced and high-quality wine. In wine growing regions that are less impacted by climate change, shade may have opposite effects, and may reduce levels of SS, acids, anthocyanins, and yield. In all regions, regardless of the predicted impact of climate change, shade is speculated to have a negative impact on flavonols and long-term anthocyanin stability.

Many management practices can be implemented in order to create vineyard agroforestry systems that maximize benefits while minimizing competition for light. More research on vineyard agroforestry systems in specific is needed in order to confirm the research findings summarized in this review. However, the existing research summarized in this review, along with other research demonstrating the other positive benefits that agroforestry brings to vineyards (including increased drought resistance, increased OM, improved soil structure, improved vine rooting capability, increased photosynthetic capacity, erosion reductions, reduced pest and disease pressure, reduced wind damage and erosion, reduced heat stress, and reduced frost damage, and ecosystem services) warrants more research to be done on light in vineyard agroforestry systems. In particular, research that focuses on light in a wide range of wine producing regions, grape varieties, and tree-vine combinations would be beneficial. 


\section{CHAPTER V}

THE EFFECT OF TREES ON MICROCLIMATE IN VINEYARD AGROFORESTRY SYSTEMS 


\section{V.1. INTRODUCTION}

Agroforestry, defined as the intentional incorporation of trees into agricultural systems (Gold and Garrett 2009), was once a common practice in vineyards, and today it is being looked to once again as a way to address many of the threats facing modern viticulture (Dupraz et al. 2009; Fabre 2014). Although vineyard agroforestry systems were, for centuries, the traditional method of wine grape cultivation, since the beginning of the $19^{\text {th }}$ century with the rise of industrialization, vineyards have shifted to monocultures, and the use of trees has largely been abandoned (Fabre 2014). This shift has brought with it a multitude of problems that affect vineyards including erosion, reduction in soil fertility, biodiversity loss, shoot and vine damage due to high winds, increased pest and disease pressure, and increased reliance on agrochemicals (Francis et al. 2004; Martínez-Casasnovas and Ramos 2006; Pimentel 2006; Dunn and Martin 2008; Henderson and Rex 2012; Borrelli et al. 2013; Pachauri and Meyer 2015; Pagay and Collins 2017; Ferreira et al. 2018; Rodrigo-Comino et al. 2018). These issues, paired with the extreme weather patterns caused by climate change, including drought, extreme precipitation, unseasonal frost, and extreme heat, result in yield losses and/or economic losses, and they point to a need for more sustainable viticulture solutions (Hennessy and Pittock 1995; Dupraz et al. 2009; Grimaldi 2018).

There is a growing body of evidence demonstrating that agroforestry has beneficial applications in viticulture in terms of its integrated pest management potentials (Altieri and Nicholls 2002; Wilson et al. 2015; Wilson et al. 2017a; Wilson et al. 2017b) and its belowground services, including increasing drought resistance, reducing erosion, building organic matter, bettering soil structure, and improving vine rooting capability (Hidalgo 1968;

Mckenry 1984; Young 1989a, 1989b; Schroeder 1993; Riha and McIntyre 1999; Thevathasan and Gordon 2004; Smart et al. 2005, Seobi et al. 2005; Udawatta et al. 2011b; Minasny and McBratney 2015; Favor and Udawatta 2020). Agroforestry also benefits viticultural systems 
in numerous ways in terms of its effects on above-ground parameters such as wind patterns and microclimate, as this review paper will summarize.

The utilization of agroforestry in vineyards affects wind patterns, preventing both direct and indirect wind damage, reducing wind erosion, increasing leaf area, increasing stomatal aperture, and maintaining high vine photosynthetic capacity. Agroforestry also alters the vineyard microclimate by buffering temperature, protecting against heat, protecting against frost, reducing water stress, and mitigating climate change. Although some interactions between grapevines and trees have negative ramifications, many of the interaction effects are positive. Paired with the fact that windbreaks also provide a host of ecosystem services including purifying water, mitigating pollution, sequestering carbon, and conserving biodiversity (Root 1973; Mize et al. 2008; Jose 2009; Garcia et al. 2018), the case can be made that the utilization of trees in vineyards may once again have its place in sustainable viticulture, especially considering the impending negative effects that climate change will have on vineyard microclimates. The intentional application of agroforestry in vineyards has the potential to modify the viticultural microclimate and create regenerative viticultural systems that are able to both resist and also mitigate many of the issues that modern viticulture is confronted with (Raj and Toppo 2018).

\section{V.2. THE EFFECT OF TREES ON WIND PATTERNS IN VINEYARD AGROFORESTRY SYSTEMS}

\section{V.2.1. The Negative Effects of Wind in Conventional Vineyards}

Wind can negatively affect vineyards in many ways, both directly and indirectly. Wind can cause direct damage to vineyards by whipping branches, buds, flowers, and fruit, and even toppling entire grapevines if strong enough (Norton 1988, Jagoutz 2004; Henderson and Rex 2012). In some cases, especially in the case of young vines, wind has been known to deform or completely break trunks, shoots, and roots (Norton 1988; Tarara et al. 2005). Wind 
can also damage buds, resulting in reduced bud fertility, and subsequently, reductions in cluster numbers per vine (Dry and Botting 1993; Bettiga et al. 1996). During the winter, winds can bring cold air into vineyards and can cause increased risk of tissue damage from frost as well (Gade 1978; Vogt and Schruft 2000).

Wind can indirectly harm vineyards by reducing the photosynthetic rate of grapevines. Wind reduces shoot length, leaf size, and stomatal density of grapevines, resulting in fewer cells that are able to perform photosynthesis and thus, lower photosynthesis rates (Dry and Botting 1993; Pienaar 2005). Wind reduces stomatal conductance as well; in response to strong wind, grapevine stomata have been observed to close several hours more quickly than those of vines exposed to light winds or reduced wind from windbreaks (Dry and Botting 1993). Wind can also permanently damage stomata by diminishing the boundary layer of leaves, damaging the grape leaf cuticle, and even damaging epidermal cells and/or their structures, which all either directly harm stomata or limit their functioning (Weyers and Hans 1990; Boyer 2015). Since photosynthesis occurs as a result of $\mathrm{CO}_{2}$ diffusing into stomata while water vapor diffuses out, stomatal closure and damage results in the direct reduction of photosynthesis (Freeman et al. 1982; Kobriger et al. 1984; Boyer 2015). Reductions in photosynthesis reduce the amount of sugars and phenolic compounds in berries, which translates to reduced quality and flavor in wine (Creasy and Creasy 2009).

Wind can also cause significant soil erosion in vineyards, which not only diminishes soil fertility and increases farmer dependence on fertilizers, but which can also cause environmental problems such as contamination in watersheds and ecosystems downstream, along with health risks from dust production (Goudie 2014; Rodrigo-Comino et al. 2018). Wind erosion occurs when wind energy itself dislodges soil particles from the soil surface, and also when these dislodged particles hit and dislodge other soil surface particles through a mechanism known as saltation (Blanco-Canqui and Lal 2010; Pennock 2019). In a study 
comparing the erosion rates of different land management systems in Spain, Marzen et al. (2019) found that $98 \%$ of erosion in the conventional vineyards studied was caused by wind, which was a significantly higher percentage than that found in other land management systems such as orchards, Mediterranean fallows, and wheat fields (Figure 18). This higher rate of wind erosion is speculated to be due to the high amount of tillage in conventional vineyards, and it is estimated to be lower in vineyards that implement low- or no-till practices or that implement windbreaks (Kirchhoff et al. 2017; Marzen et al. 2019). All in all, the negative effects of wind on grapevine tissue, yield, stomata, photosynthesis rate, and even soil fertility can result in significant losses and additional expenses for wine grape farmers worldwide.
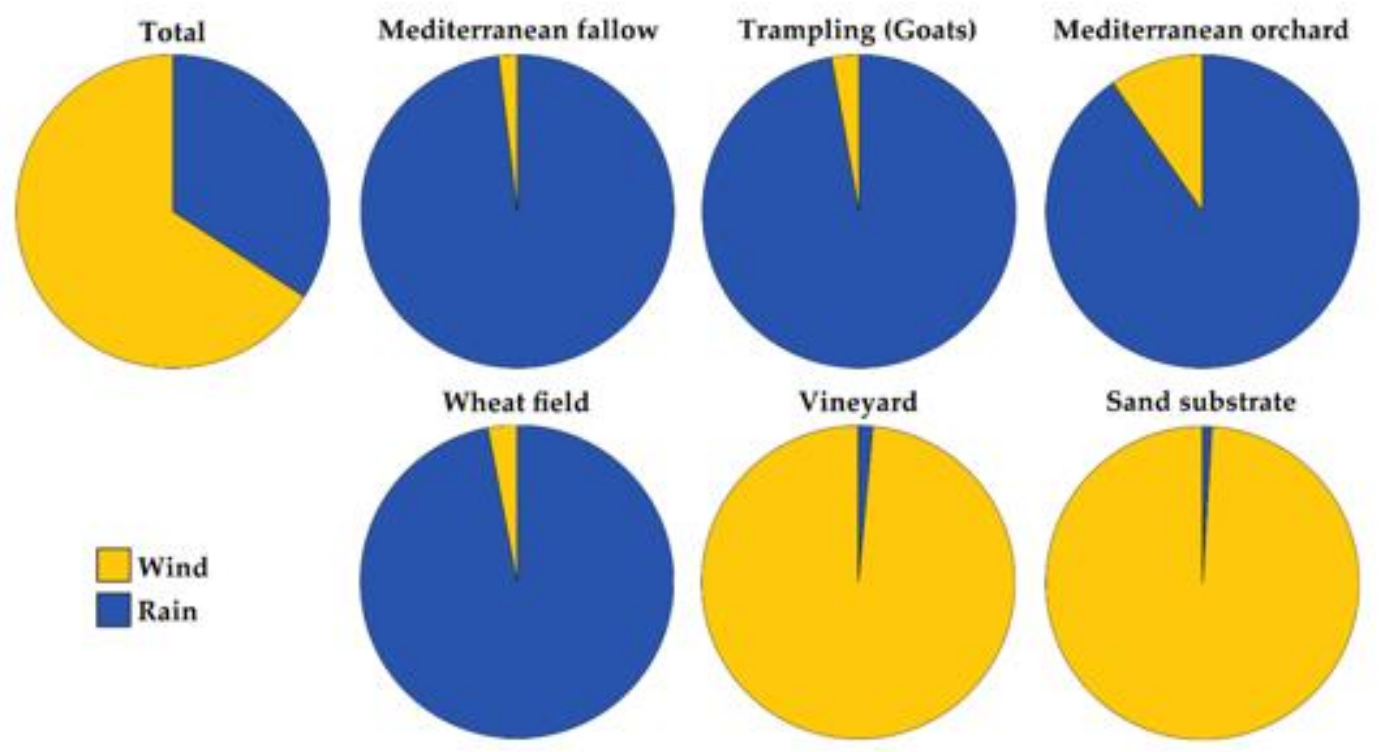

Figure 18. Percentage of erosion for wind and rain on different land management systems in Spain. Source: Marzen et al. (2019).

\section{V.2.2. Windbreaks as a Solution in Vineyard Agroforestry Systems}

Windbreaks, also known as shelterbelts, are an agroforestry practice consisting of lines of trees and shrubs that slow and change windflow patterns by intercepting wind as it 
passes through trees and by forcing air up and over trees (Mize et al. 2008; Brandle et al. 2009). As air approaches a windbreak, its surface static pressure increases as it hits the barrier of trees, sharply drops as it flows through, and then continues to stay low for some distance after the windbreak until it gradually goes up again (Brandle et al. 2009). Windbreaks are commonly used to protect livestock and crops, control snowdrift, reduce wind soil erosion, improve aesthetics, provide habitat to wildlife, improve irrigation efficiency, yield tree products, reduce odor and noise, and reduce pesticide drift (Ucar and Hall 2001; Brandle et al. 2009; Tamang et al. 2009). The design of a windbreak, including its height, length, continuity, orientation, species composition, and density (determined by number of rows and tree spacing) determines how effective windbreaks will be at reducing wind speed (Ucar and Hall 2001; Mize et al. 2008).

Both windbreaks and alley cropping systems, two types of agroforestry practices, function to slow wind in vineyards. Although the practice of incorporating agroforestry into vineyards is still relatively uncommon, several studies have demonstrated the benefits of windbreaks in vineyards in specific. Dry and Botting (1993) conducted an extensive experiment in Eden Valley, Australia over the course of six years in which grapevines exposed to wind were compared to grapevines sheltered by a $3.5 \mathrm{~m}$ high, $300 \mathrm{~m}$ long windbreak. Sheltered vines were found to have significantly more shoots per $\mathrm{m}$ cordon, longer shoot lengths, more nodes per shoot, higher stomatal density, and an overall higher mean mass per cane, showing that vegetative growth, and thus, photosynthetic capacity, is higher in vines sheltered by windbreaks (Table 5). A similar grey-literature study in Stellenbosch, South Africa also examined the effects of wind on grapevine physiology by comparing sheltered Merlot vines to wind-exposed vines over the course of two years, and found that sheltered vines had a higher number of primary and secondary leaves, higher total primary and secondary leaf area, longer shoot length, and longer internodes (Pienaar 2005). 
Researchers found that sheltered vines also had higher stomatal conductance (Pienaar 2005). In another study, Bettiga et al. (1996) compared sheltered Chardonnay grapes to windexposed Chardonnay grapes (in which wind speed was higher than $4 \mathrm{~m}$ per second). Researchers found that sheltered vines had significantly larger leaf areas; primary leaves of sheltered vines were $40 \%$ larger than those of non-sheltered vines, and lateral leaves of sheltered vines were $30 \%$ larger than those of non-sheltered vines. Additionally, the sheltered vines in this study were observed to have higher bud fertility, more bunches per $\mathrm{m}$ cordon, higher bunch mass, and overall 13\% more yield than non-sheltered vines (Table 6). All of these observations support the conclusion that windbreaks result in better physiological structure, and thus, higher photosynthetic rate and higher yield in vineyards.

Trees in vineyards can increase grape yields in more indirect ways by reducing windspeed and thus allowing for efficient applications of pesticides in precise moments when pest pressure is at the correct threshold (Norton 1988). Environmental Protection Agency regulations prohibit pesticide applications when wind speed is greater than three to ten miles per hour (depending on the pesticide), and thus, pesticides are sometimes unable to be applied at the precise moment when they would be most effective for the vineyard, which can result in losses (Norton 1988; Ucar and Hall 2001; United States Environmental Protection Agency 2019). Windbreaks reduce windspeeds, thus minimizing the conditions that cause pesticide drift, which allows for pesticide application at more precise moments throughout the year (Norton 1988). Another way that windbreaks indirectly benefit vineyards is by reducing soil erosion from wind, thereby keeping nutrients in place and reducing the need for fertilizer inputs (Tamang et al. 2009).

Windbreaks can also benefit vineyards by reducing evaporation up to a point, thus contributing to farmer water savings (Norton 1988; Davarzani et al. 2014). Windbreaks have been shown to reduce soil evaporation and maintain soil moisture, resulting in higher yields 
in dry areas (Kort 1988; McNaughton et al. 1989). However, the slowing of wind does not significantly reduce soil evaporation rate under all growing conditions, as evaporation is only increased by wind under certain local weather conditions (McNaughton 1988; Norton 1988; Cleugh 1998). This is because, although wind does increase evaporation rates up to a point, once evaporation moves from first stage evaporation (soil water flow to vapor diffusion controlled stage) to second stage evaporation (diffusion-dominant stage), wind does not affect evaporation rate significantly (Davarzani et al. 2014). Thus, although windbreaks can often positively influence the water status of grapevines by reducing evaporation, the benefits are not consistent. Still, there are sufficient benefits of windbreaks - such as increased vegetative growth, increased photosynthetic capacity, reduced soil erosion, more precise pesticide applications, increased budburst rate, and increased yield - to warrant their use in vineyards (Norton 1988; Dry and Botting 1993; Jagoutz 2004; Pienaar 2005).

Table 5.Growth response of Cabernet Franc to wind in Eden Valley, South Australia. Source: Dry and Botting (1993) (Reproduced with permission).

\begin{tabular}{|l|c|c|}
\hline \multicolumn{1}{|c|}{ Parameters } & $\begin{array}{c}\text { Exposed vines (avg. wind } \\
\left.\text { speed of }>4 \mathrm{~m} \cdot \mathrm{s}^{-1}\right)\end{array}$ & $\begin{array}{c}\text { Sheltered vines (avg. wind } \\
\text { speed of }<4 \mathrm{~m} \cdot \mathrm{s}^{-1} \text { ) }\end{array}$ \\
\hline Yield per vine $(\mathrm{kg})$ & 7.8 & $9.0^{*}$ \\
Bunches per vine & 66 & $70^{*}$ \\
Bunch mass $(\mathrm{g})$ & 119 & $131^{* *}$ \\
Berries per bunch & 83 & $88^{* *}$ \\
Berry weight $(\mathrm{g})$ & 1.44 & $1.46^{\mathrm{ns}}$ \\
\hline - significant at $p \leq 0.05 *$ significant at $p \leq 0.01 \quad \mathrm{~ns}=$ non-significant
\end{tabular}


Table 6. The effect of wind on yield parameters of Chardonnay grapes. Source: Bettiga et al. (1996) (Reproduced with permission).

\begin{tabular}{|c|c|c|}
\hline Parameters & $\begin{array}{l}\text { Sheltered vines (Mean } \\
\text { wind speed of }<4 \mathrm{~m} \cdot \mathrm{s}^{-1} \text { ) }\end{array}$ & $\begin{array}{l}\text { Exposed vines (Mean } \\
\text { wind speed of }>4 \mathrm{~m} \cdot \mathrm{s}^{-1} \text { ) }\end{array}$ \\
\hline \multicolumn{3}{|l|}{ Vegetative growth } \\
\hline Shoot number per meter cordon & 46 & $50^{*}$ \\
\hline Shoot length $(\mathrm{cm})$ & 105 & $62^{* *}$ \\
\hline Node number per shoot & 15.9 & $13.4^{*}$ \\
\hline Mean internode length $(\mathrm{cm})$ & 6.6 & $4.6^{*}$ \\
\hline Mean mass per cane $(\mathrm{g})$ & 33.5 & $17^{* *}$ \\
\hline Pruning mass per meter cordon $(\mathrm{kg} / \mathrm{m})$ & 1.63 & $0.85^{* *}$ \\
\hline \multicolumn{3}{|l|}{ Yield } \\
\hline Inflorescence number per meter cordon & 74 & 62 \\
\hline Inflorescence/shoot & 1.53 & 1.41 \\
\hline \multicolumn{3}{|l|}{ Canopy density in fruit zone } \\
\hline Leaf layer number & 4.7 & $4.1^{\circ}$ \\
\hline$\%$ Shaded leaves & 58 & $55^{\text {ns }}$ \\
\hline$\%$ Shaded bunches & 96 & $88^{\text {ns }}$ \\
\hline
\end{tabular}

* significant at $p \leq 0.05 *$ significant at $p \leq 0.01 \quad \mathrm{~ns}=$ non-significant

\section{V.3. THE EFFECT OF TREES ON MICROCLIMATE IN VINEYARD}

\section{AGROFORESTRY SYSTEMS}

\section{V.3.1. Microclimatic Issues in Conventional Viticulture}

Wine grape production is influenced by climate at the macro-, meso-, topo-, and micro-climatic scales (Neethling et al. 2019). On a macro-climatic level, the majority of the world's wine grapes are grown within a finite geographical and climatic range, typically between the $30^{\text {th }}$ and $50^{\text {th }}$ parallel in both the northern and southern hemisphere, in climates that fall under the Köppen classification as Mediterranean, mild mid-latitude, mid-latitude dry, subtropical dry, and severe mid-latitude climates (Stevenson 2005; Jones and Webb 2010; Jones et al. 2012). The macroclimates of high-quality wine grapes are typically characterized by growing season isotherms between 12 and $22{ }^{\circ} \mathrm{C}$, and high quality wine is 
generally not produced in regions whose mean growing season temperatures exceed $22{ }^{\circ} \mathrm{C}$ (Neethling et al. 2019). Meso-climatic influences are related to the daily temperatures and precipitation patterns within a region. At this level, the accumulation of growing degree days greatly influences the growth and development of the grapevine (Neethling et al. 2019). Wine grape quality varies highly depending on topo-climatic factors as well, i.e. the local climatic conditions that make up part of the "terroir" of the site (van Leeuwen and Seguin 2006; Neethling et al. 2019). The climatic influences at the topo level are often influenced by the terrain, elevation, slope, aspect, and heat and moisture exchange at this local level (Neethling et al. 2019). Microclimate specifically refers to the temperature, relative humidity, and solar radiation at the canopy-level, immediately within and around the grapevine. The microclimate includes the complex and often subtle interactions that occur between the grapevine and the mineral, vegetative, and climatic components of its surrounding ecosystem, and it is a major determinant of yield, fruit quality, and ultimately, wine quality (Wright 1989; Zahavi et al. 2001; van Leeuwen and Seguin 2006). Because there is already a narrow range of optimum climatic conditions for wine grape growing, grapes are more vulnerable to changes in climate and weather patterns than other crops are; increases or decreases in temperature, albeit a few degrees, can drastically alter the terroir of a site, and thus, the production of high quality wine (Jones and Webb 2010; Santillán et al. 2019; Neethling et al. 2019).

Heat stress, exacerbated by the increased incidence of droughts and extreme heat waves due to climate change, is increasingly becoming a cause of concern in vineyards, and heat stress is only predicted to increase in the coming years (Hennessy and Pittock 1995; Pachauri and Meyer 2015; Cook and Wolkovitch 2016). Heat stress impacts yield by reducing photosynthesis - up to $35 \%$ in some cases - and by halting berry cell division (Smart 1974; Kliewer 1977; Greer and Weedon 2013; Dokoozlian 2016). Heat stress early in 
the growing season can cause significant yield reduction due to reduced numbers of inflorescences and reduced fruit set (Stephenson 1981; Dunn and Martin 2008). Daily daytime temperatures of $40{ }^{\circ} \mathrm{C}$ during flowering and fruit set have been shown to cause high rates of flower abscission (Greer and Weston 2009), and likewise, heat stress late in the season can cause fruit abscission (Stephenson 1981; Dunn and Martin 2008; Pagay and Collins 2017). Late season heat can cause yield reductions due to berry shriveling, sunburn, and raisining, as well (McCarthy 1997; Coombe and McCarthy 2000; Spayd et al. 2002; Keller 2010; Krasnow et al. 2010; Oliveira et al. 2014).

High temperatures throughout the growing season have been shown to speed up sugar accumulation while inhibiting the production of acids, tannins, anthocyanins, and other important flavor compounds, resulting in unbalanced and lower-quality wine (Jones and Davis 2000; Sadras and Moran 2012; Rienth et al. 2016; Alikadic et al. 2019; Drappier et al. 2019). Acids, tannins, sugars, color, and phenolics must all develop in sync in order for a quality wine to be produced, but with high temperatures, sugar and organic acid metabolism are desynchronized, which results in wines which lack complexity or which have high levels of alcohol (Jones and Davis 2000; Rienth et al. 2016; Drappier et al. 2019; Santillán et al. 2019). Not only does heat prevent wine quality indicators from developing by the time harvest arrives; in many cases, heat causes the molecules that contribute to wine quality to degrade entirely. The amount of heat that vineyards experience during heat waves has been shown to degrade anthocyanins, organic acids, polyphenols, amino acids, and other qualitydriving volatiles (Bergqvist et al. 2001; Spayd et al. 2002; Lecourieux et al. 2017; MartínezLüscher et al. 2017; Drappier et al. 2019; Gouot et al. 2019). As the effects of global warming increase in the coming years, damage due to heat stress in the wine grape industry is only predicted to increase. Scientists estimate that if climate change predictions come true, 
$51 \%$ of current wine growing regions will no longer be able to grow enough high quality wine grapes to justify cultivation in the future (Morales-Castilla et al. 2020).

At the other extreme, abnormal climate change patterns can also cause grape losses due to frost. Most wine grapes are grown in areas with average growing-season-temperatures between 12 and $22{ }^{\circ} \mathrm{C}$ (Stevenson 2005, Neethling et al. 2019). Prolonged temperatures above $10{ }^{\circ} \mathrm{C}$ trigger dormancy release, and historically, this has occurred in the spring, long after the last frost has occurred (Keller 2015). However, the weather patterns in many of wine regions are now changing due to climate change, and warm temperatures earlier in the season are causing grapes to exit dormancy before the last frost hits (Kliewer and Soleimani 1972; Webb et al. 2007; Gosme et al. 2019). Early bud break followed by frost can damage delicate buds and shoots, and in some cases can even result in complete crop failure (Gosme et al. 2019). In order to prevent this, farmers must resort to measures such as lighting fires in their vineyards at night, burning straw or rubber to produce smoke and prevent radiative cooling, and inverting warm air onto vines through the use of helicopters (Gosme et al. 2019). These are extreme and expensive measures, and not all farmers are able to afford them; as a result, many farmers are forced to accept yield losses (Gosme et al. 2019).

In the coming years, climate change is also predicted to bring both periods of drought and periods of extreme precipitation to grape growing regions throughout the world (Di Carlo 2019; Santillán et al. 2019). Severe drought, especially in grape growing regions where irrigation is not common, can result in stunted vegetative growth, reduced fruit quality, and diminished fruit production (Medrano et al. 2003; Charrier et al. 2018). In regions where irrigation is common, droughts can result in groundwater depletion and/or high water bills that can impact farmer profit (Cooley et al. 2015).

Climate change is also predicted to bring patterns of extreme and unseasonal precipitation to these same regions, which can also reduce wine quality and yield. Already, 
scientists are noticing that traditional wine growing regions are experiencing climatic shifts from steady, gentle rains to scarcer yet more intense precipitation events, even though the total quantity of precipitation through the growing season may not change (Di Carlo et al. 2019). In a study based off of viticultural data from 1818 to 2012 in the Abruzzo region of Italy, intensity of rainfall (calculated by dividing precipitation amount by the number of rainy days) was shown to be correlated with earlier harvests, and it was determined to be a leading factor, second only to temperature, in terms of inducing harvest (Di Carlo et al. 2019). Early harvests result in reduced quality because grapes reach peak sugar levels before having the chance to fully develop aromas and flavors, resulting in wines which lack complexity and depth (Di Carlo et al. 2019; Santillán et al. 2019).

Today, in the face of global macroclimatic changes that are uncontrollable, being able to manipulate the vineyard microclimate is of the utmost importance in order to secure vineyard resilience well into the future (Neethling et al. 2019). Manipulation of the macroand meso-climate by the viticulturist is impossible, but the manipulation of the viticultural microclimate can significantly alter the temperature and humidity of grapevines, often making or breaking grapevine growth and production. The vineyard microclimate is already commonly manipulated by viticulturists through countless cultural practices such as fertilization, weed management, irrigation, pruning, trellis system, leaf removal, shoot positioning, and many others (Zahavi et al. 2001). The incorporation of trees into vineyards is another underutilized yet highly beneficial practice that can be employed to positively influence the viticultural microclimate, especially in light of the high temperatures and extreme weather patterns that are predicted to impact wine growing regions in the coming years.

\section{V.3.2. Microclimatic Regulation in Vineyard Agroforestry Systems}


Trees regulate the viticultural microclimate and buffer temperature extremes by providing shade during the day, by radiating thermal heat at night, and by regulating wind speeds. Trees have been shown to positively impact the vineyard microclimate without causing significant competition for light, suggesting that vineyard agroforestry could be an effective tool for protecting grapevines from the extreme weather patterns that are predicted to occur in the coming years with climate change (Dupraz et al. 2009; Dupraz et al. 2018).

Trees mitigate both high and low temperatures by providing shade and shelter, resulting in less heat and water stress among grapevines (Grimaldi 2018). In general, temperatures are roughly $10^{\circ} \mathrm{F}$ cooler during the day and $10{ }^{\circ} \mathrm{F}$ warmer at night under shade conditions, as compared to open air conditions (Krueger 1981), and in vineyard agroforestry systems in specific, temperatures have been documented to be up to $6{ }^{\circ} \mathrm{C}$ lower during the day than in monoculture vineyards (Grimaldi et al. 2017; Grimaldi 2018; Gosme et al. 2019). In an extensive, 20-year study on vineyard agroforestry systems in Montpelier, France, reduced temperatures were particularly notable in vines on the southern side of tree rows, and as a result of the reduced temperatures, vines were documented to experience both reduced water stress and subsequently increased yield (Grimaldi 2018). This finding held true with younger trees as well; in a similar study, a monoculture Sauvignon Gris vineyard was compared to an adjacent and otherwise identical vineyard agroforestry system in which grapevines were intercropped with 7-year-old Sorbus domestica L., Sorbus torminalis (L.) Crantz, and Pyrus pyraster (L). trees. Grimaldi et al. (2016) found that inner-canopy temperatures were lower in vine rows to the south of tree hedgerows. These findings were more pronounced especially when evaporative demand was high. In a later study on this same vineyard, it was confirmed that the vines nearest to trees experienced had lower Crop Water Stress Indices (Grimaldi et al. 2017). 
Although more studies regarding shade from trees in specific have yet to be undergone, studies that have examined the temperature-regulating effects of shade in general upon grapevines have shown that shade has the capacity to improve both yields and many wine quality parameters, especially in regions that are impacted by high temperatures from climate change. In warmer growing regions impacted by high temperatures, temperature reductions from shade can improve yield by increasing photosynthesis, and also by providing protection against losses from shriveling and raisining (Marshall 1967; Chorti et al. 2010; Oliveira et al. 2014; Bayer 2015). Under extremely hot conditions where berry cell division would normally cease due to high temperatures, shade can also improve yield by reducing temperatures enough to allow healthy berry cell division and functioning (Smart and Sinclair 1976; Pereira et al. 2005). Several wine quality indicators, including acidity, anthocyanins, and even soluble solids at times are negatively impacted by high temperatures (Buttrose et al. 1971; Ruffner et al. 1976; Keller 2010; Bonada et al. 2013; Sweetman et al. 2014; Abeysinghe et al. 2019). Shade can promote the development of and/or prevent the decomposition of these quality components in wine, resulting in greater wine complexity and quality (Buttrose et al. 1971; Spayd et al. 2002; Downey et al. 2006). Additionally, under hot conditions where soluble solids are known to accumulate at excessively fast rates, shade can reduce ambient temperature enough to slow the rate of accumulation of soluble solids, allowing sugars, aromas, acids, tannins, and flavors to all develop in sync with one another (Jackson and Lombard 1993; Jones et al. 2005; Rienth et al. 2016). Balanced and high quality wines can still be grown even under the unnaturally high temperatures forecasted in the future, as long as adaptive strategies such as increased shade are employed to reduce microclimatic temperature.

Trees mitigate frosts as well by creating a "night mask" which reduces radiative cooling and shelters vines from radiation frost (Norton 1988; Gosme et al. 2019). Trees 
absorb short-wave radiation during the day and radiate it out to the surrounding area in the form of sensible heat and long-wave radiation at night (Oke 1988). The height of trees, coupled with their horizontal canopies, allows them to capture more radiation than other forms of vegetation. This radiation is then emitted upwards from the canopy and down onto the the area below the canopy (Oke 1988). Under sunny daytime conditions in particular, trees absorb high amounts of shortwave radiation and are then able to radiate it out in the form of longwave irradiance throughout the day and night, at levels that have been shown to significantly impact the surrounding microclimate (Spittlehouse et al. 2004; Howard and Stull 2013) (Figure 19). Indeed, trees have been shown to increase the microclimatic temperature enough to increase the rate of snowmelt in their surrounding vicinity due to this radiation transfer (Oke 1988). When the surrounding vicinity consists of crops, trees can protect crops from radiation frost as well. At $0{ }^{\circ} \mathrm{C}$, trees release $360 \mathrm{~W} \cdot \mathrm{m}^{-2}$ of radiative energy, whereas air at this temperature only releases $236 \mathrm{~W} . \mathrm{m}^{-2}$. At $25^{\circ} \mathrm{C}$ trees release 434 $\mathrm{W} . \mathrm{m}^{-2}$, whereas air at this temperature only releases $336 \mathrm{~W} \cdot \mathrm{m}^{-2}$ (Brutsaert 1982). All in all, trees can increase surface and near-surface soil temperatures by $1-2{ }^{\circ} \mathrm{C}$, which can make all the difference when vineyards are on the brink of frost damage (Chen et al. 1995). Other sources have shown that trees also prevent frost by reducing crop transpiration, which can produce slightly higher humidity levels within the canopy, resulting in slightly greater protection against radiative heat losses (Norton 1988; Brandle et al. 2009). Indeed, in a study in Montpellier, France that compared vineyard agroforestry systems to adjacent monoculture vineyards, researchers found that the vineyard agroforestry systems suffered from significantly less frost damage than did adjacent monoculture vineyards (Gosme et al. 2019). Meso- and macro-climatic factors such as temperature, drought, precipitationintensity are more difficult to control than are microclimatic factors. The only way to change these factors is by slowing down the progression of climate change on the planet as a whole 
through concerted efforts. Humans can deal with climate change in two ways: by adapting and by mitigating (Jones and Webb 2010; Neethling et al. 2019). Trees not only can help vineyards adapt to climate change by altering microclimates, protecting against drought, protecting against frost, and protecting against extreme heat; in the long run, trees' presence in vineyards can also help mitigate climate change, even if in a small way, by sequestering carbon dioxide from the atmosphere and reducing global greenhouse gases (Raj and Toppo 2018). Estimates for carbon-sequestration potential in alley cropping agroforestry systems are 3.4 $\mathrm{Mg} \mathrm{C} \mathrm{ha}^{-1} \mathrm{yr}^{-1}$ (Udawatta and Jose 2011). If agroforestry is implemented in vineyards worldwide, vineyards could participate in collective climate change mitigation efforts in a significant way.

(a) shortwave radiations

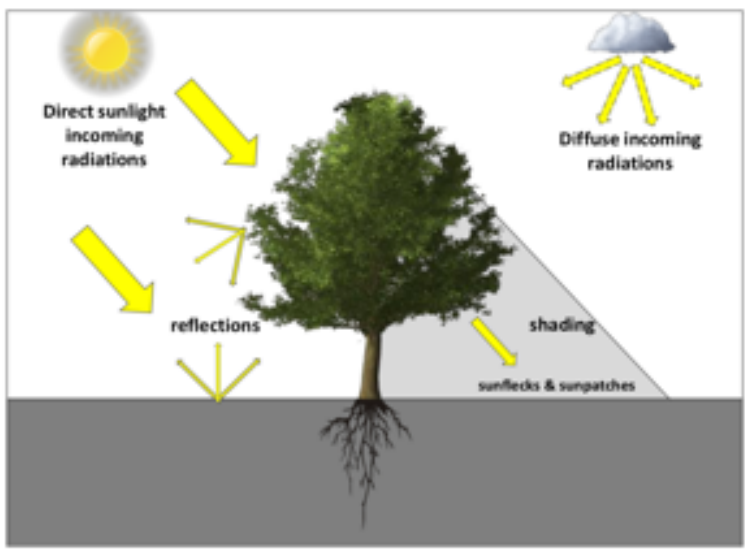

(b) longwave radiations

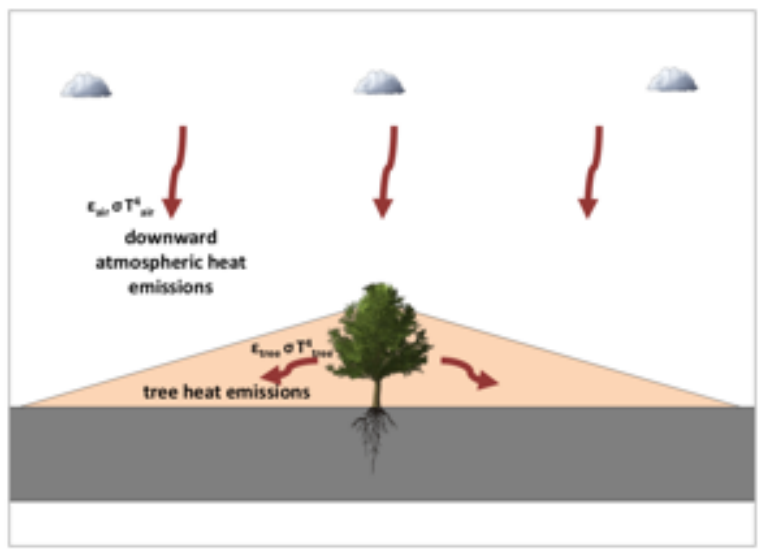

Figure 19. Modifications of the incoming radiations for an understory crop in the vicinity of a tree. (a) shows interception and reflections of the solar shortwave radiations. (b) shows the contribution of longwave radiations emitted by trees in the solid-colored triangle. Source: Grimaldi (2018).

\section{V.4. NEGATIVE IMPACTS OF TREES IN VINEYARDS}

Despite the positive impacts that trees have on wind and microclimatic patterns in vineyards, implementing agroforestry in vineyards does of course come with its challenges. Vineyard agroforestry systems are by definition more complicated to manage than are monoculture vineyards, requiring intensive management in order for both species to thrive 
(Gold and Garrett 2009; Altieri et al. 2012). Additionally, despite the many yield increases that reduced windspeed and improved microclimate might cause, trees have been observed to cause yield reductions in vines within $4 \mathrm{~m}$ of tree rows, likely due to competition for nutrients such as nitrogen (Gillespie et al. 2000; Dupraz et al. 2009; Trambouze and Goma-Fortin 2013). Trees also reduce the quality and quantity of light reaching understory grapevines, which, under certain growing conditions, may negatively affect wine quality metrics such as anthocyanin accumulation and flavonol content (Morrison and Noble 1990; Spayd et al. 2002; Blancquaert et al. 2019).

However, despite these drawbacks, vineyard agroforestry systems have the capacity to increase wine quality and yield under the projected weather patterns that are predicted to come with climate change. Additionally, despite reductions in grape yield in rows closest to trees, the farm as a whole, including the yield from associated trees, has the capacity to yield more (Raj and Toppo 2018). The savings from reduced fertilizer and pesticide inputs, along with the numerous ecosystem benefits that trees provide, could also justify the yield loss within vine rows closest to trees (Galati et al. 2015; Pachauri and Meyer 2015; Cerdà and Rodrigo-Comino 2018; Garcia et al. 2018). Weighing the benefits and drawbacks of incorporating trees into vineyards is, of course, a determination that must be made by each individual farmer, and is one that would depend upon the growing region, the variety grown, and the holistic goals of the vineyard as a whole.

\section{V.5. CONCLUSION}

Trees benefit vineyards by positively affecting wind patterns and the viticultural microclimate. Although incorporating trees into vineyards can increase management complexity, can reduce yields nearest to trees, and can negatively affect certain grape quality parameters, research suggests that the many above-ground benefits of vineyard agroforestry may very well outweigh their costs. The positive above-ground services that trees provide, 
such as preventing wind damage and erosion, increasing stomatal aperture and leaf area, increasing photosynthetic capacity, protecting against heat, protecting against frost, and reducing water stress suggest that vineyard agroforestry systems may be a wise solution to the many problems facing modern viticulture, especially considering the extreme temperatures, weather events, pest and disease pressure, and micro- and macro-climatic shifts that are predicted to come in the following years with climate change. The current literature indicates that trees may help vineyards both adapt-to and also mitigate climate change, but more research on vineyard agroforestry systems should be undergone to confirm the current findings, especially research that focuses on different grape varieties, wine producing regions, tree-vine combinations, intercropping planting structure, and canopy management choices. 
CHAPTER VI

CONCLUSION 


\section{VI.1. Practical Implications}

As with any farming technology, the use of trees in vineyards comes with tradeoffs, and if grapevines are to be successfully intercropped with trees, vineyard agroforestry systems must be designed strategically. Despite the numerous above- and below-ground services that trees provide to vineyards, agroforestry systems are inherently more complicated to manage, and they require planning, intention, and continued dedication in order to be successful (Altieri et al. 2012). Farmers must be well-prepared to address the negative impacts of incorporating trees into vineyards before attempting to utilize them. There are many management practices that can be implemented in order to maximize the benefits of agroforestry in vineyards and in order to minimize its drawbacks.

First, farmers must be aware that yield reductions have been seen in grapevines within $4 \mathrm{~m}$ of tree rows. Research suggests that the cause is below-ground competition between trees and grape vines, especially for nutrients such as N (Gillespie et al. 2000; Trambouze and Goma-Fortin 2013). Despite these reduced yields, agroforestry systems have been shown to increase overall farm yield; that is to say, although grapevines might experience reduced yield in rows nearest to trees, the farm as a whole, including the yield from associated trees, has the capacity to yield more (Raj and Toppo 2018). If grapevines are intercropped with trees that also have economic value, such as nuts, fruit, timber, etc., it may be possible to produce more income per hectare through the increased use of vertical space (Nair 1993e). Additionally, the savings from reduced fertilizer and pesticide inputs could justify the slight yield loss within vine rows closest to trees (Galati et al. 2015; Cerdà and Rodrigo-Comino 2018). This is, of course, a determination that must be made by each individual farm and that would depend upon the growing region, the variety grown, and the holistic goals of the vineyard as a whole. 
For wine grapes in particular, more important than high yields or a high growth rate in vineyards is the concept of growing a "balanced" vine - one which produces sufficient yield to be economically viable and which has sufficient vegetative growth to produce quality fruit (Wheeler and Pickering 2005). In vineyards, this balance is typically struck by allowing slight nutrient and water stress (Wheeler and Pickering 2005), and, in the case of vineyard agroforestry systems, trees could complete this function through regulated competition. However, excessive competition between trees and vines for nutrients and water is damaging and must be prevented when designing vineyard agroforestry systems (McCarthy et al. 1983; Giese et al. 2014). In vineyard agroforestry systems, competition for $\mathrm{N}$ can be addressed by planting leguminous cover crops, applying higher rates of fertilizer in vine rows closer to tree rows, or selecting $\mathrm{N}$-fixing trees for intercropping (Nair 1993c, 1993d). Competition for water has been shown to be less of an issue in vineyard agroforestry systems, but during drought years, competition for water can be addressed through management practices such as root pruning, branch pruning, and tree thinning (Peter and Lehmann 2000; Reynolds et al. 2007; Senaviratne et al. 2012; Trambouze et al. 2017) Competition for both water and N can be addressed by combining vines with tree species whose roots occupy different soil niches than grapevine roots, or by spacing trees more widely (Nair 1993e). To minimize competition, grapes can be intercropped with trees that have lower root length densities, such as apples, pears, and plums (Smart and Coombe 1983). Preservation of soil structure and quality and reductions in erosion can be achieved by choosing trees with high litterfall production (Nair 1993a; Oliveira and Merwin 2001).

To minimize competition for light, grapevines can be intercropped with tree varieties whose leaves absorb more blue light and less red light, such as conifers, which would allow higher quantities of beneficial red light to reach grapevines (Krueger 1981). Trees with lower leaf area indices (and therefore higher light transmission), would also be recommended 
(Mōttus et al. 2010). Zhang et al. (2019) found that, for plants in general, mild shade levels (leaf area index of 0.5 and $1 \mathrm{~m}^{2} / \mathrm{m}^{-2}$ ) do not significantly reduce photosynthesis rates, while heavy shade levels (leaf area index of 2 and $3 \mathrm{~m}^{2} / \mathrm{m}^{-2}$ ) can reduce photosynthesis rates. Although the ideal leaf area index for trees intercropped specifically with grapevines has yet to be determined, trees with lower leaf area indices such as Melia azedarach L. and Prosopis pallida, might be recommended for trial and further research (Angrish et al. 2009; Mōttus et al. 2010). Light transmittance levels can also be managed by manipulating tree canopies through strategic pruning practices.

Regarding orientation, in regions located at latitudes above 50 degrees in the Northern Hemisphere and below 50 degrees in the Southern Hemisphere, a north-south row orientation is preferable in order to achieve maximum homogeneity of light exposure despite an overstory canopy of trees. However, at latitudes below 40 degrees in the Northern Hemisphere and above 40 degrees in the Southern Hemisphere, planting vines in east-west row orientations allows for more heterogeneous distribution of light and shadows from trees (Artru et al. 2017; Dupraz et al. 2018).

To maximize the windbreak effect of intercropped trees, the architecture of tree alleyways should be structured so that wind does not flow around the windbreak but rather through it. In order to achieve this, each alleyway of trees should be at least 10 times the length of the height of the trees and trees should be evenly spaced with no large gaps or openings (Brandle et al. 2009).

By designing vineyard agroforestry systems with strategic species combinations, cultural practices, and spacing, grapevines and trees can be integrated into a holistic system that is resilient against climate change, pests, plagues, and extreme weather; that produces high yields and high quality wine; that improves soil fertility and quality; that reduces farmer reliance on agrochemicals; that is economically sustainable; and that betters the environment. 


\section{VI.2. Conclusion}

With growing concern over climate change, the environmental impacts of conventional viticulture, and rising production costs, sustainable viticulture solutions are needed now more than ever. Modern viticulture is both affected by and simultaneously contributes to environmental and economic problems; however, agroforestry is a sustainable solution that has the potential to both help vineyards adapt-to and also mitigate these environmental challenges. Agroforestry can benefit vineyards in many ways, both in terms of the above- and below-ground services that it provides to vineyard ecosystems. Agroforestry has been shown to affect below-ground parameters in vineyards positively by increasing drought resistance, reducing erosion, building $\mathrm{OM}$, bettering soil structure, and improving vine rooting capability. Agroforestry has been shown to affect above-ground parameters in vineyards positively by reducing pest and disease pressure, preventing wind damage and erosion, increasing stomatal aperture and leaf area, protecting against heat stress, and protecting against frost. Although incorporating trees into vineyards can increase management complexity and can reduce yields within $4 \mathrm{~m}$ of trees, research suggests that the positive benefits and the ecosystem services that trees impart to vineyards may very well outweigh these negative effects. Additionally, many of these challenges can be overcome with strategic management practices. Overall, there is sufficient scientific evidence that agroforestry has great potentials in viticulture, especially in the face of the extreme temperatures, pests, plagues, and weather events that are predicted to come with climate change. This is a judgment that is, of course, up to each individual viticulturist to decide, and determinations may be informed by more research on vineyard agroforestry systems done for all major wine producing regions and tree-vine combinations. 


\section{BIBLIOGRAPHY}

Abeysinghe SK, Greer DH, Rogiers SY (2019) The effect of light intensity and temperature on berry growth and sugar accumulation in Vitis vinifera 'Shiraz' under vineyard conditions. Vitis 58:7-16

Adetunji AT, Lewu FB, Mulidzi R, Ncube B (2017) The biological activities of $\beta$ glucosidase, phosphatase and urease as soil quality indicators: A review. J of Soil Science and Plant Nutrition, 17: 794-807

Alikadic A, Pertot I, Eccel E, Dolci C, Zarbo C, Caffarra A, De Filippi R, Furlanello C (2019) The impact of climate change on grapevine phenology and the influence of altitude: a regional study. Agricultural and Forest Meteorology 271:73-82

Altieri MA (1999) The ecological role of biodiversity in agroecosystems. Agriculture, Ecosystems \& Environment 74:19-31

Altieri MA, Nicholls CI (2002) The simplification of traditional vineyard based agroforests in northwestern Portugal: some ecological implications. Agroforestry Systems 56:185191

Altieri MA, Nicholls CI (2008) Ecologically Based Pest Management in Agroforestry Systems. In: Batish DR, Kohli RK, Jose S, Singh HP (eds) Ecological Basis of Agroforestry, CRC Press, Boca Raton, Florida, pp 95-106

Altieri MA, Nicholls CI, Ponti L (2005) Manipulating vineyard biodiversity for improved insect pest management: case studies from northern California. The International Journal of Biodiversity Science and Management 1:1-13

Altieri MA, Funes-Monzote FR, Petersen P (2012) Agroecologically efficient agricultural systems for smallholder farmers: contributions to food sovereignty. Agronomy for Sustainable Development 32:1-13

Andow DA (1991) Vegetational Diversity and Arthropod Population Response. Annual Review of Entyomology 36:561-586

Angrish R, Datta KS, Rani C, Arora V, Chawla S, Madaan S, Kumar M (2009) Comparative Biodrainage Potentail of some tree Species. In: Proceedings of the 60th International Executive Council Meeting \& 5 Asian Regional Conference, 6-11 December 2009, New Delhi, India

Antcliff AJ, Webster WJ (1955) Studies on the sultana vine. 1. Fruit bud distribution and bud burst with reference to forecasting potential crops. Australian Journal of Agricultural Research 6:565-588

Archer E, Saayman D (2018) Vine Roots. The Institute for Grape and Wine Sciences (IGWS), Stellenbosch University, South Africa

Archer E, Strauss HC (1985) Effect of Plant Density on Root Distribution of Three-Year-Old Grafted 99 Richter Grapevines. South African Journal of Enology \& Viticulture 6:2530

Archer E, Strauss HC (1989) Effect of Shading on the Performance of Vitis Vinifera L. CV. Cabernet Sauvignon. South African Journal of Enology and Viticulture 10:74-76

Artru S, Garré S, Dupraz C, Hiel MP, Blitz-Frayet C, Lassois L (2017) Impact of spatiotemporatl shade dynamics on wheat growth and yield, perspectives for temperate agroforestry. Agronomy 82:60-70

Austin CN, Wilcox WF (2012) Effects of Sunlight Exposure on Grapevine Powdery Mildew Development. Phytopathology 102:857-866

Azuma A, Yakushiji H, Koshita Y, Kobayashi S (2012) Flavonoid biosynthesis-related genes in grape skin are differentially regulated by temperature and light conditions. Planta 236:1067-1080 
Bagagiolo G, Biddoccu M, Rabino D, \& Cavallo E (2017) Monitoring erosion in sloping vineyards: effectiveness of grass covering in different periods. Convegno AIAM SIA 2017. Conference Proceedings, Milan, Italy

Baldwin JG (1964) The relation between weather and fruitfulness of the sultana vine. Australian Jouranl of Agricultural Research 15:920-928

Balesdent J, Chenu C, Balabane M (2000). Relationship of soil organic matter dynamics to physical protection and tillage. Soil and Tillage Research, 53: 215-230

Barbar Z, Tixier MS, Cheval B, Kreiter S (2010) Does agroforestry affect phytoseiid mite communities in vineyards in the South of France? Trends in Acarology.

DOI: 10.1007/978-90-481-9837-5_66

Bartolucci P, Dhakal BR (1999) Prospects for Olive Growing in Nepal. Food and Agriculture Organization of the United Nations, Department of Agriculture, Fruit Development Division Olive Production Development Project, TCP/NEP/6713, Kathmandu.

Barzman M, Bàrberi P, Birch ANE, Boonekamp P, Dachbrodt-Saaydeh S, Graf B, Hommel B, Jensen JE, Kiss J, Kudsk P, Lamichhane JR, Messéan A, Moonen AC, Ratnadass A, Ricci P, Sarah JL, Sattin M (2015) Eight principles of integrated pest management. Agronomy for Sustainable Development 35:1199-1215

Bayer LC (2015) Heat wave mitigation strategies for wine grape production and measures of the impact of heat on berry ripening and wine composition. Dissertation, University of Adelaide, South Australia

Bell SJ, Henschke PA (2008) Implications of nitrogen nutrition for grapes, fermentation and wine. Australian Journal of Grape and Wine Research 11:242-295

Bellamy AS (2013) Banana Production Systems: Identification of Alternative Systems for More Sustainable Production. Ambio A Journal of the Human Environment 42:334343

Bergqvist J, Dokoozlian N, Ebisuda N (2001) Sunlight Exposure and Temperature Effects on Berry Growth and Composition of Cabernet Sauvignon and Grenache in the Central San Joaquin Valley of California. American Journal of Enology and Viticulture 52:17

Bettiga LJ, Dokoozlian NK, Williams LE (1996) Windbreaks improve the growth and yield of Chardonnay grapevines grown in a cool climate. In: Proceedings of the $4^{\text {th }}$ International Symposium on Cool Climate Viticulture and Enology, pp 43-46

Bhadha JH, Capasso J, Khatiwada R, Swanson S, Laborde C (2018) Raising Soil Organic Matter Content to Improve Water Holding Capacity. University of Florida, IFAS Extension

Biddoccu M, Pitacco A, Ferraris S, Cavallo E (2017) Temporal variability of soil management effects on soil hydrological properties, runoff and erosion at the field scale in a hillslope vineyard, North-West Italy. Soil and Tillage Research, 165:46-58

Blanco-Canqui H, Lal R (2010) Wind Erosion. In: Principles of Soil Conservation and Management. Springer, Dordrecht

Blancquaert EH, Oberholster A, Ricardo-da-Silva JM, Deloire AJ (2019) Grape Flavonoid Evolution and Composition Under Altered Light and Temperature Conditions in Cabernet Sauvignon (Vitis vinifera L.). Frontiers in Plant Science 10:1062

Bondada BR, Keller M (2012) Not All Shrivels Are Created Equal-Morpho-Anatomical and Compositional Characteristics Differ among Different Shrivel Types That Develop during Ripening of Grape (Vitis vinifera L.) Berries. American Journal of Plant Sciences 3: 879-898

Bonada M, Sadras VO, Fuentes S (2013a) Effect of elevated temperature on the onset and rate of mesocarp cell death in berries of Shiraz and Chardonnay and its relationship with berry shrivel. Australian Journal of Grape and Wine Research 19:87-94 
Bonada M, Sadras V, Moran M, Fuentes S (2013b) Elevated temperature and water stress accelerate mesocarp cell death and shrivelling, and decouple sensory traits in Shiraz berries. Irrigation Science 31:1317-1331

Bondole BML (1999) Potential Influences of Multipurpose Tree Choice in the Development of Diseases of Associated Crops in Agroforestry Systems: What Do We Know Today? Journal of Tropical Forest Science 11:26-35

Borrelli P, Robinson DA, Fleischer LR, Lugato E, Ballabio C, Alewell C, Meusburger K, Modugno S, Schutt B, Ferro V, Bagarello V, Van Oost K, Montanarella L, Panagos P. (2013) An assessment of the global impact of 21st century land use change on soil erosion. Nature Communications 8:1-13

Boudreau IV TF, Peck GM, O'Keefe SF, Stewart A (2018) Free amino nitrogen concentration correlates to total yeast assimilable nitrogen concentration in apple juice. Food Science \& Nutrition 6:119-123

Boughey KL, Lake IR, Haysom KA, Dolman PM (2011) Improving the biodiversity benefits of hedgerows: how physical characteristics and the proximity of foraging habitat affect the use of linear features by bats. Biological Conservation 144:1790-1798

Boyer JS (2015) Turgor and the transport of CO2 and water across the cuticle (epidermis) of leaves. Journal of Experimental Botany 66:2625-2633

Branas J, Vergnes A (1957) Morphologie du système radiculaire de la vigne. Prog. Agric. Vitic. 74: 1-47

Brandle JR, Hodges L, Tyndall J, Sudmeyer RA (2009) Windbreak Practices. In: Garrett HE (ed) North American Agroforestry: An Integrated Science and Practice, 2nd edn. American Society of Agronomy, Madison, WI

Broufas GD, Pappas ML, Koveos DS (2007) Development, Survival, and Reproduction of the Predatory Mite Kampimodromus aberrans (Acari: Phytoseiidae) at Different Constant Temperatures. Environmental Entmology 36:657-665

Brunt AA, Crabtree K, Dallwitz MJ, Gibbs AJ, Watson L (1996) Viruses of plants. Descriptions and lists from the VIDE database. CAB International, Wallingford

Brutsaert W (1982) Energy Fluxes at the Earth's Surface. In: Brutsaert W (ed) Evaporation into the Atmosphere. Springer, Dordrecht, Netherlands, pp128-153

Buttrose MS (1970) Fruitfulness in grape-vines: The response of different cultivars to light, temperature and daylength. Vitis 9:121-125

Buttrose MS (1974) Climatic factors and fruitfulness in grapevines. Horticultural Abstracts 44:319-326

Buttrose MS, Hale CR, Kliewer WM (1971) Effect of Temperature on the Composition of 'Cabernet Sauvignon' Berries. American Journal of Enology and Viticulture 22:71-75

California Department of Pesticide Regulation (2017) 2017 Pesticide Use Report Highlights. California Department of Pesticide Regulation. https://www.cdpr.ca.gov/docs/pur/pur17rep/pur_highlights_2017.pdf. Accessed 19 March 2020

Calonnec A, Cartolaro P, Chadoeuf J (2009) Highlighting Features of Spatiotemporal Spread of Powdery Mildew Epidemics in the Vineyard Using Statistical Modeling on Field Experimental Data. Phytopathology 99:411-422

Carbonneau A, Casteran P (1979) Irrigation-Depressing Effect on Floral Initiation of Cabernet Sauvignon Grapevines in Bordeaux Area. American Journal of Enology and Viticulture 30: 3-7

Cardozo EG, Muchavisoy HM, Silva HR, Zelarayán MLC, Leite MFA, Rousseau GX, Gehring C (2015) Species richness increases income in agroforestry systems of eastern Amazonia. Agroforestry Systems 89:901-916 
Cartechini A, Palliotti A (1995) Effect of Shading on Vine Morphology and Productivity and Leaf Gas Exchange Characteristics in Grapevines in the Field. American Journal of Enology and Viticulture 46:227-234

Celette F, Gary C (2013) Dynamics of water and nitrogen stress along the grapevine cycle as affected by cover cropping. European Journal of Agronomy 45:142-152

Cerdà A, Rodrigo-Comino J (2018) Is the hillslope position relevant for runoff and soil loss activation under high rainfall conditions in vineyards? Ecohydrology \& Hydrobiology 20:59-72

Charrier G, Delzon S, Domec JC, Zhang L, Delmas CEL, Merlin I, Corso D, King A, Ojeda H, Ollat N, Prieto JA, Scholach T, Skinner P, van Leeuwen C, Gambetta GA (2018) Drought will not leave your glass empty: Low risk of hydraulic failure revealed by long-term drought observations in world's top wine regions. Science Advances, 4:1-9

Chen J, Franklin JF, Spies TA (1995) Growing-Season Microclimate Gradients from Clearcut Edges into Old-Growth Douglas-fir Forests. Ecological Applications 5:74-86

Chirko CP, Gold MA, Nguyen PV, Jiang JP (1996) Influence of orientation on wheat yield and photosynthetic photon flux density (Qp) at the tree and crop interface in a Paulownia-wheat intercropping system. Forest Ecology and Management 89:149-156

Chorti E, Guidoni S, Ferradino A, Novello V (2010) Effect of Different Cluster Sunlight Exposure Levels on Ripening and Anthocyanin Accumulation in Nebbiolo Grapes. American Journal of Enology and Viticulture 61:23-30

Chuine I, Yiou P, Viovy N, Seguin B, Daux V, Ladurie E (2004) Grape ripening as a past climate indicator. Nature 432:289-290

Cleugh HA (1998) Effects of windbreaks on airflow, microclimate and crop yields. Agroforestry Systems 41:55-84

Coll P, Le Cadre E, Blanchart E, Hinsinger P, Villenave C (2011) Organic viticulture and soil quality: A long-term study in Southern France. Applied Soil Ecology 50: 37-44

Comuzzo P, Battistutta F (2019) Acidification and pH Control in Red Wines. In: Morata A (ed) Red Wine Technology. Elsevier, London, pp 17-34

Cook SM, Khan ZR, Pickett JA (2007) The use of push-pull strategies in integrated pest management. Annual Review of Entomology 52:375-400

Cook BI, Wolkovich EM (2016) Climate change decouples drought from early wine grape harvests in France. Nature Climate Change 6:715-719

Cooley H, Donnelly K, Phurisamban R, Subramanian M (2015) Impacts of California's Ongoing Drought: Agriculture. Pacific Institute. Oakland, CA

Coombe BG (1987) Influence of Temperature on Composition and Quality of Grapes. Acta Horticulturae 206:23-36

Coombe BG, McCarthy MG (2000) Dynamics of grape berry growth and physiology of ripening. Australian Journal of Grape and Wine Research 6:131-135

Corbett A, Rosenheim JA (1996) Impact of a natural enemy overwintering refuge and its interaction with the surrounding landscape. Ecological Entomology 21:155-164

Creasy GL, Creasy LL (2009) Grapes. Cab International, Wallingford, UK

Crippen DD, Morrison JC (1986) The Effects of Sun Exposure on the Phenolic Content of Cabernet Sauvignon Berries During Development. American Journal of Enology and Viticulture 37:243-247

Daane KM, Wistrom C, Yokota G, Almeida R, Hashim J, Pryor M (2006) Host plant preferences and natural infectivity of insect vectors of Xylella fastidiosa on common weeds and crop plants. In: Proceedings of the 2007 Pierce's Disease Research Symposium, 12-14 December 2007, San Diego California 
Davarzani H, Smits KM, Tolene RM, Illangasekare TH (2014) Study of the effect of wind speed on evaporation from soil through integrated modeling of atmospheric boundary layer and shallow subsurface. Water Resources Research 50:661-680

Di Carlo P, Aruffo E, Brune WH (2019) Precipitation intensity under a warming climate is threatening some Italian premium wines. Science of the Total Environment 685: 508513

Dokoozlian NK, Kliewer WM (1996) Influence of Light on Grape Berry Growth and Composition Varies during Fruit Development. Journal of the American Society of Horticultural Science 121:869-874

Dokoozlian NK (2016) Grape Berry Growth and Development. In: The Grapevine. UC Davis, Davis, California

Doutt R, Nakata J (1973) The Rubus leafhopper and its egg parasitoid: an endemic biotic system useful in grape pest management. Environmental Entomology 2:381-386

Downey MO, Dokoozlian NK, Krstic MP (2006) Cultural Practice and Environmental Impacts on the Flavonoid Composition of Grapes and Wine: A Review of Recent Research. American Journal of Enology and Viticulture 57:257-268

Drappier J, Thibon C, Rabot A, Geny-Denis L (2019) Relationship between wine composition and temperature: Impact on Bordeaux wine typicity in the context of global warming - Review. Critical Reviews in Food Science and Nutrition 59:14-30

Dry PR, Botting DG (1993) The Effect of Wind on the Performance of Cabernet Franc Grapevines. Australian and New Zealand Wine Industry Journal 8:347-352

Dry PR, Loveys BR, Botting D, During H (1996) Effects of partial root-zone drying on grapevine vigour, yield, composition of fruit and use of water. Proceedings of the Ninth Australian Wine Industry Technical Conference

Dufourcq T, Lopez F, Vergnes M, Gontier L (2017) Use of Proxy Sensors to Characterize Spatial Variability on Agroforestry Vineyards. Group of International Experts for Cooperation on Vitivinicultural Systems GiESCO. Conference Paper, $20^{\text {th }}$ International GIESCO Symposium, Mendoza, Argentina

Dunn GM, Martin SR (2008) Do temperature conditions at budburst affect flower number in Vitis vinifera L. cv. Cabernet Sauvignon? Australian Journal of Grape and Wine Research 6:116-124

Dupraz C, Blitz-Frayret C, Lecomte I, Molto Q, Reyes F, Gosme M (2018) Influence of latitude on the light availabililty for intercrops in agroforestry alley-cropping system. Agroforestry Systems 92:1019-1033

Dupraz C, Burgess P, Gavaland A, Graves A, Herzog F, Incoll LD, Jackson N, Keesman K, Lawson G, Lecomte I, Liagre F, Mantzanas K, Mayus M, Moreno G, Palma J, Papanastasis V, Pilbeam PP, Reisner DJ, Van Noordwijk M, Vincent G, Werf Van der W (2005) Silvoarable Agroforestry for Europe. SAFE Project Final Report. INRA-UMR Systems Editions, Montpellier, France

Dupraz C, Goma-Fortin N, Trambouze W, Kreiter S, Tixier MS, Gary C (2009) Vineyard agroforestry: a new concept for a sustainable vineyard production. In: Proceedings from the 2nd World Congress of Agroforestry (WCA2) August 2009, Ken, France. (hal-02758349)

During $\mathrm{H}$ (1988) $\mathrm{CO}_{2}$ assimilation and photorespiration of grapevine leaves: Responses to light and drought. Vitis 27:199-208

Earnshaw S (2018) Hedgerows and Farmscaping for California Agriculture: A Resource Guide for Farmers, $2^{\text {nd }}$ Edn. Community Alliance with Family Farmers, Davis. https://www.rcdmonterey.org/images/docs/publications/CAFF_Hedgerow_Manual_2 018.pdf. Accessed 19 March 2020 
Esteban MA, Villanueva MJ, Lissarrague JR (2001) Effect of irrigation on changes in the anthocyanin composition of the skin of cv Tempranillo (Vitis vinifera L) grape berries during ripening. Journal of the Science of Food and Agriculture 81

Fabre E (2014) Des vignes entre champs et bois. Le cas de la marge pyrénéenne du vignoble languedocien (milieu XVIIIe-milieu XIXe siècle). Proceedings of the Bordeaux conference, Caen, Association for the History of Rural Societies, pp 373-386

Fargione J, Tilman D (2006) Plant Species Traits and Capacity for Resource Reduction Predict Yield and Abundance under Competition in Nitrogen-Limited Grassland. Functional Ecology 20: 533-540

Favor K, Udawatta RP (2020). Below ground services in vineyard agroforestry systems. Pp \#\#\#-\#\#\# In: Udawatta RP \& Jose S (eds.) Ecosystem Services of Agroforestry. Springer Nature, The Netherlands. In Press.

Ferreira CS, Keizera JJ, Santosa LM, Serpaa D, Silvaa V, Cerqueira M, Ferreira AJD, Abrantes N (2018). Runoff, sediment and nutrient exports from a Mediterranean vineyard under integrated production : An experiment at plot scale. Agriculture, Ecosystems \& Environment 256: 184-193

Flint SD, Jordan PW, Caldwell MM (1985) Plant Protective Response to Enhanced UV-B Radiation Under Field Conditions: Leaf Optical Properties and Photosynthesis. Photochemistry and Photobiology 41:95-99

Francis CA, Altieri MA, Nicholls CI (2004) Designing Species-Rich, Pest-Suppressive Agroecosystems through Habitat Management. In: Rickerl D, Farncis C (eds) Agroecosystems Analysis. Madison, WI, pp 49-62

Franco JC, Zada A, Mendel Z (2009) Novel Approaches for the Management of Mealybug Pests. In: Ishaaya I, Horowitz AR (eds) Biorational Control of Arthopod Pests. Springer, Dordrecht, pp 233-278

Frederick JE (1993) Ultraviolet Sunlight Reaching the Earth's Surface: A Review of Recent Research. Photochemistry and Photobiology 57:175-178

Freeman BM, Smart RE (1976) A Root Observation Laboratory for Studies with Grapevines. American Journal of Enology and Viticulture 27: 36-39

Freeman BM, Kliewer WM, Stern P (1982) Influence of Windbreaks and Climatic Region on Diurnal Fluctuation of Leaf Water Potential, Stomatal Conductance, and Leaf Temperature of Grapevines. American Journal of Enology and Viticulture 33:233-236

Froidevaux JSP, Louboutin B, Jones G (2017) Does organic farming enhance biodiversity in Mediterranean vineyards? A case study with bats and arachnids. Agriculture, Ecosystems and Environment 249:112-122

Fujita A, Goto-Yamamoto N, Aramaki I, Hashizume K (2006) Organ-Specific Transcription of Putative Flavonol Synthase Genes of Grapevine and Effects of Plant Hormones on Shading and Flavonol Biosynthesis in Grape Berry Skins. Bioscience, Biotechnology, and Biochemistry 70:632-638

Gade DW (1978) Windbreaks in the Lower Rhone Valley. Geographical Review 68:127-144

Galati A, Gristina L, Crescimanno M, Barone E, Novara A (2015) Towards More Efficient Incentives for Agri-environment Measures in Degraded and Eroded Vineyards. Land Degradation \& Development 26

Gao Y, Cahoon GA (1994) Cluster shading effects on fruit quality, fruit skin color, and anthocyanin content and composition in Reliance (Vitis hybrid). Vitis 33:205-209

Garcia L, Celette F, Gary C, Ripoche A, Valdés-Gómez H, Metay A (2018) Management of service crops for the provision of ecosystem services in vineyards: A review. Agriculture, Ecosystems, and Environment 251:158-170

Gholami R, Hadjiamiri A, Ghanbari F (2018) Effect of Plant Density and Grape Training Method on Pomological Characteristics and Yield of Olive and Grape in 
Intercropping System. Journal of Sustainable Agriculture and Production Science, 28:15-24

Giese G, Velasco-Cruz C, Roberts L, Heitman J, Wolf TK (2014) Complete vineyard floor cover crops favorably limit grapevine vegetative growth. Scientia Horticulturae 170: 256-266

Gillespie AR, Jose S, Mengel DB, Hoover WL, Pope PE, Seifert JR, Biehle DJ, Stall T, Benjamin TJ (2000) Defining competition vectors in a temperate alley cropping system in the midwestern USA: 1. Production physiology. Agroforestry Systems 48:25-40

Gobert A, Tourdot-Maréchal R, Morge C, Sparrow C, Liu Y, Quintanilla-Casas B, Vichi S, Alexandre H (2017) Non-Saccharomyches Yeasts Nitrogen Source Preferences: Impact on Sequential Fermentation and Wine Volatile Compounds Profile. Frontiers in Microbiology 8:2175

Gold MA, Garrett HE (2009) Agroforestry nomenclature, concepts, and practices. In: Garrett HE (ed) North American Agroforestry, an Integrated Science and Practice, 2nd ed. American Society of Agronomy. Madison, WI, pp 45-55

Gómez-del-Campo M, Ruiz C, Lissarrague JS (2002) Effect of Water Stress on Leaf Area Development, Photosynthesis, and Productivity in Chardonnay and Airén Grapevines. American Journal of Enology and Viticulture 53: 138-143

Gommers CMM, Visser EJW, St Onge KR, Voesenek LACJ, Pierik R (2013) Shade tolerance: when growing tall is not an option. Trends in Plant Science 18:65-71

Gosme M, Delmotte S, Grimaldi J, Trambouze W (2019) Diachronic study of the effect of growing trees on grapevine yield: 24 years of experience in the South of France. 4th World Congress on Agroforestry, INRA SYSTEM. Conference Paper, Montpellier, France

Goudie AS (2014) Desert dust and human health disorders. Environmental International 63:101-113

Gouot JC, Smith JP, Holzapfel BP, Barril C (2019) Grape Berry Flavonoid Responses to High Bunch Temperatures Post Véraison: Effect of Intensity and Duration of Exposure. Molecules 24:4341

Grab H, Danforth B, Poveda K, Loeb G (2018) Landscape simplification reduces classical biological control and crop yield. Ecological Applications 0:1-8

Greer DH, Weston C (2009) Heat stress affects flowering, berry growth, sugar accumulation and photosynthesis of Vitis vinifera $\mathrm{cv}$. Semillon grapevines grown in a controlled environment. Functional Plant Biology 37:206-214

Greer DH, Weedon MM (2013) The impact of high temperatures on Vitis vinifera cv. Semillon grapevine performance and berry ripening. Frontiers in Plant Science 4:491

Grimaldi J (2018) Impacts of agroforestry on microclimate for grape and wine production: assessment in Southern France. Dissertation, University of Toulouse, France

Grimaldi J, Fieuzal R, Pelletier C, Bustillo V, Houet T, Sheeren D (2016) Microclimate Patterns in an Agroforestry Intercropped Vineyard: First Results. In: Proceedings of the $3^{\text {rd }}$ European Agroforestry Conference, 23-25 May 2016, Montpellier, France

Grimaldi J, Trambouze W, Dufourcq T, Vergnes M, Pelletier C, Helen F, Fieuzal R, Houet T, Bustillo V (2017) Can intercropped trees mitigate heat and drought effects on grapevines? A study of microclimate patterns in agroforestry vineyards, Southern France. In: Proceedings of the IUFRO Landscape Ecology Conference, 24-29 September 2017, Halle, Germany

Guyot G (1989) Les effets aerodynamiques et microclimatiques des brise-vent et des amenagements regionaux. In: Reifsnyder WS, Darnhofer TO (eds) Meteorology and 
Agroforestry, International Council for Research in Agroforestry, Nairobi, Kenya pp 485-520

Hardie WJ, Considine JA (1976) Response of Grapes to Water-Deficit Stress in Particular Stages of Development. American Journal of Enology and Viticulture 27:55-61

Haselgrove L, Botting D, van Heeswijck R, Høj PB, Dry PR, Ford C, Land PGI (2008) Canopy microclimate and berry composition: The effect of bunch exposure on the phenolic composition of Vitis vinifera L cv. Shiraz grape berries. Australian Journal of Grape and Wine Research 6:141-149

Henderson JP, Rex D (2012) About Wine, $2^{\text {nd }}$ Edition. Clifton Park, NY

Hennessy KJ, Pittock AB (1995) Greenhouse warming and threshold temperature events in Victoria, Australia. International Journal of Climatology 15:591-612

Henry CC (1993) The effect of container volume and pore diameter on the growth of grapevines (Vitis vinifera L.). Dissertation, Lincoln University

Hidalgo L (1968) Contribuții la studiul densității radiculare la vița de vie. Revista de Horticultură şi Viticultură, 7-8:116-121

Hollósy F (2002) Effects of ultraviolet radiation on plant cells. Micron 33:179-197

Hommay G, Wiss L, Le Maguet J, Beuve M, Herrbach E (2012) First Results on Wind Dispersal of Parthenolecanium corni Larvae in a Newly Planted Vineyard. In: Proceedings of the $17^{\text {th }}$ Congress of ICVG, October 2012, Davis, United States, pp 202-203

Hopping (1975) Effect of light intensity during cane development on subsequent bud break and yield of 'Palomino' grape vines. New Zealand Journal of Experimental Agriculture 5:287-290

Howard R, Stull R (2013) IR Radiation from Trees to a Ski Run: A Case Study. Journal of Applied Meteorology and Climatology 52:1525-1539

Hunter JJ, Volschenk CG, Novello V, Strever AE, Fouché GW (2014) Integrative Effects of Vine Water Relations and Grape Ripeness Level of Vitis vinifera L. cv. Shiraz/Richter 99. I. Physiological Changes and Vegetative-Reproductive Growth Balances. South African Journal of Enology and Viticulture 35: 332-358

Jackson DI, Lombard PB (1993) Environmental and Management Practices Affecting Grape Composition and Wine Quality - A Review. American Journal of Enology and Viticulture 44:409-430

Jackson RB, Canadell J, Ehleringer JR, Mooney HA, Sala OE, Schulze ED (1996) A global analysis of root distributions for terrestrial biomes. Oecologia, 108:389-411

Jagoutz H (2004) The Effect of Wind. Geologische Abhandlungen von Hessen 114:42-53

Jones GV (2005) Climate Change in the Western United States Grape Growing Regions. In: Williams LE (ed) Proceedings of the VII ${ }^{\text {th }}$ International Symposium on Grapevine Physiology and Biotechnology. Acta Horticulturae, 689:41-51

Jones GV, Davis RE (2000) Climate Influences on Grapevine Phenology, Grape Composition, and Wine Production and Quality for Bordeaux, France. American Journal of Enology and Viticulture 51:249-261

Jones GV, Webb LB (2010) Climate Change, Viticulture, and Wine: Challenges and Opportunities. Journal of Wine Research 21:103-106

Jones GV, Reid R, Vilks A (2012) Climate, Grapes, and Wine: Structure and Suitability in a Variable and Changing Climate. In: Dougherty PH (ed) The Geography of Wine: Regions, Terroir and Techniques. Springer, Dordrecht

Jones GV, White MA, Cooper OR, Storchmann K (2005) Climate Change and Global Wine Quality. Climate Change 73:319-343 
Jonsson K, Fidjeland L, Maghembe JA, Högberg P (1988) The vertical distribution of fine roots of five tree species and maize in Morogoro, Tanzania. Agroforestry Systems 6: 63-69

Jordão AM, Vilela A, Cosme F (2015) From Sugar of Grape to Alcohol of Wine: Sensorial Impact of Alcohol in Wine. Beverages 1:292-310

Jose S (2009) Agroforestry for ecosystem services and environmental benefits: an overview. Agroforestry Systems 76: 1-10

Jose S, Holzmueller EJ, Gillespie AR (2009) Tree-Crop Interactions in Temperate Agroforestry. In: Garrett HE (ed) North American Agroforestry: An Integrated Science and Practice, 2nd edn. Madison, WI, pp 57-74

Kailis S, Harris DJ (2007) Producing Table Olives. Landlinks Press, Collingwood, VIC, Australia

Kasap I (2005) Life-history traits of the predaceous mite Kampimodromus aberrans (Oudemans) (Acarina: Phytoseiidae) on four different types of food. Biological Control 35:40-45

Keller M (2010) Managing grapevines to optimize fruit development in a challenging environment: a climate change primer for viticulturists. Australian Journal of Grape and Wine Research 16:56-69

Keller M, Hrazdina G (1998) Interaction of Nitrogen Availability During Bloom and Light Intensity During Veraison. II. Effects on Anthocyanin and Phenolic Development During Grape Ripening. American Journal of Enology and Viticulture 49:341-349

Keller M (2015) The Science of Grapevines, $2^{\text {nd }}$ edn. Elsevier Inc. London

Kelly RM, Kitzes J, Wilson H, Merenlender A (2016) Habitat diversity promotes bat activity in a vineyard landscape. Agriculture, Ecosystems and Environment 223:175-181

Kemp B, Pedneault K, Pickering G, Usher K, Willwerth J (2019) Red Winemaking in Cool Climates. In: Morata A (ed) Red Wine Technology. Elsevier, London, pp 17-34

Kennedy JA (2008) Grape and wine phenolics: Observations and recent findings. Ciencia e Investigación Agraria 35:107-120

Kido H, Flaherty DL, Bosch DF, Valero KA (1984) French Prune Trees as Overwintering Sites for Grape Leafhopper Egg Parasite. American Journal of Enology and Viticulture 35:156-160

Kimmins JP (1997) Forest Ecology: A Foundation for Sustainble Management. Prentice Hall, University of Minnesota, United States

Kirchhoff M, Rodrigo-Comino J, Seeger M, Ries JB (2017) Soil erosion in sloping vineyards under conventional and organic land use managements (Saar-Mosel Valley, Germany). Cuadernos de Investigación Geográfica 43:119-140

Kliewer WM (1975) Effect of Root Temperature on Budbreak, Shoot Growth, and Fruit-Set of 'Cabernet Sauvignon' Grapevines. American Journal of Enology and Viticulture 26:82-89

Kliewer WM (1977) Effect of High Temperatures during the Bloom-Set Period on Fruit-Set, Ovule Fertility, and Berry Growth of Several Grape Cultivars. American Journal of Enology and Viticulture 28:215-222

Kliewer WM (1982) Vineyard canopy management - a review. In: Webb AD (ed) Grape and Wine Centennial Symposium Proceedings (18-21 June 1980). University of California, Davis, California, pp 342-325

Kliewer WM, Antcliff AJ (1970) Influence of Defoliation, Leaf Darkening, and Cluster Shading on the Growth and Composition of Sultana Grapes. American Journal of Enology and Viticulture 21:26-36 
Kliewer WM, Smart RE (1989) Canopy Manipulation for Optimizing Vine Microclimate, Crop Yield, and Composition of Grapes. In: Wright CJ (ed) Manipulation of Fruiting. Butterworths, London, pp 275-291

Kliewer WM, Soleiani A (1972) Effect of Chilling on Budbreak in 'Thompson Seedless' and 'Carignane' Grapevines. American Journal of Enology and Viticulture 23:31-34

Kobriger JM, Kliewer WM, Lagier ST (1984) Effects of Wind on Water Relations of Several Grapevine Cultivars. American Journal of Enology and Viticulture 35:164-169

Kort JR (1988) 9. Benefits of windbreaks to field and forage crops. Agriculture, Ecosystems \& Environment 22-23:165-190

Krasnow MN, Matthews MA, Smith RJ, Benz J, Weber E, Shackel KA (2010) Distinctive symptoms differentiate four common types of berry shrivel disorder in grape. California Agriculture 64:155-159

Kriedemann PE (1968) Photosynthesis in vine leaves as a function of light intensity, temperature, and leaf age. Vitis 7:213-220

Krueger WC (1981) How a Forest Affects a Forage Crop. Rangelands 3:70-71

Kumar S, Anderson SH, Udawatta RP, Kallenbach RL (2012) Water infiltration influenced by agroforestry and grass buffers for a grazed pasture system. Agroforestry Systmes, $84: 325-335$

Lakso AN, Robinson TL, Pool RM (1989) Canopy Microclimate Effects on Patterns of Fruiting and Fruit Development in Apples and Grapes. In: Wright CJ (ed) Manipulation of Fruiting. Butterworth \& Co., London, UK, pp 263-274

Lal R (1989) Agroforestry systems and soil surface management of a tropical alfisol: V. Agroforestry Systems 8:217-238

Lanyon DM, Cass A, Hansen D (2004) The effect of soil properties on vine performance. Technical Report, CSIRO Land and Water, South Australia

Lavee S (2000) Grapevine (Vitis Vinifera) Growth and Performance in Warm Climates. In:

Erez A (ed) Temperate Fruit Crops in Warm Climates, Bet Dagen, Israel, pp 343-366

Lee J (2017) Light exclusion influence on grape anthocyanin. Heliyon 3:e00243

Lecourieux F, Kappel C, Pieri P, Charon J, Pillet J, Hilbert G, Renaud C, Gomès E, Delrot S, Lecourieux D (2017) Dissecting the Biochemical and Transcriptomic Effects of a Locally Applied Heat Treatment on Developing Cabernet Sauvignon Grape Berries. Frontiers in Plant Science 8:53

Letourneau DK, Armbrecht I, Salguero Rivera B, Lerma JM, Carmona EJ, Daza MC, Escobar S, Galindo V, Gutierrez C, López SD, López Mejía J, Acosta Rangel AM, Herrera Rangel J, Rivera L, Saavedra CA, Torres AM, Trujillo AR (2011). Does plant diversity benefit agroecosystems? A synthetic review. Ecological Applications 21:921

Lin BB (2007) Agroforestry management as an adaptive strategy against potential microclimate extremes in coffee agriculture. Agricultural and Forest Meteorology, 144:85-94

Lombard J, Cook NC, Bellstedt DU (2006) Endogenous cytokinin levels of table grape vines during spring budburst as influenced by hydrogen cyanamide application and pruning. Scientia Horticulturae 109:92-96

Lott JE, Khan AA, Ong CK, Black CR (1995) Sap flow measurements of lateral tree roots in agroforestry systems. Tree Physiology 16:95-1001

Maher M, Prasad M, Raviv M (2008) 11 - Organic Soilless Media Components. In: Raviv M, Lieth JH (eds) Soilless Culture: Theory and Practice, pp 459-504

Mahmood I, Imadi SR, Shazadi K, Gul A, Hakeem KR (2015) Effects of Pesticides on Environment. In: Hakeem K, Akhtar M, Abdullah S (eds) Plant, Soil and Microbes, Springer International Publishing, Switzerland, pp 253-269 
Margosian ML, Garrett KA, Hutchinson JMS, With KA (2009) Connectivity of the American Agricultural Landscape: Assessing the National Risk of Crop Pest and Disease Spread. BioScience 59:141-151

Marshall JK (1967) The effect of shelter on the productivity of grasslands and field crops. Field Crop Abstract 20:1-14

Martelli GP (2017) An Overview on Grapevine Viruses, Viroids, and the Diseases They Cause. In: Meng B, Martelli G, Golino D, Fuchs M (eds) Grapevine Viruses: Molecular Biology, Diagnostics and Management. Springer, Charm

Martínez-Casasnovas JA, Ramos MC (2006) The cost of soil erosion in vineyard fields in Penedès-Anoia Region (NE Spain). Catena 68:194-199

Martínez-Lüscher, Chen CCL, Brillante L, Kurtural SH (2017) Partial Solar Radiation Exclusion with Color Shade Nets Reduces the Degradation of Organic Acids and Flavonoids of Grape Berry (Vitis vinifera L.). Journal of Agricultural and Food Chemistry 65:10693-10702

Martínez-Lüscher, Brillante Luca, Kurtural SK (2019) Flavonol Profile is a Reliable Indicator to Assess Canopy Architecture and the Exposure of Red Wine Grapes to Solar Radiation. Frontiers in Plant Science 10:10

Martison T (2010) Sources and Sinks: Allocation of Photosynthates during the Growing Season. Appellation Cornell (4). Cornell College of Agriculture and Life Sciences. https://grapesandwine.cals.cornell.edu/newsletters/appellation-cornell/2010newsletters/issue-4/sources-and-sinks-allocation-photosynthates/. Accessed 15 January 2020

Marzen M, Iserloh T, Fister W, Seeger M, Rodrigo-Comino J, Ries JB (2019) On-Site Water and Wind Erosion Experiments Reveal Relative Impact on Total Soil Erosion. Geosciences 9:478

Mattivi F, Guzzon R, Vrhovsek U, Stefanini M, Velasco R (2006) Metabolite Profiling of Grape: Flavonols and Anthocyanins. Journal of Agricultural and Food Chemistry 54:7692-7702

May P, Antcliff AJ (1963) The Effect of Shading on Fruitfulness and Yield in the Sultana. Journal of Horticultural Science 38:85-94

McCarthy MG (1997) The effect of transient water deficit on berry development of cv. Shiras (Vitis vinifera L.). Australian Journal of Grape and Wine Research 3:41-48

McCarthy MG, Cirami RM, McCloud P (1983) Vine and Fruit Responses to Supplementary Irrigation and Canopy Management. South African Journal of Enology and Viticulture 4:67-76

Mckenry MV (1984) Grape Root Phenology Relative to Control of Parasitic Nematodes. American Journal of Enology and Viticulture 35:206-211

McNaughton KG (1988) 1. Effects of windbreaks on turbulent transport and microclimate. Agriculture, Ecosystems \& Environment 22-23:17-39

McNaughton KG, Unsworth M, Raupach M (1989) Micrometeorology of shelter belts and forest edges. Philosophical Transactions of the Royal Society of London. Series B, Biological Sciences 324:351-368

Medlyn BE (1997) Physiological basis of the light use efficiency model. Tree Physiology 18:167-176

Medrano H, Escalona JM, Cifre J, Bota J, Flexas J (2003) A ten-year study on the physiology of two Spanish grapevine cultivars under field conditions: effects of water availability from leaf photosynthesis to grape yield and quality. Functional Plant Biology 30: 607619 
Meehan TD, Werling BP, Landis DA, Gratton C (2011) Agricultural landscape simplification and insecticide use in the Midwestern United States. Proceedings of the National Academy of Sciences of the United States of America 108:11500-11505

Mériaux S, Rollin H, Rutten P, Lessut J, Lallemand R (1981) Effets de la sécheresse sur la vigne (Vitis vinifera L.) II. - Etudes sur " Grenache ". Agronomie 1:375-382

Miles A, Altieri MA, Wilson H, Nicholls CI (2012) Habitat Diversity at the Field and Landscape Level: Conservation Biological Control Research in California Viticulture. In: Bostonian NJ, Isaacs R, Vincent C (eds) Arthropod Management in Vineyards: Pests, Approaches, and Future Directions. Springer, Dordrecht, pp 159-189

Millar AA (1972) Thermal Regime of Grapevines. American Journal of Enology and Viticulture 23:173-176

Minasny B, McBratney AB (2015) Limited effect of organic matter on soil available water capacity. European Journal of Soil Science 69: 39-47

Mineau P, McLaughlin A (1996) Conservation of Biodiversity within Canadian Agricultural Landscapes: Integrating Habitat for Wildlife. Journal of Agricultural and Environmental Ethics 9:93-113

Mira de Orduña R (2010) Climate change associated effects on grape and wine quality and production. Food Research International 43:1844-1855

Mize CW, Brandle JR, Schoeneberger MM, Bentrup G (2008) Ecological Development and Function of Shelterbelts in Temperate North America. In: Jose S, Gordon AM (eds) Toward Agroforestry Design: An Ecological Approach. Springer, Lincoln, Nebraska, pp 27-54

Monteith JL (1972) Solar Radiation and Productivity in Tropical Ecosystems. Journal of Applied Ecology 9:747-766

Morales-Castilla I, García de Cortázar-Atauri I, Cook BI, Lacombe T, Parker A, van Leeuwen C, Nicholas KA, Wolkovich EM (2020) Diversity buffers winegrowing regions from climate change losses. Proceedings of the National Academy of Sciences of the United States of America 117:2864-2869

Moreira CC, Celestino D, Guerra Sobrinho T, Cardoso IM, Elliot SM (2019) Agroforestry coffee soils increase the insect-suppressive potential offered by entomopathogenic fungi over full-sun soils: A case proposing a "bait survival technique". Ecology and Evolution 9:10777-10787

Mori K, Goto-Yamamoto N, Kitayama M, Hashizume K (2007) Loss of anthocyanins in redwine grape under high temperature. Journal of Experimental Botany 58:1935-1945

Morlat R, Jacquet A (1993) The soil effects on the grapevine root system in several vineyards of the Loire Valley (France). Vitis 32:35-42

Morrison JC, Noble AC (1990) The Effects of Leaf and Cluster Shading on the Composition of Cabernet Sauvignon Grapes and on Fruit and Wine Sensory Properties. American Journal of Enology and Viticulture 41:193-200

Mōttus M, Sulev M, Baret F, Lopez-Lozano R, Reinart A (2010) Photosynthetically Active Radiation: Measurement and Modeling. In: Meyers R (ed) Encyclopedia of Sustainability Science and Technology. Springer, pp 7902-7932

Mullins MG, Bouquet A, Williams LE (1992) Biology of the Grapevine. Cambridge University Press, Cambridge UK

Murphy BC, Rosenheim JA, Granett J (1996) Habitat Diversification for Improving Biological Control: Abundance of Anagrus epos (Hymenoptera: Mymaridae) in Grape Vineyards. Environmental Entomology 25:495-504

Myburgh P, Cass A, Clingeleffer P (1998) Root systems and soils in Australian vineyards and orchards : an assessment : 1996 Barossa Valley Rotary Foundation Fellowship report. Cooperative Research Centre for Soil and Land Management, South Australia 
Nair PK (1993a) An Introduction to Agroforestry. Klgwer Academic Publishers, Dordrecht, The Netherlands

Nair PK (1993b) Nutrient cycling and soil organic matter. In: Nair PK (author) An introduction to agroforestry, Kluwer Academic Publishers, Dordrecht, The Netherlands, pp 277-306

Nair PK (1993c) Nitrogen fixation. In: Nair PK (author) An introduction to agroforestry, Kluwer Academic Publishers, Dordrecht, The Netherlands, pp 307-323

Nair PK (1993d) Alley cropping. In: Nair PK (author) An introduction to agroforestry, Kluwer Academic Publishers, Dordrecht, The Netherlands, pp 123-139

Nair PK (1993e) Component interactions. In: Nair PK (author) An introduction to agroforestry, Kluwer Academic Publishers, Dordrecht, The Netherlands, pp 243-258

Napoli M, Dalla Marta A, Zanchi CA, Orlandini S (2017) Assessment of soil and nutrient losses by runoff under different soil management practices in an Italian hilly vineyard. Soil and Tillage Research 168:71-80

Neethling E, Barbeau G, Coulon-Leroy C, Quénol H (2019) Spatial complexity and temporal dynamics in viticulture: A review of climate-driven scales. Agriculture and Forest Meteorology 276-277:107618

Neja RA, Wildman WE, Ayers RS, Kasimatis AN (1977) Grapevine Response to Irrigation and Trellis Treatments in the Salinas Valley. American Journal of Enology and Viticulture 28:16-26

Nicholls CI, Ponti L, Altieri MA (2008) Enhancing plant diversity for improved insect pest management in Northern California organic vineyards. Acta horticulturae 785:263278

Nicolopoulou-Stamati P, Maipas S, Kotampasi C, Stamatis P, Hens L (2016) Chemical Pesticides and Human Health: The Urgent Need for a New Concept in Agriculture. Frontiers in Public Health 4, 148

Northcote KH (1988) Soil and Australian viticulture. In: Coombe BG, Dry PR (eds) Viticulture: Volume 1 - Resources, $2^{\text {nd }}$ edn. Adelaide, Australia, pp 61-90

Norton RL (1988) 11. Windbreaks: Benefits to orchard and vineyard crops. Agriculture, Ecosystems \& Environment 22-23:205-213

Novara A, Pisciotta A, Minacapilli M, Maltese A, Capodici F, Cerdà A, \& Gristina L (2018) The impact of soil erosion on soil fertility and vine vigor. A multidisciplinary approach based on field, laboratory and remote sensing approaches. Science of the Total Environment 622-623: 474-480

NPCS Board of Consultants and Engineers (n.d.) Handbook on Citrus Fruits: Cultivation and Oil Extraction. Asia Pacific Business Press Inc, Kamla, Nagar, Delhi, India

Oke TR (1988) Boundary Layer Climates, $2^{\text {nd }}$ Edn. Taylor \& Francis Group

Oliveira MT, Merwin IA (2001) Soil physical conditions in a New York orchard after eight years under different groundcover management systems. Plant and Soil 234: 233-237

Oliveira M, Teles J, Barbosa P, Olazabal F, Queiroz J (2014) Shading of the fruit zone to reduce grape yield and quality losses caused by sunburn. Journal international des sciences de la vigne et du vin 48:179-187

Oliver DP, Bramley RG, Riches D, Porter IJ, Edwards J (2013) Review: Soil physical and chemical properties as indicators of soil quality in Australian viticulture. Australian Journal of Grape and Wine Research 19:129-140

Onzo A, Sabelis MW, Hanna R (2010) Effects of Ultraviolet Radiation on Predatory Mites and the Role of Refuges in Plant Structures. Environmental Entomology 39:695-701

Pachauri RK, Meyer L (2015) Climate Change 2014 Synthesis Report. Intergovernmental Panel on Climate Change, World Meteorological Organization (WMO). Report, Geneva, Switzerland 
Pagay V, Collins C (2017) Effects of timing and intensity of elevated temperatures on reproductive development of field-grown Shiraz grapevines. OENO One - Vine and Wine Open Access Journal 51:409-421

Palma BA, Jackson DI (1981) Effect of Temperature on Flower Initiation. Botanical Gazette 142:490-493

Parsons PG, Neale R, Wolski P, Green A (1998) The shady side of solar protection. Medical Journal of Australia 168:327-330

Pasek JE (1988) 30. Influence of wind and windbreaks on local dispersal of insects. Agriculture, Ecosystems \& Environment 22-23:539-554

Paudel B, Udawatta RP, Kremer RJ, Anderson SH (2011) Soil quality indicator responses to row crop, grazed pasture, and agroforestry buffer management. Agroforestry Systems 82: 311-323

Pedroza MA, Salinas MR, Alonso GL, Zalacain A (2017) Oenological Applications of Wineking By-Products. In: Galanakis CM (ed) Handbook of Grape Processing ByProducts. Elsevier, London

Pennock D (2019) Soil Erosion: the greatest challenge for sustainable soil management. Food and Agriculture Organization of the United Nations. Rome, Italy. http://www.fao.org/3/ca4395en/ca4395en.pdf. Accessed 19 March 2020

Peralta AL, Sun Y, McDaniel MD, Lennon JT (2018) Crop rotational diversity increases disease suppresive capacity of soil microbiomes. Ecosphere 9:1-16

Pereira GE, Gaudillere JP, van Leeuwen C, Hilbert G, Maucourt M, Deborde C, Moing A, Rolin D (2005) H NMR metabolite fingerprints of grape berry: Comparison of vintage and soil effects in Bordeaux grapevine growing areas. Analytica Chimica Acta 563:346-352

Peter I, Lehmann J (2000) Pruning effects on root distribution and nutrient dynamics in an acacia hedgerow planting in northern Kenya. Agroforestry Systems 50: 59-75

Petrie PR, Clingeleffer PR (2008) Effects of temperature and light (before and after budburst) on inflorescence morphology and flower number of Chardonnay grapevines (Vitis vinifera L.). Australian Journal of Grape and Wine Research 11:59-65

Petrovic G (2018) A survey of the YAN status of South African grape juices and exploration of multivariate data analysis techniques for spectrometric calibration and cultiavr discrimination purposes. Dissertation, Stellenbosch University, South Africa

Pienaar JW (2005) The effect of wind on the performance of the grapevine. Master's Thesis, Stellenbosch University, South Africa

Pimentel D (2006) Soil Erosion: A Food and Environmental Threat. Environment, Development and Sustainability 8:119-137

Pool RM, Dunst RM, Lakso AN (1990) Comparison of sod, mulch, cultivation, and herbicide floor management practices for grape production in nonirrigated vineyards. Journal of the American Society for Horticultural Science 115: 872-877

Pouget R (1981) Action de la température sur la différenciation des inflorescences et des fleurs durant les phases de pré-débourrement et de post-débourrement des bourgeons latents de la vigne. Journal international des sciences de la vigne et du vin 15:65-79

Price SF, Breen PJ, Valladao M, Watson BT (1995) Cluster Sun Exposure and Quercetin in Pinot noir Grapes and Wine. American Journal of Enology and Viticulture 46:187194

Raj AJ, Lal SB (2014) Agroforestry Theory and Practices. Scientific Publishers, Jodhpur, India

Raj A, Toppo P (2018) Role of Agroforestry in Climate Change Mitigation. Journal of Pharmacognosy and Phytochemistry 7:241-243 
Ramachandran NP, Buresh RJ, Mugendi DN, Latt CR (1999) Nutrient Cycling in Tropical Agroforestry Systems: Myths and Science. In: Buck LE, Lassoie JP, Fernandes EC (eds) Agroforestry in Sustainable Agricultural Systems. CRC Press LLC

Rashid MI, Mujawar LH, Shahzad T, Almeelbi T, Ismail IM, Oves M (2016) Bacteria and fungi can contribute to nutrients bioavailability and aggregate formation in degraded soils. Microbiological Research 183: 26-41

Rathé AA, Pilkington LJ, Hoddle MS, Spohr LJ, Daugherty MP, Gurr GM (2014) Feeding and Development of the Glassy-Winged Sharpshooter, Homalodisca vitripennis, on Australian Native Plant Species and Implications for Australian Biosecurity. PloS one, 9:e90410. https://doi.org/10.1371/journal.pone.0090410

Ratnadass A, Fernandes P, Avelino J, Habib R (2012) Plant species diversity for sustainable management of crop pests and diseases in agroecosystems: a review. Agronomy for Sustainable Development 32: 273-303

Reynolds AG, Pool RM, Mattick LR (1986) Influence of cluster exposure on fruit composition and wine quality of Seyval blanc grapes. Vitis 25:85-95

Reynolds PE, Simpson JA, Thevathasan NV, Gordon AM (2007) Effects of tree competition on corn and soybean photosynthesis, growth, and yield in a temperate tree-based agroforestry intercropping system in southern Ontario, Canada. Ecological Engineering 29: 362-371

Rienth M, Torregrosa L, Gautier S, Ardisson M, Brillouet JM, Romieu C (2016) Temperature desynchronizes sugar and organic acid metabolism in ripening grapevine fruits and remodels their transcriptome. BMC Plant Biology 16:164

Rienth M, Torregrosa L, Luchaire N, Chatbanyong R, Lecourieux D, Kelly MT, Romieu C (2014) Day and night heat stress trigger different transcriptomic responses in green and ripening grapevine (vitis vinifera) fruit. BMC Plant Biology 14:108

Riha SJ, McIntyre BD (1999) Water Management with Hedgerow Agroforestry Systems. In: Buck LE, Lassoie JP, Fernandes EC (eds) Agroforestry in Sustainable Agricultural Systems, Lewis Publishers, pp 47-67

Risch SJ, Andow D, Altieri MA (1983) Agroecosystem Diversity and Pest Control: Data, Tentative Conclusions, and New Research Directions. Environmental Entomology 12:625-628

Rodrigo-Comino J, Keesstra S, Cerdà A (2018) Soil Erosion as an Environmental Concern in Vineyards. The Case Study of Celler del Roure, Eastern Spain, by Means of Rainfall Simulation Experiments. Beverages, 4:1-11

Rodríguez-San Pedro A, Allendes JL, Beltrán CA, Chaperon PN, Saldarriaga-Córdoba MM, Silva AX, Grez AA (2020) Quantifiying ecological and economic value of pest control services provided by bats in a vineyard landscape of central Chile. Agriculture, Ecosystems and Environment 302:107063. https://doi.org/10.1016/j.agee.2020.107063

Rojas-Lara BA, Morrison JC (1989) Differential effects of shading fruit or foliage on the development and composition of grape berries. Vitis 28:199-208

Roman H, Girault T, Barbier F, Péron T, Brouard N, Penčík A, Novák O, Vian A, Sakr S, Lothier J, Le Gourrierec J, Leduc N (2016) Cytokinins Are Initial Targets of Light in the Control of Bud Outgrowth. Plant Physiology 172:489-509

Root RB (1973) Organization of a Plant-Arthropod Association in Simple and Diverse Habitats: The Fauna of Collards (Brassica Oleracea). Ecological Monographs, 43:95124

Ruffner HP, Hawker JS, Hale CR (1976) Temperature and enzymatic control of malate metabolism in berries of Vitis vinifera. Phytochemistry 15:1877-1880 
Saayman D, Huyssteen LV (1983) Preliminary Studies on the Effect of a Permanent Cover Crop and Root Pruning on an Irrigated Colombar Vineyard. South African Journal of Enology and Viticulture 4:7-12

Sadler GD, Murphy PA (2010) PH and Titratable Acidity. In: Nielsen S (ed) Food Analysis, $4^{\text {th }}$ Edition. Springer, New York, pp 219-238

Sadras VO, Moran MA (2012) Elevated temperature decouples anthocyanins and sugars in berries of Shiraz and Cabernet Franc. Australian Journal of Grape and Wine Research 18:115-122

Santillán D, Iglesias A, La Jeunesse I, Garrote L, Sotes V (2019) Vineyards in transition: A global assessment of the adaptation needs of grape producing regions under climate change. Science of the Total Environment 657:839-852

Schroeder P (1993) Organic Matter Cycling by Tropical Agroforestry Systems: A Review. Journal of Tropical Forest Science 7:462-474

Schroth G, Krauss U, Gasparotto L, Duarte Aguilar JA, Vohland K (2000) Pests and diseases in agroforestry systems of the humid tropics. Agroforestry Systems 50:199-241

Schultz HR (2003) Differences in hydraulic architecture account for nearisohydric and anisohydric behaviour of two field-grown Vitis vinifera L. cultivars during drought. Plant, Cell and Environment 26:1393-1405

Schymanski SJ, Or D (2016) Wind increases leaf water use efficiency. Plant, Cell and Environment 39:1448-1459

Šebela D, Turóczy Z, Olejníčková J, Kumšta M, Sotoláf R (2017) Effect of ambient sunlight intensity on the temporal phenolic profiles of Vitis vinifera L. Cv. Chardonnay during the ripening season - a field study. South African Journal of Enology and Viticulture 38:94-102

Sellers R, Alampi-Sottini V (2016) The influence of size on winery performance: Evidence from Italy. Wine Economics and Policy 5:33-41

Senaviratne A, Udawatta RP, Nelson KA, Shannon KK, Jose S (2012) Temporal and Spatial Influence of Perennial Upland Buffers of Corn and Soybean Yields. Semigroup Forum 104: 1356-1362

Seobi T, Anderson SH, Udawatta RP, Gantzer C (2005) Influence of Grass and Agroforestry Buffer Strips on Soil Hydraulic Properties for an Albaqualf. Soil Science Society of America Journal 69:893-901

Sepúlveda G, Kliewer WM (1986) Effect of High Temperature on Grapevines (Vitis vinifera L.). II. Distribution of Soluble Sugars. American Journal of Enology and Viticulture 37:20-25

Shantz HI (1927) Drought Resistance and Soil Moisture. Ecology 8:145-157

Shaulis NJ (1982) Responses of grapevines and grapes to spacing of and within canopies. In: Webb AD (ed) Grape and Wine Centennial Symposium Proceedings (18-21 June 1980). University of California, Davis, California, pp 353-361

Smart RE (1974) Aspects of Water Relations of the Grapevine (Vitis vinifera). American Journal of Enology and Viticulture 25:84-91

Smart RE (1987a) Canopy management to improve yield, fruit composition and vineyard mechanisation: a review. In: Lee TH (ed) Proceedings of the Sixth Australian Wine Industry Technical Conference (14-17 July 1986, Adelaide, SA). The Australian Wine Research Institute, Adelaide, pp 205-211

Smart RE (1987b) Influence of light on composition and quality of grapes. Acta Horticulturae 206:37-47

Smart DR, Carlisle E, Goebel M, Núnez BA (2005) Transverse hydraulic redistribution by a grapevine. Plant, Cell and Environment 28:157-166 
Smart RE, Coombe BG (1983) Water relations of grapevines. In: Kozlowski TT (ed) Water Deficits and Plant Growth Volume VII: Additional Woody Crop Plants. Academic Press, New York, pp 137-196

Smart RE, Robinson M (1991) Sunlight into Wine: A Handbook for Winegrape Canopy Management. Winetitles, Adelaide, Australia

Smart DR, Schwass E, Lakso A, Morano L (2006) Grapevine Rooting Patterns: A Comprehensive Analysis and a Review. American Journal of Enology and Viticulture 57:89-104

Smart RE, Sinclair TR (1976) Solar heating of grape berries and other spherical fruits. Agricultural Meteorology 17:241-259

Smart RE, Smith SM (1988) Canopy management: identifying the problems and practical solutions. In: Proceedings of the Second International Cool Climate Viticulture and Oenology Symposium (January 1988). Auckland, New Zealand, pp 316-324

Soares Cariri Lopes F, Vargas de Oliveira J, Eudes de Morais Oliveira J, Duarte de Oliveira M, Maria de Souza A (2019) Pesquisa Agropecuária Tropical 49, e54421

Spayd SE, Tarara JM, Mee DL, Ferguson JC (2002) Separation of Sunlight and Temperature Effects on the Composition of Vitis vinifera cv. Merlot Berries. American Journal of Enology and Viticulture 53:171-182

Spittlehouse DL, Adams RS, Winkler RD (2004) Forest, Edge, and Opening Microclimate at Sicamous Creek. Ministry of Forests Forest Science Program, British Columbia

Srinivasan C, Mullins MG (1981) Physiology of Flowering in the Grapevine - A Review. American Journal of Enology and Viticulture 32:47-63

Stancanelli G, Almeida R, Bosco D, Caffier D, Czwienczek E (2015) Assessing the risk posed to plant health by Xylella fastidiosa in the European Union. CIHEAM International Centre for Advanced Mediterranean Agronomic Studies, Watch Letter 33: $1-8$

Stephenson AG (1981) Flower and Fruit Abortion: Proximate Causes anad Ultimate Functions. Annual Review of Ecology, Evolution, and Systematics 12:253-279

Stevens RM, Harvey G, Aspinall D (1995) Grapevine growth of shoots and fruit linearly correlate with water stress indices based on root-weighted soil matric potential. Australian Journal of Grape and Wine Research 1:58-66

Stevenson T (2005) The Sotheby's Wine Encyclopedia, $4^{\text {th }}$ edn. Dorling Kindersley, London

Stock M, Gerstengarbe FW, Kartschall T, Werner PC (2005) Reliability of Climate Change Impact Assessments for Viticulture. Acta Horticulturae 689:29-40

Sudmeyer R, Flugge F (2004) The economics of managing tree-crop competition in windbreak and alley systems. Australian Journal of Experimental Agriculture 45:1403 $-1414$

Sun R, Cheng G, Li Q, He Y, Wang Y, Lan Y, Li S, Zhu Y, Song W, Zhang X, Cui X, Chen W, Wang J (2017) Light-induced Variation in Phenolic Compounds in Cabernet Sauvignon Grapes (Vitis vinifera L.) Involves Extensive Transcriptome Reprogramming of Biosynthetic Enzymes, Transcription Factors, and Phytohormonal Regulators. Frontiers in Plant Science 8:547

Sun D, Wang Q (2018) Linear Relationships between Photosynthetic Rate and Photochemical Energy Expressed by PAR $x F v / F m$. American Journal of Plant Sciences 9:125-138

Sweetman C, Sadras VO, Hancock RD, Soole KL, Ford CM (2014) Metabolic effects of elevated temperature on organic acid degradadtion in ripening Vitis vinifera fruit. Journal of Experimental Botany 65:5975-5988

Szegedi E, Civerolo EL (2011) Bacterial diseases of grapevine. International Journal of Horticultural Science 17:45-49 
Tamang B, Rockwood DL, Andreu MG (2009) Microclimate Modification by Tree Windbreaks in Florida Farms. In: Gold MA, Hall MM (Eds.) Agroforestry Comes of Age: Putting Science into Practice. Proceedings of the $11^{\text {th }}$ North American Agroforestry Conference, May 31-June 3, 2009. Columbia, Missouri, pp 339 - 348

Tarara J, Ferguson J, Hoheisel G, Perez J (2005) Assymetrical canopy architecture due to prevailing wind direction and row orientation creates an imbalance in irradiance at the fruiting zone of grapevines. Agricultural and Forest Meteorology 135:144-155

Tauzin AS, Giardina T (2014) Sucrose and invertases, a part of the plant defense response to the biotic stresses. Frontiers in Plant Science 5:293

Thevathasan N, Gordon AM (2004) Ecology of tree intercropping systems in the North temperate region: Experiences from southern Ontario, Canada. Agroforestry Systems 61:257-268

Thomazini A, Mendonça ES, Cardoso IM, Garbin ML (2015) SOC dynamics and soil quality index of agroforestry systems in the Atlantic rainforest of Brazil. Geoderma Regional 5:15-24

Tixier MS, Arnaud A, Douin M, Kreiter S (2015) Effects of agroforestry on Phytoseiidae communities (Acari: Mesostigmata) in vineyards. A synthesis of a 10-year period of observation. Acarologia 55:361-375

Trambouze W, Goma-Fortin N (2013) Agroforesterie viticole : résultats de 11 ans d'étude sur la production et la vigueur des vignes. Chambre d'agriculture de l'Hérault, Portugal

Trambouze W, Gouttesoulard D, Saubion C (2017) Agroforesterie viticole : 20 ans de complantation arbres/vignes, pour quels résultats agronomiques? Report, RMT Agroforesteries Chambre D' Agriculture Hérault, Paris, France

Ucar T, Hall FR (2001) Windbreaks as a pesticide drift mitigation strategy: a review. Pest Management Science 57:663-675

Udawatta RP, Anderson SH, Motavalli PP, Garrett HE (2011a) Calibration of a water content reflectometer and soil water dynamics for an agroforestry practice. Agroforestry Systems 82: 61-75

Udawatta RP, Garrett HE, Kallenbach RL (2011b) Agroforestry buffers for non-point source pollution reductions from agricultural watersheds. Journal of Environmental Quality 40:800-806

Udawatta RP, Jose S (2011) Carbon Sequestration Potential of Agroforestry Practices in Temperate North America. In: Kumar B, Nair P (eds) Carbon Sequestration Potential of Agroforestry Systems. Advances in Agroforestry, Vol 8. Springer, Dordrecht

Udawatta RP, Nelson KA, Jose S, Motavalli PP (2014) Temporal and spatial differences in crop yields of a mature silver maple alley cropping system. Agronomy Journal 106:407-415

Udawatta RP, Gantzer CJ, Reinbott TM, Wright RL, Pierce RA II (2016) Yield differences influenced by distance from riparian buffers and CRP. Agronomy Journal 108:647655

Udawatta RP, Anderson SH, Kremer RJ (2020) Soil benefits of agroforestry. In: Garrett HE, Jose S, Gold M (eds.) North American Agroforestry: An Integrated Science and Practice $3^{\text {rd }}$ Edition. American Society of Agronomy-Crop Science Society of America-Soil Science Society of America (ASA-CSSA-SSSA). Madison, WI, USA, pp \#\#-\#\#

United States Environmental Protection Agency (2019) PRN 2001-X Draft: Spray and Dust Drift Label Statements for Pesticide Products. EPA. https://www.epa.gov/pesticideregistration/prn-2001-x-draft-spray-and-dust-drift-label-statements-pesticideproducts. Accessed 18 March 2020 
Ussahatanonta S, Jackson DI, Rowe RN (2008) Effects of nutrient and water stress on vegetative and reproductive growth in Vitis vinifera L. Australian Journal of Grape and Wine Research 2:64-69

Valdés-Gómez H, Fermaud M, Roudet J, Calonnec A, Gary C (2008) Grey mould incidence is reduced on grapevines with lower vegetative and reproductive growth. Crop Protection 27:1174-1186

Valdés-Gómez H, Gary C, Cartolaro P, Lolas-Caneo M, Calonnec A (2011) Powdery mildew development is positively influenced by grapevine vegetative growth induced by different soil management strategies. Crop Protection 30:1168-1177

Van Leeuwen C, Seguin G (2006) The concept of terroir in viticulture. Journal of Wine Research 17:1-10

Van zyl JL (1984) Response of Colombar Grapevines to Irrigation as Regards Quality Aspects and Growth. South African Journal of Enology and Viticulture 5:19-28

Vasconcelos MC, Greven M, Winefield CS, Trought MCT, Raw V (2009) The Flowering Process of Vitis vinifera: A Review. American Journal of Enology and Viticulture 60:411-434

Vogt E, Schruft G (2000) Weinbau $8^{\text {th }}$ Edition. Ulmer, Stuttgart, Germany

Wallingford AK, Fuchs MF, Martinson T, Hesler S, Loeb GM (2015) Slowing the Spread of Grapevine Leafroll-Associated Viruses in Commercial Vineyards With Insecticide Control of the Vector, Pseudococcus maritimus (Hemiptera: Pseudococcidae). Journal of Insect Science 15:1-6

Webb LB, Whetton PH, Barlow EWR (2007) Modelled impact of future climate change on the phenology of winegrapes in Australia. Australian Journal of Grape and Wine Research 13:165-175

Wetzel WC, Kharouba HM, Robinson M, Holyoak M, Karban R (2016) Variability in plant nutrients reduces insect herbivore performance. Nature 539: 425-427

Weyers JD, Hans M (1990) Methods in Stomatal Research. Harlow, Longman Scientific \& Technical

Wezel A, David C, Ferrer A, Letort A, Feret S, Peigné J, Vian JF, Celette F (2014) Agroecological practices supporting the provision of goods and services in agriculture. Examples from France and Europe. ISARA Lyon, France and the Food and Agriculture Organization, Rome, Italy. https://www.researchgate.net/publication/266143585_Agroecological_practices_supp orting_the_provision_of_goods_and_services_in_agriculture_Examples_from_France _and_Europe. Accessed 16 January 2020

Wheeler SJ, Pickering GJ (2003) Optimizing grape quality through soil management practices. Journal of Food Agriculture and Environment 1:190-197

Wheeler SJ, Pickering GJ (2005) Effects of Soil Management Techniques on Grape and Wine Quality. In: Dris R (author) Fruits: Growth, Nutrition, and Quality, WFL Publisher, Helsinki, Finland, pp 195-208

Wheeler SJ, Black AS, Pickering GJ (2005) Vineyard floor management improves wine quality in highly vigorous Vitis vinifera 'Cabernet Sauvignon' in New Zealand. New Zealand Journal of Crop and Horticultural Science 33:317-328

Wilson H, Daane K, Miles A, Altieri MA (2015) Landscape Diversity and Crop Vigor Influence Biological Control of the Western Grape Leafhopper (E. elegantula Osborn) in Vineyards. PLoS ONE 10:e0141752

Wilson H, Miles AF, Daane KM, Altieri MA (2017a). Landscape diversity and crop vigor outweigh influence of local diversification on biological control of a vineyard pest. Ecosphere 8:1-18 
Wilson H, Miles AF, Daane KM, Altieri MA (2017b) Vineyard proximity to riparian habitat influences Western grapeleafhopper (Erythroneura elegantula Osborn) populations. Agriculture, Ecosystems and Environment 211:43-50

Winkel T, Rambal S (1993) Influence of Water Stress on Grapevines Growing in the Field: from Leaf to Whole-plant Response. Australian Journal of Plant Physiology 20:143157

Winkler AJ, Cook JA, Kliewer WM, Lider LA (1974) General viticulture. University of California Press, Berkeley, CA

Wistrom C, Sisterson MS, Pryor M, Hashim-Buckey JM, Daane KM (2010) Distribution of Glassy-Winged Sharpshooter and Threecornered Alfalfa Hopper on Plant Hosts in the San Joaquin Valley, California. Journal of Economic Entomology 103:1051-1059

World Commission on Environment and Development (1987) Report of the World Commission on Environment and Development: Our Common Future. Oxford University Press, United Nations

Wright CJ (1989) Manipulation of Fruiting. Butterworths, London

Young A (1989a) Effects of Trees on Soils. In: Young A (author) Agroforestry for Soil Conservation. Wallingford, UK, pp 93-103

Young A (1989b) Soil Organic Matter. In: Young A (author) Agroforestry for Soil Conservation. Wallingford, UK, pp 105-128

Young A (1989c) Trends in Soil-Conservation Research and Policy. In: Young A (author) Agroforestry for Soil Conservation. Wallingford, UK pp 17-52

Zahavi T, Reuveni M, Scheglov D, Lavee S (2001) Effect of Grapevine Training Systems on Development of Powdery Mildew. European Journal of Plant Pathology 107:495-501

Zhang N, van Westreenen Av, Anten NPR, Evers JB, Marcelis LFM (2019) Disentangling the effects of photosynthetically active radiation and red to far-red ratio on plant photosynthesis under canopy shading: a simulation study using a functional-structural plant model. Annals of Botany mcz197 
CHAPTER VII

INTERSPECIFIC INTERACTIONS BETWEEN OLIVE TREES AND GRAPEVINES IN VINEYARD AGROFORESTRY SYSTEMS IN AN ARID CLIMATE REGION 


\section{VII.1. ABSTRACT}

Agroforestry is a sustainable land use system with proven benefits in vineyards, including increased climate resilience, improved pest management, improved soil fertility, and other enhanced ecosystem services. Previous studies on vineyard agroforestry systems have focused on Mediterranean climate regions, but the purpose of this study was to quantify the interspecific interactions between trees and grapevines in an arid and irrigated grape growing region of Argentina. The study took place in an 8-year-old Malbec vineyard in Mendoza, Argentina that was intercropped with hedgerows of 70-year-old olive trees. Grape quality, growth, and production parameters were examined at five different distances from an olive tree hedgerow. Results revealed that proximity of grapevines to the hedgerow was associated with significantly higher quality must, including higher glucose/fructose levels, higher brix levels, higher must density, and higher total acidity. However, proximity of grapevines to the hedgerow was also associated with significantly lower vigor and lower yield, with yield reductions up to $50 \%$ in vines closest to the hedgerow.

To investigate the potential causes of variance among these variables, nutritional analyses were undergone by examining vine tissue during the period of flowering, in order to determine whether the variation observed was due to competition for nutrients. Results revealed that there were no significant differences in nutrient status between treatments in any pattern that would indicate competition, suggesting that competition for nutrients was not a major limiting factor.

The results of this study broaden our understanding of vineyard agroforestry systems in different growing contexts and can help determine under which conditions agroforestry should be utilized as an appropriate technology in vineyards. In an arid region with a treecrop combination of olives and grapevines, the presence of trees was correlated with higher must quality but lower yields. Depending on winemaker goals, the beneficial effects that trees 
impart on grape must quality parameters, in addition to their beneficial ecosystem services, may be determined to outweigh the negative effects that trees have on yield in the rows nearest to trees. Additionally, as many arid grape growing regions anticipate destructively high temperatures in the coming years due to climate change, utilizing trees in vineyards may be an adaptive strategy for preventing future quality and yield reductions.

\section{VII.2. INTRODUCTION}

Grapevines (Vitis vinifera L.) and olive trees (Olea europaea L.) have been intercropped in Mendoza, Argentina for hundreds of years. Previous studies on vineyard agroforestry systems and on agroforestry systems in general in other growing regions have shown that the presence of trees in vineyards increases biodiversity, reduces pest damage, regulates the microclimate, protects vines from heat and frost damage, protects vines from wind, and improves soil fertility, in addition to providing many ecosystem services. However, studies about the impact of trees on grapevine yield, production, and quality parameters in arid climate regions have not been undergone. This study aims to scientifically document the effects of olive trees on grapevine growth, yield, and quality parameters. By studying vineyard agroforestry systems and measuring these various grapevine parameters at different distances from olive trees, we can quantify the extent of the competitive and beneficial interactions between grapevines and olive trees in vineyard agroforestry systems in Mendoza, Argentina.

\section{VII.3. PURPOSE AND OBJECTIVES}

The purpose of this study is to quantify the interspecific interactions between olive trees and grapevines at different distances from an olive tree hedgerow in an arid and irrigated wine growing region of Argentina. Quality, growth, and production parameters were 
examined at five different distances from an olive tree hedgerow, and the specific variables measured included: glucose/fructose levels in must, brix levels at harvest, must density, total acidity (TA), pH, malic acid, yeast assimilable nitrogen (YAN), total skin phenolics, total skin anthocyanins, total skin tannins, total seed phenolics, total seed tannins, pruning weight, yield, and the Ravaz Index. Each variable was measured for one year. In order to investigate the potential causes of variance among these parameters, vine nutritional status was studied through vine tissue samples, in order to determine if competition for nutrients was the main competitive factor. The following nutrients were measured: petiole nitrate, leaf blade $\mathrm{N}$, petiole total $\mathrm{N}$, leaf blade $\mathrm{P}$, petiole $\mathrm{P}$, leaf blade $\mathrm{K}$, petiole $\mathrm{K}$, leaf blade $\mathrm{Mg}$, and petiole $\mathrm{Mg}$.

\section{VII.3.1. Specific Objectives}

1. Measure glucose/fructose levels (g/L) in grape must at harvest from vines at different distances from an olive tree hedgerow.

2. Measure brix levels in grape must at harvest from vines at different distances from an olive tree hedgerow.

3. Measure grape must density $(\mathrm{g} / \mathrm{L})$ at harvest from vines at different distances from an olive tree hedgerow.

4. Measure TA $(\mathrm{g} / \mathrm{L})$ in grape must at harvest from vines at different distances from an olive tree hedgerow.

5. Measure $\mathrm{pH}$ in grape must at harvest from vines at different distances from an olive tree hedgerow.

6. Measure malic acid $(\mathrm{g} / \mathrm{L})$ in grape must at harvest from vines at different distances from an olive tree hedgerow.

7. Measure YAN $(\mathrm{g} / \mathrm{L})$ in grape must at harvest from vines at different distances from an olive tree hedgerow. 
8. Measure total skin phenolics in berries at harvest ( $\mathrm{mg} / \mathrm{g}$ fruit) from vines at different distances from an olive tree hedgerow.

9. Measure total skin anthocyanins in berries at harvest ( $\mathrm{mg} / \mathrm{g}$ fruit) from vines at different distances from an olive tree hedgerow.

10. Measure total skin tannins in berries at harvest ( $\mathrm{mg} / \mathrm{g}$ fruit) from vines at different distances from an olive tree hedgerow.

11. Measure total seed phenolics in berries at harvest $(\mathrm{mg} / \mathrm{g}$ fruit) from vines at different distances from an olive tree hedgerow.

12. Measure total seed tannins in berries at harvest $(\mathrm{mg} / \mathrm{g}$ fruit) from vines at different distances from an olive tree hedgerow.

13. Measure yield (kg/vine) from vines at different distances from an olive tree hedgerow.

14. Determine the vegetative growth from pruning weights ( $\mathrm{g} / \mathrm{m}$ cordon) of grapevines at different distances from an olive tree hedgerow.

15. Evaluate vine balance (using the Ravaz Index) of grapevines at different distances from an olive tree hedgerow.

16. Measure the quantity of $\mathrm{N}-\mathrm{NO}_{3}(\mathrm{mg} / \mathrm{kg})$ in the tissue of grapevine petioles (during the period of flowering) at different distances from an olive tree hedgerow.

17. Measure the quantity of total $\mathrm{N}$ (g/100 g dry tissue) in the tissue of grapevine leaf blades (during the period of flowering) at different distances from an olive tree hedgerow.

18. Measure the quantity of total $\mathrm{N}(\mathrm{g} / 100 \mathrm{~g}$ dry tissue) in the tissue of grapevine petioles (during the period of flowering) at different distances from an olive tree hedgerow.

19. Measure the quantity of $P$ ( $g / 100 \mathrm{~g}$ dry tissue) in the tissue of grapevine leaf blades (during the period of flowering) at different distances from an olive tree hedgerow. 
20. Measure the quantity of $\mathrm{P}(\mathrm{g} / 100 \mathrm{~g}$ dry tissue) in the tissue of grapevine petioles (during the period of flowering) at different distances from an olive tree hedgerow.

21. Measure the quantity of $\mathrm{K}(\mathrm{g} / 100 \mathrm{~g}$ dry tissue) in the tissue of grapevine leaf blades (during the period of flowering) at different distances from an olive tree hedgerow.

22. Measure the quantity of $\mathrm{K}(\mathrm{g} / 100 \mathrm{~g}$ dry tissue) in the tissue of grapevine petioles (during the period of flowering) at different distances from an olive tree hedgerow.

23. Measure the quantity of $\mathrm{Mg}(\mathrm{g} / 100 \mathrm{~g}$ dry tissue) in the tissue of grapevine leaf blades (during the period of flowering) at different distances from an olive tree hedgerow.

24. Measure the quantity of $\mathrm{Mg}(\mathrm{g} / 100 \mathrm{~g}$ dry tissue) in the tissue of grapevine petioles (during the period of flowering) at different distances from an olive tree hedgerow.

\section{VII.4. MATERIALS AND METHODS}

VII.4.1. Site

The study was performed at Catapano Family Vineyard in Maipu, Mendoza,

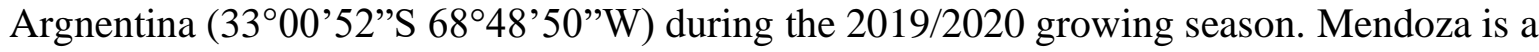
temperate, arid wine growing region in western Argentina, located at the foothills of the Andes mountain range. It is famous for its high-end red wines, particularly Malbec, and its distinct high-altitude terroir (Liberman 2014; Fushing et al. 2019). Its climate can be technically classified as Mediterranean and Continental. Maipu is a premier wine growing region within Mendoza characterized by large day-night temperature variations, with warm days during the growing season and cool nights, and with temperatures that do not typically exceed $30{ }^{\circ} \mathrm{C}$ during the growing season (Fushing et al. 2019). Maximum, minimum, and median monthly temperatures during 2018, 2019, and 2020 were taken from the Perdriel weather station at Belasco de Baquedano in Lujan de Cuyo, Argentina, which was the weather station nearest to the site (Appendix A, Table 1). Maipu is located in the foothills 
and plains region of Mendoza, with the Andes mountains to the west and the plateaus and volcanoes of La Payunia to the South. Rainfall in this region is on average $220 \mathrm{~mm}$ per year (Departamento General de Irrigación 2016). Typical soil nutrient levels in the Maipu region of Mendoza, Argentina are summarized in Appendix A, Table 2.

The site consists of 1.64 hectares of 8-year-old Malbec grapevines spaced at $1 \mathrm{~m} \mathrm{x} 2$ $\mathrm{m}$, with approximately 127 vines per row in a north-south orientation. The trellis system is single cordon vertical shoot positioned with approximately 12 spurs per cordon and a cordon length of $1 \mathrm{~m}$. To the east of the vine rows is a hedgerow of 1770 -year-old olive trees, spaced $7 \mathrm{~m}$ apart, with a mean $\mathrm{DBH}$ of $36.34 \mathrm{~cm}$. The olive tree hedgerow is separated from the first vine row by $2 \mathrm{~m}$. All vines are irrigated uniformly by drip irrigation; vines receive on average $10 \mathrm{~mm}$ per day per $\mathrm{m}^{3}$ of water. Olive trees are irrigated by flood irrigation every six days for 72 hours using a furrow to the east of the hedgerow (on the opposite side of the grapevine rows, at approximately $5 \mathrm{~m}$ from the first grape row).

During the year prior to this study, during the 2018/2019 growing season, vines were fertilized with $30 \mathrm{~kg} / \mathrm{ha}$ ammonium sulfate during the period of budbreak to bloom, $30 \mathrm{~kg} / \mathrm{ha}$ ammonium sulfate during the period of veraison to harvest, and $30 \mathrm{~kg} / \mathrm{ha}$ ammonium sulfate during the period of post-harvest. During the 2019/2020 growing season when the study was undertaken, vines were fertilized with $30 \mathrm{~kg} / \mathrm{ha}$ ammonium sulfate during the period of budbreak to bloom, $30 \mathrm{kgs} / \mathrm{ha}$ ammonium sulfate during the period of veraison to harvest, 50 kilos/ha ammonium sulfate post-harvest, and $15 \mathrm{~kg} / \mathrm{ha}$ phosphoric acid post-harvest. The soil is regularly disc harrowed to manage weeds. Deep ploughing and herbicide usage are avoided but have been used in the past. To manage powdery mildew, Copper Sulfate and Sulfur are sprayed as needed.

VII.4.2. Experimental Design 
The site was divided into five treatment blocks at varying distances from an olive tree hedgerow: $2 \mathrm{~m}$ from the hedgerow, $4 \mathrm{~m}$ from the hedgerow, $6 \mathrm{~m}$ from the hedgerow, $12 \mathrm{~m}$ from the hedgerow, and $40 \mathrm{~m}$ from the hedgerow. The spacing of blocks was determined on the basis of three assumptions: 1. Mature olive tree roots extend up to $12 \mathrm{~m}$ from their trunk, which is what other studies have observed (Kailis and Harris 2007), 2. Shade from trees at this site is cast out to $5 \mathrm{~m}$ from the hedgerow for approximately 6 hours per day, and shade from trees is cast out to $20 \mathrm{~m}$ from the hedgerow for approximately 2 hours per day. This determination was made from our observations. 3. Vines at $40 \mathrm{~m}$ from the hedgerow experience little to no influence from trees whatsoever, as neither shade nor root niche overlap nor microclimatic shifts occur at this distance.

The experiment was set up in a randomized complete block design with five treatment blocks in total. Each treatment block was divided into three equally-sized repetitions along the north-south gradient, to control for potential differences in soil and microclimate. Within each repetition, five observational units (five grapevines) were sampled. The experimental setup can be seen in Figure 20 and is summarized as follow:

- Blocks: Blocks consist of a factorial design with five treatment blocks in total: 2 $\mathrm{m}$ from hedgerow, $4 \mathrm{~m}$ from hedgerow, $6 \mathrm{~m}$ from hedgerow, $12 \mathrm{~m}$ from hedgerow, and $40 \mathrm{~m}$ from hedgerow.

○ Block 1: $2 \mathrm{~m}$ from tree row ( $1^{\text {st }}$ vine row on west side of hedgerow).

○ Block 2: $4 \mathrm{~m}$ from tree row ( $2^{\text {nd }}$ vine row on west side of hedgerow).

- Block 3: $6 \mathrm{~m}$ from tree row ( $3^{\text {rd }}$ vine row on west side of hedgerow).

○ Block 4: $12 \mathrm{~m}$ from tree row ( $6^{\text {th }}$ vine row on west side of hedgerow).

○ Block 5: $40 \mathrm{~m}$ from tree row (20 th vine row on west side of hedgerow).

- Repetitions: There were three repetitions per treatment, each equal in size (consisting of 32 vines each), divided from North to South, to control for differences in soil and microclimate across the North-South gradient.

- Observational Unit: There were five observational units per repetition (five individual vines sampled per repetition), all with similar mean trunk diameters

\section{VII.4.2.i. Background Uniformity Tests}

In order to determine that the background conditions of the site were uniform across repetitions and treatments, several tests were undergone. First, every row in the vineyard was 
walked and changes in vegetation type and quantity were looked for to determine if there might be possible underlying differences in growing conditions. No differences in vegetation were observed. Data from Google Earth was used to ensure homogeneity of the topography of the site. No differences in terrain nor slope were found; elevation was $856 \mathrm{~m}$ throughout site. Treatment rows were walked to determine that there were no leaks in the irrigation drip line, so as to ensure rough irrigation uniformity between treatments; no leaks were observed. Diameter at Breast Height of trees was taken as well, to determine that all trees had roughly the same growth and thus, uniform influence on vines (See Appendix B, Table 1). Diameter at Breast Height was measured at 4.5 feet using a DBH tape measurer. The mean DBH was $36.34 \mathrm{~cm}$ with a standard deviation of 16.52 . Out of the 17 trees, only one was found to be an outlier, suggesting an overall uniform influence of conditions among the olive trees.

To determine the composition and uniformity of the soil within the experimental site, background soil tests were performed. The site was divided into four equal transects: northwest, northeast, southwest, and southeast. Following the recommendation of previous studies (Chirko et al. 1996; Nair 2011), in each transect a randomly selected location was selected in which holes would be dug. At each hole, two soil cores were taken: one at 0-30 $\mathrm{cm}$ and one at 30-60 $\mathrm{cm}$, in accordance with the breakdown of horizons in the soil profile. Sub-samples were mixed within horizons. A total of eight samples were sent into the laboratory for testing of soil texture, $\mathrm{EC}, \mathrm{pH}, \mathrm{N}, \mathrm{P}, \mathrm{K}, \mathrm{Na}, \mathrm{Ca}, \mathrm{Mg}$, carbonates, bicarbonates, chlorides, sulfates, sodium absorption ratio, $\mathrm{OM}$, and $\mathrm{C} / \mathrm{N}$ ratio (see Appendix $\mathrm{B}$, Table 2 and 3). Analyses revealed that the dominant soil at the site was Typic Torrifluvent, a class of Entisols deposited from alluvial plains and characterized by their deep, medium-textured profiles (Abraham and Martínez 2000). Soil texture at this site was found to be loam in the northwest, southwest, and southeast sectors, and silty loam in the northeast sector (Appendix B, Table 2). Salinity levels were low to medium, and sodium levels were found to be normal. 
Soil was found to be calcareous, saturated in gypsum, and slightly alkaline, which is normal for this region. Chloride levels at the site were higher than average for this region. Nitrogen, $\mathrm{P}, \mathrm{K}$, and organic matter were all high, and there was a high $\mathrm{C} / \mathrm{N}$ ratio, suggesting good mineralization rates.

Photosynthetic photon flux density (PPFD) measurements were taken at each treatment row every hour from 8 am to $7 \mathrm{pm}$ during one day in spring in order to estimate how much shade the olive trees were casting on grapevines. Photosynthetic photon flux density was measured using the Korona light measurement application on an iPhone 7, which had a PPFD limit of $3000 \mu \mathrm{mol} / \mathrm{m}^{-2} / \mathrm{s}^{-1}$. Throughout the course of 11 hours, grapevines $2 \mathrm{~m}$ from the hedgerow were found to receive an average of $1,868.93 \mu \mathrm{mol} / \mathrm{m}^{-2} / \mathrm{s}^{-1}$, vines $4 \mathrm{~m}$ from the hedgerow received an average of $2,282.55 \mu \mathrm{mol} / \mathrm{m}^{-2} / \mathrm{s}^{-1}$, vines $6 \mathrm{~m}$ from the hedgerow received an average of $2,340.34 \mu \mathrm{mol} / \mathrm{m}^{-2} / \mathrm{s}^{-1}$, vines $12 \mathrm{~m}$ from the hedgerow received an average of $2,371.53 \mu \mathrm{mol} / \mathrm{m}^{-2} / \mathrm{s}^{-1}$, and vines $40 \mathrm{~m}$ from the hedgerow received an average of an average of $2,416.28 \mu \mathrm{mol} / \mathrm{m}^{-2} / \mathrm{s}^{-1}$ light. All of these measurements were considerably higher than the light saturation point of grapevines, which is 499 to $598.8 \mu \mathrm{mol}$ quanta $\mathrm{m}^{-2} \mathrm{~s}^{-1}$ (Kriedemann 1968). Full sunlight has a PPFD of 2,000 to 3,000 $\mu$ mol quanta $\mathrm{m}^{-2} \mathrm{~s}^{-1}$, however, under full sunlight only a grapevines' leaves which are exposed at right angles to incident light are able to absorb full PPFD, and because of canopy density and varying leaf angles within the canopy, grapevines in general absorb less PPFD in the field. A map of the light distribution from the hours of 8 am to $7 \mathrm{pm}$ on a clear day in spring can be seen in Figure 21. In general, significant reductions in light were only seen in vines within a 2 $\mathrm{m}$ distance of the olive tree hedgerow.

\section{VII.4.2.ii. Selection of Observational Units}

In addition to background uniformity checks of the site, uniformity checks of the initial vigor of each observational unit (each sampled vine) were also undergone, and outliers 
were removed from the sampling pool. First, in order to control for "edge effect," the first 13 vines on both the north and south sides of the row (vines within $13 \mathrm{~m}$ from the edge) were eliminated from the sampling pool and only the middle 96 vines within each treatment were considered for sampling.

In order to determine uniformity amongst sampling units within the same treatment block, vine diameter at a height of $40 \mathrm{~cm}$ from soil was taken for every vine within the five determined sampling blocks (a total of 480 vines) (Appendix C, Table 1). Outliers were determined by calculating the trimmed mean and the interquartile range of all vines within each block. If an outlier was detected it was eliminated from the sampling pool, and sampling units were subsequently drawn from an outlier-free sampling pool within each treatment block (Appendix C, Table 1). In general, vine diameter was mostly uniform throughout the repetitions; in the row $40 \mathrm{~m}$ from the hedgerow only four vines needed to be removed from the sampling pool, in the row $12 \mathrm{~m}$ from the hedgerow five vines were removed, in the row 6 $\mathrm{m}$ from the hedgerow three vines were removed, in the row $4 \mathrm{~m}$ from the hedgerow two vines were removed, and in the row $2 \mathrm{~m}$ from the hedgerow six vines were removed.

A random number generator was used to select five observational units (five individual vines) within each repetition. In the random generator, the following information was entered. Each treatment had a total of 96 vines, and each repetition had a total of 32 vines; therefore, a number range of 1-32 was entered. This process was repeated three times per treatment for a total of 15 times. If a vine that was an outlier was selected, it was discarded and another randomly selected vine was chosen. The diameters of these five randomly selected vines were then again compared between repetitions, within treatments, to ensure that all vines within a given treatment had no statistically significant differences between trunk diameter. Final selected observational units can be seen in Appendix C, Table 2. 


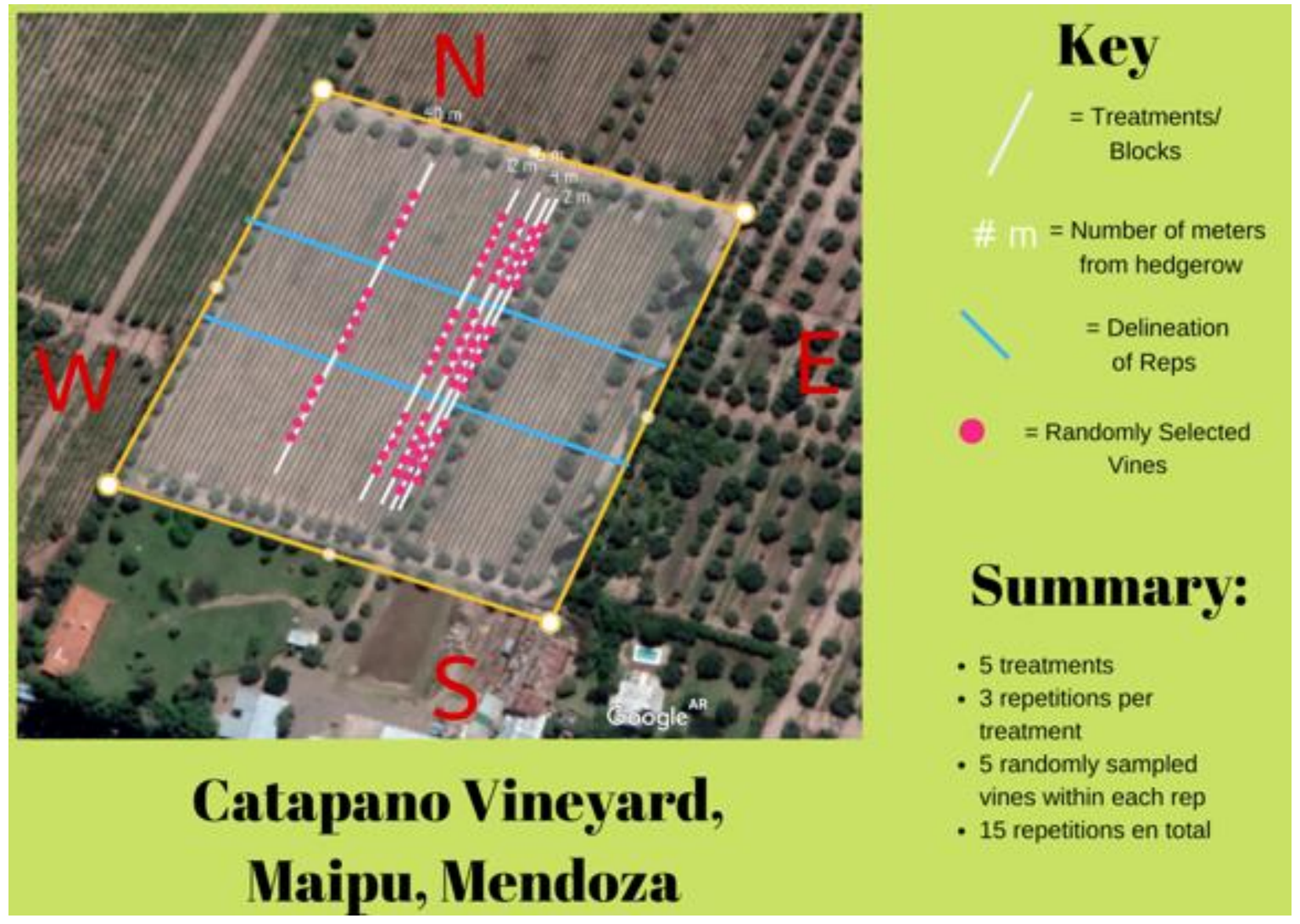

Figure 20. Experimental design setup of Catapano Vineyard, with five treatment blocks at five distances from an olive tree hedgerow. Within each treatment block there were three repetitions, and within each repetition, five vines with uniform trunk diameters were selected at random for sampling. 


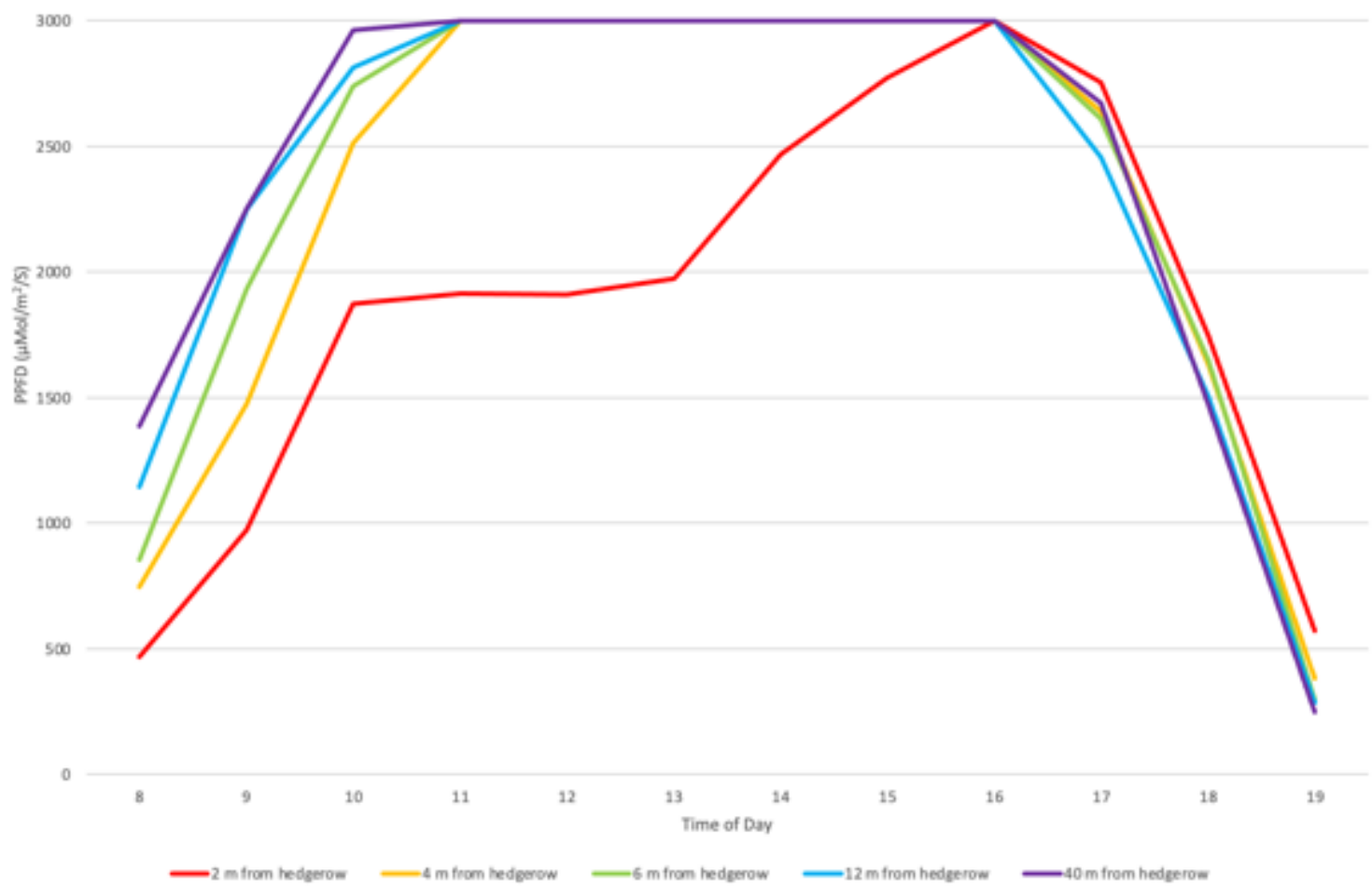

Figure 21. Average photosynthetic photon flux density measurements $\left(\mu \mathrm{Mol} / \mathrm{m}^{2} / \mathrm{S}\right)$ in grapevine rows at $2 \mathrm{~m}, 4 \mathrm{~m}, 6 \mathrm{~m}, 12 \mathrm{~m}$, and $40 \mathrm{~m}$ from an olive tree hedgerow from the hours of 8 am to $7 \mathrm{pm}$ on a clear spring day in Mendoza, Argentina.

\section{VII.4.3. Data Collection}

Various variables were collected and measured in order to determine the effect of olive tree hedgerows on three broad parameter categories: must quality parameters, grapevine growth parameters, and production parameters. Then, in order to investigate the causes of variation in the aforementioned parameters, a tissue nutritional analysis was undergone, to determine if competition for nutrients between olive trees and grapevines contributed to the variation observed. The following data was taken.

\section{VII.4.3.i. Quality Parameters}

To measure quality parameters, grapes were harvested when the winemaker determined them to be ripe, on March 13, 2020. 500 berries were randomly sampled from each repetition; this was done by randomly sampling 100 berries from each of the five 
observational units (sampled vines) in the repetition. Berries were sampled from different parts of clusters: top, bottom, middle, and from both sides of each cluster. From this sample of 500 berries a clean extraction was performed in the Pedology Laboratory at the College of Agricultural Sciences to produce grape must. $100 \mathrm{~mL}$ samples of the must were sent to MAG S.R.L. Laboratory, in Mendoza, Argentina, where levels of Glucose + Fructose (g/L), ${ }^{\circ}$ Brix, density (g/L) TA (g/L), pH, Malic Acid (g/L), and YAN (mg/L) were measured. An additional $100 \mathrm{~mL}$ of must was sent to the laboratory of the National Institute for Agricultural Technology (INTA) in Lujan de Cuyo, Argentina, where a panel of total skin phenolics, total skin anthocyanins, total skin tannins, total seed phenolics, and total seed tannins was performed. Raw data can be seen in Appendix D, Table 1 and 2, and documentation of the analysis process can be seen in Appendix D, Figure 1.

\section{VII.4.3.ii. Vine Growth Parameters}

The effect of olive tree hedgerows on vine vigor was analyzed by measuring pruning weights $\left(\mathrm{g} \mathrm{m}^{-1}\right)$, which is a common measurement of vine vigor. During the pruning season when vines were dormant, on June 22, 2020, vines were spur pruned by hand and all pruned canes were collected and weighed using an electronic scale. Because each vine cordon was exactly one $\mathrm{m}$ in length, the pruning mass per vine was equivalent to the standard pruning weights metric of pruning mass per linear meter of canopy (Smart et al. 1990).

Vine balance was calculated by comparing yield to pruning weight using the Ravaz Index, which is the most common and widely accepted method for calculating vine balance (Skinkis and Vance 2013). The Ravaz Index is calculated by dividing yield by pruning weight; a detailed formula is outlined in Appendix D, Table 5. Well-balanced vines are indicated by Ravaz Index values between 300 and $600 \mathrm{~g} \mathrm{~m}^{-1}$ (Smart et al. 1990). Results can be seen in Appendix D, Table 3. 


\section{VII.4.3.iii. Production Parameters}

The effect of olive tree hedgerows on grape yield was analyzed by measuring the total yield in kg of all clusters per vine at harvest on March 13, 2020. Vines were harvested clean, and the weight of all clusters per vine was taken using an electronic scale. Raw data can be seen in Appendix D, Table 3, and documentation of the measurement process can be seen in Appendix D, Figure 2.

\section{VII.4.3.iv. Vine Nutritional Parameters}

To determine vine nutrient status, petiole and leaf blade samples were taken in accordance with the internationally accepted viticultural tissue sampling standards (Wolf 2008). Petiole analyses are widely considered to be the most accurate and objective method for measuring grapevine nutrition status, as they measure the actual amounts of nutrients absorbed by grapevines, rather than simply the amount of nutrients that are in the soil (Robinson 1992). Samples were taken at peak bloom (80\% flowering) on November 11, 2019, and on November 2, 2020. At each of the five observational units within each repetition (at each sampled vine) 12 petioles and 12 leaf blades were sampled, for a total of 60 petioles and 60 leaf blades per repetition. Samples were taken near the base of the shoot, opposite inflorescences. Leaves were separated from petioles manually and were delivered to the laboratory for analysis. In 2019 foliar tissue was taken to the Pedology Laboratory at the College of Agricultural Sciences, in Lujan de Cuyo, Argentina, and in 2020, tissue was taken to Agroas Laboratory in Mendoza, Argentina. Tissue was washed with deionized water, dried at $55^{\circ} \mathrm{C}$ for 24 hours, and then analyzed for $\mathrm{N}, \mathrm{N}-\mathrm{NO}_{3}, \mathrm{P}, \mathrm{K}$, and $\mathrm{Mg}$ levels. Nitrate levels were analyzed using the Micro-Kjeldalh method and Bremner-Keeney method, total $\mathrm{N}$ was analyzed using the Macro Kjeldalh method, $\mathrm{Mg}$ was determined using Complexometric Titration with EDTA, P was measured using colorimetric estimation by the nitro-vanadomolybdic method of Mission, and $\mathrm{K}$ was measured by a flame photometer through the 
process of hydrochloric acid extraction. Data from 2019 can be seen in Appendix D. Table 4. Typical levels of petiole and leaf blade macro and micronutrients for the region of Maipu, Mendoza, Argentina can be seen in Appendix E.

\section{VII.5. DATA ANALYSIS}

Two different statistical analyses were undergone in this experiment. In order to determine if distance of grapevines from an olive tree hedgerow had an effect on grape must quality parameters and nutritional parameters, a randomized complete block design one-way analysis of variance was undergone using SAS software and the GLM procedure (see Appendix F). For the analyses of these parameters, vines were classified into five treatment groups: $2 \mathrm{~m}$ from hedgerow $(\mathrm{n}=3), 4 \mathrm{~m}$ from hedgerow $(\mathrm{n}=3), 6 \mathrm{~m}$ from hedgerow $(\mathrm{n}=3)$, $12 \mathrm{~m}$ from hedgerow $(\mathrm{n}=3)$ and $40 \mathrm{~m}$ from hedgerow $(\mathrm{n}=3)$.

In order to determine if distance of grapevines from an olive tree hedgerow had an effect on production and growth parameters, a repeated randomized complete block design one-way analysis of variance was undergone using SAS software and the glimmix procedure (see Appendix G). For production and growth parameters, vines were classified into five groups: $2 \mathrm{~m}$ from hedgerow $(n=15), 4 \mathrm{~m}$ from hedgerow $(n=15), 6 \mathrm{~m}$ from hedgerow $(n=$ 15), $12 \mathrm{~m}$ from hedgerow $(n=15)$ and $40 \mathrm{~m}$ from hedgerow $(n=15)$.

For both the randomized complete block design and the repeated randomized complete block design, each treatment group was broken into three blocks, from north to south. Upon analysis, the blocks did not affect results for the majority of variables; all $\mathrm{p}$ values were greater than .05 for all variables except for leaf blade K $(\mathrm{p}=.0146)$. For post-hoc analyses, Fisher's Least Significant Differences multiple comparison procedure was selected due to its liberalism, given the pioneer nature of this study. Results from the one-way 
ANOVA can be summarized in Tables 7,8 , and 9. For all results, data is presented as mean \pm model standard error.

Table 7. Quality parameters in grape must at different distances from an olive tree hedgerow. Variables with significant differences between treatment are designated by an asterisk.

\begin{tabular}{|c|c|c|c|c|c|c|}
\hline Variable & $\begin{array}{c}\text { Num } \\
\text { DF }\end{array}$ & $\begin{array}{c}\text { Den } \\
\text { DF }\end{array}$ & SS & MS & F Value & $\boldsymbol{p}$ \\
\hline Glucose/fructose* & 4 & 10 & 1534.02 & 383.51 & 10.31 & 0.0030 \\
\hline Brix* & 4 & 10 & 11.27 & 2.82 & 9.61 & 0.0038 \\
\hline Density* & 4 & 10 & 0.00 & 0.00 & 10.02 & 0.0033 \\
\hline Total acidity* & 4 & 10 & 0.38 & 0.09 & 8.41 & 0.0058 \\
\hline $\begin{array}{c}\text { Total berry skin } \\
\text { tannins* }\end{array}$ & 4 & 10 & 0.12 & 0.03 & 4.85 & 0.0279 \\
\hline \hline pH & 4 & 10 & 0.08 & 0.02 & 2.47 & 0.1287 \\
\hline Malic acid & 4 & 10 & 0.10 & 0.03 & 1.15 & 0.4007 \\
\hline $\begin{array}{c}\text { Yeast assimilable } \\
\text { nitrogen }\end{array}$ & 4 & 10 & 1144.23 & 286.06 & 0.46 & 0.7629 \\
\hline $\begin{array}{c}\text { Total berry skin } \\
\text { phenolics }\end{array}$ & 4 & 10 & 0.17 & 0.04 & 0.20 & 0.9332 \\
\hline $\begin{array}{c}\text { Total berry skin } \\
\text { anthocyanins }\end{array}$ & 4 & 10 & 0.32 & 0.08 & 2.74 & 0.1047 \\
\hline $\begin{array}{c}\text { Total seed } \\
\text { phenolics }\end{array}$ & 4 & 10 & 0.88 & 0.22 & 1.18 & 0.3882 \\
\hline Total seed tannins & 4 & 10 & 0.54 & 0.14 & 1.66 & 0.2503 \\
\hline
\end{tabular}

Table 8. Grapevine production and growth parameters for the 2019/2020 growing seasons. Variables with significant differences between treatment are designated by an asterisk.

\begin{tabular}{|c|c|c|c|c|}
\hline Variable & Num DF & Den DF & F Value & $\boldsymbol{p}$ \\
\hline $\begin{array}{c}\text { Vine yield } \\
(\mathrm{kg})^{*}\end{array}$ & 4 & 68 & 6.60 & 0.0002 \\
\hline $\begin{array}{c}\text { Pruning } \\
\text { weights* }\end{array}$ & 4 & 68 & 4.12 & 0.0048 \\
\hline Ravaz index & 4 & 68 & 1.06 & 0.381 \\
\hline
\end{tabular}


Table 9. Grapevine nutritional parameters from tissue samples taken at bloom in November 2019. Variables with significant differences between treatment are designated by an asterisk.

\begin{tabular}{|c|c|c|c|c|c|c|}
\hline Variable & $\begin{array}{c}\text { Num } \\
\text { DF }\end{array}$ & Den DF & SS & MS & F Value & $p$ \\
\hline $\begin{array}{c}\text { Leaf Blade } \\
\text { K}^{*}\end{array}$ & 4 & 10 & 0.319 & 0.079 & 30.23 & $<.0001$ \\
\hline $\begin{array}{c}\text { Petiole N- } \\
\text { NO3 }\end{array}$ & 4 & 10 & 5540.40 & 1385.100 & 1.51 & 0.287 \\
\hline $\begin{array}{c}\text { Leaf Blade } \\
\text { Total N }\end{array}$ & 4 & 10 & 0.55 & 0.137 & 2.23 & 0.155 \\
\hline $\begin{array}{c}\text { Petiole Total } \\
\text { N }\end{array}$ & 4 & 10 & 0.03 & 0.007 & 0.73 & 0.595 \\
\hline $\begin{array}{c}\text { Leaf Blade } \\
\text { Total P }\end{array}$ & 4 & 10 & 0.03 & 0.008 & 0.88 & 0.5165 \\
\hline Petiole P & 4 & 10 & 0.02 & 0.006 & 3.54 & 0.0603 \\
\hline Petiole K & 4 & 10 & 0.44 & 0.110 & 1.25 & 0.3636 \\
\hline $\begin{array}{c}\text { Leaf Blade } \\
\text { Mg }\end{array}$ & 4 & 10 & 0.21 & 0.052 & 1.48 & 0.295 \\
\hline Petiole Mg & 4 & 10 & 0.24 & 0.061 & 0.77 & 0.575 \\
\hline
\end{tabular}

\section{VII.6. RESULTS}

\section{VII.6.1. Quality Parameter Results}

\section{VII.6.1.i. Glucose/Fructose}

Glucose/fructose $(\mathrm{g} / \mathrm{L})$ is a common metric for measuring the amount of sugar in grape must and indicates the alcohol content that wine will have post-fermentation (Kemp et al. 2019). The data for glucose/fructose levels in this experiment satisfied the assumptions of the one-way ANOVA. Residuals for sugar content, measured in glucose/fructose levels in grape must $(\mathrm{g} / \mathrm{L})$, were normally distributed for all groups, as assessed by the Shapiro-Wilk's test $(p=0.928)$. There were no outliers in the data, as assessed by inspection of a boxplot. No differences were found between repetitions to indicate a blocking effect ( $p=0.7032)$.

A strong association between distance and glucose/fructose levels was found; the oneway ANOVA revealed that the relationship between distance of vine from hedgerow and glucose/fructose levels was significant, $F(4,10)=10.31, p=.003$ (see Table 7).

Glucose/fructose levels in grape must at harvest $(\mathrm{g} / \mathrm{L})$ were lowest in vines farthest from the 
hedgerow and increased linearly as vine proximity to trees increased (See Figure 22), from vines $40 \mathrm{~m}$ from the hedgerow $(234.94 \mathrm{~g} / \mathrm{L} \pm 3.52)$ to $12 \mathrm{~m}$ from the hedgerow $(247.05 \mathrm{~g} / \mathrm{L} \pm$ 3.52), to $6 \mathrm{~m}$ from the hedgerow $(253.73 \mathrm{~g} / \mathrm{L} \pm 3.52)$, to $4 \mathrm{~m}$ from the hedgerow $(259.72 \mathrm{~g} / \mathrm{L}$ $\pm 3.52)$, to $2 \mathrm{~m}$ from the hedgerow $(\mathrm{M}=263.56 \mathrm{~g} / \mathrm{L} \pm 3.52)$. Fisher's LSD post hoc analyses revealed that mean glucose/fructose levels $(\mathrm{g} / \mathrm{L})$ were significantly lower in vines $40 \mathrm{~m}$ from the hedgerow as compared to all other rows $(\mathrm{p}<.05)$ (See Table 10 and Figure 22). From 40 $\mathrm{m}$ from the hedgerow to $2 \mathrm{~m}$ from the hedgerow, glucose/fructose levels went up $12.18 \%$, which is a consequential increase when making wine.

Vines $2 \mathrm{~m}$ from the hedgerow did not have glucose/fructose levels significantly different from vines $4 \mathrm{~m}$ from the hedgerow or $6 \mathrm{~m}$ from the hedgerow, but at a distance of $12 \mathrm{~m}$ from the hedgerow, glucose/fructose levels began decreasing significantly. (See Table 10 and Figure 22). These results suggest that trees may have a favorable effect on glucose/fructose levels in grapevines up to at least $6 \mathrm{~m}$ from a hedgerow. Higher levels of glucose/fructose in wine grapes at harvest often corresponds to higher quality wine, especially when in tandem with balanced levels of aromatics and acidity (Boulton et al. 1999). Therefore, these results suggest that trees could play a role in the cultivation of higher quality grapes, and ultimately, higher quality wine. Further studies should be undergone to better ascertain up to which distance olive trees have a favorable effect on glucose/fructose levels.

Table 10. Fisher's Least Squares Means post-hoc analyses at 0.05 significance level for glucose/fructose levels $(\mathrm{g} / \mathrm{L})$ in must from grapevines at different distances from an olive tree hedgerow. Significant differences are indicated by an asterisk.

\begin{tabular}{|c|c|c|c|c|c|}
\hline \multicolumn{7}{|c|}{ Post Hoc Least Squares Means for Effect Distance } \\
\hline Distance (m) & $\mathbf{2}$ & $\mathbf{4}$ & $\mathbf{6}$ & $\mathbf{1 2}$ & $\mathbf{4 0}$ \\
\hline $\mathbf{2}$ & & 0.4629 & 0.0841 & $0.0106^{*}$ & $0.0004^{*}$ \\
\hline $\mathbf{4}$ & 0.4629 & & $0.02640^{*}$ & $0.0345^{*}$ & $0.0011^{*}$ \\
\hline $\mathbf{6}$ & 0.0841 & 0.2640 & & 0.2165 & $0.0054^{*}$ \\
\hline $\mathbf{1 2}$ & $0.0106^{*}$ & $0.0345^{*}$ & 0.2165 & & $0.0412^{*}$ \\
\hline $\mathbf{4 0}$ & $0.0004^{*}$ & $0.0011^{*}$ & $0.0054^{*}$ & $0.0412^{*}$ & \\
\hline
\end{tabular}




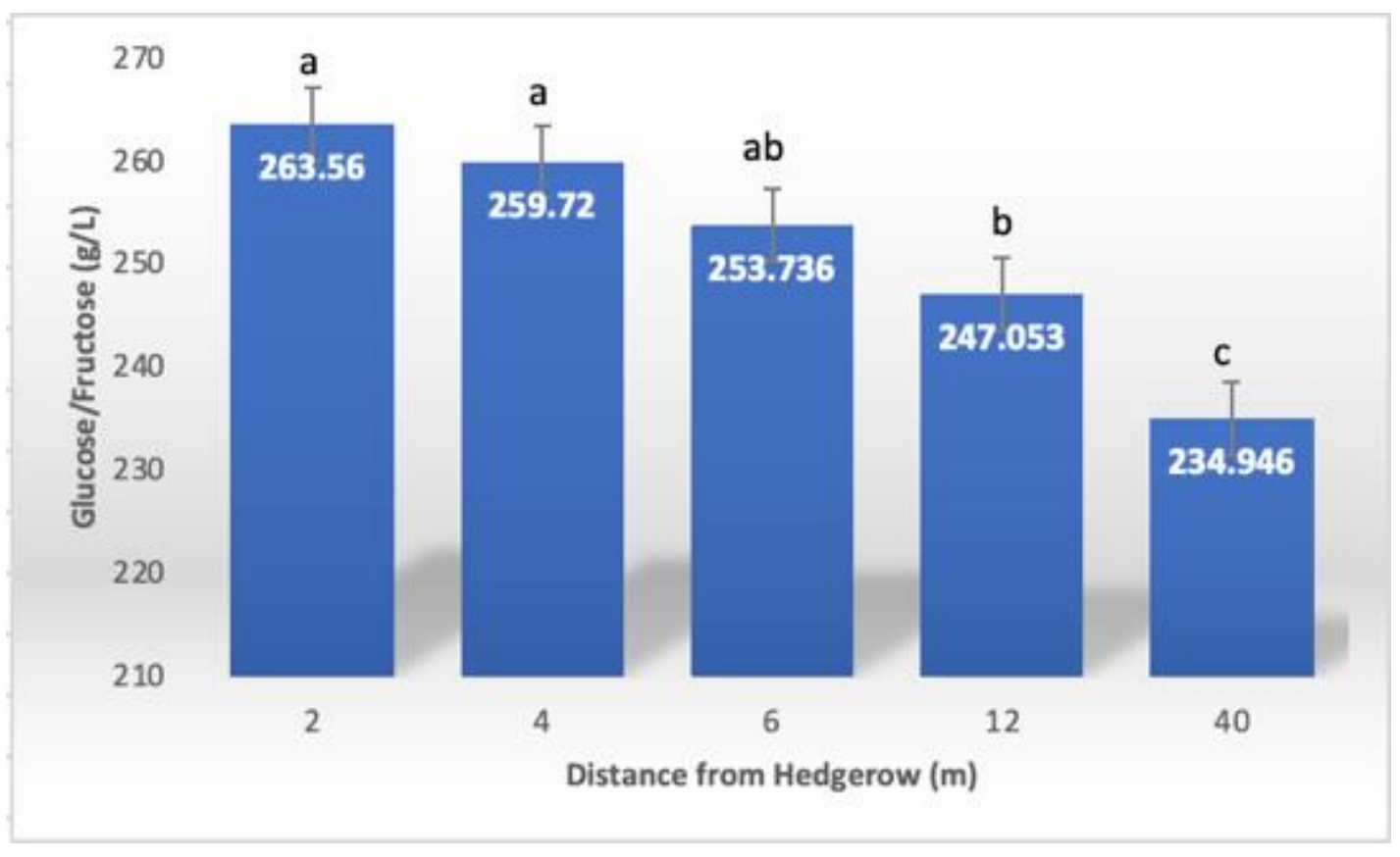

Figure 22. The relationship between distance from an olive tree hedgerow and glucose/fructose levels in grape must at harvest in 8-year-old Malbec grapevines in Mendoza Argentina, 2020.

VII.6.1.ii. Brix

Soluble solid levels (sugar levels) are measured in degrees Brix (Kemp et al. 2019). In general, SS levels range from $18.0-22.5^{\circ}$ Brix for dry white wine, $21.5-24.5^{\circ}$ Brix for fruity white wine, 18.0-23.0 ${ }^{\circ}$ Brix for dry red wine, and 23.0-26.0 ${ }^{\circ}$ Brix for full-bodied red wine (Considine and Frankish 2014). Soluble solid content in the higher range is usually considered more desirable, although it is undesirable if a high SS content is reached too quickly, before other flavors, acids, and tannins have the chance to develop (Kliewer and Smart 1989; Comuzzo and Battistutta 2019). Brix are highly correlated with glucose/fructose levels, as brix are a measure of sucrose levels, and sucrose is a molecule composed of both glucose and fructose molecules (Kimball, 1991).

Data for brix levels in this experiment satisfied the assumptions of the one-way ANOVA; residuals for brix levels in grape must were normally distributed for all groups, as 
assessed by Shapiro-Wilk's test ( $p=0.943$ ), and there were no outliers in the data, as assessed by inspection of a boxplot. No differences were found between repetitions to indicate any blocking effect $(p=0.618)$.

The ANOVA revealed that the relationship between distance of vine from hedgerow and brix levels was significant, $F(4,10)=9.61, p=.0038$ (see Table 7). Parallel to the results for glucose/fructose levels, brix levels were lowest in vines farthest from the olive tree hedgerow and increased linearly as proximity to the hedgerow increased. Brix levels increased from vines $40 \mathrm{~m}$ from the hedgerow $(23.133 \pm 0.31)$, to vines $12 \mathrm{~m}$ from the hedgerow $(24.167 \pm 0.31)$, to vines $6 \mathrm{~m}$ from the hedgerow $(24.867 \pm 0.31)$, to vines $4 \mathrm{~m}$ from the hedgerow $(25.333 \pm 0.31)$, to vines $2 \mathrm{~m}$ from the hedgerow $(M=25.500 \pm 0.31)$. Fisher's LSD post hoc analyses revealed that brix levels in vines $40 \mathrm{~m}$ from the hedgerow were significantly lower as compared to vines at all other distances from the hedgerow $(p<$ .05 for all treatments; see Figure 23). Brix levels at $40 \mathrm{~m}$ from the hedgerow were $9.4 \%$ lower than brix levels at $2 \mathrm{~m}$ from the hedgerow, were $8.6 \%$ lower than brix levels at $4 \mathrm{~m}$ from the hedgerow, and were $7 \%$ lower than brix levels at $6 \mathrm{~m}$ from the hedgerow. Brix levels in vines $2 \mathrm{~m}$ from the hedgerow were not significantly different from vines $4 \mathrm{~m}$ from the hedgerow nor vines $6 \mathrm{~m}$ from the hedgerow, however, at $12 \mathrm{~m}$ from the hedgerow, brix levels were significantly lower (See Figure 23 and Table 11). These finding suggest that trees may increase brix levels up to at least $6 \mathrm{~m}$ from a hedgerow.

Higher brix levels, like glucose/fructose levels, often indicate higher quality wine, especially when higher levels of brix are paired with equally balanced levels of acidity and aromatics. Therefore, these results indicate that proximity to trees may impart favorable effects on brix levels in grape must at harvest. Further studies should be undergone to determine precisely up to which distance from a hedgerow brix levels may be positively influenced by trees. 
Table 11. Fisher's Least Squares Means post-hoc analyses at 0.05 significance level for brix levels in must from grapevines at different distances from an olive tree hedgerow. Significant differences are indicated by an asterisk.

\begin{tabular}{|c|c|c|c|c|c|}
\hline \multicolumn{7}{|c|}{ Post Hoc Least Squares Means for Effect Distance } \\
\hline Distance (m) & $\mathbf{2}$ & $\mathbf{4}$ & $\mathbf{6}$ & $\mathbf{1 2}$ & $\mathbf{4 0}$ \\
\hline $\mathbf{2}$ & & 0.7161 & 0.1900 & $0.0167^{*}$ & $0.0007^{*}$ \\
\hline $\mathbf{4}$ & 0.7161 & & 0.3221 & $0.0298^{*}$ & $0.0011^{*}$ \\
\hline $\mathbf{6}$ & 0.1900 & 0.3221 & & 0.1521 & $0.0044^{*}$ \\
\hline $\mathbf{1 2}$ & 0.0167 & $0.0298^{*}$ & 0.1521 & & $0.0477^{*}$ \\
\hline $\mathbf{4 0}$ & $0.0007^{*}$ & $0.0011^{*}$ & $0.0044^{*}$ & $0.0477^{*}$ & \\
\hline
\end{tabular}

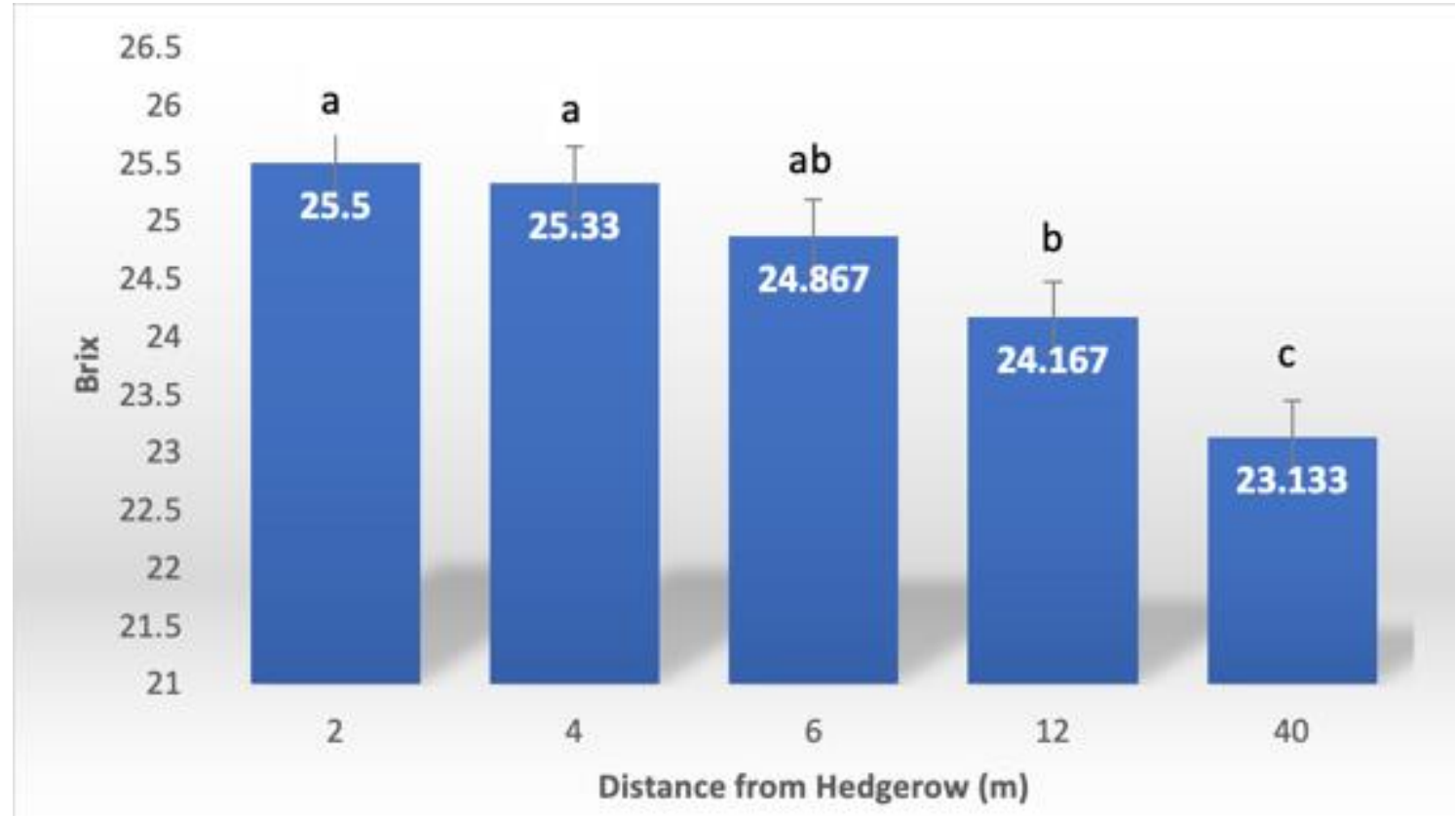

Figure 23. The relationship between distance from an olive tree hedgerow and brix levels in grape must at harvest in 8-year-old Malbec grapevines in Mendoza Argentina, 2020.

\section{VII.6.1.iii. Density}

Residuals for density of grape must (g/L) were normally distributed for all groups, as assessed by the Shapiro-Wilk's test $(p=0.943)$. There were no outliers in the data, as assessed by inspection of a boxplot. No differences were found between repetitions to indicate a blocking effect $(p=0.7941)$. The ANOVA revealed that the relationship between 
distance of vine from hedgerow and must density was significant, $F(4,10)=10.02, p=.0033$ (see Table 7).

Density is an indicator of ripeness and of sugar content. When temperature is held constant, density of grape must is largely affected by soluble solid (brix) levels, with high levels of soluble solids, especially glucose and fructose, resulting in higher density ratings (Zuritz et al. 2005). It therefore is no surprise that, just as brix levels and glucose/fructose levels increased as vine proximity to the olive tree hedgerow increased, so did density levels (g/L). Mean density increased linearly as vine proximity to the hedgerow increased, from 40 $\mathrm{m}$ from the hedgerow $(1.090 \pm 0.001)$ to $12 \mathrm{~m}$ from the hedgerow $(1.104 \pm 0.001)$, to $6 \mathrm{~m}$ from the hedgerow $(1.107 \pm 0.001)$, to $4 \mathrm{~m}$ from the hedgerow $(1.109 \pm 0.001)$, to $2 \mathrm{~m}$ from the hedgerow $(1.110 \pm 0.001)$ (see Table 12 and Figure 24). Fisher's LSD post hoc analyses revealed that density was significantly lower in vines $40 \mathrm{~m}$ from the hedgerow as compared to vines at all other distances from the hedgerow $(p<.05)$. However, even though there were significant differences, these differences may be negligible in the context of real world applications; density levels at $40 \mathrm{~m}$ from the hedgerow were only $0.9 \%$ lower than density levels at $2 \mathrm{~m}$ from the hedgerow.

Density levels in vines $2 \mathrm{~m}$ from the hedgerow did not differ significantly from vines $4 \mathrm{~m}$ from the hedgerow nor vines $6 \mathrm{~m}$ from the hedgerow, but they began to decrease significantly at $12 \mathrm{~m}$ from the hedgerow (see Table 12). More studies are needed to determine the optimal distance from a hedgerow for ideal density levels, but these data appear to suggest that trees impart a positive effect on grape must density levels, albeit small, at least up to $6 \mathrm{~m}$ from the hedgerow. 
Table 12. Fisher's Least Squares Means post-hoc analyses at 0.05 significance level for density levels in must $(\mathrm{g} / \mathrm{L})$ from grapevines at different distances from an olive tree hedgerow. Significant differences are indicated by an asterisk.

\begin{tabular}{|c|c|c|c|c|c|}
\hline \multicolumn{7}{|c|}{ Post Hoc Least Squares Means for Effect Distance } \\
\hline Distance $(\mathrm{m})$ & $\mathbf{2}$ & $\mathbf{4}$ & $\mathbf{6}$ & $\mathbf{1 2}$ & $\mathbf{4 0}$ \\
\hline $\mathbf{2}$ & & 0.6277 & 0.1688 & $0.0164^{*}$ & $0.0005^{*}$ \\
\hline $\mathbf{4}$ & 0.6277 & & 0.3428 & $0.0357^{*}$ & $0.0010^{*}$ \\
\hline $\mathbf{6}$ & 0.1688 & 0.3428 & & 0.1688 & $0.0038^{*}$ \\
\hline $\mathbf{1 2}$ & 0.0164 & $0.0357^{*}$ & 0.1688 & & $0.0357^{*}$ \\
\hline $\mathbf{4 0}$ & $0.0005^{*}$ & $0.0010^{*}$ & $0.0038^{*}$ & $0.0357^{*}$ & \\
\hline
\end{tabular}

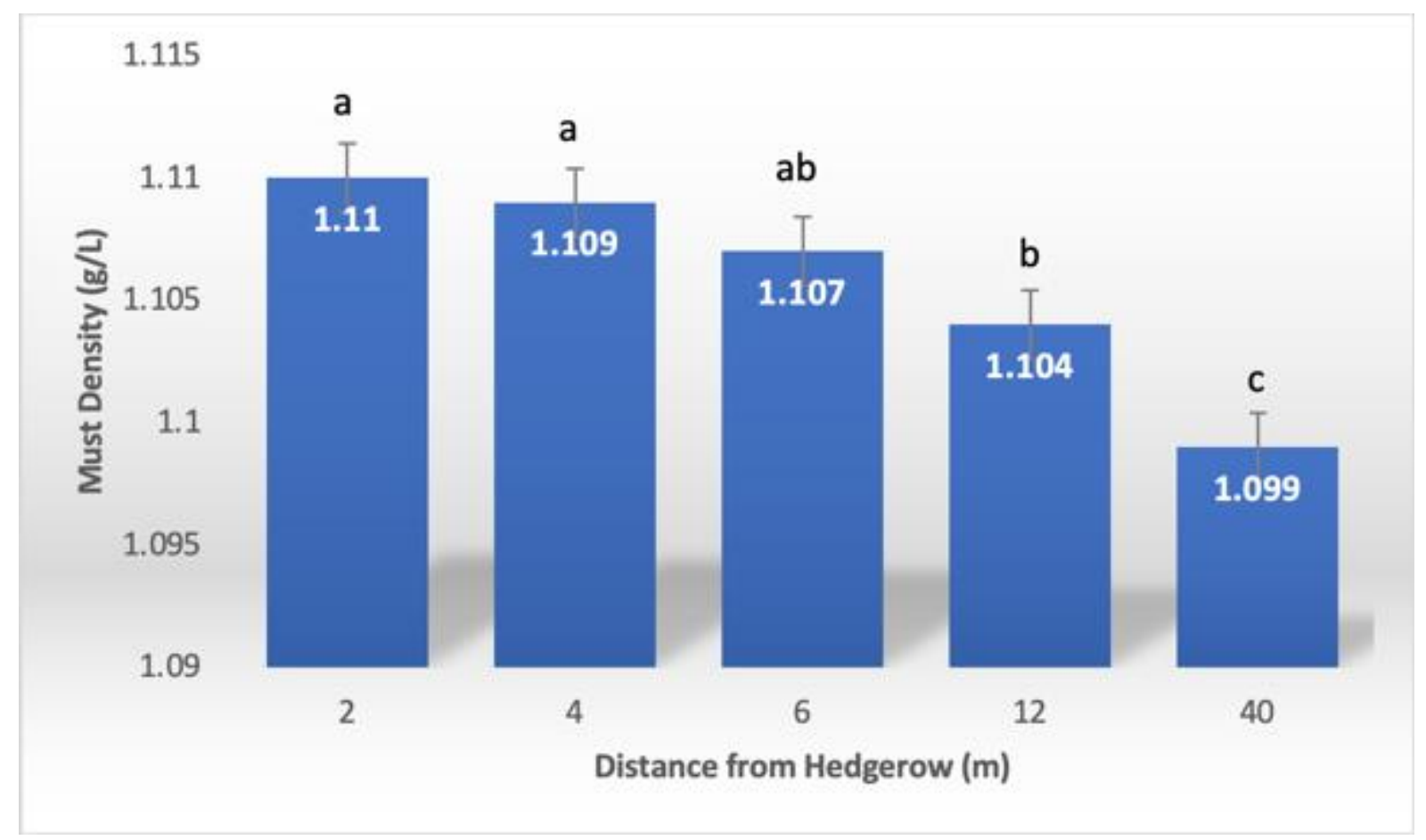

Figure 24. The relationship between distance from an olive tree hedgerow and density levels of grape must at harvest in 8-year-old Malbec grapevines in Mendoza Argentina, 2020.

\section{VII.6.1.iv. Total Acidity}

Total acidity (TA) is "the equivalence of the acid anions as measured by spectrophotometric or chromatographic methods" and is the sum of the total amounts of acid in must or wine: mainly malic, tartaric, and citric acids (Boulton 1980; Sadler and Murphy 2010), however, it is typically measured by measuring tartaric acid alone. Total acidity values 
are nearly the same as Titratable acidity values, and thus, the terms are often used interchangeably, but Titratable acidity is technically defined as "the number of protons recovered during a titration with a strong base to a specified endpoint" (Boulton 1980). Total acidity levels range from 4.5 to $10 \mathrm{~g} \mathrm{~L}^{-1}$ but in general, TA levels of around $6 \mathrm{~g} / \mathrm{L}$ are desirable in a balanced wine (Ferreira and Mendes-Faia 2020). Total acidity is an important quality component of wine, and it also is a major factor in the stability of a wine over time. High quality wines are generally characterized by a balance of high sugar and high acid (Boulton et al. 1999).

In this study the data for TA satisfied the assumptions of the one-way ANOVA. Residuals for TA levels (g/L) in grape must were normally distributed for all groups, as assessed by Shapiro-Wilk's test $(p=0.973)$. There were no outliers in the data, as assessed by inspection of a boxplot. No differences were found between repetitions to indicate a blocking effect $(p=0.1629)$. The ANOVA revealed that the relationship between distance of vine from hedgerow and TA was significant, $F(4,10)=8.41, p=.0058$.

Fisher's LSD post hoc analyses revealed that TA was significantly higher in vines 2 $\mathrm{m}$ from the hedgerow $(2.17 \mathrm{~g} / \mathrm{L} \pm 0.061)$, as compared to vines $4 \mathrm{~m}$ from the hedgerow $(1.87$ $\mathrm{g} / \mathrm{L} \pm 0.061), 6 \mathrm{~m}$ from the hedgerow $(1.76 \mathrm{~g} / \mathrm{L} \pm 0.061), 12 \mathrm{~m}$ from the hedgerow $(1.80 \mathrm{~g} / \mathrm{L}$ $\pm 0.061)$, and $40 \mathrm{~m}$ from the hedgerow (1.75 $\mathrm{g} / \mathrm{L} \pm 0.061)$ (see Table 13 and Figure 25). This translates to a $24.3 \%$ increase in TA in vines at $2 \mathrm{~m}$ from the hedgerow as compared to at 40 $\mathrm{m}$ from the hedgerow, which, practically speaking, is a consequential increase when considering wine quality. No other significant differences in TA were observed at any other distances from the hedgerow, indicating that trees may not influence TA levels beyond $2 \mathrm{~m}$ from the hedgerow. 
Table 13. Fisher's Least Squares Means post-hoc analyses at 0.05 significance level for total acidity levels $(\mathrm{g} / \mathrm{L})$ in must from grapevines at different distances from an olive tree hedgerow. Significant differences are indicated by an asterisk.

\begin{tabular}{|c|c|c|c|c|c|}
\hline \multicolumn{7}{|c|}{ Post Hoc Least Squares Means for Effect Distance } \\
\hline Distance (m) & $\mathbf{2}$ & $\mathbf{4}$ & $\mathbf{6}$ & $\mathbf{1 2}$ & $\mathbf{4 0}$ \\
\hline $\mathbf{2}$ & & $0.0076^{*}$ & $0.0013^{*}$ & $0.0025^{*}$ & $0.0012^{*}$ \\
\hline $\mathbf{4}$ & $0.0076^{*}$ & & 0.2271 & 0.4424 & 0.2034 \\
\hline $\mathbf{6}$ & $0.0013^{*}$ & 0.2271 & & 0.6304 & 0.9405 \\
\hline $\mathbf{1 2}$ & $0.0025^{*}$ & 0.4424 & 0.6304 & & 0.5797 \\
\hline $\mathbf{4 0}$ & $0.0012^{*}$ & 0.2034 & 0.9405 & 0.5797 & \\
\hline
\end{tabular}

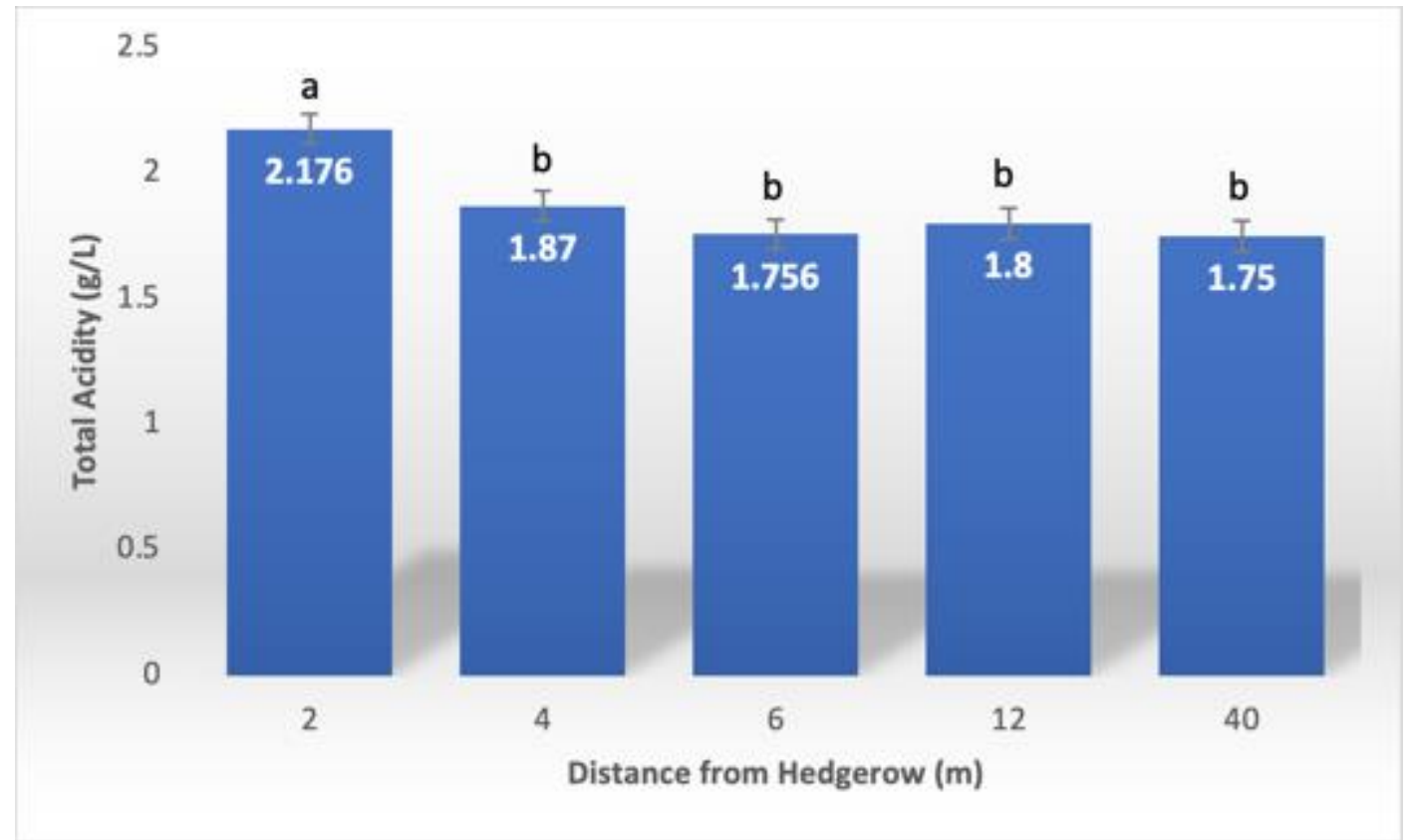

Figure 25. The relationship between distance from an olive tree hedgerow and total acidity levels in grape must at harvest in 8-year-old Malbec grapevines in Mendoza Argentina, 2020.

VII.6.1.v. pH

The $\mathrm{pH}$ of grape must determines its chemical stability, its conducivity to fermentation, and the types of microorganisms that are present in the winemaking process (Comuzzo and Battistutta 2019). It balances sulfur dioxide content in wine, determines the stability of anthocyanins and thus color, and affects flavor (Comuzzo and Battistutta 2019). In general, a must $\mathrm{pH}$ of between 3.3 and 3.8 is considered ideal, with lower $\mathrm{pH}$ levels within 
this range typically corresponding to higher quality (Kliewer and Smart 1989; Kodur 2011; Commuzo and Battistutta 2019). Total acidity and $\mathrm{pH}$ are inversely related.

In this experiment the data for $\mathrm{pH}$ satisfied the assumptions of the one-way ANOVA. Residuals for $\mathrm{pH}$ in grape must were normally distributed for all groups, as assessed by Shapiro-Wilk's test $(p=0.987)$. There were no outliers in the data, as assessed by inspection of a boxplot. No differences were found between repetitions to indicate a blocking effect $(p=$ 0.7397). The ANOVA revealed that the relationship between distance of vine from hedgerow and $\mathrm{pH}$ was not significant, $F(4,10)=2.47, p=.128$.

\section{VII.6.1.vi. Malic Acid}

Malic acid is the second greatest contributor to grape acidity, and it is thus also an important indicator of wine quality (Comuzzo and Battistutta 2019). Ideal malic acid content ranges from 1-3 g/L in must from warm climates, to $4-6.5 \mathrm{~g} / \mathrm{L}$ in musts from cool climates (Comuzzo and Battistutta 2019). Malic acid is an important component of acidity and wine quality, but if malic acid levels are too high, they can have negative effects on flavor when converted to lactic acid through malolactic fermentation (Comuzzo and Battistutta 2019).

In this experiment, residuals for malic acid levels in grape must at harvest $(\mathrm{g} / \mathrm{L})$ were normally distributed for all groups, as assessed by Shapiro-Wilk's test $(p=0.948)$. There were no outliers in the data, as assessed by inspection of a boxplot. No differences were found between repetitions to indicate a blocking effect $(p=0.617)$. The ANOVA revealed that the relationship between distance of vine from hedgerow and malic acid levels was not significant, $F(4,10)=1.15, p=.4007$.

\section{VII.6.1.vii. Yeast Assimilable Nitrogen}

Yeast Assimilable Nitrogen (YAN) plays a role in determining the alcohol content and post-fermentation sugar content of wine; YAN consists of ammonium ions and free amino $\mathrm{N}$, and it is an essential nutrient for yeast growth during fermentation (Boudreau et al. 
2018). It is responsible for ensuring complete fermentation and also is responsible for the formation of many aromas (Petrovic 2018). Values for YAN generally fall between 120 and $300 \mathrm{mg} / \mathrm{L}$ (Gobert et al. 2017). Higher values indicate higher $\mathrm{N}$ absorption in grapevines but can result in faster fermentations that lead to less-complex aromas and even undesirable aromas (Stewart 2013; Kemp et al. 2019). Lower values are associated with hydrogen sulfide aromas and excessively high alcohol production (Bell and Henschke 2008). Therefore, YAN values around $140 \mathrm{mg} / \mathrm{L}$ are typically desirable, although, as sugar levels increase, YAN requirements also increase (Stewart 2013; Kemp et al. 2019).

In this study, the data for YAN satisfied the assumptions of the one-way ANOVA. Residuals for YAN levels in grape must at harvest $(\mathrm{g} / \mathrm{L})$ were normally distributed for all groups, as assessed by Shapiro-Wilk's test $(p=0.951)$. There were no outliers in the data, as assessed by inspection of a boxplot. No differences were found between repetitions to indicate a blocking effect $(p=0.9841)$. The ANOVA revealed that the relationship between distance of vine from hedgerow and YAN levels was not significant, $F(4,10)=0.46, p=$ .7629.

\section{VII.6.1.viii. Total Skin Phenolics}

Total phenolics refer to the many phenol and polyphenol components that compose the flavors, aromas, color, and body of wine, including phenolic acids, flavonoids, oligomeric proanthocyanidins, and polymeric condensed tannins (Waterhouse 2003). All phenolics are characterized by an aromatic ring with at least one hydroxyl group, and they are found in the skin, pulp, and seeds of grapes (Harbertson and Spayd 2005). The phenolics in this study were analyzed using the Adams-Harbertson method.

In this study, data for total skin phenolics satisfied the assumptions of normality for the one-way ANOVA. Residuals for total phenolics levels in berry skins (mg/g fruit) were normally distributed for all groups, as assessed by Shapiro-Wilk's test $(p=0.928)$. There 
were no outliers in the data, as assessed by inspection of a boxplot. No differences were found between repetitions to indicate a blocking effect $(p=0.9922)$. The ANOVA revealed that the relationship between distance of vine from hedgerow and berry skin phenolics levels was not significant, $F(4,10)=.20, p=.9332$.

\section{VII.6.1.ix. Total Skin Anthocyanins}

Anthocyanins are pigments that are responsible for giving wine its color, and they are mainly found in grape skin (Mattivi et al. 2006). In this study, data for total skin anthocyanins satisfied the assumptions of the one-way ANOVA. Residuals for total anthocyanins in berry skins at harvest (mg/g fruit) were normally distributed for all groups, as assessed by ShapiroWilk's test $(p=0.917)$. There were no outliers in the data, as assessed by inspection of a boxplot. No differences were found between repetitions to indicate a blocking effect ( $p=$ 0.0869). The ANOVA revealed that the relationship between distance of vine from hedgerow and skin anthocyanin levels was not significant, $F(4,10)=2.74, p=.104$.

\section{VII.6.1.x. Total Skin Tannins}

Flavan-3-ols, better known as tannins, are polyphenolic compounds that are present in grape seeds, skin, pulp, and stem. The flavonols that compose tannins include (+)-catechin, (-)-epicatechin, and (-)-epicatechin-gallate. These compounds are the biggest contributors to wine body, and are important components of wine quality, especially when they are balanced with high sugar levels and high acidity, as they account for the feel and body of a wine (Bogs 2005; Adams 2006; Rice et al. 2017).

Residuals for total tannins in berry skin (mg/g fruit) in this experiment were normally distributed for all groups, as assessed by Shapiro-Wilk's test $(p=0.921)$. There were no outliers in the data, as assessed by inspection of a boxplot. No differences were found between repetitions to indicate a blocking effect $(p=0.4437)$. The ANOVA revealed that the 
relationship between distance of vine from hedgerow and berry skin tannin levels was significant, $F(4,10)=4.85, p=.0279$.

Mean skin tannin levels (mg/g fruit) were lowest in vines $2 \mathrm{~m}$ from the hedgerow $(0.702 \pm 0.045)$ and increased to vines $40 \mathrm{~m}$ from the hedgerow $(0.89 \pm 0.045)$, to vines $4 \mathrm{~m}$ from the hedgerow $(0.893 \pm 0.045)$ to vines $6 \mathrm{~m}$ from the hedgerow $(0.92 \pm 0.045)$ to vines $12 \mathrm{~m}$ from the hedgerow $(0.959 \pm 0.045)$ in an inexplicable pattern; however Fisher's LSD post hoc analyses revealed that these differences were only significant in vines $2 \mathrm{~m}$ from the hedgerow as compared to all other treatments $(p<.05)$ (See Table 14 and Figure 26). We observed a $21.1 \%$ reduction in skin tannins in vines at $2 \mathrm{~m}$ from the hedgerow as compared to vines at $40 \mathrm{~m}$, and, practically speaking, this amount of reduction in tannins would most likely have consequential negative ramifications for wine quality.

Because the lower tannin levels seen in vines closest to the hedgerow were in association with higher brix levels and higher TA levels, these low tannin levels may indicate that wine made from this must could be unbalanced and lack the body required to complement high sugar and acid levels, however wine would need to be made from the must in order to determine this definitively.

Table 14. Fisher's Least Squares Means post-hoc analyses at 0.05 significance level for total skin tannin levels (mg/g fruit) in must from grapevines at different distances from an olive tree hedgerow. Significant differences are indicated by an asterisk.

\begin{tabular}{|c|c|c|c|c|c|}
\hline \multicolumn{7}{|c|}{ Post Hoc Least Squares Means for Effect Distance } \\
\hline Distance $(\mathrm{m})$ & $\mathbf{2}$ & $\mathbf{4}$ & $\mathbf{6}$ & $\mathbf{1 2}$ & $\mathbf{4 0}$ \\
\hline $\mathbf{2}$ & & $0.0175^{*}$ & $0.0091^{*}$ & $0.0038^{*}$ & $0.0188^{*}$ \\
\hline $\mathbf{4}$ & $0.0175^{*}$ & & 0.6732 & 0.3278 & 0.9633 \\
\hline $\mathbf{6}$ & $0.0091^{*}$ & 0.6732 & & 0.5623 & 0.6406 \\
\hline $\mathbf{1 2}$ & $0.0038^{*}$ & 0.3278 & 0.5623 & & 0.3076 \\
\hline $\mathbf{4 0}$ & $0.0188^{*}$ & 0.9633 & 0.6406 & 0.3076 & \\
\hline
\end{tabular}




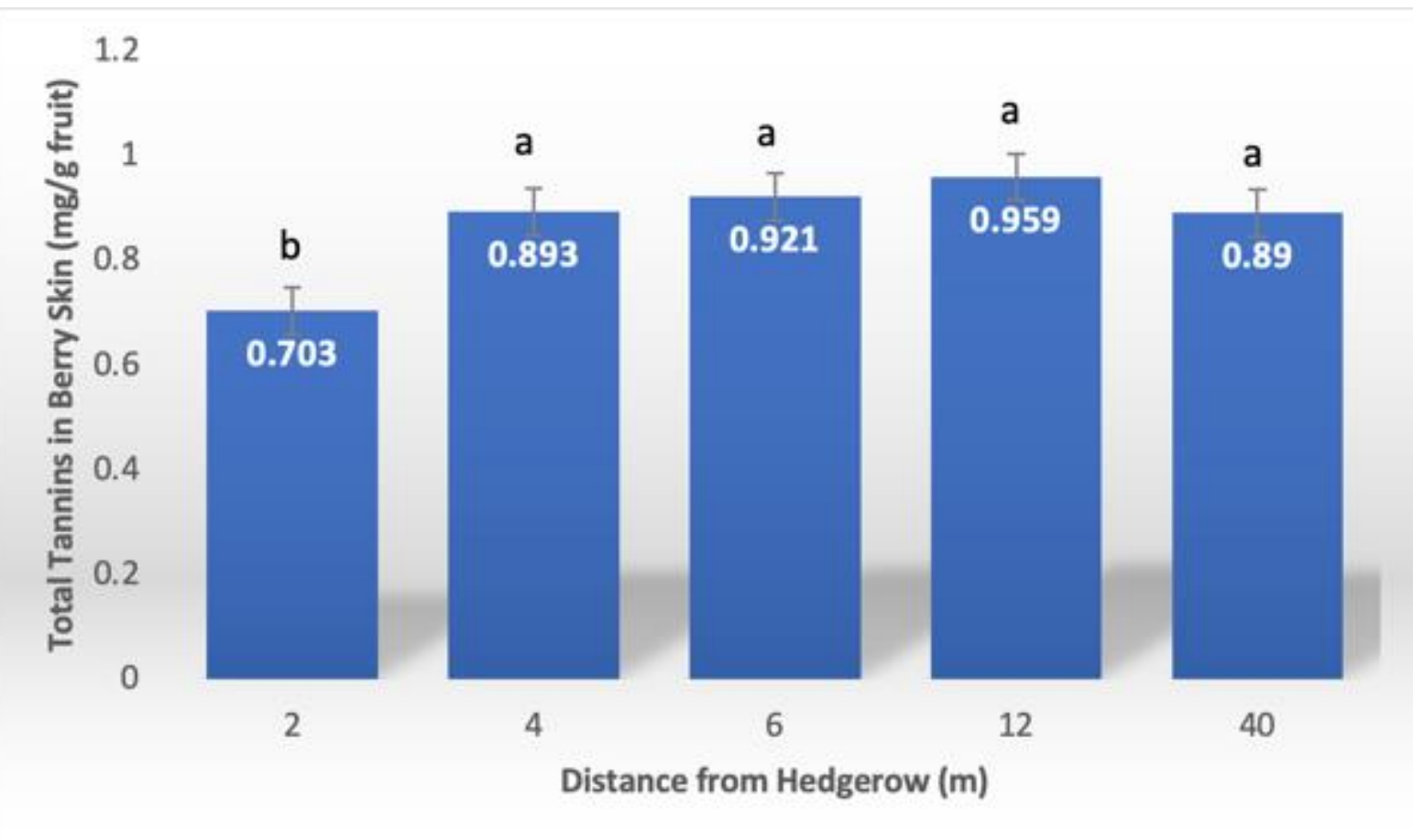

Figure 26. The relationship between distance from an olive tree hedgerow and total skin tannin levels in grape must at harvest in 8-year-old Malbec grapevines in Mendoza Argentina, 2020.

\section{VII.6.1.xi. Total Seed Phenolics}

The data for total seed phenolics satisfied the assumptions of the one-way ANOVA. Residuals for phenolics levels in grape seeds (mg/g fruit) were normally distributed for all groups, as assessed by Shapiro-Wilk's test $(p=0.938)$. There were no outliers in the data, as assessed by inspection of a boxplot. No differences were found between repetitions to indicate a blocking effect $(p=0.3115)$. The ANOVA revealed that the relationship between distance of vine from hedgerow and total phenolics levels in seeds was not significant, $F(4,10)=1.18, p=.3882$.

\section{VII.6.1.xii. Total Seed Tannins}

The data for total seed tannins satisfied the assumptions of the one-way ANOVA. Residuals for tannin levels in grape seeds (mg/g fruit) were normally distributed for all groups, as assessed by Shapiro-Wilk's test $(p=0.965)$. There were no outliers in the data, as assessed by inspection of a boxplot. No differences were found between repetitions to 
indicate a blocking effect $(p=0.7758)$. The ANOVA revealed that the relationship between distance of vine from hedgerow and seed tannin levels was not significant, $F(4,10)=1.66, p$ $=.2503$.

\section{VII.6.2. Growth Parameter Results}

\section{VII.6.2.i. Vigor}

Pruning weights measure the amount of vegetative growth in a vine in a given growing season, and are a standard indicator of vine vigor. In this experiment, we found that within the dataset for pruning weights there were two outliers, as assessed by boxplot. However, given the large sample size, two outliers does not suggest a lack of normality, and outliers were left in the analysis. Data was normally distributed for each group, as assessed by Shapiro-Wilk test $(p=.973)$.

The ANOVA found that pruning weights $(\mathrm{g})$ were significantly different between groups at different distances from the olive tree hedgerow, $F(4,68)=4.12, p=.0048$. Pruning weights were lowest in vines $12 \mathrm{~m}$ from the hedgerow (209.53 $\mathrm{g} \pm 29.67)$, then increased to vines $2 \mathrm{~m}$ from the hedgerow $(249.13 \mathrm{~g} \pm 29.67)$, to vines $4 \mathrm{~m}$ from the hedgerow $(282.27 \mathrm{~g}$ $\pm 29.67)$, to $6 \mathrm{~m}$ from the hedgerow (323 $\mathrm{g} \pm 29.67)$, to vines $40 \mathrm{~m}$ from the hedgerow $(363 \mathrm{~g}$ $\pm 29.67)$ in an inexplicable pattern. Fisher's LSD post hoc analyses revealed that vigor was significantly higher in vines $40 \mathrm{~m}$ from the hedgerow as compared to $12 \mathrm{~m}(p=.0005)$ and 2 $\mathrm{m}(p=0.0084)$ from the hedgerow, however there were no differences between pruning weights at $40 \mathrm{~m}$ and $6 \mathrm{~m}$ from the hedgerow $(p=0.3438)$ nor between $40 \mathrm{~m}$ and $4 \mathrm{~m}(p=$ 0.059) (See Table 15 and Figure 27). Vines at $12 \mathrm{~m}$ from the hedgerow also had significantly lower vigor than did vines at $6 \mathrm{~m}$ from the hedgerow $(p=0.0086)$. Competition between olive trees and grapevines would explain the decrease in vigor in vines nearest to the hedgerow, and it would explain the increase in vigor in vines farther from the hedgerow, but 
it does not explain why vines $12 \mathrm{~m}$ from the hedgerow had such low vigor. There are no known factors to explain why vines at $12 \mathrm{~m}$ from the hedgerow had such a sharp drop in vigor, while all other rows experienced increases in vigor in a linear pattern as distance from the hedgerow increased. There may have been undetected differences in soil makeup or in vine health in row 12 that could explain this unexpected pattern. The row could have been impacted by hail, frost, herbicide exposure, tractor damage, or another factor that we are unaware of. A one-way ANOVA was undergone to see if there were any differences in vine diameter in row 12 that might be contributing to the unexpected results we observed; however, the ANOVA revealed that there were no significant differences in vine diameter between row 12 and any other row, thus ruling out the possibility that vines in row 12 were smaller than vines in other treatments (see Appendix H, Table 1).

When examining exclusively the "control row" at $40 \mathrm{~m}$ from the hedgerow as compared to vines closest to the hedgerow at a $2 \mathrm{~m}$ distance, large differences were in vine vigor observed. Vigor was $31.3 \%$ lower in vines closest to the hedgerow as compared to the "control" vines at $40 \mathrm{~m}$ from the hedgerow. However, at $6 \mathrm{~m}$ from the hedgerow, no differences in vigor were observed as compared to the "control" at $40 \mathrm{~m}$ from the hedgerow.

Table 15. Fisher's Least Squares Means post-hoc analyses at 0.05 significance level for pruning weights $(\mathrm{g})$ in grapevines at different distances from an olive tree hedgerow. Significant differences are indicated by an asterisk.

\begin{tabular}{|c|c|c|c|c|c|}
\hline \multicolumn{7}{|c|}{ Post Hoc Least Squares Means for Effect Distance } \\
\hline Distance $(\mathrm{m})$ & $\mathbf{2}$ & $\mathbf{4}$ & $\mathbf{6}$ & $\mathbf{1 2}$ & $\mathbf{4 0}$ \\
\hline $\mathbf{2}$ & & 0.4325 & 0.0829 & 0.3487 & $0.0084^{*}$ \\
\hline $\mathbf{4}$ & 0.4325 & & 0.3351 & 0.0876 & 0.0585 \\
\hline $\mathbf{6}$ & 0.0829 & 0.3351 & & $0.0086^{*}$ & 0.3438 \\
\hline $\mathbf{1 2}$ & 0.3487 & 0.0876 & $0.0086^{*}$ & & $0.0005^{*}$ \\
\hline $\mathbf{4 0}$ & $0.0084^{*}$ & 0.0585 & 0.3438 & $0.0005^{*}$ & \\
\hline
\end{tabular}




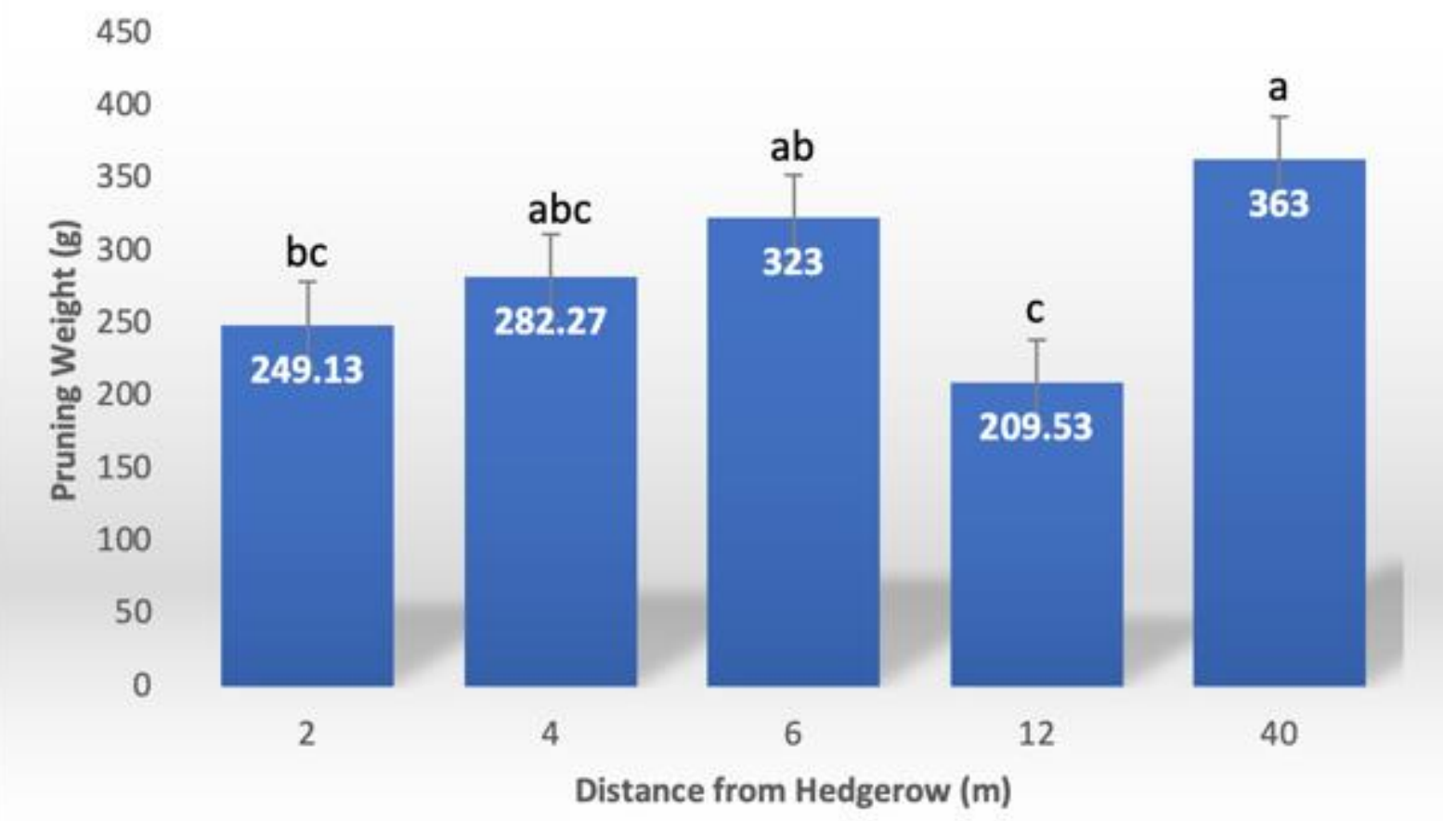

Figure 27. The relationship between distance from an olive tree hedgerow and pruning weight taken in dormancy in 8-year-old Malbec grapevines in Mendoza Argentina, 2020 .

\section{VII.6.2.ii. Ravaz Index}

A one-way ANOVA was conducted to determine if vine balance, measured by the Ravaz Index ratio of yield to pruning weights per meter, was different for vines at different distances from an olive tree hedgerow. The square root of all observed values was taken to correct for skewness. There were two outliers, as assessed by boxplot, but given the large sample size, two outliers does not suggest a lack of normality. Outliers were left in the analysis. Data was normally distributed for all groups, as assessed by the Shapiro-Wilk test (p $=.9752$ ). Vine balance was not statistically significantly different at different distances from the olive tree hedgerow, $F(4,68)=1.06, p=.381$. This can be explained by the fact that both vine vigor and vine yield were diminished at relatively the same rate as proximity to the hedgerow increased. 


\section{VII.6.3. Production Parameter Results}

\section{VII.6.3.i. Yield}

The data for yield satisfied the assumptions of the one-way ANOVA. In this dataset there were two outliers, as assessed by boxplot, but given the large sample size, two outliers do not suggest a lack of normality, and outliers were left in the analysis. Data was normally distributed for each group, as assessed by Shapiro-Wilk test $(p=.985)$.

The ANOVA found that yield $(\mathrm{kg})$ was significantly different between groups at different distances from the olive tree hedgerow, $F(4,68)=6.60, p=.0002$. Yield increased from vines at $2 \mathrm{~m}$ from hedgerow $(1.133 \mathrm{~kg} \pm 0.1636)$, to vines $12 \mathrm{~m}$ from hedgerow (1.473 $\pm 0.1636)$, to vines $4 \mathrm{~m}$ from hedgerow $(1.553 \pm 0.1636)$, to vines $6 \mathrm{~m}$ from hedgerow $(1.813$ $\pm 0.1636)$, to vines $40 \mathrm{~m}$ from hedgerow $(2.260 \pm 0.1636)$ in an inexplicable pattern. Fisher's LSD post hoc analyses revealed that yield was significantly higher in vines $40 \mathrm{~m}$ from the hedgerow as compared to all other rows except for the row $6 \mathrm{~m}$ from the hedgerow $(p=$ 0.0577), and that vines $2 \mathrm{~m}$ from the rows had significantly lower yield than vines $6 \mathrm{~m}$ and 40 $\mathrm{m}$ from the hedgerow (see Table 16, Figure 28).

Compared to the "control" vines at $40 \mathrm{~m}$ from the hedgerow, vines closest to the hedgerow at a $2 \mathrm{~m}$ distance experienced a 50\% reduction in yield, and vines at $4 \mathrm{~m}$ from the hedgerow experienced a $31.3 \%$ reduction in yield. Practically speaking, both of these percentages translate to consequential and serious yield reductions. This is comparable with existing literature, which also observed significant yield decreases within $4 \mathrm{~m}$ from a hedgerow (Grimaldi 2018). However, previous studies did not observe any differences in yield beyond $4 \mathrm{~m}$ from the hedgerow, while in this study, vines $12 \mathrm{~m}$ from the hedgerow had significantly lower yields than did vines at $40 \mathrm{~m}$ from the hedgerow (although vines at $6 \mathrm{~m}$ from the hedgerow did not). It is not known why reductions in yield at $12 \mathrm{~m}$ beyond the hedgerow but not at $6 \mathrm{~m}$ beyond the hedgerow were occurring, as at $12 \mathrm{~m}$ from the hedgerow 
there are few olive tree roots to compete with grapevine roots, and there are negligible differences in light. Because there were no differences observed between vines $6 \mathrm{~m}$ from the hedgerow and vines $40 \mathrm{~m}$ from the hedgerow, the question remains open as to why vines at $12 \mathrm{~m}$ from the hedgerow exhibited lower yield. We cannot conclude that this has anything to do with distance from the hedgerow or competition from the hedgerow. More detailed soil uniformity analyses should be undergone in the row of vines $12 \mathrm{~m}$ from the hedgerow to see if there might be a reason why row 12 exhibited such abnormal patterns, not only for yield but for vigor and several other variables as well. Although it is unknown why vines $12 \mathrm{~m}$ from the hedgerow would be experiencing such low yields, previous studies on vineyard agroforestry systems suggest that the yield reductions in vines at $2 \mathrm{~m}$ and $4 \mathrm{~m}$ from the hedgerow can likely be explained by competition between the olive trees and grapevines.

Table 16. Fisher's Least Squares Means post-hoc analyses at 0.05 significance level for vine yield $(\mathrm{kg})$ in must from grapevines at different distances from an olive tree hedgerow. Significant differences are indicated by an asterisk.

\begin{tabular}{|c|c|c|c|c|c|}
\hline \multicolumn{7}{|c|}{ Post Hoc Least Squares Means for Effect Distance } \\
\hline Distance (m) & $\mathbf{2}$ & $\mathbf{4}$ & $\mathbf{6}$ & $\mathbf{1 2}$ & $\mathbf{4 0}$ \\
\hline $\mathbf{2}$ & & 0.0738 & $0.0045^{*}$ & 0.1462 & $<.0001^{*}$ \\
\hline $\mathbf{4}$ & 0.0738 & & 0.2650 & 0.7305 & $0.0032^{*}$ \\
\hline $\mathbf{6}$ & $0.0045^{*}$ & 0.2650 & & 0.1462 & 0.0577 \\
\hline $\mathbf{1 2}$ & 0.1462 & 0.7305 & 0.1462 & & $0.0011^{*}$ \\
\hline $\mathbf{4 0}$ & $<.0001^{*}$ & $0.0032^{*}$ & 0.0577 & $0.0011^{*}$ & \\
\hline
\end{tabular}




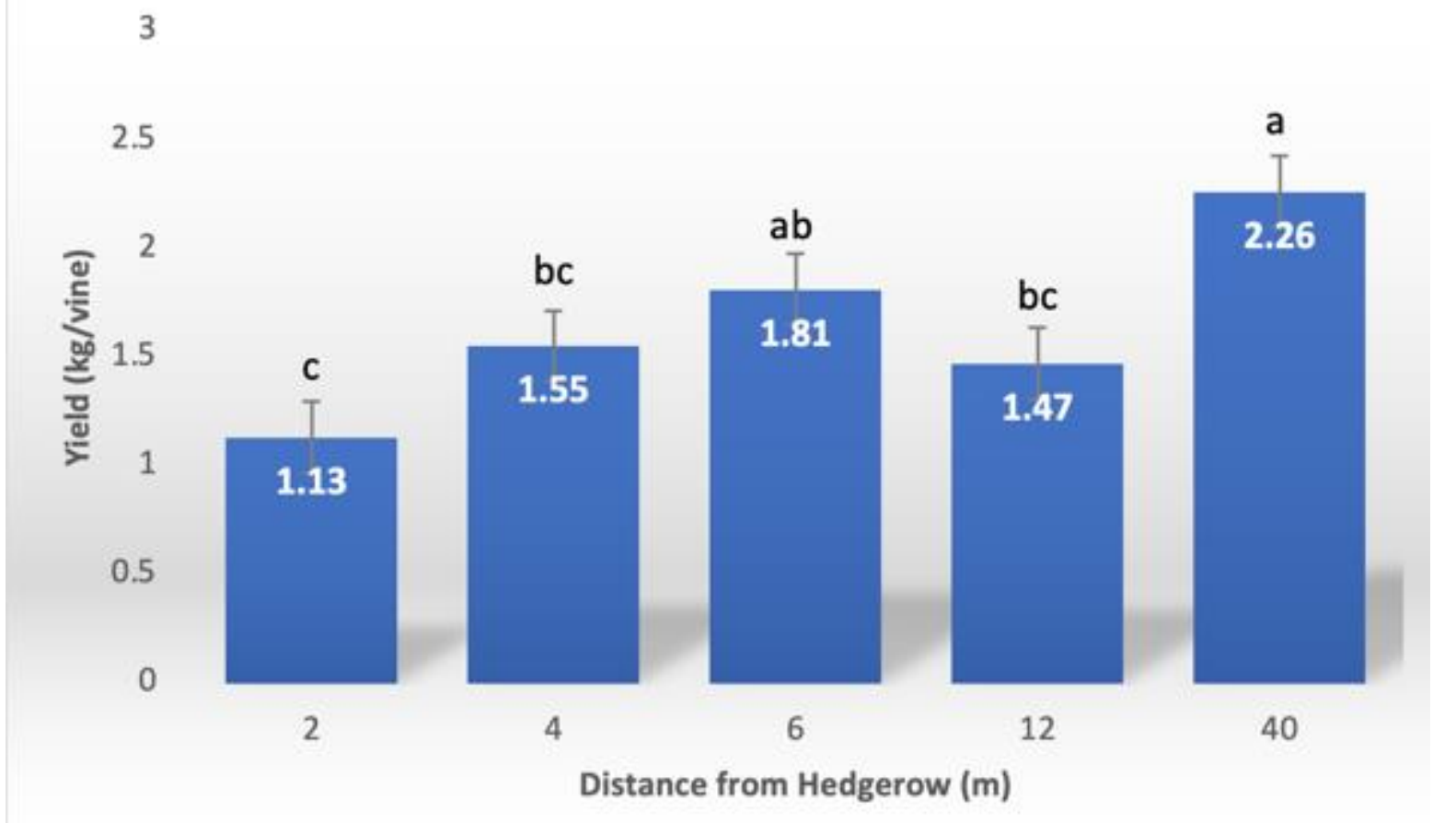

Figure 28. The relationship between distance from an olive tree hedgerow and total yield per vine of 8-year-old Malbec grapevines in Mendoza Argentina, 2020.

\section{VII.6.4. Nutritional Parameter Results}

\section{VII.6.4.i. Petiole Nitrate}

Residuals for petiole nitrate levels ( $\mathrm{mg} / \mathrm{kg}$ ) were normally distributed for all groups, as assessed by Shapiro-Wilk's test $(p=0.888)$. There were no outliers in the data, as assessed by inspection of a boxplot. No differences were found between repetitions to indicate a blocking effect $(p=0.7984)$. The ANOVA revealed that the relationship between distance of vine from hedgerow and petiole N-NO3levels was not significant, $F(4,10)=1.51, p=.2870)$.

\section{VII.6.4.ii. Leaf Blade Total N}

Residuals for leaf blade total $\mathrm{N}$ levels (g/100 g dry tissue) were normally distributed for all groups, as assessed by Shapiro-Wilk's test $(p=0.976)$. There were no outliers in the data, as assessed by inspection of a boxplot. No differences were found between repetitions to indicate a blocking effect $(p=0.8289)$. The ANOVA revealed that the relationship 
between distance of vine from hedgerow and leaf blade total $\mathrm{N}$ was not significant, $F(4,10)=$ $2.23, p=.1555)$.

\section{VII.6.4.iii. Petiole Total N}

Residuals for petiole total $\mathrm{N}$ levels (g/100 g dry tissue) were normally distributed for all groups, as assessed by Shapiro-Wilk's test $(p=0.942)$. There were no outliers in the data, as assessed by inspection of a boxplot. No differences were found between repetitions to indicate a blocking effect $(p=0.8108)$. The ANOVA revealed that the relationship between distance of vine from hedgerow and petiole total $\mathrm{N}$ was not significant, $F(4,10)=.73, p=$ $.5955)$.

\section{VII.6.4.iv. Leaf Blade P}

Residuals for leaf blade phosphorous levels ( $\mathrm{g} / 100 \mathrm{~g}$ dry tissue) were normally distributed for all groups, as assessed by Shapiro-Wilk's test $(p=0.938)$. There were no outliers in the data, as assessed by inspection of a boxplot. No differences were found between repetitions to indicate a blocking effect $(p=0.566)$. The ANOVA revealed that the relationship between distance of vine from hedgerow and leaf blade $\mathrm{P}$ was not significant, $F(4,10)=.88, p=.5165)$.

\section{VII.6.4.v. Petiole P}

Residuals for petiole phosphorous levels (g/100 g dry tissue) were normally distributed for all groups, as assessed by Shapiro-Wilk's test $(p=0.941)$. There were two outliers in the data, as assessed by inspection of a boxplot. No differences were found between repetitions to indicate a blocking effect $(p=0.522)$. The ANOVA revealed that the relationship between distance of vine from hedgerow and petiole $\mathrm{P}$ was not significant, $F(4,10)=3.54, p=.0603)$.

\section{VII.6.4.vi. Leaf Blade K}


The data for leaf blade $\mathrm{K}$ in this experiment satisfied the assumptions of the one-way ANOVA. Residuals for leaf blade K levels (g/100 g dry tissue) in this experiment were normally distributed for all groups, as assessed by Shapiro-Wilk's test ( $p=0.938)$. There were no outliers in the data, as assessed by inspection of a boxplot. The ANOVA revealed that the relationship between distance of vine from hedgerow and leaf blade $\mathrm{K}$ was significant, $F(4,10)=30.23, p<.0001$. However, repetitions did have a significant blocking effect, indicating that, although distance from hedgerow was a factor in the differences in leaf blade K seen between treatments, other factors likely also played a role $(p=0.0146)$.

Potassium levels were lowest in vines $40 \mathrm{~m}$ from the hedgerow $(0.73 \mathrm{~g} / 100 \mathrm{~g}$ dry tissue \pm 0.03$)$, and increased to vines $2 \mathrm{~m}$ from the hedgerow $(0.89 \mathrm{~g} / 100 \mathrm{~g}$ dry tissue \pm 0.03 ), to vines $4 \mathrm{~m}$ from the hedgerow ( $1.06 \mathrm{~g} / 100 \mathrm{~g}$ dry tissue \pm 0.03$)$, to vines $6 \mathrm{~m}$ from the hedgerow $(1.06 \mathrm{~g} / 100 \mathrm{~g}$ dry tissue \pm 0.03$)$, to vines $12 \mathrm{~m}$ from the hedgerow $(1.12 \mathrm{~g} / 100 \mathrm{~g}$ dry tissue \pm 0.03 ) in an inexplicable pattern. Fisher's LSD post hoc analysis revealed that K levels in vines $40 \mathrm{~m}$ from the hedgerow were significantly lower than all other treatments, and that $\mathrm{K}$ levels in vines $2 \mathrm{~m}$ from the hedgerow were significantly higher than vines $40 \mathrm{~m}$ from the hedgerow, but significantly lower than vines 4, 6, and $12 \mathrm{~m}$ from the hedgerow (see Table 17 and Figure 29). Compared to vines closest to the hedgerow at a $2 \mathrm{~m}$ distance, vines at $40 \mathrm{~m}$ from the hedgerow suffered a $19 \%$ reduction in $\mathrm{K}$ levels.

More data is needed to explain this interesting pattern of $\mathrm{K}$ levels. $\mathrm{K}$ levels were expected to be low at $2 \mathrm{~m}$ from the hedgerow due to competition from olive trees. However, it is unknown why $\mathrm{K}$ levels would be lowest in vines at $40 \mathrm{~m}$ from the hedgerow. Because there was a significant blocking effect for this variable, these results could be partially explained by another unknown variable besides proximity to the hedgerow, such as soil variability. 
Table 17. Fisher's Least Squares Means post-hoc analyses at 0.05 significance level for leaf blade potassium levels ( $\mathrm{g} / 100 \mathrm{~g}$ dry tissue) in grapevines at different distances from an olive tree hedgerow. Significant differences are indicated by an asterisk.

\begin{tabular}{|c|c|c|c|c|c|}
\hline \multicolumn{7}{|c|}{ Post Hoc Least Squares Means for Effect Distance } \\
\hline Distance (m) & $\mathbf{2}$ & $\mathbf{4}$ & $\mathbf{6}$ & $\mathbf{1 2}$ & $\mathbf{4 0}$ \\
\hline $\mathbf{2}$ & & $0.0041^{*}$ & $0.0041^{*}$ & $0.0006^{*}$ & $0.0037^{*}$ \\
\hline $\mathbf{4}$ & $0.0041^{*}$ & & 1.000 & 0.1696 & $<.0001^{*}$ \\
\hline $\mathbf{6}$ & $0.0041^{*}$ & 1.000 & & 0.1696 & $<.0001^{*}$ \\
\hline $\mathbf{1 2}$ & $0.0006^{*}$ & 0.1696 & 0.1696 & & $<.0001^{*}$ \\
\hline $\mathbf{4 0}$ & $0.0037^{*}$ & $<.0001^{*}$ & $<.0001^{*}$ & $<.0001^{*}$ & \\
\hline
\end{tabular}

\section{4}

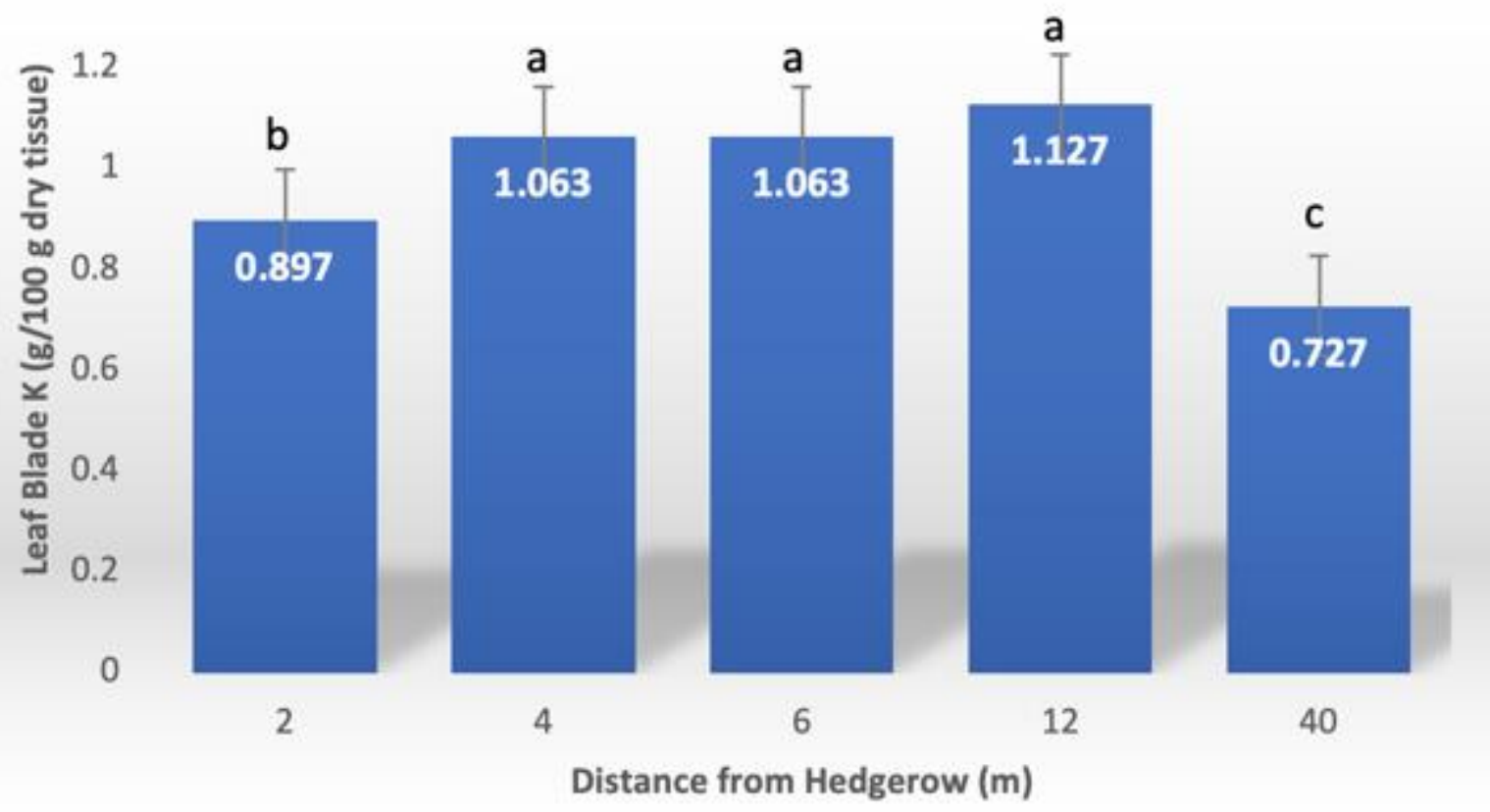

Figure 29. The relationship between distance from an olive tree hedgerow and leaf blade $\mathrm{K}$ levels in 8-year-old Malbec grapevines in Mendoza Argentina, 2019.

\section{VII.6.4.vii. Petiole K}

Residuals for petiole potassium levels (g/100 g dry tissue) were normally distributed for all groups, as assessed by Shapiro-Wilk's test $(p=0.975)$. There were no outliers in the data, as assessed by inspection of a boxplot. No differences were found between repetitions 
to indicate a blocking effect $(p=0.7632)$. The ANOVA revealed that the relationship between distance of vine from hedgerow and petiole $\mathrm{K}$ was significant, $F(4,10)=1.25, p=.3636$ ).

\section{VII.6.4.viii. Leaf Blade $M g$}

Residuals for leaf blade magnesium levels (g/100 g dry tissue) were normally distributed for all groups, as assessed by Shapiro-Wilk's test $(p=0.979)$. There were no outliers in the data, as assessed by inspection of a boxplot. No differences were found between repetitions to indicate a blocking effect $(p=0.3079)$. The ANOVA revealed that the relationship between distance of vine from hedgerow and leaf blade $\mathrm{Mg}$ was not significant, $F(4,10)=1.48, p=0.2948)$.

\section{VII.6.4.ix. Petiole $\mathrm{Mg}$}

Residuals for petiole magnesium levels (g/100 g dry tissue) were normally distributed for all groups, as assessed by Shapiro-Wilk's test $(p=0.9655)$. There were no outliers in the data, as assessed by inspection of a boxplot. No differences were found between repetitions to indicate a blocking effect ( $p=0.8187)$. The ANOVA revealed that the relationship between distance of vine from hedgerow and petiole $\mathrm{Mg}$ was not significant, $F(4,10)=.77, p$ $=.575)$.

\section{VII.6.4.x. Nutritional Results Summary}

Mean nutrition levels for all vines in the 2019 growing season are summarized in Table 18. Compared to normal nutrition values for vines in the Maipu growing region of Argentina, all vines were found to have lower-than-normal values for N-NO3 in petioles, Total $\mathrm{N}$ in petioles, and total $\mathrm{N}$ in leaf blades. All vines at this site were found to have aboveaverage values for $\mathrm{P}$ in leaf blades, $\mathrm{P}$ in petioles, and $\mathrm{K}$ in leaf blades. $\mathrm{K}$ and $\mathrm{Mg}$ levels in petioles were found to be roughly normal for this region. Vines in rows $2 \mathrm{~m}, 4 \mathrm{~m}$, and $40 \mathrm{~m}$ from the hedgerow had adequate levels of leaf blade $\mathrm{Mg}$, while vines in rows 6 and $12 \mathrm{~m}$ from the hedgerow had low levels of leaf blade Mg. Nutrient levels of grapevines at this site 
as compared to typical Maipu, Argentina nutrient levels can be summarized in Figure 30 and Appendix E, Table 1.

Table 18. Mean foliar nutrient values for vines at different distances from an olive tree hedgerow, taken at Catapano Family Vineyard, Maipu, Mendoza, Argentina, during the flowering period of 2019.

\begin{tabular}{|c|c|c|c|c|c|}
\hline $\begin{array}{l}\text { Distance from } \\
\text { Hedgerow }\end{array}$ & $2 \mathrm{~m}$ & $4 \mathrm{~m}$ & $6 \mathrm{~m}$ & $12 \mathrm{~m}$ & $40 \mathrm{~m}$ \\
\hline $\begin{array}{c}\text { Petiole N-NO3 } \\
(\mathrm{mg} / \mathrm{kg})\end{array}$ & 266.00 & 256.67 & 263.67 & 259.00 & 308.66 \\
\hline $\begin{array}{c}\text { Leaf Blade } N \\
\text { (g/100 g dry tissue) }\end{array}$ & 2.65 & 2.86 & 3.15 & 2.96 & 3.17 \\
\hline $\begin{array}{c}\text { Petiole N }(\mathrm{g} / 100 \mathrm{~g} \\
\text { dry tissue) }\end{array}$ & 0.82 & 0.92 & 0.91 & 0.81 & 0.87 \\
\hline $\begin{array}{c}\text { Leaf Blade } P \\
\text { (g/100 g dry tissue) }\end{array}$ & 0.20 & 0.26 & 0.27 & 0.14 & 0.21 \\
\hline $\begin{array}{l}\text { Petiole } P(g / 100 ~ g \\
\text { dry tissue })\end{array}$ & 0.34 & 0.35 & 0.45 & 0.39 & 0.38 \\
\hline $\begin{array}{c}\text { Leaf Blade } K \\
\text { (g/100 g dry tissue) }\end{array}$ & 0.89 & 1.06 & 1.06 & 1.13 & 0.73 \\
\hline $\begin{array}{c}\text { Petiole } \mathrm{K}(\mathrm{g} / 100 \mathrm{~g} \\
\text { dry tissue) }\end{array}$ & 1.51 & 1.58 & 1.84 & 1.98 & 1.70 \\
\hline $\begin{array}{c}\text { Leaf Blade Mg } \\
\text { (g/100 g dry tissue) }\end{array}$ & 0.32 & 0.39 & 0.14 & 0.15 & 0.40 \\
\hline $\begin{array}{l}\text { Petiole Mg }(\mathrm{g} / 100 \\
\text { g dry tissue) }\end{array}$ & 0.51 & 0.71 & 0.59 & 0.89 & 0.69 \\
\hline
\end{tabular}



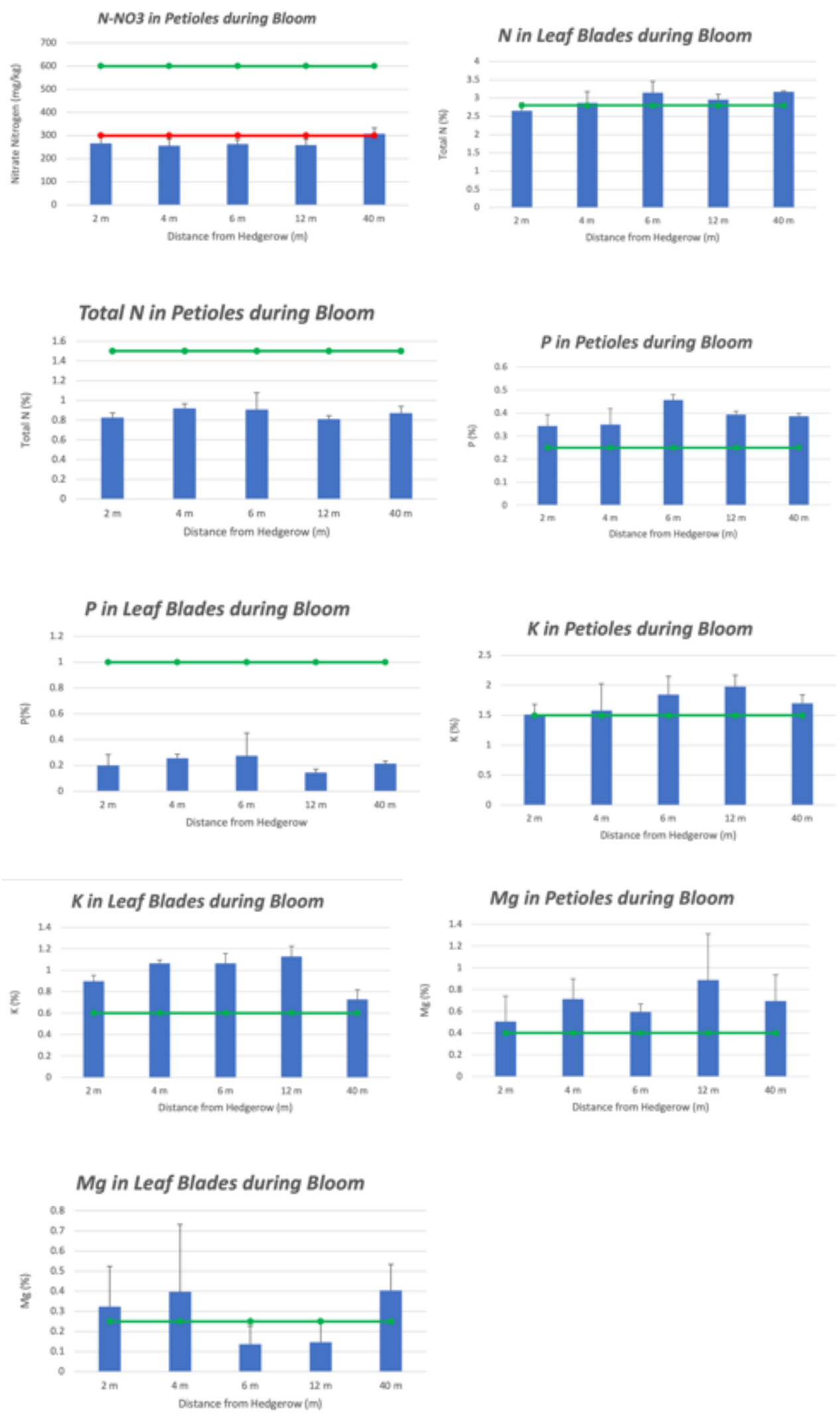

Figure 30. Mean foliar nutrient values for grapevines at Catapano Family Vineyard, Maipu, Mendoza, Argentina, as compared to typical nutrient values for grapevines in this region. Green bars represent adequate nutrient levels for this growing region, while red bars indicate the deficiency thresholds for this region. 


\section{VII.7. Discussion}

\section{VII.7.1. The Relationship Between Nutrients, Yield, and Vigor}

In this study we observed significant differences in glucose/fructose levels, brix, density, TA, skin tannins, vigor, and yield in vines at different distances from the olive tree hedgerow. In agroforestry systems in general, the most common causes for such differences stem from competition for water, nutrients, and light. Wind, or conversely, shelter from wind, along with microclimatic influences, can also cause differences in crops. Because this study was limited in funding and time, we were only able to measure vine tissue nutrient status, which can help us draw conclusions about the effect of competition for nutrients in this particular system. The following discussion explores the impact of competition for nutrients in this study.

We observed no differences in vine nutrient status for $\mathrm{N}, \mathrm{N}-\mathrm{NO}_{3}, \mathrm{P}$, or $\mathrm{Mg}$ at different distances from the hedgerow. We did observe differences in leaf blade $\mathrm{K}$ levels; however, these differences were not distributed in any type of pattern that would imply that proximity to the hedgerow caused these differences. To explore this question further, we investigated whether or not $\mathrm{K}$ levels, or other macronutrient levels, were correlated with differences in vine yield and vigor. A Pearson's product-moment correlation was undergone to examine the relationship between vine nutrient status, and both vine yield and vine vigor. Significant correlations are detailed below, and all correlations are summarized in Table 19.

Analyses revealed that there was no correlation between vine yield and any macronutrient except for total leaf blade $\mathrm{N}$, and that there was no correlation between vine vigor and any macronutrient except for total petiole $\mathrm{N}$. Because there were no correlations between $\mathrm{K}$ and yield nor between $\mathrm{K}$ and vigor, this leads us to conclude that the significant differences we observed in leaf blade $\mathrm{K}$ in our study indeed did not contribute to the differences we observed in vine yield and vine vigor. 
In our experiment there were no significant differences in $\mathrm{N}$ levels at different distances from the hedgerow, but we did observe differences in yield and vigor at different distances from the hedgerow. Even though our study results suggested that $\mathrm{N}$ did not cause the differences in yield and vigor that we observed, a Pearson's product-moment correlations was undergone and the correlation between total $\mathrm{N}$ levels in leaves and vine yield was found to be significant.

In the Pearson's product-moment correlation the assumptions of linearity and lack of outliers were satisfied through observation of a boxplot and histogram, and the assumption of normality was satisfied with a Shapiro-Wilk's test $(p>.05)$. There was a strong positive correlation between total $\mathrm{N}$ levels in leaves and vine yield $r(15)=.784, p=.001$, with leaf $\mathrm{N}$ levels accounting for $61.47 \%$ of the variability in yield.

There was also a significant correlation between vigor and petiole N. For the comparison between petiole $\mathrm{N}$ and vigor, assumptions of linearity and lack of outliers were satisfied. The assumption of normality was satisfied with a Shapiro-Wilk's test $(p>.05)$. There was a significant correlation between total $\mathrm{N}$ levels in petioles and pruning weights $r(15)=.578, p=.024$, with petiole $\mathrm{N}$ levels explaining $33.4 \%$ of the variation in pruning weights.

These results suggest that even though there were no significant differences between petiole nor leaf blade $\mathrm{N}$ levels at different distances from the olive tree hedgerow, competition for $\mathrm{N}$ may still explain some of the yield and vigor differences that were observed. However, because no significant differences in nutrients were observed between treatments in our study except for leaf $\mathrm{K}$, these correlations still lead us to speculate that competition for water or light, rather than competition for nutrients, were most likely the main factors contributing to the low yield and vigor in vines closer to the hedgerow. 
Table 19. Correlations between various nutrients in both petioles and leaf blades and yield and vigor. Significant correlations are indicated with an asterisk. In this study, leaf blade N levels and petiole $\mathrm{N}$ levels were strongly correlated with the yield and vigor results that were observed in grapevines at all five distances from an olive tree hedgerow.

\begin{tabular}{|c|c|c|c|c|}
\hline Variable 1 & Variable 2 & n & $\begin{array}{c}\text { Pearson } \\
\text { Coefficient }\end{array}$ & p-value \\
\hline Petiole N-NO3 & Yield & 15 & 0.484 & 0.068 \\
\hline Leaf N & Yield & 15 & 0.784 & $0.001^{*}$ \\
\hline Petiole P & Yield & 15 & 0.370 & 0.175 \\
\hline Leaf P & Yield & 15 & -0.116 & 0.681 \\
\hline Petiole K & Yield & 15 & 0.277 & 0.317 \\
\hline Leaf K & Yield & 15 & -0.378 & 0.165 \\
\hline Petiole N-NO3 & Vigor & 15 & 0.009 & 0.974 \\
\hline Leaf N & Vigor & 15 & 0.330 & 0.229 \\
\hline Petiole N & Vigor & 15 & 0.578 & $0.024 *$ \\
\hline Petiole P & Vigor & 15 & 0.198 & 0.480 \\
\hline Leaf P & Vigor & 15 & 0.499 & 0.058 \\
\hline Petiole K & Vigor & 15 & -0.391 & 0.150 \\
\hline Leaf K & Vigor & 15 & -0.418 & 0.121 \\
\hline
\end{tabular}

\section{VII.7.2. The Influence of Light and Competition for Water}

Although we were not able to quantify water status, wind speed, or light distribution in this experiment, we can speculate about the influences that these factors may have had on the differences we observed in glucose/fructose, brix, density, TA, skin tannins, yield, and vigor.

\section{VII.7.2.i. Speculations About the Effect of Light Competition}

Shade from trees influences crops below by reducing light and also reducing daytime temperatures, both of which have been shown to have an effect on grapevines. Grapevine photosynthesis can be negatively affected by tree shade because shade reduces PAR, however shade also reduces thermal radiation, which can actually increase photosynthesis in certain situations. Leaf temperatures are increased significantly by sunlight, and this can sometimes have detrimental effects on photosynthesis. This is because excess solar radiation can reduce leaf water potential, which in turn can cause a reduction in stomatal conductance, and thus, 
photosynthesis (Smart 1974). In Australia, temperatures of $40{ }^{\circ} \mathrm{C}$ for 14 days were shown to reduce Semillon grapevine photosynthesis by 35\% (Greer and Weedon 2013). Shading can reduce both ambient temperatures and leaf temperatures, thus actually increasing photosynthesis when grapevines are experiencing heat stress (Marshall 1967). In this experiment, temperatures were observed to have reached $38^{\circ} \mathrm{C}$ only for one month in 2018 , which may not have been high enough to be considered heat stress, given the amount of irrigation the vines were receiving (Appendix A, Table 1.), so we do not think that this would be the case. Therefore, we speculate that tree shade's reductions of PAR may have had a negative impact on vine photosynthesis, especially given the fact that ambient temperatures were not high enough for reduced temperature from shade to have a positive impact on vine photosynthesis.

Shading can have significant effects on wine grape yield by decreasing bud fruitfulness, fruit bud initiation, inflorescence formation, bunch mass, and potentially berry mass. Buttrose (1970) studied bud fruitfulness in five Vitis vinifera L. varieties which were grown in a laboratory and exposed to differing levels of light intensity $(900,1800$, and 3600 foot candles for 16 hours per day). Researchers found that as light intensity increased, mean number of bunch primordia per bud (an indicator of fruitfulness) also increased (Figure 14). These results echoed those of a study on Sultana table grapes, which found that $70 \%$ shade during the phenological period of inflorescence initiation depresses fruit bud initiation (May and Antcliff 1963), and those of another study, in which 18 years of data showed that the percentage of fruitful buds in Sultana grapes decreased with decreased sunlight (Baldwin 1964). In two other similar studies, Kliewer (1982) and Shaulis (1982) both found that fruit bud initiation in Vitis vinifera L. grapevines was depressed by shade, thus causing lower yield. In a study on Palomino grapes, grapevines which received full light were compared to grapevines which received only $26 \%$ of light, and researchers found that the $74 \%$ shade 
treatment caused not only reduced bud break in the current year, but also caused decreased budbreak, lower numbers of fruitful shoots, and reduced cluster weight the following year (Hopping 1975). Overwhelmingly, evidence shows that bud fruitfulness is dependent upon light. Maximum fruitfulness of latent buds is also dependent on temperature to a certain extent, but the main factor in influencing fruitfulness is light (Srinivasan and Mullins 1981). It is highly probable that the reductions in light that we observed at $2 \mathrm{~m}$ from the olive tree hedgerow had a negative influence on photosynthesis and yield.

Competition for PAR itself has been shown to negatively affect sugar levels in some studies but not in others. Spayd et al. (2002) found that PAR did not affect SS accumulation in berries, neither when temperature was controlled for nor not-controlled-for in sun-exposed vs shaded treatments. Similarly, Crippen and Morrison (1986) did not find significant differences between SS content in clusters that received different quantities of light. However, Dokoozlian and Kliewer (1996) compared sun-exposed clusters to shaded clusters and observed that, overall, shaded clusters did have lower and slower SS accumulation than did sun-exposed clusters. Although heat sometimes speeds the accumulation of sugars, extreme temperature can negatively affect accumulation of sugar in grapes (Abeysinghe et al. 2019). Therefore, when shade reduces not only PAR but also heat, sugars can actually accumulate more quickly. We suspect that the high temperatures of this growing region may negatively affect sugar accumulation, and we suspect that the olive trees in this study may have alleviated some heat stress, thus causing higher sugar levels in grapevines closer to trees.

In other studies, shade has been shown to have a significant effect on grape must acidity, mostly due to reductions in temperature under shade conditions. In this study we were not able to monitor temperature at different treatments, but other studies on vineyard agroforestry systems have documented temperatures up to $6{ }^{\circ} \mathrm{C}$ lower during the day in vine 
rows close to trees (Grimaldi et al. 2017; Grimaldi 2018; Gosme et al. 2019). We observed higher acidity in vine rows closest to trees ( $2 \mathrm{~m}$ from trees), and we speculate that this may have been due to temperature reductions from increased shade in that row. It is widely accepted that high temperatures are the main cause of acid degradation in wine grapes (Buttrose et al. 1971; Ruffner et al. 1976; Bergqvist et al. 2001; Spayd et al. 2002; Keller 2010; Bonada et al. 2013; Sweetman et al. 2014; Martínez-Lüscher et al. 2017). Light also can cause acid degradation, but in studies where shade and temperature were decoupled, researchers found that temperature was more of an influencing factor on acid degradation than light was (Spayd et al. 2002). We suspect that increased shade from trees at $2 \mathrm{~m}$ from the hedgerow provided enough temperature alleviation to increase acidity in favorable ways.

We observed significant reductions in berry skin tannins in vines closest to the hedgerow ( $2 \mathrm{~m}$ from the hedgerow), however no reductions in seed tannins were observed. Previous studies found similar results and determined that light does not have a significant effect on seed tannins (Lee 2017; Sun et al. 2017; Gouot et al. 2019). Researchers speculate that this may be because the tannins in seeds remain relatively protected against changes in light and temperature by berry flesh (Gouot et al. 2019). However skin tannins have been shown to be reduced by shade in other studies (Blancquaert et al. 2019). We hypothesize that reduced shade in the vine row closest to the hedgerow ( $2 \mathrm{~m}$ from the hedgerow) most likely caused the reductions in skin tannins levels that we observed.

\section{VII.7.2.ii. Speculations About the Effect of Water Competition}

The reductions in vine yield that we observed could have been caused by competition between grapevines and olive trees for water. Numerous studies have shown that excess water stress can cause reduced photosynthesis, reduced yield, and reduced vigor in grapevines (McCarthy et al. 1983; Winkel and Rambal 1993; Stevens et al. 1995; Gómez-delCampo et al. 2002; Schultz 2003). We hypothesize that competition for water was the main 
factor contributing to the reduced vigor observed in the vine rows closer to the olive tree hedgerow.

The increases in glucose/fructose, brix, and density that we observed likely were induced by water stress as well. Studies have shown that, when administered in the right amounts and at the right times, water stress can result in higher quality wine with higher sugar levels (McCarthy et al. 1983). Moderate water stress prevents sugars from being allocated to vegetative growth and instead directs accumulation of sugars to berries (Wheeler and Pickering 2005). Additionally, moderate water stress prevents inflation of berry cells, thus concentrating sugars and flavors and avoiding dilution. We hypothesize that water stress may have caused the increases in sugar levels that we observed, although more studies are needed to test this hypothesis.

We do not expect that the reduction in berry skin tannins that we observed in vines 2 $\mathrm{m}$ from the hedgerow was due to competition for water. On the contrary, other studies have shown that increased water stress in grapes was correlated with higher berry skin tannins (Esteban et al. 2001). We expect that the differences observed in skin tannins were due to competition for light.

\section{VII.7.2.iii. Speculations About the Effect of Wind}

We do not expect that that any of the reductions in yield or vigor were associated with the hedgerow acting as a windbreak. A study by Dry and Botting (1993) found that, on the contrary, vines in Australia had increased vegetative growth and yield when they were protected by a windbreak. These results are the opposite of what we observed, and therefore we do not think it is likely that slowing of wind had anything to do with changes in any of the variables we documented in this study.

\section{VII.8. CONCLUSION}




\section{VII.8.1. Conclusion}

Vineyard agroforestry has the potential to be a beneficial appropriate technology for buffering extreme temperature and weather events, for controlling pests, and for improving soil fertility. However, just as with any appropriate technology, it is important that agroforestry be carried out in a way that is appropriate to the site, in a way that satisfies the goals of the producer, and in a way that maximizes benefits while minimizing disadvantages.

The results of this study indicate that for this particular growing region, this tree-crop species combination, and this management system, the presence of trees was associated with several negative results including 50\% lower yields in vines $2 \mathrm{~m}$ from the hedgerow, $31 \%$ lower yields in vines $4 \mathrm{~m}$ from the hedgerow, and $21 \%$ fewer tannins in must in vines within $2 \mathrm{~m}$ of the hedgerow. However, the presence of trees was also associated with indicators of high quality wine, including higher glucose/fructose levels, higher brix levels, higher density, and higher TA. Beyond $6 \mathrm{~m}$ it appears that trees did not have a significant effect on any variables, although this should be investigated further before conclusions are drawn. Because the most severe negative effects on yield were observed within $4 \mathrm{~m}$ of the hedgerow, we maintain that vineyard agroforestry systems may very well be a viable practice, as long as farmers are prepared to deal with the reductions in yield within $4 \mathrm{~m}$ of the hedgerow and/or implement management strategies to address them.

The differences in glucose/fructose, brix, density, TA, tannins, vigor, and yield that we observed could have been caused by interactions between grapevines and olive trees such as competition for nutrients, competition for water, competition for light, a windbreak effect, or a microclimatic effect. Due to the limitations of this study, we were only able to examine competition for nutrients. We cannot conclude that competition for nutrients between grapevines and olive trees played any role in any of the changes that we observed in vines at different distances from the olive tree hedgerow. 
From previous studies examining the effect of shade and competition for water in vineyards, we can speculate that many of the grape yield and quality differences we observed were impacted by competition for light and competition for water. Because shade from trees reduces both PAR and temperature, we hypothesize that many of the differences we observed are affected by temperature or the interaction between temperature and PAR.

Depending on winemaker goals, the beneficial effects that trees appear to have on grape must quality parameters, in addition to the ecosystem services they provide, may outweigh the negative effects that trees have on yield in vines close to trees. Additionally, given that climate change models predict yield and quality reductions in vineyards in the coming years due to higher temperatures and earlier budbreak, and given the fact that vineyard agroforestry systems mitigate many of these detrimental effects, farmers may determine that vineyard agroforestry systems are more beneficial than harmful. Presented with the options of either lower yield yet higher quality due to the incorporation of trees into vineyards, or lower yield and lower quality due to climate change, many farmers likely will decide that vineyard agroforestry systems are indeed the better choice.

\section{VII.8.2. Future Research}

This study examined a very specific Malbec grapevine and olive tree agroforestry system in an arid and irrigated climate region. Vitis vinifera sp. as a species is highly sensitive to both terroir and vineyard management practices, so it is important to not extrapolate the findings of this study to other climate regions and growing conditions, but rather, to use them as a base for future studies. Similar studies with other tree-vine combinations, design layouts, trellis systems, vine row orientations, and growing regions are important to undergo. 
Because of limited funding for this study, there were many variables that we were unable to measure, such as percent fruit set, number of berries per cluster, and number of clusters per vine. If time was not a limiting factor it would have also been interesting to analyze the wine made from each treatment, so as to determine if the individual quality metrics that we observed resulted in overall balanced or unbalanced flavor profiles in fermented and aged wine.

Another limitation of this study was that, although significant differences were observed in many of the variables that we measured, we were unable to determine the causes of those differences. There are many competitive interactions that could have caused the differences we observed, including competition for light, differences in wind exposure, competition for water, competition for nutrients, or a combination of all of the above. This study only examined competition for nutrients, but future studies should investigate other competitive factors.

Future studies should include examining PAR and PPFD to determine the amount of shade imparted by olive trees throughout the entire growing season, measuring water stress through C13 isotope spectrometry, quantifying actual water use in each species through sap flow measurements, and monitoring microclimatic effects through heat balance and heat pulse technology. By determining the limiting factors contributing to reduced vigor and yield in vineyard agroforestry systems, management strategies for controlling competition can be developed, and vineyard agroforestry systems can begin to be adopted. 


\section{BIBLIOGRAPHY}

Abeysinghe SK, Greer DH, Rogiers SY (2019) The effect of light intensity and temperature on berry growth and sugar accumulation in Vitis vinifera 'Shiraz' under vineyard conditions. Vitis 58:7-16

Abraham EM, Martínez FR (2000) Inventario de Recursos para la Planificación y Gestión de la Región Andina Argentina. Secretaría de Ciencia y Tenología de Argentina. https://www.mendoza-conicet.gob.ar/ladyot/catalogo/cdandes/start.htm. Accessed 6 April 2020

Adams DO (2006) Phenolics and Ripening in Grape Berries. American Journal of Enology and Viticulture 57:249-256

Archer E, Strauss HC (1989) Effect of Shading on the Performance of Vitis Vinifera L. CV. Cabernet Sauvignon. South African Journal of Enology and Viticulture 10:74-76

Azuma A, Yakushiji H, Koshita Y, Kobayashi S (2012) Flavonoid biosynthesis-related genes in grape skin are differentially regulated by temperature and light conditions. Planta 236:1067-1080

Baldwin JG (1964) The relation between weather and fruitfulness of the sultana vine. Australian Jouranl of Agricultural Research 15:920-928

Bergqvist J, Dokoozlian N, Ebisuda N (2001) Sunlight Exposure and Temperature Effects on Berry Growth and Composition of Cabernet Sauvignon and Grenache in the Central San Joaquin Valley of California. American Journal of Enology and Viticulture 52:17

Blancquaert EH, Oberholster A, Ricardo-da-Silva JM, Deloire AJ (2019) Grape Flavonoid Evolution and Composition Under Altered Light and Temperature Conditions in Cabernet Sauvignon (Vitis vinifera L.). Frontiers in Plant Science 10:1062

Bogs J, Downey MO, Harvey JS, Ashton AR, Tanner GJ, Robinson SP (2005) Proanthocyanidin Synthesis and Expression of Genes Encoding Leucoanthocyanidin Reductase and Anthocyanidin Reductase in Developing Grape Berries and Grapevine Leaves. Plant Physiology 139:652-663

Bonada M, Sadras V, Moran M, Fuentes S (2013) Elevated temperature and water stress accelerate mesocarp cell death and shrivelling, and decouple sensory traits in Shiraz berries. Irrigation Science 31:1317-1331

Boudreau IV TF, Peck GM, O'Keefe SF, Stewart A (2018) Free amino nitrogen concentration correlates to total yeast assimilable nitrogen concentration in apple juice. Food Science \& Nutrition 6:119-123

Boulton R (1980) The relationship between total acidity, titratable acidity, and $\mathrm{pH}$ in wine. American Journal of Enology and Viticulture 31:76-80

Boulton RB, Singleton VL, Bisson LF, Kunkee RE (1999) Juice and Wine Acidity. In: Principles and Practices of Winemaking. Springer, Boston, MA

Buttrose MS (1970) Fruitfulness in grape-vines: The response of different cultivars to light, temperature and daylength. Vitis 9:121-125

Buttrose MS, Hale CR, Kliewer WM (1971) Effect of Temperature on the Composition of 'Cabernet Sauvignon' Berries. American Journal of Enology and Viticulture 22:71-75

Chirko CP, Gold MA, Nguyen PV, Jiang JP (1996) Influence of orientation on wheat yield and photosynthetic photon flux density (Qp) at the tree and crop interface in a Paulownia-wheat intercropping system. Forest Ecology and Management 89:149-156

Comuzzo P, Battistutta F (2019) Chapter 2 - Acidification and pH Control in Red Wines. In: Morata A (ed) Red Wine Technology. Elsevier, pp 17-34 
Considine JA, Frankish E (2014) Chapter 10 - Essential Analyses. In: Considine JA, Frankish E (eds) A Complete Guide to Quality in Small-Scale Winemaking. Elsevier, London, pp 137-154

Crippen DD, Morrison JC (1986) The Effects of Sun Exposure on the Phenolic Content of Cabernet Sauvignon Berries During Development. American Journal of Enology and Viticulture 37:243-247

Departamento General de Irrigación (2016) Climatología y fisiografía de Mendoza. Aquabook. http://aquabook.agua.gob.ar/384_0. Accessed 6 April 2020

Dokoozlian NK (2016) Grape Berry Growth and Development. In: The Grapevine. UC Davis, Davis, California

Dokoozlian NK, Kliewer WM (1996) Influence of Light on Grape Berry Growth and Composition Varies during Fruit Development. Journal of the American Society of Horticultural Science 121:869-874

Dry PR, Botting DG (1993) The Effect of Wind on the Performance of Cabernet Franc Grapevines. Australian and New Zealand Wine Industry Journal 8:347-352

Esteban MA, Villanueva MJ, Lissarrague JR (2001) Effect of irrigation on changes in the anthocyanin composition of the skin of cv Tempranillo (Vitis vinifera L) grape berries during ripening. Journal of the Science of Food and Agriculture 81

Ferreira AM, Mendes-Faia A (2020) The Role of Yeasts and Lactic Acid Bacteria on the Metabolism of Organic Acids during Winemaking. Foods 9:1231

Fujita A, Goto-Yamamoto N, Aramaki I, Hashizume K (2006) Organ-Specific Transcription of Putative Flavonol Synthase Genes of Grapevine and Effects of Plant Hormones on Shading and Flavonol Biosynthesis in Grape Berry Skins. Bioscience, Biotechnology, and Biochemistry 70:632-638

Fushing H, Lee O, Heitkamp C, Heymann H, Ebeler SE, Boulton RB, Koehl P (2019) Unraveling the Regional Specificities of Malbec Wines from Mendoza, Argentina, and from Northern California. Agronomy 9:234

Gómez-del-Campo M, Ruiz C, Lissarrague JS (2002) Effect of Water Stress on Leaf Area Development, Photosynthesis, and Productivity in Chardonnay and Airén Grapevines. American Journal of Enology and Viticulture 53: 138-143

Gosme M, Delmotte S, Grimaldi J, Trambouze W (2019) Diachronic study of the effect of growing trees on grapevine yield: 24 years of experience in the South of France. 4th World Congress on Agroforestry, INRA SYSTEM. Conference Paper, Montpellier, France

Greer DH, Weedon MM (2013) The impact of high temperatures on Vitis vinifera cv. Semillon grapevine performance and berry ripening. Frontiers in Plant Science 4:491

Grimaldi J (2018) Impacts of agroforestry on microclimate for grape and wine production: assessment in Southern France. Dissertation, University of Toulouse, France

Grimaldi J, Trambouze W, Dufourcq T, Vergnes M, Pelletier C, Helen F, Fieuzal R, Houet T, Bustillo V (2017) Can intercropped trees mitigate heat and drought effects on grapevines? A study of microclimate patterns in agroforestry vineyards, Southern France. In: Proceedings of the IUFRO Landscape Ecology Conference, 24-29 September 2017, Halle, Germany

Gouot JC, Smith JP, Holzapfel BP, Barril C (2019) Grape Berry Flavonoid Responses to High Bunch Temperatures Post Véraison: Effect of Intensity and Duration of Exposure. Molecules 24:4341

Harbertson J, Spayd S (2005) Measuring Phenolics in the Winery. American Journal of Enology and Viticulture 57:280-288 
Hopping (1975) Effect of light intensity during cane development on subsequent bud break and yield of 'Palomino' grape vines. New Zealand Journal of Experimental Agriculture 5:287-290

Kailis S, Harris DJ (2007) Producing Table Olives. Landlinks Press, Collingwood, VIC, Australia

Keller M (2010) Managing grapevines to optimize fruit development in a challenging environment: a climate change primer for viticulturists. Australian Journal of Grape and Wine Research 16:56-69

Kemp B, Pedneault K, Pickering G, Usher K, Willwerth J (2019) Red Winemaking in Cool Climates. In: Morata A (ed) Red Wine Technology. Elsevier, London, pp 17-34

Kimball D (1991) Brix and Soluble Solids. In: Kimball D (ed) Citrus Processing: Quality Control and Technology. Van Nostrand Reinhold, New York, NY pp $7-33$

Kliewer WM (1982) Vineyard canopy management - a review. In: Webb AD (ed) Grape and Wine Centennial Symposium Proceedings (18-21 June 1980). University of California, Davis, California, pp 342-325

Kliewer WM, Smart RE (1989) Canopy Manipulation for Optimizing Vine Microclimate, Crop Yield, and Composition of Grapes. In: Wright CJ (ed) Manipulation of Fruiting. Butterworths, London, pp 275-291

Kodur S (2011) Effects of juice $\mathrm{pH}$ and potassium on juice and wine quality, and regulation of potassium in grapevines through rootstocks (Vitis): a short review. VITIS Journal of Grapevine Research 50: 1-6

Kriedemann PE (1968) Photosynthesis in vine leaves as a function of light intensity, temperature, and leaf age. Vitis 7:213-220

Lee J (2017) Light exclusion influence on grape anthocyanin. Heliyon 3:e00243

Liberman GL (2014) The Argentine wine industry: creating new spaces for coordination? Prometheus 31:305-318

Marshall JK (1967) The effect of shelter on the productivity of grasslands and field crops. Field Crop Abstract 20:1-14

Martínez-Lüscher, Chen CCL, Brillante L, Kurtural SH (2017) Partial Solar Radiation Exclusion with Color Shade Nets Reduces the Degradation of Organic Acids and Flavonoids of Grape Berry (Vitis vinifera L.). Journal of Agricultural and Food Chemistry 65:10693-10702

Mattivi F, Guzzon R, Vrhovsek U, Stefanini M, Velasco R (2006) Metabolite Profiling of Grape: Flavonols and Anthocyanins. Journal of Agricultural and Food Chemistry 54:7692-7702

May P, Antcliff AJ (1963) The Effect of Shading on Fruitfulness and Yield in the Sultana. Journal of Horticultural Science 38:85-94

McCarthy MG, Cirami RM, McCloud P (1983) Vine and Fruit Responses to Supplementary Irrigation and Canopy Management. South African Journal of Enology and Viticulture 4:67-76

Millar AA (1972) Thermal Regime of Grapevines. American Journal of Enology and Viticulture 23:173-176

Mendoza Gobierno (2021) Agrometeorología: Datos Estadísticos - Anuales. Retrieved 5 April 2021 from https://www.mendoza.gov.ar/contingencias/agrometeorologia/

Morrison JC, Noble AC (1990) The Effects of Leaf and Cluster Shading on the Composition of Cabernet Sauvignon Grapes and on Fruit and Wine Sensory Properties. American Journal of Enology and Viticulture 41:193-200

Nair PK (2011) Methodological Challenges in Estimating Carbon Sequestration Potential of Agroforestry Systems. In: Mohan Kumar B, Nair PK (eds) Carbon Sequestration 
Potential of Agroforestry Systems - Opportunities and Challenges. Springer, Dordrecht, pp 3-16

Pachauri RK, Meyer L (2015) Climate Change 2014 Synthesis Report. Intergovernmental Panel on Climate Change, World Meteorological Organization (WMO). Report, Geneva, Switzerland

Price SF, Breen PJ, Valladao M, Watson BT (1995) Cluster Sun Exposure and Quercetin in Pinot noir Grapes and Wine. American Journal of Enology and Viticulture 46:187194

Rice S, Koziel JA, Dharmadhikari M, Fennell A (2017) Evaluation of Tannins and Anthocyanins in Marquette, Frontenac, and St. Croix Cold-Hardy Grape Cultivars. Fermentation 3:47

Robinson JB (1992) Grapevine Nutrition. In: Coombe BG, Dry PR (eds) Viticulture: Volume 2, Practices. Winetitle, Adelaide, Australia, pp 178-208

Ruffner HP, Hawker JS, Hale CR (1976) Temperature and enzymatic control of malate metabolism in berries of Vitis vinifera. Phytochemistry 15:1877-1880

Sadler GD, Murphy PA (2010) PH and Titratable Acidity. In: Nielsen S (ed) Food Analysis, $4^{\text {th }}$ Edition. Springer, New York, pp 219-238

Sánchez LA, Dokoozlian NK (2005) Bud Microclimate and Fruitfulness in Vitis vinifera L. American Journal of Enology and Viticulture 56:319-329

Schultz HR (2003) Differences in hydraulic architecture account for nearisohydric and anisohydric behaviour of two field-grown Vitis vinifera L. cultivars during drought. Plant, Cell and Environment 26:1393-1405

Shaulis NJ (1982) Responses of grapevines and grapes to spacing of and within canopies. In: Webb AD (ed) Grape and Wine Centennial Symposium Proceedings (18-21 June 1980). University of California, Davis, California, pp 353-361

Skinkis PA, Vance AJ (2013) Understanding Vine Balance: An Important Concept in Vineyard Management. Oregon State University Extension Service. https://catalog.extension.oregonstate.edu/em9068. Accessed 6 April 2020

Smart RE (1974) Aspects of Water Relations of the Grapevine (Vitis vinifera). American Journal of Enology and Viticulture 25:84-91

Smart RE, Dick JK, Gravett IM, Fisher BM (1990) Canopy Management to Improve Grape Yield and Wine Quality - Principles and Practices. South African Journal of Enology and Viticulture 11:3-17

Smart RE, Robinson M (1991) Sunlight into Wine: A Handbook for Winegrape Canopy Management. Winetitles, Adelaide, Australia

Spayd SE, Tarara JM, Mee DL, Ferguson JC (2002) Separation of Sunlight and Temperature Effects on the Composition of Vitis vinifera cv. Merlot Berries. American Journal of Enology and Viticulture 53:171-182

Srinivasan C, Mullins MG (1981) Physiology of Flowering in the Grapevine - A Review. American Journal of Enology and Viticulture 32:47-63

Stevens RM, Harvey G, Aspinall D (1995) Grapevine growth of shoots and fruit linearly correlate with water stress indices based on root-weighted soil matric potential. Australian Journal of Grape and Wine Research 1:58-66

Sun R, Cheng G, Li Q, He Y, Wang Y, Lan Y, Li S, Zhu Y, Song W, Zhang X, Cui X, Chen W, Wang J (2017) Light-induced Variation in Phenolic Compounds in Cabernet Sauvignon Grapes (Vitis vinifera L.) Involves Extensive Transcriptome Reprogramming of Biosynthetic Enzymes, Transcription Factors, and Phytohormonal Regulators. Frontiers in Plant Science 8:547 
Sweetman C, Sadras VO, Hancock RD, Soole KL, Ford CM (2014) Metabolic effects of elevated temperature on organic acid degradadtion in ripening Vitis vinifera fruit. Journal of Experimental Botany 65:5975-5988

Tarara J, Ferguson J, Hoheisel G, Perez J (2005) Assymetrical canopy architecture due to prevailing wind direction and row orientation creates an imbalance in irradiance at the fruiting zone of grapevines. Agricultural and Forest Meteorology 135:144-155

Van zyl JL (1984) Response of Colombar Grapevines to Irrigation as Regards Quality Aspects and Growth. South African Journal of Enology and Viticulture 5:19-28

Waterhouse AL (2003) Determination of Total Phenolics. Current Protocols in Food Analytical Chemistry 6: I1.1.1-I1.1.8

Winkel T, Rambal S (1993) Influence of Water Stress on Grapevines Growing in the Field: from Leaf to Whole-plant Response. Australian Journal of Plant Physiology 20:143157

Wolf T (2008) Wine Grape Production Guide for Eastern North America. Natural Resource, Agriculture, and Engineering Service

Zuritz CA, Muñoz Puntes E, Cabeza MS (2005) Density, viscosity and coefficient of thermal expansion of clear grape juice at different soluble solid concentrations and temperatures. Journal of Food Engineering 71: 143-149 


\section{APPENDIX A}

\section{REGIONAL CLIMATE CHARACTERISTICS}

Table 1. Maximum, minimum, and median monthly temperatures in ${ }^{\circ} \mathrm{C}$ taken during 2018 , 2019, and 2020 from the Perdriel weather station at Belasco de Baquedano in Lujan de Cuyo, Argentina. Source: Mendoza Gobierno (2021).

\begin{tabular}{|r|r|r|r|}
\hline Date & Max & Median & \multicolumn{1}{c|}{ Min } \\
\hline $01-2018$ & 38.0 & 21.6 & 9.3 \\
\hline $02-2018$ & 36.0 & 20.8 & 3.4 \\
\hline $03-2018$ & 30.6 & 16.2 & -1.1 \\
\hline $04-2018$ & 29.8 & 14.0 & -0.5 \\
\hline $05-2018$ & 21.0 & 8.3 & -1.8 \\
\hline $06-2018$ & 23.2 & 3.8 & -9.4 \\
\hline $07-2018$ & 25.6 & 3.0 & -8.7 \\
\hline $08-2018$ & 25.3 & 6.4 & -7.9 \\
\hline $09-2018$ & 33.1 & 12.5 & -4.6 \\
\hline $10-2018$ & 29.3 & 14.2 & -1.4 \\
\hline $11-2018$ & 34.8 & 17.9 & 3.8 \\
\hline $12-2018$ & 34.6 & 19.7 & 5.0 \\
\hline
\end{tabular}

\begin{tabular}{|r|r|r|r|}
\hline Date & \multicolumn{1}{|c|}{ Max } & Median & Min \\
\hline $01-2018$ & 37.2 & 21.1 & 5.5 \\
\hline $02-2018$ & 34.2 & 20.5 & 4.8 \\
\hline $03-2018$ & 31.8 & 15.7 & 0.9 \\
\hline $04-2018$ & 28.8 & 13.7 & 1.3 \\
\hline $05-2018$ & 23.3 & 8.2 & -3.5 \\
\hline $06-2018$ & 20.2 & 5.1 & -6.5 \\
\hline $07-2018$ & 20.2 & 4.5 & -9.4 \\
\hline $08-2018$ & 28.6 & 0.8 & -8.6 \\
\hline $09-2018$ & 29.6 & 10.3 & -7.4 \\
\hline $10-2018$ & 30.3 & 13.9 & -0.8 \\
\hline $11-2018$ & 32.7 & 20.0 & 4.4 \\
\hline $12-2018$ & 35.6 & 21.1 & 4.4 \\
\hline
\end{tabular}

\begin{tabular}{|r|r|r|r|}
\hline Date & \multicolumn{1}{|c|}{ Max } & Median & \multicolumn{1}{c|}{ Min } \\
\hline $01-2018$ & 35.9 & 22.6 & 6.4 \\
\hline $02-2018$ & 34.3 & 19.4 & 6.5 \\
\hline $03-2018$ & 33.4 & 19.4 & 7.0 \\
\hline $04-2018$ & 25.3 & 12.5 & 1.2 \\
\hline $05-2018$ & 26.4 & 7.5 & -5.1 \\
\hline $06-2018$ & 29.0 & 4.1 & -7.7 \\
\hline $07-2018$ & 21.2 & 3.6 & -7.3 \\
\hline $08-2018$ & 22.0 & 6.3 & -9.9 \\
\hline $09-2018$ & 26.7 & 11.6 & -4.8 \\
\hline $10-2018$ & 31.5 & 14.6 & -2.7 \\
\hline $11-2018$ & 31.9 & 18.7 & 4.6 \\
\hline $12-2018$ & 36.7 & 20.5 & 5.6 \\
\hline
\end{tabular}

Table 2. Typical Soil Characteristics for the Maipu region of Mendoza, Argentina. Data retrieved from the National Institute of Agricultural Technology (INTA).

\begin{tabular}{|l|l|}
\hline \multicolumn{2}{|c|}{ Total N } \\
\hline$>1000$ & Very high \\
\hline $800-1000$ & High \\
\hline $600-800$ & Medium \\
\hline $400-600$ & Low \\
\hline$<400$ & Very Low \\
\hline
\end{tabular}

\begin{tabular}{|c|c|}
\hline $\mathrm{P} \mathrm{H}_{2} \mathrm{CO}_{3}$ & 1:10 $\left(\mathrm{mg} \mathrm{kg}^{-1}\right)$ \\
\hline$>6.5$ & Very high \\
\hline $4.5-6.5$ & High \\
\hline $3.5-4.5$ & Medium \\
\hline $2.5-3.5$ & Low \\
\hline$<2.5$ & Very Low \\
\hline
\end{tabular}

\begin{tabular}{|l|l|}
\hline K Int NH4OAc & pH 7 $\left(\mathbf{m g ~ k g}^{-1}\right)$ \\
\hline$>200$ & High \\
\hline $150-200$ & Good \\
\hline $100-150$ & Poor \\
\hline $50-100$ & Poor \\
\hline$<50$ & Very Poor \\
\hline
\end{tabular}

\begin{tabular}{|c|c|}
\hline Sedimentation & Volume $\left(\mathrm{cm}^{3} \%\right)$ \\
\hline$<80$ & Sand \\
\hline $80-93$ & Silty Sand \\
\hline $94-104$ & Silt \\
\hline $105-115$ & Silt Loam \\
\hline $116-135$ & Loamy Clay \\
\hline 136-139 & $\begin{array}{l}\text { Loamy Clayey } \\
\text { Silt }\end{array}$ \\
\hline$>140$ & Clay \\
\hline
\end{tabular}




\section{APPENDIX B}

\section{BACKGROUND SITE UNIFORMITY TESTS}

Table 1. Circumference and diameter at breast height of all 17 olive trees in the olive tree hedgerow "treatment" at the experimental site, Catapano Family Vineyard, Maipu, Mendoza, Argentina, 2019.

\begin{tabular}{|c|c|c|}
\hline Tree Number & Circumference (cm) & Diameter (cm) \\
\hline 1 & 192 & 61.0 \\
\hline 2 & 173 & 55.0 \\
\hline 3 & 105 & 33.5 \\
\hline 4 & 59 & 19.0 \\
\hline 5 & 125 & 40.0 \\
\hline 6 & 97 & 31.0 \\
\hline 7 & 71 & 22.5 \\
\hline 8 & 215 & 68.5 \\
\hline 9 & 125 & 40.0 \\
\hline 10 & 110 & 35.0 \\
\hline 11 & 200 & 64.0 \\
\hline 12 & 117 & 37.0 \\
\hline 13 & 89 & 28.0 \\
\hline 14 & 80 & 25.5 \\
\hline 15 & 58 & 18.5 \\
\hline 16 & 69 & 22.0 \\
\hline 17 & 55 & 17.5 \\
\hline
\end{tabular}

Table 2. Soil uniformity analysis at Catapano Family Vineyard, Maipu, Mendoza, Argentina, 2019. The site was divided into four equal-sized transects: northwest, northeast, southwest, and southeast. The analysis of soil quality and nutritional characteristics was performed at the Laboratory of Pedology (Laboratorio Cátedra de Edafología) at the College of Agricultural Sciences in Lujan de Cuyo, Argentina.

\begin{tabular}{|c|c|c|c|c|c|c|c|c|c|c|c|}
\hline North East Sector & $\mathrm{EC}(\mathrm{dS} / \mathrm{m})$ & $\mathrm{PH}$ & $\mathbf{N}$ & $\mathbf{P}$ & $\mathrm{K}$ & $\mathrm{d}$ & $\mathrm{Na}(\mathrm{me} / \mathrm{L})$ & $\mathrm{Ca}(\mathrm{me} / \mathrm{L})$ & $\mathrm{Mg}$ (me/l) & $\mathrm{OM}$ & $\mathrm{C} / \mathrm{N}$ \\
\hline Silt Loam 0-30 & 2.61 & 7.44 & 1332.00 & 10.50 & 348.00 & 17.00 & 6.50 & 24.80 & 7.30 & 2.44 & 10.60 \\
\hline Silt Loam 30-60 & 3.13 & 7.37 & 1037.00 & 10.50 & 178.00 & 21.00 & 10.90 & 23.60 & 5,40 & 1.77 & 9.90 \\
\hline North West Sector & $E C(d S / m)$ & $\mathrm{PH}$ & $\mathbf{N}$ & $\mathbf{P}$ & K & d & $\mathrm{Na}(\mathrm{me} / \mathrm{L})$ & $\mathrm{Ca}(\mathrm{me} / \mathrm{L})$ & $\mathrm{Mg}(\mathrm{me} / \mathrm{L})$ & OM & $C / N$ \\
\hline $\operatorname{Lam} 0-30$ & 7.28 & 7.58 & 1099.00 & 10.80 & 312.00 & 53.00 & 21.70 & 50.40 & 14.30 & 1.74 & 9.20 \\
\hline Loam $30-60$ & 4.33 & 7.41 & 681.00 & 8.30 & 182.00 & 29.00 & 14.10 & 37.60 & 2.90 & 0.99 & 8.50 \\
\hline South East Sector & $E C(\mathrm{dS} / \mathrm{m})$ & PH & N & $\mathbf{P}$ & K & a & $\mathrm{Na}(\mathrm{me} / \mathrm{L})$ & $\mathrm{Ca}(\mathrm{me} / \mathrm{L})$ & $\mathrm{Mg}(\mathrm{me} / \mathrm{h})$ & $\mathrm{OM}$ & $C / N$ \\
\hline $\operatorname{Lam} 0-30$ & 2.22 & 7.58 & 2044.00 & 9.33 & 424.00 & 8.60 & 5.40 & 16.40 & 3.00 & 2.69 & 7.60 \\
\hline Loam $30-60$ & 2.16 & 7.71 & 573.00 & 5.90 & 306.00 & 9.00 & 7.60 & 17.60 & 2.60 & 0.72 & 7.30 \\
\hline South West Sector & $E C(d S / m)$ & PH & $\mathbf{N}$ & $\mathbf{P}$ & K & d & $\mathrm{Na}(\mathrm{me} / \mathrm{L})$ & $C a(m e / L)$ & $\mathrm{Mg}(\mathrm{me} / \mathrm{L})$ & OM & $C / N$ \\
\hline Loam 0-30 & 4.31 & 7.55 & 1254.00 & 7.40 & 296.00 & 18.00 & 17.40 & 33.20 & 8.50 & 2.00 & 9.20 \\
\hline Loam 30-60 & 3.78 & 7.59 & 526.00 & 7.80 & 158.00 & 15.00 & 18.50 & 25.60 & 5.40 & 0.91 & 10.00 \\
\hline
\end{tabular}


Table 3. Additional background uniformity soil analyses at Catapano Vineyard, Maipu, Mendoza, Argentina. The site was divided into four equal-sized transects: northwest, northeast, southwest, and southeast. The analysis of soil quality and nutritional characteristics was performed at the Laboratory of Pedology (Laboratorio Cátedra de Edafología) at the College of Agricultural Sciences in Lujan de Cuyo, Argentina.

\begin{tabular}{|c|c|c|c|c|c|c|}
\hline Area & $\begin{array}{c}\text { Depth } \\
(\mathbf{c m})\end{array}$ & $\begin{array}{c}\text { Sodium } \\
\text { Absorption } \\
\text { Ratio }\end{array}$ & $\begin{array}{c}\text { Carbonates } \\
(\mathbf{m e} / \mathbf{L})\end{array}$ & $\begin{array}{c}\text { Bicarbonates } \\
(\mathbf{m e} / \mathbf{L})\end{array}$ & $\begin{array}{c}\text { Chlorides } \\
(\mathbf{m e} / \mathbf{L})\end{array}$ & $\begin{array}{c}\text { Sulfates } \\
(\mathbf{m e} / \mathbf{L})\end{array}$ \\
\hline $\mathrm{NW}$ & $0-30$ & 3.8 & 0.0 & 4.0 & 53.0 & 29.4 \\
\hline $\mathrm{NE}$ & $0-30$ & 1.6 & 0.0 & 2.5 & 17.0 & 19.2 \\
\hline $\mathrm{SW}$ & $0-30$ & 3.8 & 0.0 & 2.0 & 18.0 & 39.1 \\
\hline $\mathrm{SE}$ & $0-30$ & 1.7 & 0.0 & 3.0 & 8.0 & 13.9 \\
\hline $\mathrm{NW}$ & $30-60$ & 3.1 & 0.0 & 2.5 & 29.0 & 23.1 \\
\hline $\mathrm{NE}$ & $30-60$ & 2.9 & 0.0 & 2.5 & 21.0 & 16.3 \\
\hline $\mathrm{SW}$ & $30-60$ & 4.7 & 0.0 & 2.0 & 15.0 & 32.4 \\
\hline $\mathrm{SE}$ & $30-60$ & 2.4 & 0.0 & 1.5 & 9.0 & 17.3 \\
\hline
\end{tabular}




\section{APPENDIX C}

\section{SELECTION OF OBSERVATIONAL UNITS}

Table 1. Vine trunk diameter values for all vines within all treatment blocks, taken at $40 \mathrm{~cm}$ above soil. Trunk diameter values determined to be outliers are highlighted in red and were removed from the sampling pool. 


\begin{tabular}{|c|c|}
\hline & $\begin{array}{l}\text { Vine } \\
\text { Number }\end{array}$ \\
\hline & 1 \\
\hline & 2 \\
\hline & 3 \\
\hline & 4 \\
\hline & 5 \\
\hline & 6 \\
\hline & 7 \\
\hline & 8 \\
\hline & 9 \\
\hline & 10 \\
\hline & 11 \\
\hline & 12 \\
\hline & 13 \\
\hline & 14 \\
\hline & 15 \\
\hline & 16 \\
\hline Rep 1 & 17 \\
\hline & 18 \\
\hline & 19 \\
\hline & 20 \\
\hline & 21 \\
\hline & 22 \\
\hline & 23 \\
\hline & 24 \\
\hline & 25 \\
\hline & 26 \\
\hline & 27 \\
\hline & 28 \\
\hline & 29 \\
\hline & 30 \\
\hline & 31 \\
\hline & 32 \\
\hline & 33 \\
\hline & 34 \\
\hline & 35 \\
\hline & 36 \\
\hline & 37 \\
\hline & 38 \\
\hline & 39 \\
\hline & 40 \\
\hline & 41 \\
\hline & 42 \\
\hline & 43 \\
\hline & 44 \\
\hline & 45 \\
\hline & 46 \\
\hline & 47 \\
\hline Rep 2 & 48 \\
\hline Kep 2 & 49 \\
\hline & 50 \\
\hline & 51 \\
\hline & 52 \\
\hline & 53 \\
\hline & 54 \\
\hline & 55 \\
\hline & 56 \\
\hline & 57 \\
\hline & 58 \\
\hline & 59 \\
\hline & 60 \\
\hline & 61 \\
\hline & 62 \\
\hline & 63 \\
\hline & 64 \\
\hline & 65 \\
\hline & 66 \\
\hline & 67 \\
\hline & 68 \\
\hline & 69 \\
\hline & 70 \\
\hline & 71 \\
\hline & 72 \\
\hline & 73 \\
\hline & 74 \\
\hline & 75 \\
\hline & 76 \\
\hline & 77 \\
\hline & 78 \\
\hline & 79 \\
\hline & 80 \\
\hline Rep 3 & 81 \\
\hline & 82 \\
\hline & 83 \\
\hline & 84 \\
\hline & 85 \\
\hline & 86 \\
\hline & 87 \\
\hline & 88 \\
\hline & 89 \\
\hline & 90 \\
\hline & 91 \\
\hline & 92 \\
\hline & 93 \\
\hline & 94 \\
\hline & 95 \\
\hline & 96 \\
\hline
\end{tabular}


Table 2. Selection of observational units. Final observational units were selected after having discarded vines with diameters outside of the interquartile range. Vines were numbered from 1-96 from North to South, beginning at the 13th vine from the North in each treatment row so as to remove vines impacted by the edge effect from the sampling pool.

○ $40 \mathrm{~m}$ from Hedgerow:

- Rep 1:2, 6, 14, 23, 31

- Rep 2: 46, 49, 51, 60, 62

- Rep 3:69, 75, 86, 88, 95

○ $12 \mathrm{~m}$ from Hedgerow:

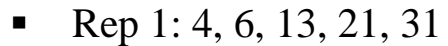

- $\operatorname{Rep} 2: 35,40,49,57,60$

- Rep 3: 70, 75, 78, 82, 94

- $6 \mathrm{~m}$ from Hedgerow:

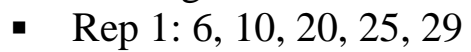

- Rep 2: 34, 52, 55, 61, 64

- Rep 3: 71, 73, 79, 81, 94

○ $4 \mathrm{~m}$ from Hedgerow:

- $\quad$ Rep 1: 7, 10, 16, 17, 32

- Rep 2: 36, 39, 46, 56, 60

- Rep 3: 71, 73, 75, 89, 94

- $2 \mathrm{~m}$ from Hedgerow:

- $\operatorname{Rep~1:4,8,18,25,26}$

- Rep 2: 33, 40, 42, 49, 60

- Rep 3: 66, 77, 86, 88, 90 


\section{APPENDIX D}

\section{RAW DATA FOR QUALITY, PRODUCTION, GROWTH, AND NUTRITIONAL PARAMETERS}

Table 1. Grape must quality data, analyzed by MAG S.R.L. Laboratory, in Mendoza, Argentina, March 2020.

\begin{tabular}{|c|c|c|c|c|c|c|c|c|}
\hline $\begin{array}{l}\text { Distance } \\
\text { from } \\
\text { Hedgerow } \\
\text { (m) }\end{array}$ & Rep & Glucose + Fructose $(\mathrm{g} / \mathrm{L})$ & Brix & $\begin{array}{c}\text { Density } \\
(\mathrm{g} / \mathrm{L})\end{array}$ & $\begin{array}{c}\text { Total Acidity } \\
\text { (B/L) }\end{array}$ & $\mathrm{pH}$ & $\begin{array}{l}\text { Malic Acid } \\
\qquad(\mathrm{g} / \mathrm{L})\end{array}$ & $\begin{array}{l}\text { Yeast Assimilable } \\
\text { Nitrogen (mg/L) }\end{array}$ \\
\hline 40 & 1 & 238.58 & 23.40 & 1.10 & 1.80 & 4.12 & 0.45 & 205.78 \\
\hline 40 & 2 & 235.58 & 23.30 & 1.10 & 1.75 & 4.13 & 0.60 & 216.30 \\
\hline 40 & 3 & 230.68 & 22.70 & 1.10 & 1.70 & 4.07 & 0.50 & 202.00 \\
\hline 12 & 1 & 243.51 & 23.80 & 1.10 & 1.92 & 3.99 & 0.51 & 246.45 \\
\hline 12 & 2 & 242.51 & 23.80 & 1.10 & 1.70 & 4.06 & 0.50 & 176.73 \\
\hline 12 & 3 & 255.14 & 24.90 & 1.11 & 1.78 & 4.11 & 0.35 & 195.75 \\
\hline 6 & 1 & 251.87 & 24.60 & 1.11 & 1.82 & 4.09 & 0.58 & 171.59 \\
\hline 6 & 2 & 250.91 & 24.70 & 1.11 & 1.75 & 4.28 & 0.55 & 233.28 \\
\hline 6 & 3 & 258.43 & 25.30 & 1.11 & 1.70 & 4.29 & 0.61 & 222.03 \\
\hline 4 & 1 & 258.55 & 25.20 & 1.11 & 1.80 & 4.29 & 0.51 & 195.20 \\
\hline 4 & 2 & 258.99 & 25.30 & 1.11 & 1.75 & 4.16 & 0.49 & 196.57 \\
\hline 4 & 3 & 261.62 & 25.50 & 1.11 & 2.06 & 4.07 & 0.64 & 193.67 \\
\hline 2 & 1 & 257.24 & 25.00 & 1.11 & 2.30 & 4.07 & 1.02 & 194.15 \\
\hline 2 & 2 & 273.64 & 26.40 & 1.11 & 2.00 & 4.06 & 0.52 & 179.18 \\
\hline 2 & 3 & 259.80 & 25.10 & 1.11 & 2.23 & 3.92 & 0.56 & 186.60 \\
\hline
\end{tabular}

Table 2. Grape must quality data, analyzed by the laboratory at the National Institute for Agricultural Technology (INTA) in Lujan de Cuyo, Argentina, March 2020.

\begin{tabular}{|c|c|c|c|c|c|c|}
\hline $\begin{array}{l}\text { Distance } \\
\text { from } \\
\text { Hedgerow } \\
\text { (m) }\end{array}$ & Rep & $\begin{array}{c}\text { Total Berry } \\
\text { Skin } \\
\text { Phenolics } \\
\text { (mg/g fruit) }\end{array}$ & $\begin{array}{c}\text { Total Berry } \\
\text { Skin } \\
\text { Anthocyanins } \\
\text { (mg/g fruit) }\end{array}$ & $\begin{array}{c}\text { Total Berry } \\
\text { Skin } \\
\text { Tannins } \\
\text { (mg/g fruit) }\end{array}$ & $\begin{array}{l}\text { Total Seed } \\
\text { Phenolics } \\
\text { (mg/g fruit) }\end{array}$ & $\begin{array}{c}\text { Total Seed } \\
\text { Tannins } \\
\text { (mg/g fruit) }\end{array}$ \\
\hline 40 & 1 & 1.51 & 0.93 & 0.92 & 1.71 & 0.85 \\
\hline 40 & 2 & 1.17 & 1.10 & 0.80 & 2.00 & 1.16 \\
\hline 40 & 3 & 1.39 & 1.01 & 0.95 & 1.66 & 0.81 \\
\hline 12 & 1 & 1.26 & 1.06 & 0.99 & 2.37 & 1.34 \\
\hline 12 & 2 & 1.55 & 1.56 & 0.99 & 2.29 & 0.98 \\
\hline 12 & 3 & 1.46 & 1.45 & 0.90 & 2.38 & 0.68 \\
\hline 6 & 1 & 1.00 & 1.14 & 0.79 & 0.86 & 0.45 \\
\hline 6 & 2 & 1.65 & 1.10 & 1.02 & 2.68 & 1.18 \\
\hline 6 & 3 & 1.44 & 1.07 & 0.96 & 2.10 & 1.13 \\
\hline 4 & 1 & 1.22 & 1.17 & 0.83 & 1.71 & 0.68 \\
\hline 4 & 2 & 1.88 & 1.54 & 0.94 & 1.95 & 0.31 \\
\hline 4 & 3 & 1.79 & 1.29 & 0.91 & 1.33 & 0.41 \\
\hline 2 & 1 & 2.43 & 1.39 & 0.65 & 1.82 & 0.87 \\
\hline 2 & 2 & 1.03 & 1.66 & 0.76 & 1.75 & 0.80 \\
\hline 2 & 3 & 1.18 & 1.03 & 0.70 & 1.64 & 0.75 \\
\hline
\end{tabular}


Table 3. Grapevine production, vigor, and vine balance data, measured using an electronic scale. Ravaz Index was calculated using the Ravaz Index formula in Table 5.

\begin{tabular}{|c|c|c|c|c|c|}
\hline $\begin{array}{l}\text { Distance } \\
\text { from } \\
\text { Hedgerow } \\
\text { (m) }\end{array}$ & Rep & $\begin{array}{c}\text { Vine Number (Beginning at 13th } \\
\text { Vine from North) }\end{array}$ & $\begin{array}{l}\text { Total Vine } \\
\text { Yield }(\mathbf{k g})\end{array}$ & $\begin{array}{c}\text { Pruning } \\
\text { Weights } \\
(\mathrm{g} / \mathrm{m})\end{array}$ & Ravaz Index \\
\hline 40 & 1 & 2 & 1.3 & 388 & 3.35051546 \\
\hline 40 & 1 & 6 & 3.2 & 310 & 10.3225806 \\
\hline 40 & 1 & 14 & 2.7 & 220 & 12.2727273 \\
\hline 40 & 1 & 23 & 1.4 & 604 & 2.31788079 \\
\hline 40 & 1 & 31 & 0.9 & 428 & 2.10280374 \\
\hline 40 & 2 & 46 & 1.9 & 276 & 6.88405797 \\
\hline 40 & 2 & 49 & 2.5 & 379 & 6.59630607 \\
\hline 40 & 2 & 51 & 2.3 & 330 & 6.96969697 \\
\hline 40 & 2 & 60 & 3.2 & 375 & 8.53333333 \\
\hline 40 & 2 & 62 & 1.9 & 416 & 4.56730769 \\
\hline 40 & 3 & 69 & 2.1 & 367 & 5.72207084 \\
\hline 40 & 3 & 75 & 3.9 & 375 & 10.4 \\
\hline 40 & 3 & 86 & 1.8 & 258 & 6.97674419 \\
\hline 40 & 3 & 88 & 1.9 & 241 & 7.88381743 \\
\hline 40 & 3 & 95 & 2.9 & 478 & 6.06694561 \\
\hline 12 & 1 & 4 & 1.7 & 123 & 13.8211382 \\
\hline 12 & 1 & 6 & 1.3 & 98 & 13.2653061 \\
\hline 12 & 1 & 13 & 0.2 & 60 & 3.33333333 \\
\hline 12 & 1 & 21 & 2.3 & 129 & 17.8294574 \\
\hline 12 & 1 & 31 & 1.3 & 144 & 9.02777778 \\
\hline 12 & 2 & 35 & 1.8 & 261 & 6.89655172 \\
\hline 12 & 2 & 40 & 1.8 & 365 & 4.93150685 \\
\hline 12 & 2 & 49 & 2.1 & 260 & 8.07692308 \\
\hline 12 & 2 & 57 & 2 & 145 & 13.7931034 \\
\hline 12 & 2 & 60 & 0.7 & 133 & 5.26315789 \\
\hline 12 & 3 & 70 & 1.8 & 158 & 11.3924051 \\
\hline 12 & 3 & 75 & 0.8 & 459 & 1.74291939 \\
\hline 12 & 3 & 78 & 1.3 & 202 & 6.43564356 \\
\hline 12 & 3 & 82 & 1.9 & 274 & 6.93430657 \\
\hline 12 & 3 & 94 & 1.1 & 332 & 3.31325301 \\
\hline 6 & 1 & 6 & 2.3 & 274 & 8.39416058 \\
\hline 6 & 1 & 10 & 2.9 & 268 & 10.8208955 \\
\hline 6 & 1 & 20 & 1.5 & 94 & 15.9574468 \\
\hline 6 & 1 & 25 & 2.1 & 235 & 8.93617021 \\
\hline 6 & 1 & 29 & 2.1 & 376 & 5.58510638 \\
\hline 6 & 2 & 34 & 1.3 & 346 & 3.75722543 \\
\hline 6 & 2 & 52 & 1.4 & 362 & 3.86740331 \\
\hline 6 & 2 & 55 & 2 & 295 & 6.77966102 \\
\hline 6 & 2 & 61 & 2.3 & 490 & 4.69387755 \\
\hline 6 & 2 & 64 & 0.5 & 95 & 5.26315789 \\
\hline 6 & 3 & 71 & 1.2 & 347 & 3.45821326 \\
\hline 6 & 3 & 73 & 1.8 & 500 & 3.6 \\
\hline 6 & 3 & 79 & 2.7 & 452 & 5.97345133 \\
\hline 6 & 3 & 81 & 1.3 & 451 & 2.88248337 \\
\hline 6 & 3 & 94 & 1.8 & 260 & 6.92307692 \\
\hline 4 & 1 & 7 & 1.6 & 306 & 5.22875817 \\
\hline 4 & 1 & 10 & 1.8 & 280 & 6.42857143 \\
\hline 4 & 1 & 16 & 1.4 & 275 & 5.09090909 \\
\hline 4 & 1 & 17 & 1.9 & 310 & 6.12903226 \\
\hline 4 & 1 & 32 & 1.3 & 361 & 3.60110803 \\
\hline 4 & 2 & 36 & 1.3 & 344 & 3.77906977 \\
\hline 4 & 2 & 39 & 1.3 & 204 & 6.37254902 \\
\hline 4 & 2 & 46 & 2.6 & 355 & 7.32394366 \\
\hline 4 & 2 & 56 & 1.5 & 342 & 4.38596491 \\
\hline 4 & 2 & 60 & 2 & 156 & 12.8205128 \\
\hline 4 & 3 & 71 & 0.8 & 219 & 3.65296804 \\
\hline 4 & 3 & 73 & 1 & 181 & 5.52486188 \\
\hline 4 & 3 & 75 & 1.9 & 204 & 9.31372549 \\
\hline 4 & 3 & 89 & 1.5 & 387 & 3.87596899 \\
\hline 4 & 3 & 94 & 1.4 & 310 & 4.51612903 \\
\hline 2 & 1 & 4 & 1.5 & 530 & 2.83018868 \\
\hline 2 & 1 & 8 & 1.4 & 566 & 2.47349823 \\
\hline 2 & 1 & 18 & 1.1 & 212 & 5.18867925 \\
\hline 2 & 1 & 25 & 0.9 & 164 & 5.48780488 \\
\hline 2 & 1 & 26 & 0 & 162 & 0 \\
\hline 2 & 2 & 33 & 2.6 & 389 & 6.68380463 \\
\hline 2 & 2 & 40 & 0.8 & 148 & 5.40540541 \\
\hline 2 & 2 & 42 & 0.9 & 203 & 4.43349754 \\
\hline 2 & 2 & 49 & 0.9 & 42 & 21.4285714 \\
\hline 2 & 2 & 60 & 0.9 & 297 & 3.03030303 \\
\hline 2 & 3 & 66 & 1.1 & 214 & 5.14018692 \\
\hline 2 & 3 & 77 & 0.9 & 114 & 7.89473684 \\
\hline 2 & 3 & 86 & 1.4 & 108 & 12.962963 \\
\hline 2 & 3 & 88 & 0.4 & 294 & 1.36054422 \\
\hline 2 & 3 & 90 & 2.2 & 294 & 7.4829932 \\
\hline
\end{tabular}


Table 4. Grapevine nutritional status data, taken from petioles and leaf blades at peak bloom ( $80 \%$ flowering) on November 11, 2019. Samples were processed by the Pedology Laboratory of the College of Agricultural Sciences at the National University of Cuyo, Mendoza, Argentina.

\begin{tabular}{|c|c|c|c|c|c|c|c|}
\hline Tissue Type & $\begin{array}{l}\text { Distance from } \\
\text { Hedgerow } \\
\text { (m) }\end{array}$ & Rep & $\mathrm{N}-\mathrm{NO} 3$ & N & $\mathbf{P}$ & K & Mg \\
\hline Leaf & 40 & 1 & N/A & 3.16 & 0.23 & 0.67 & 0.55 \\
\hline Leaf & 40 & 2 & N/A & 3.19 & 0.22 & 0.83 & 0.36 \\
\hline Leaf & 40 & 3 & N/A & 3.17 & 0.19 & 0.68 & 0.3 \\
\hline Leaf & 12 & 1 & N/A & 2.96 & 0.16 & 1.07 & 0.26 \\
\hline Leaf & 12 & 2 & N/A & 3.1 & 0.16 & 1.24 & 0.07 \\
\hline Leaf & 12 & 3 & N/A & 2.82 & 0.11 & 1.07 & 0.11 \\
\hline Leaf & 6 & 1 & N/A & 3.39 & 0.08 & 1 & 0.1 \\
\hline Leaf & 6 & 2 & N/A & 2.8 & 0.43 & 1.17 & 0.24 \\
\hline Leaf & 6 & 3 & N/A & 3.25 & 0.31 & 1.02 & 0.07 \\
\hline Leaf & 4 & 1 & N/A & 2.88 & 0.29 & 1.1 & 0.07 \\
\hline Leaf & 4 & 2 & N/A & 3.17 & 0.25 & 1.04 & 0.74 \\
\hline Leaf & 4 & 3 & N/A & 2.55 & 0.23 & 1.05 & 0.38 \\
\hline Leaf & 2 & 1 & N/A & 2.69 & 0.28 & 0.86 & 0.25 \\
\hline Leaf & 2 & 2 & N/A & 2.42 & 0.21 & 0.96 & 0.55 \\
\hline Leaf & 2 & 3 & N/A & 2.85 & 0.11 & 0.87 & 0.17 \\
\hline Petiole & 40 & 1 & 322 & 0.91 & 0.38 & 1.55 & 0.66 \\
\hline Petiole & 40 & 2 & 280 & 0.91 & 0.38 & 1.83 & 0.47 \\
\hline Petiole & 40 & 3 & 324 & 0.79 & 0.4 & 1.72 & 0.95 \\
\hline Petiole & 12 & 1 & 266 & 0.77 & 0.41 & 2.1 & 1.33 \\
\hline Petiole & 12 & 2 & 280 & 0.84 & 0.39 & 1.76 & 0.85 \\
\hline Petiole & 12 & 3 & 231 & 0.82 & 0.38 & 2.08 & 0.48 \\
\hline Petiole & 6 & 1 & 280 & 0.85 & 0.47 & 2.18 & 0.67 \\
\hline Petiole & 6 & 2 & 266 & 0.77 & 0.47 & 1.77 & 0.52 \\
\hline Petiole & 6 & 3 & 245 & 1.1 & 0.43 & 1.58 & 0.59 \\
\hline Petiole & 4 & 1 & 231 & 0.87 & 0.31 & 1.11 & 0.73 \\
\hline Petiole & 4 & 2 & 252 & 0.96 & 0.43 & 1.99 & 0.52 \\
\hline Petiole & 4 & 3 & 287 & 0.93 & 0.31 & 1.64 & 0.89 \\
\hline Petiole & 2 & 1 & 224 & 0.88 & 0.4 & 1.31 & 0.3 \\
\hline Petiole & 2 & 2 & 273 & 0.79 & 0.31 & 1.6 & 0.76 \\
\hline Petiole & 2 & 3 & 301 & 0.81 & 0.32 & 1.62 & 0.46 \\
\hline
\end{tabular}



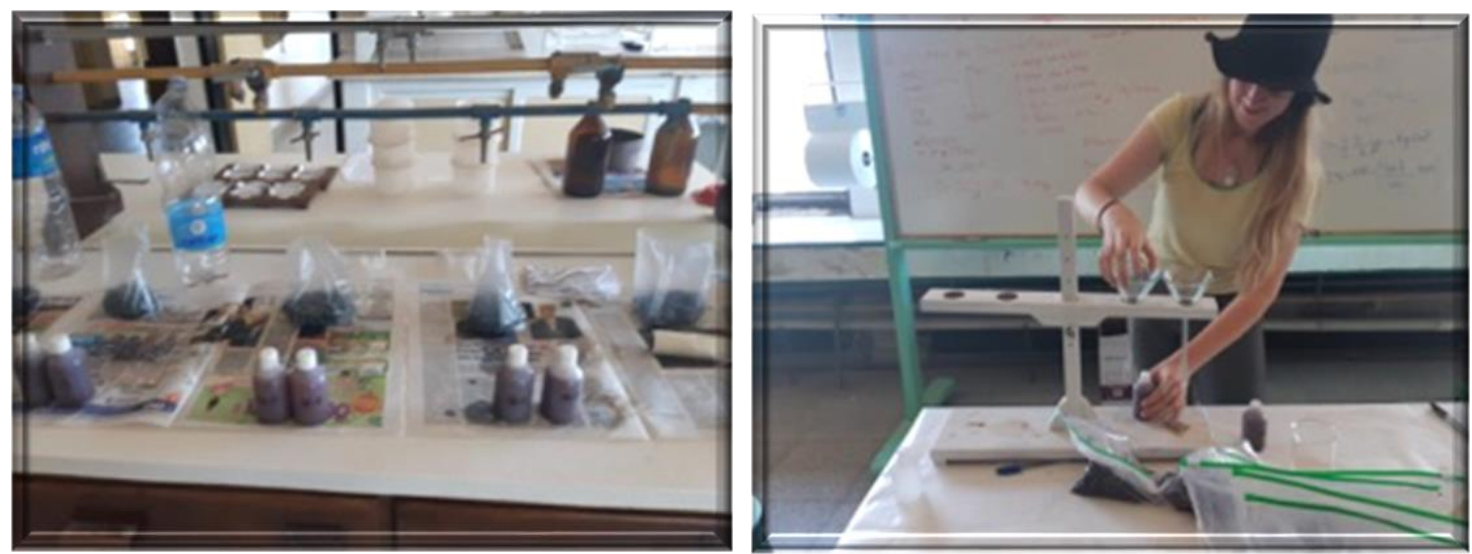

Figure 1. Extraction of juice from berries in the Pedology Laboratory at the College of Agricultural Sciences (Facultad de Ciencias Agrarias) in Lujan de Cuyo Argentina, March 13, 2020.

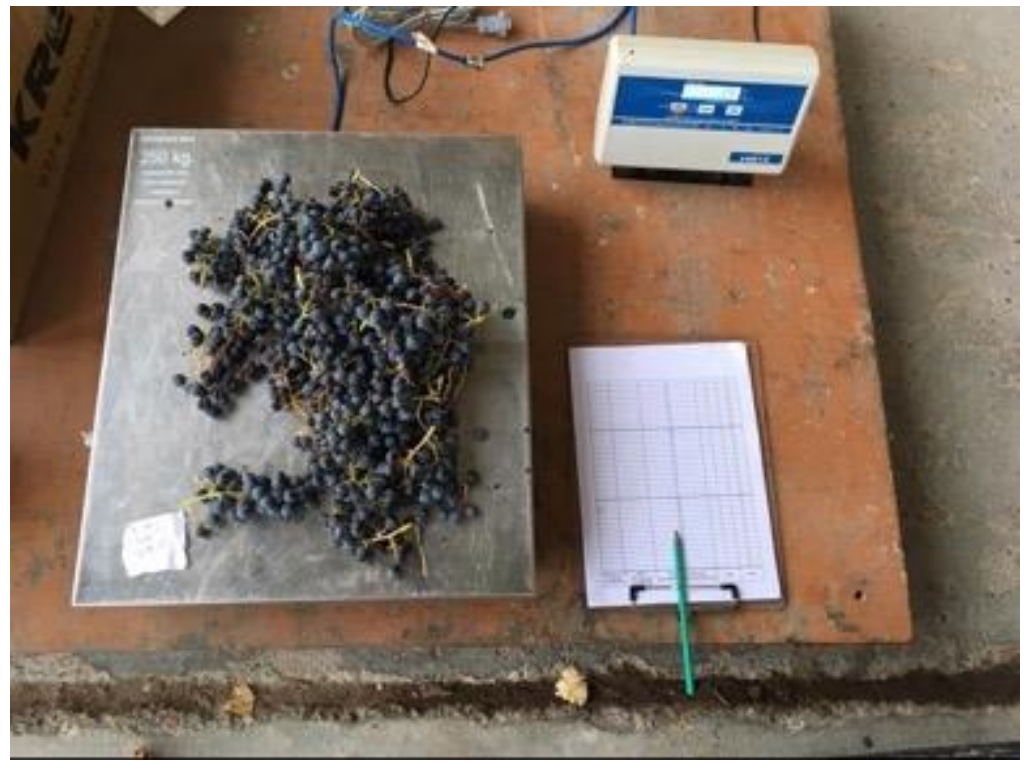

Figure 2. Measuring yield by weighing total berries per observational unit (per sampled vine) on the day of harvest, March 12, 2020.

Table 5. Ravaz Index Formula. The Ravaz Index can be calculated as follows:

$$
\text { Ravaz index }=\text { Yield/Pruning Weight }
$$

where the yield from the current harvest is used against the pruning weight in the following dormant season. 


\section{APPENDIX E}

\section{NORMAL VALUES OF MACRO AND MICRONUTRIENTS IN GRAPEVINE TISSUE AT FULL BLOOM IN MENDOZA, ARGENTINA}

Table 1. Normal macro and micronutrient values for grapevine petioles and leaf blades for the region of Maipu, Mendoza, Argentina, as determined by the National Institute of Agricultural Technology in Argentina (INTA).

\begin{tabular}{|c|c|c|c|c|c|}
\hline \multirow{4}{*}{ Petioles } & $\mathrm{N}-\mathrm{NO}_{3}$ ppm & P\% & $\mathrm{K} \%$ & $\mathrm{Ca} \%$ & Mg\% \\
\hline & 600.00 & 0.25 & 1.50 & 1.10 & 0.40 \\
\hline & Fe ppm & Mn ppm & Cu ppm & Zn ppm & $\mathrm{Na}$ (*) $^{*}$ ppm \\
\hline & 25.00 & 30.00 & 5.00 & 25.00 & $<500$ \\
\hline \multirow{4}{*}{ Leaf Blades } & $\mathrm{N}-\mathrm{NO}_{3}$ ppm & $\mathbf{P \%}$ & $\mathrm{K} \%$ & $\mathrm{Ca} \%$ & Mg\% \\
\hline & 2.80 & 0.20 & 0.60 & 1.20 & 0.25 \\
\hline & Fe ppm & Mn ppm & Cu ppm & Zn ppm & $\mathrm{Na}\left(^{*}\right)$ ppm \\
\hline & 50.00 & 50.00 & 5.00 & 20.00 & $<2000$ \\
\hline
\end{tabular}

(*) Sodium is not an essential nutrient however it can cause salinity problems and it is recommended to maintain its concentration below the levels indicated 


\section{APPENDIX F}

\section{SAS STATISTICAL OUTPUT USING GLM PROCEDURE}

Table 1. SAS output for the variable glucose/fructose levels (g/L).

\section{Quality Data \\ Glucose_Fructose \\ The GLM Procedure}

Dependent Variable: Glucose_Fructose Glucose_Fructose

\begin{tabular}{|l|r|r|r|r|r|}
\hline Source & DF & $\begin{array}{r}\text { Sum of } \\
\text { Squares }\end{array}$ & Mean Square & F Value & Pr > F \\
\hline Model & 6 & 1561.414427 & 260.235738 & 6.99 & 0.0075 \\
\hline Error & 8 & 297.704507 & 37.213063 & & \\
\hline Corrected Total & 14 & 1859.118933 & & & \\
\hline
\end{tabular}

\begin{tabular}{|l|r|r|r|r|r|}
\hline Source & DF & Type II SS & Mean Square & F Value & Pr > F \\
\hline Distance & 4 & 1534.020933 & 383.505233 & 10.31 & 0.0030 \\
\hline Rep & 2 & 27.393493 & 13.696747 & 0.37 & 0.7032 \\
\hline
\end{tabular}

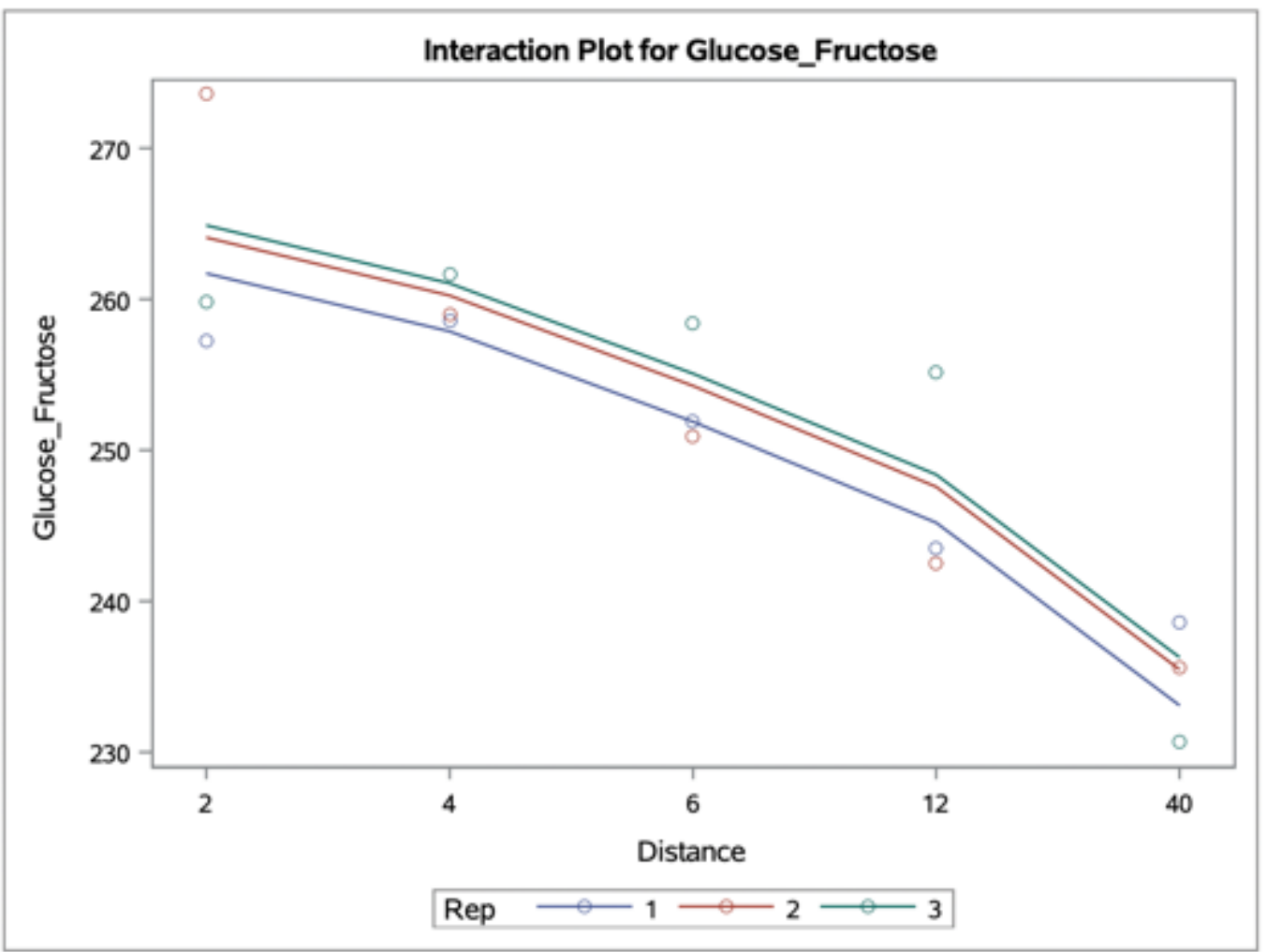


The GLM Procedure

Least Squares Means

\begin{tabular}{|l|r|r|r|r|}
\hline Distance & $\begin{array}{r}\text { Glucose_Fructose } \\
\text { LSMEAN }\end{array}$ & $\begin{array}{r}\text { Standard } \\
\text { Error }\end{array}$ & $\operatorname{Pr}>|t|$ & $\begin{array}{r}\text { LSMEAN } \\
\text { Number }\end{array}$ \\
\hline $\mathbf{2}$ & 263.560000 & 3.521982 & $<.0001$ & 1 \\
\hline $\mathbf{4}$ & 259.720000 & 3.521982 & $<.0001$ & 2 \\
\hline 6 & 253.736667 & 3.521982 & $<.0001$ & 3 \\
\hline 12 & 247.053333 & 3.521982 & $<.0001$ & 4 \\
\hline 40 & 234.946667 & 3.521982 & $<.0001$ & 5 \\
\hline
\end{tabular}

\begin{tabular}{|l|r|r|r|r|r|}
\hline \multicolumn{7}{|c|}{$\begin{array}{c}\text { Least Squares Means for effect Distance } \\
\text { Pr > |t| for H0: LSMean(i)=LSMean(j) }\end{array}$} \\
\hline \multicolumn{7}{|c|}{ Dependent Variable: Glucose_Fructose } \\
\hline ij & $\mathbf{1}$ & $\mathbf{2}$ & $\mathbf{3}$ & $\mathbf{4}$ & $\mathbf{5}$ \\
\hline $\mathbf{1}$ & & 0.4629 & 0.0841 & 0.0106 & 0.0004 \\
\hline $\mathbf{2}$ & 0.4629 & & 0.2640 & 0.0345 & 0.0011 \\
\hline $\mathbf{3}$ & 0.0841 & 0.2640 & & 0.2165 & 0.0054 \\
\hline $\mathbf{4}$ & 0.0106 & 0.0345 & 0.2165 & & 0.0412 \\
\hline $\mathbf{5}$ & 0.0004 & 0.0011 & 0.0054 & 0.0412 & \\
\hline
\end{tabular}

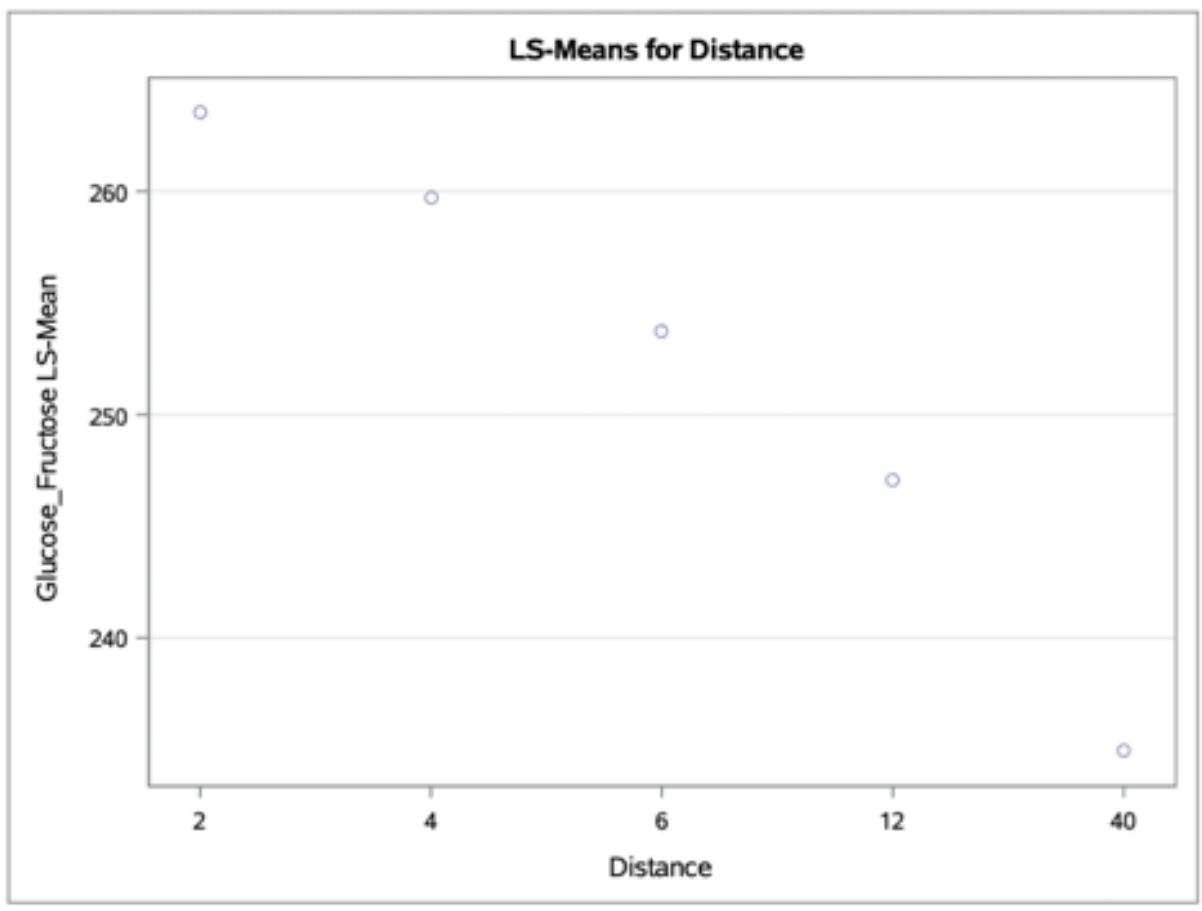




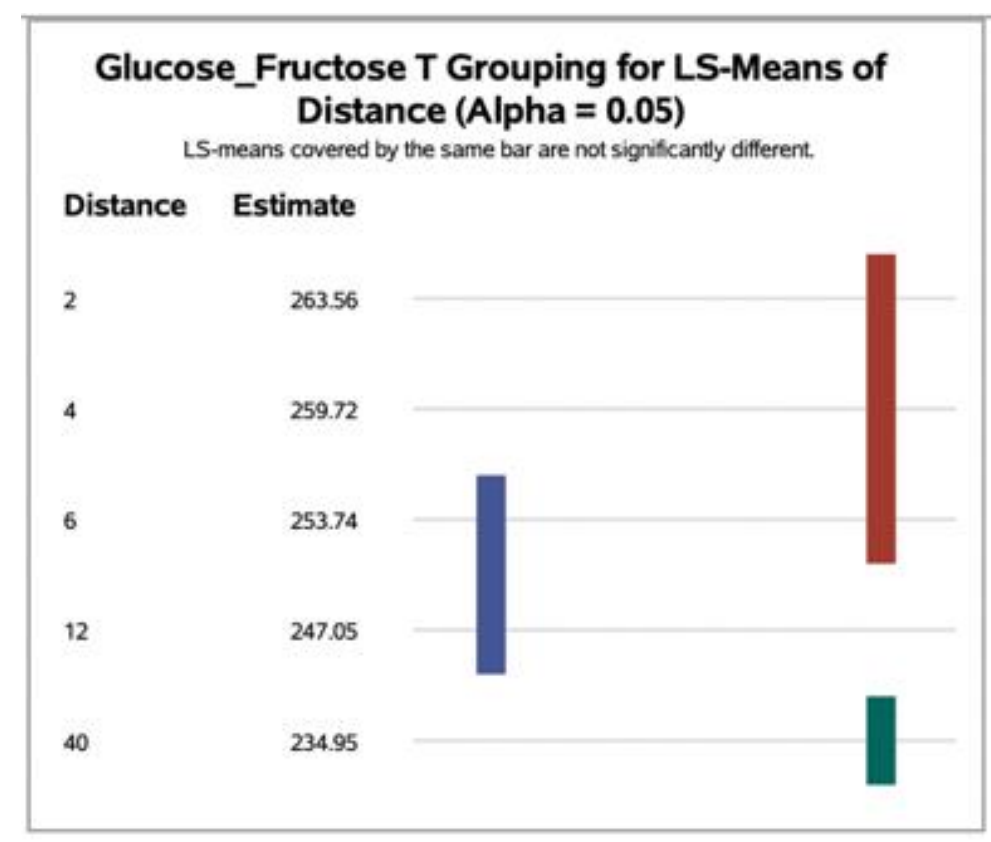

The UNIVARIATE Procedure

Variable: $\mathbf{R}$

\begin{tabular}{|l|r|l|r|}
\hline \multicolumn{4}{|c|}{ Moments } \\
\hline N & 15 & Sum Weights & 15 \\
\hline Mean & 0 & Sum Observations & 0 \\
\hline Std Deviation & 4.61135638 & Variance & 21.2646076 \\
\hline Skewness & 0.68438835 & Kurtosis & -0.2921975 \\
\hline Uncorrected SS & 297.704507 & Corrected SS & 297.704507 \\
\hline Coeff Variation & & Std Error Mean & 1.1906471 \\
\hline
\end{tabular}

\begin{tabular}{|l|l|l|l|r|}
\hline \multicolumn{5}{|c|}{ Tests for Normality } \\
\hline Test & \multicolumn{2}{|c|}{ Statistic } & \multicolumn{2}{c|}{ p Value } \\
\hline Shapiro-Wilk & W & 0.928672 & Pr $<$ W & 0.2607 \\
\hline Kolmogorov-Smirnov & D & 0.174432 & Pr $>$ D & $>0.1500$ \\
\hline Cramer-von Mises & W-Sq & 0.05829 & Pr $>$ W-Sq & $>0.2500$ \\
\hline Anderson-Darling & A-Sq & 0.385369 & Pr $>$ A-Sq & $>0.2500$ \\
\hline
\end{tabular}


The UNIVARIATE Procedure

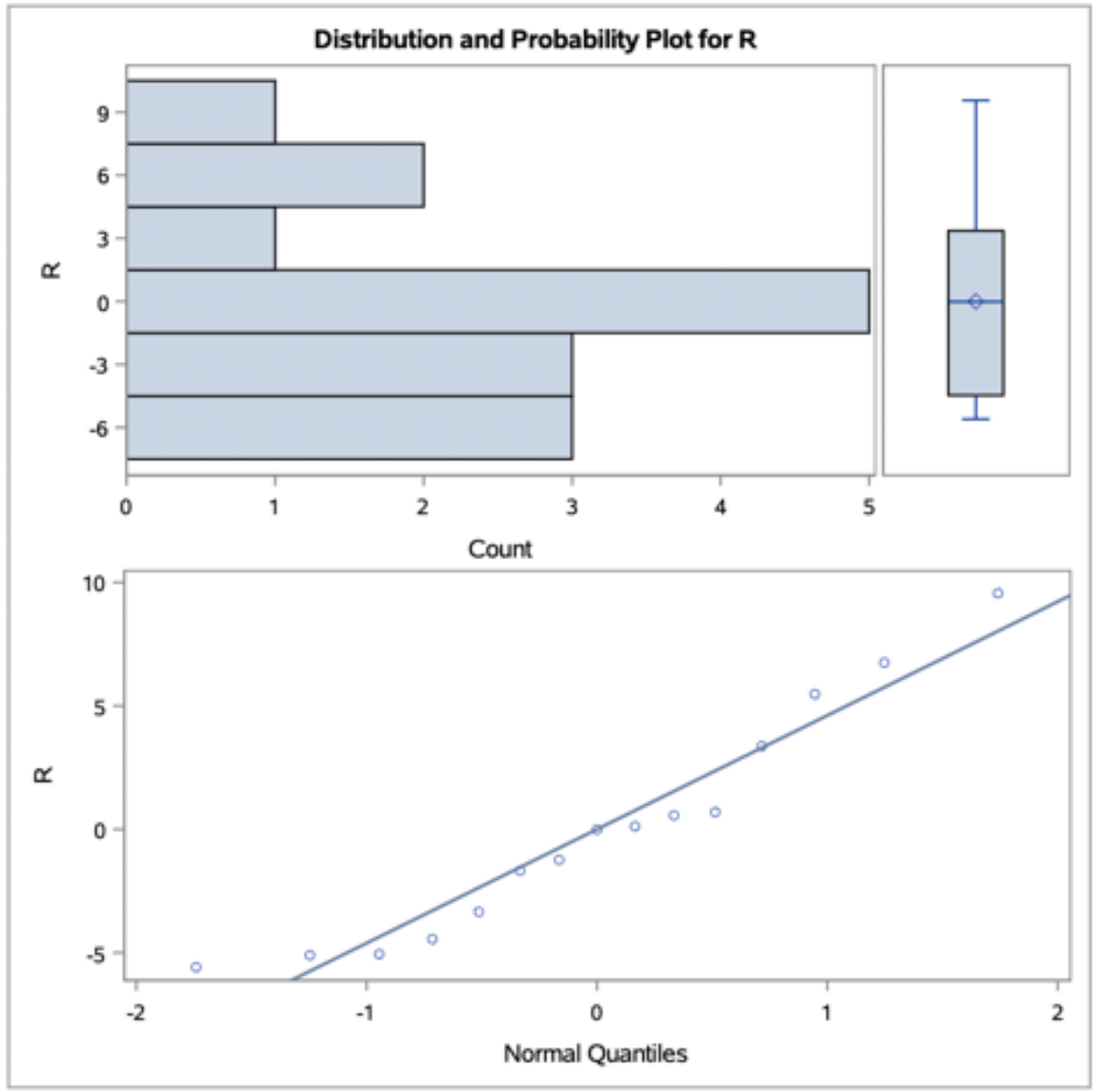


Table 2. SAS output for the variable brix levels.

\section{Quality Data}

Brix

\section{The GLM Procedure}

\section{Dependent Variable: Brix Brix}

\begin{tabular}{|l|r|r|r|r|r|}
\hline Source & DF & $\begin{array}{r}\text { Sum of } \\
\text { Squares }\end{array}$ & Mean Square & F Value & $\operatorname{Pr}>$ F \\
\hline Model & 6 & 11.57333333 & 1.92888889 & 6.58 & 0.0091 \\
\hline Error & 8 & 2.34666667 & 0.29333333 & & \\
\hline Corrected Total & 14 & 13.92000000 & & & \\
\hline
\end{tabular}

\begin{tabular}{|l|r|r|r|r|r|}
\hline Source & DF & Type III SS & Mean Square & F Value & Pr $>$ F \\
\hline Distance & 4 & 11.27333333 & 2.81833333 & 9.61 & 0.0038 \\
\hline Rep & 2 & 0.30000000 & 0.15000000 & 0.51 & 0.6180 \\
\hline
\end{tabular}

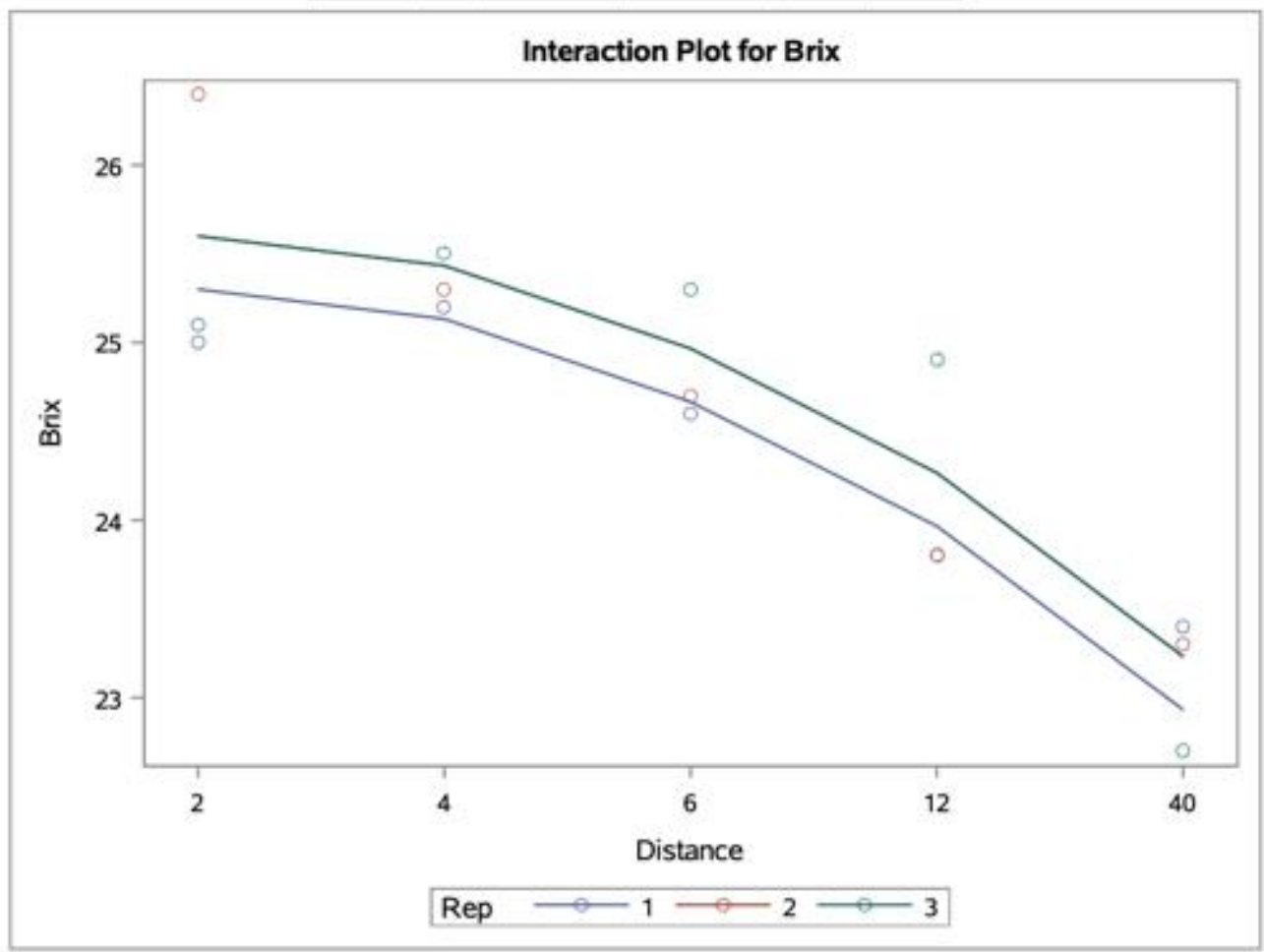


The GLM Procedure Least Squares Means

\begin{tabular}{|l|r|r|r|r|}
\hline Distance & Brix LSMEAN & $\begin{array}{r}\text { Standard } \\
\text { Error }\end{array}$ & $\operatorname{Pr}>\mid \mathbf{| t |}$ & $\begin{array}{r}\text { LSMEAN } \\
\text { Number }\end{array}$ \\
\hline $\mathbf{2}$ & 25.5000000 & 0.3126944 & $<.0001$ & 1 \\
\hline 4 & 25.3333333 & 0.3126944 & $<.0001$ & 2 \\
\hline $\mathbf{6}$ & 24.8666667 & 0.3126944 & $<.0001$ & 3 \\
\hline 12 & 24.1666667 & 0.3126944 & $<.0001$ & 4 \\
\hline 40 & 23.1333333 & 0.3126944 & $<.0001$ & 5 \\
\hline
\end{tabular}

\begin{tabular}{|l|r|r|r|r|r|}
\hline \multicolumn{7}{|c|}{$\begin{array}{c}\text { Least Squares Means for effect Distance } \\
\text { Pr }>\text { ( } 1 \text { for H0: LSMean(1) }=\text { LSMean(0) } \\
\text { Dependent Variable: Brix }\end{array}$} \\
\hline Vj & 1 & 2 & 3 & 4 & 5 \\
\hline 1 & & 0.7161 & 0.1900 & 0.0167 & 0.0007 \\
\hline 2 & 0.7161 & & 0.3221 & 0.0298 & 0.0011 \\
\hline 3 & 0.1900 & 0.3221 & & 0.1521 & 0.0044 \\
\hline 4 & 0.0167 & 0.0298 & 0.1521 & & 0.0477 \\
\hline 5 & 0.0007 & 0.0011 & 0.0044 & 0.0477 & \\
\hline
\end{tabular}

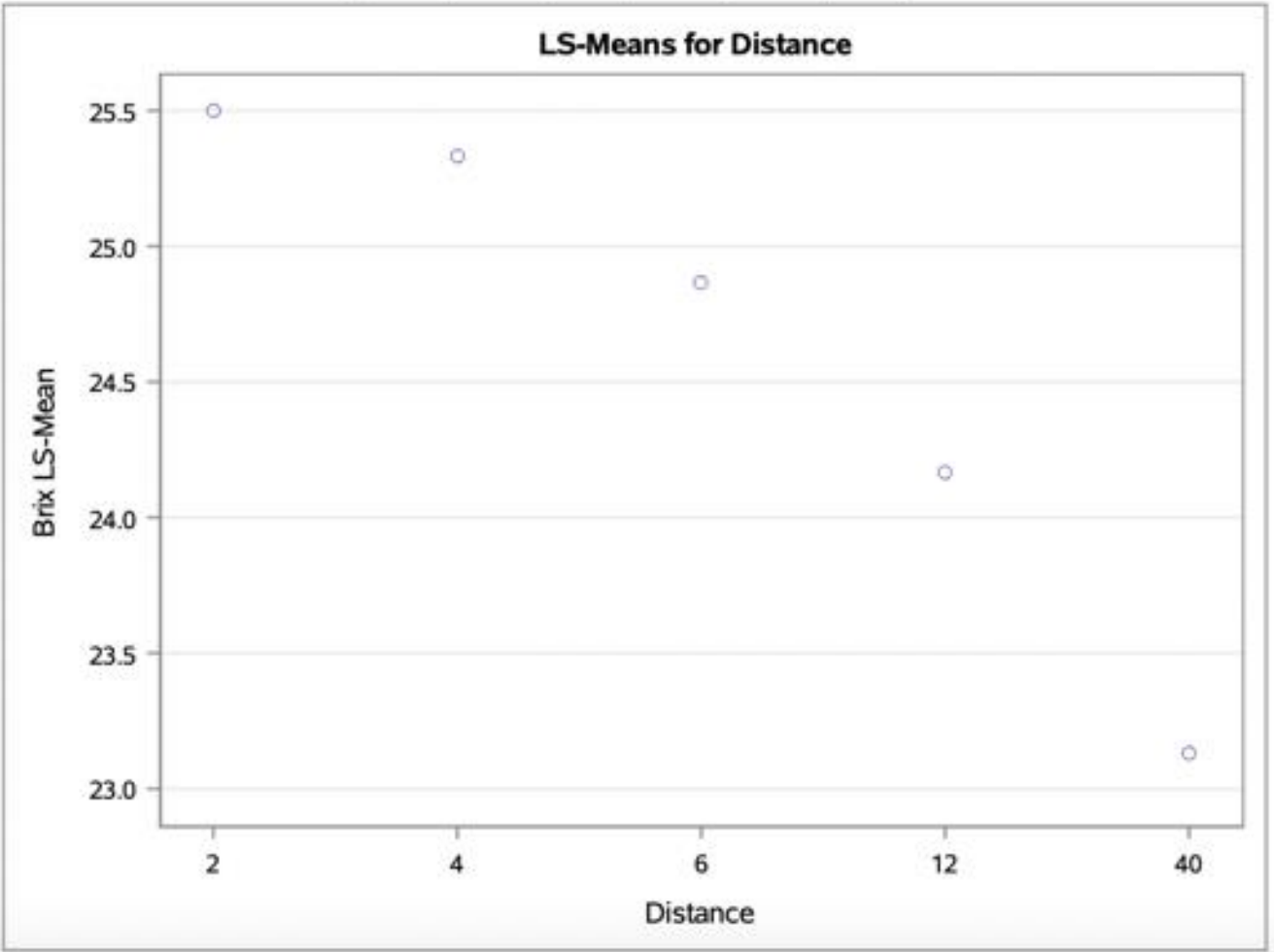




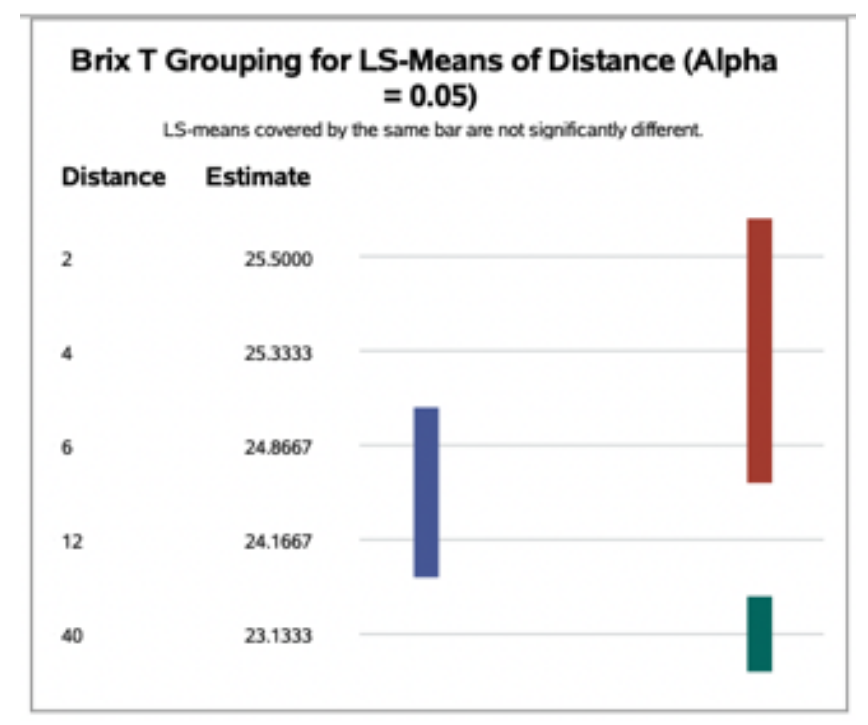

The UNIVARIATE Procedure

Variable: $\mathbf{R}$

\begin{tabular}{|l|r|l|r|}
\hline \multicolumn{4}{|c|}{ Moments } \\
\hline N & 15 & Sum Weights & 15 \\
\hline Mean & 0 & Sum Observations & 0 \\
\hline Std Deviation & 0.40941305 & Variance & 0.16761905 \\
\hline Skewness & 0.56926327 & Kurtosis & -0.5017135 \\
\hline Uncorrected SS & 2.34666667 & Corrected SS & 2.34666667 \\
\hline Coeff Variation & & Std Error Mean & 0.10571 \\
\hline
\end{tabular}

\begin{tabular}{|l|l|l|l|l|}
\hline \multicolumn{5}{|c|}{ Tests for Normality } \\
\hline Test & \multicolumn{2}{|c|}{ Statistic } & \multicolumn{2}{c|}{ P Value } \\
\hline Shapiro-Wilk & W & 0.942817 & Pr $<$ W & 0.4191 \\
\hline Kolmogorov-Smirnov & D & 0.168658 & Pr $>$ D & $>0.1500$ \\
\hline Cramer-von Mises & W-Sq & 0.048368 & Pr $>$ W-Sq & $>0.2500$ \\
\hline Anderson-Darling & A-Sq & 0.312342 & Pr $>$ A-Sq & $>0.2500$ \\
\hline
\end{tabular}


The UNIVARIATE Procedure

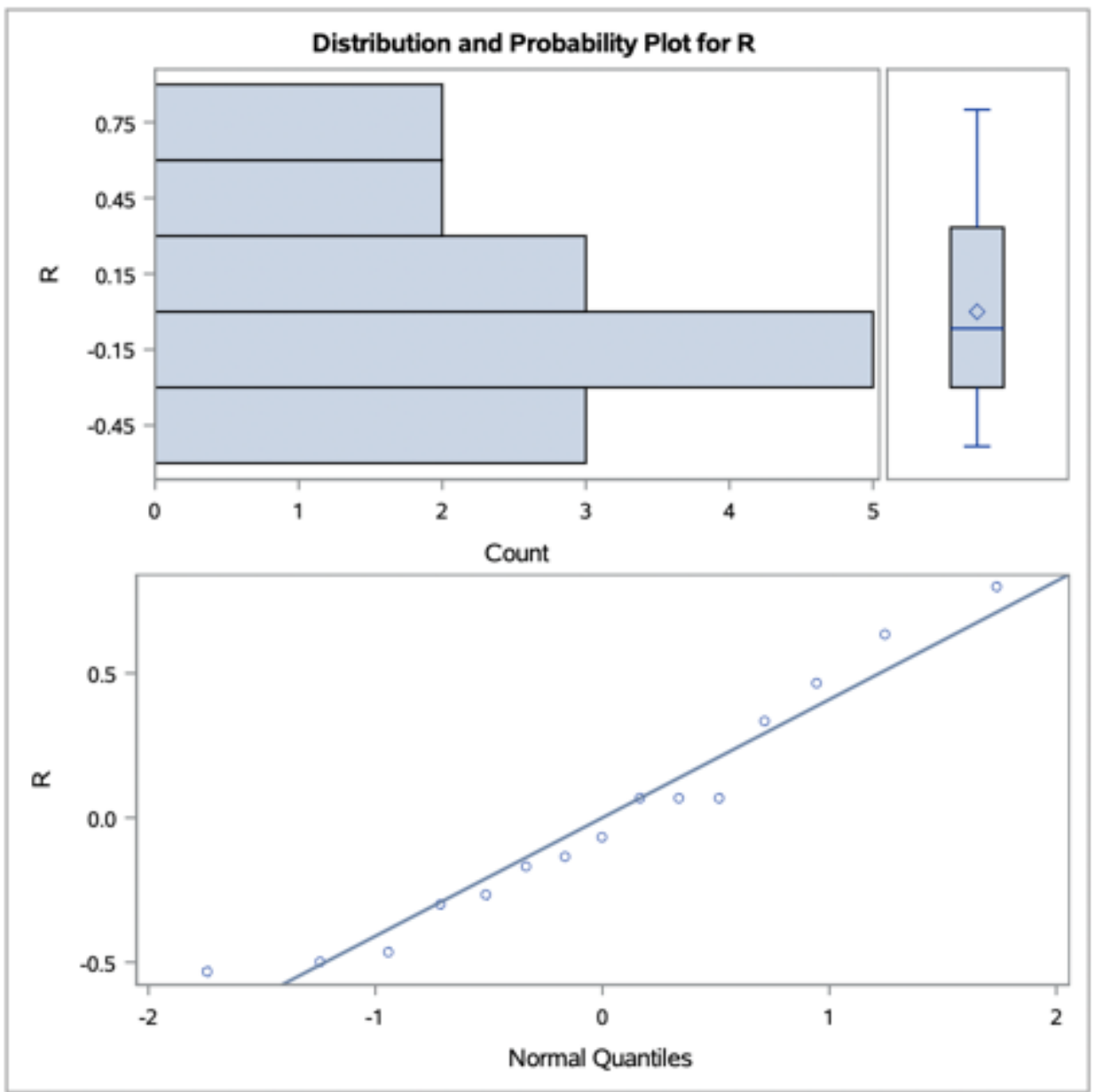


Table 3. SAS output for the variable density $(\mathrm{g} / \mathrm{L})$

\section{Quality Data}

Density_g_L

\section{The GLM Procedure}

Dependent Variable: Density_g_L Density_g_L

\begin{tabular}{|l|r|r|r|r|r|}
\hline Source & DF & $\begin{array}{r}\text { Sum of } \\
\text { Squares }\end{array}$ & Mean Square & F Value & Pr $>$ F \\
\hline Model & 6 & 0.00023920 & 0.00003987 & 6.76 & 0.0083 \\
\hline Error & 8 & 0.00004720 & 0.00000590 & & \\
\hline Corrected Total & 14 & 0.00028640 & & & \\
\hline
\end{tabular}

\begin{tabular}{|l|r|r|r|r|r|}
\hline Source & DF & Type III SS & Mean Square & F Value & Pr > F \\
\hline Distance & 4 & 0.00023640 & 0.00005910 & 10.02 & 0.0033 \\
\hline Rep & 2 & 0.00000280 & 0.00000140 & 0.24 & 0.7941 \\
\hline
\end{tabular}

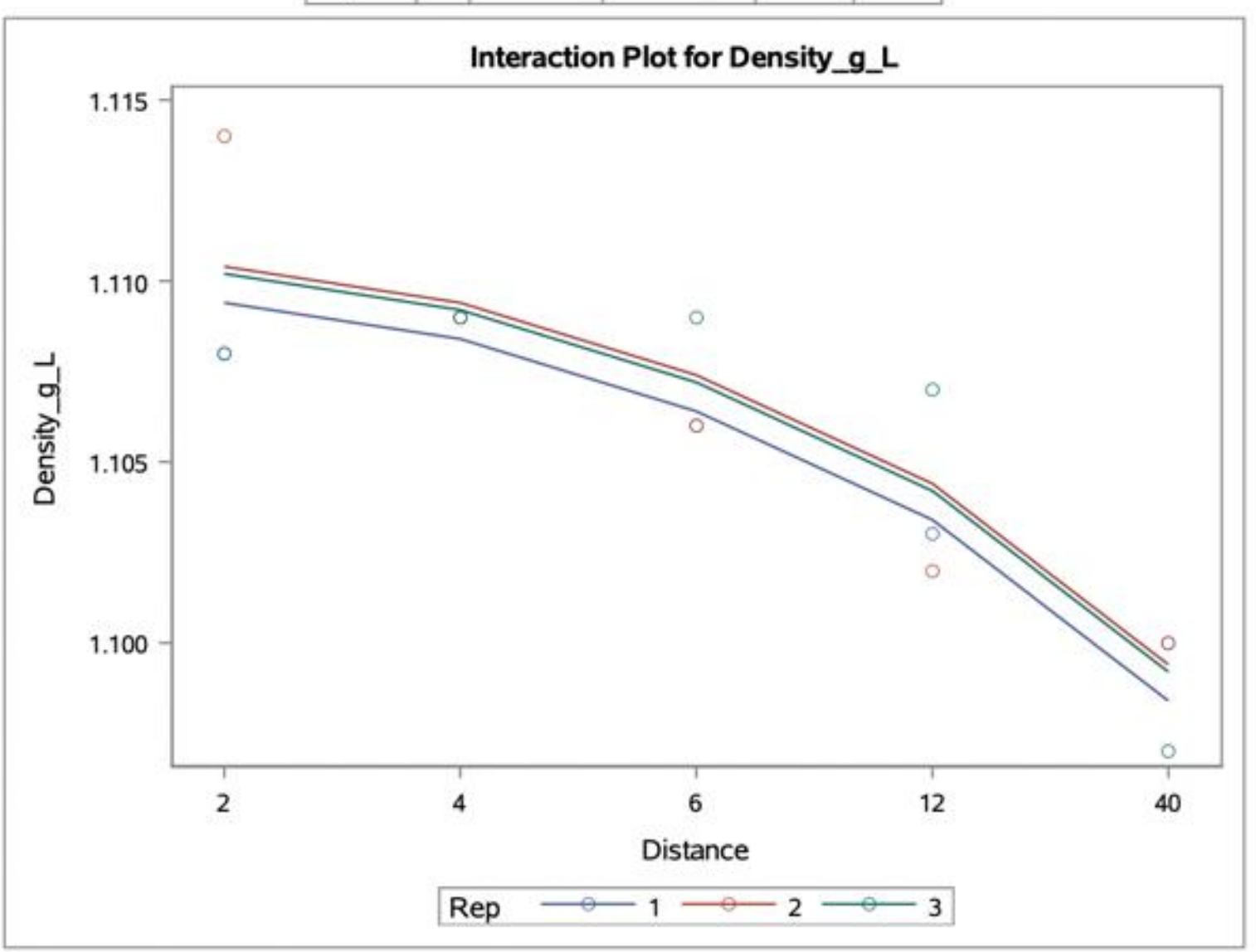


The GLM Procedure

Least Squares Means

\begin{tabular}{|l|r|r|r|r|}
\hline Distance & $\begin{array}{r}\text { Density_g_L } \\
\text { LSMEAN }\end{array}$ & $\begin{array}{r}\text { Standard } \\
\text { Error }\end{array}$ & $\operatorname{Pr}>$ 清 & $\begin{array}{r}\text { LSMEAN } \\
\text { Number }\end{array}$ \\
\hline 2 & 1.11000000 & 0.00140238 & $<.0001$ & 1 \\
\hline 4 & 1.10900000 & 0.00140238 & $<.0001$ & 2 \\
\hline 6 & 1.10700000 & 0.00140238 & $<.0001$ & 3 \\
\hline 12 & 1.10400000 & 0.00140238 & $<.0001$ & 4 \\
\hline 40 & 1.09900000 & 0.00140238 & $<.0001$ & 5 \\
\hline
\end{tabular}

\begin{tabular}{|c|c|c|c|c|c|}
\hline \multicolumn{6}{|c|}{$\begin{array}{l}\text { Least Squares Means for effect Distance } \\
\operatorname{Pr}>\mid \mathrm{It} \text { for } \mathrm{HO} \text { : LSMean }(0)=\text { LSMean } 0 \\
\text { Dependent Variable: Density_g_L }\end{array}$} \\
\hline vj & 1 & 2 & 3 & 4 & 5 \\
\hline 1 & & 0.6277 & 0.1688 & 0.0164 & 0.0005 \\
\hline 2 & 0.6277 & & 0.3428 & 0.0357 & 0.0010 \\
\hline 3 & 0.1688 & 0.3428 & & 0.1688 & 0.0038 \\
\hline 4 & 0.0164 & 0.0357 & 0.1688 & & 0.0357 \\
\hline 5 & 0.0005 & 0.0010 & 0.0038 & 0.0357 & \\
\hline
\end{tabular}

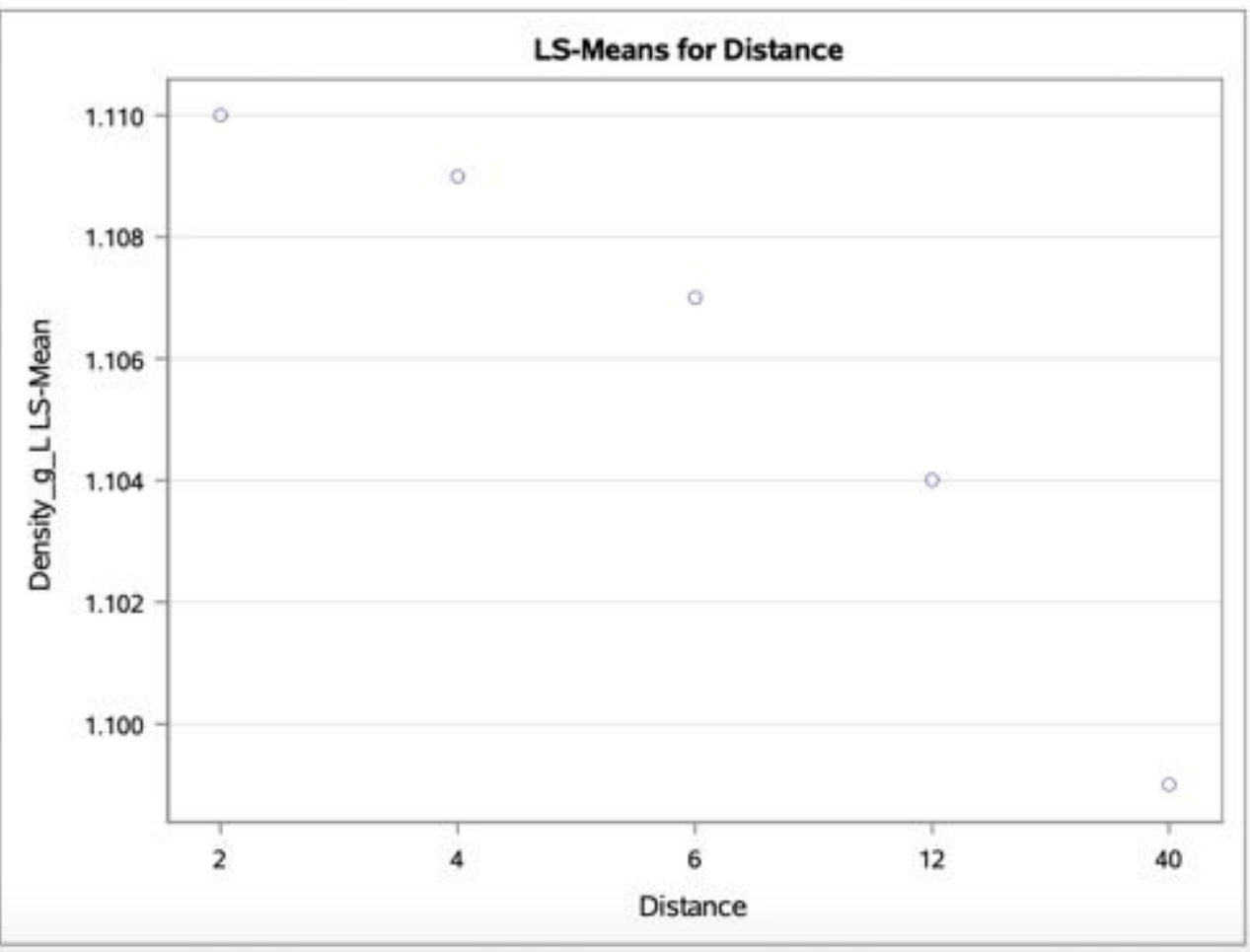




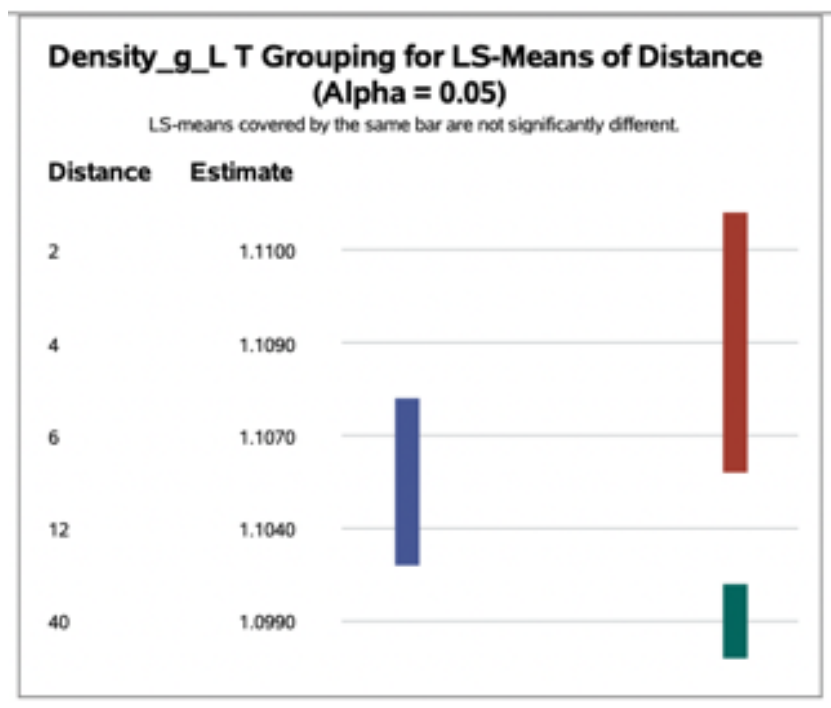

The UNIVARIATE Procedure

Variable: $\mathbf{R}$

\begin{tabular}{|l|r|l|r|}
\hline \multicolumn{4}{|c|}{ Moments } \\
\hline N & 15 & Sum Weights & 15 \\
\hline Mean & 0 & Sum Observations & 0 \\
\hline Std Deviation & 0.00183615 & Variance & $3.37143 \mathrm{E}-6$ \\
\hline Skewness & 0.50805098 & Kurtosis & -0.5350584 \\
\hline Uncorrected SS & 0.0000472 & Corrected SS & 0.0000472 \\
\hline Coeff Variation & & Std Error Mean & 0.00047409 \\
\hline
\end{tabular}

\begin{tabular}{|l|l|l|l|r|}
\hline \multicolumn{5}{|c|}{ Tests for Normality } \\
\hline Test & \multicolumn{2}{|c|}{ Statistic } & \multicolumn{2}{c|}{ P Value } \\
\hline Shapiro-Wilk & W & 0.943049 & Pr $<$ W & 0.4223 \\
\hline Kolmogorov-Smirnov & D & 0.143369 & Pr $>$ D & $>0.1500$ \\
\hline Cramer-von Mises & W-Sq & 0.048825 & Pr $>$ W-Sq & $>0.2500$ \\
\hline Anderson-Darling & A-Sq & 0.316975 & Pr $>$ A-Sq & $>0.2500$ \\
\hline
\end{tabular}




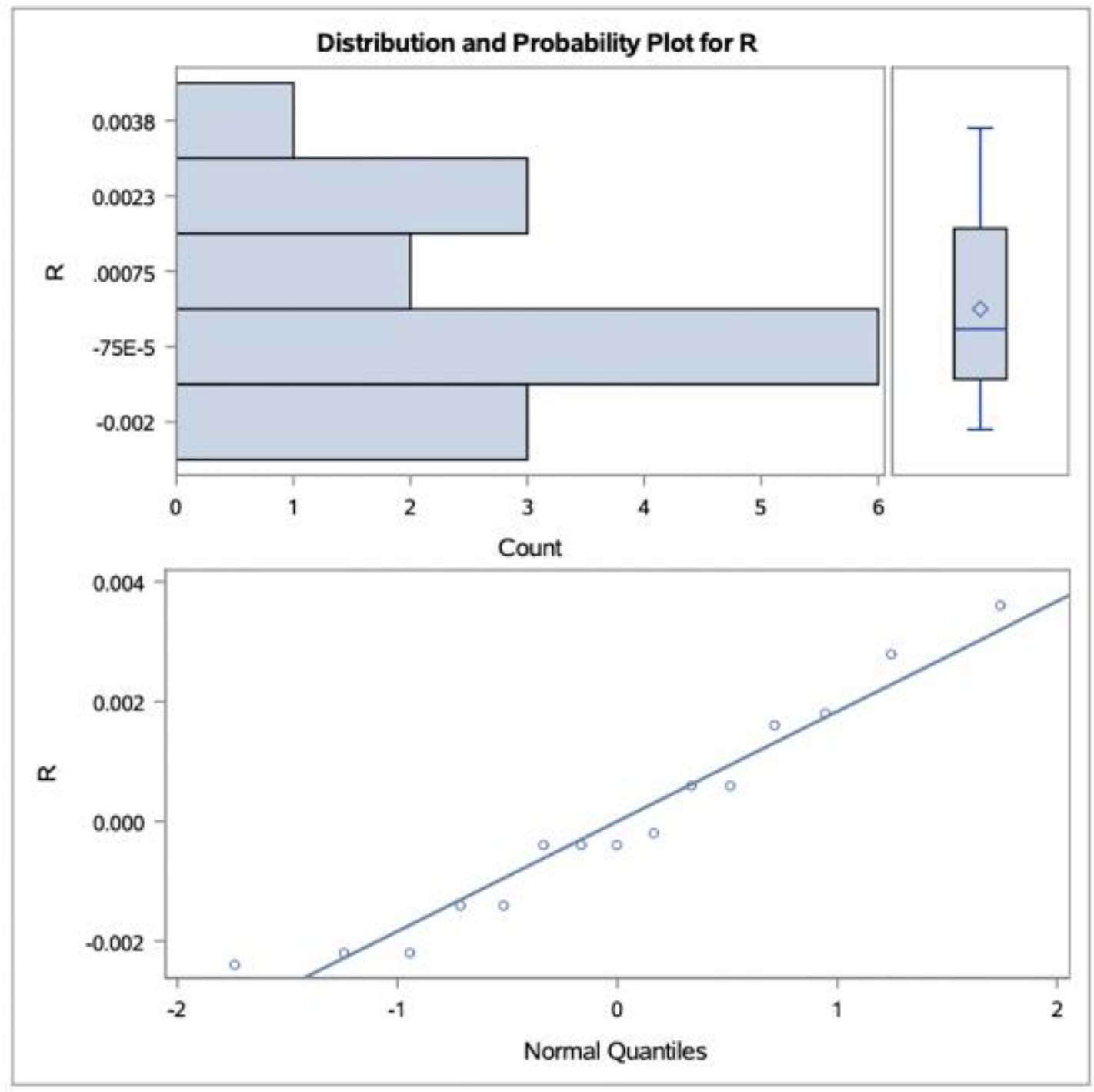


Table 4. SAS output for the variable total acidity (g/L)

Quality Data

Total_Acidity

The GLM Procedure

Dependent Variable: Total_Acidity Total_Acidity

\begin{tabular}{|l|r|r|r|r|r|}
\hline Source & DF & $\begin{array}{r}\text { Sum of } \\
\text { Squares }\end{array}$ & Mean Square & F Value & Pr $>$ F \\
\hline Model & 6 & 0.43025333 & 0.07170889 & 6.37 & 0.0100 \\
\hline Error & 8 & 0.09004000 & 0.01125500 & & \\
\hline Corrected Total & 14 & 0.52029333 & & & \\
\hline
\end{tabular}

\begin{tabular}{|l|r|r|r|r|r|}
\hline Source & DF & Type lil SS & Mean Square & F Value & Pr > F \\
\hline Distance & 4 & 0.37856000 & 0.09464000 & 8.41 & 0.0058 \\
\hline Rep & 2 & 0.05169333 & 0.02584667 & 2.30 & 0.1629 \\
\hline
\end{tabular}

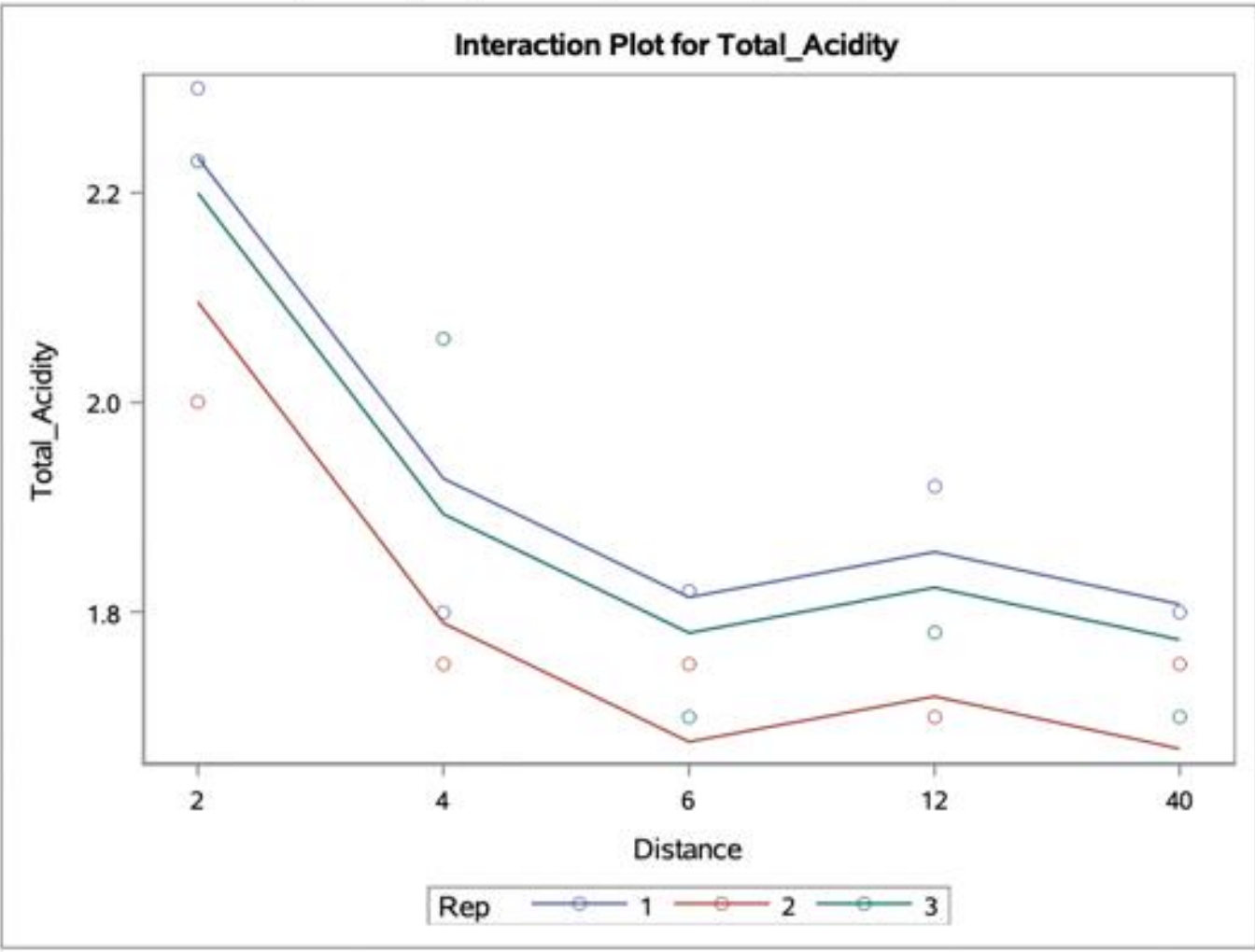


The GLM Procedure

Least Squares Means

\begin{tabular}{|l|r|r|r|r|}
\hline Distance & $\begin{array}{r}\text { Total_Acidity } \\
\text { LSMEAN }\end{array}$ & $\begin{array}{r}\text { Standard } \\
\text { Error }\end{array}$ & $\operatorname{Pr}>$ I4 & $\begin{array}{r}\text { LSMEAN } \\
\text { Number }\end{array}$ \\
\hline 2 & 2.17666667 & 0.06125085 & $<.0001$ & 1 \\
\hline 4 & 1.87000000 & 0.06125085 & $<.0001$ & 2 \\
\hline 6 & 1.75666667 & 0.06125085 & $<.0001$ & 3 \\
\hline 12 & 1.80000000 & 0.06125085 & $<.0001$ & 4 \\
\hline 40 & 1.75000000 & 0.06125085 & $<.0001$ & 5 \\
\hline
\end{tabular}

\begin{tabular}{|l|r|r|r|r|r|}
\hline \multicolumn{6}{|c|}{$\begin{array}{c}\text { Least Squares Means for effect Distance } \\
\text { Pr > If for H0; LSMean(i)=LSMean(j) }\end{array}$} \\
Dependent Variable: Total_Acidity \\
\hline if & $\mathbf{1}$ & $\mathbf{2}$ & $\mathbf{3}$ & $\mathbf{4}$ & $\mathbf{5}$ \\
\hline $\mathbf{1}$ & & 0.0076 & 0.0013 & 0.0025 & 0.0012 \\
\hline $\mathbf{2}$ & 0.0076 & & 0.2271 & 0.4424 & 0.2034 \\
\hline $\mathbf{3}$ & 0.0013 & 0.2271 & & 0.6304 & 0.9405 \\
\hline $\mathbf{4}$ & 0.0025 & 0.4424 & 0.6304 & & 0.5797 \\
\hline $\mathbf{5}$ & 0.0012 & 0.2034 & 0.9405 & 0.5797 & \\
\hline
\end{tabular}

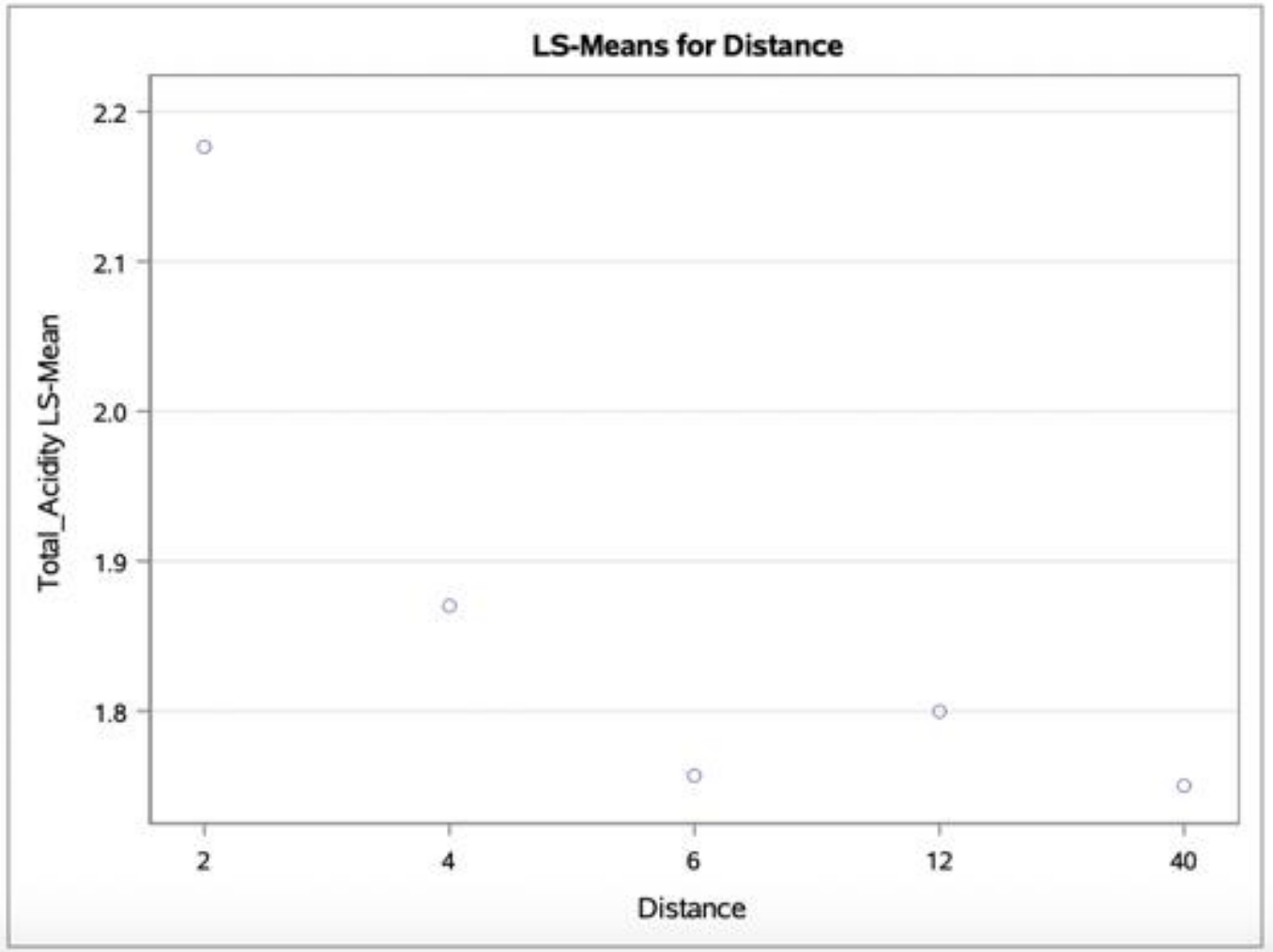




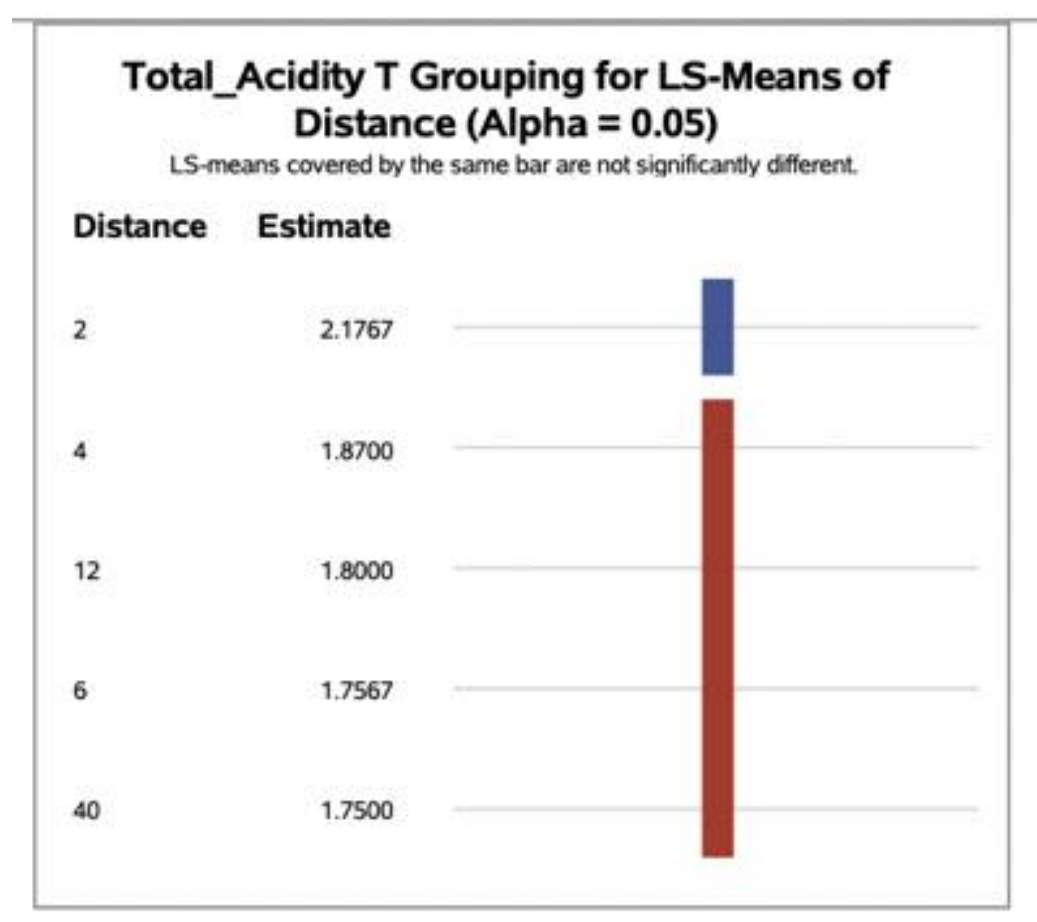

The UNIVARIATE Procedure

Variable: $\mathbf{R}$

\begin{tabular}{|l|r|l|r|}
\hline \multicolumn{4}{|c|}{ Moments } \\
\hline N & 15 & Sum Weights & 15 \\
\hline Mean & 0 & Sum Observations & 0 \\
\hline Std Deviation & 0.08019619 & Variance & 0.00643143 \\
\hline Skewness & 0.33797358 & Kurtosis & -0.3077904 \\
\hline Uncorrected SS & 0.09004 & Corrected SS & 0.09004 \\
\hline Coeff Variation & & Std Error Mean & 0.02070657 \\
\hline
\end{tabular}

\begin{tabular}{|l|l|l|l|r|}
\hline \multicolumn{5}{|c|}{ Tests for Normality } \\
\hline Test & \multicolumn{2}{|c|}{ Statistic } & \multicolumn{2}{c|}{ p Value } \\
\hline Shapiro-Wilk & W & 0.972798 & Pr $<$ W & 0.8971 \\
\hline Kolmogorov-Smirnov & D & 0.116055 & Pr $>$ D & $>0.1500$ \\
\hline Cramer-von Mises & W-Sq & 0.02713 & Pr $>$ W-Sq & $>0.2500$ \\
\hline Anderson-Darling & A-Sq & 0.196051 & Pr $>$ A-Sq & $>0.2500$ \\
\hline
\end{tabular}


The UNIVARIATE Procedure

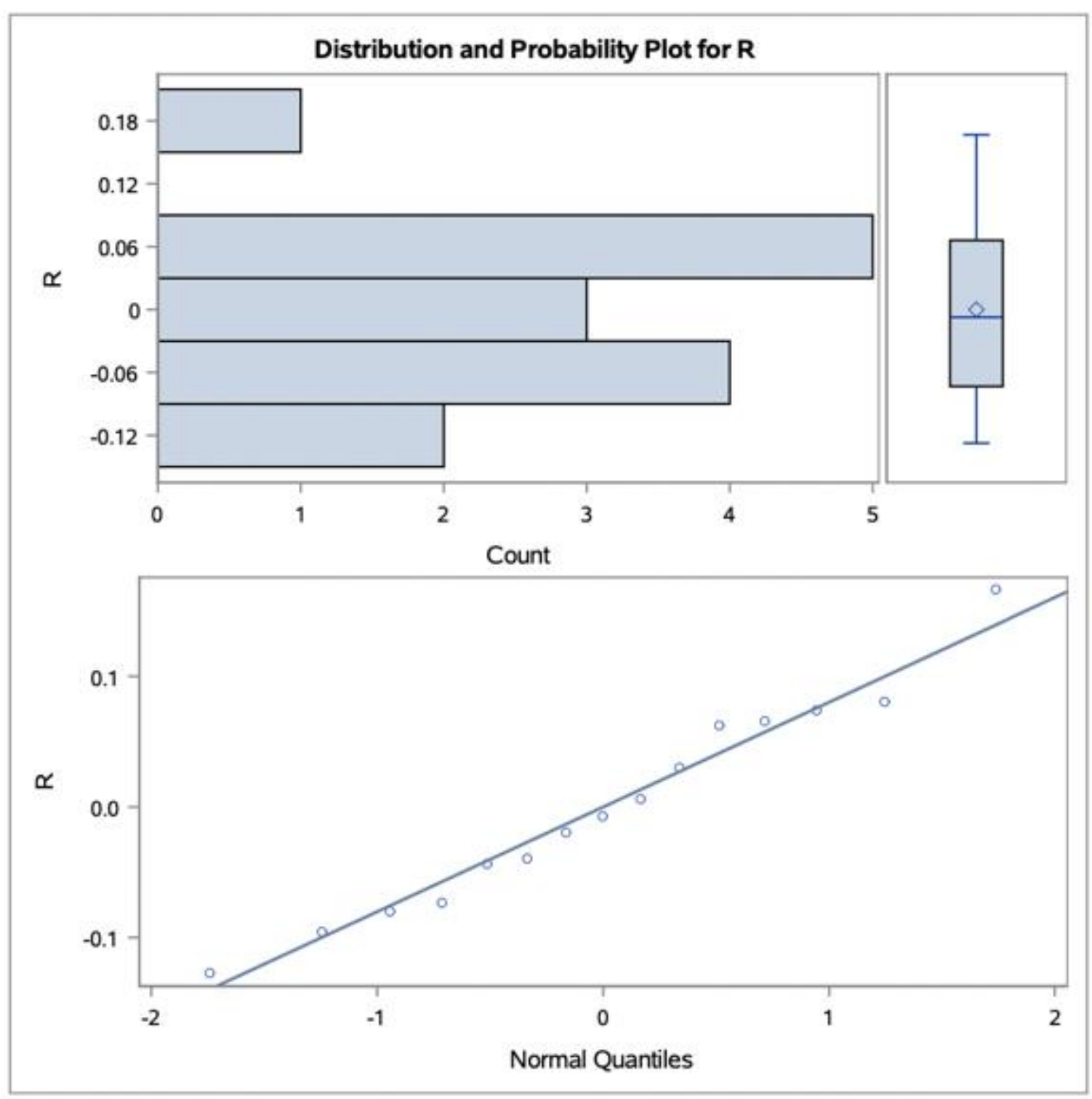


Table 5. SAS output for the variable $\mathrm{pH}$

\section{Quality Data}

$\mathrm{pH}$

The GLM Procedure

Dependent Variable: $\mathrm{pH}$ pH

\begin{tabular}{|l|r|r|r|r|r|}
\hline Source & DF & $\begin{array}{r}\text { Sum of } \\
\text { Squares }\end{array}$ & Mean Square & F Value & Pr > F \\
\hline Model & 6 & 0.08921333 & 0.01486889 & 1.75 & 0.2269 \\
\hline Error & 8 & 0.06794667 & 0.00849333 & & \\
\hline Corrected Total & 14 & 0.15716000 & & & \\
\hline
\end{tabular}

\begin{tabular}{|l|r|r|r|r|r|}
\hline Source & DF & Type III SS & Mean Square & F Value & Pr $>$ F \\
\hline Distance & 4 & 0.08389333 & 0.02097333 & 2.47 & 0.1287 \\
\hline Rep & 2 & 0.00532000 & 0.00266000 & 0.31 & 0.7397 \\
\hline
\end{tabular}

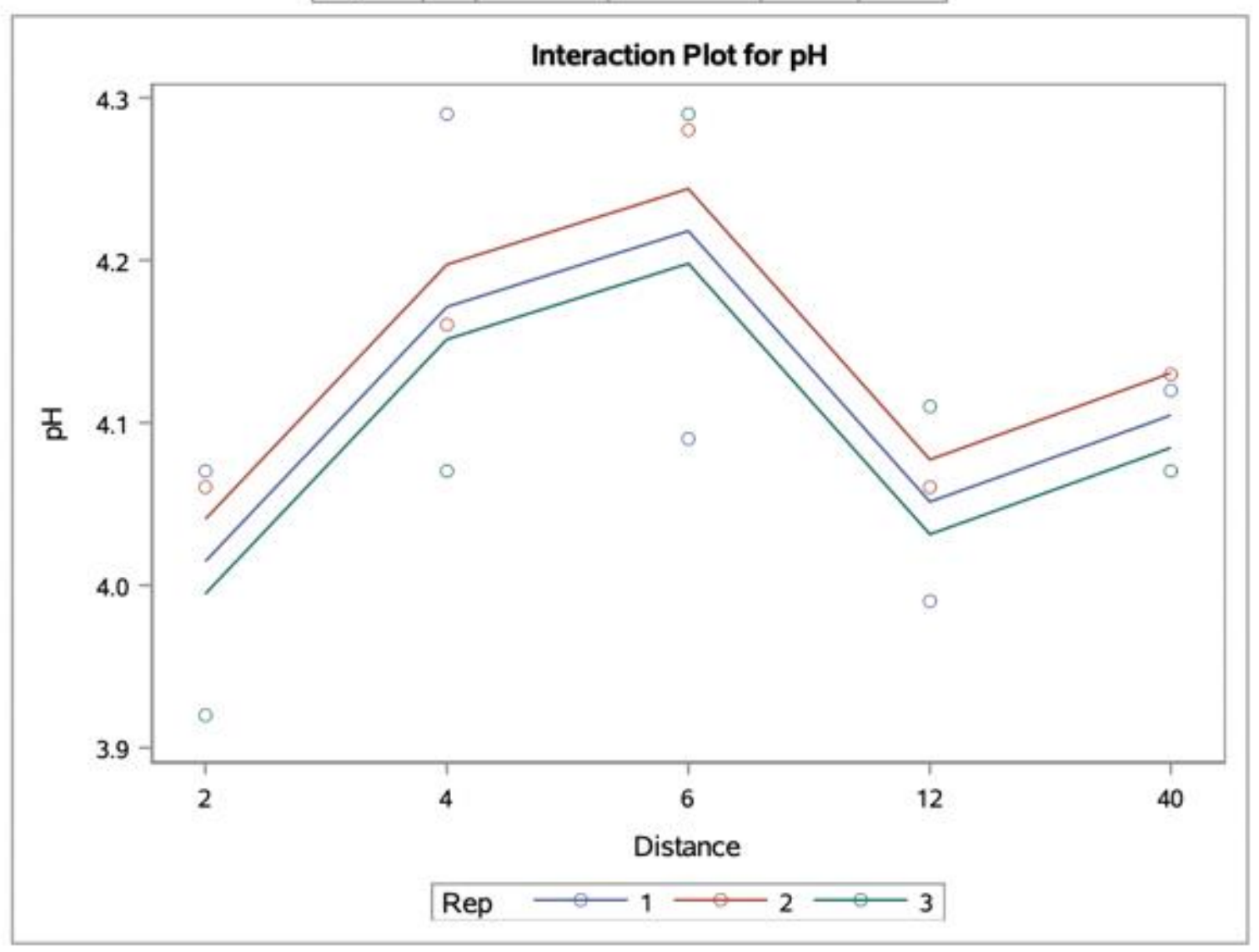


The GLM Procedure

Least Squares Means

\begin{tabular}{|l|r|r|r|r|}
\hline Distance & pHLSMEAN & $\begin{array}{r}\text { Standard } \\
\text { Error }\end{array}$ & Pr > |t| & $\begin{array}{r}\text { LSMEAN } \\
\text { Number }\end{array}$ \\
\hline $\mathbf{2}$ & 4.01666667 & 0.05320819 & $<.0001$ & 1 \\
\hline 4 & 4.17333333 & 0.05320819 & $<.0001$ & 2 \\
\hline 6 & 4.22000000 & 0.05320819 & $<.0001$ & 3 \\
\hline 12 & 4.05333333 & 0.05320819 & $<.0001$ & 4 \\
\hline 40 & 4.10666667 & 0.05320819 & $<.0001$ & 5 \\
\hline
\end{tabular}

\begin{tabular}{|l|r|r|r|r|r|}
\hline \multicolumn{7}{|c|}{$\begin{array}{c}\text { Least Squares Means for effect Distance } \\
\text { Pr > It| for H0: LSMean(D)=LSMean(0) }\end{array}$} \\
Dependent Variable: pH \\
\hline $\mathbf{1 j}$ & $\mathbf{1}$ & $\mathbf{2}$ & $\mathbf{3}$ & $\mathbf{4}$ & $\mathbf{5}$ \\
\hline $\mathbf{1}$ & & 0.0709 & 0.0270 & 0.6391 & 0.2659 \\
\hline $\mathbf{2}$ & 0.0709 & & 0.5524 & 0.1494 & 0.4015 \\
\hline $\mathbf{3}$ & 0.0270 & 0.5524 & & 0.0576 & 0.1705 \\
\hline $\mathbf{4}$ & 0.6391 & $\mathbf{0 . 1 4 9 4}$ & 0.0576 & & 0.4986 \\
\hline $\mathbf{5}$ & 0.2659 & 0.4015 & 0.1705 & 0.4986 & \\
\hline
\end{tabular}

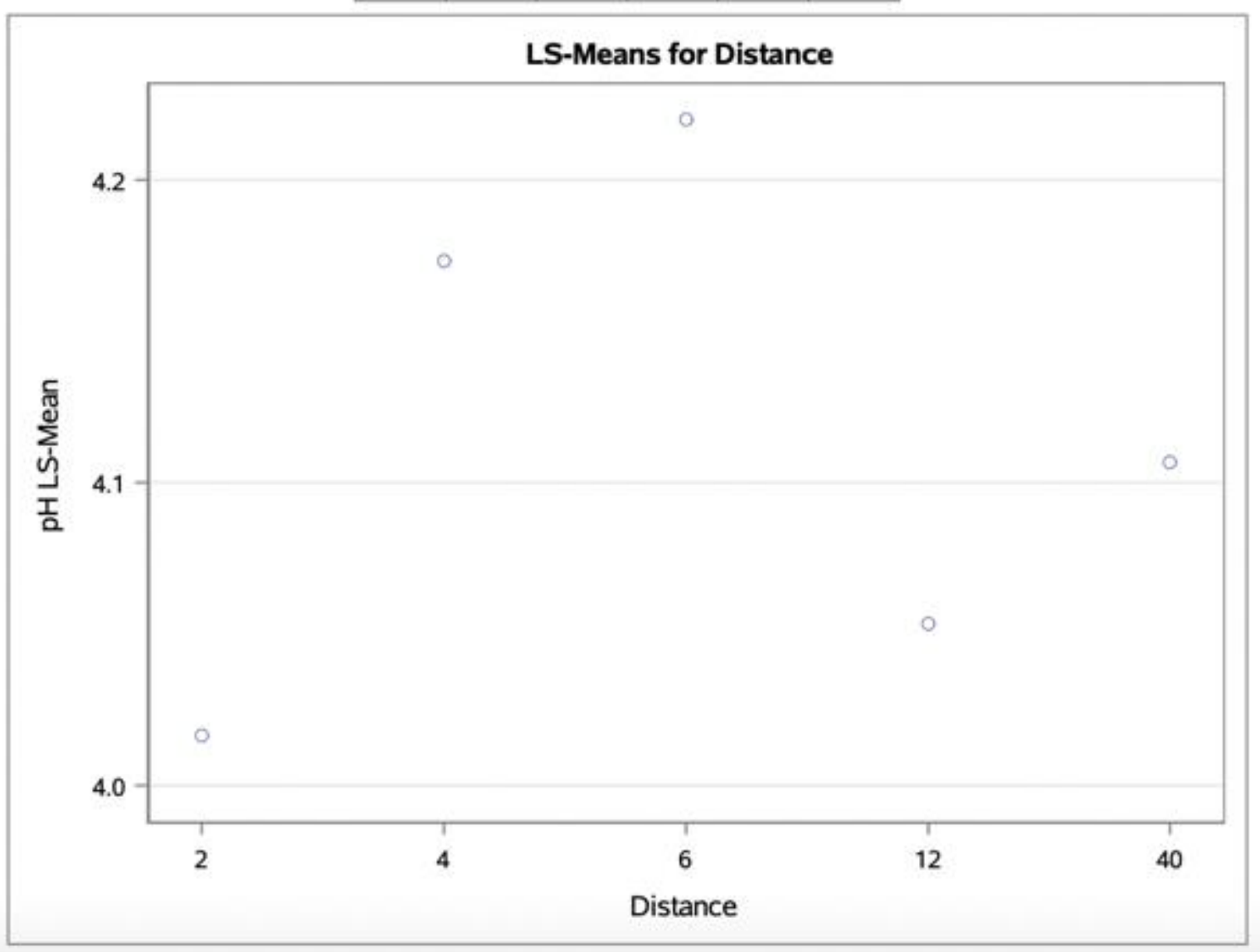




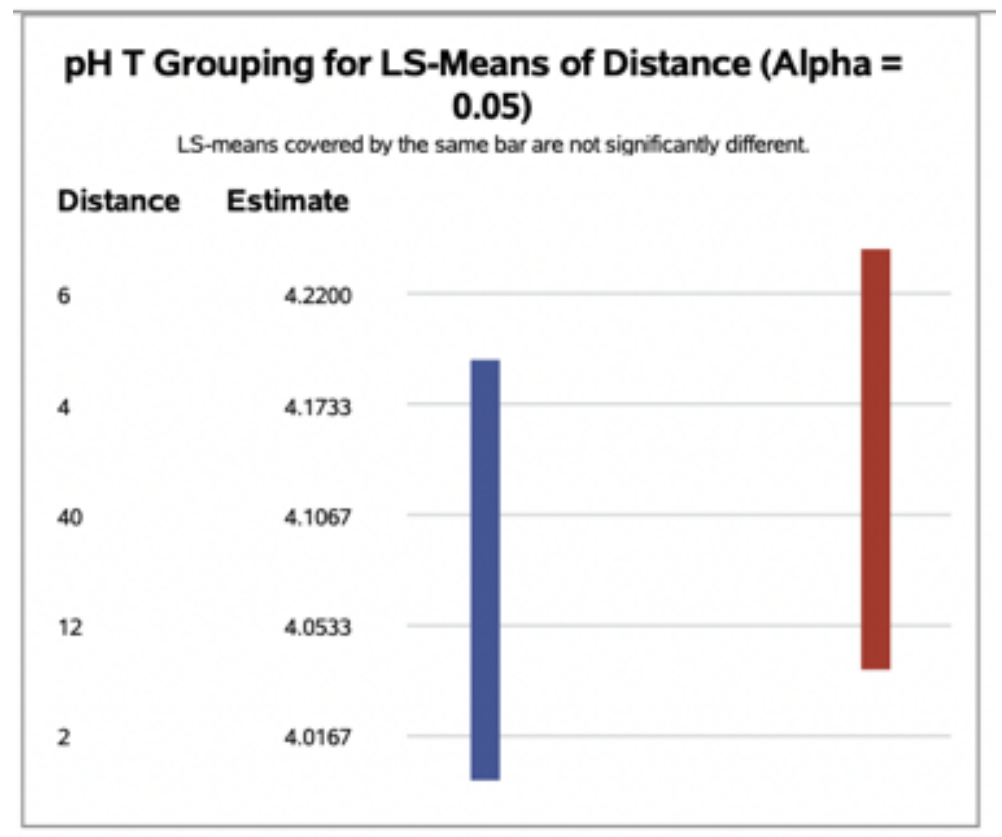

The UNIVARIATE Procedure

Variable: $\mathbf{R}$

\begin{tabular}{|l|r|l|r|}
\hline \multicolumn{4}{|c|}{ Moments } \\
\hline N & 15 & Sum Weights & 15 \\
\hline Mean & 0 & Sum Observations & 0 \\
\hline Std Deviation & 0.06966587 & Variance & 0.00485333 \\
\hline Skewness & -0.043662 & Kurtosis & -0.601553 \\
\hline Uncorrected SS & 0.06794667 & Corrected SS & 0.06794667 \\
\hline Coeff Variation & & Std Error Mean & 0.01798765 \\
\hline
\end{tabular}

\begin{tabular}{|l|l|c|l|r|}
\hline \multicolumn{5}{|c|}{ Tests for Normality } \\
\hline Test & \multicolumn{2}{|c|}{ Statistic } & \multicolumn{2}{c|}{ P Value } \\
\hline Shapiro-Wilk & W & 0.98688 & Pr $<$ W & 0.9966 \\
\hline Kolmogorov-Smirnov & D & 0.077343 & Pr $>$ D & $>0.1500$ \\
\hline Cramer-von Mises & W-Sq & 0.013055 & Pr $>$ W-Sq & $>0.2500$ \\
\hline Anderson-Darling & A-Sq & 0.104863 & Pr $>$ A-Sq & $>0.2500$ \\
\hline
\end{tabular}


The UNIVARIATE Procedure

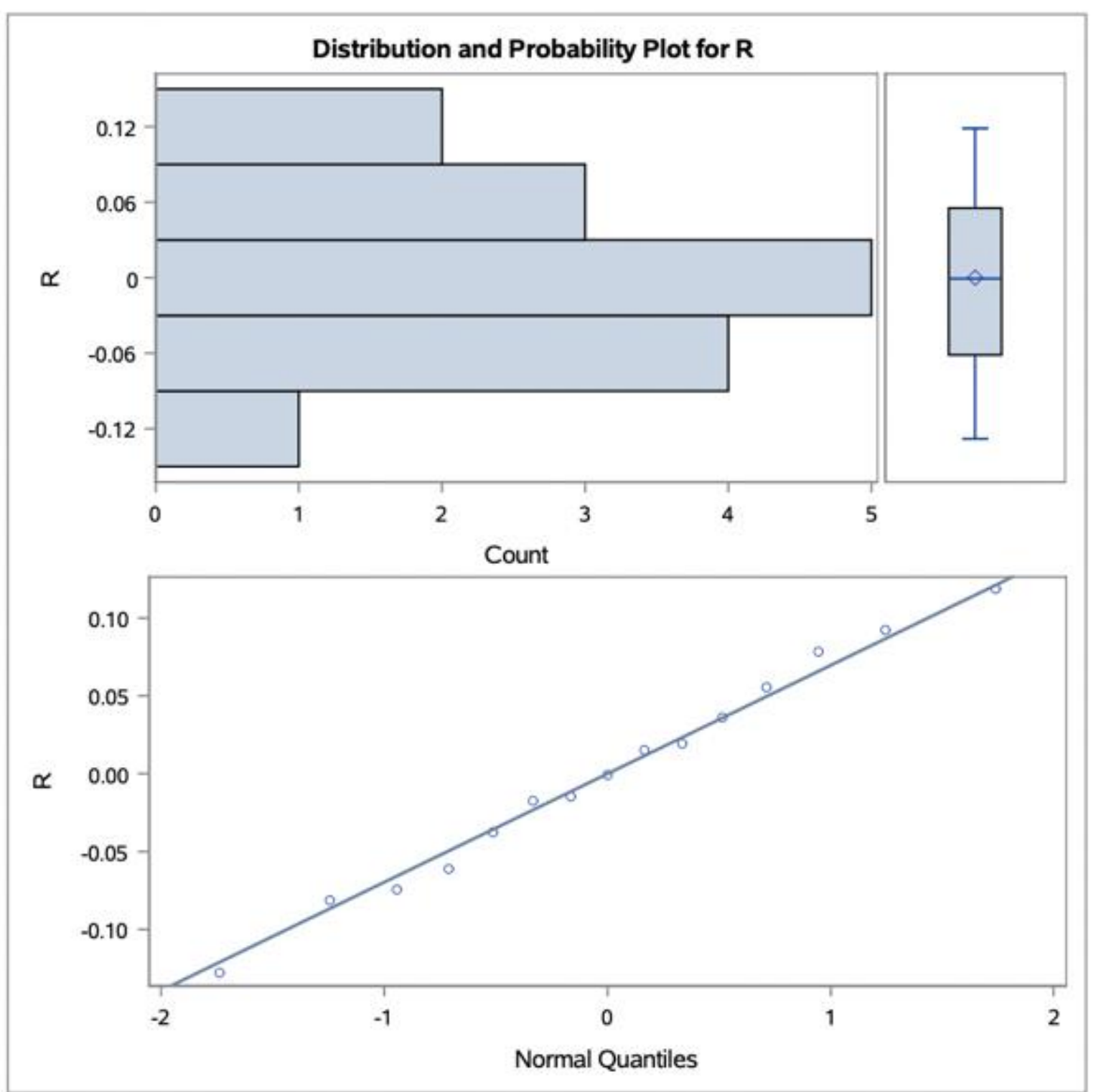


Table 6. SAS output for the variable malic acid $(\mathrm{g} / \mathrm{L})$

\section{Quality Data \\ Malic_Acid}

\section{The GLM Procedure}

Dependent Variable: Malic_Acid Malic_Acid

\begin{tabular}{|l|r|r|r|r|r|}
\hline Source & DF & $\begin{array}{r}\text { Sum of } \\
\text { Squares }\end{array}$ & Mean Square & F Value & Pr $>$ F \\
\hline Model & 6 & 0.12270667 & 0.02045111 & 0.94 & 0.5185 \\
\hline Error & 8 & 0.17478667 & 0.02184833 & & \\
\hline Corrected Total & 14 & 0.29749333 & & & \\
\hline
\end{tabular}

\begin{tabular}{|l|r|r|r|r|r|}
\hline Source & DF & Type III SS & Mean Square & F Value & Pr $>$ F \\
\hline Distance & 4 & 0.10029333 & 0.02507333 & 1.15 & 0.4007 \\
\hline Rep & 2 & 0.02241333 & 0.01120667 & 0.51 & 0.6172 \\
\hline
\end{tabular}

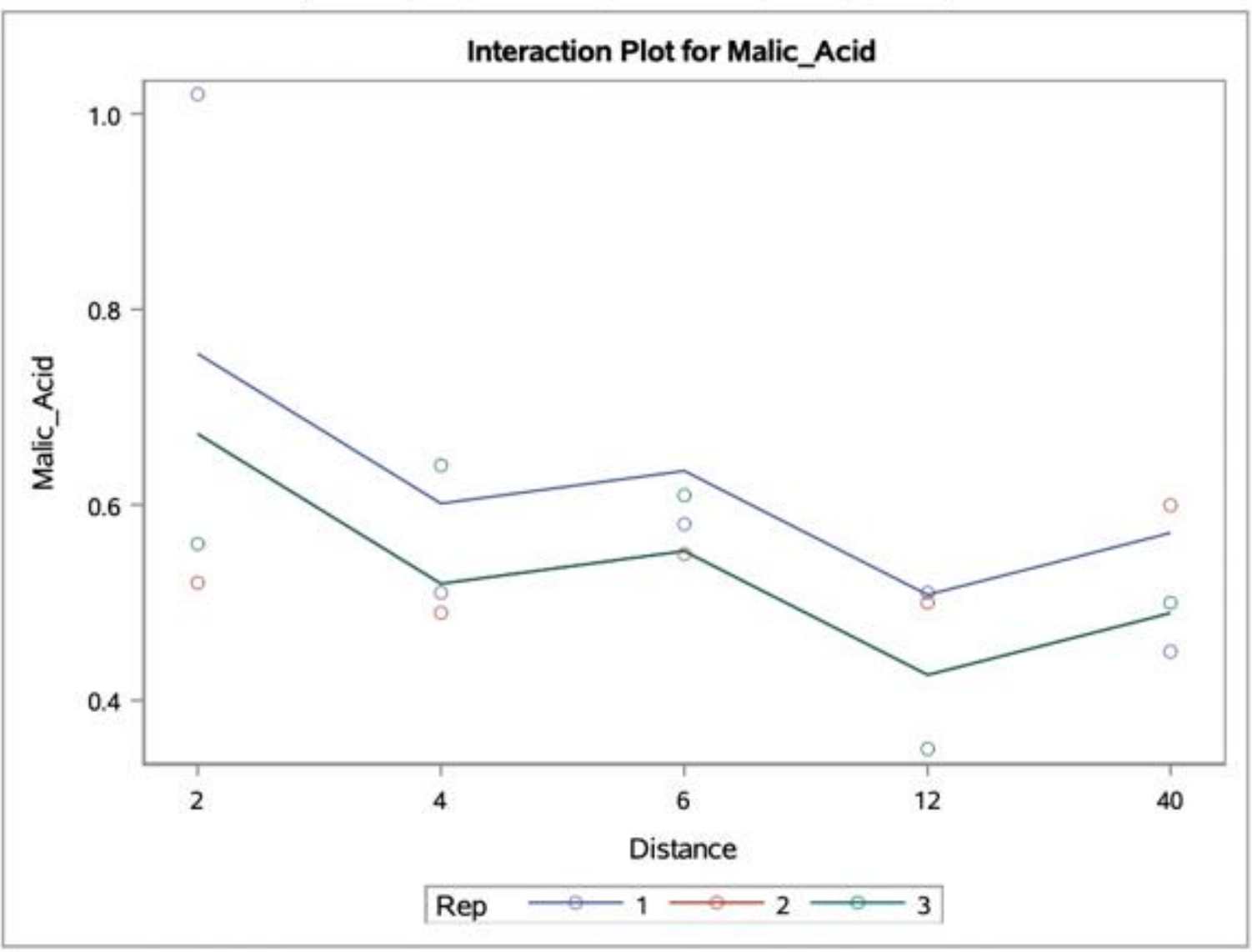


The GLM Procedure Least Squares Means

\begin{tabular}{|l|r|r|r|r|}
\hline Distance & $\begin{array}{r}\text { Malic_Acid } \\
\text { LSMEAN }\end{array}$ & $\begin{array}{r}\text { Standard } \\
\text { Error }\end{array}$ & Pr $>$ | |t| & $\begin{array}{r}\text { LSMEAN } \\
\text { Number }\end{array}$ \\
\hline $\mathbf{2}$ & 0.70000000 & 0.08533919 & $<.0001$ & 1 \\
\hline $\mathbf{4}$ & 0.54666667 & 0.08533919 & 0.0002 & 2 \\
\hline $\mathbf{6}$ & 0.58000000 & 0.08533919 & 0.0001 & 3 \\
\hline $\mathbf{1 2}$ & 0.45333333 & 0.08533919 & 0.0007 & 4 \\
\hline 40 & 0.51666667 & 0.08533919 & 0.0003 & 5 \\
\hline
\end{tabular}

\begin{tabular}{|l|r|r|r|r|r|}
\hline \multicolumn{7}{|c|}{$\begin{array}{c}\text { Least Squares Means for effect Distance } \\
\text { Pr > It for H0: LSMean(i)=LSMean(j) }\end{array}$} \\
Dependent Variable: Malic_Acid \\
\hline i/j & $\mathbf{1}$ & $\mathbf{2}$ & $\mathbf{3}$ & $\mathbf{4}$ & $\mathbf{5}$ \\
\hline $\mathbf{1}$ & & 0.2396 & 0.3492 & 0.0752 & 0.1672 \\
\hline $\mathbf{2}$ & 0.2396 & & 0.7894 & 0.4616 & 0.8100 \\
\hline $\mathbf{3}$ & 0.3492 & 0.7894 & & 0.3246 & 0.6140 \\
\hline $\mathbf{4}$ & 0.0752 & 0.4616 & 0.3246 & & 0.6140 \\
\hline $\mathbf{5}$ & 0.1672 & 0.8100 & 0.6140 & 0.6140 & \\
\hline
\end{tabular}

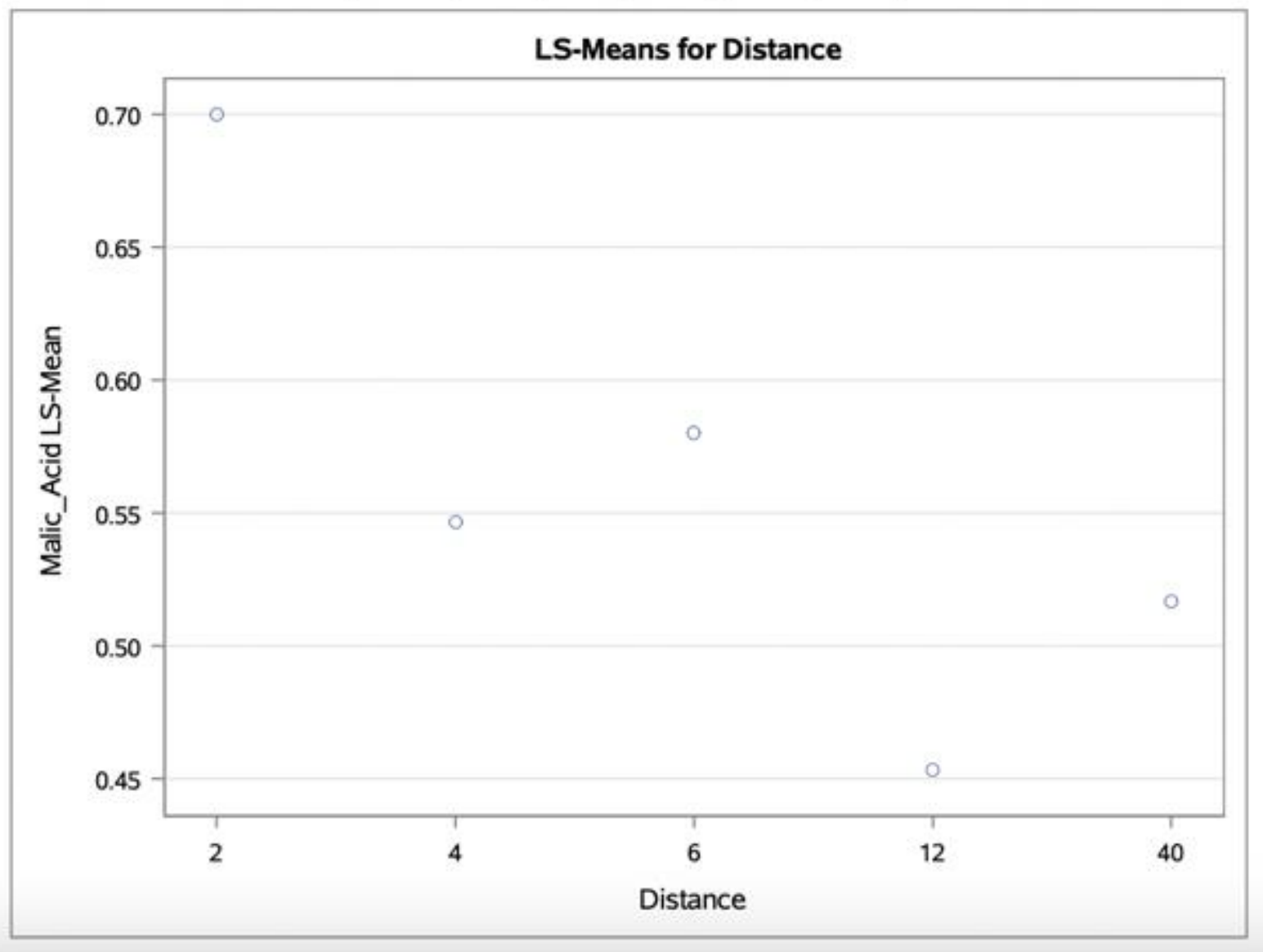




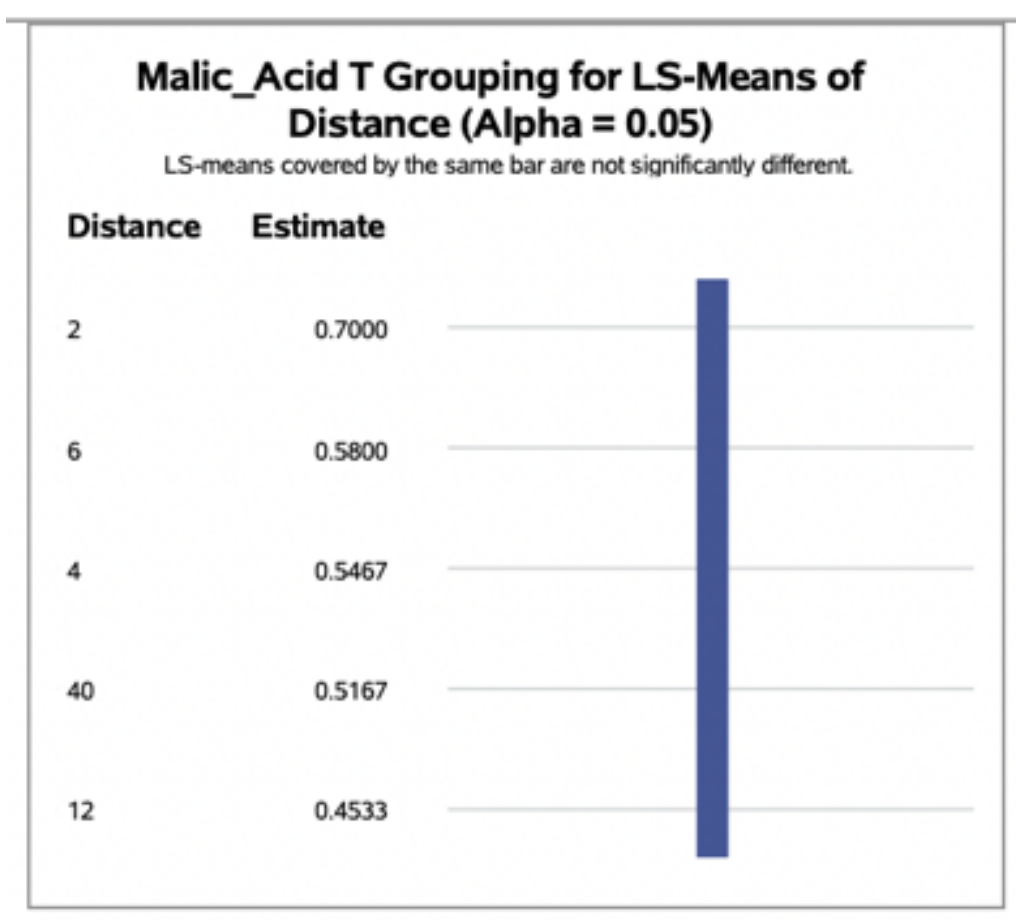

The UNIVARIATE Procedure

Variable: $\mathbf{R}$

\begin{tabular}{|l|r|l|r|}
\hline \multicolumn{4}{|c|}{ Moments } \\
\hline $\mathrm{N}$ & 15 & Sum Weights & 15 \\
\hline Mean & 0 & Sum Observations & 0 \\
\hline Std Deviation & 0.11173523 & Variance & 0.01248476 \\
\hline Skewness & 0.84031459 & Kurtosis & 0.73786804 \\
\hline Uncorrected SS & 0.17478667 & Corrected SS & 0.17478667 \\
\hline Coeff Variation & & Std Error Mean & 0.02884991 \\
\hline
\end{tabular}

\begin{tabular}{|l|l|l|l|r|}
\hline \multicolumn{5}{|c|}{ Tests for Normality } \\
\hline Test & \multicolumn{2}{|c|}{ Statistic } & \multicolumn{2}{c|}{ p Value } \\
\hline Shapiro-Wilk & W & 0.948612 & $\mathrm{Pr}<$ W & 0.5029 \\
\hline Kolmogorov-Smirnov & D & 0.12864 & $\mathrm{Pr}>$ D & $>0.1500$ \\
\hline Cramer-von Mises & W-Sq & 0.033018 & $\mathrm{Pr}>$ W-Sq & $>0.2500$ \\
\hline Anderson-Darling & A-Sq & 0.261305 & $\mathrm{Pr}>$ A-Sq & $>0.2500$ \\
\hline
\end{tabular}


The UNIVARIATE Procedure

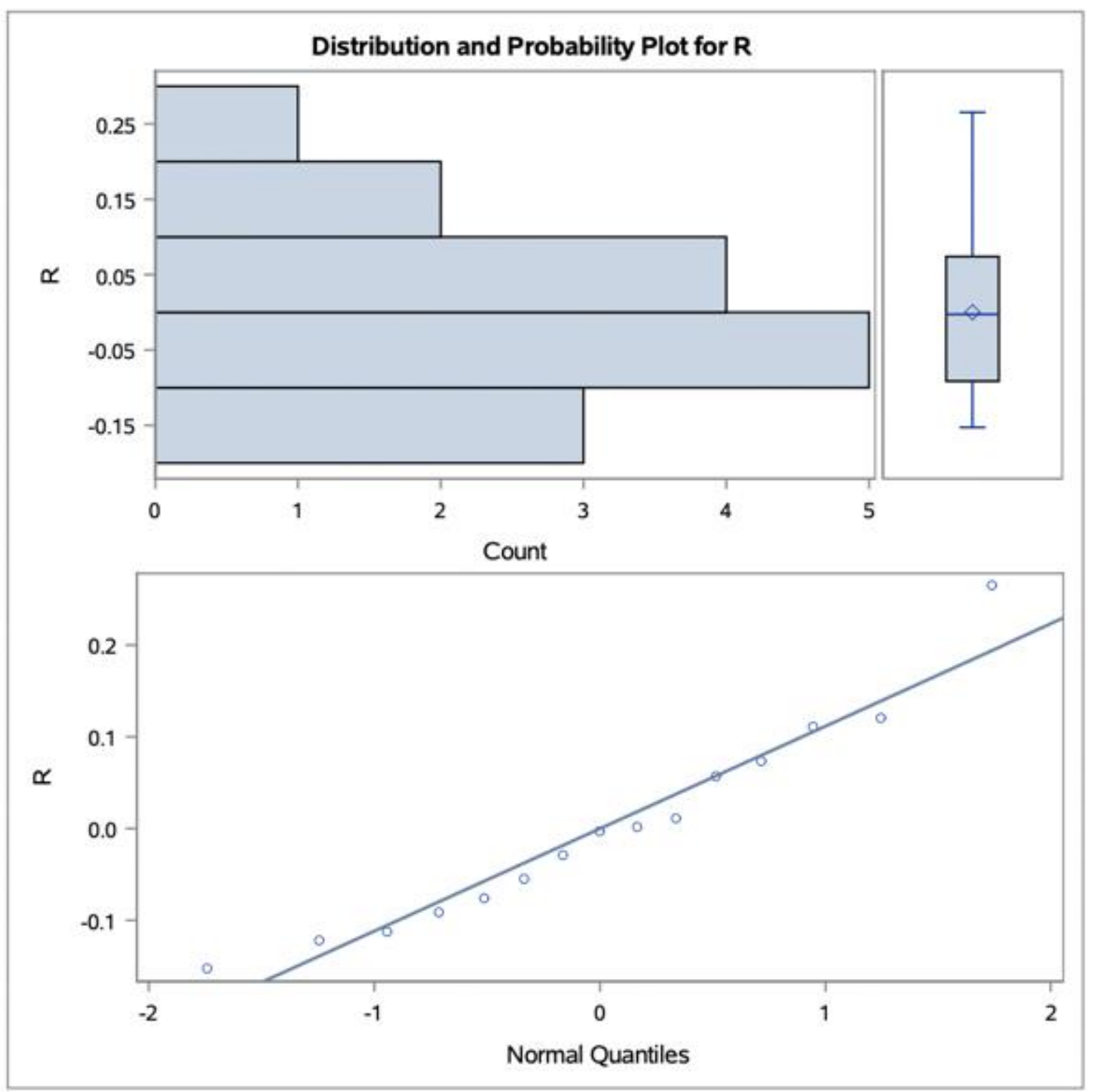


Table 7. SAS output for the variable YAN (g/L)

\section{Quality Data \\ YAN}

The GLM Procedure

Dependent Variable: YAN YAN

\begin{tabular}{|l|r|r|r|r|r|}
\hline Source & DF & $\begin{array}{r}\text { Sum of } \\
\text { Squares }\end{array}$ & Mean Square & F Value & Pr > F \\
\hline Model & 6 & 1164.208480 & 194.034747 & 0.31 & 0.9130 \\
\hline Error & 8 & 4962.618693 & 620.327337 & & \\
\hline Corrected Total & 14 & 6126.827173 & & & \\
\hline
\end{tabular}

\begin{tabular}{|l|r|r|r|r|r|}
\hline Source & DF & Type III SS & Mean Square & F Value & Pr $>$ F \\
\hline Distance & 4 & 1144.234707 & 286.058677 & 0.46 & 0.7629 \\
\hline Rep & 2 & 19.973773 & 9.986887 & 0.02 & 0.9841 \\
\hline
\end{tabular}

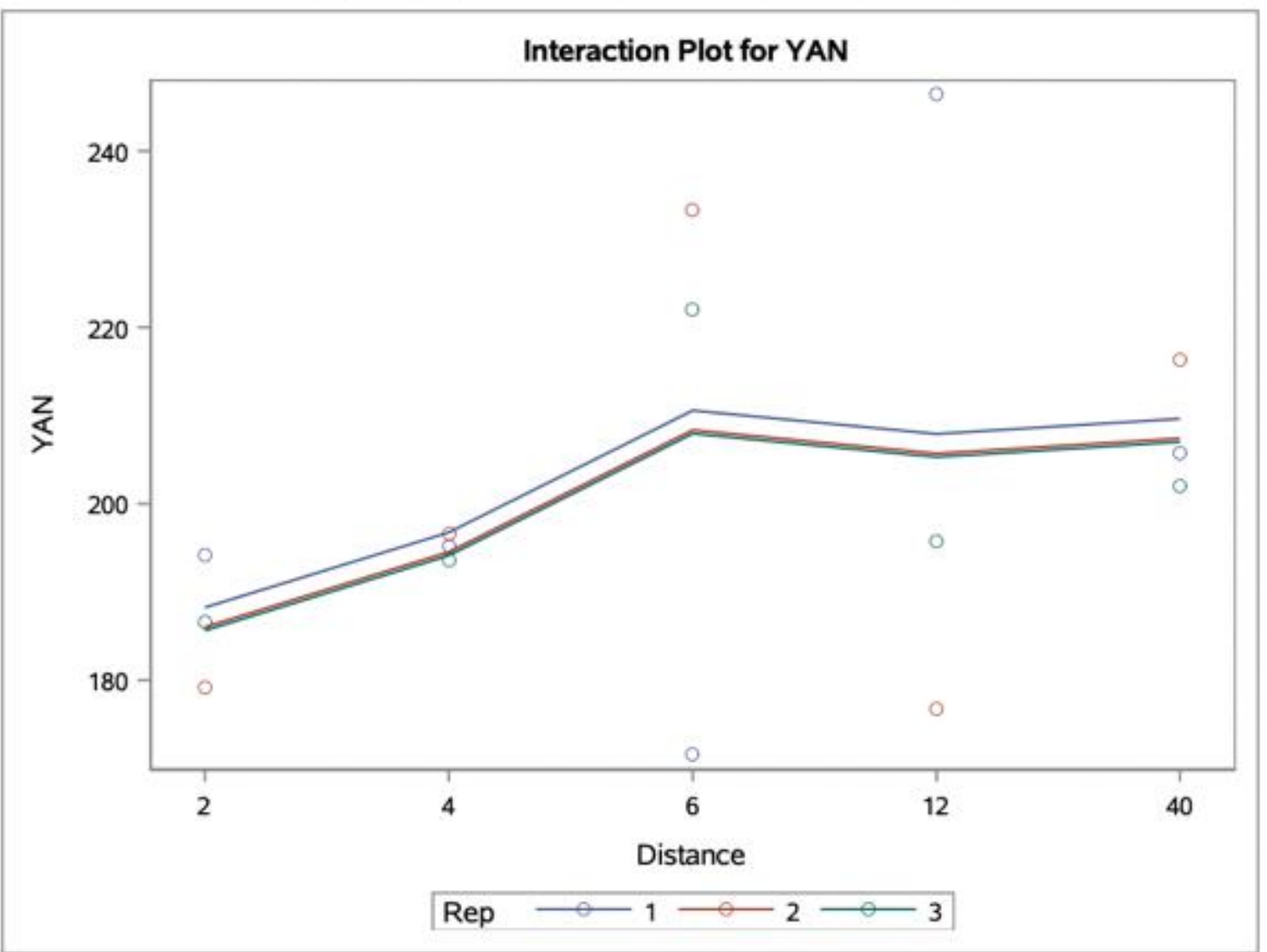


The GLM Procedure

Least Squares Means

\begin{tabular}{|l|r|r|r|r|}
\hline Distance & YAN LSMEAN & $\begin{array}{r}\text { Standard } \\
\text { Error }\end{array}$ & $\operatorname{Pr}>\mathbf{I t}$ & $\begin{array}{r}\text { LSMEAN } \\
\text { Number }\end{array}$ \\
\hline $\mathbf{2}$ & 186.643333 & 14.379700 & $<.0001$ & 1 \\
\hline 4 & 195.146667 & 14.379700 & $<.0001$ & 2 \\
\hline 6 & 208.966667 & 14.379700 & $<.0001$ & 3 \\
\hline 12 & 206.310000 & 14.379700 & $<.0001$ & 4 \\
\hline 40 & 208.026667 & 14.379700 & $<.0001$ & 5 \\
\hline
\end{tabular}

\begin{tabular}{|l|r|r|r|r|r|}
\hline \multicolumn{7}{|c|}{$\begin{array}{c}\text { Least Squares Means for effect Distance } \\
\text { Pr > 14 for H0: LSMean(i)=LSMean(j) } \\
\text { Dependent Variable: YAN }\end{array}$} \\
\hline i/j & $\mathbf{1}$ & $\mathbf{2}$ & $\mathbf{3}$ & $\mathbf{4}$ & $\mathbf{5}$ \\
\hline $\mathbf{1}$ & & 0.6868 & 0.3043 & 0.3618 & 0.3237 \\
\hline $\mathbf{2}$ & 0.6868 & & 0.5159 & 0.5980 & 0.5442 \\
\hline $\mathbf{3}$ & 0.3043 & 0.5159 & & 0.8993 & 0.9643 \\
\hline $\mathbf{4}$ & 0.3618 & 0.5980 & 0.8993 & & 0.9348 \\
\hline $\mathbf{5}$ & 0.3237 & 0.5442 & 0.9643 & 0.9348 & \\
\hline
\end{tabular}

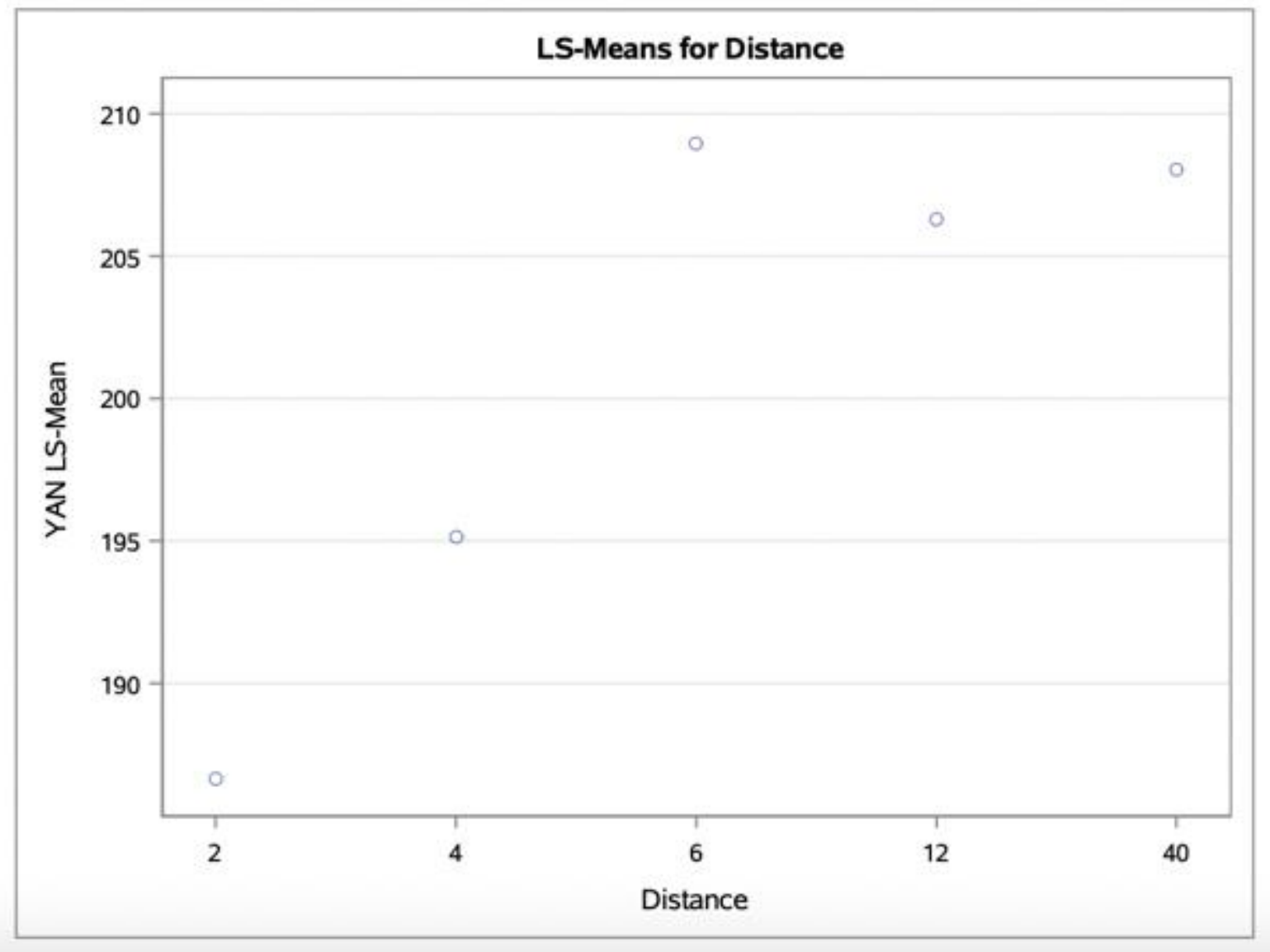




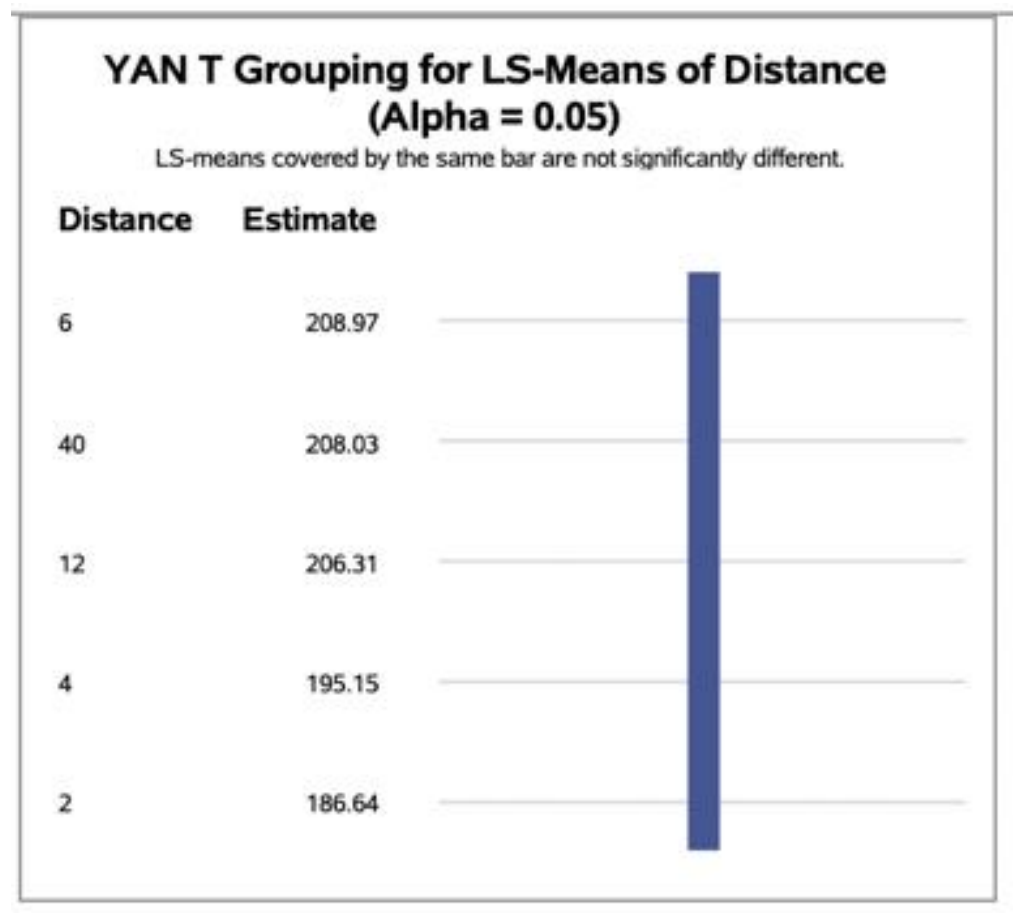

The UNIVARIATE Procedure

Variable: $\mathbf{R}$

\begin{tabular}{|l|r|l|r|}
\hline \multicolumn{4}{|c|}{ Moments } \\
\hline N & 15 & Sum Weights & 15 \\
\hline Mean & 0 & Sum Observations & 0 \\
\hline Std Deviation & 18.8274471 & Variance & 354.472764 \\
\hline Skewness & -0.1066182 & Kurtosis & 1.18311141 \\
\hline Uncorrected SS & 4962.61869 & Corrected SS & 4962.61869 \\
\hline Coeff Variation & & Std Error Mean & 4.86122593 \\
\hline
\end{tabular}

\begin{tabular}{|l|l|l|l|r|}
\hline \multicolumn{5}{|c|}{ Tests for Normality } \\
\hline Test & \multicolumn{2}{|c|}{ Statistic } & \multicolumn{2}{c|}{ P Value } \\
\hline Shapiro-Wilk & W & 0.951004 & Pr $<$ W & 0.5404 \\
\hline Kolmogorov-Smirnov & D & 0.172636 & Pr $>$ D & $>0.1500$ \\
\hline Cramer-von Mises & W-Sq & 0.082508 & Pr $>$ W-Sq & 0.1838 \\
\hline Anderson-Darling & A-Sq & 0.449352 & Pr $>$ A-Sq & 0.2431 \\
\hline
\end{tabular}


The UNIVARIATE Procedure

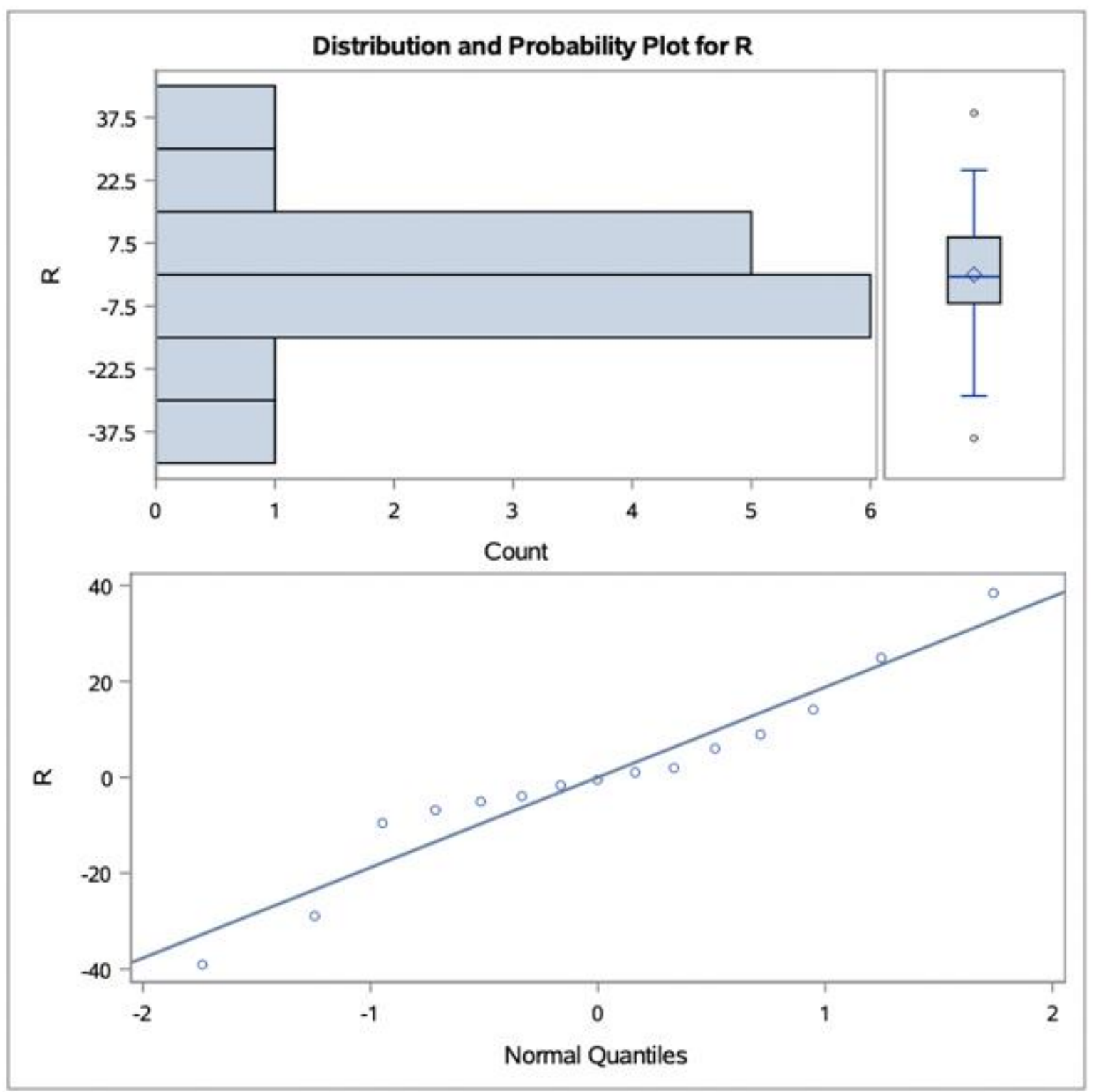


Table 8 . SAS output for the variable total berry skin phenolics (mg/g fruit)

Quality Data 1 Total_Phenolics_Skins

The GLM Procedure

Dependent Variable: Total_Phenolics_Skins Total_Phenolics_Skins

\begin{tabular}{|l|r|r|r|r|r|}
\hline Source & DF & $\begin{array}{r}\text { Sum of } \\
\text { Squares }\end{array}$ & Mean Square & F Value & Pr $>$ F \\
\hline Model & 6 & 0.17592448 & 0.02932075 & 0.13 & 0.9877 \\
\hline Error & 8 & 1.75285406 & 0.21910676 & & \\
\hline Corrected Total & 14 & 1.92877855 & & & \\
\hline
\end{tabular}

\begin{tabular}{|l|r|r|r|r|r|}
\hline Source & DF & Type III SS & Mean Square & F Value & Pr $>$ F \\
\hline Distance & 4 & 0.17248566 & 0.04312142 & 0.20 & 0.9332 \\
\hline Rep & 2 & 0.00343882 & 0.00171941 & 0.01 & 0.9922 \\
\hline
\end{tabular}

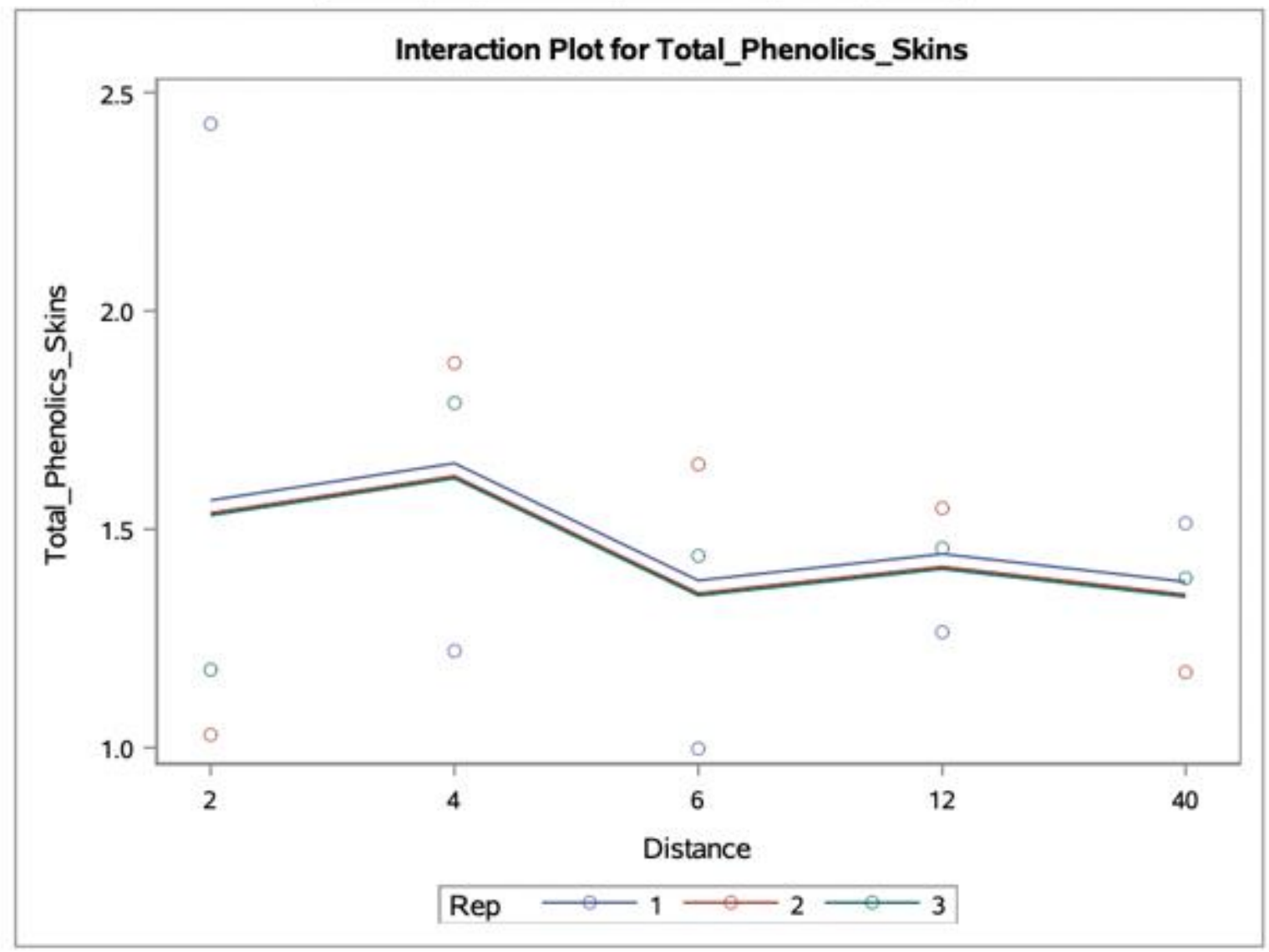


The GLM Procedure

Least Squares Means

\begin{tabular}{|l|r|r|r|r|}
\hline Distance & $\begin{array}{r}\text { Total_Phenolics_Skins } \\
\text { LSMEAN }\end{array}$ & $\begin{array}{r}\text { Standard } \\
\text { Error }\end{array}$ & $\mathbf{P r}>\mathbf{| r |}$ & $\begin{array}{r}\text { LSMEAN } \\
\text { Number }\end{array}$ \\
\hline $\mathbf{2}$ & 1.54501123 & 0.27025097 & 0.0004 & 1 \\
\hline $\mathbf{4}$ & 1.62979925 & 0.27025097 & 0.0003 & 2 \\
\hline $\mathbf{6}$ & 1.36139504 & 0.27025097 & 0.0010 & 3 \\
\hline $\mathbf{1 2}$ & 1.42222796 & 0.27025097 & 0.0008 & 4 \\
\hline $\mathbf{4 0}$ & 1.35830013 & 0.27025097 & 0.0010 & $\mathbf{5}$ \\
\hline
\end{tabular}

\begin{tabular}{|l|r|r|r|r|r|}
\hline \multicolumn{7}{|c|}{$\begin{array}{c}\text { Least Squares Means for effect Distance } \\
\text { Pr }>\text { It for H0: LSMean(i)=LSMean(j) }\end{array}$} \\
Dependent Variable: Total_Phenolics_Skins \\
\hline if & $\mathbf{1}$ & $\mathbf{2}$ & $\mathbf{3}$ & $\mathbf{4}$ & $\mathbf{5}$ \\
\hline $\mathbf{1}$ & & 0.8300 & 0.6438 & 0.7562 & 0.6383 \\
\hline $\mathbf{2}$ & 0.8300 & & 0.5024 & 0.6019 & 0.4977 \\
\hline $\mathbf{3}$ & 0.6438 & 0.5024 & & 0.8775 & 0.9937 \\
\hline $\mathbf{4}$ & 0.7562 & 0.6019 & 0.8775 & & 0.8713 \\
\hline $\mathbf{5}$ & 0.6383 & 0.4977 & 0.9937 & 0.8713 & \\
\hline
\end{tabular}

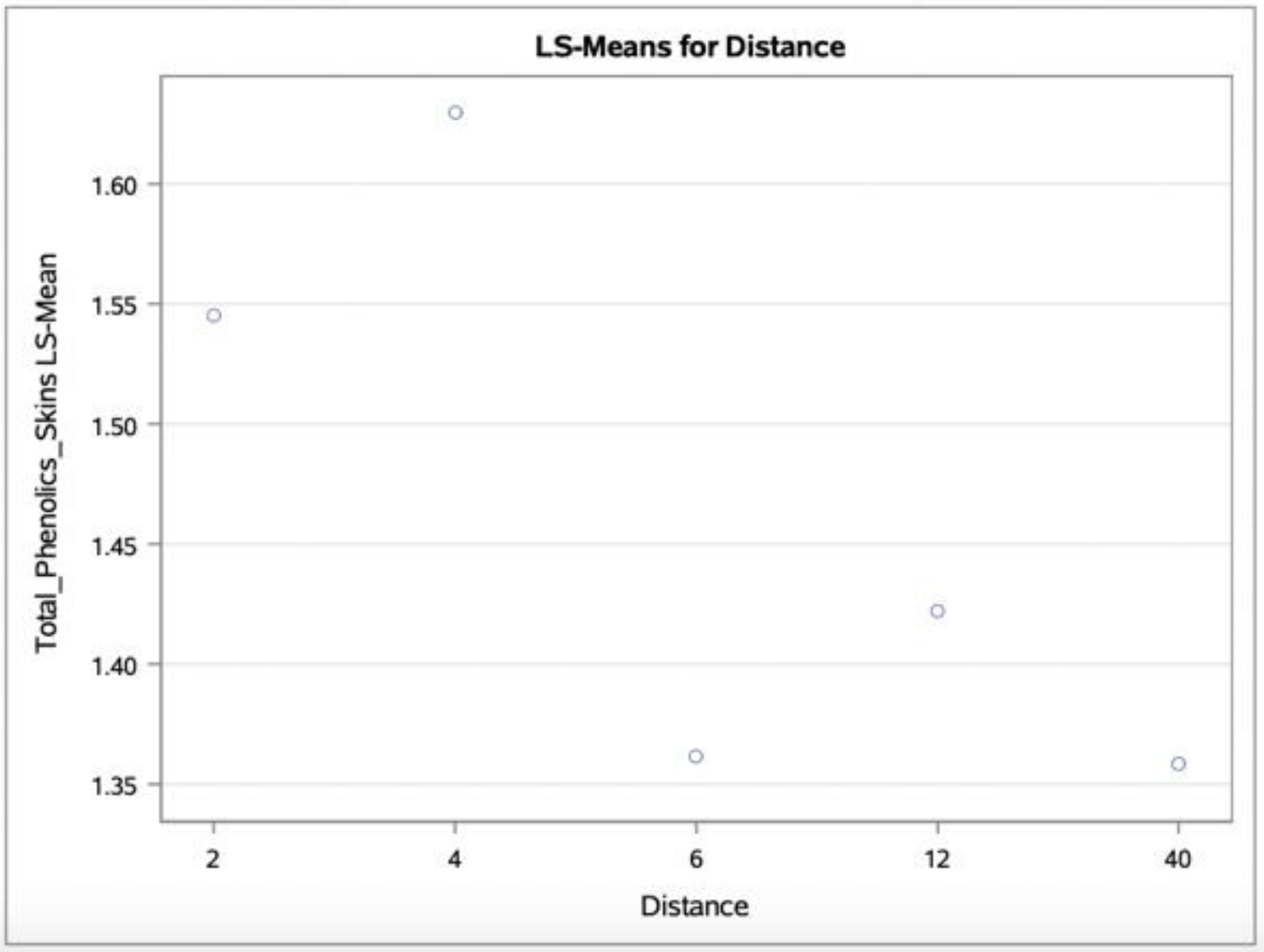




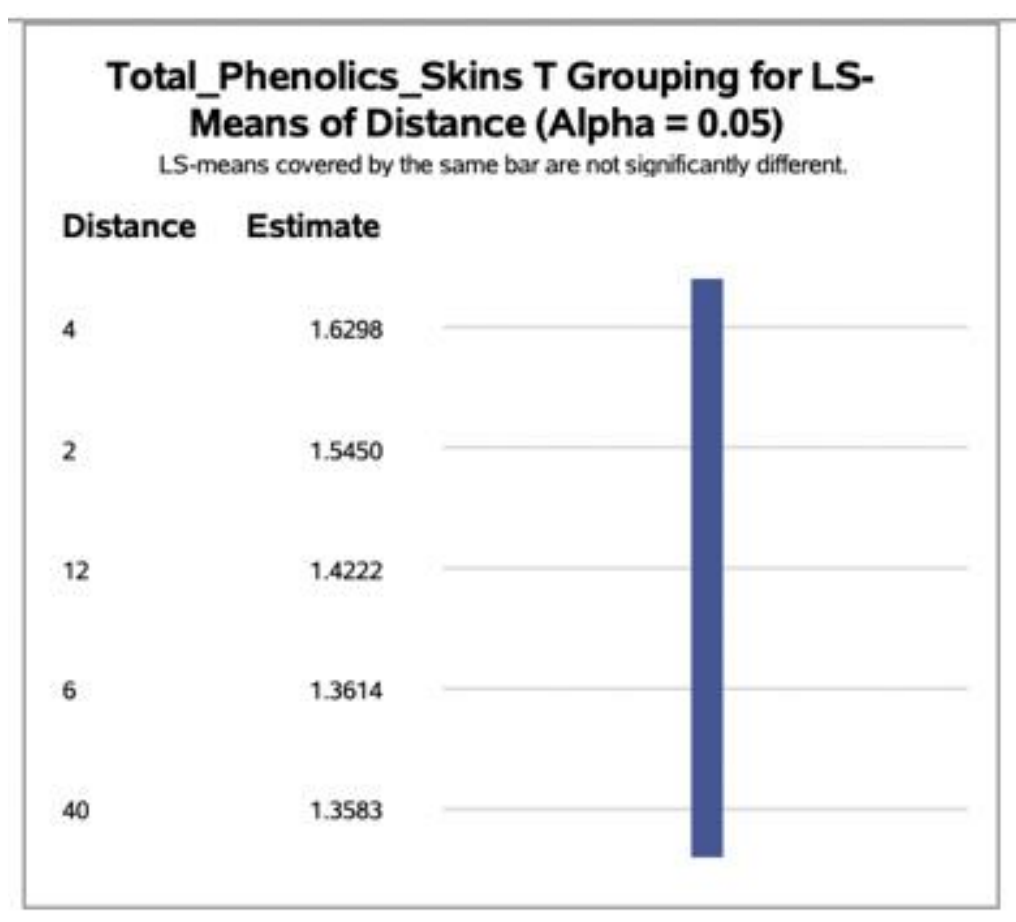

The UNIVARIATE Procedure Variable: $\mathbf{R}$

\begin{tabular}{|l|r|l|r|}
\hline \multicolumn{4}{|c|}{ Moments } \\
\hline N & 15 & Sum Weights & 15 \\
\hline Mean & 0 & Sum Observations & 0 \\
\hline Std Deviation & 0.35384158 & Variance & 0.12520386 \\
\hline Skewness & 0.68388531 & Kurtosis & 1.15790965 \\
\hline Uncorrected SS & 1.75285406 & Corrected SS & 1.75285406 \\
\hline Coeff Variation & & Std Error Mean & 0.0913615 \\
\hline
\end{tabular}

\begin{tabular}{|l|l|l|l|r|}
\hline \multicolumn{5}{|c|}{ Tests for Normality } \\
\hline Test & \multicolumn{2}{|c|}{ Statistic } & \multicolumn{2}{c|}{ p Value } \\
\hline Shapiro-Wilk & W & 0.928825 & Pr $<$ W & 0.2620 \\
\hline Kolmogorov-Smirnov & D & 0.147945 & Pr $>$ D & $>0.1500$ \\
\hline Cramer-von Mises & W-Sq & 0.059094 & Pr $>$ W-Sq & $>0.2500$ \\
\hline Anderson-Darling & A-Sq & 0.412062 & Pr $>$ A-Sq & $>0.2500$ \\
\hline
\end{tabular}


The UNIVARIATE Procedure

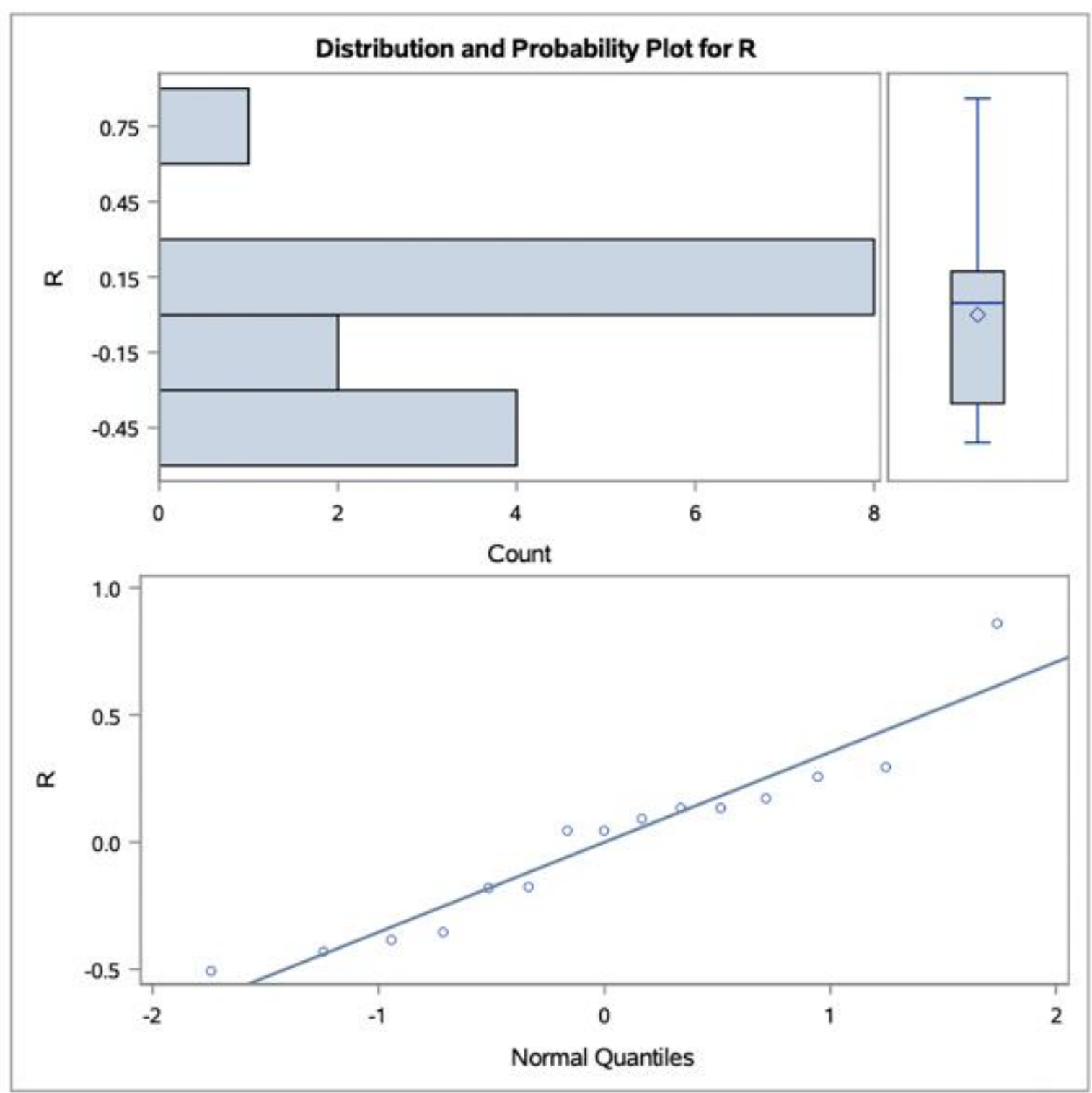


Table 9. SAS output for the variable total berry skin anthocyanins ( $\mathrm{mg} / \mathrm{g}$ fruit)

Quality Data

Total_Anthocyanins_Skins

\section{The GLM Procedure}

\section{Dependent Variable: Total_Anthocyanins_Skins Total_Anthocyanins_Skins}

\begin{tabular}{|l|r|r|r|r|r|}
\hline Source & DF & $\begin{array}{r}\text { Sum of } \\
\text { Squares }\end{array}$ & Mean Square & F Value & Pr > F \\
\hline Model & 6 & 0.52124657 & 0.08687443 & 2.95 & 0.0797 \\
\hline Error & 8 & 0.23551041 & 0.02943880 & & \\
\hline Corrected Total & 14 & 0.75675699 & & & \\
\hline
\end{tabular}

\begin{tabular}{|l|r|r|r|r|r|}
\hline Source & DF & Type III SS & Mean Square & F Value & Pr $>$ F \\
\hline Distance & 4 & 0.32305205 & 0.08076301 & 2.74 & 0.1047 \\
\hline Rep & 2 & 0.19819453 & 0.09909726 & 3.37 & 0.0869 \\
\hline
\end{tabular}

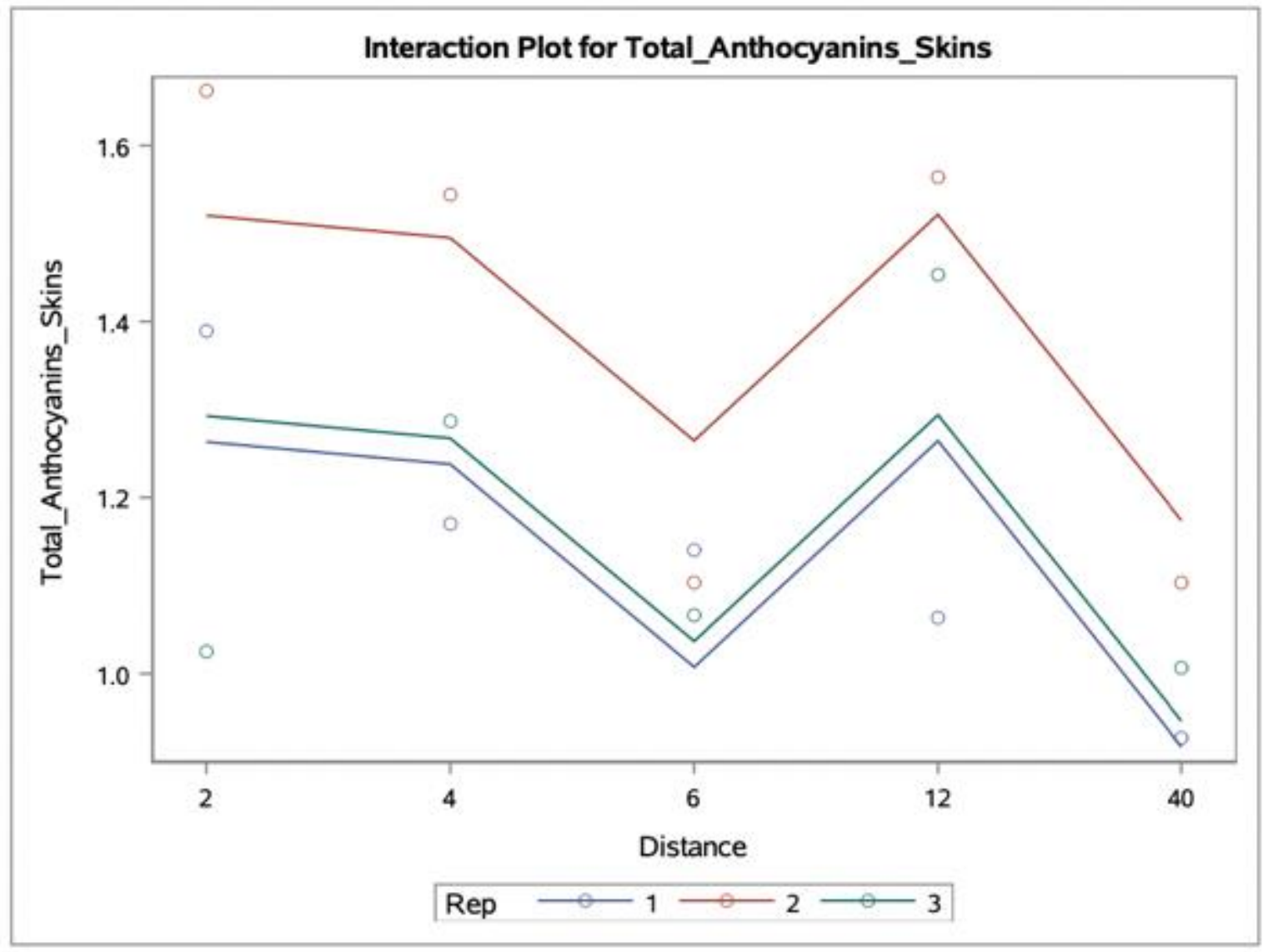


The GLM Procedure

Least Squares Means

\begin{tabular}{|l|r|r|r|r|}
\hline Distance & $\begin{array}{r}\text { Total_Anthocyanins_Skins } \\
\text { LSMEAN }\end{array}$ & $\begin{array}{r}\text { Standard } \\
\text { Error }\end{array}$ & $\operatorname{Pr}>\operatorname{It|}$ & $\begin{array}{r}\text { LSMEAN } \\
\text { Number }\end{array}$ \\
\hline $\mathbf{2}$ & 1.35884996 & 0.09906025 & $<.0001$ & 1 \\
\hline $\mathbf{4}$ & 1.33345874 & 0.09906025 & $<.0001$ & 2 \\
\hline 6 & 1.10298827 & 0.09906025 & $<.0001$ & 3 \\
\hline 12 & 1.35999984 & 0.09906025 & $<.0001$ & 4 \\
\hline 40 & 1.01226679 & 0.09906025 & $<.0001$ & 5 \\
\hline
\end{tabular}

\begin{tabular}{|l|r|r|r|r|r|}
\hline \multicolumn{7}{|c|}{$\begin{array}{c}\text { Least Squares Means for effect Distance } \\
\text { Pr > It for H0: LSMean(i)=LSMean(j) }\end{array}$} \\
Dependent Variable: Total_Anthocyanins_Skins \\
\hline ij & $\mathbf{1}$ & $\mathbf{2}$ & $\mathbf{3}$ & $\mathbf{4}$ & $\mathbf{5}$ \\
\hline $\mathbf{1}$ & & 0.8607 & 0.1052 & 0.9937 & 0.0385 \\
\hline $\mathbf{2}$ & 0.8607 & & 0.1386 & 0.8545 & 0.0510 \\
\hline $\mathbf{3}$ & 0.1052 & 0.1386 & & 0.1039 & 0.5354 \\
\hline $\mathbf{4}$ & $\mathbf{0 . 9 9 3 7}$ & $\mathbf{0 . 8 5 4 5}$ & 0.1039 & & 0.0380 \\
\hline $\mathbf{5}$ & $\mathbf{0 . 0 3 8 5}$ & $\mathbf{0 . 0 5 1 0}$ & $\mathbf{0 . 5 3 5 4}$ & 0.0380 & \\
\hline
\end{tabular}

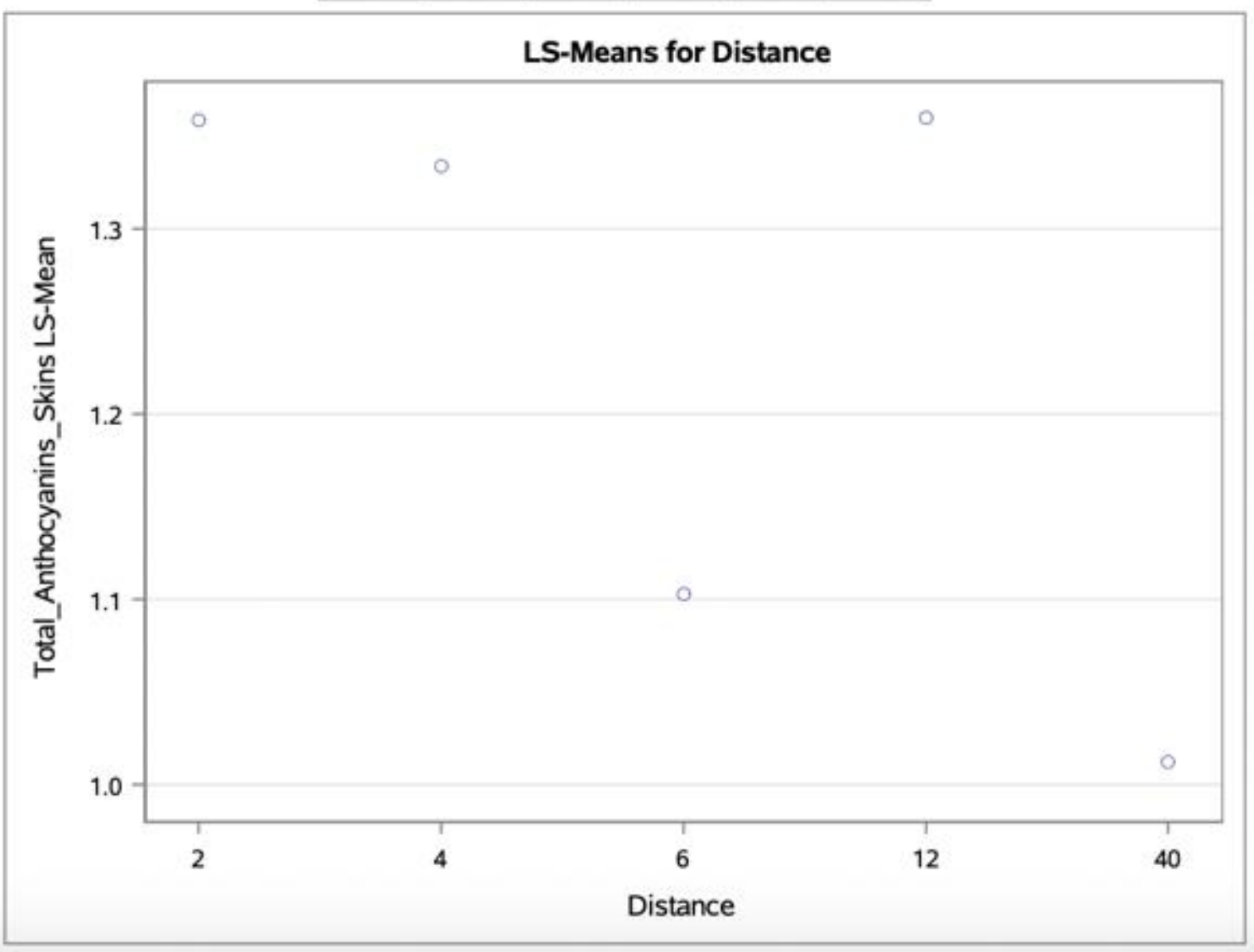




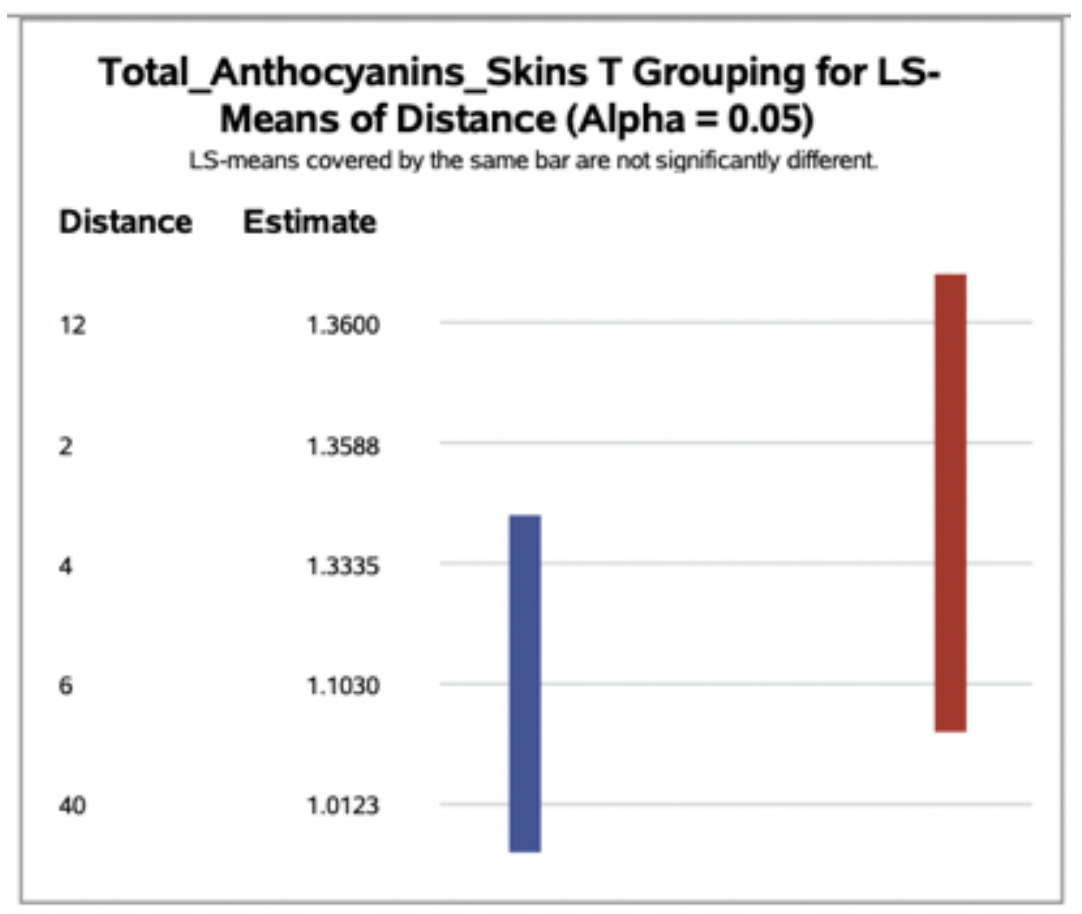

The UNIVARIATE Procedure

Variable: $\mathbf{R}$

\begin{tabular}{|l|r|l|r|}
\hline \multicolumn{4}{|c|}{ Moments } \\
\hline N & 15 & Sum Weights & 15 \\
\hline Mean & 0 & Sum Observations & 0 \\
\hline Std Deviation & 0.12970032 & Variance & 0.01682217 \\
\hline Skewness & -0.7765827 & Kurtosis & -0.2341927 \\
\hline Uncorrected SS & 0.23551041 & Corrected SS & 0.23551041 \\
\hline Coeff Variation & & Std Error Mean & 0.03348848 \\
\hline
\end{tabular}

\begin{tabular}{|l|l|l|l|l|}
\hline \multicolumn{5}{|c|}{ Tests for Normality } \\
\hline Test & \multicolumn{2}{|c|}{ Statistic } & \multicolumn{2}{c|}{ p Value } \\
\hline Shapiro-Wilk & W & 0.917483 & Pr $<$ W & 0.1763 \\
\hline Kolmogorov-Smirnov & D & 0.198204 & Pr $>$ D & 0.1112 \\
\hline Cramer-von Mises & W-Sq & 0.081708 & Pr $>$ W-Sq & 0.1886 \\
\hline Anderson-Darling & A-Sq & 0.486453 & Pr $>$ A-Sq & 0.1998 \\
\hline
\end{tabular}


The UNIVARIATE Procedure

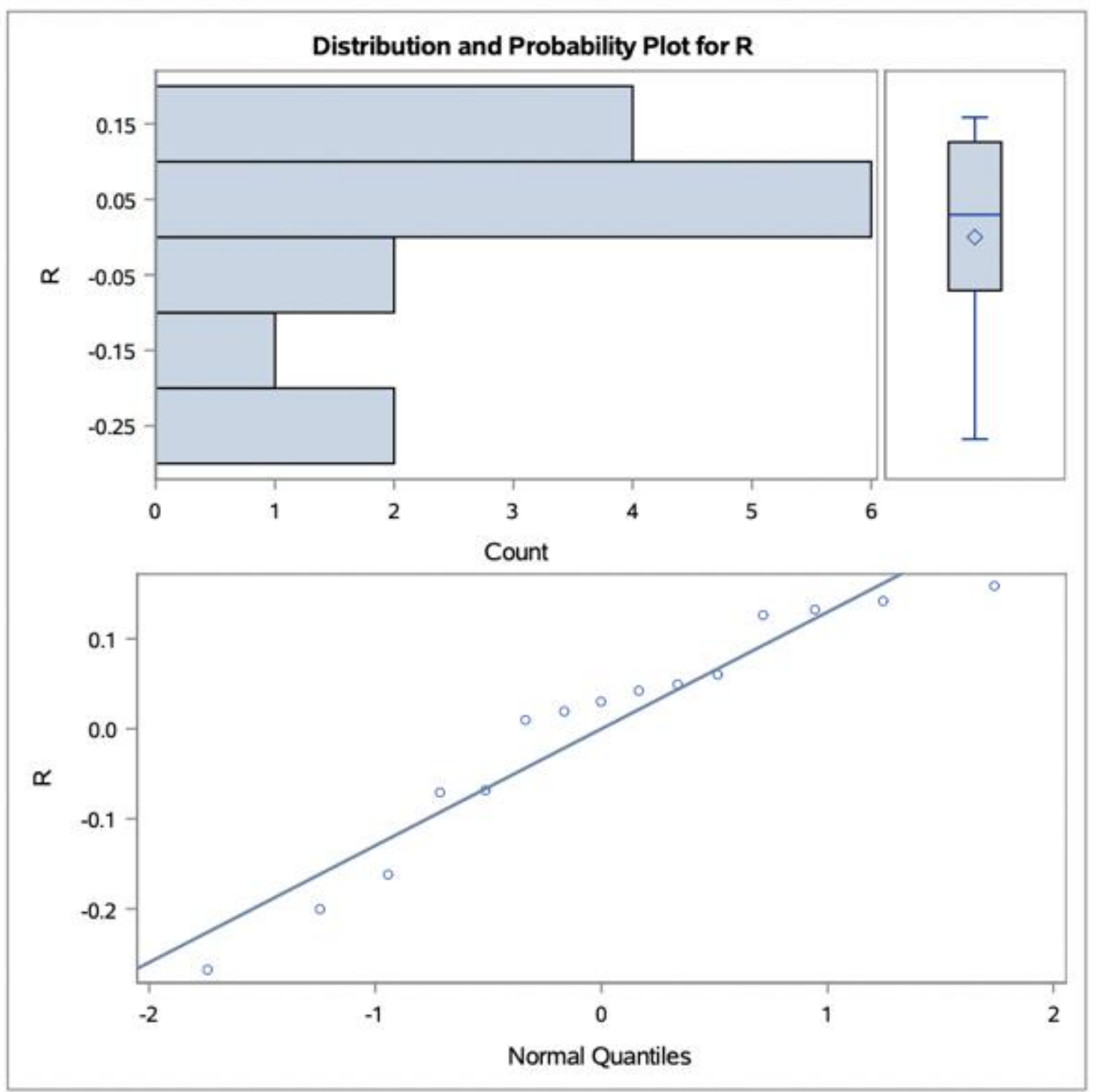


Table 10. SAS output for the variable total berry skin tannins ( $\mathrm{g} / \mathrm{mg}$ fruit)

Quality Data

Total_Tannins_Skins

\section{The GLM Procedure}

Dependent Variable: Total_Tannins_Skins Total_Tannins_Skins

\begin{tabular}{|l|r|r|r|r|r|}
\hline Source & DF & $\begin{array}{r}\text { Sum of } \\
\text { Squares }\end{array}$ & Mean Square & F Value & Pr $>$ F \\
\hline Model & 6 & 0.12981952 & 0.02163659 & 3.53 & 0.0517 \\
\hline Error & 8 & 0.04900061 & 0.00612508 & & \\
\hline Corrected Total & 14 & 0.17882013 & & & \\
\hline
\end{tabular}

\begin{tabular}{|l|r|r|r|r|r|}
\hline Source & DF & Type III SS & Mean Square & F Value & Pr $>$ F \\
\hline Distance & 4 & 0.11878007 & 0.02969502 & 4.85 & 0.0279 \\
\hline Rep & 2 & 0.01103946 & 0.00551973 & 0.90 & 0.4437 \\
\hline
\end{tabular}

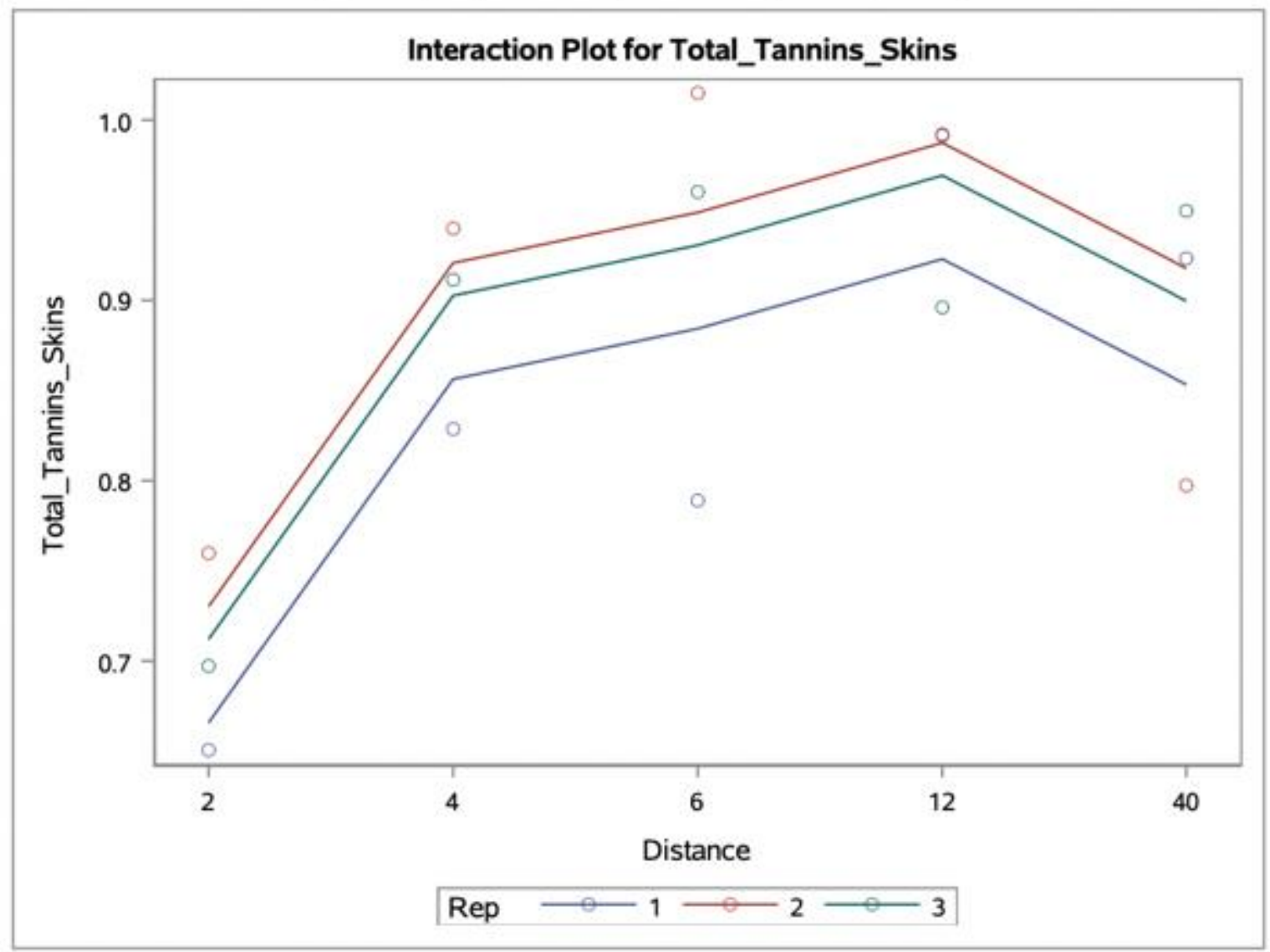


The GLM Procedure

Least Squares Means

\begin{tabular}{|l|r|r|r|r|}
\hline Distance & $\begin{array}{r}\text { Total_Tannins_Skins } \\
\text { LSMEAN }\end{array}$ & $\begin{array}{r}\text { Standard } \\
\text { Error }\end{array}$ & Pr $>$ |t| & $\begin{array}{r}\text { LSMEAN } \\
\text { Number }\end{array}$ \\
\hline $\mathbf{2}$ & 0.70258506 & 0.04518509 & $<.0001$ & 1 \\
\hline $\mathbf{4}$ & 0.89319264 & 0.04518509 & $<.0001$ & 2 \\
\hline $\mathbf{6}$ & 0.92115969 & 0.04518509 & $<.0001$ & 3 \\
\hline $\mathbf{1 2}$ & 0.95978274 & 0.04518509 & $<.0001$ & 4 \\
\hline 40 & 0.89016011 & 0.04518509 & $<.0001$ & 5 \\
\hline
\end{tabular}

\begin{tabular}{|l|r|r|r|r|r|}
\hline \multicolumn{7}{|c|}{$\begin{array}{c}\text { Least Squares Means for effect Distance } \\
\mathrm{Pr}>1 \mathrm{t} \mid \text { for H0: LSMean(i)=LSMean }(\mathbf{)})\end{array}$} \\
Dependent Variable: Total_Tannins_Skins \\
\hline i5 & $\mathbf{1}$ & $\mathbf{2}$ & $\mathbf{3}$ & $\mathbf{4}$ & $\mathbf{5}$ \\
\hline $\mathbf{1}$ & & 0.0175 & 0.0091 & 0.0038 & 0.0188 \\
\hline $\mathbf{2}$ & 0.0175 & & 0.6732 & 0.3278 & 0.9633 \\
\hline $\mathbf{3}$ & 0.0091 & 0.6732 & & 0.5623 & 0.6406 \\
\hline $\mathbf{4}$ & 0.0038 & 0.3278 & 0.5623 & & 0.3076 \\
\hline $\mathbf{5}$ & 0.0188 & 0.9633 & 0.6406 & 0.3076 & \\
\hline
\end{tabular}

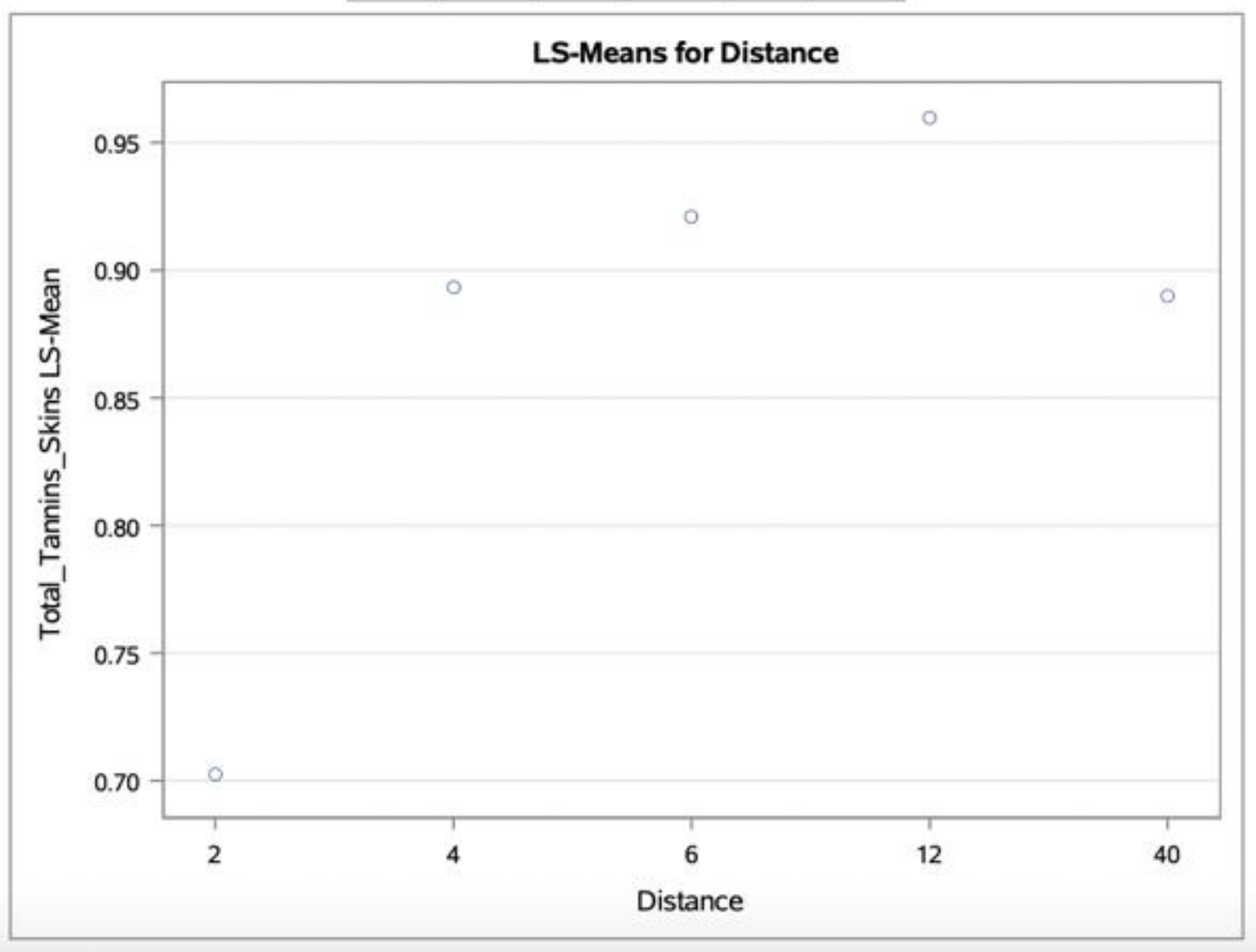




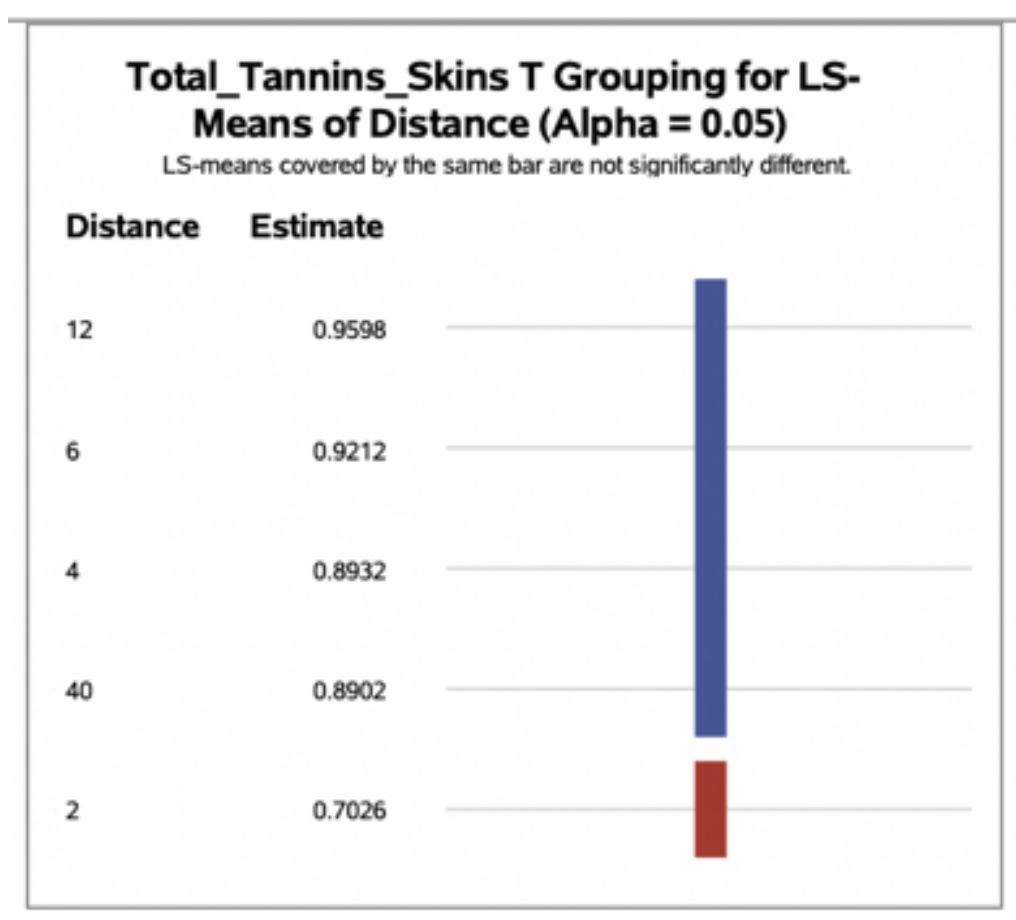

The UNIVARIATE Procedure

Variable: $\mathbf{R}$

\begin{tabular}{|l|r|l|r|}
\hline \multicolumn{4}{|c|}{ Moments } \\
\hline N & 15 & Sum Weights & 15 \\
\hline Mean & 0 & Sum Observations & 0 \\
\hline Std Deviation & 0.05916117 & Variance & 0.00350004 \\
\hline Skewness & -0.7536588 & Kurtosis & -0.2109174 \\
\hline Uncorrected SS & 0.04900061 & Corrected SS & 0.04900061 \\
\hline Coeff Variation & & Std Error Mean & 0.01527535 \\
\hline
\end{tabular}

\begin{tabular}{|l|l|l|l|r|}
\hline \multicolumn{5}{|c|}{ Tests for Normality } \\
\hline Test & \multicolumn{2}{|c|}{ Statistic } & \multicolumn{2}{c|}{ p Value } \\
\hline Shapiro-Wilk & W & 0.921532 & Pr $<$ W & 0.2033 \\
\hline Kolmogorov-Smirnov & D & 0.132089 & Pr $>$ D & $>0.1500$ \\
\hline Cramer-von Mises & W-Sq & 0.059863 & Pr $>$ W-Sq & $>0.2500$ \\
\hline Anderson-Darling & A-Sq & 0.410536 & Pr $>$ A-Sq & $>0.2500$ \\
\hline
\end{tabular}


The UNIVARIATE Procedure

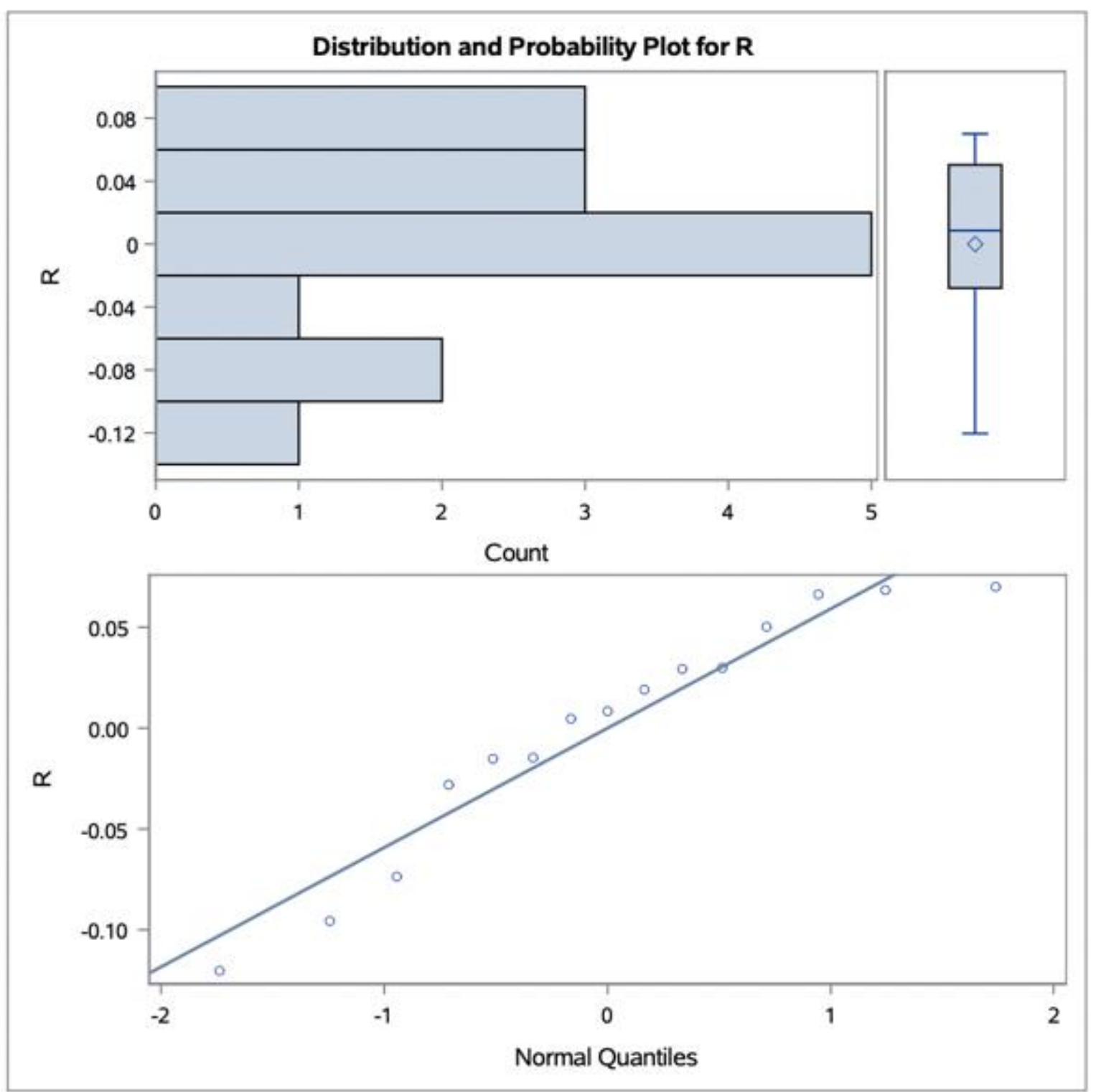


Table 11. SAS output for the variable total seed phenolics (mg/g fruit)

\section{Quality Data \\ Total_Phenolics_Seeds}

\section{The GLM Procedure}

\section{Dependent Variable: Total_Phenolics_Seeds Total_Phenolics_Seeds}

\begin{tabular}{|l|r|r|r|r|r|}
\hline Source & DF & $\begin{array}{r}\text { Sum of } \\
\text { Squares }\end{array}$ & Mean Square & F Value & Pr $>$ F \\
\hline Model & 6 & 1.38765511 & 0.23127585 & 1.24 & 0.3788 \\
\hline Error & 8 & 1.49347868 & 0.18668484 & & \\
\hline Corrected Total & 14 & 2.88113379 & & & \\
\hline
\end{tabular}

\begin{tabular}{|l|r|r|r|r|r|}
\hline Source & DF & Type III SS & Mean Square & F Value & Pr $>$ F \\
\hline Distance & 4 & 0.88208575 & 0.22052144 & 1.18 & 0.3882 \\
\hline Rep & 2 & 0.50556936 & 0.25278468 & 1.35 & 0.3115 \\
\hline
\end{tabular}

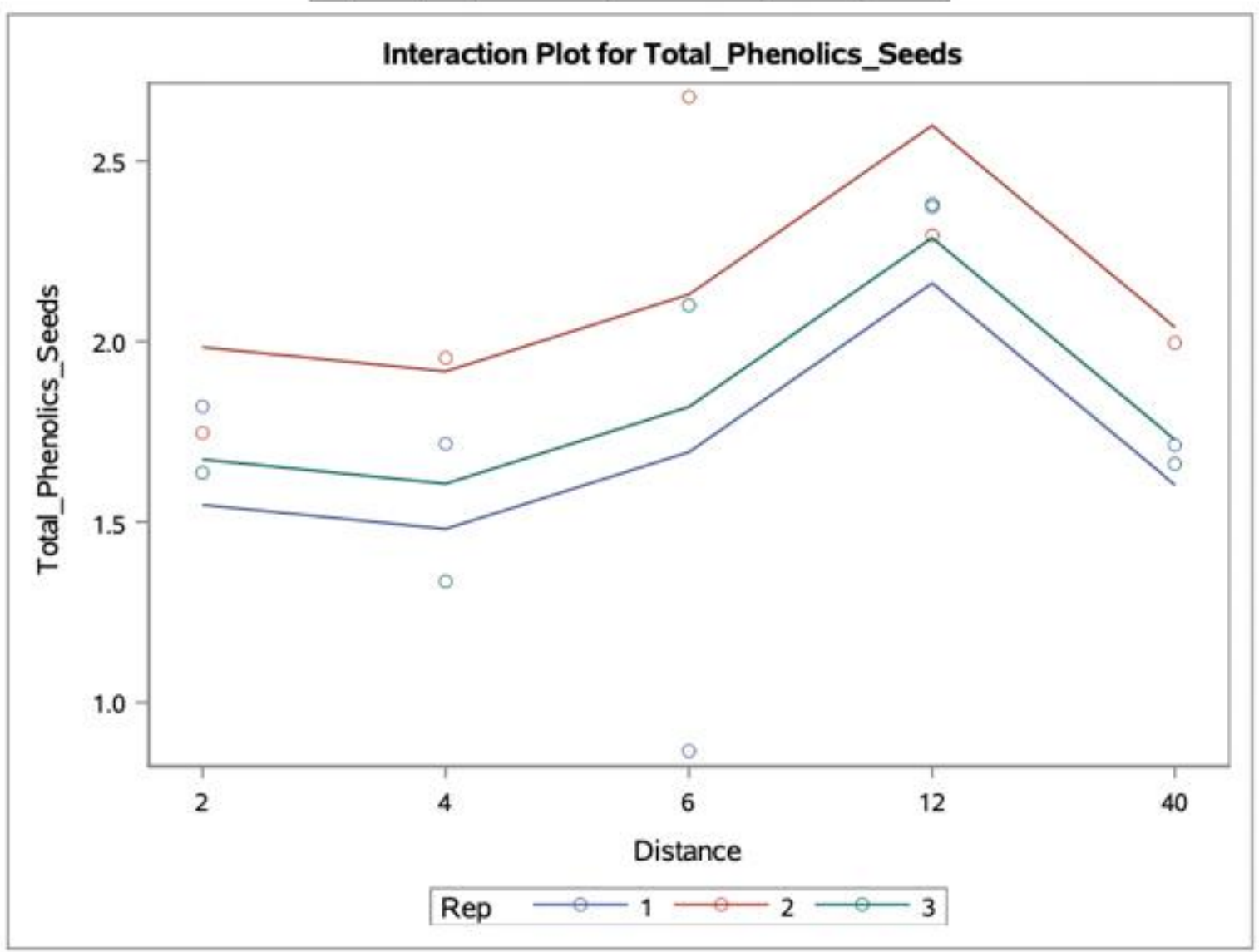


The GLM Procedure

Least Squares Means

\begin{tabular}{|l|r|r|r|r|}
\hline Distance & $\begin{array}{r}\text { Total_Phenolics_Seeds } \\
\text { LSMEAN }\end{array}$ & $\begin{array}{r}\text { Standard } \\
\text { Error }\end{array}$ & Pr $>$ 14 & $\begin{array}{r}\text { LSMEAN } \\
\text { Number }\end{array}$ \\
\hline $\mathbf{2}$ & 1.73527199 & 0.24945596 & 0.0001 & 1 \\
\hline $\mathbf{4}$ & 1.66806465 & 0.24945596 & 0.0002 & 2 \\
\hline $\mathbf{6}$ & 1.88099080 & 0.24945596 & $<.0001$ & 3 \\
\hline $\mathbf{1 2}$ & 2.34918163 & 0.24945596 & $<.0001$ & 4 \\
\hline $\mathbf{4 0}$ & 1.78976821 & 0.24945596 & $<.0001$ & 5 \\
\hline
\end{tabular}

\begin{tabular}{|l|r|r|r|r|r|}
\hline \multicolumn{7}{|c|}{$\begin{array}{c}\text { Least Squares Means for effect Distance } \\
\text { Pr > If for H0: LSMean(i)=LSMean(j) } \\
\text { Dependent Variable: Total_Phenolics_Seeds }\end{array}$} \\
\hline ij & $\mathbf{1}$ & $\mathbf{2}$ & $\mathbf{3}$ & $\mathbf{4}$ & $\mathbf{5}$ \\
\hline $\mathbf{1}$ & & 0.8537 & 0.6904 & 0.1200 & 0.8811 \\
\hline $\mathbf{2}$ & 0.8537 & & 0.5629 & 0.0896 & 0.7390 \\
\hline $\mathbf{3}$ & 0.6904 & 0.5629 & & 0.2211 & 0.8025 \\
\hline $\mathbf{4}$ & 0.1200 & 0.0896 & 0.2211 & & 0.1515 \\
\hline $\mathbf{5}$ & 0.8811 & 0.7390 & 0.8025 & 0.1515 & \\
\hline
\end{tabular}

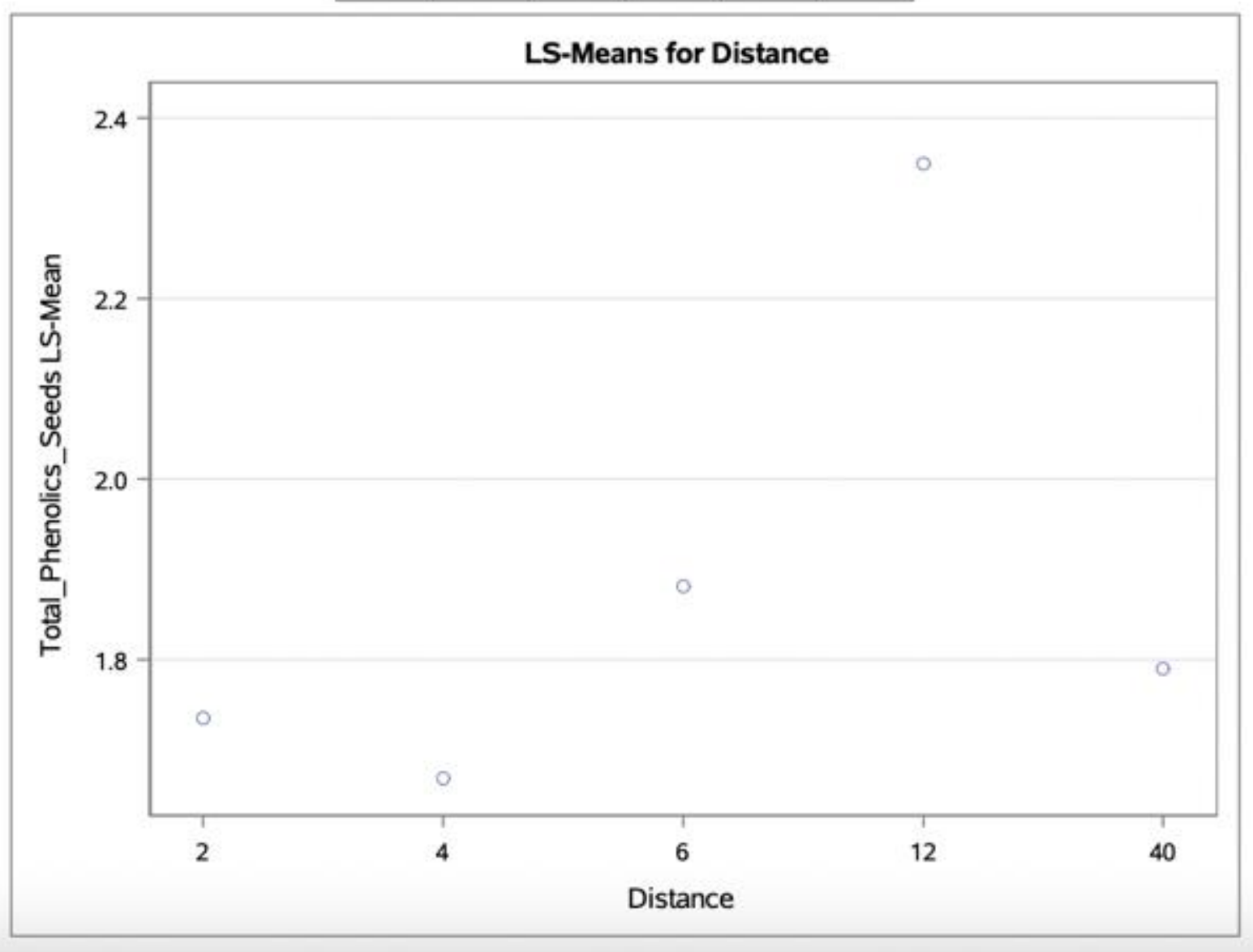




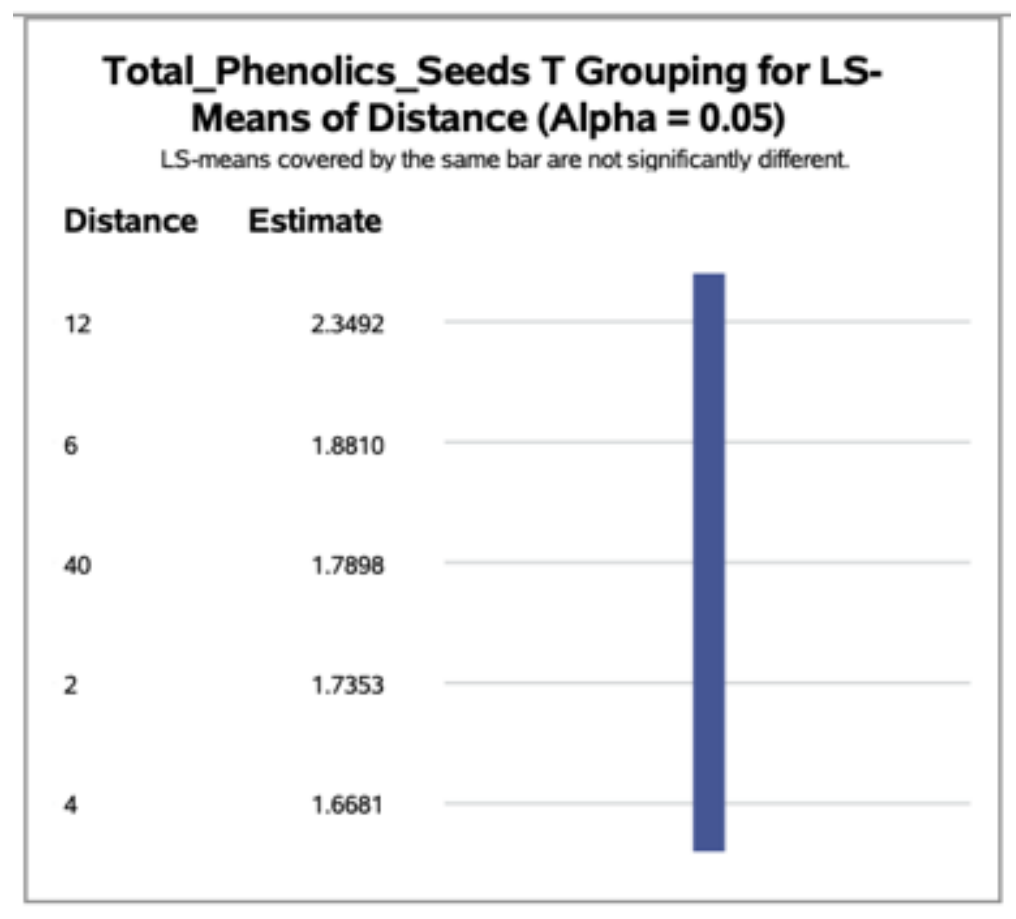

The UNIVARIATE Procedure Variable: $\mathbf{R}$

\begin{tabular}{|l|r|l|r|}
\hline \multicolumn{4}{|c|}{ Moments } \\
\hline N & 15 & Sum Weights & 15 \\
\hline Mean & 0 & Sum Observations & 0 \\
\hline Std Deviation & 0.32661453 & Variance & 0.10667705 \\
\hline Skewness & -0.9468877 & Kurtosis & 1.98824433 \\
\hline Uncorrected SS & 1.49347868 & Corrected SS & 1.49347868 \\
\hline Coeff Variation & & Std Error Mean & 0.08433151 \\
\hline
\end{tabular}

\begin{tabular}{|l|l|l|l|l|}
\hline \multicolumn{5}{|c|}{ Tests for Normality } \\
\hline Test & \multicolumn{2}{|c|}{ Statistic } & \multicolumn{2}{c|}{ p Value } \\
\hline Shapiro-Wilk & W & 0.938687 & Pr $<$ W & 0.3661 \\
\hline Kolmogorov-Smirnov & D & 0.152225 & Pr $>$ D & $>0.1500$ \\
\hline Cramer-von Mises & W-Sq & 0.050866 & Pr $>$ W-Sq & $>0.2500$ \\
\hline Anderson-Darling & A-Sq & 0.367991 & Pr $>$ A-Sq & $>0.2500$ \\
\hline
\end{tabular}


The UNIVARIATE Procedure

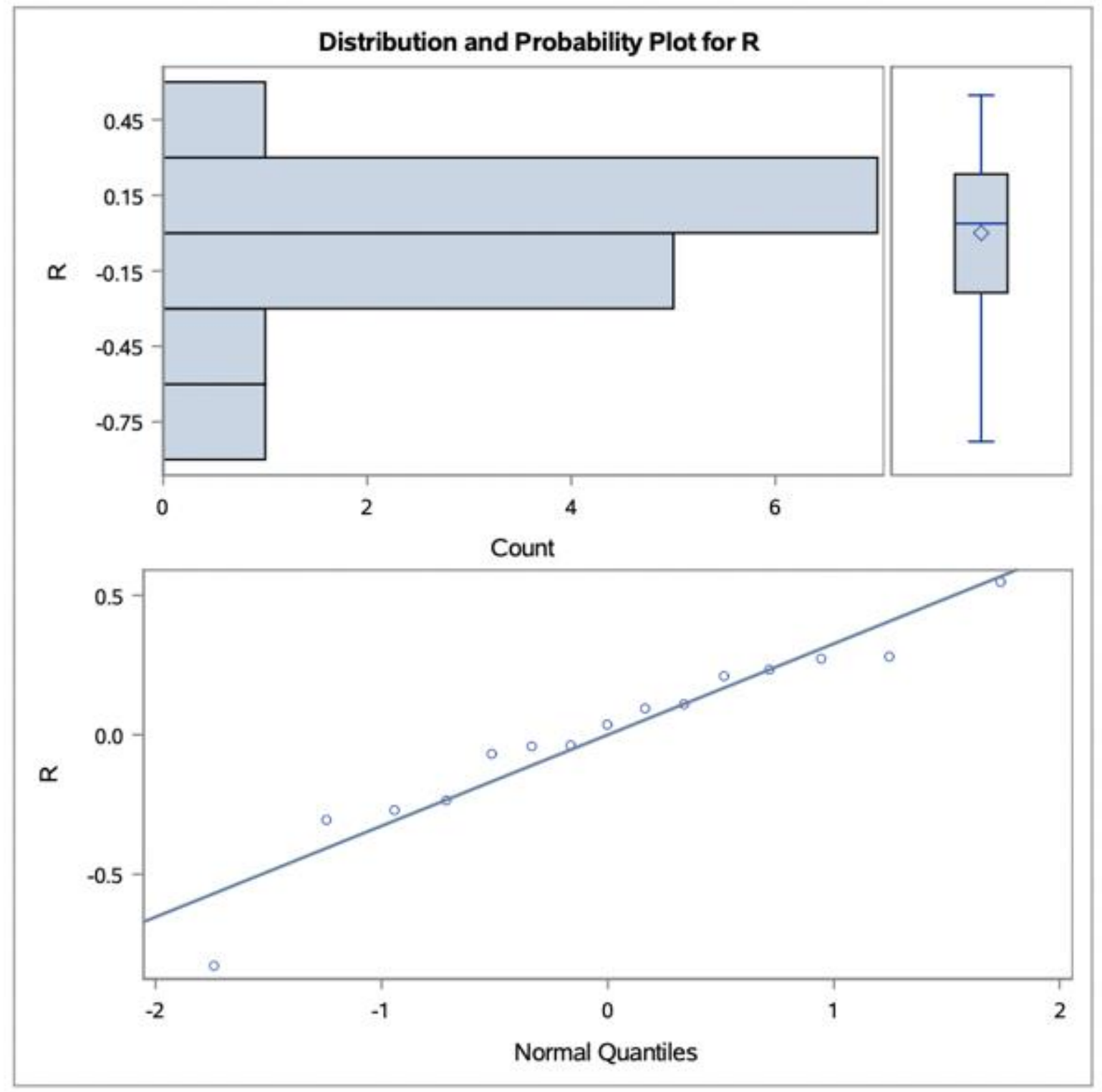


Table 12. SAS output for the variable total seed tannins (mg/g fruit)

\section{Quality Data \\ Total_Tannins_Seeds \\ The GLM Procedure}

Dependent Variable: Total_Tannins_Seeds Total_Tannins_Seeds

\begin{tabular}{|l|r|r|r|r|r|}
\hline Source & DF & $\begin{array}{r}\text { Sum of } \\
\text { Squares }\end{array}$ & Mean Square & F Value & Pr > F \\
\hline Model & 6 & 0.58660225 & 0.09776704 & 1.20 & 0.3959 \\
\hline Error & 8 & 0.65393790 & 0.08174224 & & \\
\hline Corrected Total & 14 & 1.24054015 & & & \\
\hline
\end{tabular}

\begin{tabular}{|l|r|r|r|r|r|}
\hline Source & DF & Type III SS & Mean Square & F Value & Pr $>$ F \\
\hline Distance & 4 & 0.54376138 & 0.13594034 & 1.66 & 0.2503 \\
\hline Rep & 2 & 0.04284087 & 0.02142043 & 0.26 & 0.7758 \\
\hline
\end{tabular}

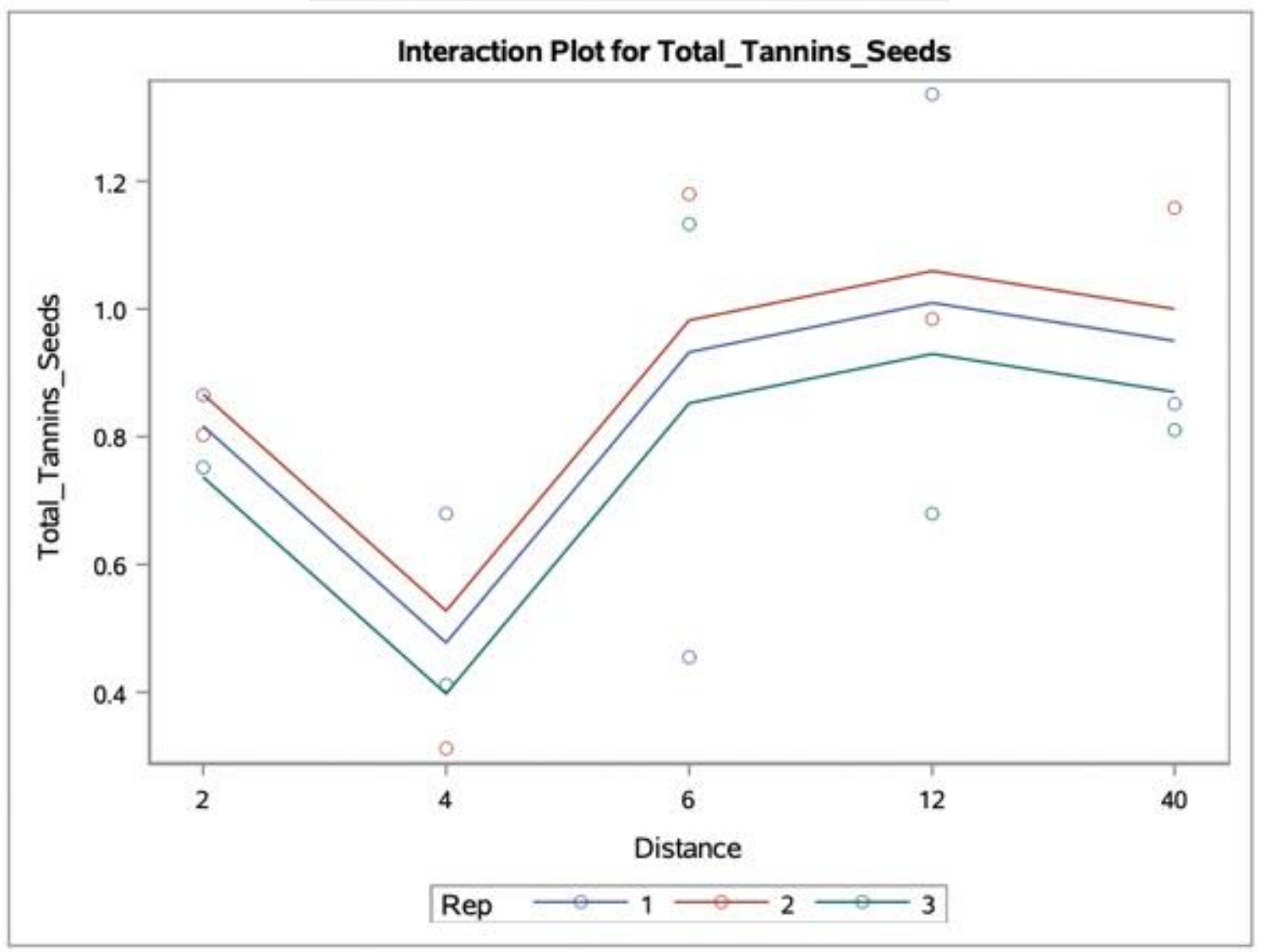


The GLM Procedure

Least Squares Means

\begin{tabular}{|l|r|r|r|r|}
\hline Distance & $\begin{array}{r}\text { Total_Tannins_Seeds } \\
\text { LSMEAN }\end{array}$ & $\begin{array}{r}\text { Standard } \\
\text { Error }\end{array}$ & Pr $>$ It & $\begin{array}{r}\text { LSMEAN } \\
\text { Number }\end{array}$ \\
\hline $\mathbf{2}$ & 0.80678865 & 0.16506790 & 0.0012 & 1 \\
\hline $\mathbf{4}$ & 0.46754589 & 0.16506790 & 0.0221 & 2 \\
\hline $\mathbf{6}$ & 0.92235329 & 0.16506790 & 0.0005 & 3 \\
\hline 12 & 0.99955254 & 0.16506790 & 0.0003 & 4 \\
\hline 40 & 0.94001202 & 0.16506790 & 0.0005 & 5 \\
\hline
\end{tabular}

\begin{tabular}{|l|r|r|r|r|r|}
\hline \multicolumn{7}{|c|}{$\begin{array}{c}\text { Least Squares Means for effect Distance } \\
\operatorname{Pr}>\text { It for H0: LSMean(i)=LSMean(j) }\end{array}$} \\
Dependent Variable: Total_Tannins_Seeds \\
\hline if & $\mathbf{1}$ & $\mathbf{2}$ & $\mathbf{3}$ & $\mathbf{4}$ & $\mathbf{5}$ \\
\hline $\mathbf{1}$ & & 0.1842 & 0.6339 & 0.4329 & 0.5839 \\
\hline $\mathbf{2}$ & 0.1842 & & 0.0872 & 0.0522 & 0.0776 \\
\hline $\mathbf{3}$ & 0.6339 & 0.0872 & & 0.7494 & 0.9416 \\
\hline $\mathbf{4}$ & 0.4329 & 0.0522 & 0.7494 & & 0.8051 \\
\hline $\mathbf{5}$ & 0.5839 & 0.0776 & 0.9416 & 0.8051 & \\
\hline
\end{tabular}

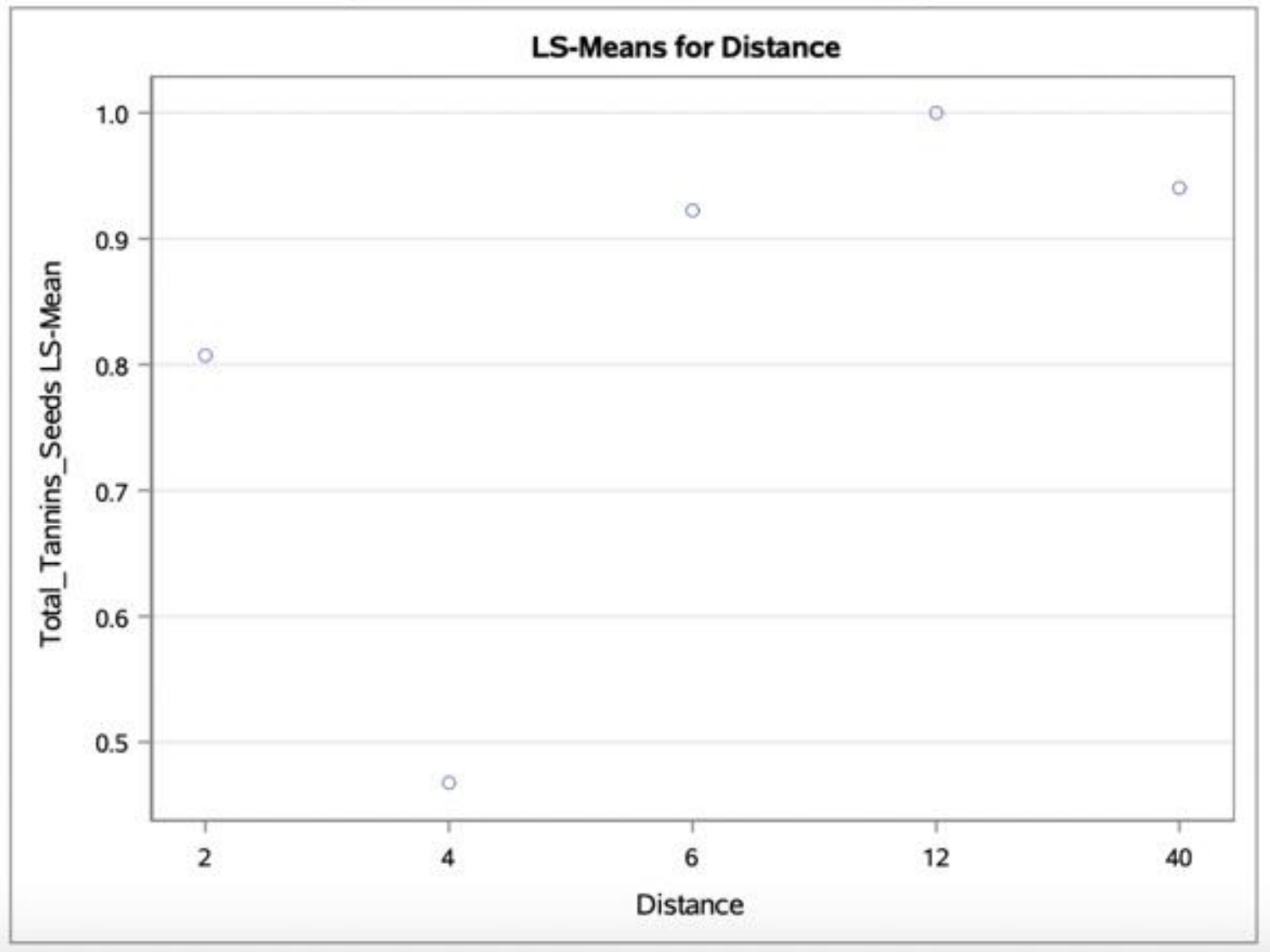




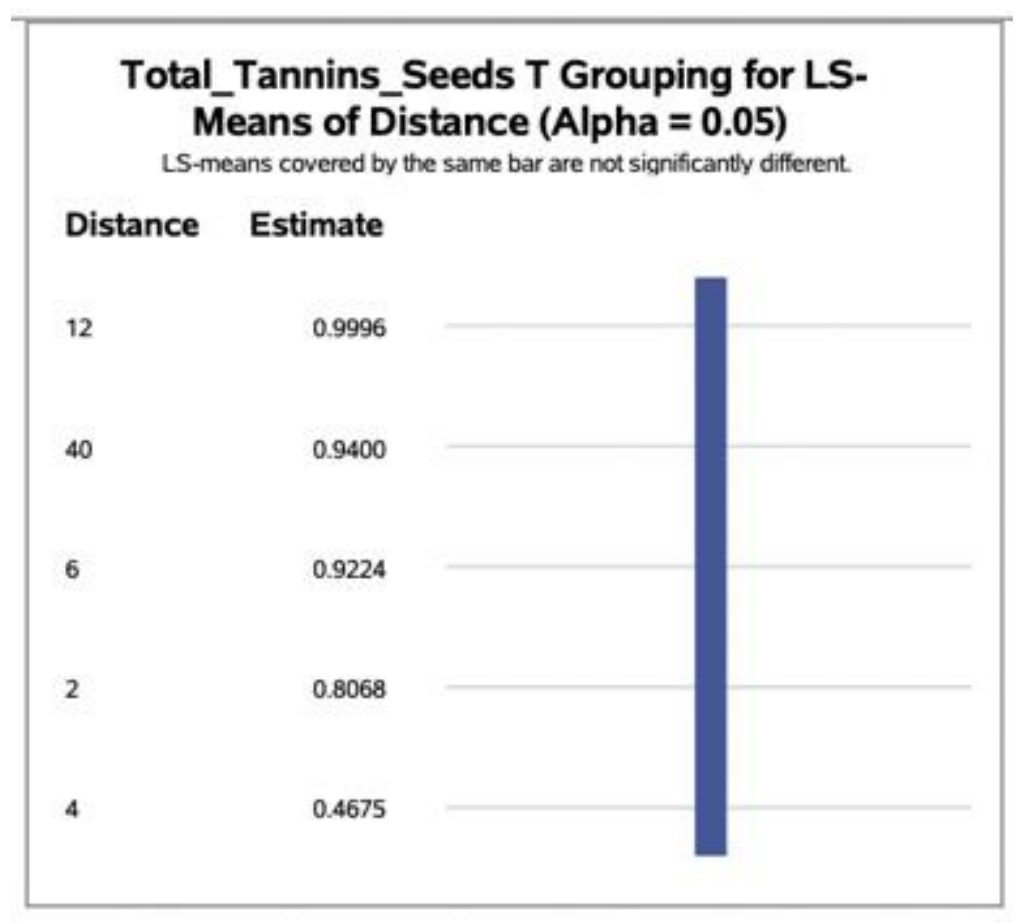

The UNIVARIATE Procedure

Variable: $\mathbf{R}$

\begin{tabular}{|l|r|l|r|}
\hline \multicolumn{4}{|c|}{ Moments } \\
\hline N & 15 & Sum Weights & 15 \\
\hline Mean & 0 & Sum Observations & 0 \\
\hline Std Deviation & 0.21612462 & Variance & 0.04670985 \\
\hline Skewness & -0.4883119 & Kurtosis & 0.25240648 \\
\hline Uncorrected SS & 0.6539379 & Corrected SS & 0.6539379 \\
\hline Coeff Variation & - & Std Error Mean & 0.05580314 \\
\hline
\end{tabular}

\begin{tabular}{|l|l|l|l|r|}
\hline \multicolumn{5}{|c|}{ Tests for Normality } \\
\hline Test & \multicolumn{2}{|c|}{ Statistic } & \multicolumn{2}{c|}{ p Value } \\
\hline Shapiro-Wilk & W & 0.965511 & Pr $<$ W & 0.7869 \\
\hline Kolmogorov-Smirnov & D & 0.124127 & Pr $>$ D & $>0.1500$ \\
\hline Cramer-von Mises & W-Sq & 0.033583 & Pr $>$ W-Sq & $>0.2500$ \\
\hline Anderson-Darling & A-Sq & 0.228688 & Pr $>$ A-Sq & $>0.2500$ \\
\hline
\end{tabular}


The UNIVARIATE Procedure

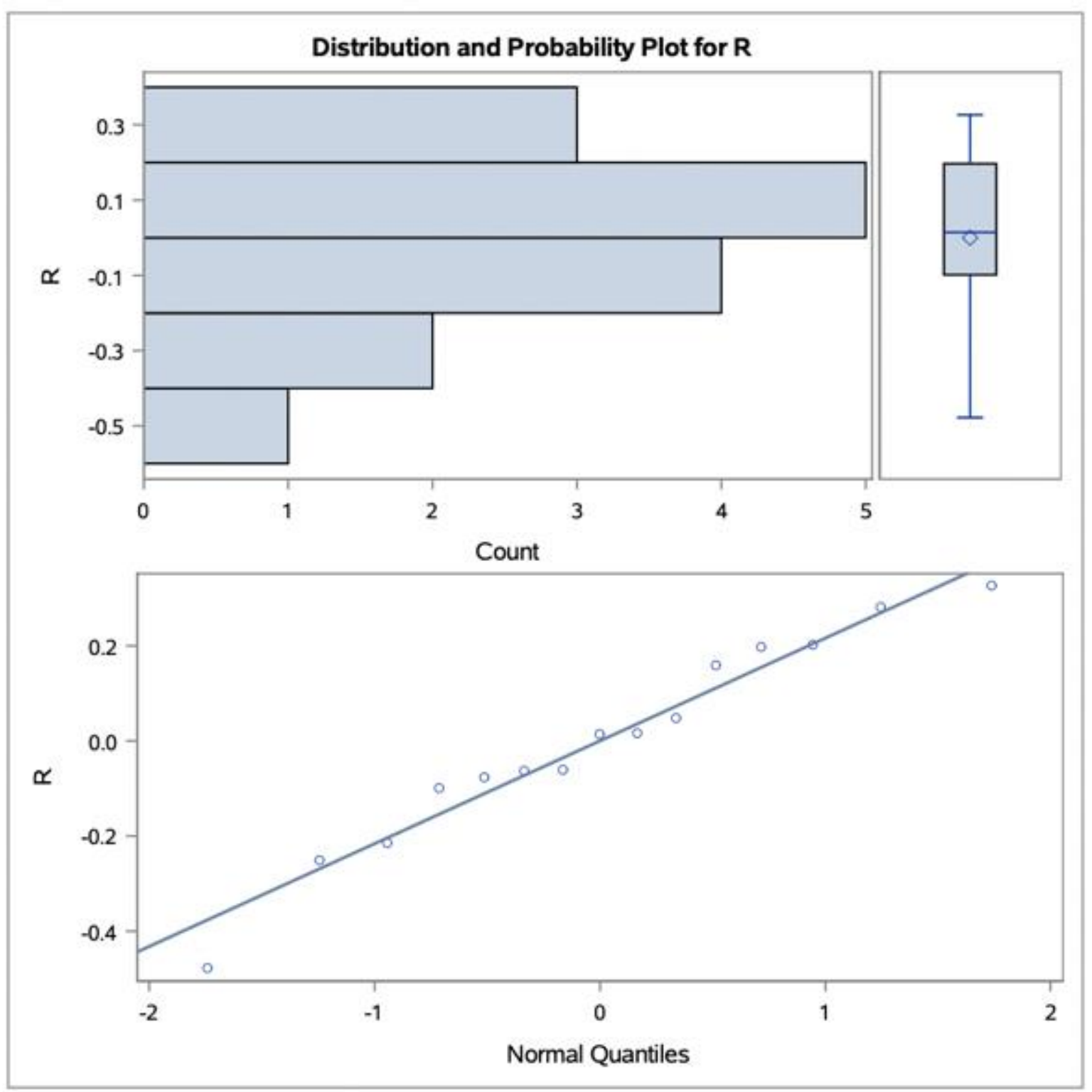


Table 13. SAS output for the variable petiole nitrate

\section{Foliars Data \\ N_NO3_Petiole}

The GLM Procedure

Dependent Variable: N_NO3_Petiole N_NO3_Petiole

\begin{tabular}{|l|r|r|r|r|r|}
\hline Source & DF & $\begin{array}{r}\text { Sum of } \\
\text { Squares }\end{array}$ & Mean Square & F Value & Pr > F \\
\hline Model & 6 & 5965.60000 & 994.26667 & 1.08 & 0.4450 \\
\hline Error & 8 & 7342.80000 & 917.85000 & & \\
\hline Corrected Total & 14 & 13308.40000 & & & \\
\hline
\end{tabular}

\begin{tabular}{|l|r|r|r|r|r|}
\hline Source & DF & Type III SS & Mean Square & F Value & Pr > F \\
\hline Distance & 4 & 5540.400000 & 1385.100000 & 1.51 & 0.2870 \\
\hline Rep & 2 & 425.200000 & 212.600000 & 0.23 & 0.7984 \\
\hline
\end{tabular}

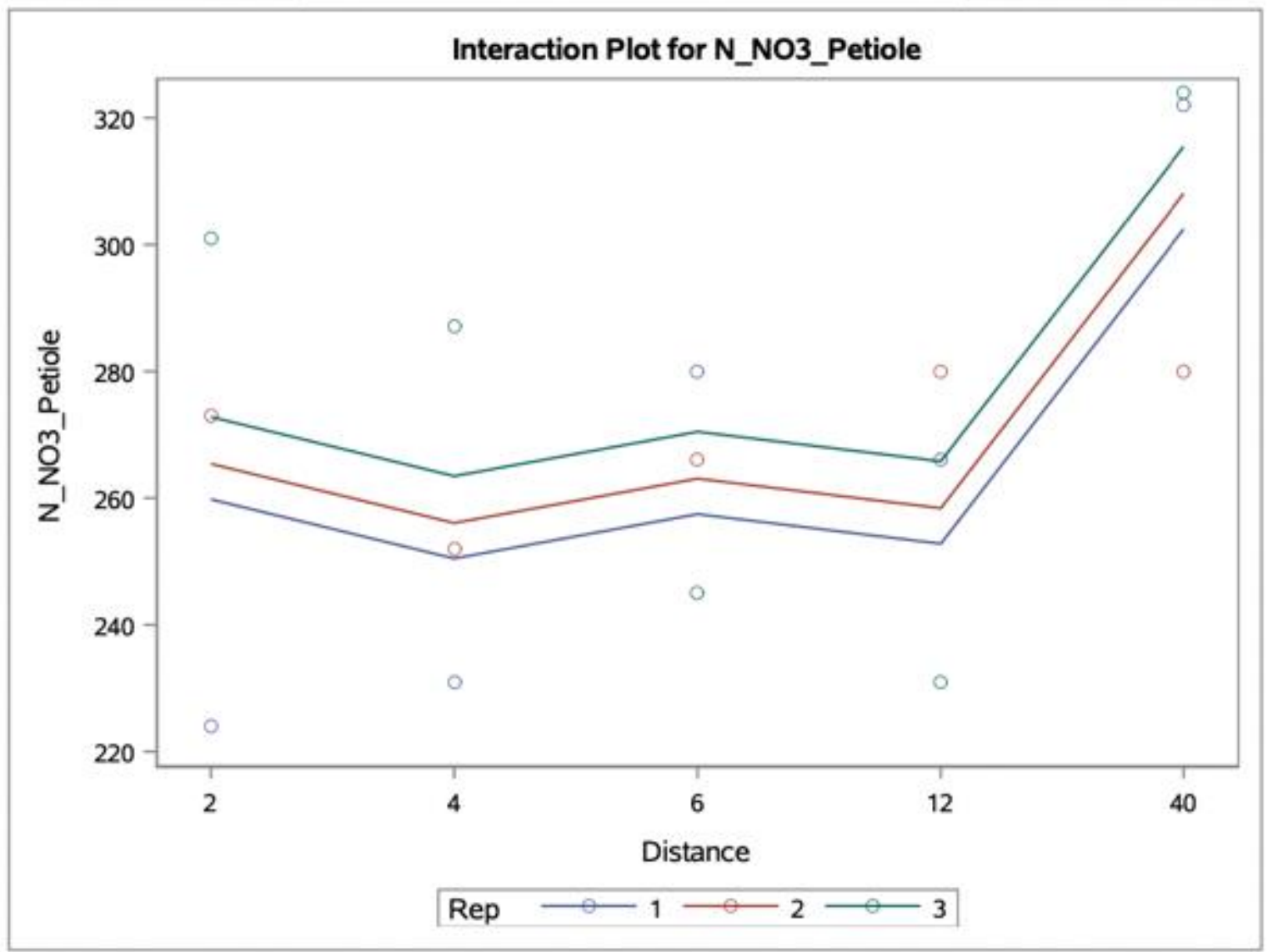


The GLM Procedure Least Squares Means

\begin{tabular}{|l|r|r|r|r|}
\hline Distance & $\begin{array}{r}\text { N_NO3_Petiole } \\
\text { LSMEAN }\end{array}$ & $\begin{array}{r}\text { Standard } \\
\text { Error }\end{array}$ & $\operatorname{Pr}>|\mathrm{t}|$ & $\begin{array}{r}\text { LSMEAN } \\
\text { Number }\end{array}$ \\
\hline $\mathbf{2}$ & 266.000000 & 17.491426 & $<.0001$ & 1 \\
\hline $\mathbf{4}$ & 256.666667 & 17.491426 & $<.0001$ & 2 \\
\hline $\mathbf{6}$ & 263.666667 & 17.491426 & $<.0001$ & 3 \\
\hline 12 & 259.000000 & 17.491426 & $<.0001$ & 4 \\
\hline 40 & 308.666667 & 17.491426 & $<.0001$ & 5 \\
\hline
\end{tabular}

\begin{tabular}{|l|r|r|r|r|r|}
\hline \multicolumn{7}{|c|}{$\begin{array}{c}\text { Least Squares Means for effect Distance } \\
\text { Pr }>\mid \text { it for H0: LSMean(i)=LSMean(j) }\end{array}$} \\
Dependent Variable: N_NO3_Petiole \\
\hline i j & $\mathbf{1}$ & $\mathbf{2}$ & $\mathbf{3}$ & $\mathbf{4}$ & $\mathbf{5}$ \\
\hline $\mathbf{1}$ & & 0.7158 & 0.9272 & 0.7844 & 0.1228 \\
\hline $\mathbf{2}$ & 0.7158 & & 0.7844 & 0.9272 & 0.0687 \\
\hline $\mathbf{3}$ & 0.9272 & $\mathbf{0 . 7 8 4 4}$ & & 0.8551 & 0.1064 \\
\hline $\mathbf{4}$ & 0.7844 & 0.9272 & 0.8551 & & 0.0795 \\
\hline $\mathbf{5}$ & 0.1228 & 0.0687 & 0.1064 & 0.0795 & \\
\hline
\end{tabular}

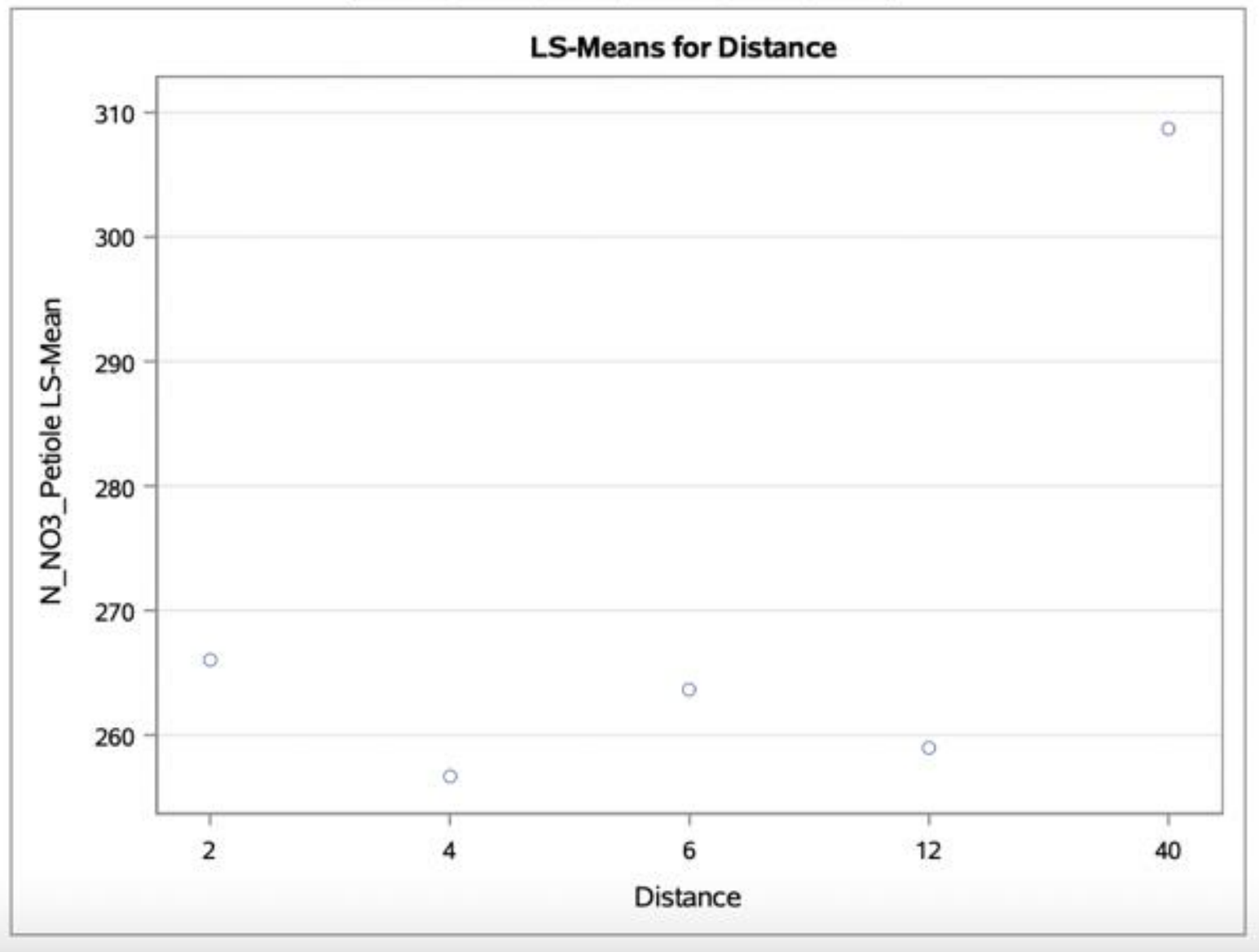




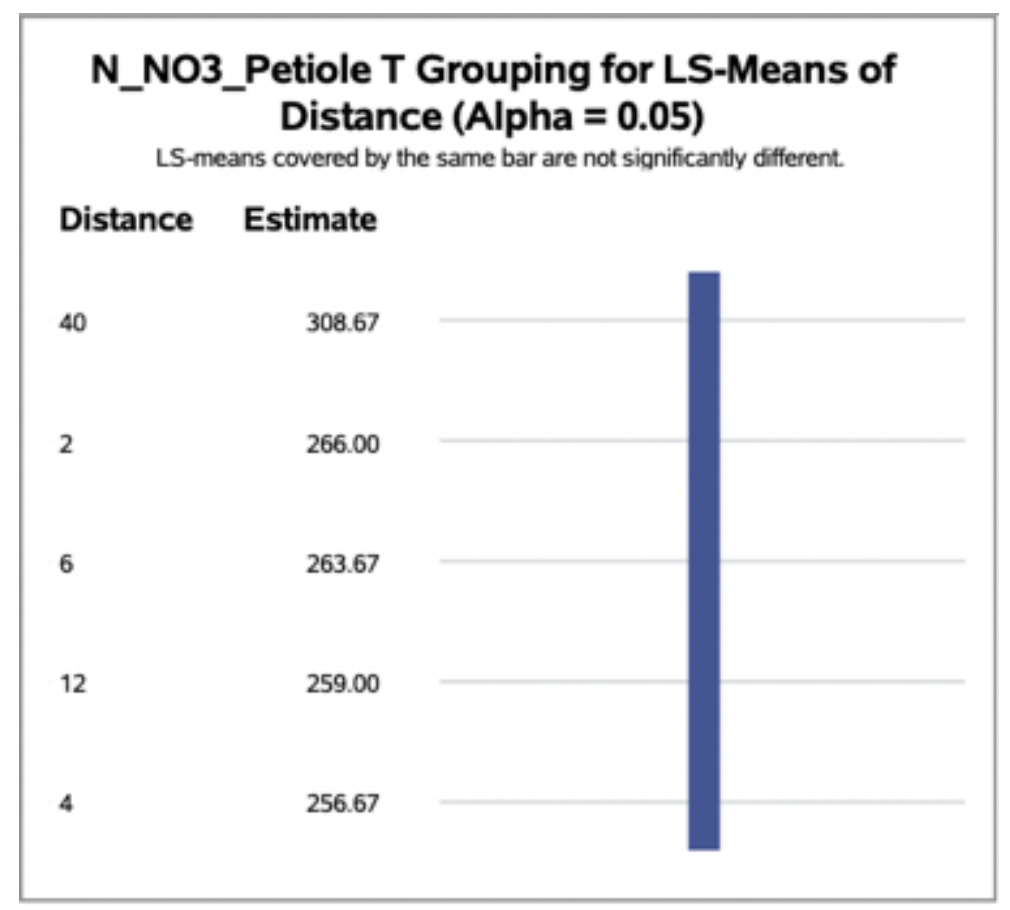

The UNIVARIATE Procedure

Variable: $\mathbf{R}$

\begin{tabular}{|l|r|l|r|}
\hline \multicolumn{4}{|c|}{ Moments } \\
\hline N & 15 & Sum Weights & 15 \\
\hline Mean & 0 & Sum Observations & 0 \\
\hline Std Deviation & 22.9016531 & Variance & 524.485714 \\
\hline Skewness & -0.4547818 & Kurtosis & -1.414912 \\
\hline Uncorrected SS & 7342.8 & Corrected SS & 7342.8 \\
\hline Coeff Variation & & Std Error Mean & 5.9131814 \\
\hline
\end{tabular}

\begin{tabular}{|l|l|l|l|r|}
\hline \multicolumn{5}{|c|}{ Tests for Normality } \\
\hline Test & \multicolumn{2}{|c|}{ Statistic } & \multicolumn{2}{c|}{ p Value } \\
\hline Shapiro-Wilk & W & 0.888071 & Pr $<$ W & 0.0627 \\
\hline Kolmogorov-Smirnov & D & 0.163333 & Pr $>$ D & $>0.1500$ \\
\hline Cramer-von Mises & W-Sq & 0.101982 & Pr $>$ W-Sq & 0.0969 \\
\hline Anderson-Darling & A-Sq & 0.637295 & Pr $>$ A-Sq & 0.0816 \\
\hline
\end{tabular}


The UNIVARIATE Procedure

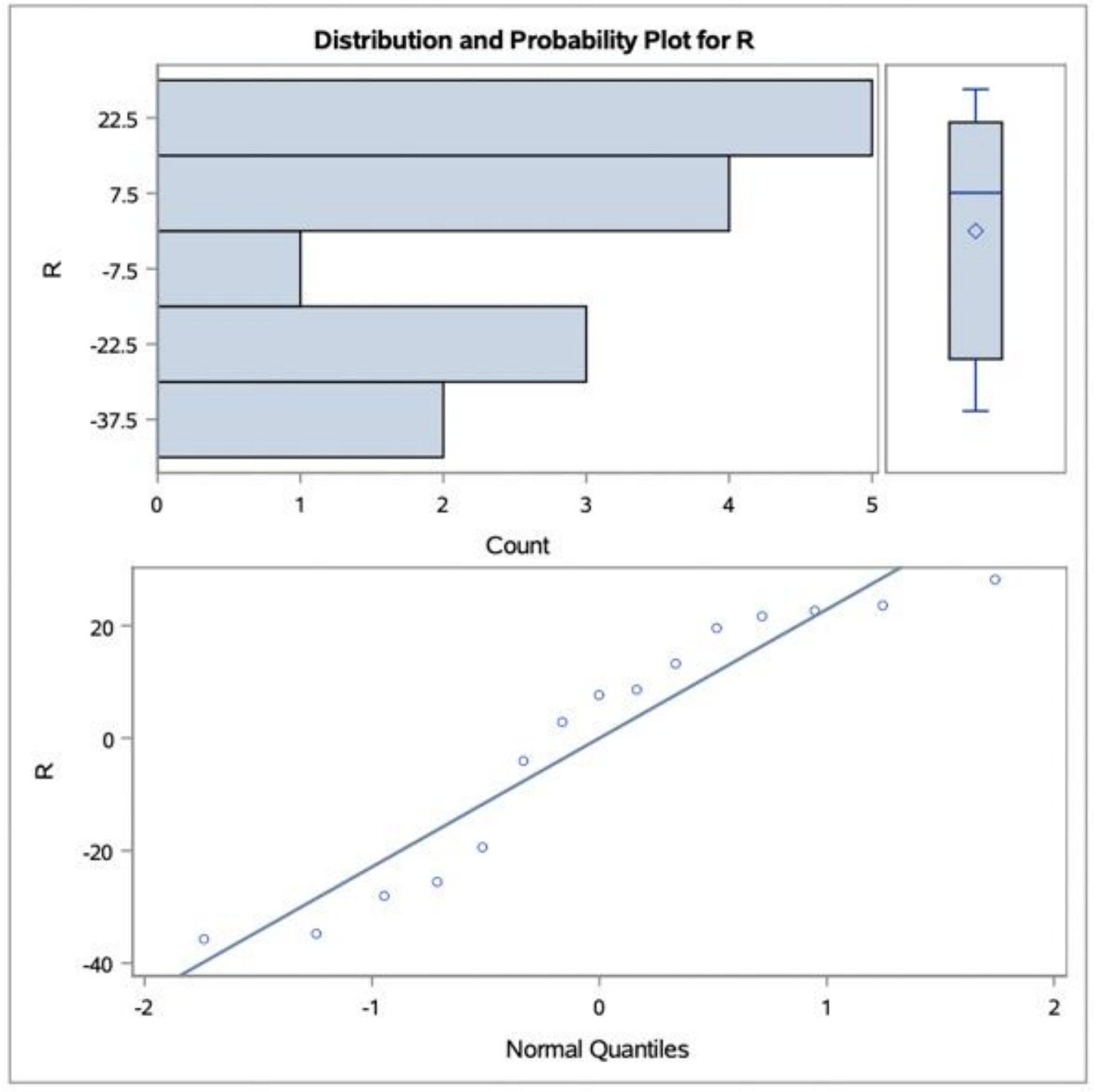


Table 14. SAS output for the variable total leaf blade nitrogen

\section{Foliars Data \\ N_Leaf}

The GLM Procedure

Dependent Variable: N_Leaf N_Leaf

\begin{tabular}{|l|r|r|r|r|r|}
\hline Source & DF & $\begin{array}{r}\text { Sum of } \\
\text { Squares }\end{array}$ & Mean Square & F Value & Pr $>$ F \\
\hline Model & 6 & 0.57301333 & 0.09550222 & 1.55 & 0.2763 \\
\hline Error & 8 & 0.49298667 & 0.06162333 & & \\
\hline Corrected Total & 14 & 1.06600000 & & & \\
\hline
\end{tabular}

\begin{tabular}{|l|r|r|r|r|r|}
\hline Source & DF & Type III SS & Mean Square & F Value & Pr > F \\
\hline Distance & 4 & 0.54933333 & 0.13733333 & 2.23 & 0.1555 \\
\hline Rep & 2 & 0.02368000 & 0.01184000 & 0.19 & 0.8289 \\
\hline
\end{tabular}

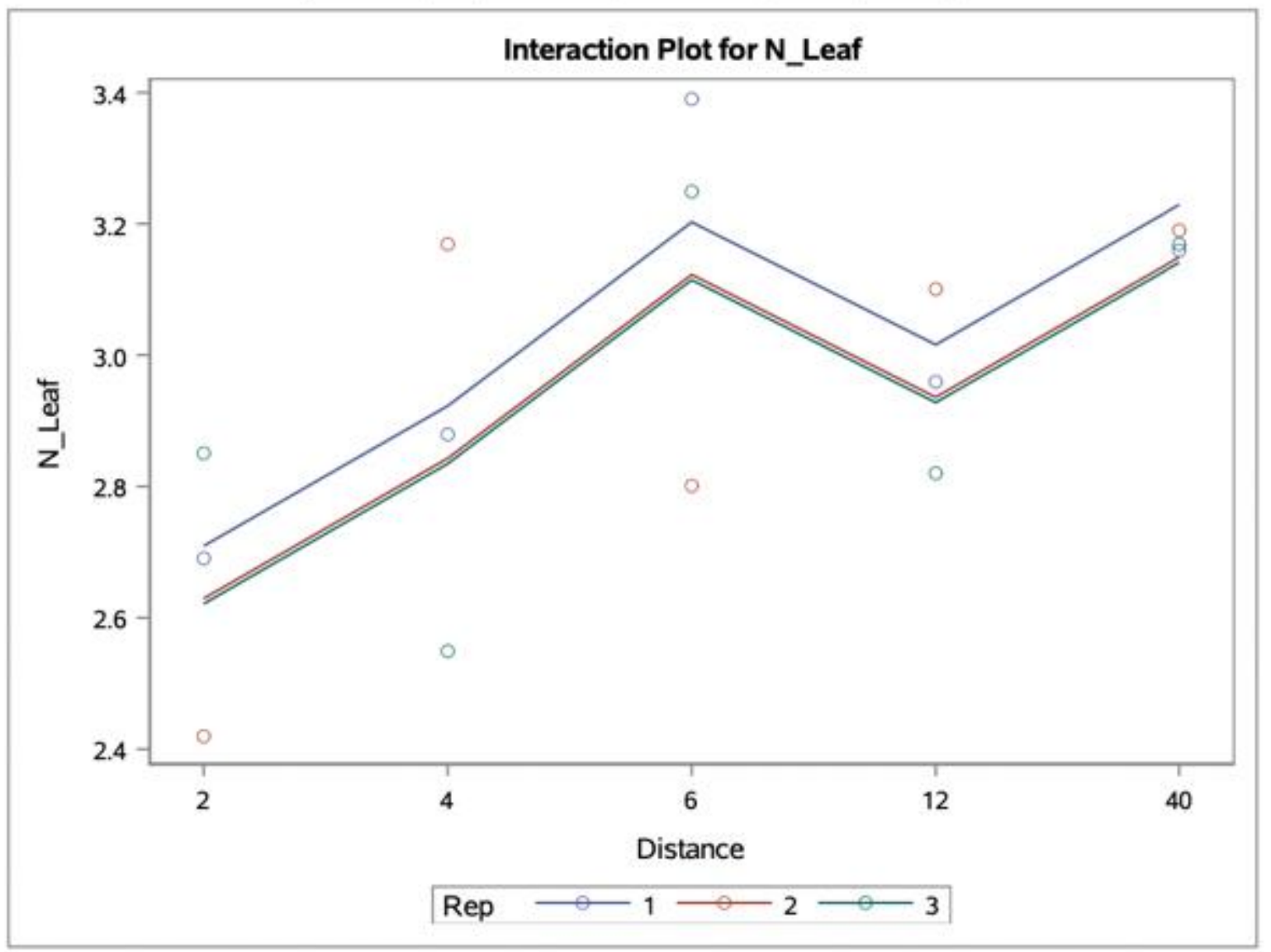


The GLM Procedure

Least Squares Means

\begin{tabular}{|l|r|r|r|r|}
\hline Distance & $\begin{array}{r}\text { N_Leaf } \\
\text { LSMEAN }\end{array}$ & $\begin{array}{r}\text { Standard } \\
\text { Error }\end{array}$ & $\operatorname{Pr}>\mid \mathrm{|t|}$ & $\begin{array}{r}\text { LSMEAN } \\
\text { Number }\end{array}$ \\
\hline 2 & 2.65333333 & 0.14332170 & $<.0001$ & 1 \\
\hline 4 & 2.86666667 & 0.14332170 & $<.0001$ & 2 \\
\hline 6 & 3.14666667 & 0.14332170 & $<.0001$ & 3 \\
\hline 12 & 2.96000000 & 0.14332170 & $<.0001$ & 4 \\
\hline 40 & 3.17333333 & 0.14332170 & $<.0001$ & 5 \\
\hline
\end{tabular}

\begin{tabular}{|l|r|r|r|r|r|}
\hline \multicolumn{7}{|c|}{$\begin{array}{c}\text { Least Squares Means for effect Distance } \\
\text { Pr > |t| for H0: LSMean(i)=LSMean(j) } \\
\text { Dependent Variable: N_Leaf }\end{array}$} \\
\hline i/j & $\mathbf{1}$ & $\mathbf{2}$ & $\mathbf{3}$ & $\mathbf{4}$ & $\mathbf{5}$ \\
\hline $\mathbf{1}$ & & 0.3233 & 0.0409 & 0.1687 & 0.0334 \\
\hline $\mathbf{2}$ & 0.3233 & & 0.2045 & 0.6574 & 0.1687 \\
\hline $\mathbf{3}$ & 0.0409 & 0.2045 & & 0.3840 & 0.8986 \\
\hline $\mathbf{4}$ & 0.1687 & 0.6574 & 0.3840 & & 0.3233 \\
\hline $\mathbf{5}$ & 0.0334 & 0.1687 & 0.8986 & 0.3233 & \\
\hline
\end{tabular}

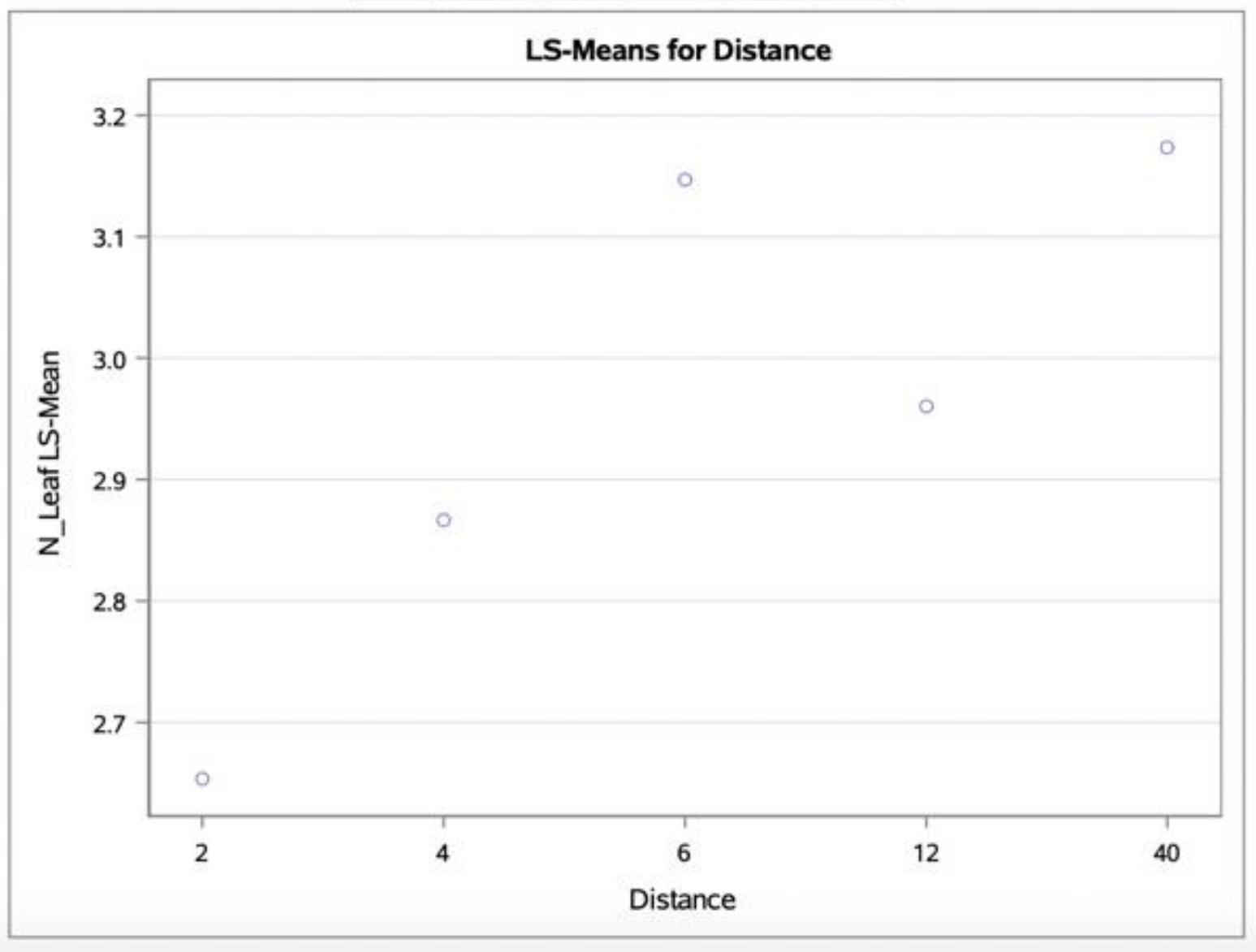


N_Leaf T Grouping for LS-Means of Distance

(Alpha $=0.05$ )

LS-means covered by the same bar are not significantly different.

Distance Estimate

$40 \quad 3,1733$

$6 \quad 3.1467$

$12 \quad 2.9600$

4

2.9600
2.8667
2.6533

2

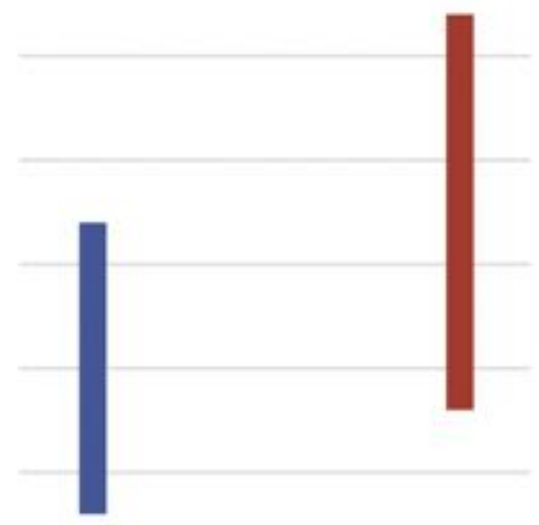

\begin{tabular}{|l|l|l|l|r|}
\hline \multicolumn{5}{|c|}{ Tests for Normality } \\
\hline Test & \multicolumn{2}{|c|}{ Statistic } & \multicolumn{2}{c|}{ p Value } \\
\hline Shapiro-Wilk & W & 0.97645 & Pr $<$ W & 0.9395 \\
\hline Kolmogorov-Smirnov & D & 0.097938 & Pr $>$ D & $>0.1500$ \\
\hline Cramer-von Mises & W-Sq & 0.024593 & Pr $>$ W-Sq & $>0.2500$ \\
\hline Anderson-Darling & A-Sq & 0.16757 & Pr $>$ A-Sq & $>0.2500$ \\
\hline
\end{tabular}


The UNIVARIATE Procedure

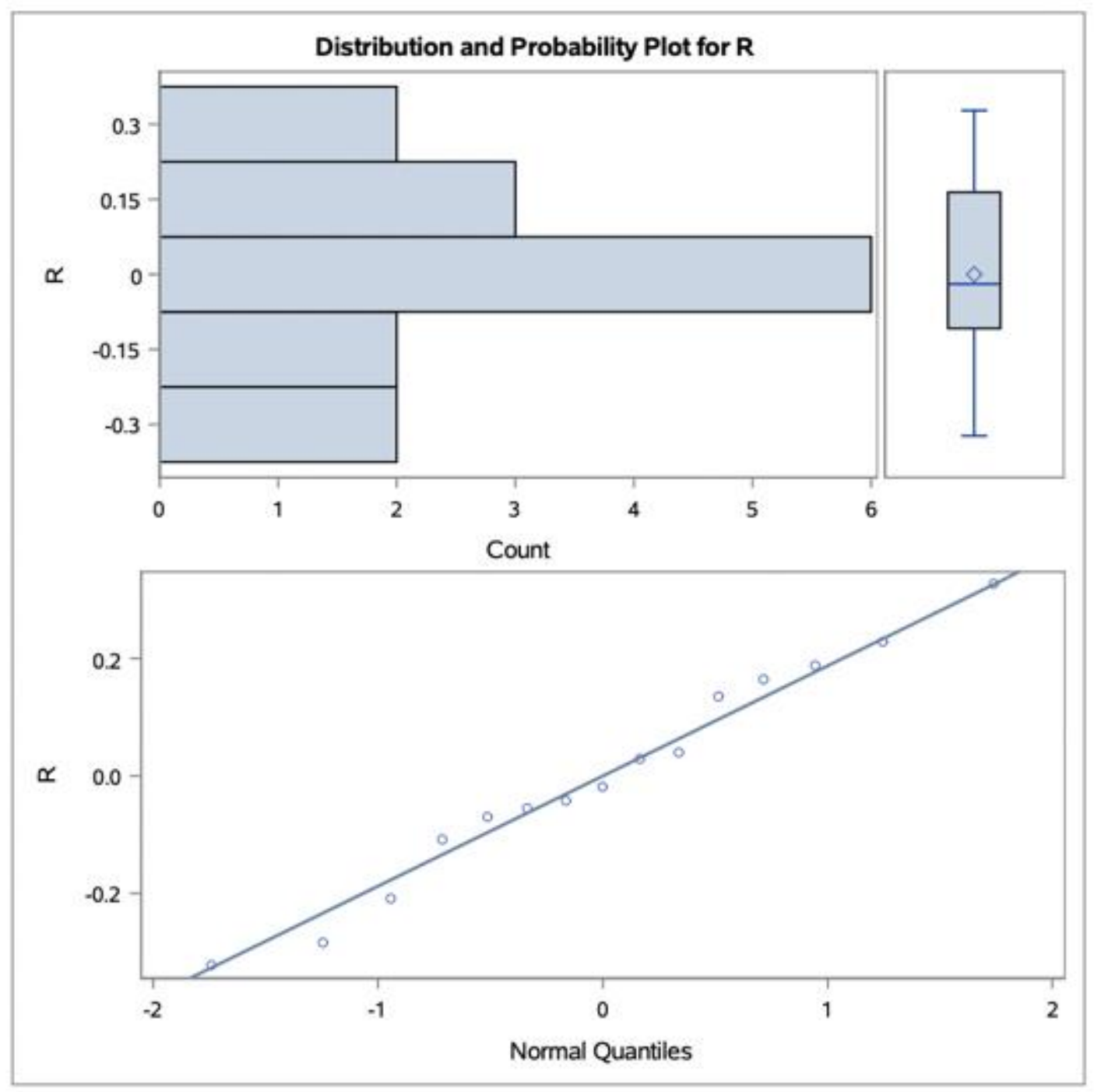


Table 15. SAS for the variable total petiole nitrogen

Foliars Data

N_Petiole

The GLM Procedure

Dependent Variable: N_Petiole N_Petiole

\begin{tabular}{|l|r|r|r|r|r|}
\hline Source & DF & $\begin{array}{r}\text { Sum of } \\
\text { Squares }\end{array}$ & Mean Square & F Value & Pr > F \\
\hline Model & 6 & 0.03189333 & 0.00531556 & 0.56 & 0.7526 \\
\hline Error & 8 & 0.07604000 & 0.00950500 & & \\
\hline Corrected Total & 14 & 0.10793333 & & & \\
\hline
\end{tabular}

\begin{tabular}{|l|r|r|r|r|r|}
\hline Source & DF & Type III SS & Mean Square & F Value & Pr $>$ F \\
\hline Distance & 4 & 0.02780000 & 0.00695000 & 0.73 & 0.5955 \\
\hline Rep & 2 & 0.00409333 & 0.00204667 & 0.22 & 0.8108 \\
\hline
\end{tabular}

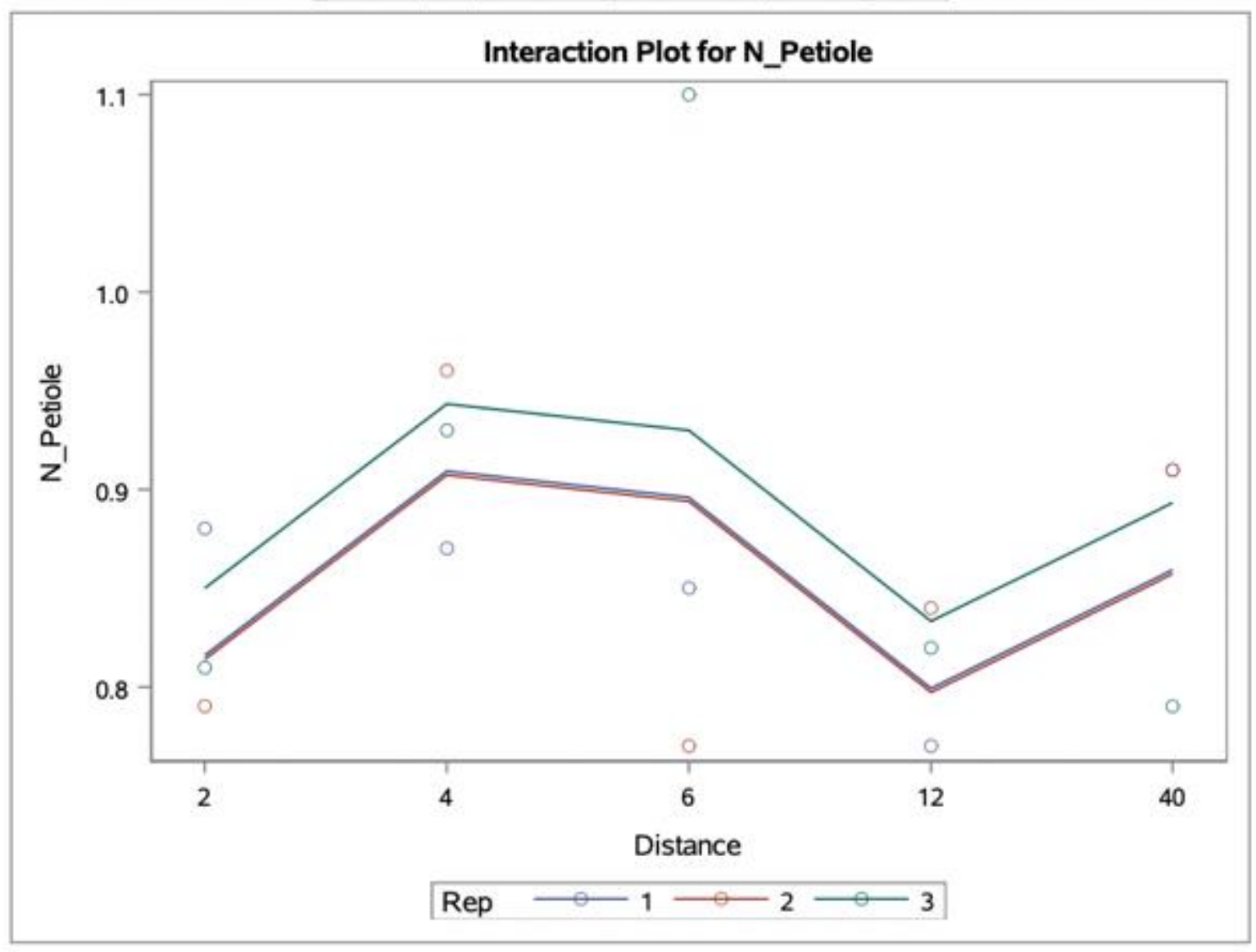


The GLM Procedure

Least Squares Means

\begin{tabular}{|l|r|r|r|r|}
\hline Distance & $\begin{array}{r}\text { N_Petiole } \\
\text { LSMEAN }\end{array}$ & $\begin{array}{r}\text { Standard } \\
\text { Error }\end{array}$ & Pr $>\mid$ tt $\mid$ & $\begin{array}{r}\text { LSMEAN } \\
\text { Number }\end{array}$ \\
\hline $\mathbf{2}$ & 0.82666667 & 0.05628795 & $<.0001$ & 1 \\
\hline 4 & 0.92000000 & 0.05628795 & $<.0001$ & 2 \\
\hline 6 & 0.90666667 & 0.05628795 & $<.0001$ & 3 \\
\hline 12 & 0.81000000 & 0.05628795 & $<.0001$ & 4 \\
\hline 40 & 0.87000000 & 0.05628795 & $<.0001$ & 5 \\
\hline
\end{tabular}

\begin{tabular}{|l|r|r|r|r|r|}
\hline \multicolumn{7}{|c|}{$\begin{array}{c}\text { Least Squares Means for effect Distance } \\
\text { Pr }>\text { | } 1 \text { for H0: LSMean(i)=LSMean }(\mathbf{)}) \\
\text { Dependent Variable: N_Petiole }\end{array}$} \\
\hline ij & $\mathbf{1}$ & $\mathbf{2}$ & $\mathbf{3}$ & $\mathbf{4}$ & $\mathbf{5}$ \\
\hline $\mathbf{1}$ & & 0.2747 & 0.3443 & 0.8394 & 0.6010 \\
\hline $\mathbf{2}$ & 0.2747 & & 0.8711 & 0.2044 & 0.5474 \\
\hline $\mathbf{3}$ & 0.3443 & 0.8711 & & 0.2592 & 0.6573 \\
\hline $\mathbf{4}$ & 0.8394 & 0.2044 & 0.2592 & & 0.4726 \\
\hline $\mathbf{5}$ & 0.6010 & 0.5474 & 0.6573 & 0.4726 & \\
\hline
\end{tabular}

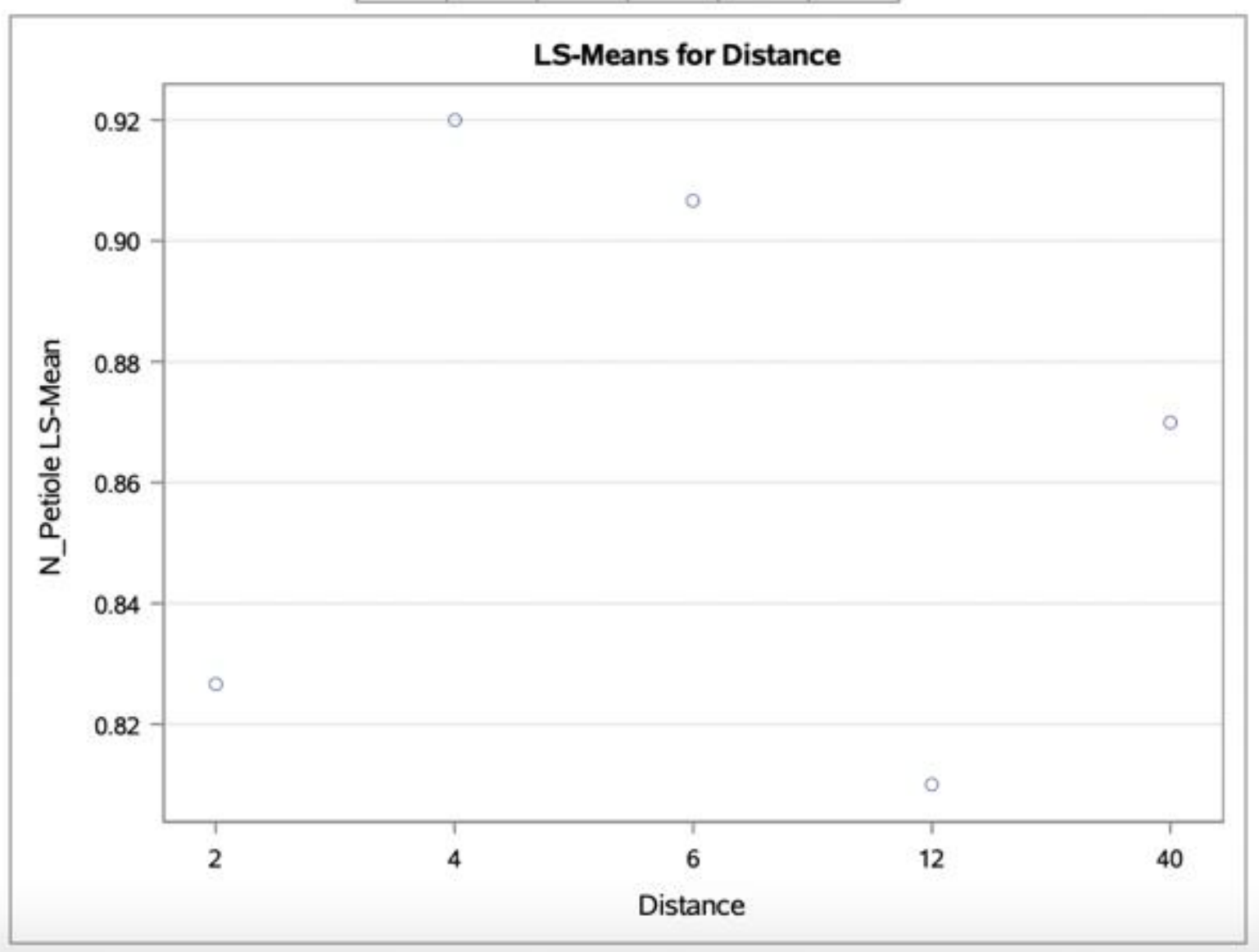




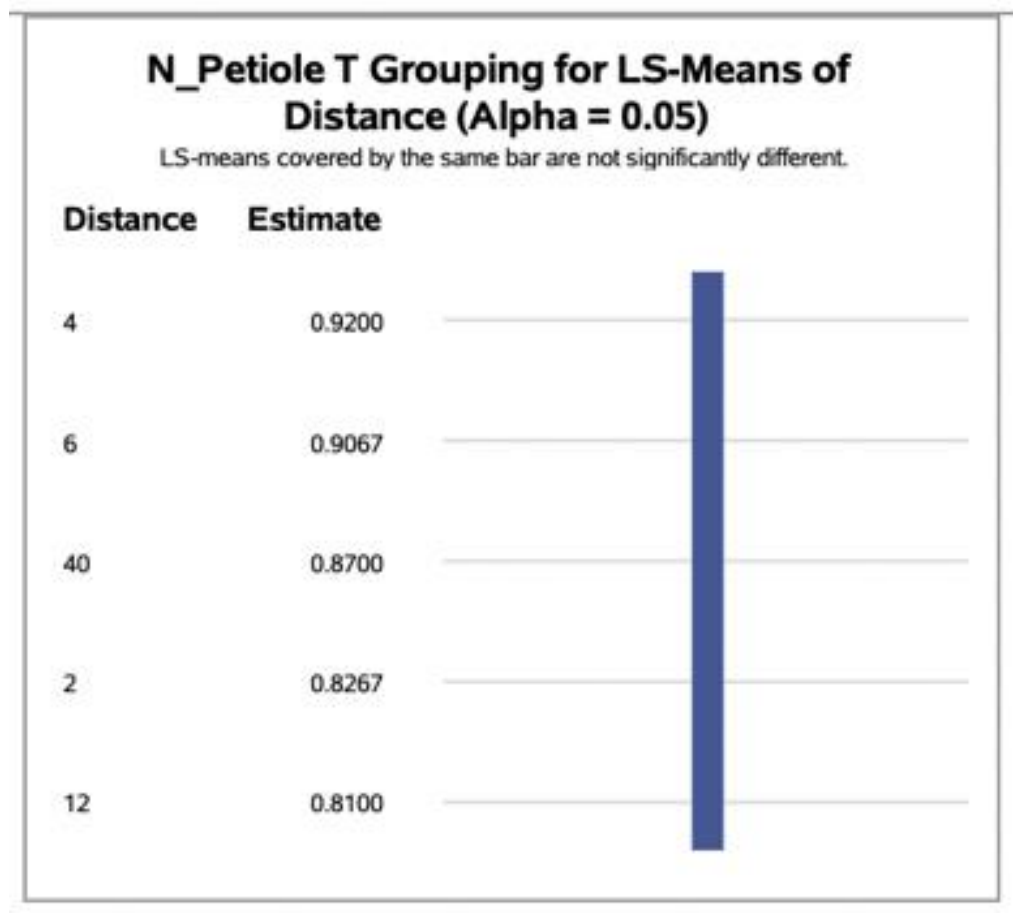

The UNIVARIATE Procedure

Variable: $\mathbf{R}$

\begin{tabular}{|l|r|l|r|}
\hline \multicolumn{4}{|c|}{ Moments } \\
\hline $\mathrm{N}$ & 15 & Sum Weights & 15 \\
\hline Mean & 0 & Sum Observations & 0 \\
\hline Std Deviation & 0.07369823 & Variance & 0.00543143 \\
\hline Skewness & 0.4939592 & Kurtosis & 0.84341284 \\
\hline Uncorrected SS & 0.07604 & Corrected SS & 0.07604 \\
\hline Coeff Variation & & Std Error Mean & 0.0190288 \\
\hline
\end{tabular}

\begin{tabular}{|l|l|l|l|r|}
\hline \multicolumn{5}{|c|}{ Tests for Normality } \\
\hline Test & \multicolumn{2}{|c|}{ Statistic } & \multicolumn{2}{c|}{ p Value } \\
\hline Shapiro-Wilk & W & 0.942836 & Pr $<$ W & 0.4194 \\
\hline Kolmogorov-Smirnov & D & 0.171784 & Pr $>$ D & $>0.1500$ \\
\hline Cramer-von Mises & W-Sq & 0.072497 & Pr $>$ W-Sq & 0.2446 \\
\hline Anderson-Darling & A-Sq & 0.429919 & Pr $>$ A-Sq & $>0.2500$ \\
\hline
\end{tabular}


The UNIVARIATE Procedure

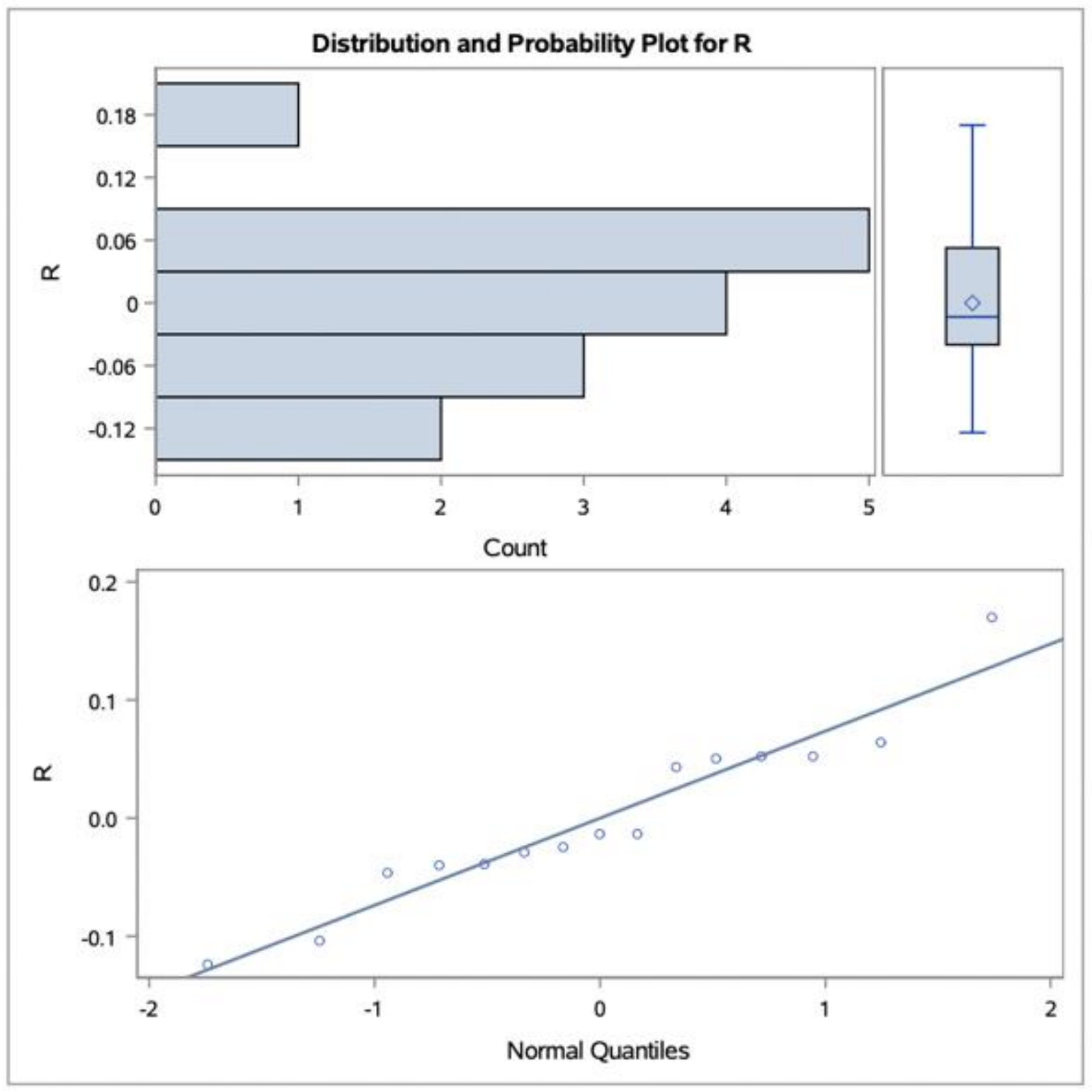


Table 16. SAS output for the variable leaf blade phosphorous

\section{Foliars Data \\ P_Leaf}

The GLM Procedure

Dependent Variable: P_Leaf P_Leaf

\begin{tabular}{|l|r|r|r|r|r|}
\hline Source & DF & $\begin{array}{r}\text { Sum of } \\
\text { Squares }\end{array}$ & Mean Square & F Value & $\operatorname{Pr}>$ F \\
\hline Model & 6 & 0.04232000 & 0.00705333 & 0.79 & 0.6017 \\
\hline Error & 8 & 0.07137333 & 0.00892167 & & \\
\hline Corrected Total & 14 & 0.11369333 & & & \\
\hline
\end{tabular}

\begin{tabular}{|l|r|r|r|r|r|}
\hline Source & DF & Type III SS & Mean Square & F Value & Pr $>$ F \\
\hline Distance & 4 & 0.03142667 & 0.00785667 & 0.88 & 0.5165 \\
\hline Rep & 2 & 0.01089333 & 0.00544667 & 0.61 & 0.5666 \\
\hline
\end{tabular}

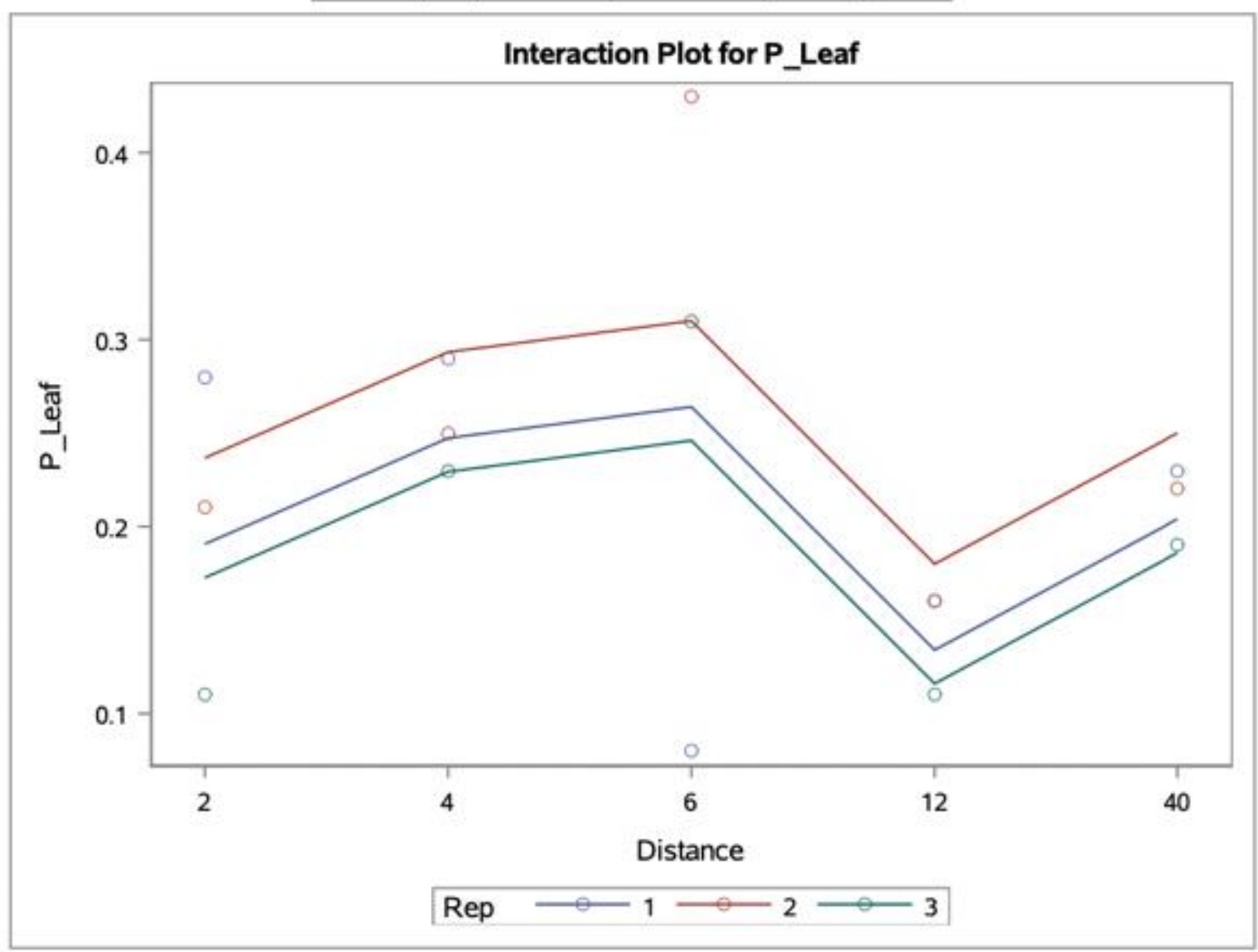


The GLM Procedure

Least Squares Means

\begin{tabular}{|l|r|r|r|r|}
\hline Distance & $\begin{array}{r}\text { P_Leaf } \\
\text { LSMEAN }\end{array}$ & $\begin{array}{r}\text { Standard } \\
\text { Error }\end{array}$ & Pr > It & $\begin{array}{r}\text { LSMEAN } \\
\text { Number }\end{array}$ \\
\hline 2 & 0.20000000 & 0.05453337 & 0.0063 & 1 \\
\hline 4 & 0.25666667 & 0.05453337 & 0.0015 & 2 \\
\hline 6 & 0.27333333 & 0.05453337 & 0.0010 & 3 \\
\hline 12 & 0.14333333 & 0.05453337 & 0.0303 & 4 \\
\hline 40 & 0.21333333 & 0.05453337 & 0.0045 & 5 \\
\hline
\end{tabular}

\begin{tabular}{|l|r|r|r|r|r|}
\hline \multicolumn{7}{|c|}{$\begin{array}{c}\text { Least Squares Means for effect Distance } \\
\text { Pr > | It for H0: LSMean(i)=LSMean(j) } \\
\text { Dependent Variable: P_Leaf }\end{array}$} \\
\hline Vj & $\mathbf{1}$ & $\mathbf{2}$ & $\mathbf{3}$ & $\mathbf{4}$ & $\mathbf{5}$ \\
\hline $\mathbf{1}$ & & 0.4835 & 0.3695 & 0.4835 & 0.8670 \\
\hline $\mathbf{2}$ & 0.4835 & & 0.8343 & 0.1799 & 0.5896 \\
\hline $\mathbf{3}$ & 0.3695 & 0.8343 & & 0.1304 & 0.4590 \\
\hline $\mathbf{4}$ & 0.4835 & 0.1799 & 0.1304 & & 0.3906 \\
\hline $\mathbf{5}$ & 0.8670 & 0.5896 & 0.4590 & 0.3906 & \\
\hline
\end{tabular}

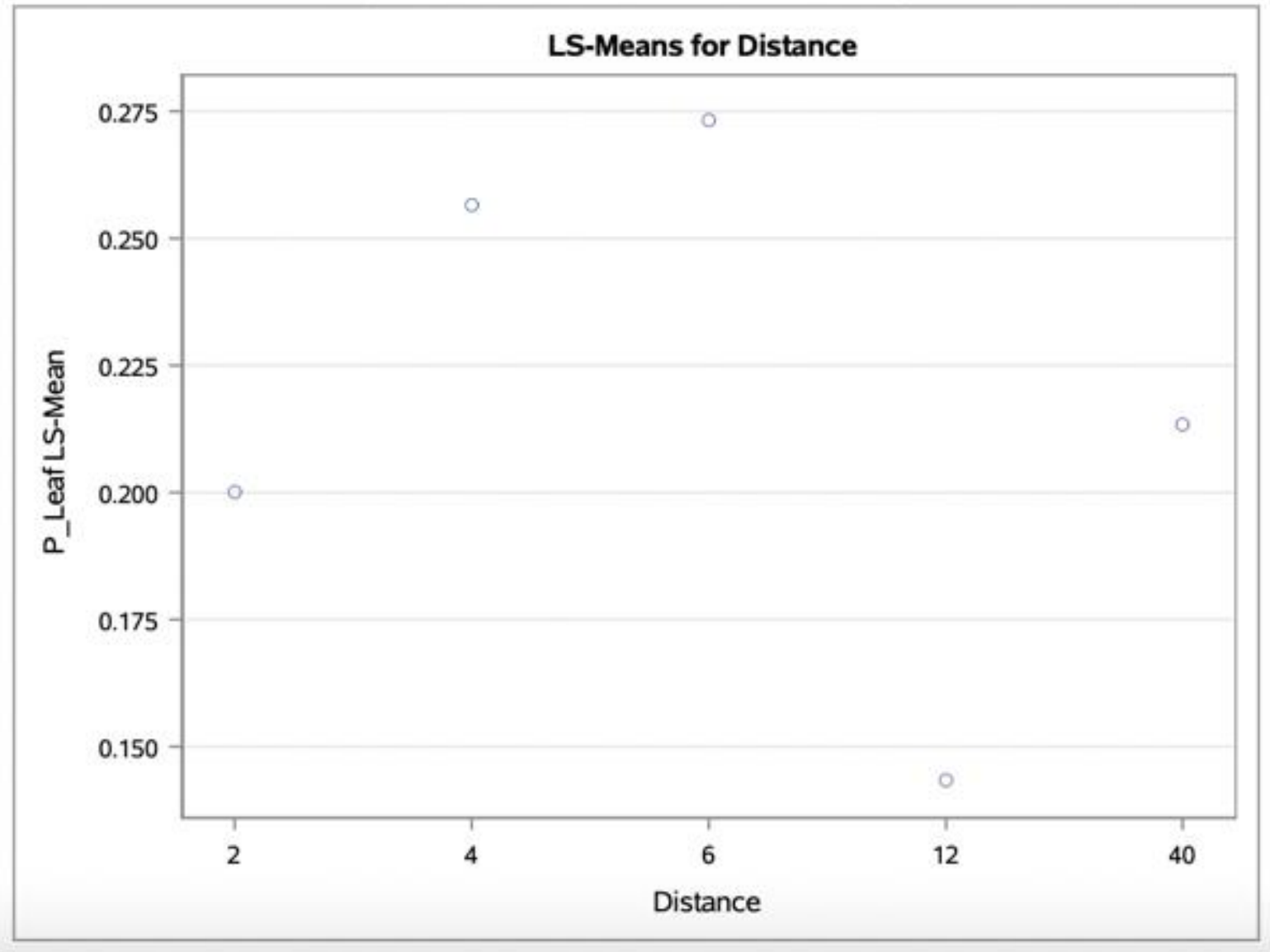




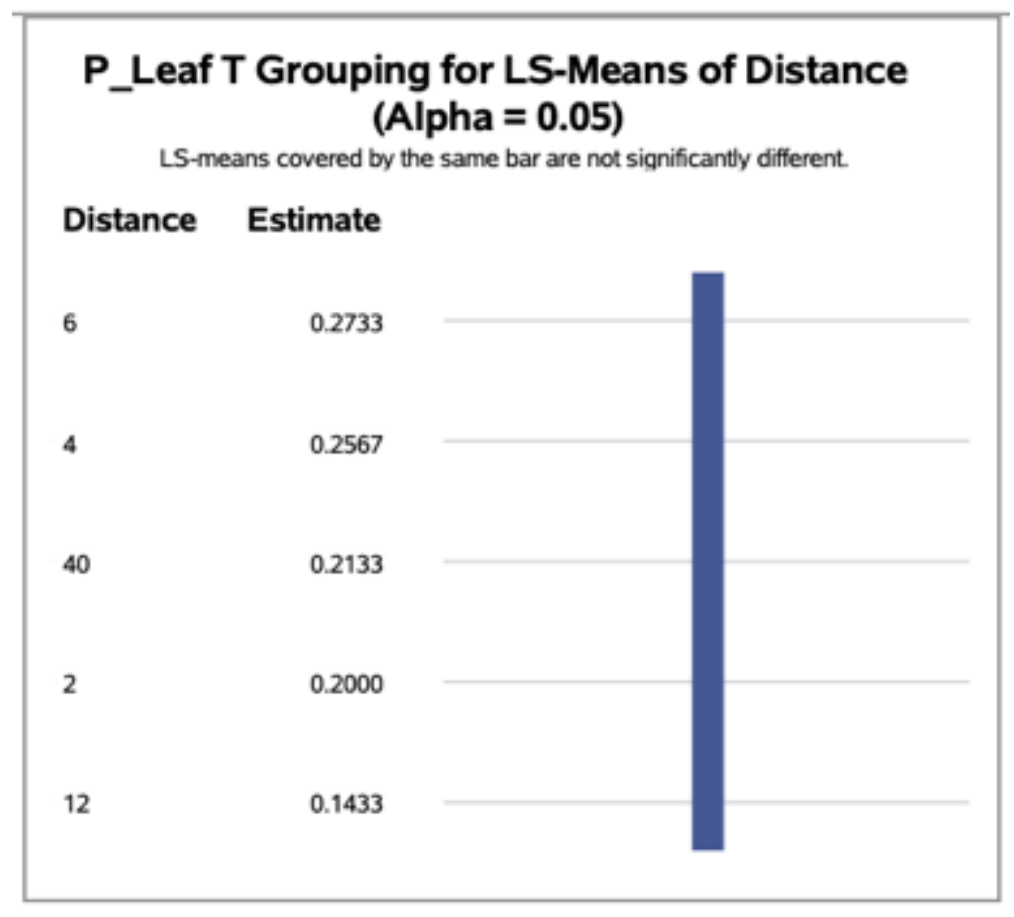

The UNIVARIATE Procedure

Variable: $\mathbf{R}$

\begin{tabular}{|l|r|l|r|}
\hline \multicolumn{4}{|c|}{ Moments } \\
\hline $\mathrm{N}$ & 15 & Sum Weights & 15 \\
\hline Mean & 0 & Sum Observations & 0 \\
\hline Std Deviation & 0.07140095 & Variance & 0.0050981 \\
\hline Skewness & -0.8592957 & Kurtosis & 2.39829192 \\
\hline Uncorrected SS & 0.07137333 & Corrected SS & 0.07137333 \\
\hline Coeff Variation & & Std Error Mean & 0.01843565 \\
\hline
\end{tabular}




\begin{tabular}{|l|l|l|l|r|}
\hline \multicolumn{5}{|c|}{ Tests for Normality } \\
\hline Test & \multicolumn{2}{|c|}{ Statistic } & \multicolumn{2}{c|}{ p Value } \\
\hline Shapiro-Wilk & W & 0.938774 & Pr $<$ W & 0.3672 \\
\hline Kolmogorov-Smirnov & D & 0.138625 & Pr $>$ D & $>0.1500$ \\
\hline Cramer-von Mises & W-Sq & 0.048617 & Pr $>$ W-Sq & $>0.2500$ \\
\hline Anderson-Darling & A-Sq & 0.360161 & Pr $>$ A-Sq & $>0.2500$ \\
\hline
\end{tabular}

The UNIVARIATE Procedure

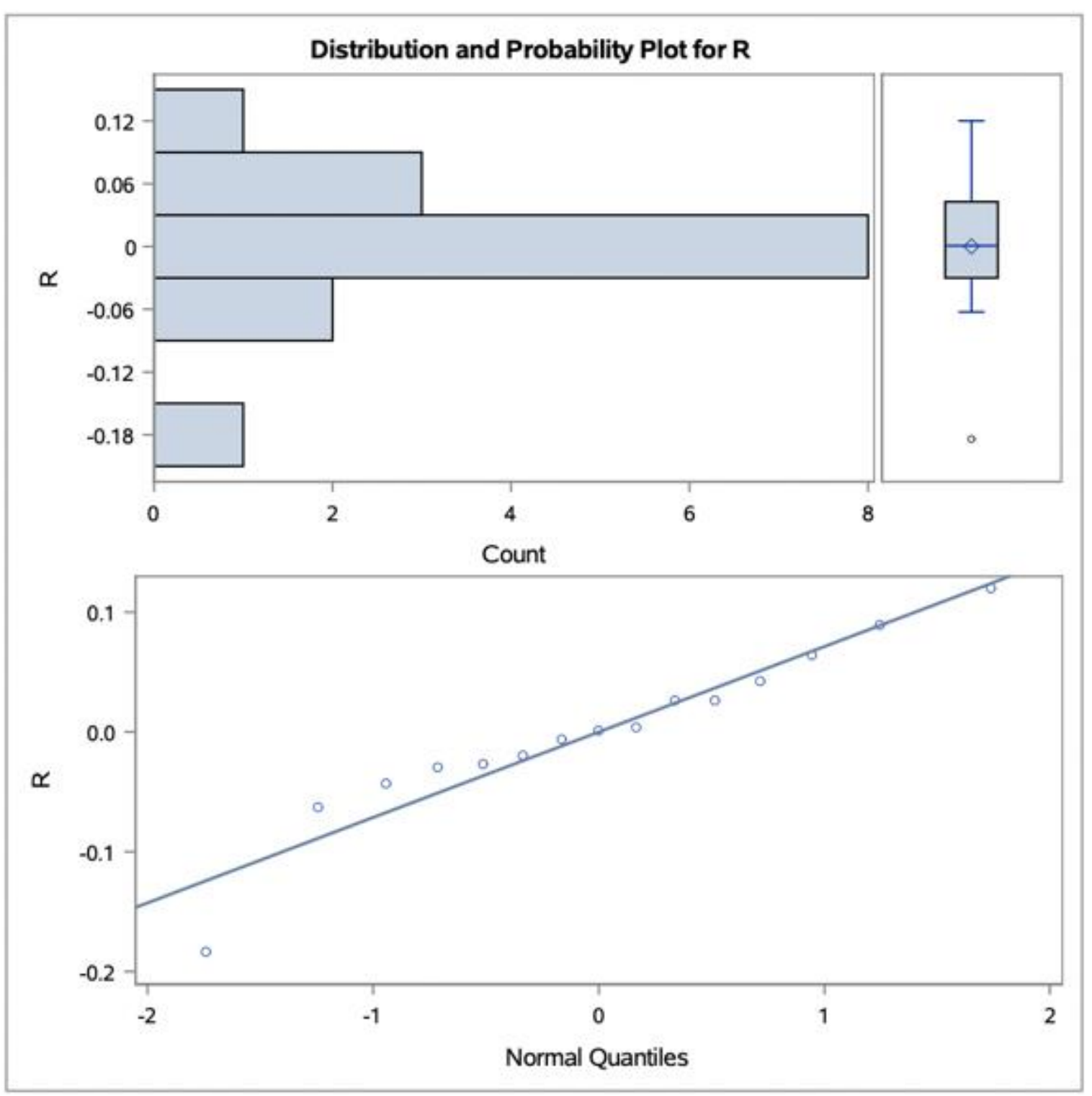


Table 17. SAS output for the variable petiole phosphorus

\section{Foliars Data \\ P_Petiole}

The GLM Procedure

Dependent Variable: P_Petiole P_Petiole

\begin{tabular}{|l|r|r|r|r|r|}
\hline Source & DF & $\begin{array}{r}\text { Sum of } \\
\text { Squares }\end{array}$ & Mean Square & F Value & Pr $>$ F \\
\hline Model & 6 & 0.02693333 & 0.00448889 & 2.60 & 0.1061 \\
\hline Error & 8 & 0.01382667 & 0.00172833 & & \\
\hline Corrected Total & 14 & 0.04076000 & & & \\
\hline
\end{tabular}

\begin{tabular}{|l|r|r|r|r|r|}
\hline Source & DF & Type III SS & Mean Square & F Value & Pr > F \\
\hline Distance & 4 & 0.02449333 & 0.00612333 & 3.54 & 0.0603 \\
\hline Rep & 2 & 0.00244000 & 0.00122000 & 0.71 & 0.5220 \\
\hline
\end{tabular}

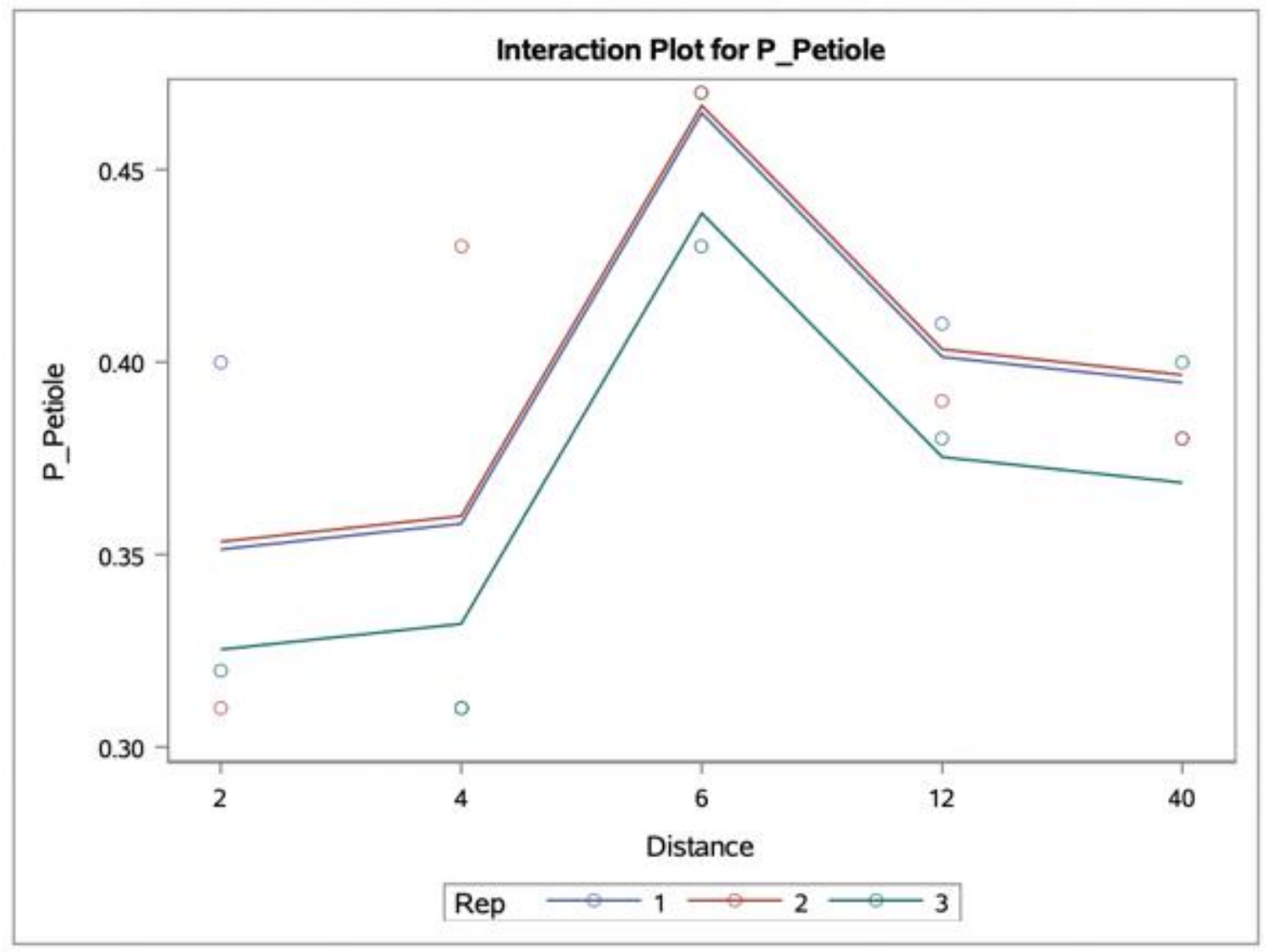


The GLM Procedure

Least Squares Means

\begin{tabular}{|l|r|r|r|r|}
\hline Distance & $\begin{array}{r}\text { P.Petiole } \\
\text { LSMEAN }\end{array}$ & $\begin{array}{r}\text { Standard } \\
\text { Error }\end{array}$ & $\operatorname{Pr}>141$ & $\begin{array}{r}\text { LSMEAN } \\
\text { Number }\end{array}$ \\
\hline $\mathbf{2}$ & 0.34333333 & 0.02400231 & $<.0001$ & 1 \\
\hline $\mathbf{4}$ & 0.35000000 & 0.02400231 & $<.0001$ & 2 \\
\hline 6 & 0.45666667 & 0.02400231 & $<.0001$ & 3 \\
\hline 12 & 0.39333333 & 0.02400231 & $<.0001$ & 4 \\
\hline 40 & 0.38666667 & 0.02400231 & $<.0001$ & 5 \\
\hline
\end{tabular}

\begin{tabular}{|l|r|r|r|r|r|}
\hline \multicolumn{7}{|c|}{$\begin{array}{c}\text { Least Squares Means for effect Distance } \\
\text { Pr > |t| for H0: LSMean(i)=LSMean(j) } \\
\text { Dependent Variable: P_Petiole }\end{array}$} \\
\hline ij & $\mathbf{1}$ & $\mathbf{2}$ & $\mathbf{3}$ & $\mathbf{4}$ & $\mathbf{5}$ \\
\hline $\mathbf{1}$ & & 0.8492 & 0.0102 & 0.1790 & 0.2376 \\
\hline $\mathbf{2}$ & 0.8492 & & 0.0138 & 0.2376 & 0.3115 \\
\hline $\mathbf{3}$ & 0.0102 & 0.0138 & & 0.0990 & 0.0731 \\
\hline $\mathbf{4}$ & 0.1790 & 0.2376 & 0.0990 & & 0.8492 \\
\hline $\mathbf{5}$ & 0.2376 & 0.3115 & 0.0731 & 0.8492 & \\
\hline
\end{tabular}

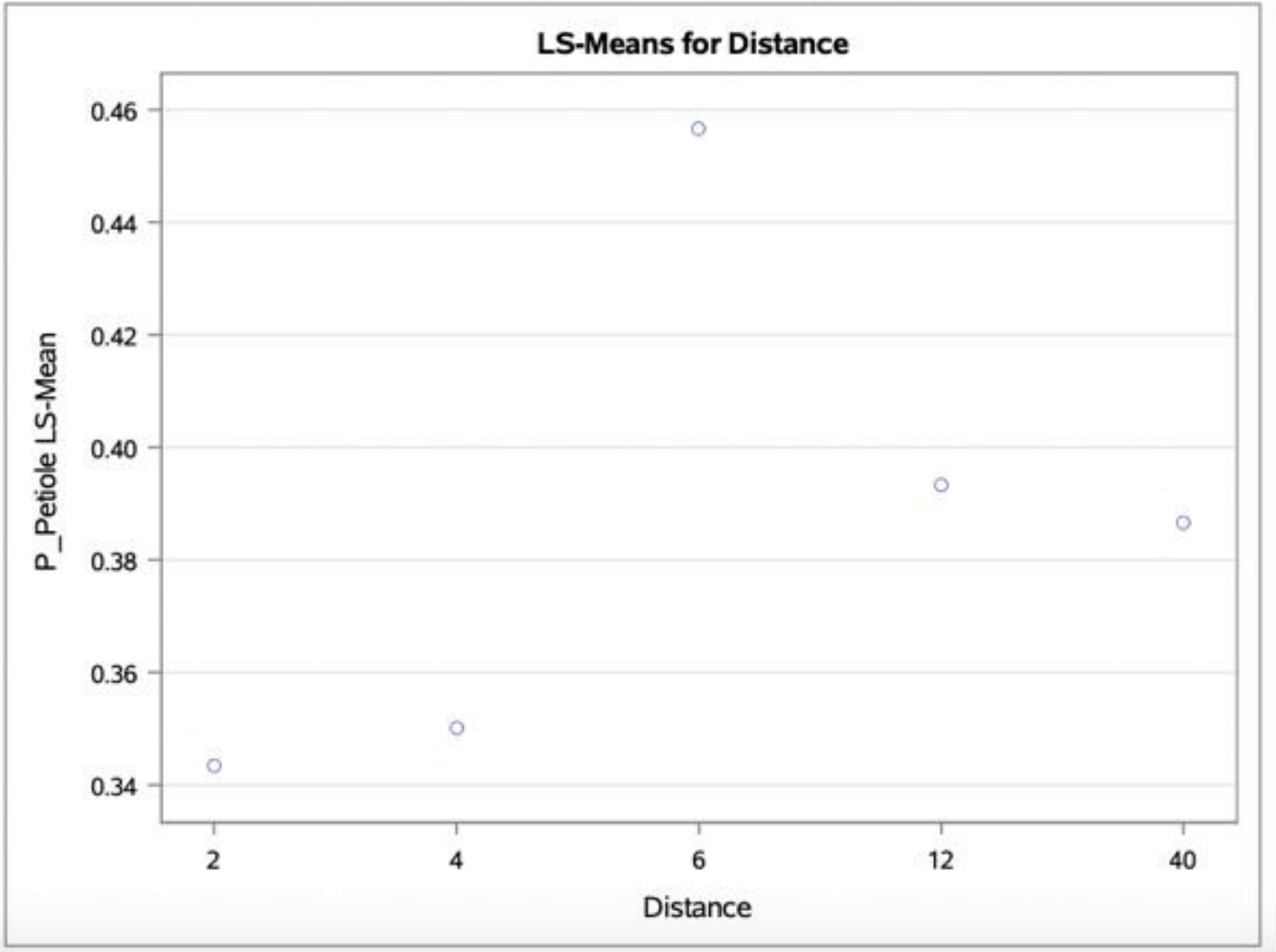




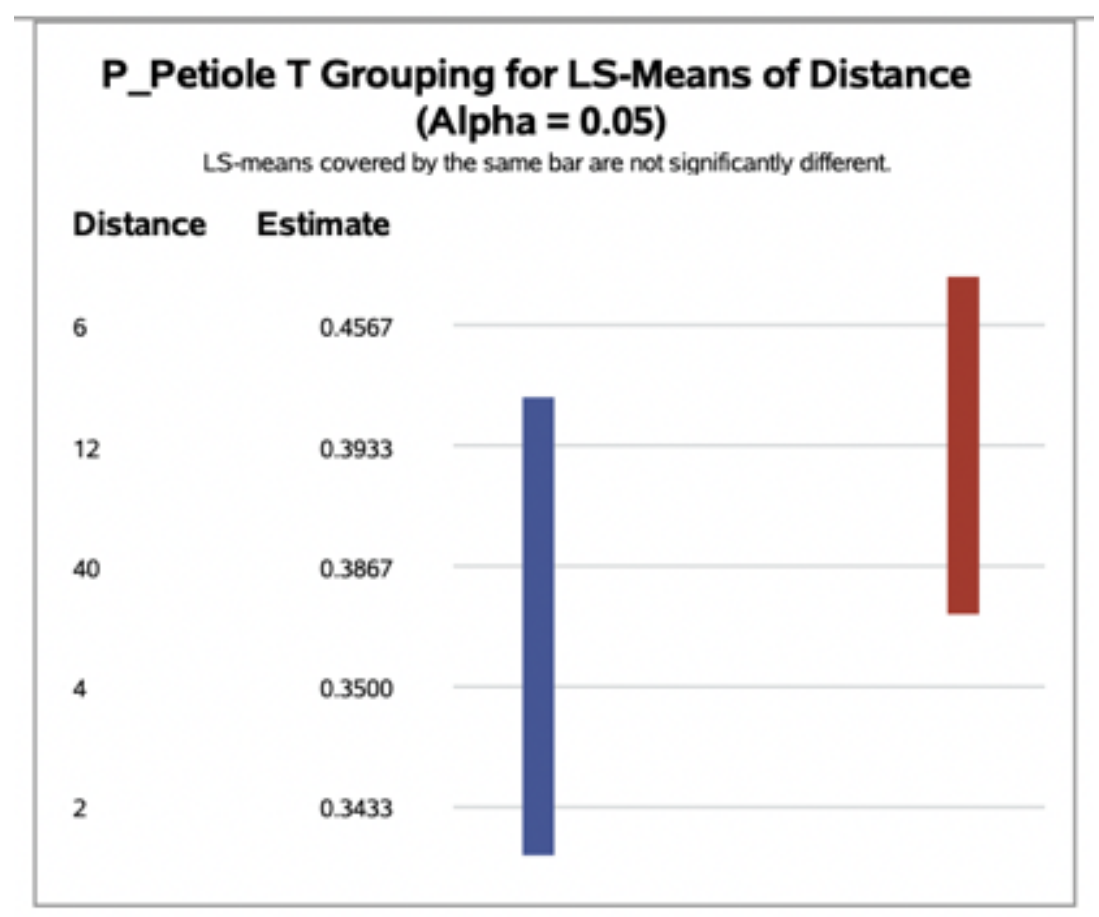

The UNIVARIATE Procedure

Variable: $\mathbf{R}$

\begin{tabular}{|l|r|l|r|}
\hline \multicolumn{4}{|c|}{ Moments } \\
\hline $\mathrm{N}$ & 15 & Sum Weights & 15 \\
\hline Mean & 0 & Sum Observations & 0 \\
\hline Std Deviation & 0.03142641 & Variance & 0.00098762 \\
\hline Skewness & 0.73396225 & Kurtosis & 0.71706928 \\
\hline Uncorrected SS & 0.01382667 & Corrected SS & 0.01382667 \\
\hline Coeff Variation & & Std Error Mean & 0.00811426 \\
\hline
\end{tabular}

\begin{tabular}{|l|l|l|l|r|}
\hline \multicolumn{5}{|c|}{ Tests for Normality } \\
\hline Test & \multicolumn{2}{|c|}{ Statistic } & \multicolumn{2}{c|}{ P Value } \\
\hline Shapiro-Wilk & W & 0.941022 & Pr $<$ W & 0.3954 \\
\hline Kolmogorov-Smirnov & D & 0.19136 & Pr $>$ D & 0.1429 \\
\hline Cramer-von Mises & W-Sq & 0.074919 & Pr $>$ W-Sq & 0.2299 \\
\hline Anderson-Darling & A-Sq & 0.421266 & Pr $>$ A-Sq & $>0.2500$ \\
\hline
\end{tabular}


The UNIVARIATE Procedure

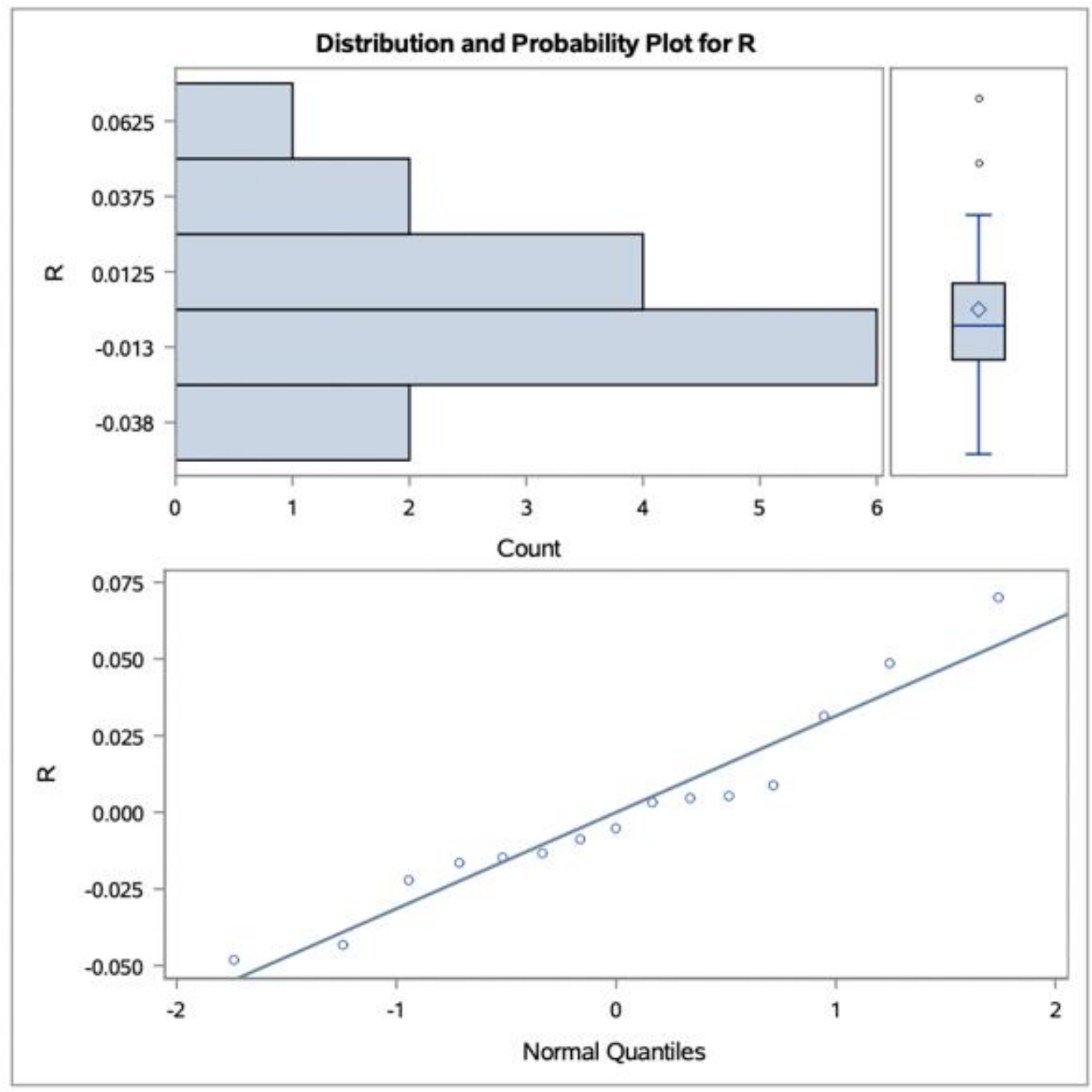


Table 18. SAS output for the variable leaf blade potassium

\section{Foliars Data \\ K_Leaf}

The GLM Procedure

Dependent Variable: K_Leaf K_Leaf

\begin{tabular}{|l|r|r|r|r|r|}
\hline Source & DF & $\begin{array}{r}\text { Sum of } \\
\text { Squares }\end{array}$ & Mean Square & F Value & Pr $>$ F \\
\hline Model & 6 & 0.35885333 & 0.05980889 & 22.65 & 0.0001 \\
\hline Error & 8 & 0.02112000 & 0.00264000 & & \\
\hline Corrected Total & 14 & 0.37997333 & & & \\
\hline
\end{tabular}

\begin{tabular}{|l|r|r|r|r|r|}
\hline Source & DF & Type III SS & Mean Square & F Value & Pr $>$ F \\
\hline Distance & 4 & 0.31924000 & 0.07981000 & 30.23 & $<.0001$ \\
\hline Rep & 2 & 0.03961333 & 0.01980667 & 7.50 & 0.0146 \\
\hline
\end{tabular}

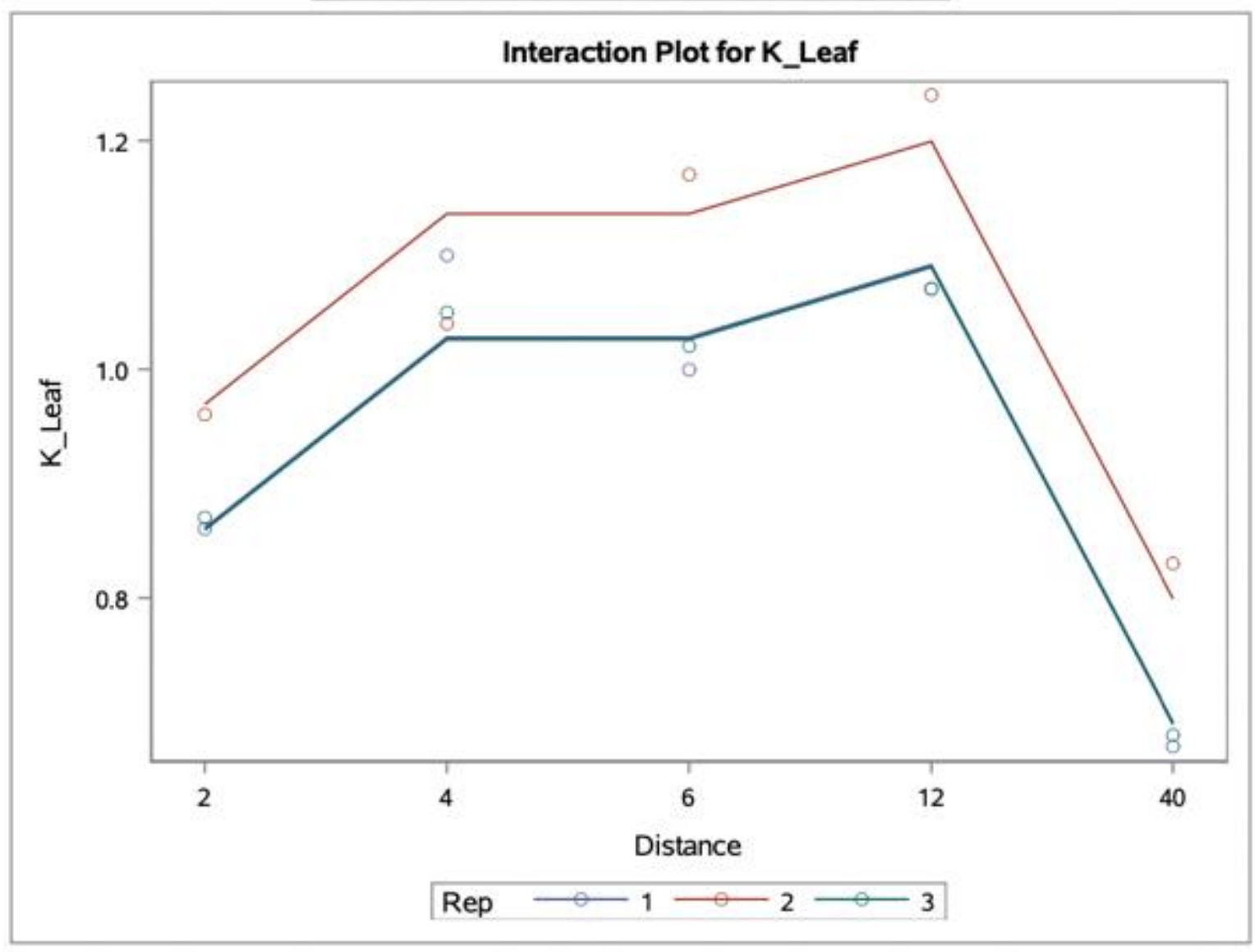


The GLM Procedure

Least Squares Means

\begin{tabular}{|l|r|r|r|r|}
\hline Distance & $\begin{array}{r}\text { K_Leaf } \\
\text { LSMEAN }\end{array}$ & $\begin{array}{r}\text { Standard } \\
\text { Error }\end{array}$ & $\operatorname{Pr}>\mid$ t $\mid$ & $\begin{array}{r}\text { LSMEAN } \\
\text { Number }\end{array}$ \\
\hline $\mathbf{2}$ & 0.89666667 & 0.02966479 & $<.0001$ & 1 \\
\hline 4 & 1.06333333 & 0.02966479 & $<.0001$ & 2 \\
\hline 6 & 1.06333333 & 0.02966479 & $<.0001$ & 3 \\
\hline 12 & 1.12666667 & 0.02966479 & $<.0001$ & 4 \\
\hline 40 & 0.72666667 & 0.02966479 & $<.0001$ & 5 \\
\hline
\end{tabular}

\begin{tabular}{|l|r|r|r|r|r|}
\hline \multicolumn{7}{|c|}{$\begin{array}{c}\text { Least Squares Means for effect Distance } \\
\text { Pr }>\text { it for H0: LSMean(i)=LSMean(i) } \\
\text { Dependent Variable: K_Leaf }\end{array}$} \\
\hline ij & $\mathbf{1}$ & $\mathbf{2}$ & $\mathbf{3}$ & $\mathbf{4}$ & $\mathbf{5}$ \\
\hline $\mathbf{1}$ & & 0.0041 & 0.0041 & 0.0006 & 0.0037 \\
\hline $\mathbf{2}$ & 0.0041 & & 1.0000 & 0.1696 & $<.0001$ \\
\hline $\mathbf{3}$ & 0.0041 & 1.0000 & & 0.1696 & $<.0001$ \\
\hline $\mathbf{4}$ & 0.0006 & 0.1696 & 0.1696 & & $<.0001$ \\
\hline $\mathbf{5}$ & 0.0037 & $<.0001$ & $<.0001$ & $<.0001$ & \\
\hline
\end{tabular}

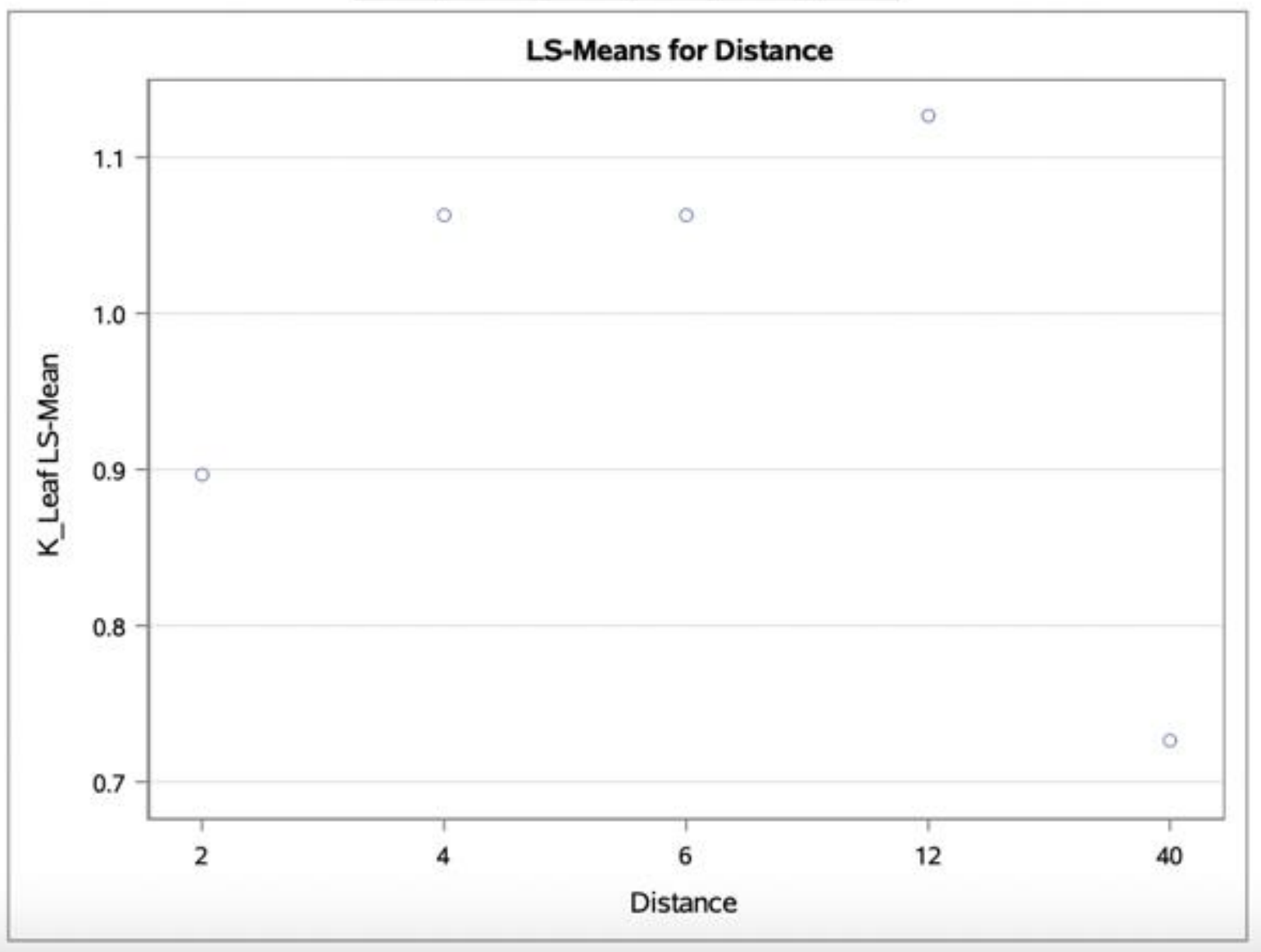




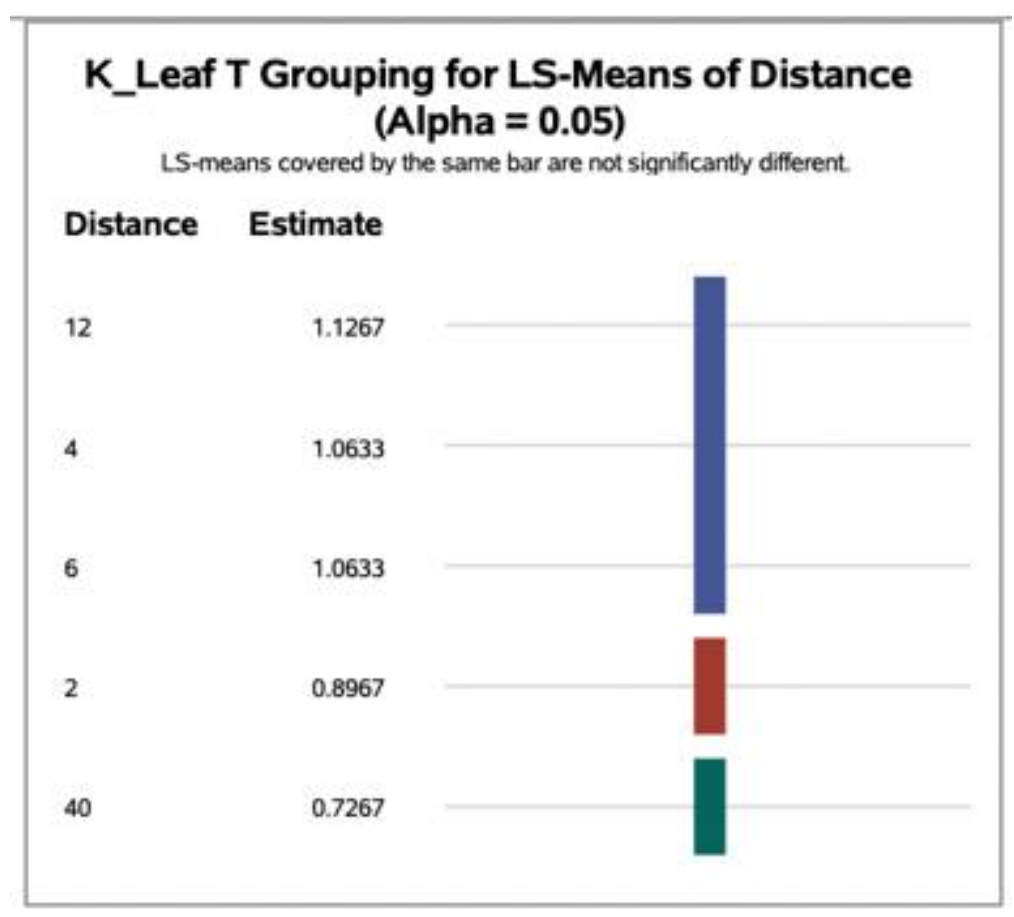

The UNIVARIATE Procedure

Variable: $\mathbf{R}$

\begin{tabular}{|l|r|l|r|}
\hline \multicolumn{4}{|c|}{ Moments } \\
\hline N & 15 & Sum Weights & 15 \\
\hline Mean & 0 & Sum Observations & 0 \\
\hline Std Deviation & 0.03884033 & Variance & 0.00150857 \\
\hline Skewness & -0.5788071 & Kurtosis & 1.94279111 \\
\hline Uncorrected SS & 0.02112 & Corrected SS & 0.02112 \\
\hline Coeff Variation & & Std Error Mean & 0.01002853 \\
\hline
\end{tabular}




\begin{tabular}{|l|l|l|l|r|}
\hline \multicolumn{5}{|c|}{ Tests for Normality } \\
\hline Test & \multicolumn{2}{|c|}{ Statistic } & \multicolumn{2}{c|}{ P Value } \\
\hline Shapiro-Wilk & W & 0.938215 & Pr $<$ W & 0.3605 \\
\hline Kolmogorov-Smirnov & D & 0.168819 & Pr $>$ D & $>0.1500$ \\
\hline Cramer-von Mises & W-Sq & 0.060956 & Pr $>$ W-Sq & $>0.2500$ \\
\hline Anderson-Darling & A-Sq & 0.417687 & Pr $>$ A-Sq & $>0.2500$ \\
\hline
\end{tabular}

The UNIVARIATE Procedure

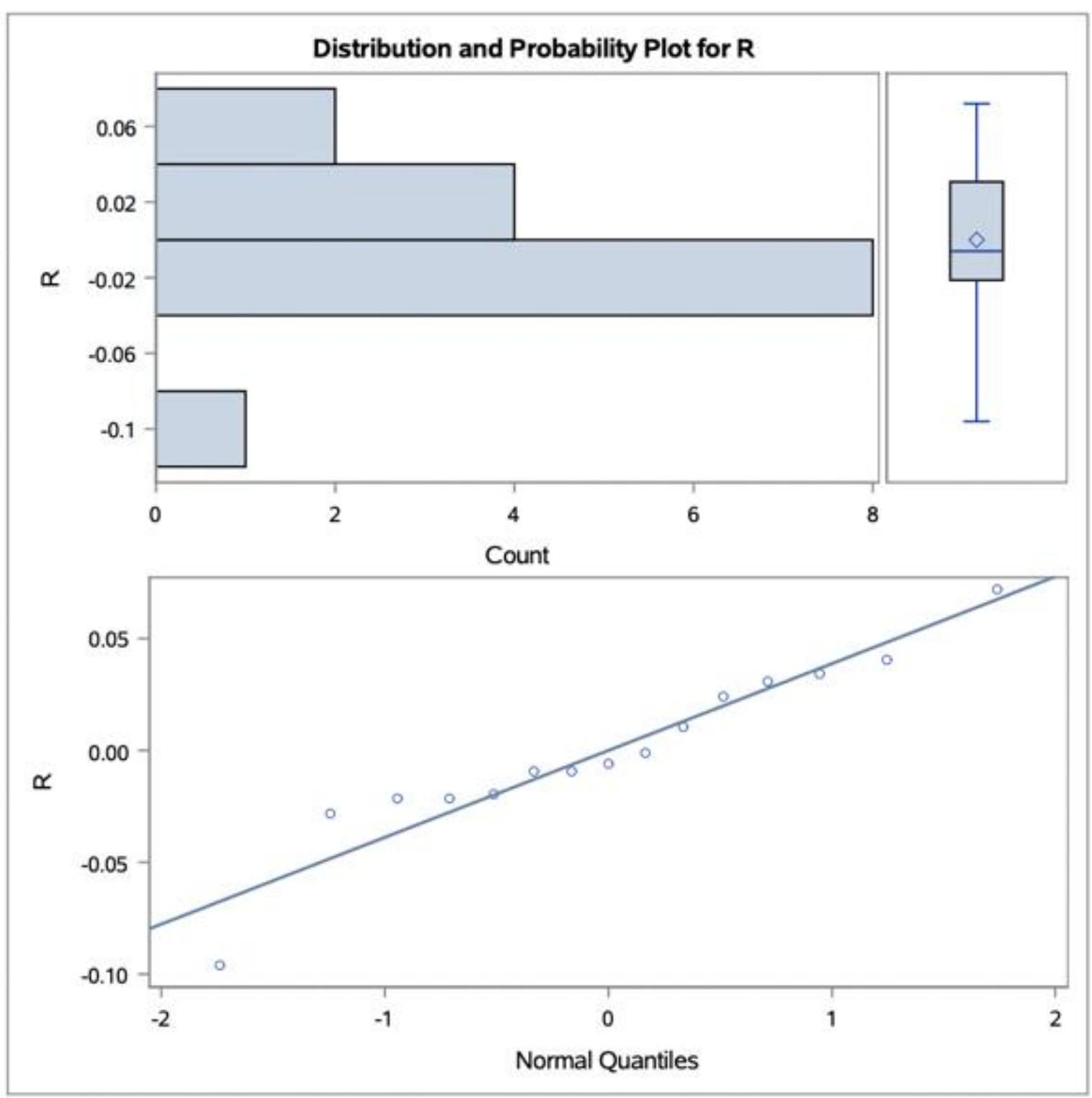


Table 19. SAS output for the variable petiole potassium

\section{Foliars Data \\ K_Petiole}

The GLM Procedure

Dependent Variable: K_Petiole K_Petiole

\begin{tabular}{|l|r|r|r|r|r|}
\hline Source & DF & $\begin{array}{r}\text { Sum of } \\
\text { Squares }\end{array}$ & Mean Square & F Value & Pr $>$ F \\
\hline Model & 6 & 0.48984000 & 0.08164000 & 0.93 & 0.5231 \\
\hline Error & 8 & 0.70425333 & 0.08803167 & & \\
\hline Corrected Total & 14 & 1.19409333 & & & \\
\hline
\end{tabular}

\begin{tabular}{|l|r|r|r|r|r|}
\hline Source & DF & Type III SS & Mean Square & F Value & Pr > F \\
\hline Distance & 4 & 0.44062667 & 0.11015667 & 1.25 & 0.3636 \\
\hline Rep & 2 & 0.04921333 & 0.02460667 & 0.28 & 0.7632 \\
\hline
\end{tabular}

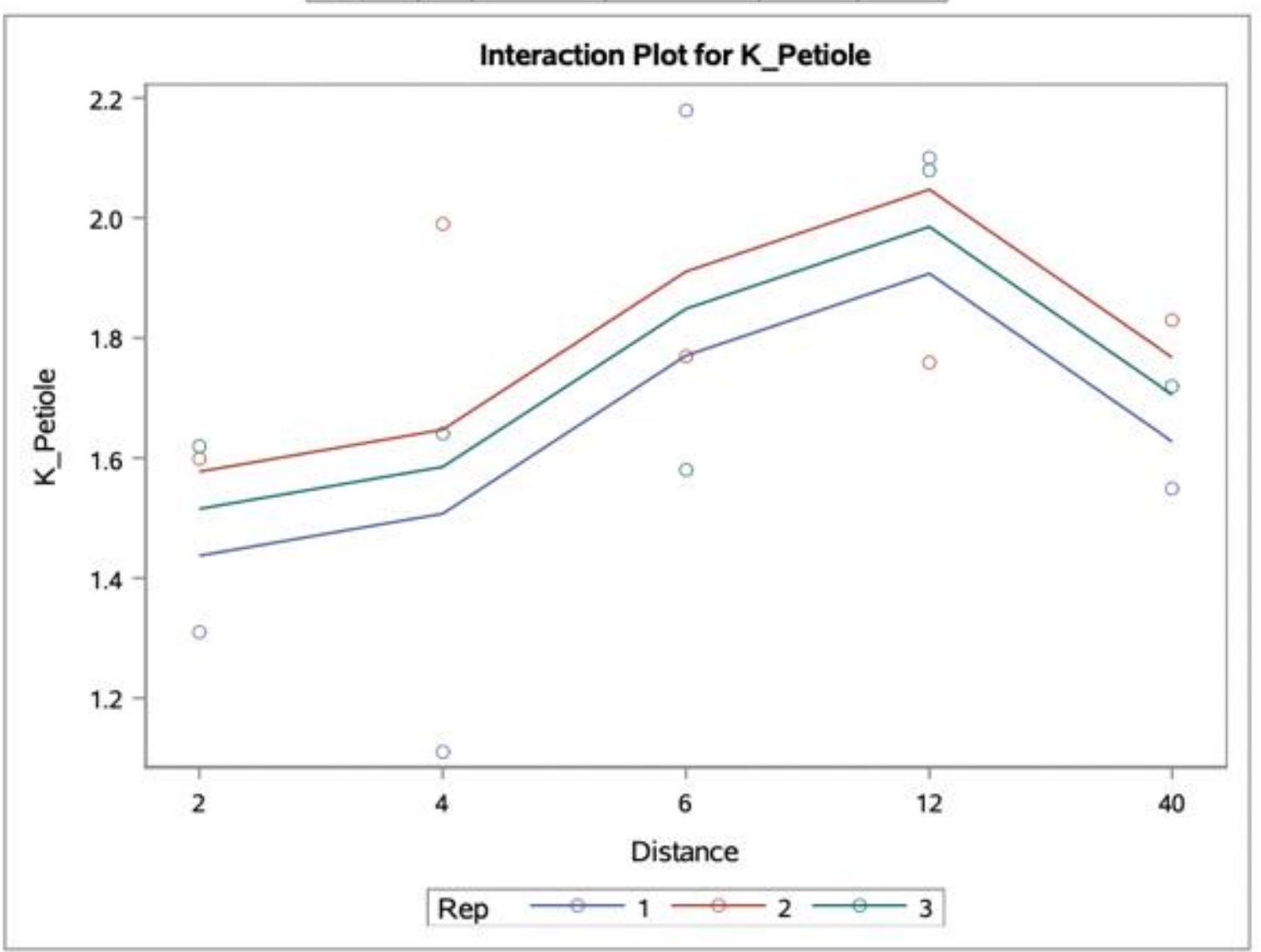


The GLM Procedure

Least Squares Means

\begin{tabular}{|l|r|r|r|r|}
\hline Distance & $\begin{array}{r}\text { K_Petiole } \\
\text { LSMEAN }\end{array}$ & $\begin{array}{r}\text { Standard } \\
\text { Error }\end{array}$ & $\operatorname{Pr}>\mid \mathbf{| t |}$ & $\begin{array}{r}\text { LSMEAN } \\
\text { Number }\end{array}$ \\
\hline $\mathbf{2}$ & 1.51000000 & 0.17130058 & $<.0001$ & 1 \\
\hline $\mathbf{4}$ & 1.58000000 & 0.17130058 & $<.0001$ & 2 \\
\hline $\mathbf{6}$ & 1.84333333 & 0.17130058 & $<.0001$ & 3 \\
\hline $\mathbf{1 2}$ & 1.98000000 & 0.17130058 & $<.0001$ & 4 \\
\hline $\mathbf{4 0}$ & 1.70000000 & 0.17130058 & $<.0001$ & 5 \\
\hline
\end{tabular}

\begin{tabular}{|l|r|r|r|r|r|}
\hline \multicolumn{7}{|c|}{$\begin{array}{c}\text { Least Squares Means for effect Distance } \\
\text { Pr > | |4 for H0: LSMean(i)=LSMean(j) } \\
\text { Dependent Variable: K_Petiole }\end{array}$} \\
\hline i/j & $\mathbf{1}$ & $\mathbf{2}$ & $\mathbf{3}$ & $\mathbf{4}$ & $\mathbf{5}$ \\
\hline $\mathbf{1}$ & & 0.7800 & 0.2061 & 0.0883 & 0.4555 \\
\hline $\mathbf{2}$ & 0.7800 & & 0.3087 & 0.1373 & 0.6337 \\
\hline $\mathbf{3}$ & 0.2061 & 0.3087 & & 0.5881 & 0.5704 \\
\hline $\mathbf{4}$ & 0.0883 & 0.1373 & 0.5881 & & 0.2811 \\
\hline $\mathbf{5}$ & 0.4555 & 0.6337 & 0.5704 & 0.2811 & \\
\hline
\end{tabular}

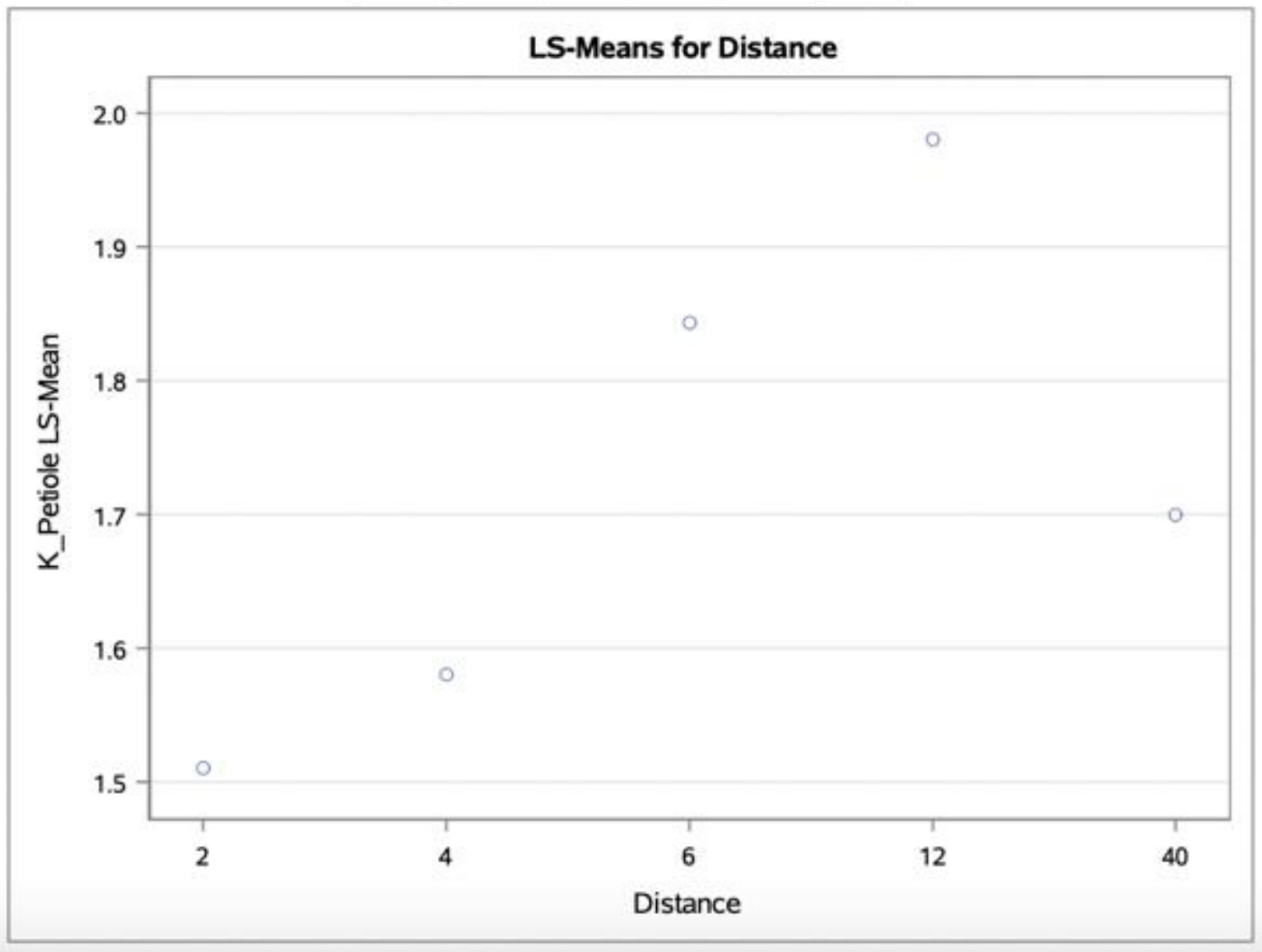


K_Petiole T Grouping for LS-Means of Distance $($ Alpha $=0.05)$

LS-means covered by the same bar are not significantly different.

\section{Distance Estimate}

12

1.9800

6

1.8433

40

1.7000

4

1.5800

2

1.5100

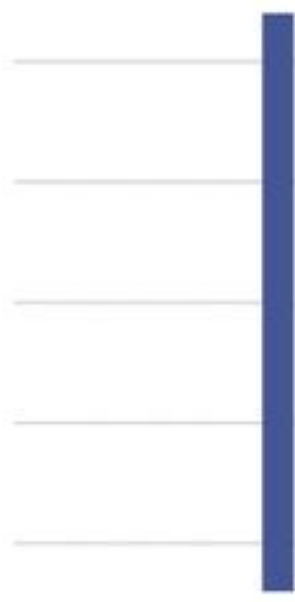

The UNIVARIATE Procedure

Variable: $\mathbf{R}$

\begin{tabular}{|l|r|l|r|}
\hline \multicolumn{4}{|c|}{ Moments } \\
\hline N & 15 & Sum Weights & 15 \\
\hline Mean & 0 & Sum Observations & 0 \\
\hline Std Deviation & 0.22428511 & Variance & 0.05030381 \\
\hline Skewness & 0.0528765 & Kurtosis & -0.2470865 \\
\hline Uncorrected SS & 0.70425333 & Corrected SS & 0.70425333 \\
\hline Coeff Variation & & Std Error Mean & 0.05791017 \\
\hline
\end{tabular}




\begin{tabular}{|l|l|l|l|r|}
\hline \multicolumn{5}{|c|}{ Tests for Normality } \\
\hline Test & \multicolumn{2}{|c|}{ Statistic } & \multicolumn{2}{c|}{ p Value } \\
\hline Shapiro-Wilk & W & 0.975833 & Pr $<$ W & 0.9331 \\
\hline Kolmogorov-Smirnov & D & 0.126069 & Pr $>$ D & $>0.1500$ \\
\hline Cramer-von Mises & W-Sq & 0.032151 & Pr $>$ W-Sq & $>0.2500$ \\
\hline Anderson-Darling & A-Sq & 0.200378 & Pr $>$ A-Sq & $>0.2500$ \\
\hline
\end{tabular}

The UNIVARIATE Procedure

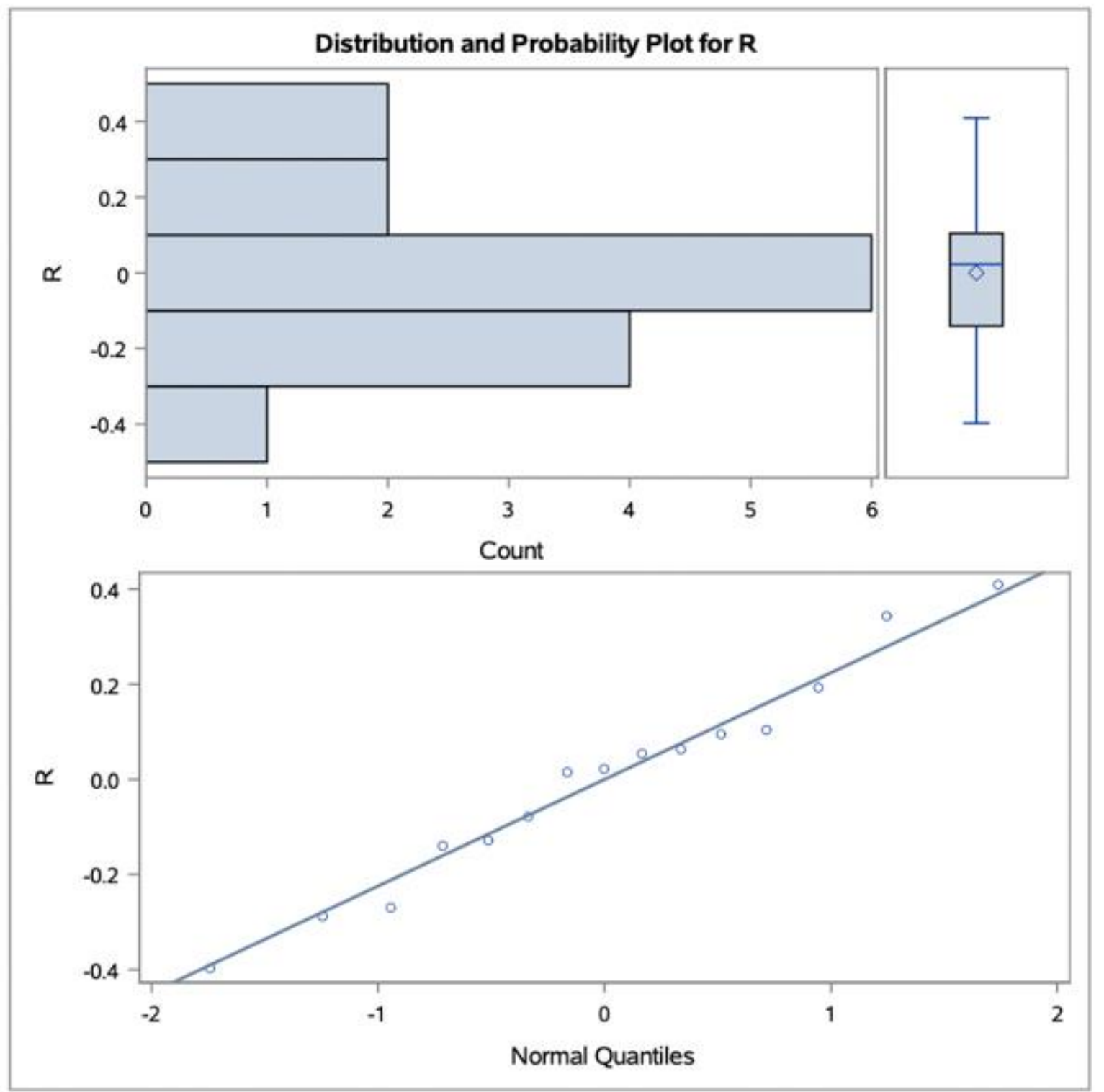


Table 20. SAS output for the variable leaf blade magnesium

\section{Foliars Data}

Mg_Leaf

The GLM Procedure

Dependent Variable: Mg_Leaf Mg_Leaf

\begin{tabular}{|l|r|r|r|r|r|}
\hline Source & DF & $\begin{array}{r}\text { Sum of } \\
\text { Squares }\end{array}$ & Mean Square & F Value & Pr $>$ F \\
\hline Model & 6 & 0.30289333 & 0.05048222 & 1.44 & 0.3075 \\
\hline Error & 8 & 0.27988000 & 0.03498500 & & \\
\hline Corrected Total & 14 & 0.58277333 & & & \\
\hline
\end{tabular}

\begin{tabular}{|l|r|r|r|r|r|}
\hline Source & DF & Type III SS & Mean Square & F Value & Pr $>$ F \\
\hline Distance & 4 & 0.20704000 & 0.05176000 & 1.48 & 0.2948 \\
\hline Rep & 2 & 0.09585333 & 0.04792667 & 1.37 & 0.3079 \\
\hline
\end{tabular}

Interaction Plot for Mg_Leaf


The GLM Procedure

Least Squares Means

\begin{tabular}{|l|r|r|r|r|}
\hline Distance & $\begin{array}{r}\text { Mg_Leaf } \\
\text { LSMEAN }\end{array}$ & $\begin{array}{r}\text { Standard } \\
\text { Error }\end{array}$ & Pr > |t| & $\begin{array}{r}\text { LSMEAN } \\
\text { Number }\end{array}$ \\
\hline 2 & 0.32333333 & 0.10798920 & 0.0172 & 1 \\
\hline 4 & 0.39666667 & 0.10798920 & 0.0063 & 2 \\
\hline 6 & 0.13666667 & 0.10798920 & 0.2413 & 3 \\
\hline 12 & 0.14666667 & 0.10798920 & 0.2115 & 4 \\
\hline 40 & 0.40333333 & 0.10798920 & 0.0057 & 5 \\
\hline
\end{tabular}

\begin{tabular}{|l|r|r|r|r|r|}
\hline \multicolumn{7}{|c|}{$\begin{array}{c}\text { Least Squares Means for effect Distance } \\
\text { Pr }>\text { |t for H0: LSMean(i)=LSMean(j) }\end{array}$} \\
Dependent Variable: Mg_Leaf \\
\hline i/j & $\mathbf{1}$ & $\mathbf{2}$ & $\mathbf{3}$ & $\mathbf{4}$ & $\mathbf{5}$ \\
\hline $\mathbf{1}$ & & 0.6440 & 0.2564 & 0.2807 & 0.6146 \\
\hline $\mathbf{2}$ & 0.6440 & & 0.1271 & 0.1403 & 0.9663 \\
\hline $\mathbf{3}$ & 0.2564 & 0.1271 & & 0.9494 & 0.1189 \\
\hline $\mathbf{4}$ & 0.2807 & 0.1403 & 0.9494 & & 0.1313 \\
\hline $\mathbf{5}$ & 0.6146 & 0.9663 & 0.1189 & 0.1313 & \\
\hline
\end{tabular}

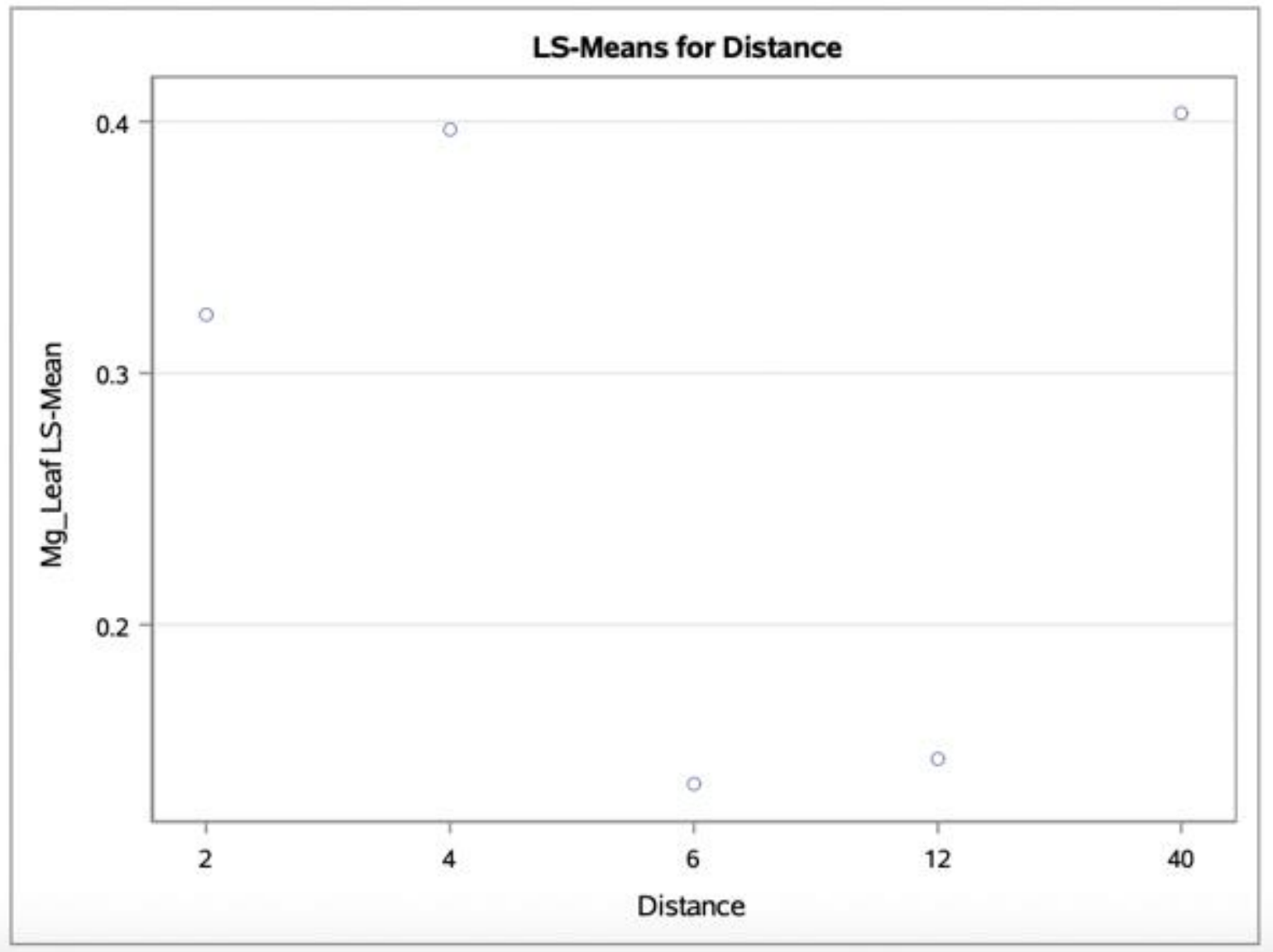




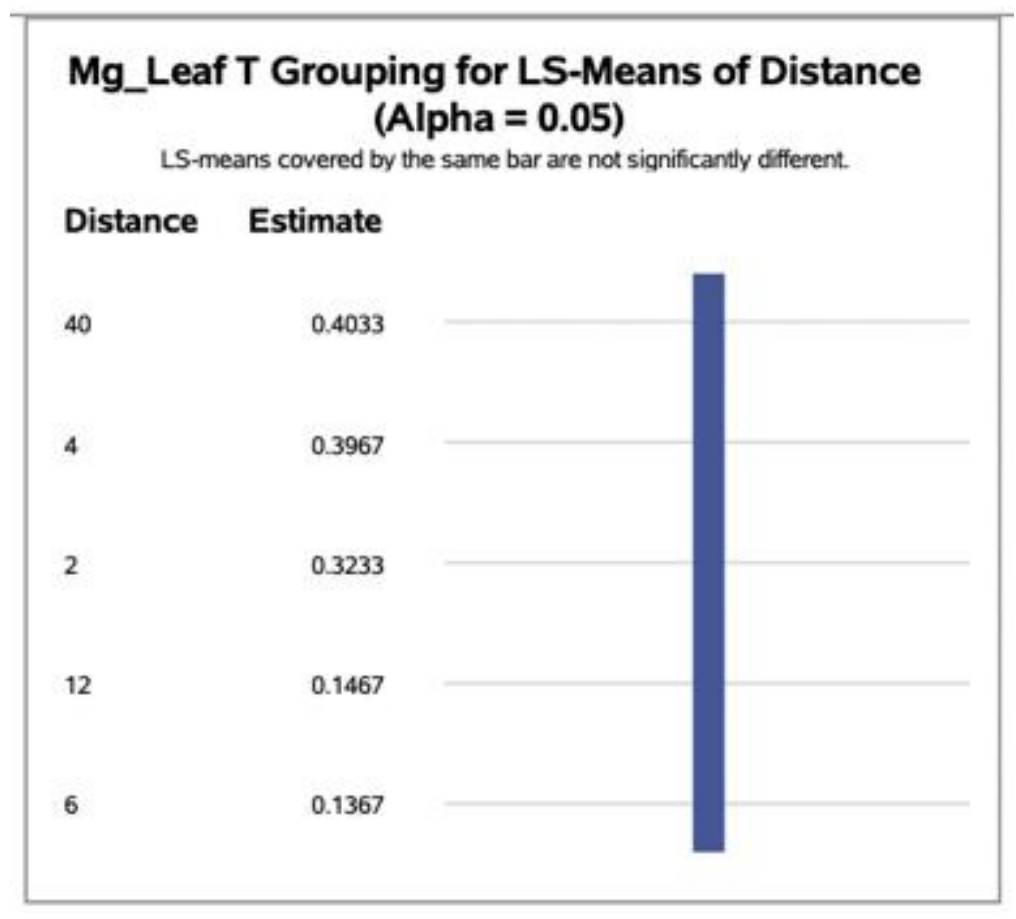

The UNIVARIATE Procedure

Variable: $\mathbf{R}$

\begin{tabular}{|l|r|l|r|}
\hline \multicolumn{4}{|c|}{ Moments } \\
\hline N & 15 & Sum Weights & 15 \\
\hline Mean & 0 & Sum Observations & 0 \\
\hline Std Deviation & 0.14139105 & Variance & 0.01999143 \\
\hline Skewness & -0.3433167 & Kurtosis & 0.01115963 \\
\hline Uncorrected SS & 0.27988 & Corrected SS & 0.27988 \\
\hline Coeff Variation & & Std Error Mean & 0.03650701 \\
\hline
\end{tabular}

\begin{tabular}{|l|l|l|l|r|}
\hline \multicolumn{5}{|c|}{ Tests for Normality } \\
\hline Test & \multicolumn{2}{|c|}{ Statistic } & \multicolumn{2}{c|}{ p Value } \\
\hline Shapiro-Wilk & W & 0.979295 & Pr $<$ W & 0.9645 \\
\hline Kolmogorov-Smirnov & D & 0.127391 & Pr $>$ D & $>0.1500$ \\
\hline Cramer-von Mises & W-Sq & 0.029274 & Pr $>$ W-Sq & $>0.2500$ \\
\hline Anderson-Darling & A-Sq & 0.177826 & Pr $>$ A-Sq & $>0.2500$ \\
\hline
\end{tabular}


The UNIVARIATE Procedure

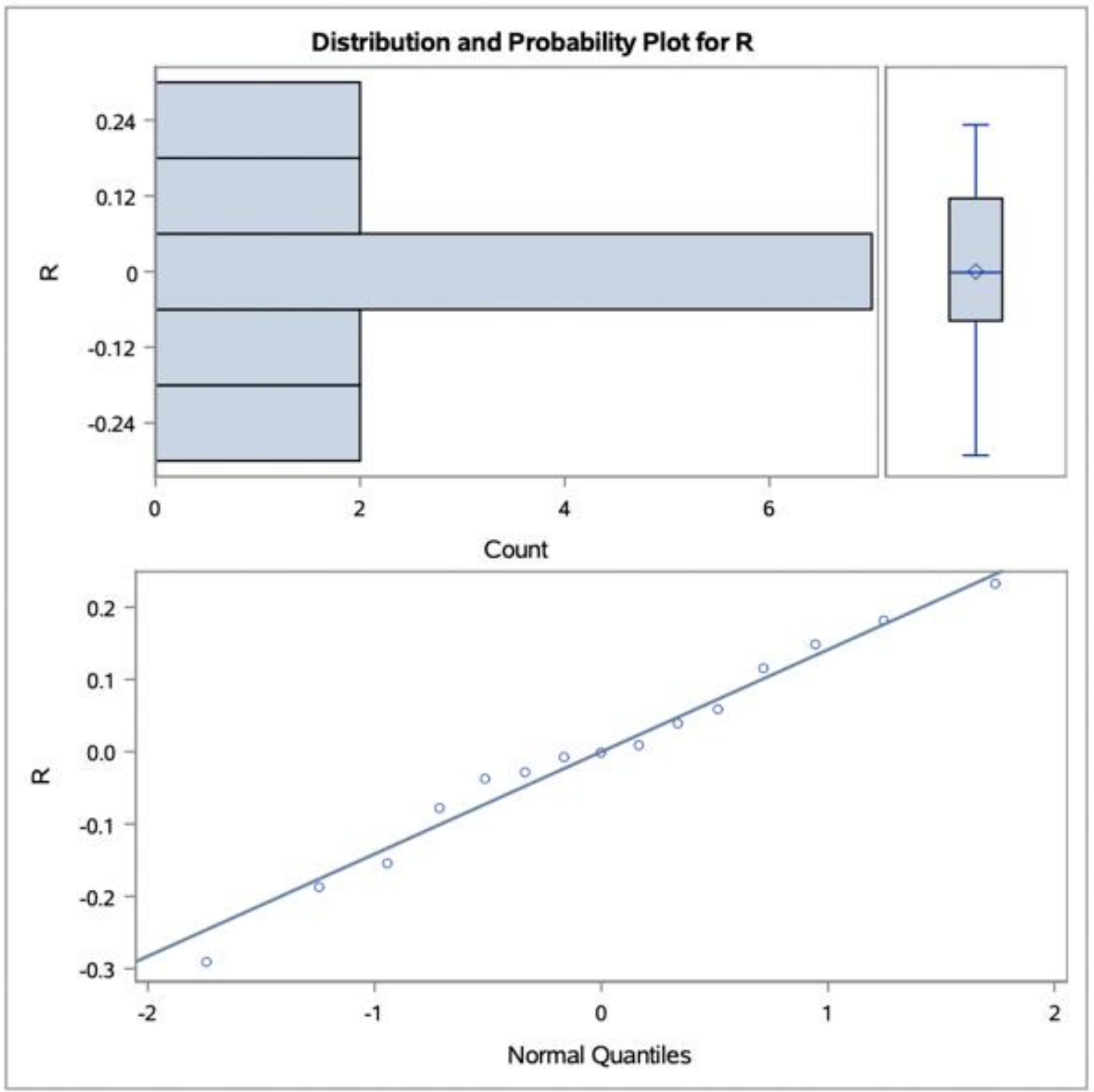


Table 21. SAS output for the variable petiole magnesium

Foliars Data

Mg_Petiole

The GLM Procedure

Dependent Variable: Mg_Petiole Mg_Petiole

\begin{tabular}{|l|r|r|r|r|r|}
\hline Source & DF & $\begin{array}{r}\text { Sum of } \\
\text { Squares }\end{array}$ & Mean Square & F Value & Pr $>$ F \\
\hline Model & 6 & 0.27729333 & 0.04621556 & 0.58 & 0.7380 \\
\hline Error & 8 & 0.63668000 & 0.07958500 & & \\
\hline Corrected Total & 14 & 0.91397333 & & & \\
\hline
\end{tabular}

\begin{tabular}{|l|r|r|r|r|r|}
\hline Source & DF & Type III SS & Mean Square & F Value & Pr $>$ F \\
\hline Distance & 4 & 0.24464000 & 0.06116000 & 0.77 & 0.5748 \\
\hline Rep & 2 & 0.03265333 & 0.01632667 & 0.21 & 0.8187 \\
\hline
\end{tabular}

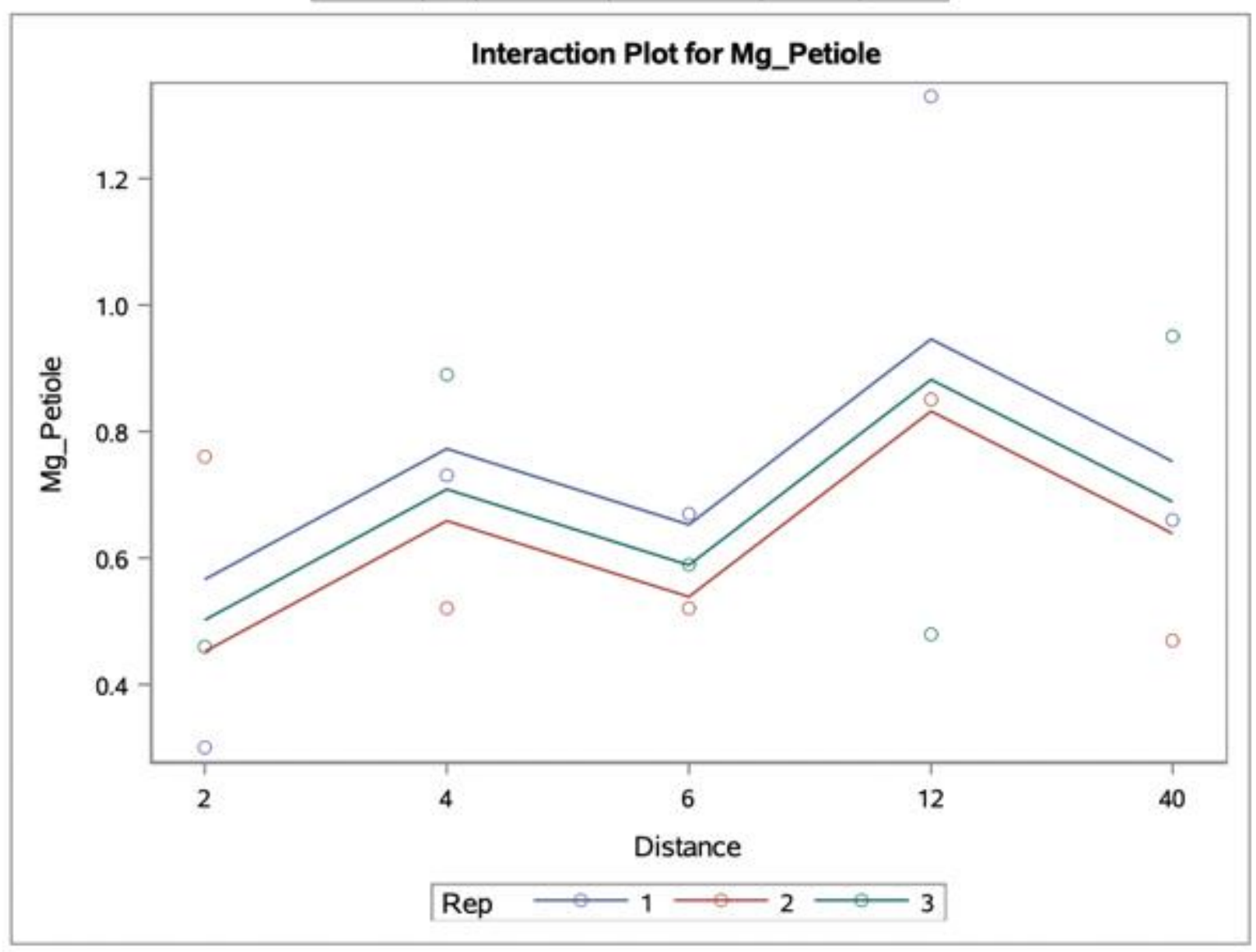


The GLM Procedure

Least Squares Means

\begin{tabular}{|l|r|r|r|r|}
\hline Distance & $\begin{array}{r}\text { Mg_Petiole } \\
\text { LSMEAN }\end{array}$ & $\begin{array}{r}\text { Standard } \\
\text { Error }\end{array}$ & $\operatorname{Pr}^{>} \mathbf{| t |}$ & $\begin{array}{r}\text { LSMEAN } \\
\text { Number }\end{array}$ \\
\hline $\mathbf{2}$ & 0.50666667 & 0.16287521 & 0.0144 & 1 \\
\hline $\mathbf{4}$ & 0.71333333 & 0.16287521 & 0.0023 & 2 \\
\hline $\mathbf{6}$ & 0.59333333 & 0.16287521 & 0.0066 & 3 \\
\hline 12 & 0.88666667 & 0.16287521 & 0.0006 & 4 \\
\hline 40 & 0.69333333 & 0.16287521 & 0.0028 & 5 \\
\hline
\end{tabular}

\begin{tabular}{|l|r|r|r|r|r|}
\hline \multicolumn{7}{|c|}{$\begin{array}{c}\text { Least Squares Means for effect Distance } \\
\text { Pr }>\text { 14 for H0: LSMean(1)=LSMean() } \\
\text { Dependent Variable: Mg_Petiole }\end{array}$} \\
\hline ij & $\mathbf{1}$ & $\mathbf{2}$ & $\mathbf{3}$ & $\mathbf{4}$ & $\mathbf{5}$ \\
\hline $\mathbf{1}$ & & 0.3958 & 0.7165 & 0.1376 & 0.4412 \\
\hline $\mathbf{2}$ & 0.3958 & & 0.6165 & 0.4733 & 0.9329 \\
\hline $\mathbf{3}$ & 0.7165 & 0.6165 & & 0.2386 & 0.6757 \\
\hline $\mathbf{4}$ & 0.1376 & 0.4733 & 0.2386 & & 0.4256 \\
\hline $\mathbf{5}$ & 0.4412 & 0.9329 & 0.6757 & 0.4256 & \\
\hline
\end{tabular}

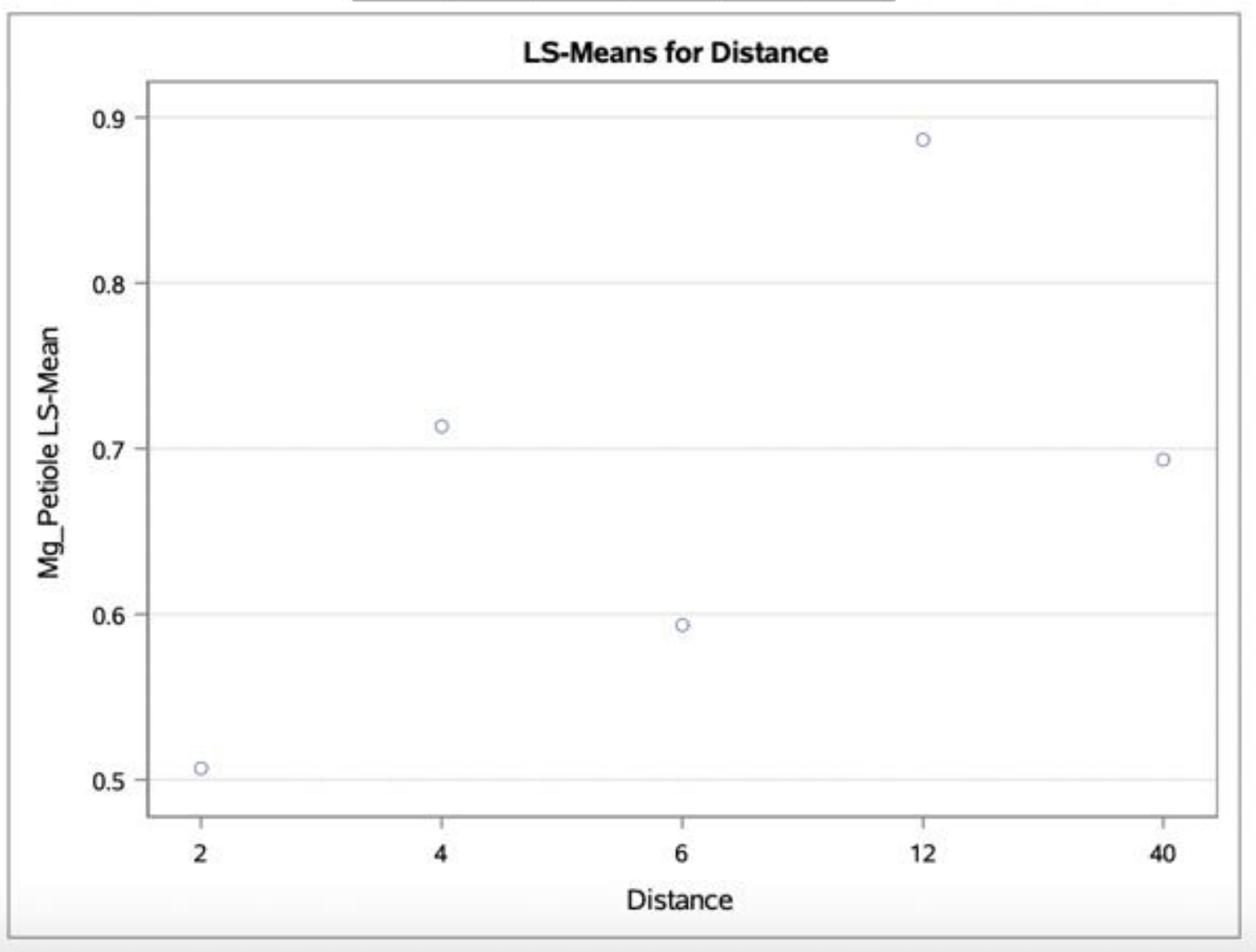




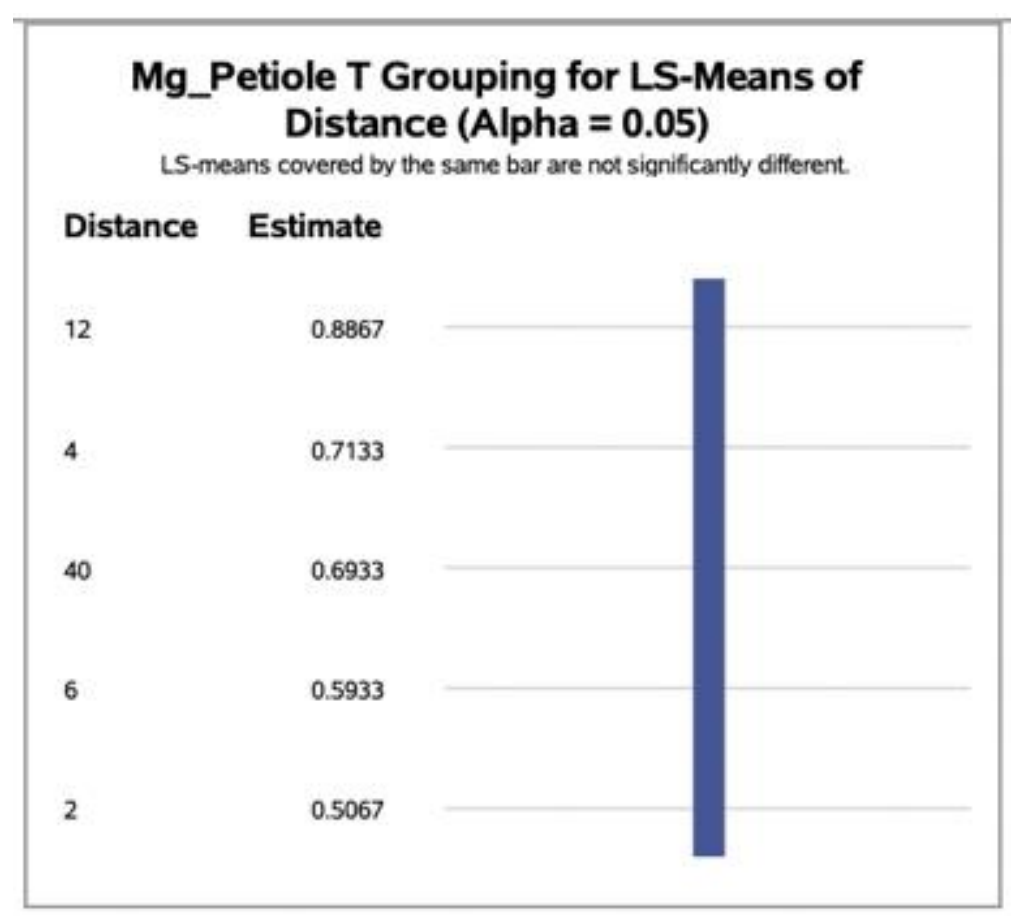

The UNIVARIATE Procedure

Variable: $\mathbf{R}$

\begin{tabular}{|l|r|l|r|}
\hline \multicolumn{4}{|c|}{ Moments } \\
\hline N & 15 & Sum Weights & 15 \\
\hline Mean & 0 & Sum Observations & 0 \\
\hline Std Deviation & 0.21325371 & Variance & 0.04547714 \\
\hline Skewness & 0.14836311 & Kurtosis & -0.1099115 \\
\hline Uncorrected SS & 0.63668 & Corrected SS & 0.63668 \\
\hline Coeff Variation & & Std Error Mean & 0.05506187 \\
\hline
\end{tabular}

\begin{tabular}{|l|l|r|l|r|}
\hline \multicolumn{5}{|c|}{ Tests for Normality } \\
\hline Test & \multicolumn{2}{|c|}{ Statistic } & \multicolumn{2}{c|}{ P Value } \\
\hline Shapiro-Wilk & W & 0.965529 & Pr $<$ W & 0.7872 \\
\hline Kolmogorov-Smirnov & D & 0.1997 & Pr $>$ D & 0.1042 \\
\hline Cramer-von Mises & W-Sq & 0.060897 & Pr $>$ W-Sq & $>0.2500$ \\
\hline Anderson-Darling & A-Sq & 0.314824 & Pr $>$ A-Sq & $>0.2500$ \\
\hline
\end{tabular}


The UNIVARIATE Procedure

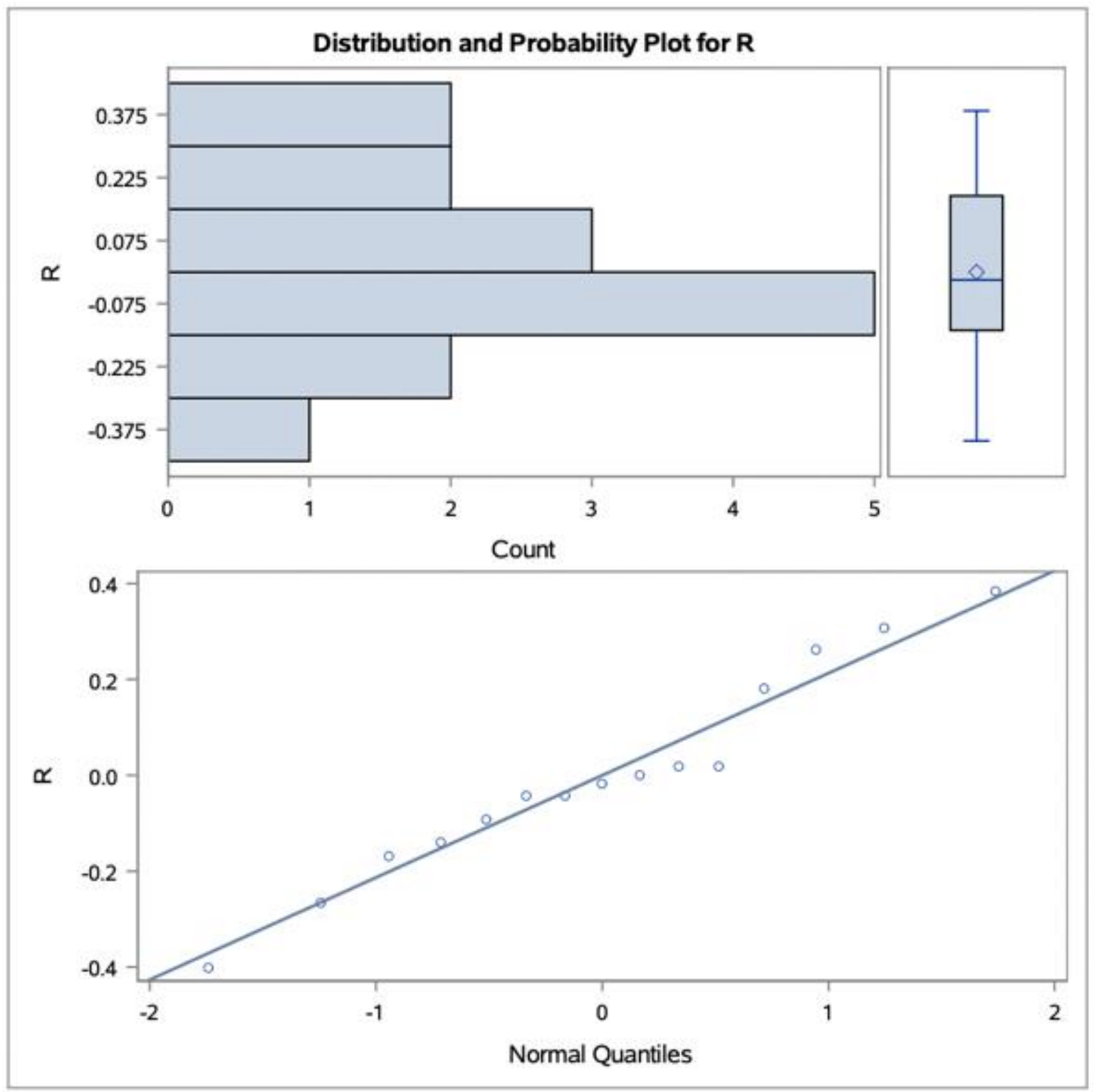




\section{APPENDIX G}

\section{SAS STATISTICAL OUTPUT USING THE GLIMMIX PROCEDURE}

Table 1. SAS output for the variable total vine yield $(\mathrm{kg})$

Yield Data

Yield_of_Vine_kg

The GLIMMIX Procedure

\begin{tabular}{|l|l|}
\hline \multicolumn{2}{|c|}{ Model Information } \\
\hline Data Set & WORK.YIELD \\
\hline Response Variable & Yield_of_Vine_kg \\
\hline Response Distribution & Gaussian \\
\hline Link Function & Identity \\
\hline Variance Function & Default \\
\hline Variance Matrix & Not blocked \\
\hline Estimation Technique & Restricted Maximum Likelihood \\
\hline Degrees of Freedom Method & Containment \\
\hline
\end{tabular}

\begin{tabular}{|l|r|l|}
\hline \multicolumn{3}{|c|}{ Class Level Information } \\
\hline Class & Levels & Values \\
\hline Distance & 5 & 2461240 \\
\hline Rep & 3 & 123 \\
\hline
\end{tabular}

\begin{tabular}{|l|l|}
\hline Number of Observations Read & 75 \\
\hline Number of Observations Used & 75 \\
\hline
\end{tabular}




\begin{tabular}{|l|r|}
\hline \multicolumn{2}{|c|}{ Dimensions } \\
\hline G-side Cov. Parameters & 1 \\
\hline R-side Cov. Parameters & 1 \\
\hline Columns in X & 6 \\
\hline Columns in Z & 3 \\
\hline Subjects (Blocks in V) & 1 \\
\hline Max Obs per Subject & 75 \\
\hline
\end{tabular}

\begin{tabular}{|l|l|}
\hline \multicolumn{2}{|c|}{ Optimization Information } \\
\hline Optimization Technique & Dual Quasi-Newton \\
\hline Parameters in Optimization & 1 \\
\hline Lower Boundaries & 1 \\
\hline Upper Boundaries & 0 \\
\hline Fixed Effects & Profled \\
\hline Residual Variance & Profled \\
\hline Starting From & Data \\
\hline
\end{tabular}

\begin{tabular}{|l|r|r|r|r|}
\hline \multicolumn{5}{|c|}{ Type III Tests of Fixed Effects } \\
\hline Effect & $\begin{array}{r}\text { Num } \\
\text { DF }\end{array}$ & $\begin{array}{r}\text { Den } \\
\text { DF }\end{array}$ & F Value & Pr > F \\
\hline Distance & 4 & 68 & 6.60 & 0.0002 \\
\hline
\end{tabular}

\begin{tabular}{|l|r|r|r|r|r|}
\hline \multicolumn{7}{|c|}{ Distance Least Squares Means } \\
\hline Distance & Estimate & $\begin{array}{r}\text { Standard } \\
\text { Error }\end{array}$ & DF & $t$ Value & $\operatorname{Pr}>|t|$ \\
\hline 2 & 1.1333 & 0.1636 & 68 & 6.93 & $<.0001$ \\
\hline 4 & 1.5533 & 0.1636 & 68 & 9.50 & $<.0001$ \\
\hline 6 & 1.8133 & 0.1636 & 68 & 11.09 & $<.0001$ \\
\hline 12 & 1.4733 & 0.1636 & 68 & 9.01 & $<.0001$ \\
\hline 40 & 2.2600 & 0.1636 & 68 & 13.82 & $<.0001$ \\
\hline
\end{tabular}


The GLIMMIX Procedure

\begin{tabular}{|l|l|r|r|r|r|r|}
\hline \multicolumn{7}{|c|}{ Differences of Distance Least Squares Means } \\
\hline Distance & Distance & Estimate & $\begin{array}{r}\text { Standard } \\
\text { Error }\end{array}$ & DF & $t$ Value & Pr > It \\
\hline 2 & 4 & -0.4200 & 0.2313 & 68 & -1.82 & 0.0738 \\
\hline 2 & 6 & -0.6800 & 0.2313 & 68 & -2.94 & 0.0045 \\
\hline 2 & 12 & -0.3400 & 0.2313 & 68 & -1.47 & 0.1462 \\
\hline 2 & 40 & -1.1267 & 0.2313 & 68 & -4.87 & $<.0001$ \\
\hline 4 & 6 & -0.2600 & 0.2313 & 68 & -1.12 & 0.2650 \\
\hline 4 & 12 & 0.08000 & 0.2313 & 68 & 0.35 & 0.7305 \\
\hline 4 & 40 & -0.7067 & 0.2313 & 68 & -3.05 & 0.0032 \\
\hline 6 & 12 & 0.3400 & 0.2313 & 68 & 1.47 & 0.1462 \\
\hline 6 & 40 & -0.4467 & 0.2313 & 68 & -1.93 & 0.0577 \\
\hline 12 & 40 & -0.7867 & 0.2313 & 68 & -3.40 & 0.0011 \\
\hline
\end{tabular}

\begin{tabular}{|l|r|l|l|}
\hline \multicolumn{4}{|c|}{$\begin{array}{c}\text { T Grouping for Distance Least } \\
\text { Squares Means (Alpha=0.05) }\end{array}$} \\
\hline $\begin{array}{l}\text { LS-means with the same letter } \\
\text { are not significantly different. }\end{array}$ \\
\hline Distance & Estimate & \\
\hline 40 & 2.2600 & & A \\
\hline & & & A \\
\hline 6 & 1.8133 & B & A \\
\hline & & B & \\
\hline 4 & 1.5533 & B & C \\
\hline & & B & C \\
\hline 12 & 1.4733 & B & C \\
\hline & & & C \\
\hline 2 & 1.1333 & & C \\
\hline
\end{tabular}


The UNIVARIATE Procedure

Variable: R (Residual)

\begin{tabular}{|l|r|l|r|}
\hline \multicolumn{4}{|c|}{ Moments } \\
\hline $\mathrm{N}$ & 75 & Sum Weights & 75 \\
\hline Mean & 0 & Sum Observations & 0 \\
\hline Std Deviation & 0.61614904 & Variance & 0.37963964 \\
\hline Skewness & 0.17742335 & Kurtosis & 0.22497986 \\
\hline Uncorrected SS & 28.0933333 & Corrected SS & 28.0933333 \\
\hline Coeff Variation & & Std Error Mean & 0.07114676 \\
\hline
\end{tabular}




\begin{tabular}{|l|l|l|l|r|}
\hline \multicolumn{5}{|c|}{ Tests for Normality } \\
\hline Test & \multicolumn{2}{|c|}{ Statistic } & \multicolumn{2}{c|}{ p Value } \\
\hline Shapiro-Wilk & W & 0.985545 & Pr $<$ W & 0.5527 \\
\hline Kolmogorov-Smirnov & D & 0.078265 & Pr $>$ D & $>0.1500$ \\
\hline Cramer-von Mises & W-Sq & 0.071154 & Pr $>$ W-Sq & $>0.2500$ \\
\hline Anderson-Darling & A-Sq & 0.405008 & Pr $>$ A-Sq & $>0.2500$ \\
\hline
\end{tabular}

The UNIVARIATE Procedure

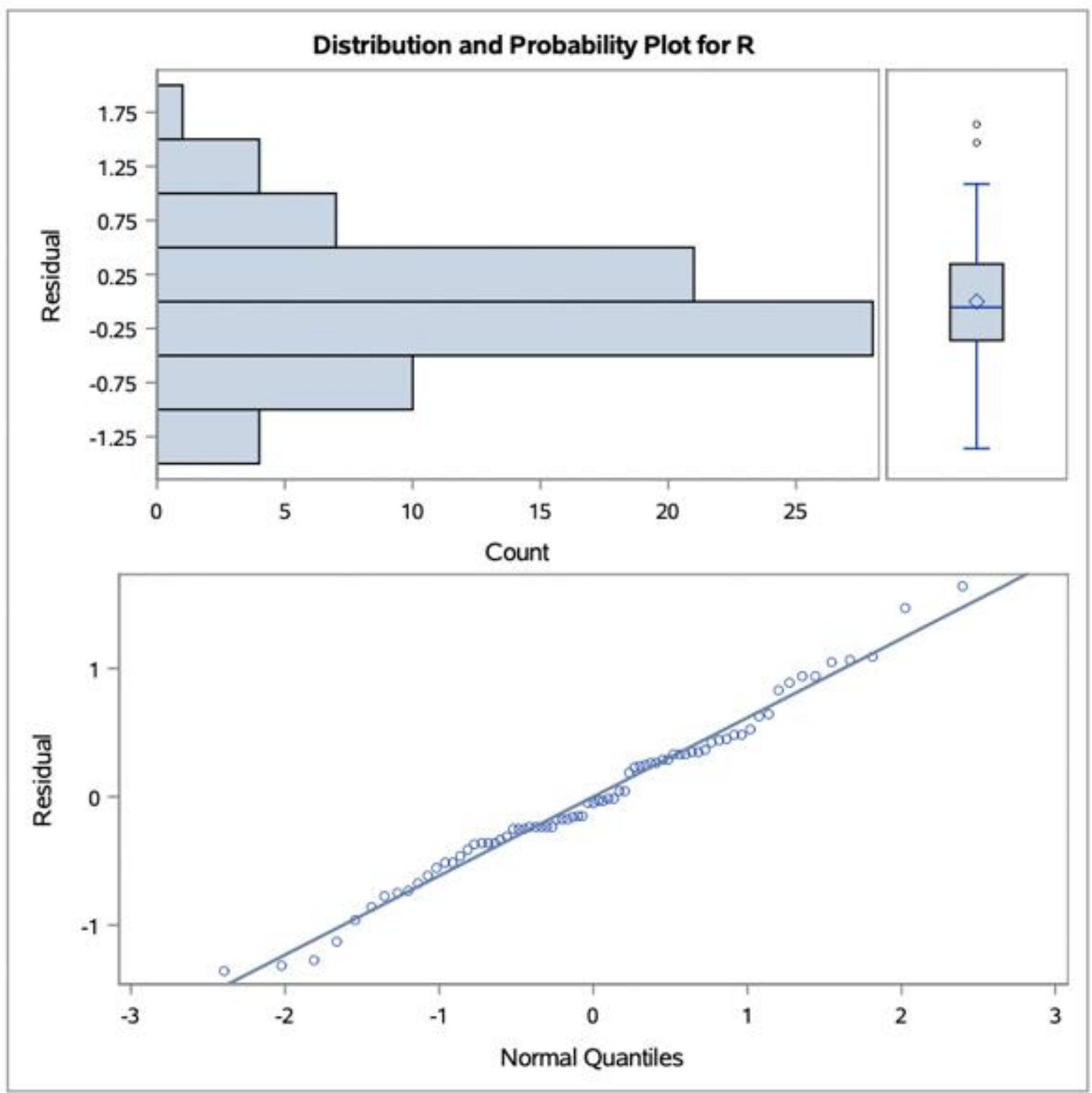


Table 2. SAS output for the variable pruning weight $(\mathrm{g} / \mathrm{m})$

Yield Data

\section{Pruning_Weight_g}

\section{The GLIMMIX Procedure}

\begin{tabular}{|r|r|r|r|r|r|}
\hline \multicolumn{5}{|c|}{ Iteration History } \\
\hline Iteration & Restarts & Evaluations & $\begin{array}{r}\text { Objective } \\
\text { Function }\end{array}$ & Change & $\begin{array}{r}\text { Max } \\
\text { Gradient }\end{array}$ \\
\hline 0 & 0 & 4 & 876.38335183 & & 0 \\
\hline
\end{tabular}

Convergence criterion ( $A B S G C O N V=0.00001$ ) satisfied.

Estimated G matrix is not positive definite.

\begin{tabular}{|l|r|}
\hline \multicolumn{2}{|c|}{ Fit Statistics } \\
\hline-2 Res Log Likelihood & 876.38 \\
\hline AIC (smaller is better) & 878.38 \\
\hline AICC (smaller is better) & 878.44 \\
\hline BIC (smaller is better) & 877.48 \\
\hline CAIC (smaller is better) & 878.48 \\
\hline HQIC (smaller is better) & 876.57 \\
\hline Generalized Chi-Square & 924444.4 \\
\hline Gener. Chi-Square / DF & 13206.35 \\
\hline
\end{tabular}

Covariance Parameter Estimates

\begin{tabular}{|l|r|r|}
\hline Cov Parm & Estimate & $\begin{array}{r}\text { Standard } \\
\text { Error }\end{array}$ \\
\hline Rep & 0 & \\
\hline Residual & 13206 & 2232.28 \\
\hline
\end{tabular}

Type III Tests of Fixed Effects

\begin{tabular}{|l|r|r|r|r|}
\hline Effect & $\begin{array}{r}\text { Num } \\
\text { DF }\end{array}$ & $\begin{array}{r}\text { Den } \\
\text { DF }\end{array}$ & F Value & Pr > F \\
\hline Distance & 4 & 68 & 4.12 & 0.0048 \\
\hline
\end{tabular}

\begin{tabular}{|l|r|r|r|r|r|}
\hline \multicolumn{7}{|c|}{ Distance Least Squares Means } \\
\hline Distance & Estimate & $\begin{array}{r}\text { Standard } \\
\text { Error }\end{array}$ & DF & $t$ Value & Pr $>$ It \\
\hline 2 & 249.13 & 29.6719 & 68 & 8.40 & $<.0001$ \\
\hline 4 & 282.27 & 29.6719 & 68 & 9.51 & $<.0001$ \\
\hline 6 & 323.00 & 29.6719 & 68 & 10.89 & $<.0001$ \\
\hline 12 & 209.53 & 29.6719 & 68 & 7.06 & $<.0001$ \\
\hline 40 & 363.00 & 29.6719 & 68 & 12.23 & $<.0001$ \\
\hline & & & & & \\
\hline
\end{tabular}




\section{The GLIMMIX Procedure}

\begin{tabular}{|l|l|r|r|r|r|r|}
\hline \multicolumn{7}{|c|}{ Differences of Distance Least Squares Means } \\
\hline Distance & Distance & Estimate & $\begin{array}{r}\text { Standard } \\
\text { Error }\end{array}$ & DF & t Value & $\operatorname{Pr}>|t|$ \\
\hline 2 & 4 & -33.1333 & 41.9624 & 68 & -0.79 & 0.4325 \\
\hline 2 & 6 & -73.8667 & 41.9624 & 68 & -1.76 & 0.0829 \\
\hline 2 & 12 & 39.6000 & 41.9624 & 68 & 0.94 & 0.3487 \\
\hline 2 & 40 & -113.87 & 41.9624 & 68 & -2.71 & 0.0084 \\
\hline 4 & 6 & -40.7333 & 41.9624 & 68 & -0.97 & 0.3351 \\
\hline 4 & 12 & 72.7333 & 41.9624 & 68 & 1.73 & 0.0876 \\
\hline 4 & 40 & -80.7333 & 41.9624 & 68 & -1.92 & 0.0585 \\
\hline 6 & 12 & 113.47 & 41.9624 & 68 & 2.70 & 0.0086 \\
\hline 6 & 40 & -40.0000 & 41.9624 & 68 & -0.95 & 0.3438 \\
\hline 12 & 40 & -153.47 & 41.9624 & 68 & -3.66 & 0.0005 \\
\hline
\end{tabular}

\begin{tabular}{|l|r|l|l|l|}
\hline \multicolumn{5}{|c|}{$\begin{array}{c}\text { T Grouping for Distance Least } \\
\text { Squares Means (Alpha=0.05) }\end{array}$} \\
\hline $\begin{array}{c}\text { LS-means with the same letter are } \\
\text { not significantly different. }\end{array}$ \\
\hline Distance & Estimate & \multicolumn{3}{|c|}{} \\
\hline 40 & 363.00 & & A & \\
\hline & & & A & \\
\hline 6 & 323.00 & B & A & \\
\hline & & B & A & \\
\hline 4 & 282.27 & B & A & C \\
\hline & & B & & C \\
\hline 2 & 249.13 & B & & C \\
\hline & & & & C \\
\hline 12 & 209.53 & & & C \\
\hline
\end{tabular}




\begin{tabular}{|l|l|l|l|r|}
\hline \multicolumn{5}{|c|}{ Tests for Normality } \\
\hline Test & \multicolumn{2}{|c|}{ Statistic } & \multicolumn{2}{c|}{ p Value } \\
\hline Shapiro-Wilk & W & 0.973878 & Pr $<$ W & 0.1232 \\
\hline Kolmogorov-Smirnov & D & 0.080434 & Pr $>$ D & $>0.1500$ \\
\hline Cramer-von Mises & W-Sq & 0.087052 & Pr $>$ W-Sq & 0.1698 \\
\hline Anderson-Darling & A-Sq & 0.579945 & Pr $>$ A-Sq & 0.1322 \\
\hline
\end{tabular}

The UNIVARIATE Procedure

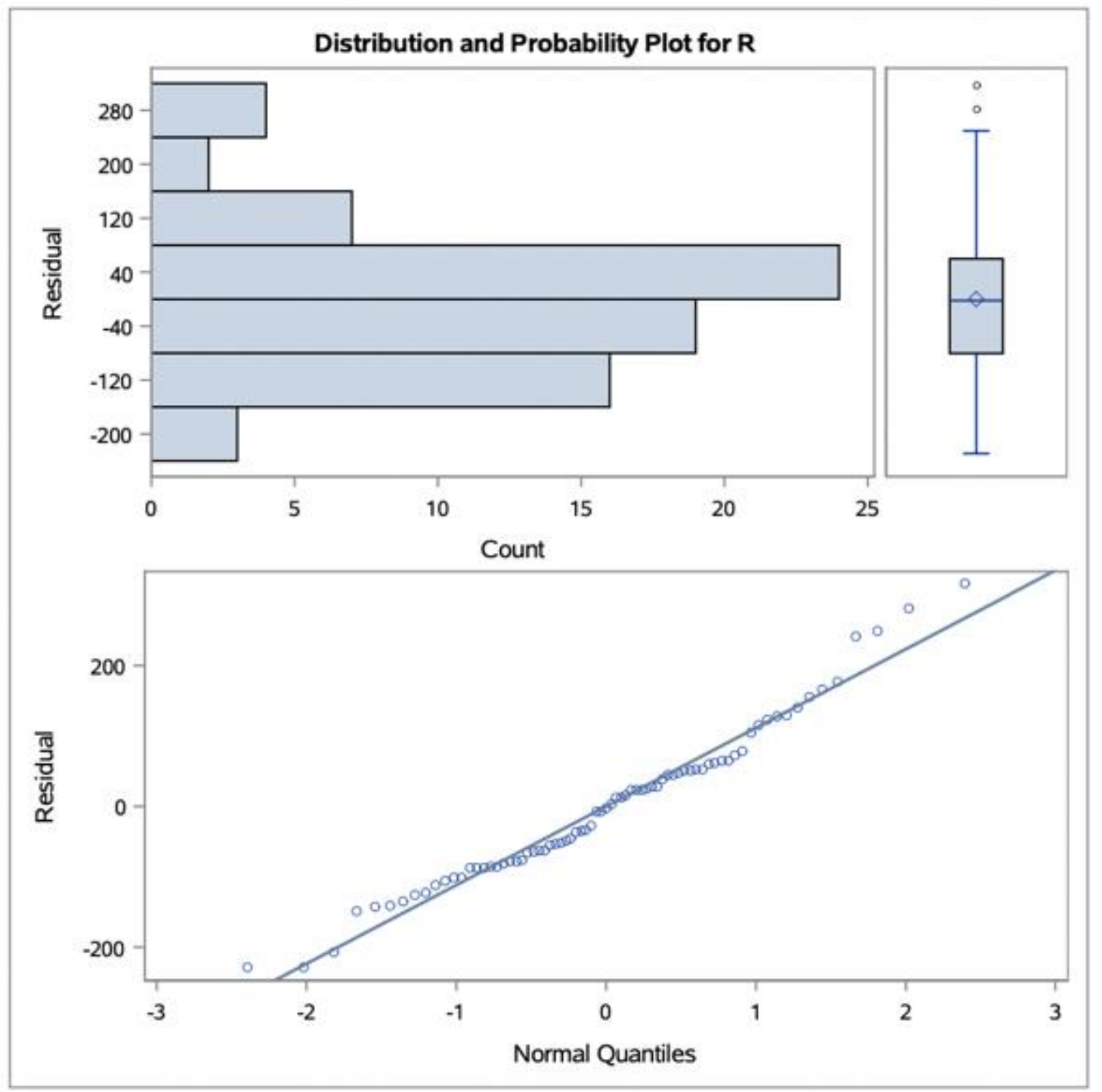


Table 3. SAS output for the variable of vine balance, as measured by the Ravaz Index. For the purpose of this analysis the square root of the Ravaz Index was taken.

Yield Data

Square Root of Ravaz_Index

The GLIMMIX Procedure

\begin{tabular}{|l|l|}
\hline \multicolumn{2}{|c|}{ Model Information } \\
\hline Data Set & WORK.YIELD \\
\hline Response Variable & sqriRavaz \\
\hline Response Distribution & Gaussian \\
\hline Link Function & Identity \\
\hline Variance Function & Default \\
\hline Variance Matrix & Not blocked \\
\hline Estimation Technique & Restricted Maximum Likelihood \\
\hline Degrees of Freedom Method & Containment \\
\hline
\end{tabular}

\begin{tabular}{|l|r|l|}
\hline \multicolumn{3}{|c|}{ Class Level Information } \\
\hline Class & Levels & Values \\
\hline Distance & 5 & 2461240 \\
\hline Rep & 3 & 123 \\
\hline
\end{tabular}

\begin{tabular}{|l|l|}
\hline Number of Observations Read & 75 \\
\hline Number of Observations Used & 75 \\
\hline
\end{tabular}

Number of Observations Used 75

\begin{tabular}{|l|r|}
\hline \multicolumn{2}{|c|}{ Dimensions } \\
\hline G-side Cov. Parameters & 1 \\
\hline R-side Cov. Parameters & 1 \\
\hline Columns in X & 6 \\
\hline Columns in Z & 3 \\
\hline Subjects (Blocks in V) & 1 \\
\hline Max Obs per Subject & 75 \\
\hline
\end{tabular}

Optimization Information

\begin{tabular}{|l|l|}
\hline Optimization Technique & Dual Quasi-Newon \\
\hline Parameters in Optimization & 1 \\
\hline Lower Boundaries & 1 \\
\hline Upper Boundaries & 0 \\
\hline Fixed Effects & Profiled \\
\hline Residual Variance & Profiled \\
\hline Starting From & Data \\
\hline
\end{tabular}




\begin{tabular}{|l|r|r|r|r|r|}
\hline \multicolumn{7}{|c|}{ Distance Least Squares Means } \\
\hline Distance & Estimate & $\begin{array}{r}\text { Standard } \\
\text { Error }\end{array}$ & DF & t Value & Pr > It \\
\hline 2 & 2.2560 & 0.1916 & 68 & 11.77 & $<.0001$ \\
\hline 4 & 2.3806 & 0.1916 & 68 & 12.42 & $<.0001$ \\
\hline 6 & 2.4689 & 0.1916 & 68 & 12.88 & $<.0001$ \\
\hline 12 & 2.7864 & 0.1916 & 68 & 14.54 & $<.0001$ \\
\hline 40 & 2.5293 & 0.1916 & 68 & 13.20 & $<.0001$ \\
\hline
\end{tabular}

The GLIMMIX Procedure

\begin{tabular}{|l|l|r|r|r|r|r|}
\hline \multicolumn{7}{|c|}{ Differences of Distance Least Squares Means } \\
\hline Distance & Distance & Estimate & $\begin{array}{r}\text { Standard } \\
\text { Error }\end{array}$ & DF & $t$ Value & Pr > 14 \\
\hline 2 & 4 & -0.1245 & 0.2710 & 68 & -0.46 & 0.6473 \\
\hline 2 & 6 & -0.2129 & 0.2710 & 68 & -0.79 & 0.4349 \\
\hline 2 & 12 & -0.5303 & 0.2710 & 68 & -1.96 & 0.0545 \\
\hline 2 & 40 & -0.2732 & 0.2710 & 68 & -1.01 & 0.3170 \\
\hline 4 & 6 & -0.08832 & 0.2710 & 68 & -0.33 & 0.7455 \\
\hline 4 & 12 & -0.4058 & 0.2710 & 68 & -1.50 & 0.1390 \\
\hline 4 & 40 & -0.1487 & 0.2710 & 68 & -0.55 & 0.5851 \\
\hline 6 & 12 & -0.3175 & 0.2710 & 68 & -1.17 & 0.2456 \\
\hline 6 & 40 & -0.06035 & 0.2710 & 68 & -0.22 & 0.8244 \\
\hline 12 & 40 & 0.2571 & 0.2710 & 68 & 0.95 & 0.3462 \\
\hline
\end{tabular}

\begin{tabular}{|l|r|l|}
\hline \multicolumn{2}{|c|}{$\begin{array}{c}\text { T Grouping for Distance } \\
\text { Least Squares Means } \\
\text { (Alpha=0.05) }\end{array}$} \\
\hline $\begin{array}{c}\text { LS-means with the same } \\
\text { letter are not significantly } \\
\text { different. }\end{array}$ \\
\hline Distance & Estimate & \\
\hline 12 & 2.7864 & $\mathrm{~A}$ \\
\hline & 2.5293 & $\mathrm{~A}$ \\
\hline 40 & $\mathrm{~A}$ \\
\hline & $\mathrm{A}$ \\
\hline 6 & 2.4689 & $\mathrm{~A}$ \\
\hline & $\mathrm{A}$ \\
\hline 4 & 2.3806 & $\mathrm{~A}$ \\
\hline & $\mathrm{A}$ \\
\hline & & $\mathrm{A}$ \\
\hline
\end{tabular}


The UNIVARIATE Procedure

Variable: R (Residual)

\begin{tabular}{|l|r|l|r|}
\hline \multicolumn{4}{|c|}{ Moments } \\
\hline $\mathrm{N}$ & 75 & Sum Weights & 75 \\
\hline Mean & 0 & Sum Observations & 0 \\
\hline Std Deviation & 0.72189578 & Variance & 0.52113351 \\
\hline Skewness & 0.24451386 & Kurtosis & 1.6767274 \\
\hline Uncorrected SS & 38.5638798 & Corrected SS & 38.5638798 \\
\hline Coeff Variation & & Std Error Mean & 0.08335734 \\
\hline
\end{tabular}

\begin{tabular}{|l|l|l|l|l|}
\hline \multicolumn{5}{|c|}{ Tests for Normality } \\
\hline Test & \multicolumn{2}{|c|}{ Statistic } & \multicolumn{2}{c|}{ p Value } \\
\hline Shapiro-Wilk & W & 0.97527 & Pr $<$ W & 0.1492 \\
\hline Kolmogorov-Smirnov & D & 0.104405 & $\operatorname{Pr}>$ D & 0.0423 \\
\hline Cramer-von Mises & W-Sq & 0.101747 & Pr $>$ W-Sq & 0.1061 \\
\hline Anderson-Darling & A-Sq & 0.593431 & Pr $>$ A-Sq & 0.1224 \\
\hline
\end{tabular}


The UNIVARIATE Procedure

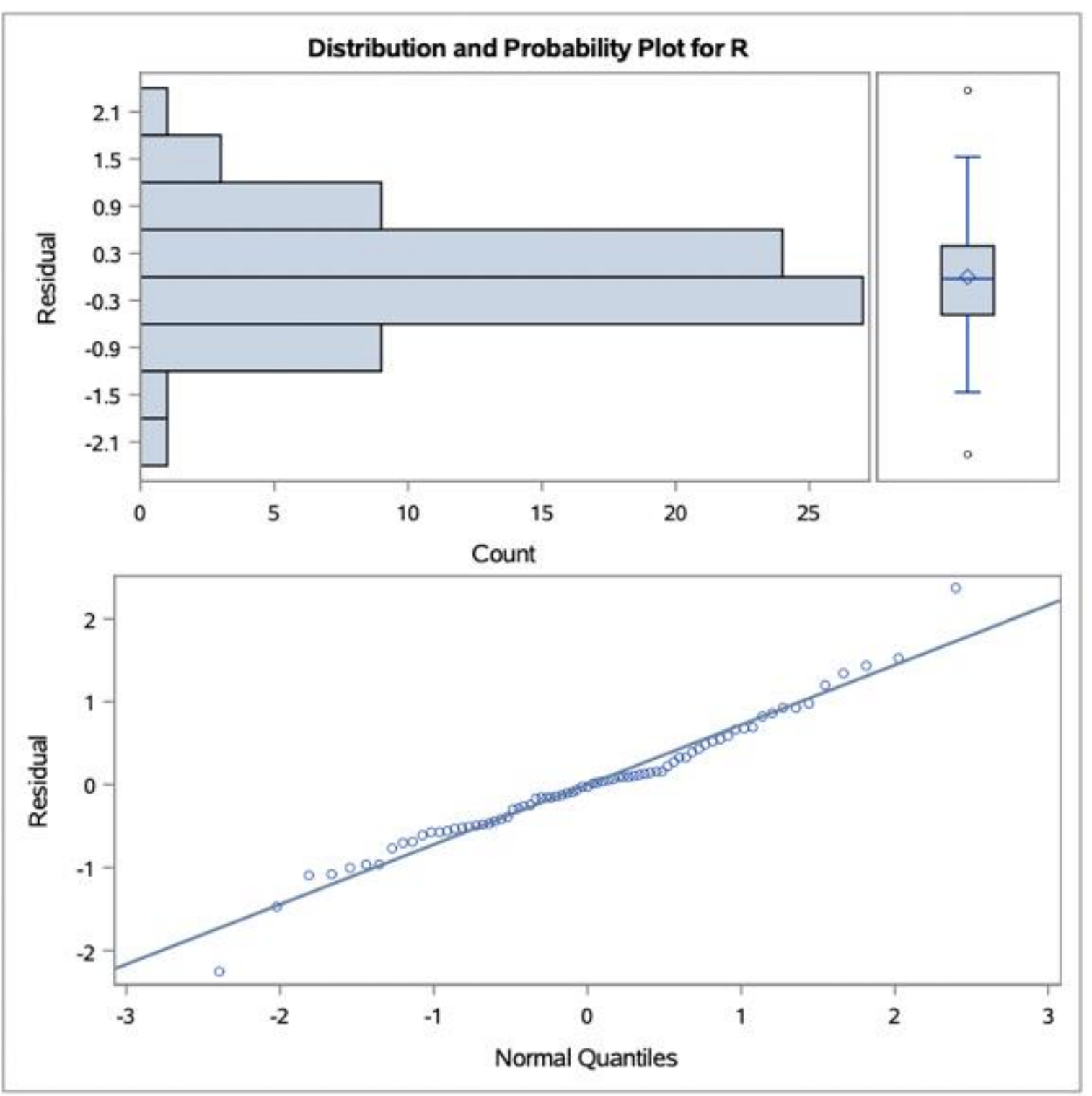




\section{APPENDIX H}

\section{SPSS STATISTICAL OUTPUT FOR VINE DIAMETER}

Table 1. SPSS statistical output for vine diameter at $40 \mathrm{~cm}$ from soil $(\mathrm{cm})$

Oneway

\section{Descriptives}

\begin{tabular}{|c|c|c|c|c|c|c|c|c|}
\hline & \multirow[b]{2}{*}{$\mathrm{N}$} & \multirow[b]{2}{*}{ Mean } & \multirow{2}{*}{$\begin{array}{l}\text { Std. } \\
\text { Deviation }\end{array}$} & \multirow[b]{2}{*}{ Std. Error } & \multicolumn{2}{|c|}{$\begin{array}{c}\text { 95\% Confidence Interval for } \\
\text { Mean }\end{array}$} & \multirow[b]{2}{*}{ Minimum } & \multirow[b]{2}{*}{ Maximum } \\
\hline & & & & & Lower Bound & Upper Bound & & \\
\hline 2.00 & 15 & 3.3800 & .55703 & .14383 & 3.0715 & 3.6885 & 2.40 & 4.10 \\
\hline 4.00 & 15 & 3.9200 & .25128 & .06488 & 3.7808 & 4.0592 & 3.50 & 4.50 \\
\hline 6.00 & 15 & 3.9333 & .64660 & .16695 & 3.5753 & 4.2914 & 2.50 & 5.00 \\
\hline 12.00 & 15 & 3.7000 & .60356 & .15584 & 3.3658 & 4.0342 & 2.50 & 4.40 \\
\hline 40.00 & 15 & 3.9333 & .33094 & .08545 & 3.7501 & 4.1166 & 3.30 & 4.50 \\
\hline Total & 75 & 3.7733 & .53533 & .06181 & 3.6502 & 3.8965 & 2.40 & 5.00 \\
\hline
\end{tabular}

Tests of Homogeneity of Variances

\begin{tabular}{|c|c|c|c|c|c|}
\hline & & $\begin{array}{l}\text { Levene } \\
\text { Statistic }\end{array}$ & df1 & df2 & Sig. \\
\hline \multirow[t]{4}{*}{ Vine_Diameter } & Based on Mean & 3.907 & 4 & 70 & .006 \\
\hline & Based on Median & 2.848 & 4 & 70 & .030 \\
\hline & $\begin{array}{l}\text { Based on Median and } \\
\text { with adjusted df }\end{array}$ & 2.848 & 4 & 54.049 & .032 \\
\hline & $\begin{array}{l}\text { Based on trimmed } \\
\text { mean }\end{array}$ & 3.773 & 4 & 70 & .008 \\
\hline
\end{tabular}

ANOVA

\begin{tabular}{|c|c|c|c|c|c|}
\hline & $\begin{array}{l}\text { Sum of } \\
\text { Squares }\end{array}$ & df & Mean Square & $\mathrm{F}$ & Sig. \\
\hline Between Groups & 3.492 & 4 & .873 & 3.450 & .012 \\
\hline Within Groups & 17.715 & 70 & .253 & & \\
\hline Total & 21.207 & 74 & & & \\
\hline
\end{tabular}




\section{Post Hoc Tests}

\section{Multiple Comparisons}

Dependent Variable: Vine_Diameter

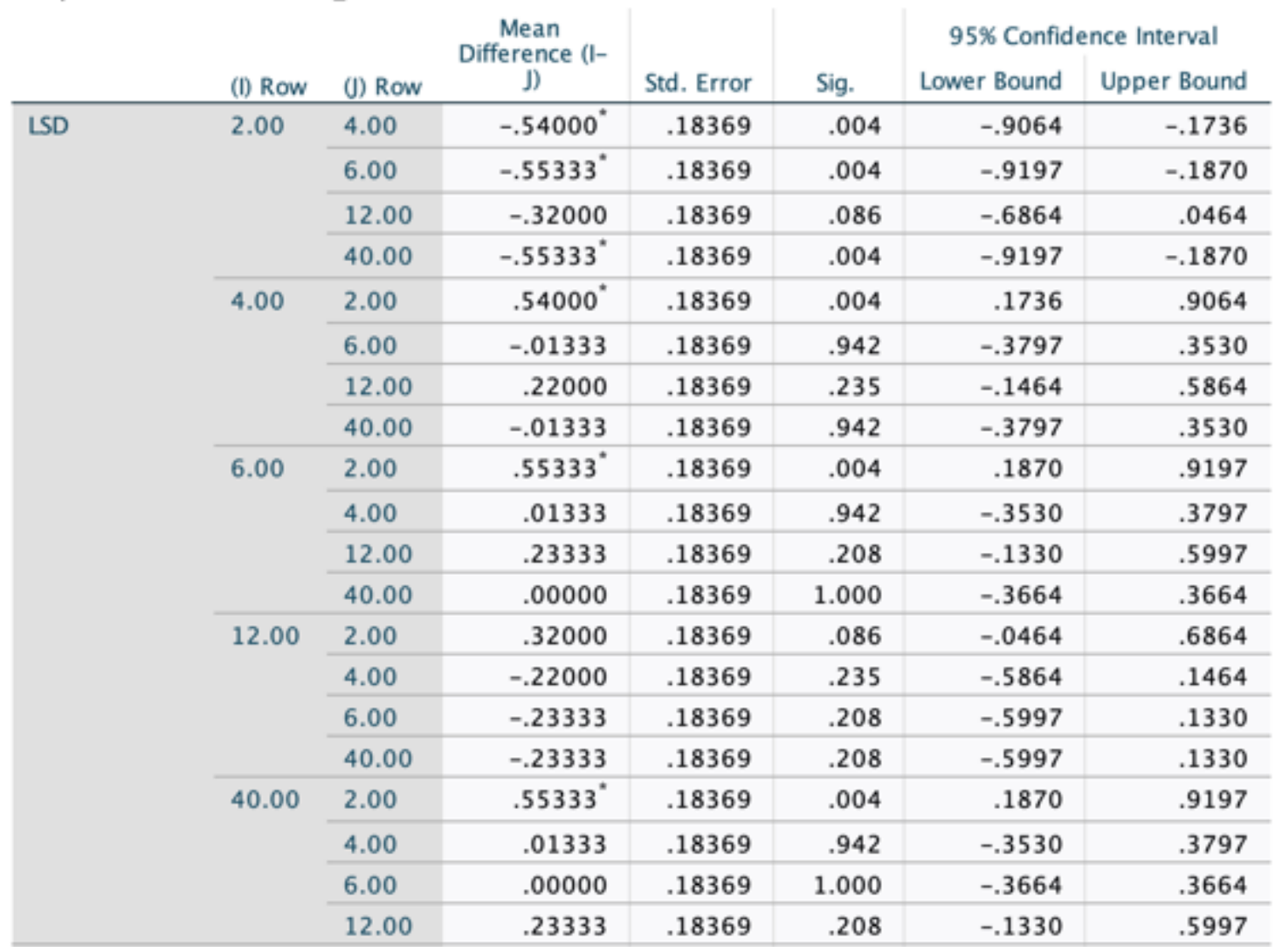

